I $\mathrm{X}+\mathrm{BA} \mathrm{IO}$

$D E$

TESIS

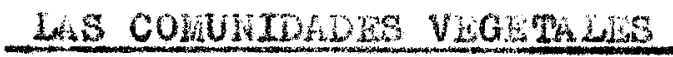

DE LES TSLES

CQRCA

Jorge More110

br11 da 1949

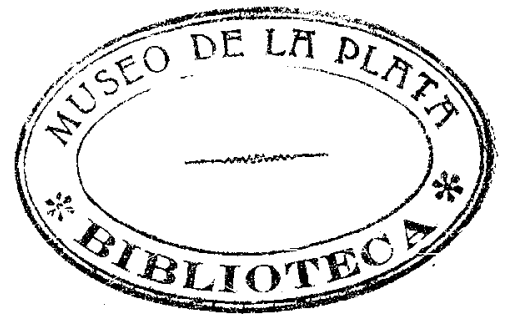


"Las is la vienen Inviale do pasos ráplios o ma bion marehan hacia ol mat.

"II Juneo as el primer of de $2 a$ creación de las 1 las. las carda y el selbo bacen! maftana y $1 a$ tarie del día se.

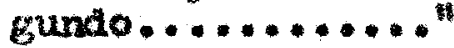

Domingo E. Sarmitanto

"E1 We cions 1", aledel bx 1855 . 


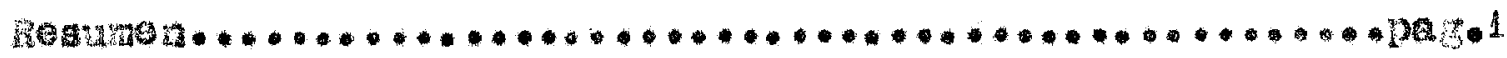

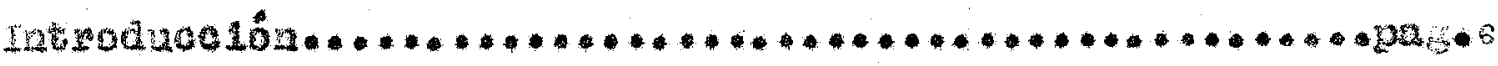

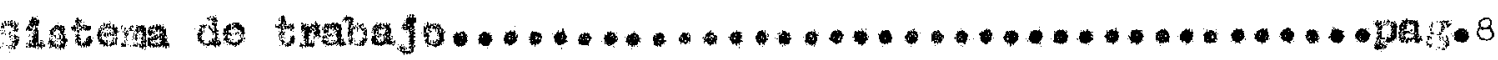

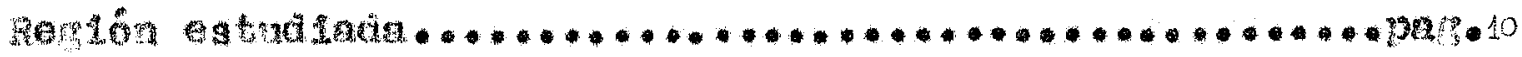

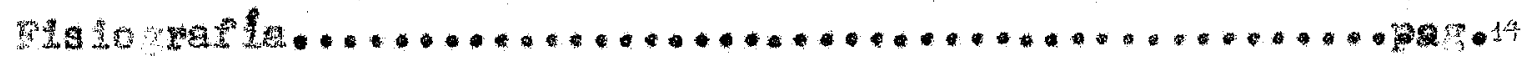

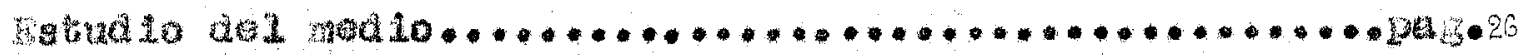

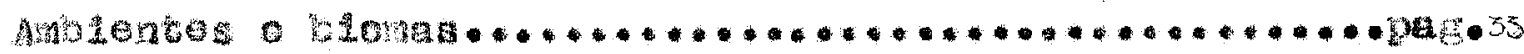

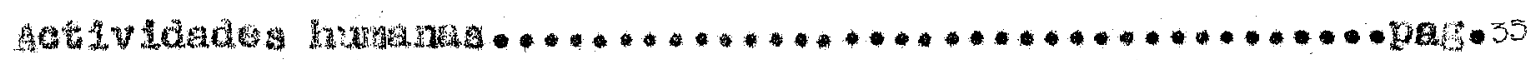

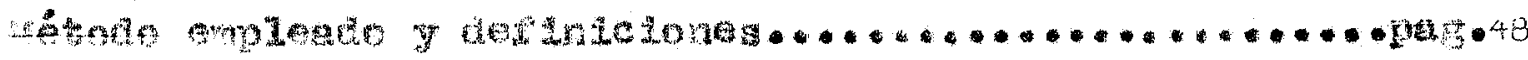

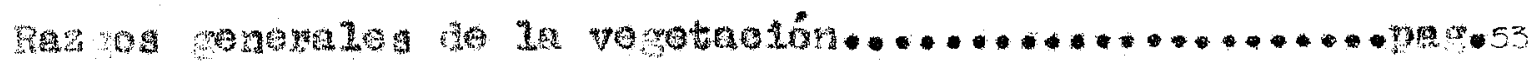

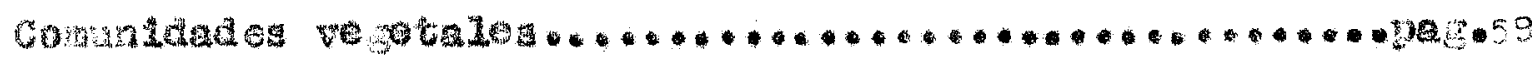

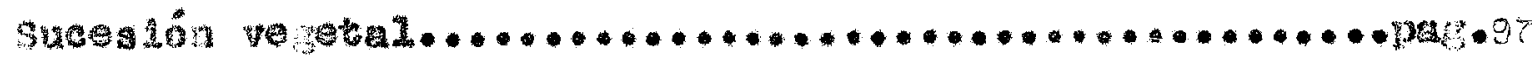

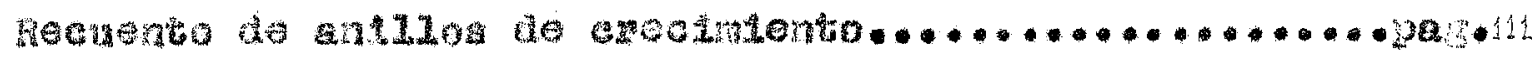

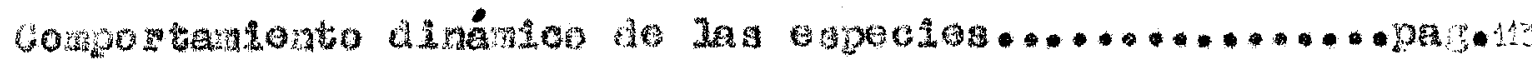

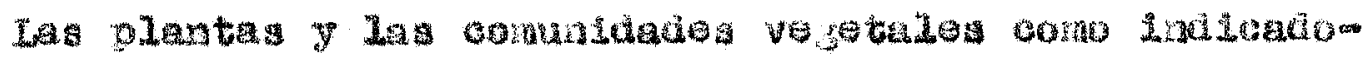

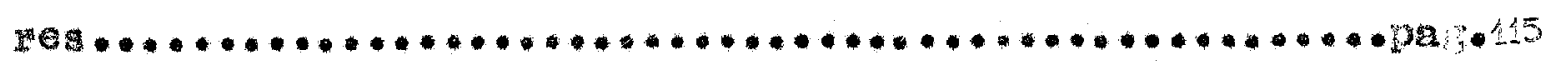

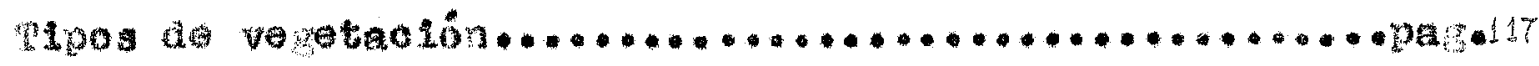

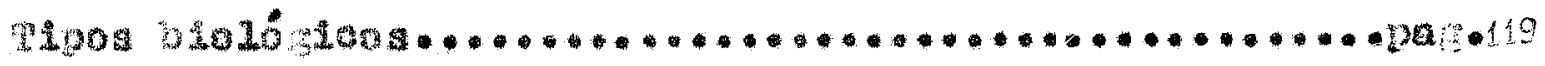

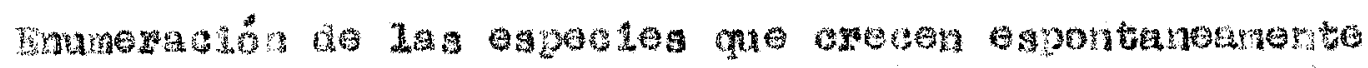

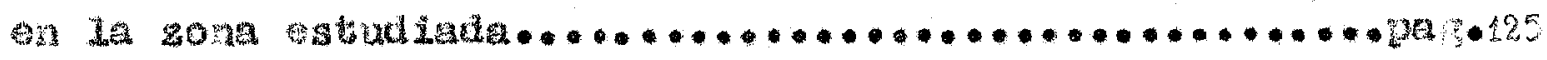

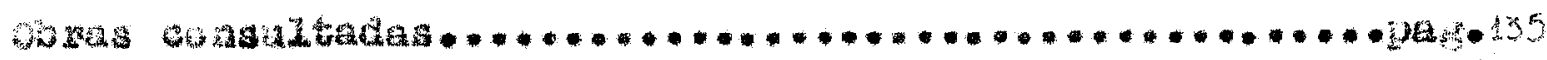


$1401 \mathrm{~s}$

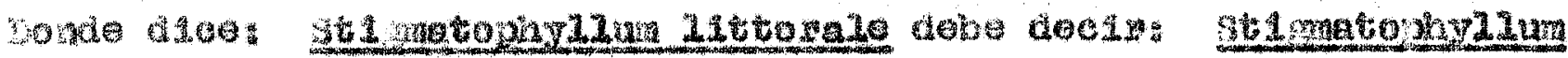

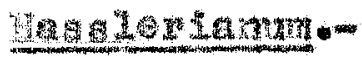

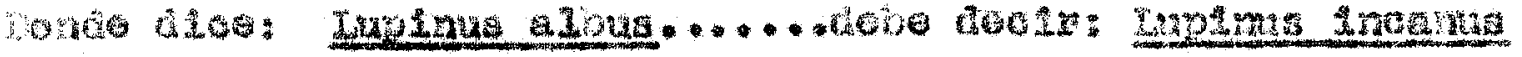

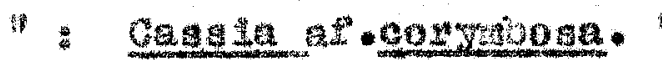

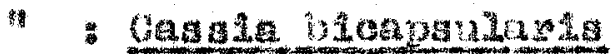

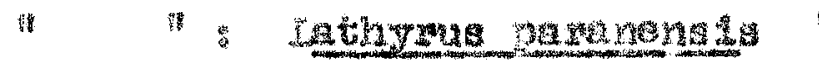

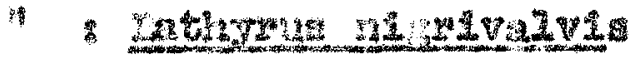

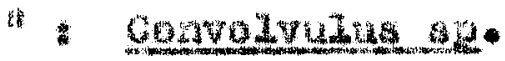

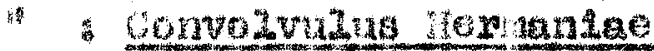

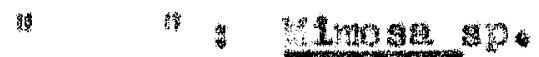

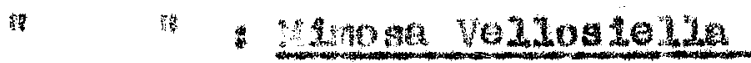


La región estudiada Incluye el ambiente ingular de la costa santafecina del Parana, entre Rogario y Puerto Gaboto.

Las peculiares carecteríticas edáficas $\mathrm{y}$ microclimétleas que crea la gran vena 11quida, permiten el desarrollo, en un ambiente estéplco, de comunladaes que tienen su climax mucho más al norte. Hemos particularizado en el estudio del régimen del rio sus crecientes y estrajes: su accsón constructora de creas desnuda $y$. formadora de barrancas vivas en activo retroceso, por ser la vegetación la que recibe la influencla inmediata de este régimen flu. vial y la que colonlza con sus plonners las areas creadas por el Parand.

En el clima se consideró a 1 rio como regulador del régimen pluviométrico, anulador de la helade $y$ etemperador de 1 as aiferenola diaria estacionales de cemperatura.

Hemos caracterizado los siguientes ambientes fisicos:

Bancos arenosos: 1slas jóvenes, 1slas madura: madrejones: albardones: lagunas, riachos, arroyos, bocas 7 arroyos.

Estualamos la acción del hombre sobre la vegetación y $1 a$ serle de interacciones que entre ellos se establecen y que son:

I - $\triangle$ COIOI DIRECW

a) Dsgtrigición de la vegetación aln aporte (Explotación)

1) Desmonte

2) Corte de la paga (Panicum prionitis)

3) Inecratios

b) Spor te cespués de 1 destrucción

1) herorestación

2) cuitivos

II ZACCION INDIRLOTA

a) Anima 1 es domesticos

b) Fora adventicia

En 10 referente a 1 estudo particular de la vegetación se adoptó como método de trabajo un slstema axto; la nomenc1:tura de 
las comunidades corresponde a la escuela de Nebruska (Weaver y Clements, 1944): su califioucion $\mathrm{y}$ cuantificko16n estadistios se he he

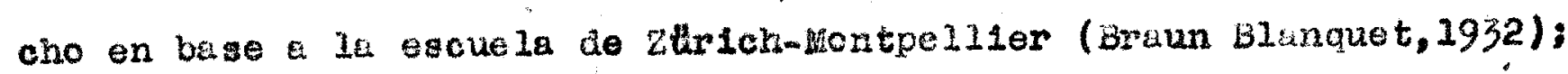
en la caracterización de los tipos blológloos se sigulo la de Upaap la (Du Rletz y por fitimo, en ciertos aspectos anditicos $\mathrm{J}$ sin teticos a cain (1947).

Ierborizando, delinitando pximero a ojo y luego astudiando estadsticamente cada comunided determinando las especies dominantes o controlantes serales jealizando fnventarios para kreciur abundancla, sociablilad, presencia y frecuencta y censos graficos se 11 gé a las siguientes conclusiones:

1) En el ambiente insular no existen comunidades olimáxicas poxque la sere es detenida inderinidamente por factores de compensacion (edeficos $\mathrm{y}$ microcilnuticos) en la etapa subelnal de su evo. Iución.

2) Las dos comunialates que representen el maximum aquo puefen llegar las hiaroseres en su evolución son: el bosque fluvial (Asoc1es de Erythrina crista-gi11i. Sapium ha amapermum. Nectandra membranacea y Pstheeollobium mult1florum) y ol oppin11lar (Consocies de Acacia cavenial.

3) Estas dos comunidades son del mismo rango evolutivo $\$$. so las considera dos" aubclinax " vinouladas a conalciones especia1es, el bosque pluvial al palsaje de albarabn, con suelos arcilió.

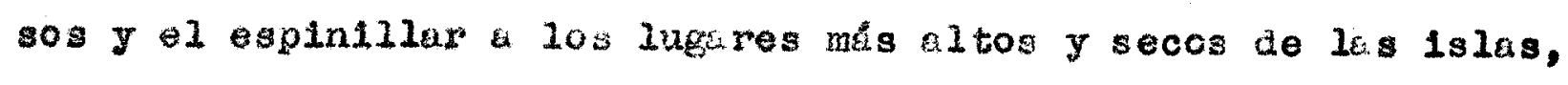
con suelos arenosos suejtos.

4) Como unidades menores del bosque insular se reconocie. xon 1a facled do Erythrina crista-gel11 (Selbal), de P1thoceliobium mult1florum (Timbosal). de Sapium hnemetospermum y Erythrina cristaga111 (bosquecilios claros de curupl y se1bo) y Socie de Rapanea laetevirens (bosque de canelon).

5) Las comunidades "nriserales" que pudieron sor identifleadas son:

a) Comunidades de planta sumergidus, do escasa importancia en esta región. 
b) Comuniades de plantas flotantes

I - Asoc1es do E1chhornia azures, Elchhornia crassipes y Limnanthemura fiumboldtianum con dos facies, Is de Iimmantheinum Humboldtienum y 12 de Elchhornia azurak.

II - ssocies de panicum elephantipes, Paspa lum repens y Eohlnochloa helodes con una facies de Echinochloa Mo 10008.

III - Verdolagel (Consocles de Jussiaea repens).

c) Comunläades de plentas anfibia

I - Cataysu 1 (Consocies de Polygonum acuminatua)

II - Asocies de Sageltaria montevidensis y Pontoderla cordata.

III - Juncal Asocies do Groerus giganteus y Scirpus ceilfornicusl.

IV - Consocies de Enhydra anaga 1118

$V$ - Varilla1 (Consoc1es de Solamum glaucurn)

a) Comundadoe terrestrea

$I$ - Consoctes de cleome apinosa

$I I$ - Artemisal (Consoc1es de Ambrosia tenulfo11g)

III - Conscoies de Baccharia Pingraea.

IV - CardaI (Congoules de Erynglum eburneum)

$V$ - Gerrizal (Consoeles de panicum grumosum)

VI - Conut1llar (Asocles de Hemarthria altissime y Setexia genteulatey

VII - Inrtedel (Consocies de solanum amygdalyfollum).

VIIT - Pajont I (Asocles do Panicum prionitis y SchaeffeSén uruguatens is)

IX - Asocles de Alternanthera Relneckil y Glinus realatus

$X$ - Asocies de Eragrostis hypooldes y Fimbristy11s - çuarrosa

XI - Sauza 1 (Consocies de Sa1ix Humboldtiana) 
XII - Alial 1 Bobadal (Consocies de Tessarla Integr 1 (0112)

XII - Matorral riberento (Asocies de Baccharis Ianceolata J Sesbanla marginata con una facles el chlleal (Bacehar1s lanceolata)

XIV - Consoc1es de Aap111a gilphio1des

XV - Agocles de Cyperus Luzulae g Echinochloa polyg tachyea

6) En 1a observeciones sobre sucesión se determinaron las squientes curas próactoras de dreas desnudas:

$$
\begin{aligned}
& \text { A - Causas topogxacleas (erosión y sedimentación) } \\
& \text { I Aroas asciude debidas a la erosión fformación } \\
& \text { de bercaneas } \\
& \text { IT - Area desnuda debiaas a sedimentación }
\end{aligned}
$$

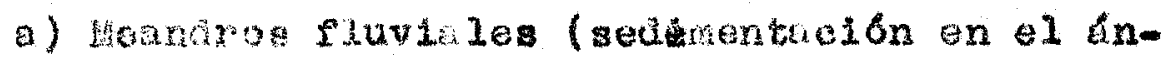

$$
\begin{aligned}
& \text { (M10 murto) } \\
& \text { b) Ensfaberfiento oraco del carce de inundación } \\
& \text { c) Irengfomatón do arroyos en sacos (tapona- } \\
& \text { utanto) } \\
& \text { B - causag clindtigas (eatiajea) } \\
& \text { c - Geusas bietloag (inconalos, ciesmonte) }
\end{aligned}
$$

7) Derko de las arateriatlas de la priare insular, que se origina siempre on un śrea desnadk pepresentada por el agua, se so conelderan 10 s gujentes thriantes:

a) Harosere an los binecs arenosos

b) Harosere en lagunas y marejones con una varlante on las lagunas de morgenes areno. 8 和果。

c) Hinrosero en los aucos y arroyos.

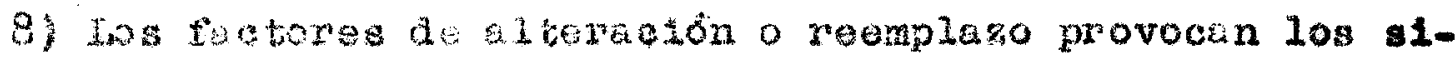
guientes subseres:
a) Stubere en el bosque blanoo incendiado
o) Subsere an el pojond destruldo por al fuegc 
o) Subsere provocada por inundaciones

d) Subsere produciak por el desnonte

9) 30 ostudít 1 comportamianto alnimico do varias ospee

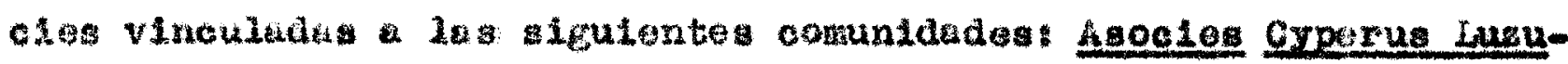

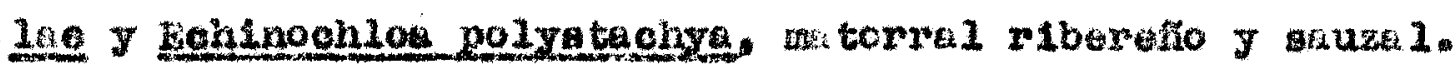

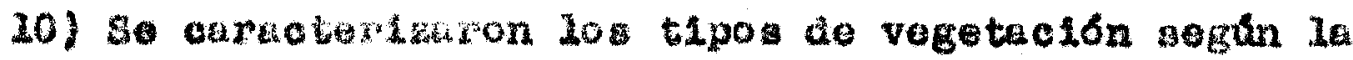

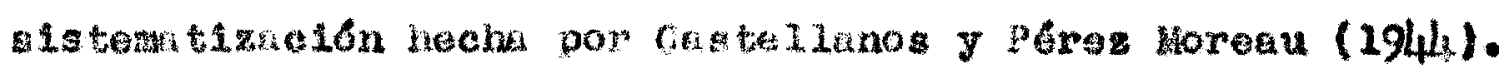

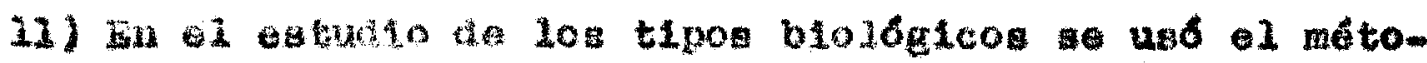

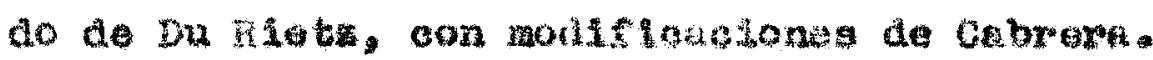

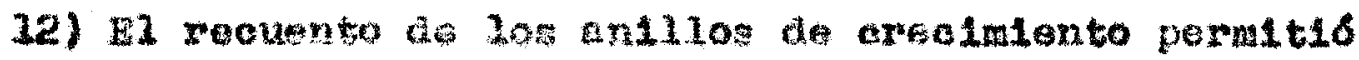

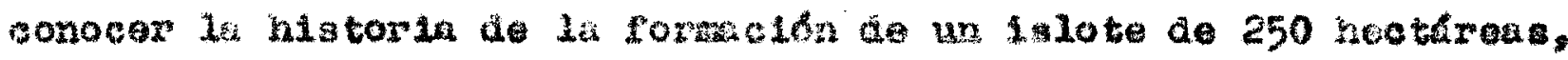
con una edia no miyor de 45 wos.

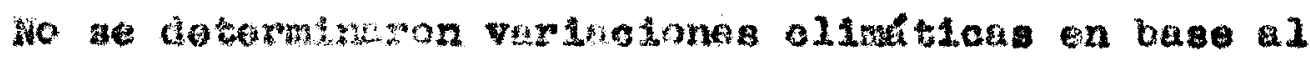

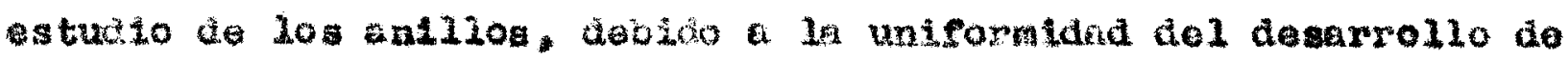
30 m natos.

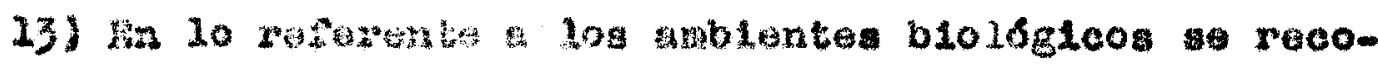
nocleron:

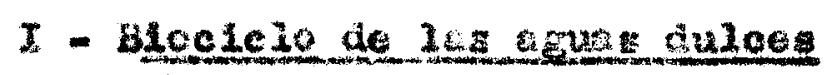

$$
\begin{aligned}
& \text { A. Potsnose } 10 \\
& \text { a) Arablente de radrejon (reguto } \\
& \text { b) inaturato de } \text { to } \\
& \text { - Ljangetc20 } \\
& \text { a) Ohuses } \\
& \text { b) } \sin \sin 2
\end{aligned}
$$

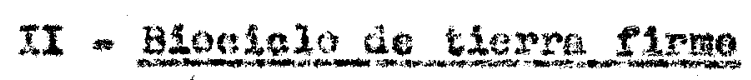

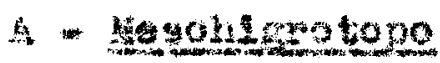

$$
\begin{aligned}
& \text { B - hasotopo } \\
& 0 \text { - Eorestat } \\
& \text { a) Tatatoso } \\
& \text { 1) Cremotopo } \\
& \text { a) andopo }
\end{aligned}
$$

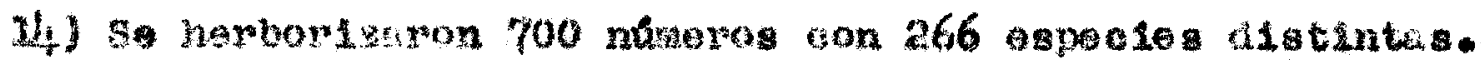


Le onorme superficle de captución del Parand, las extonas reciones que utruviesa, el aporte de somillis que aeratran sua agues; su ace16n regulucora del reglnen pluviométrico, Envlaciora de 1. heladus, atemperidora de las condiciones alimeticas generties, etc., permiten rue un caralno de osenclas forestales, on forma do cortink arbórea, pase por zona ande controlan lis climx los gene. ros Stlpa, Poa, P1ptochaetiun, kriatlda, Helick, Vulpia, Hriza, Eragrostis, etc.: In catepk pampouna.

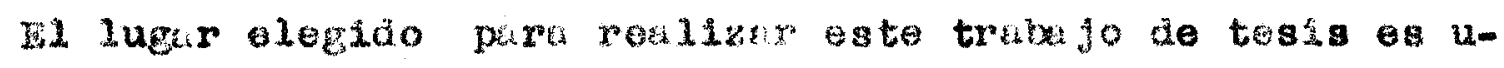
n. pequetia zon del amblente deltáico, rocostada sobre la burran-

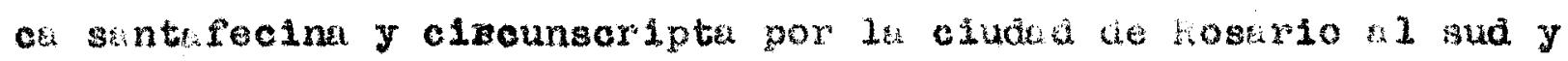
Puorto Gaboto al Norte. Su Plora cal desconociar, su vegetación

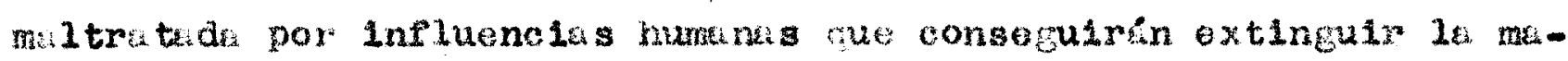
yor prote de sus esencles mầtables; el maruvilloso mecnismo de construccion de nuevos hebitute que las pluntes llevun a cabo en

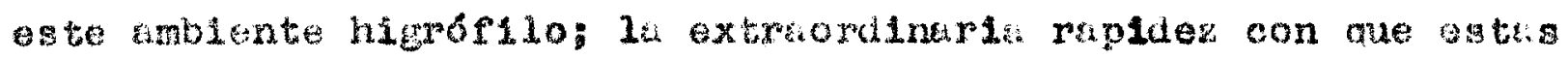

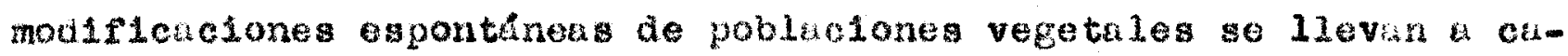

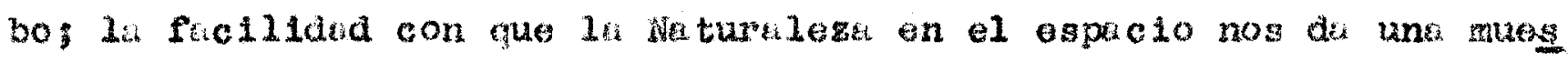

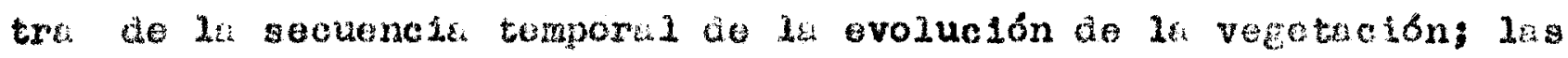

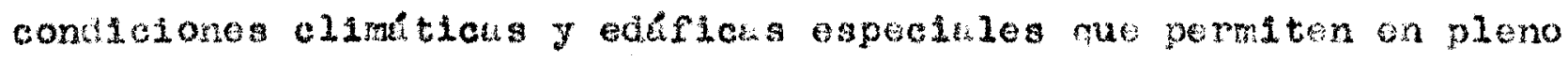
ambionte entepleo observe comuniandes que adquisen su miximo deaaxrollo mucho mis al norte, son Is razones fundamentales que ne

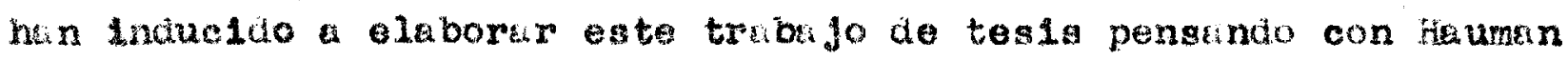
que "entre los doberes huranos mis sugrudos figura... el de estu-

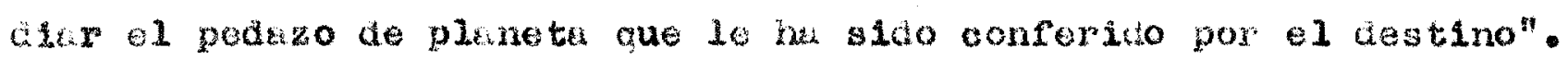

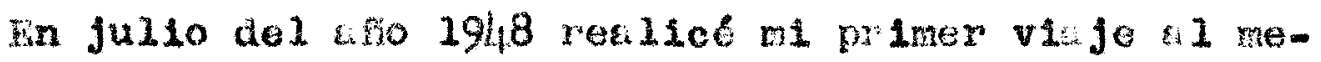

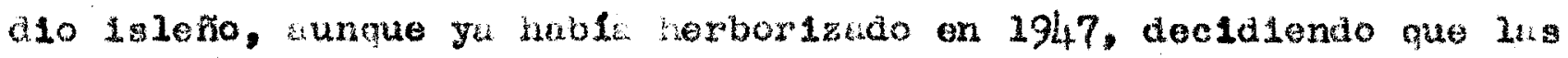

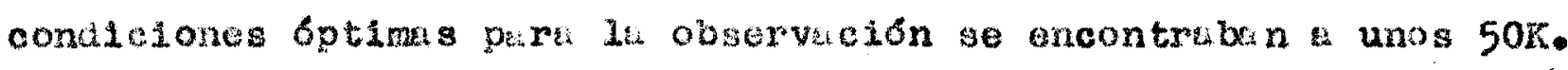

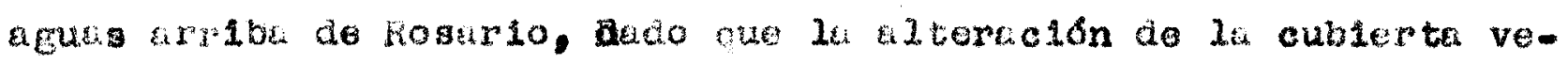

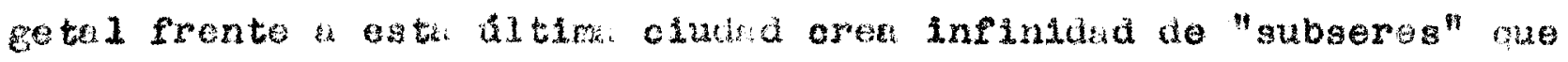




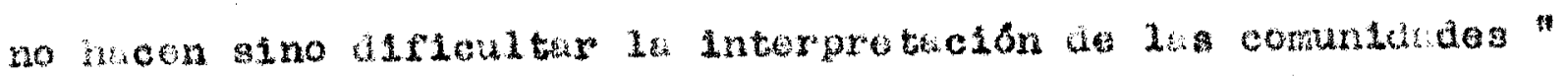

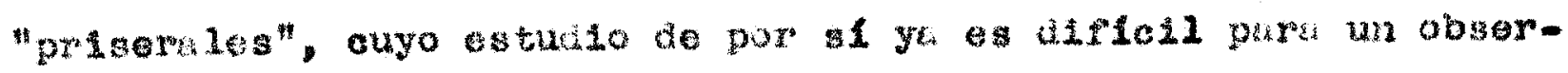

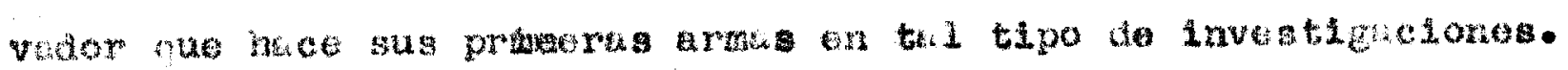

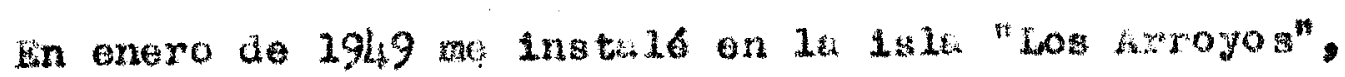

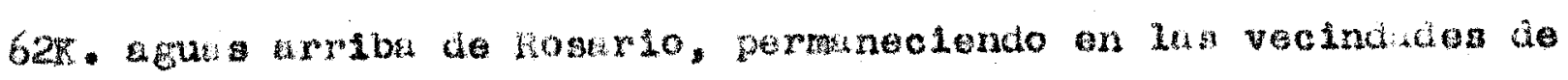

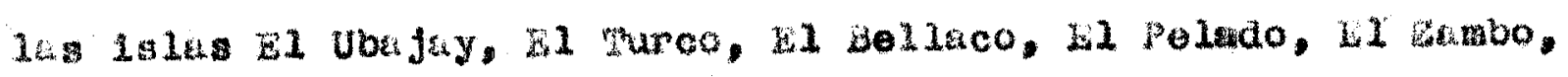

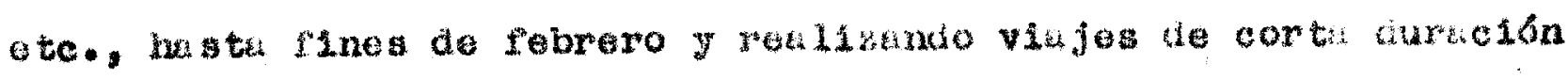
- Las cuevea y Minmente, abre le costa entrerriuna y a las "Cur-

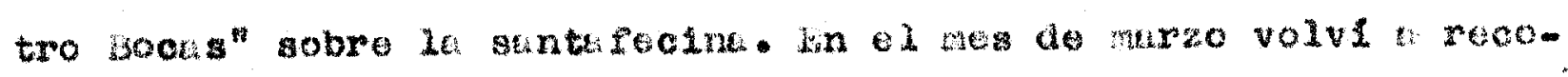

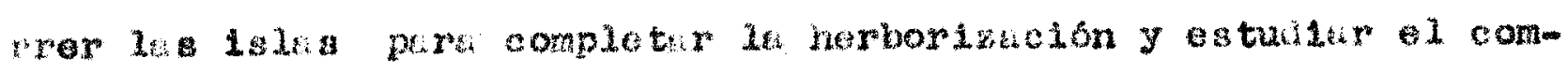
porterionto dinamico de leunis ospectos.

L1 resultado de osta excursiones a el presente trabujo con el que trito do contribuir a mojor conocialento de un pedizo de ni provineia netal, ouyo valor cono rearva forestal y pas toxil as Inmonao.

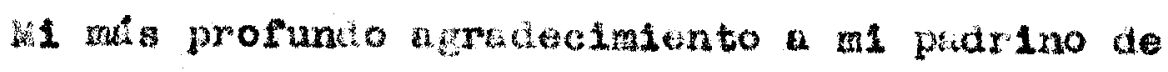
tesis, Dr. Ankel cabrora, por su proocupheion constante $\mathrm{g}$ cortecclones opostands.

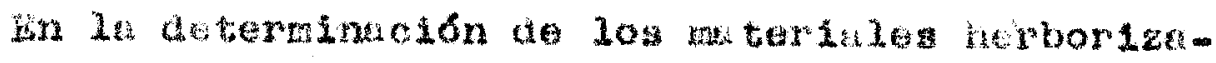

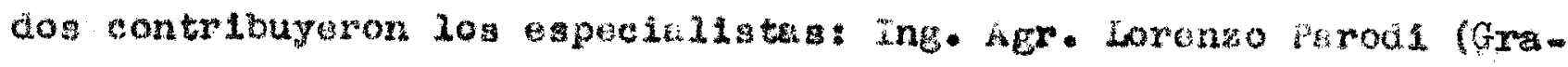

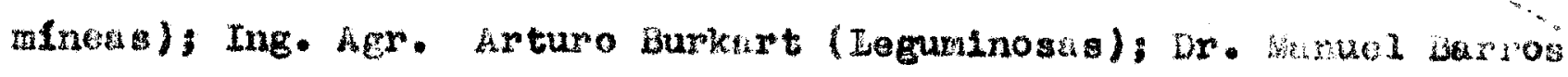

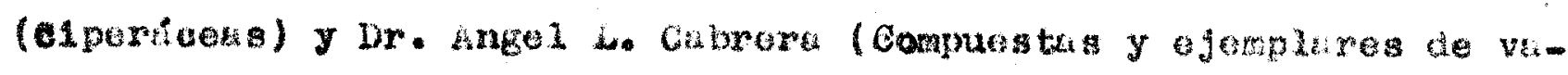

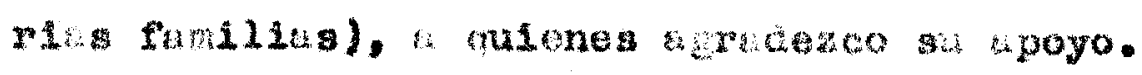

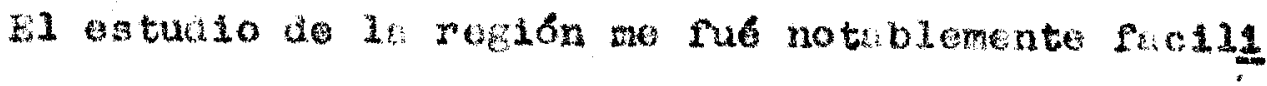

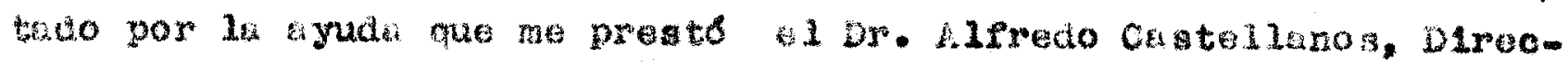

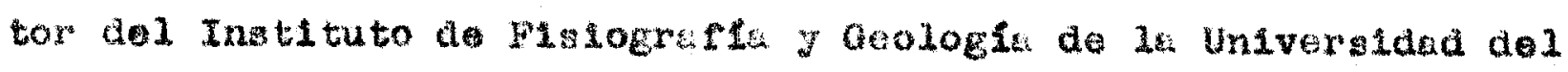
Ltorat 1 .

Taribien comprometen al ponocimiento los soño

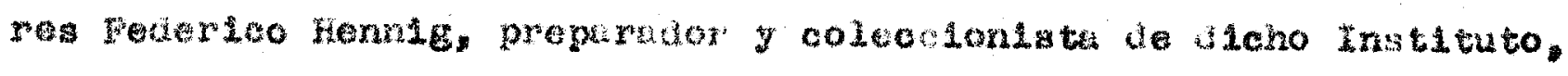

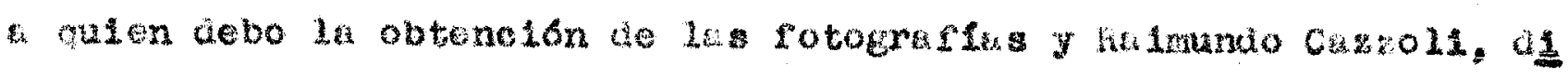

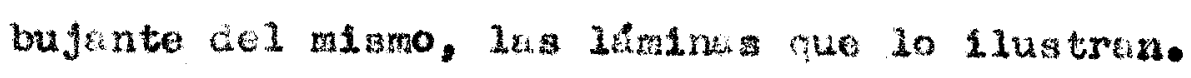

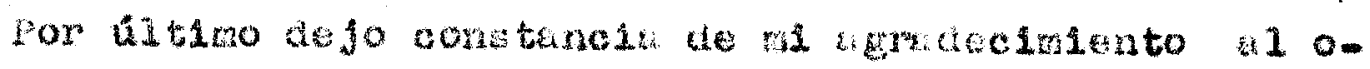




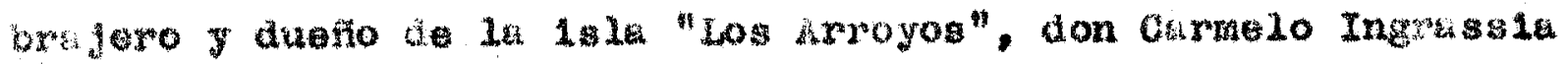

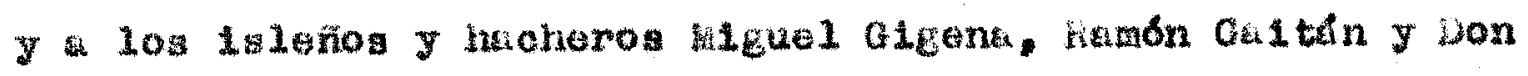
disos.

\section{STSTHWL DE THESAO}

se ha aegulo 1 sigudente metodo de trabajo:

1) Horbortacion exhus tiva de la gonta.

2) Determinatión a ojo de la oomunadas vegetales tra-

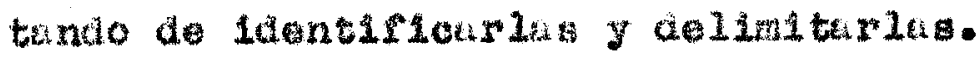

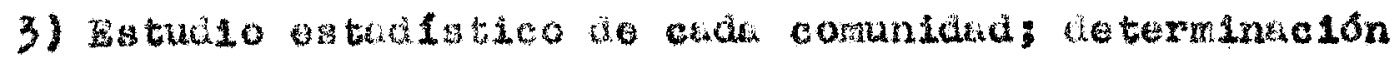

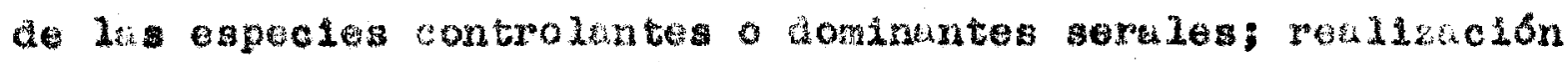

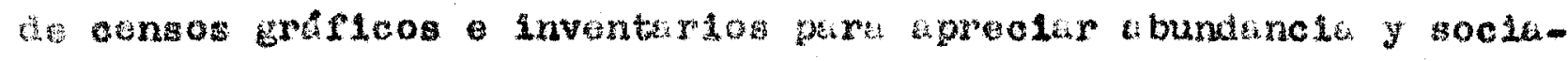

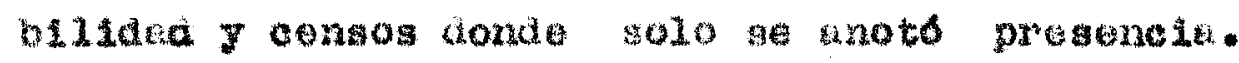

4) Mecuento de anillos de creciniento.

5) Satudio de la gheston vogetal.

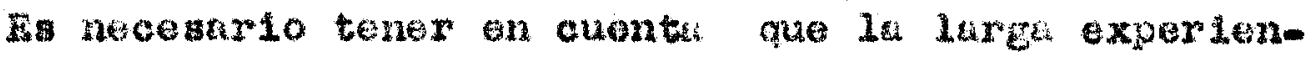

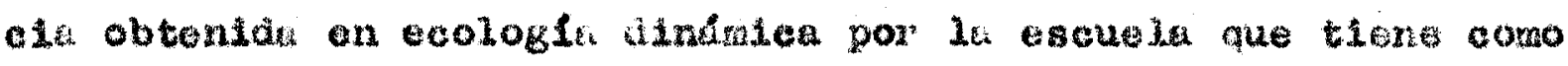

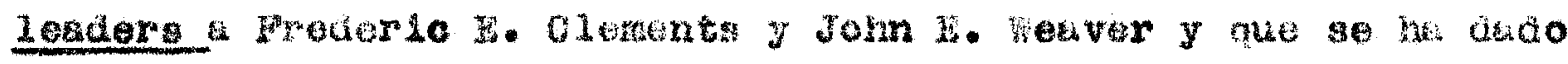

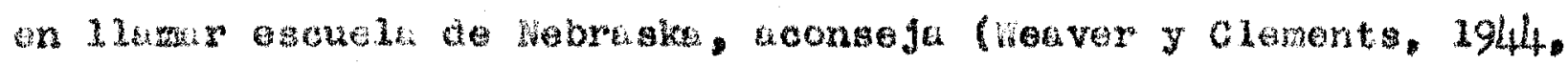

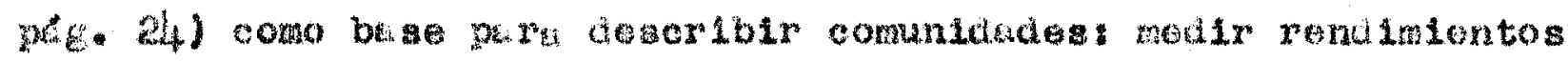

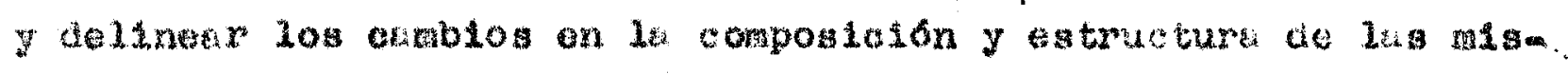

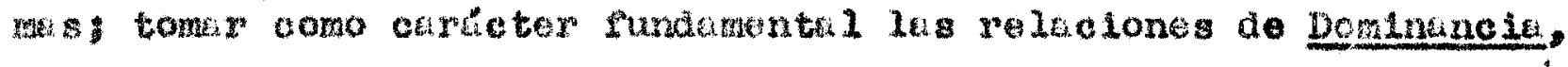

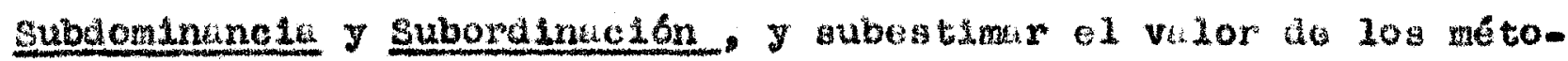

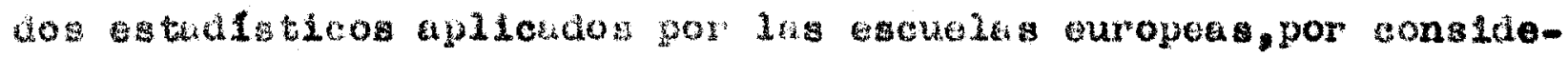

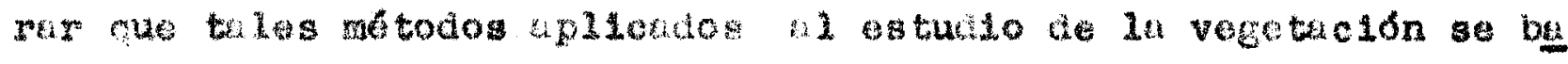

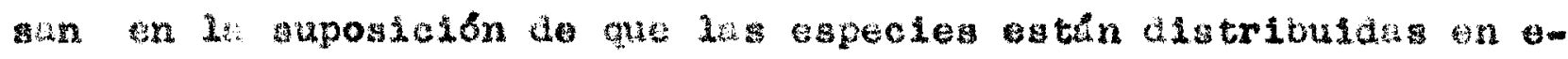

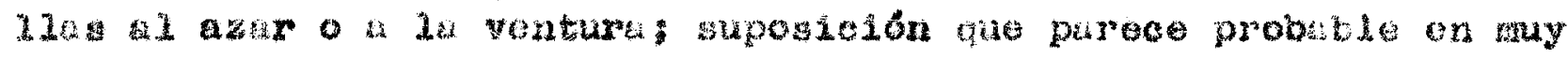
poups easos.

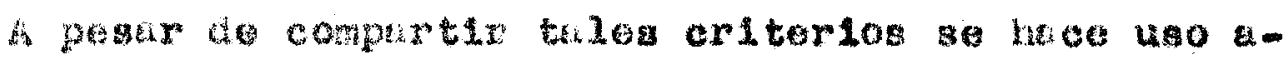

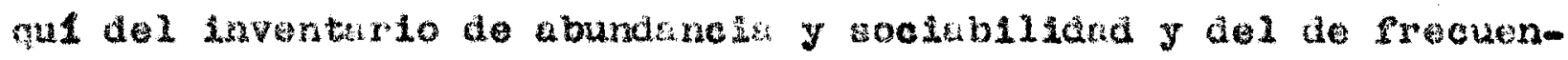
cie porque: 2) on un ostukio rípico son los ankos metodos que nos

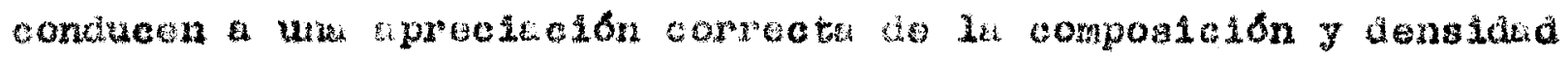

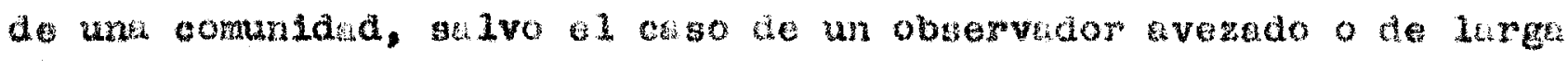

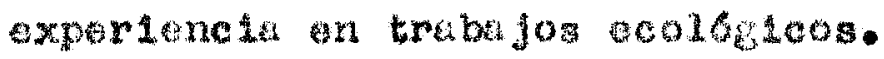




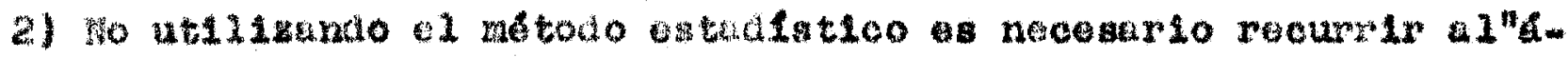

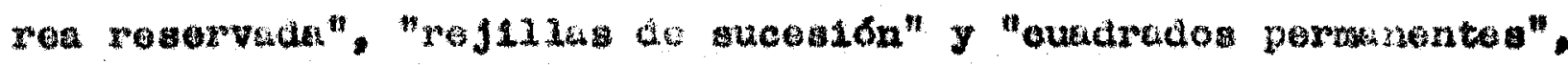

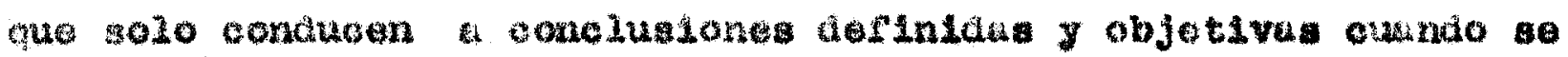

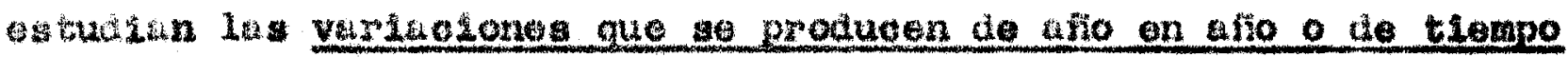

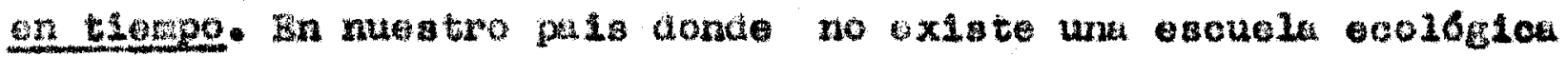

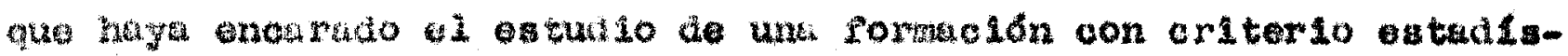

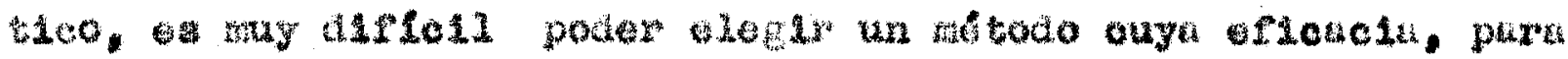

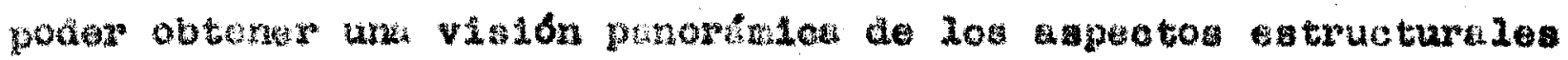

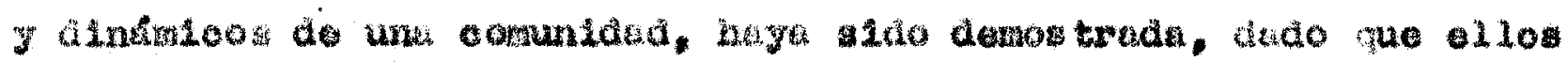

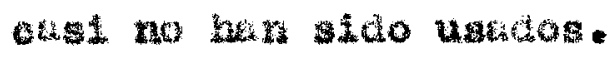

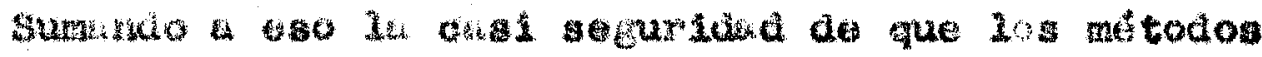

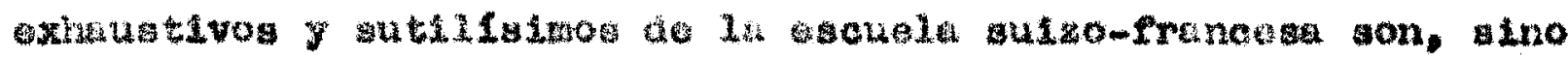

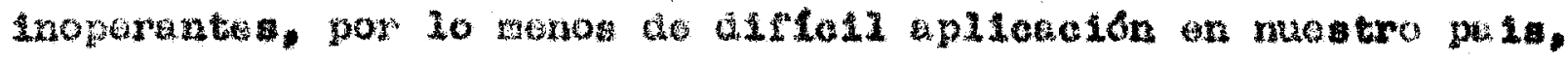

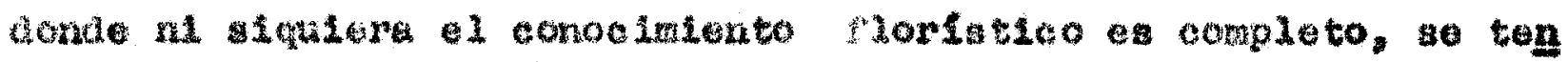

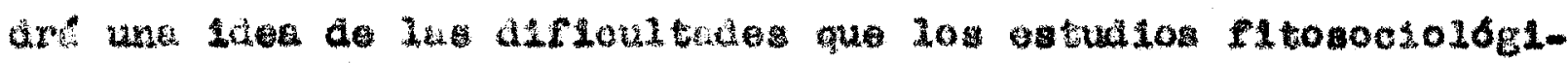
cos anoweren.

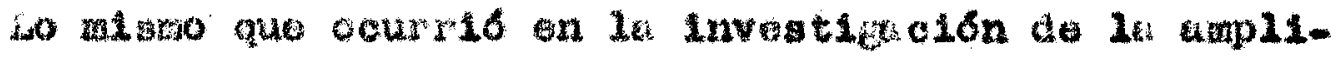

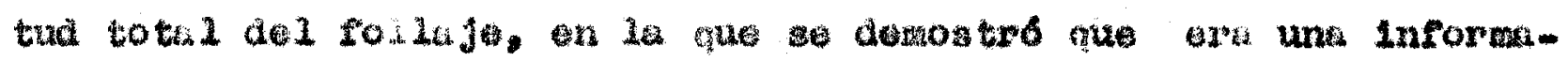

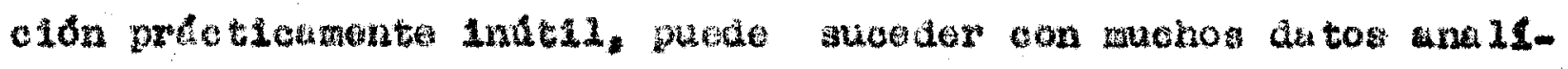

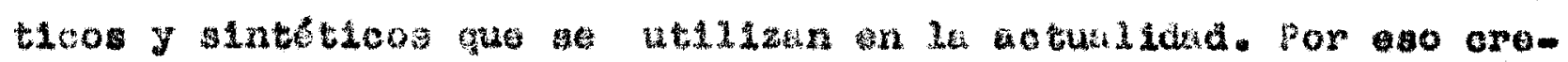

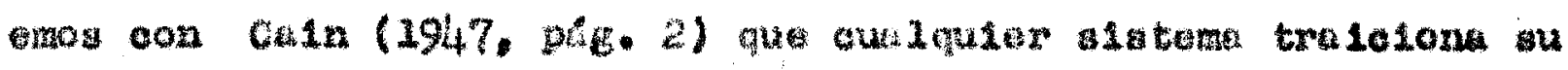

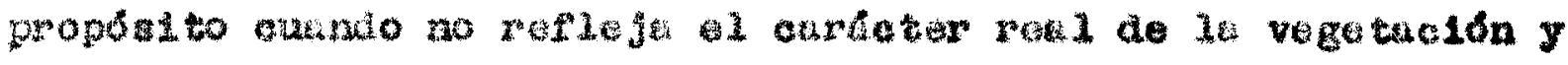

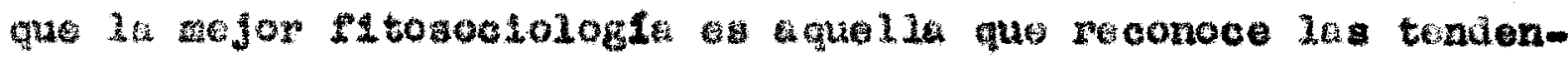

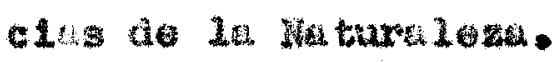




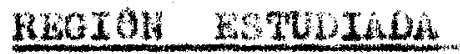

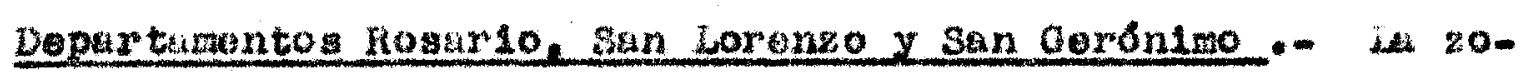

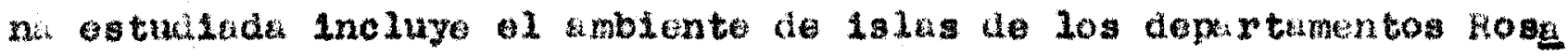

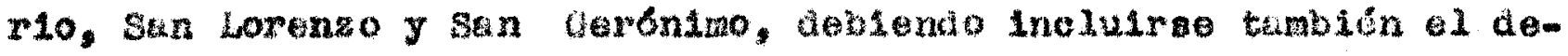

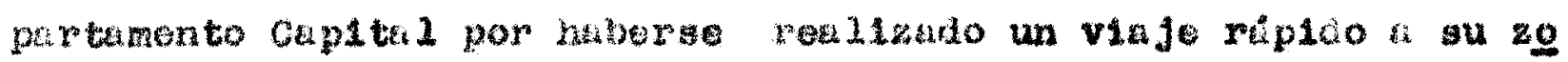

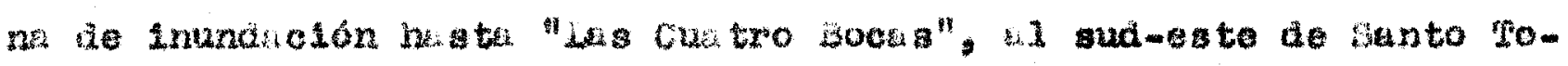
wad.

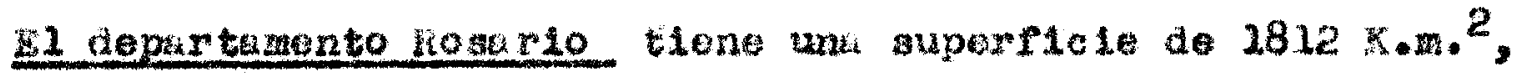

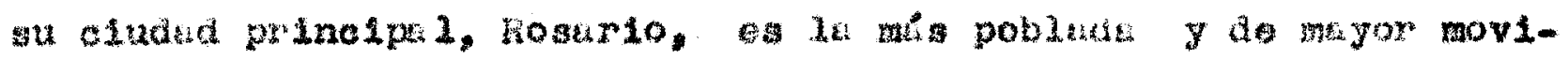

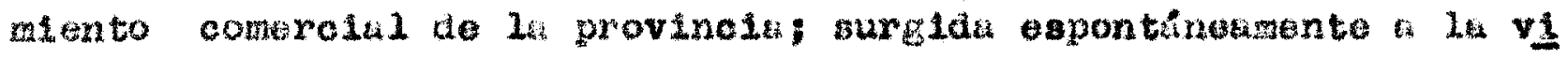

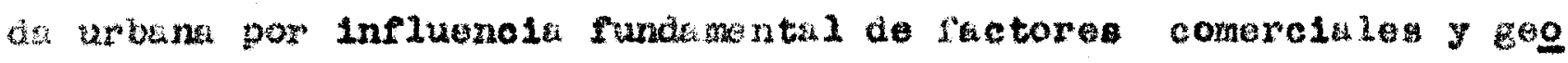
grifleos, comienas a hacer sentir su influjo wobro la colonias y

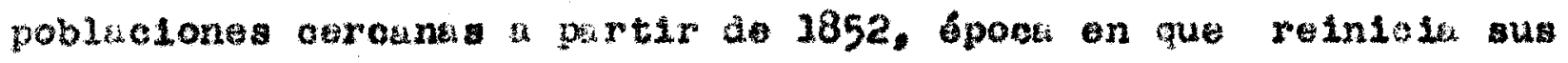
actividsdos al puento $y$ el cubotajo adquiere gran increnento. Bn 2857, por lu sepernoion temporurla (1857-1859) antro

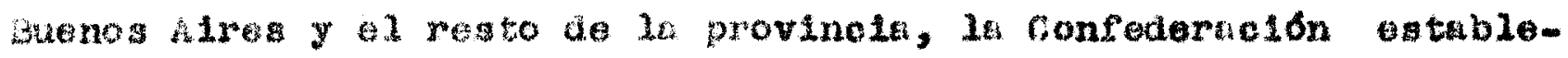
co 105 12amdos "deroches derenciales" ous dan privilegtos hosar10 $y$ permiten su surglmiento vigoroso ininterrumplao haste hoy, const1tuyendo ol puerto conerolal mís importants del parank. con unt poblucion de mis o menos 516.668 (1940) hebitentes. Rosario

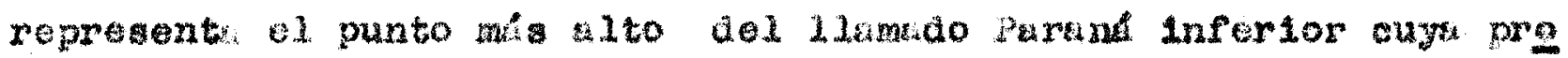

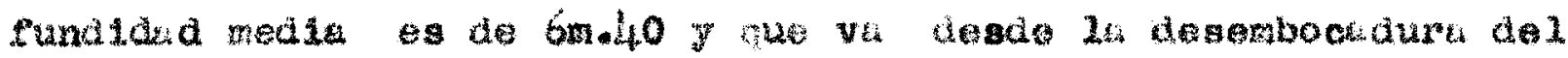

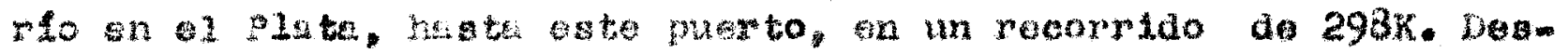

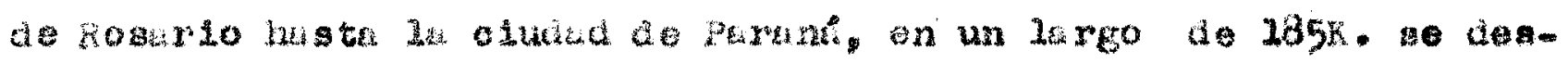

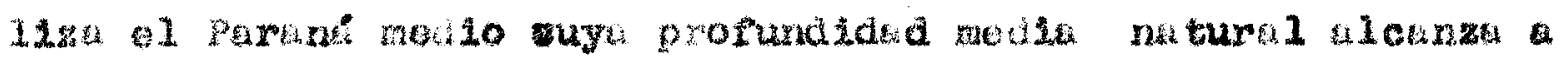

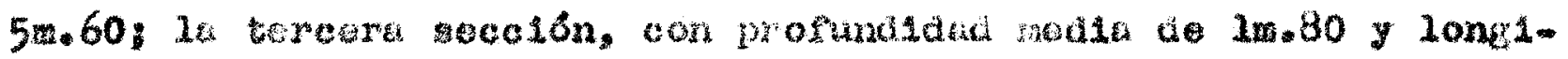

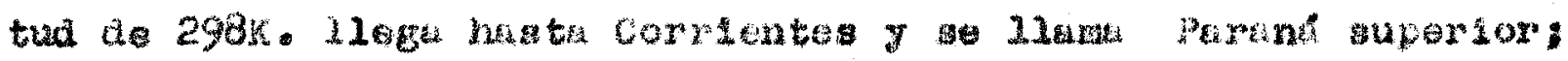

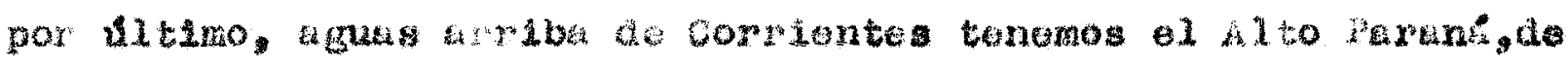
rondo rocoso y encejond do deste poseda. 


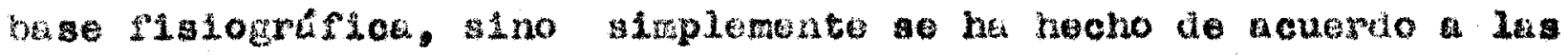
posibilidude do navegaeion.

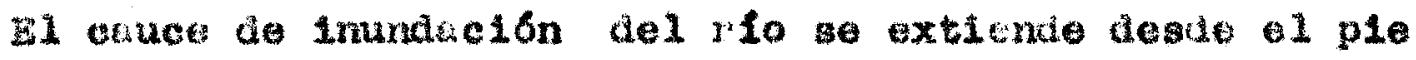
de la barranea del Fuerto, que corresponde al angulo vivo de un

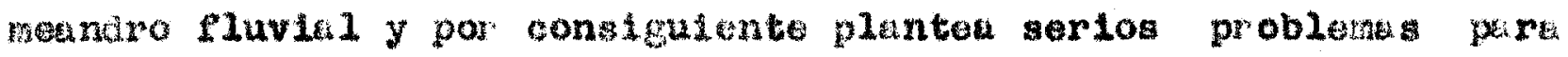

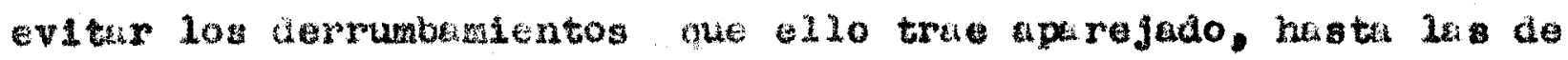

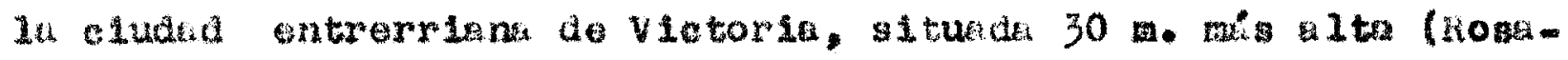

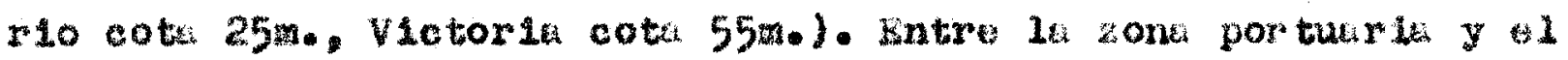

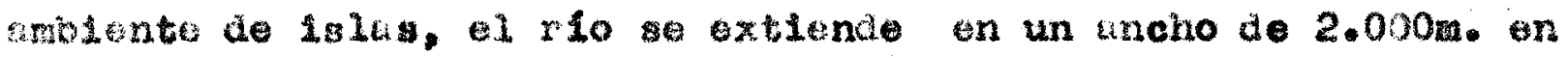
- 1 cani prinoipal para los panobotes do ultramar y desa 14 des-

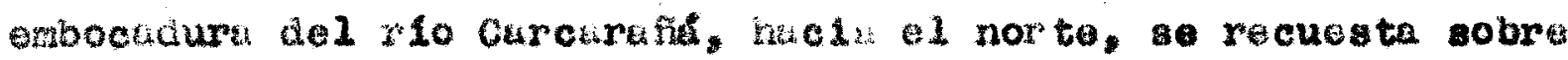

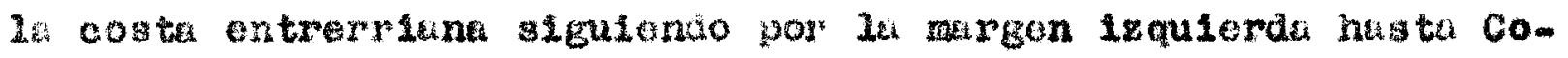

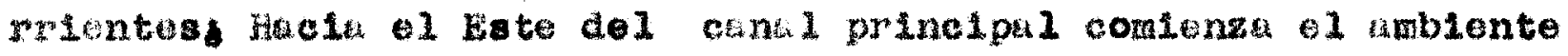
delta1co repreaentado por una geria de lalas (Dod Eapinil2o, La In vermata, castelinnos. te.). Interrumpiaf por sele rlachos que de

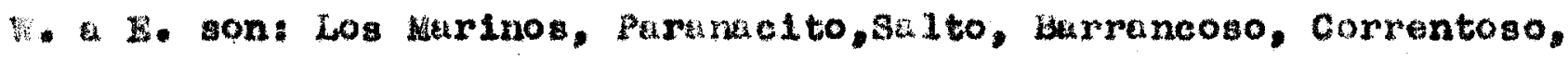
I Parunuclto Entrorriano: eato palsuje do delta termina fronte a Victorla en el iacho del miamo nombre, que gracits al arigado pef-

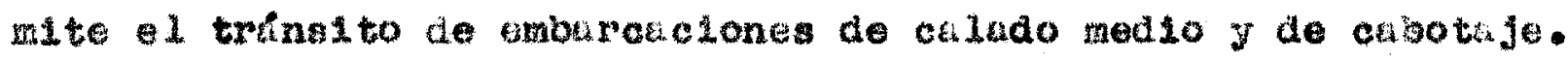

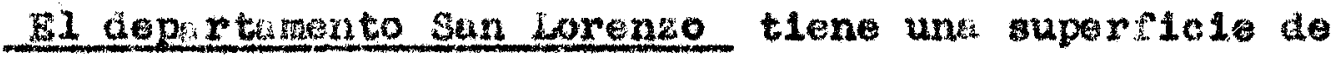

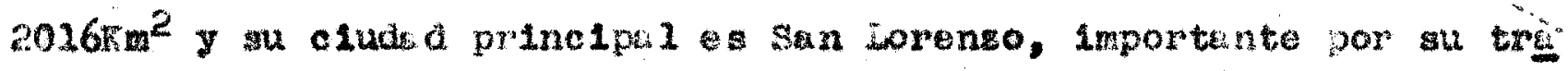

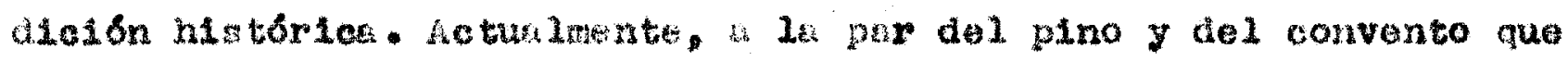

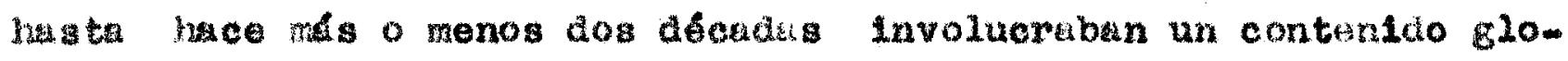

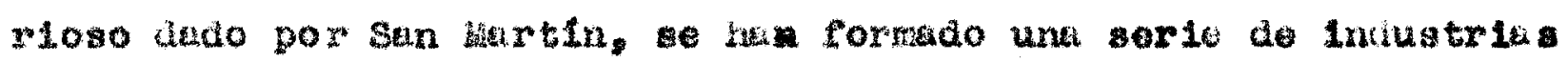

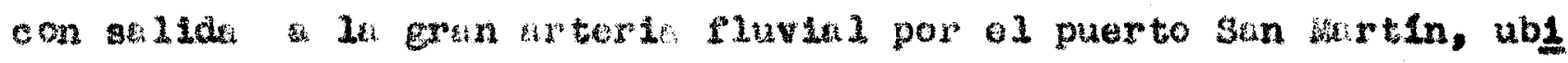
cado un poco més ud nor to $y$ que he adquirido grin inoromento gra-

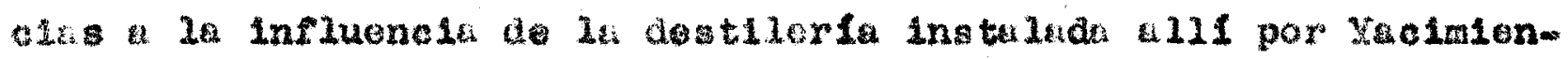
tos petroliforog fischles y otras Indutrias menores y olevadores gue descongestonan el puer to de hosurio.

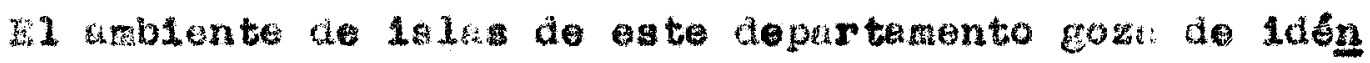

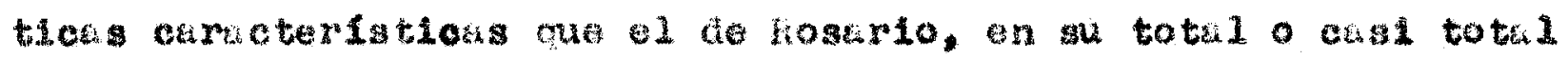

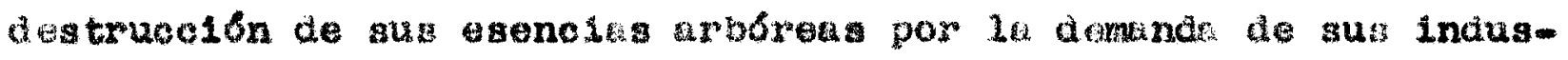



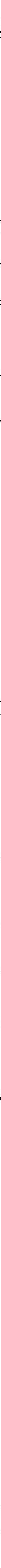



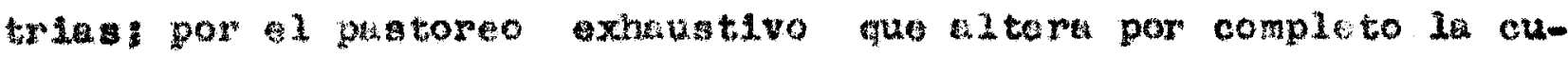

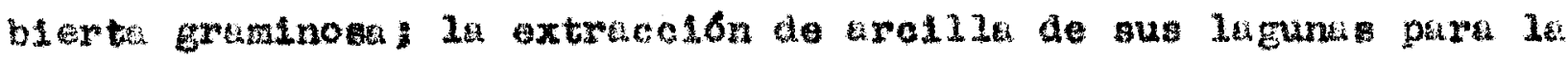

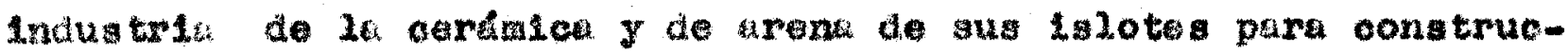

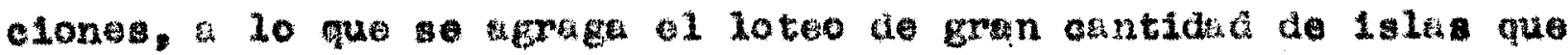

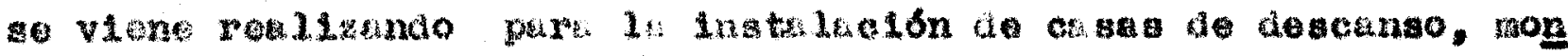

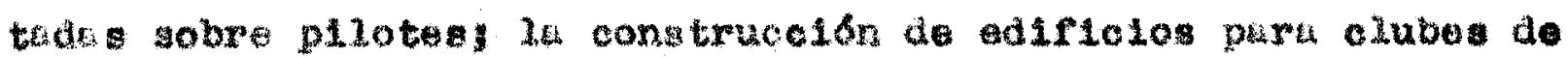

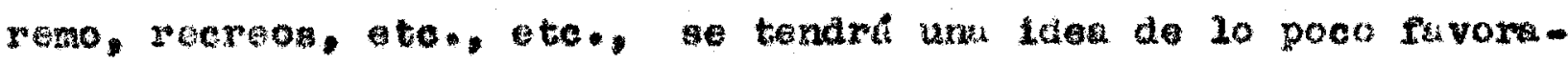
blo guo won ota lale pure 1 atudio floriatco.

E1 deartamento San Gergnimo tione uns supere1010 de 4.192

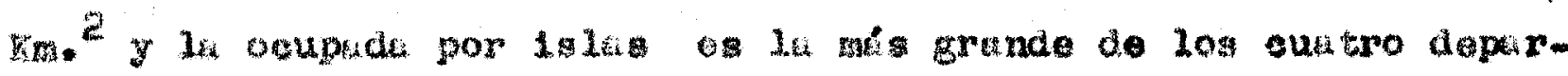

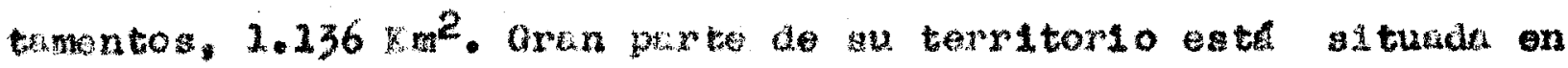

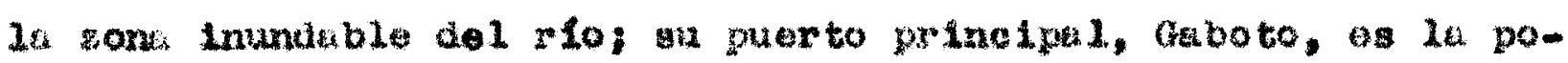

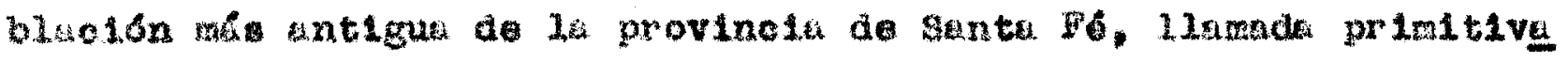

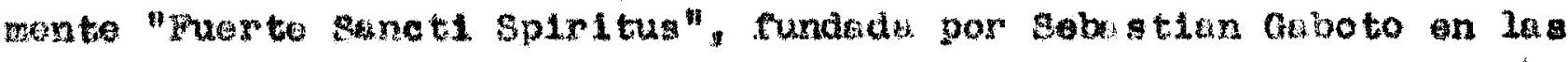

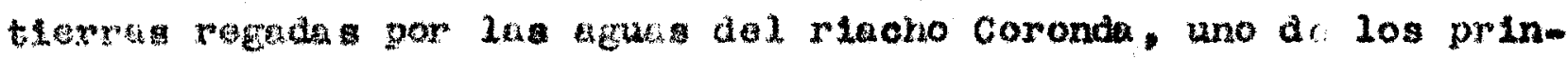
opplos cursos do agur dol anblante inaular de oste departamento $y$

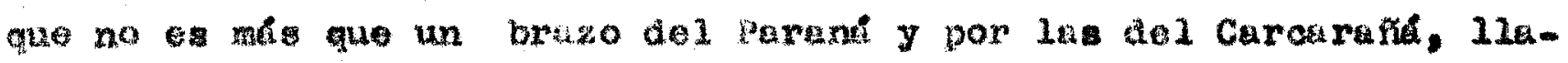

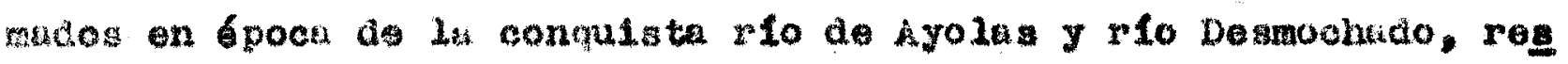
potivisente.

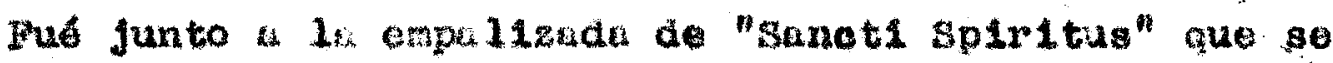
hicloron 10 prineros sultivos de cereales ouropes (trigo y cebaae) Inletinaose junto con Ia crik do gunado en el "fincón do Gabo-

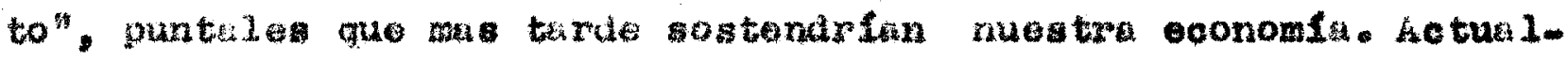

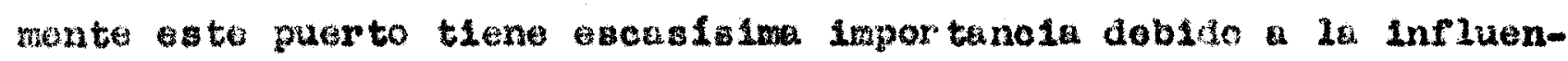

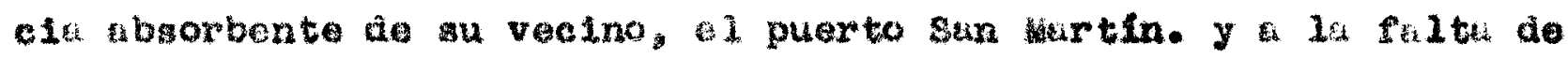

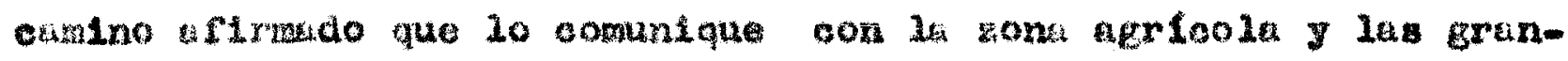
des arrocera que lo clreundan. Su pobliaton, ar busca de trabujo,

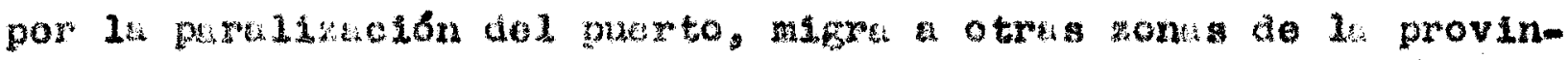

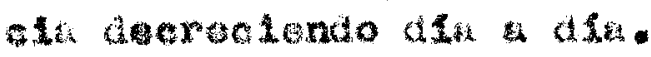

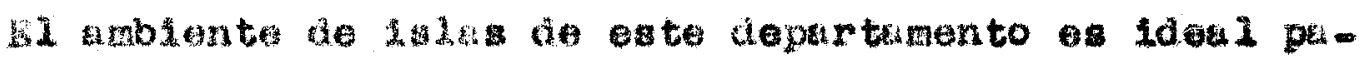

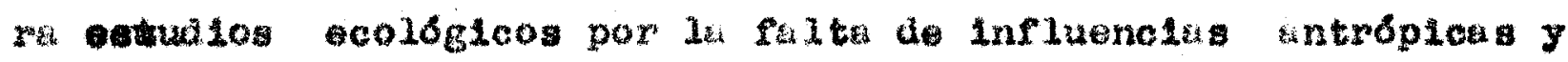

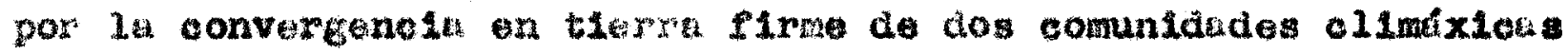


ZONA INSULAP DEL DIO SAN GEPONIMO

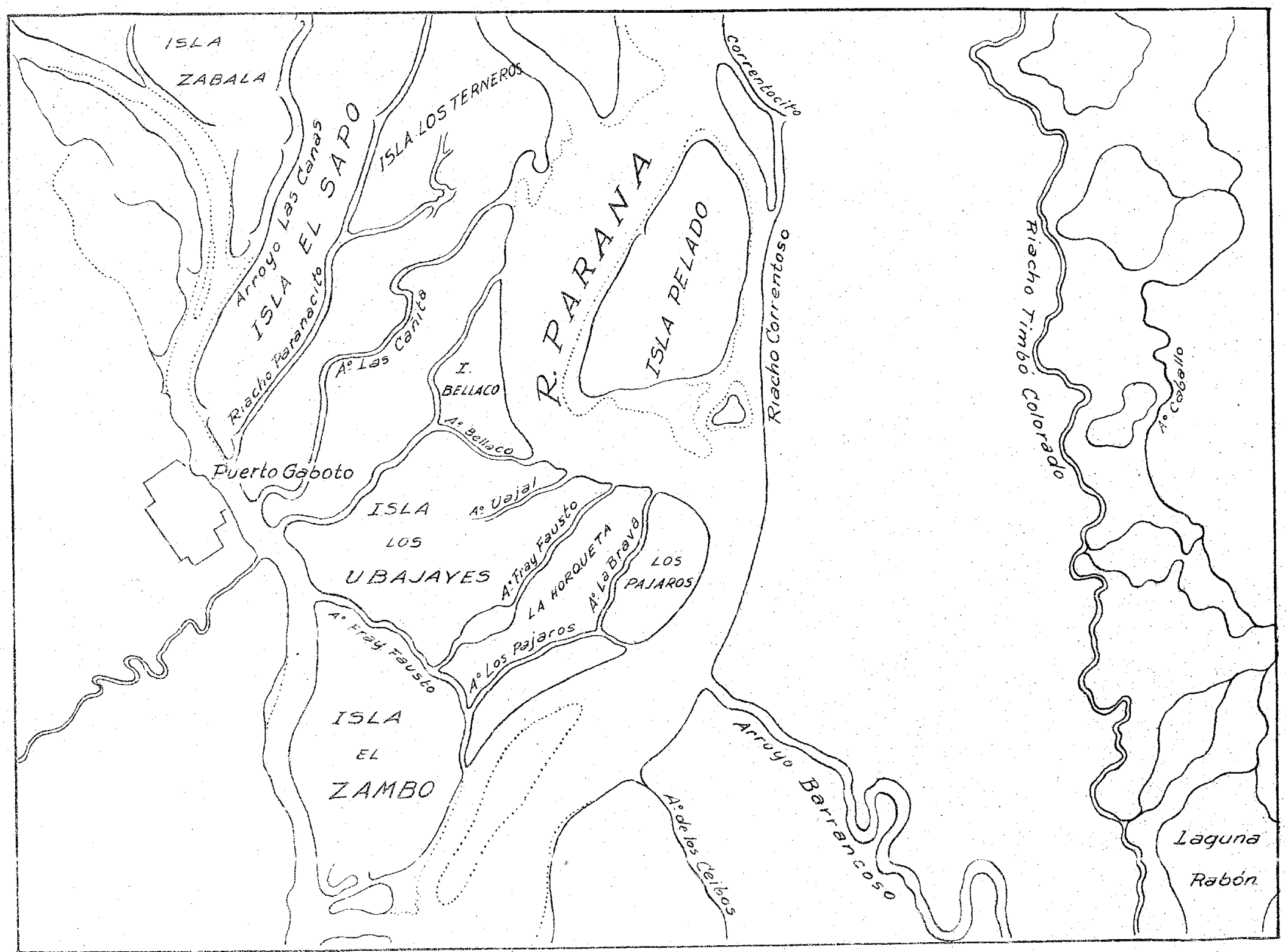




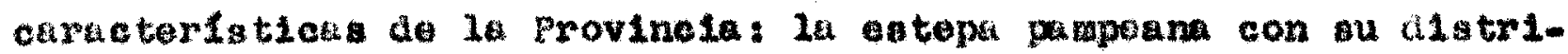

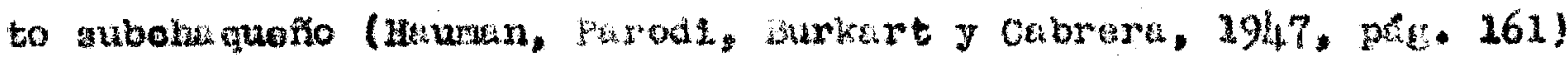
que a

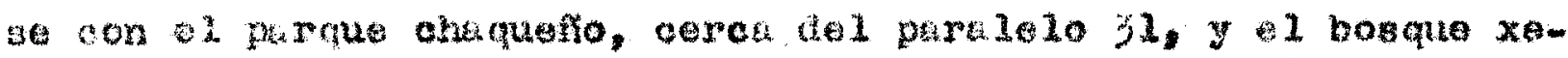

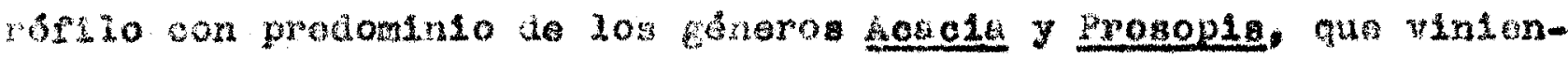

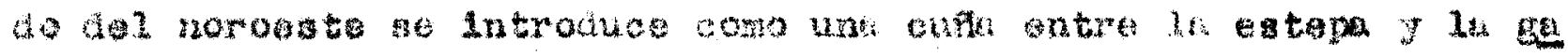

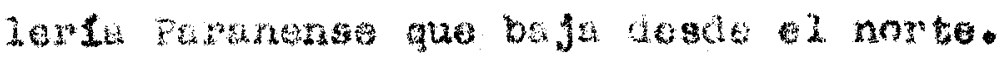

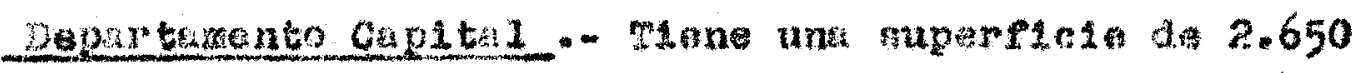

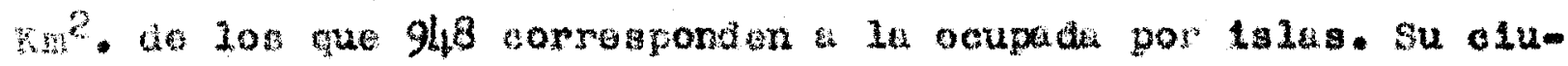

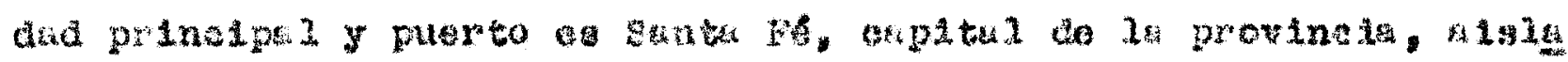

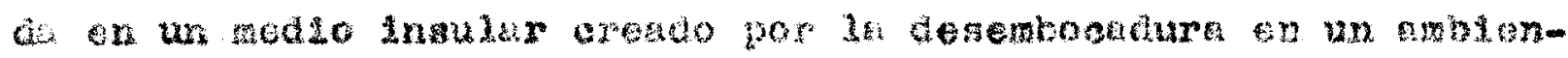

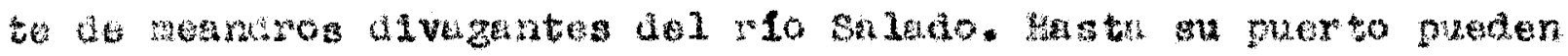

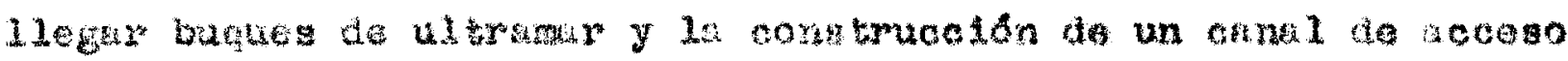

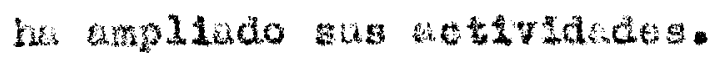

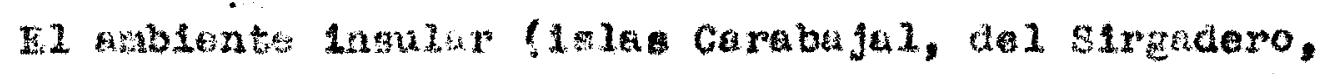

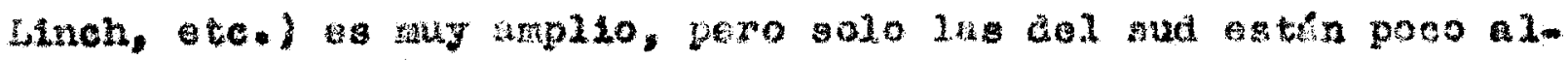

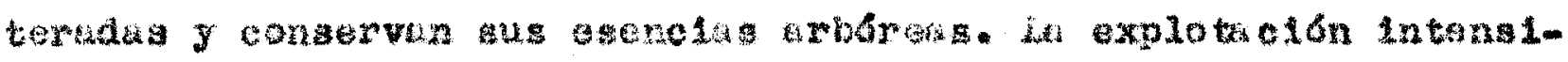

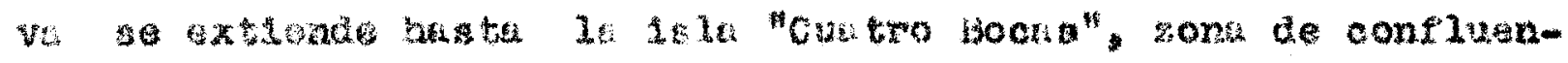

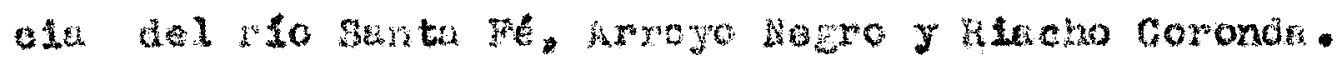


Dentro del eusaro flatogriflco generul de la hepublica

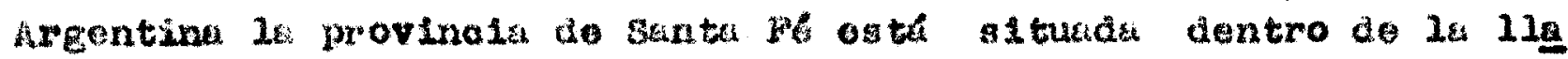
nuxa chaco-panpoana.

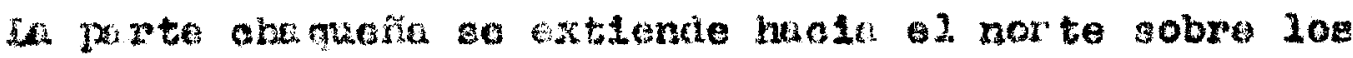

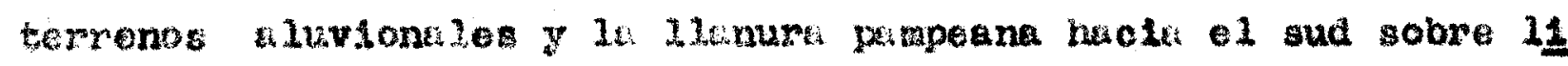
mos I loesa purapunos.

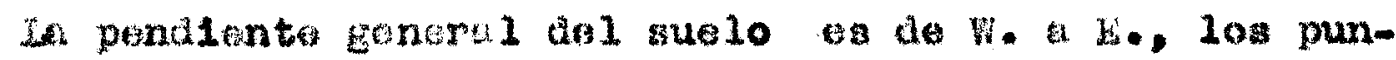

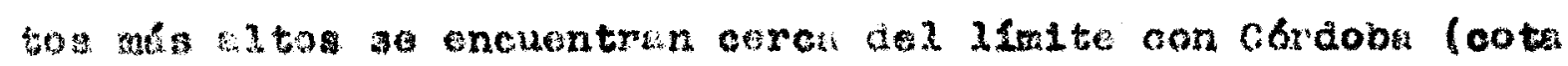

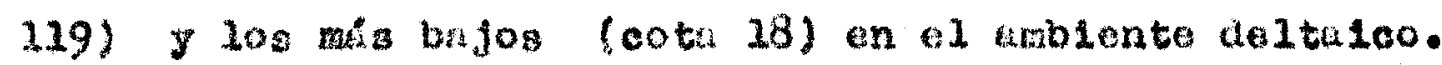

El relieve genorel as cheto, auvenente onculato y

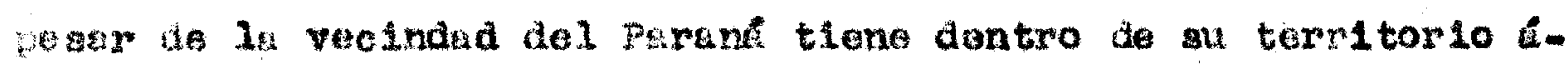
rous de deseghe alficul toro.

\section{4larografla}

Los curgog de cega forman cauces colectores, de diroe

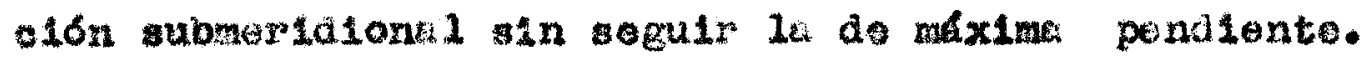

$$
\text { Los princlpales rios, exaluyendo ol parami, son: el }
$$

salado que desemboed on lu veolndud de santa 6 , no tiene importan ela para la navogación y solo 10 aruan pequefit embaraciones de

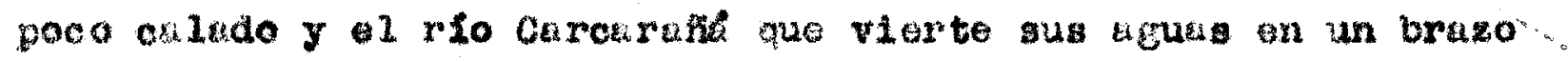

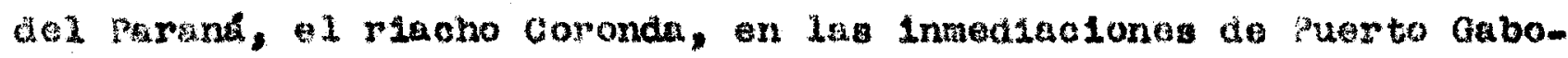

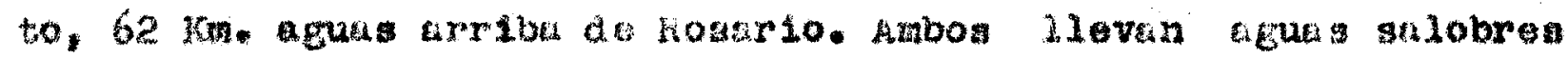

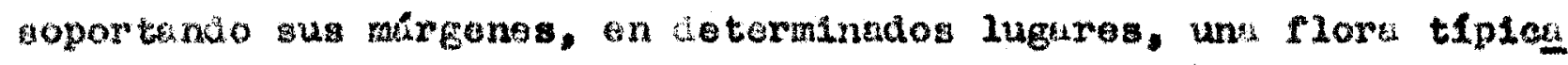

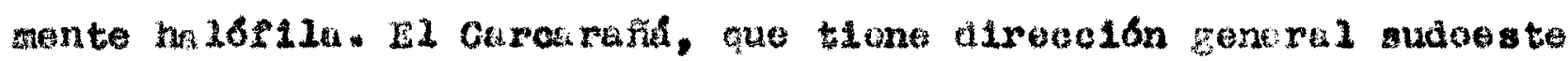

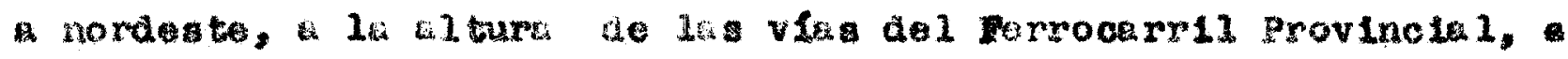

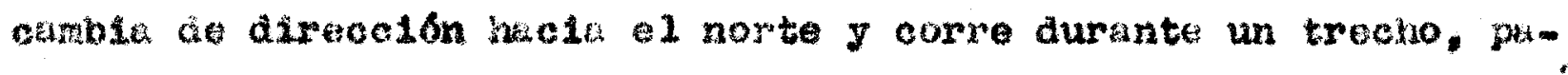

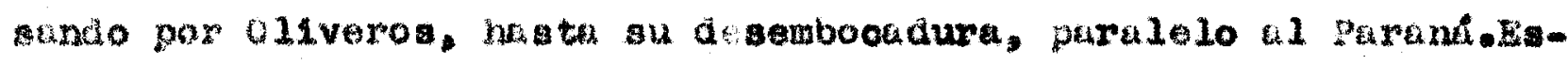
ta zona 1Lama "xinoon de Grondona" conserva, pesar de estar o.

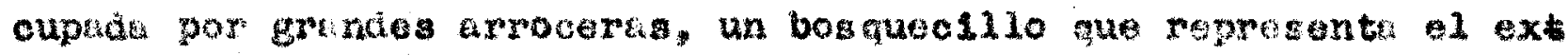

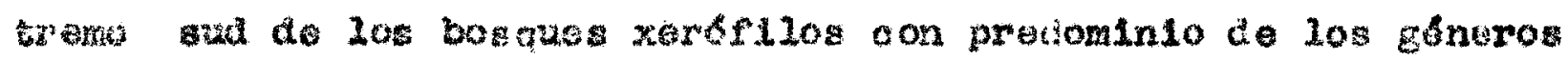

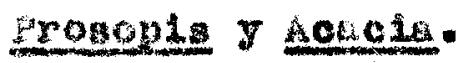

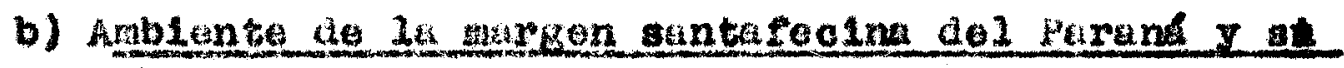


desde krome (dopartamento General obligudo) hasta la cludad de

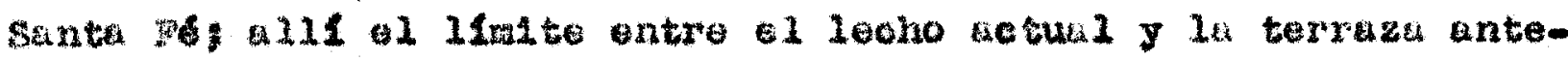
xlor ae hace notable gracias a la presencla de un eatrecho alburabn, interrumpido solo por exntiles artifletvies de desagte. y por arroyos na turules hacl*a el sua.

Desde Puerto Gaboto hacla abijo aparoeen carcterlati-

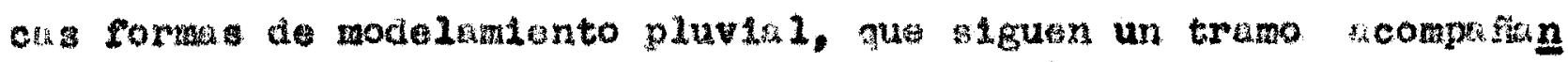
do la márgenes del rlo ctrouraña partentrar oores de colón on la provinelis de Buenos Alres.

EI rolleve caratertatioo de las lolas del Parana se ex tiende on una faja de ancho varlable antwe $25 \mathrm{y} / 40 \mathrm{~km}$. y compronde el actual rlo con sus xlachos parant Minf, saladillo, Dulce, Salad110 urargo, san Javior, Colastine y Corondk. (Deade 16.s "Cuatro Bocas" hack ol and os costumbre llamar al cance costero Rlo filucho coronda cundo on reclidad es une continudeton del rio sa1ndo). Sus 1slas con a lbardone y lagunas internas y uns fuja 11toral, son cartacteriaticas que lo vinoulan al amblente doltaleo. Segin J. Gollan y Dama so Laohrag (1939, pag. 192 y sie.) dentro de ests mirded exiaten tres elementos morfológicos:

1) Un eatrecho albarán de 3 a $10 \mathrm{Km}$. de uncho que corre adoado al lecho de Inundactón actuiz del Parsinh.

2) Une terraza de relieve cha to con ondulacionese

3) Lomaka que se levintan sobre la terraza con caricter de ex-1sias del antiguo lecho del Parant.

S1 relleve es easenclidiente chato, poro la erosion esta

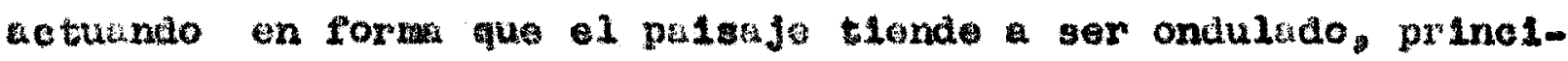
pelmente sobre al tuburión de lo costa.

Jo: la la aguas pluvilites de la provincle de Santa fe llegan al mar mediante dog rlos, ol parana y el salado do $2 a$ provineta de Luones Azres. 


\section{c) 1 l ko parking}

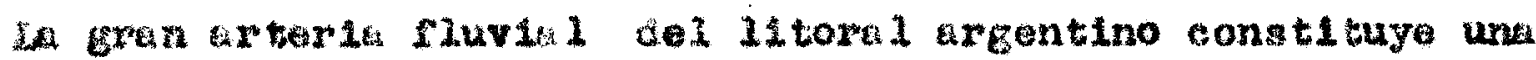

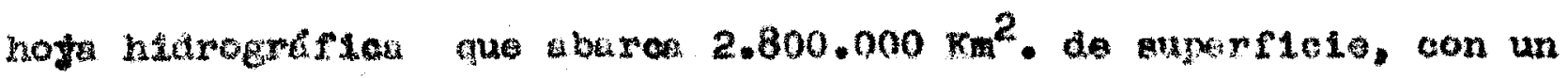

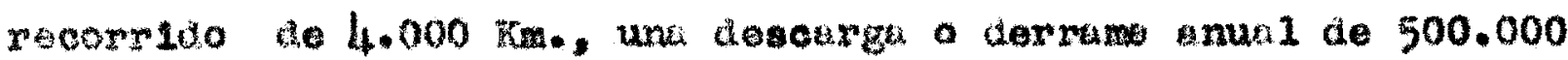

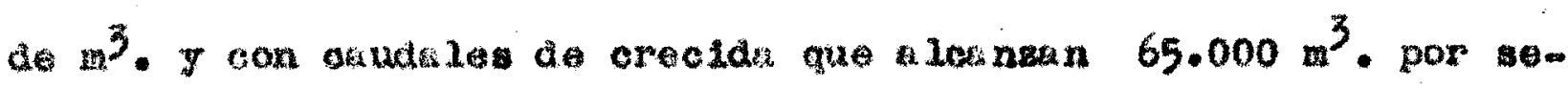

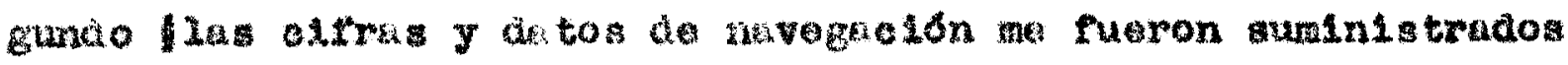

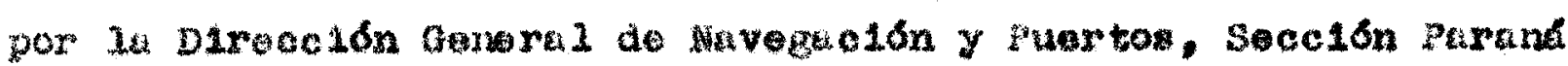

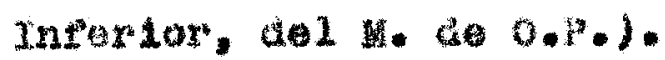

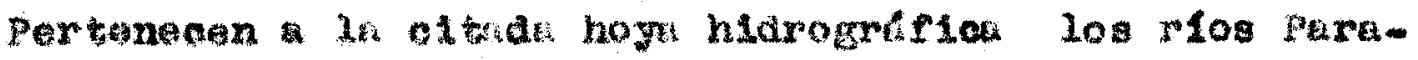

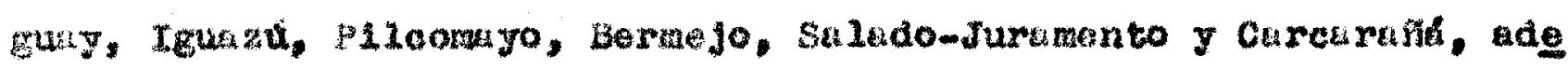

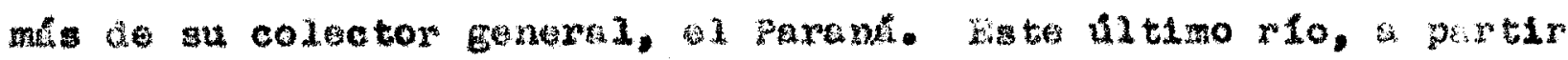

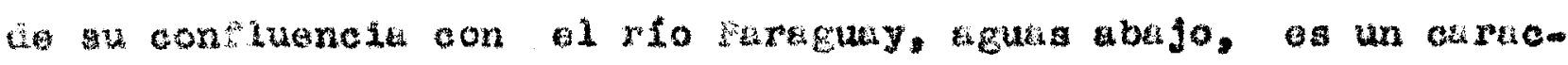

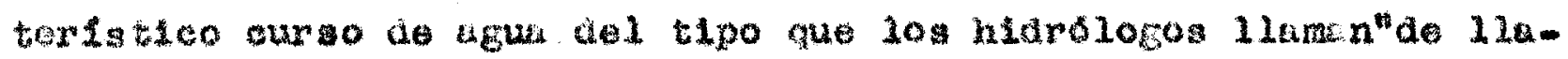
nurs con locho de Pondo movible".

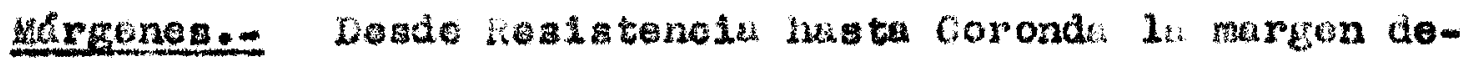

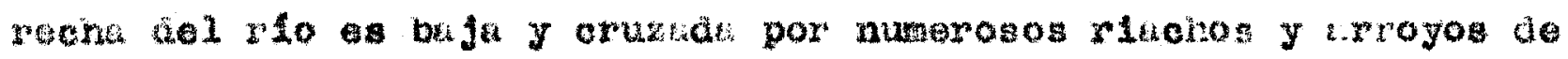

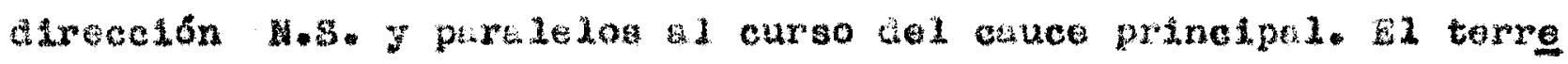

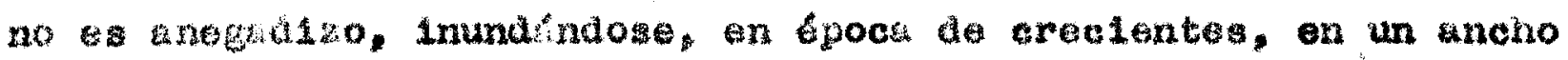

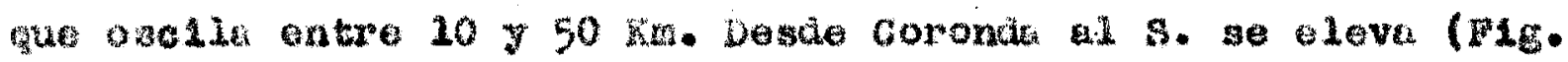

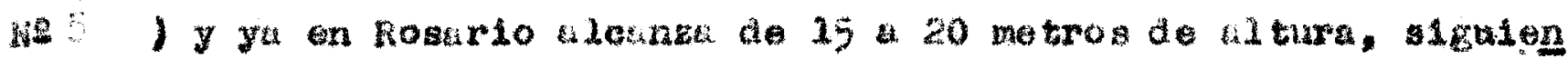
do esta media hasta del dea inferior.

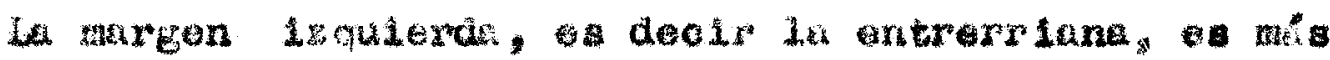

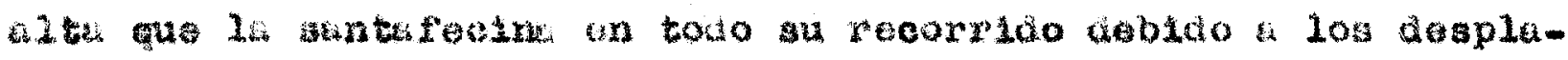

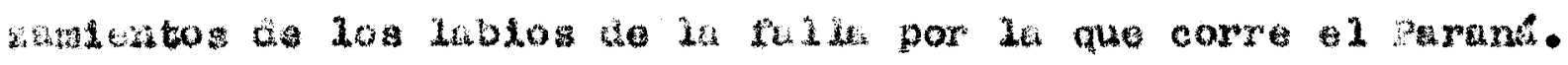

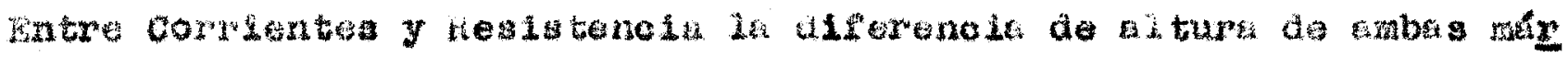

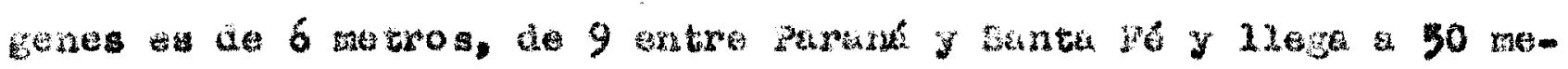
tros a domivel entro hosurio y victaria.

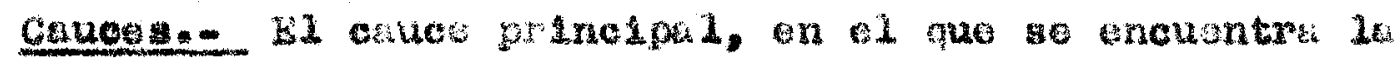

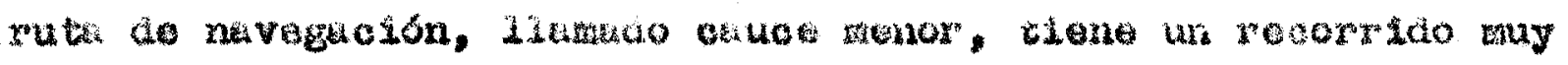

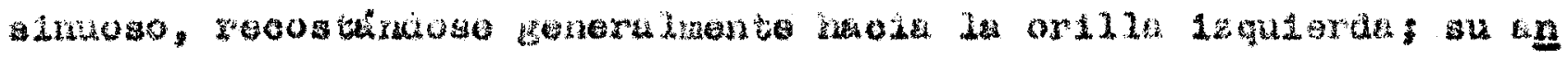

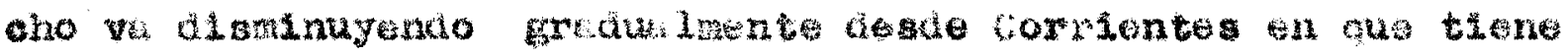

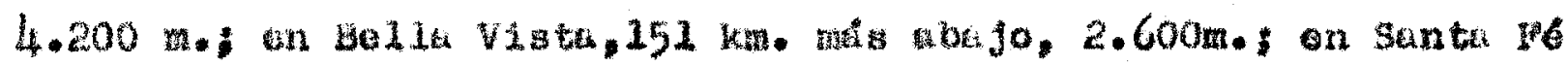


$2.300 y$ on hosario 2.000

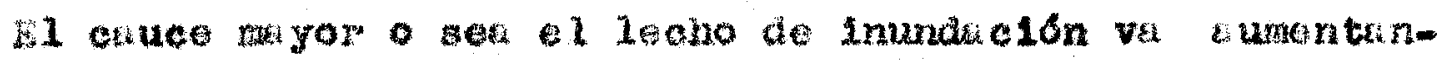

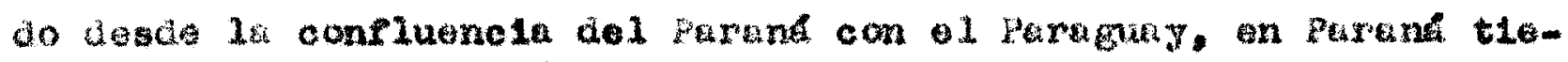

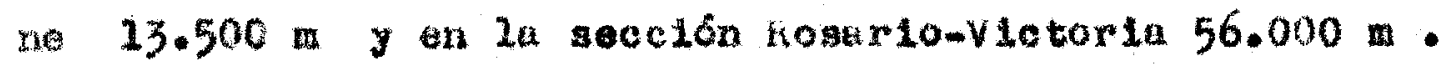

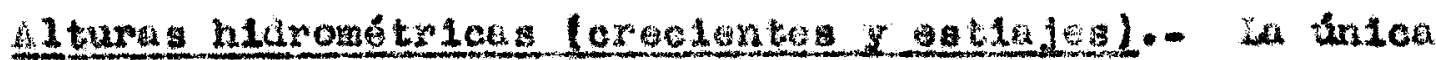

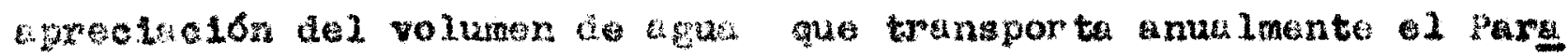
nt fue herk on 1899, chloulo dudoso que nnde nos d1ce de las at-

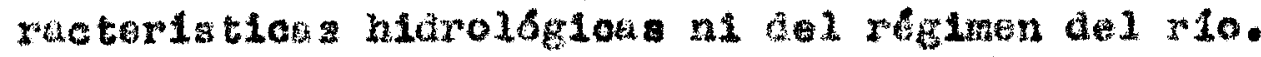

EI cudaro ne' no

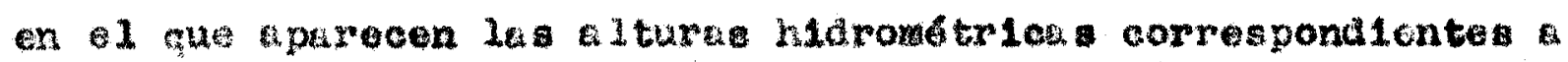

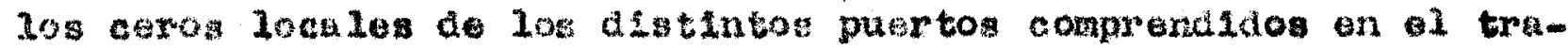

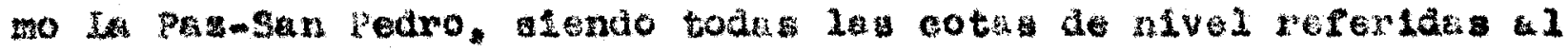

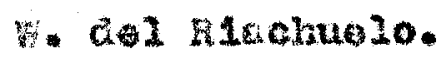

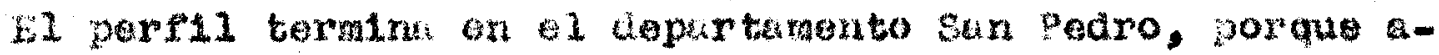

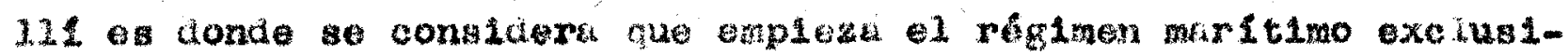
vamente, ea deolr influenoludo por la mases.

Sn ol trano koskio-sun paro ol regtan as mixto.

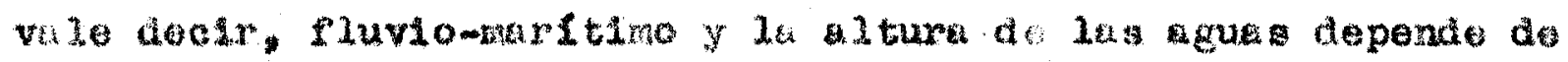

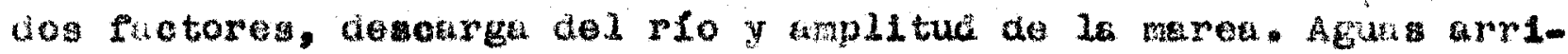

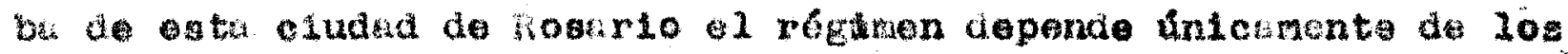
elentontos hidrologlcos, as de euricter fluvind.

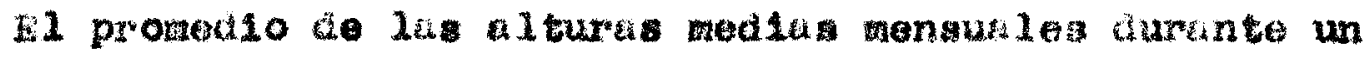

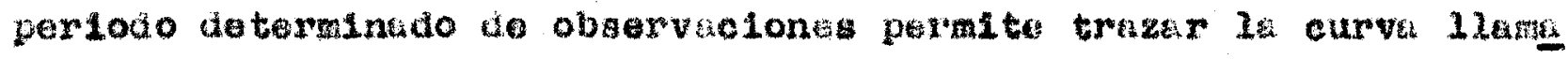

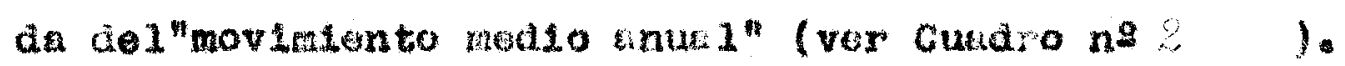

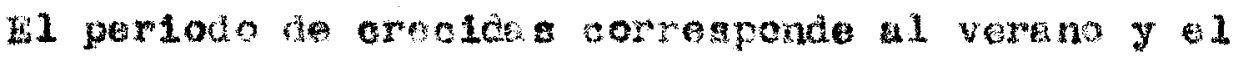

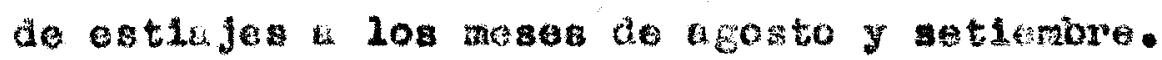

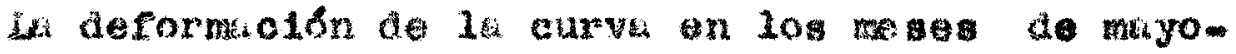
junlo corresponde a un repunte 1 iamdo "ropunto del pejarrey",

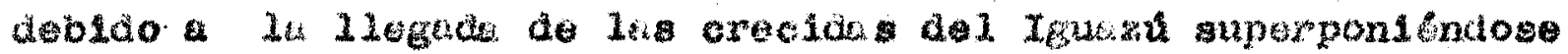
5. 1 a cous del parank.

Qutudiano la curve del cuadro ne vamos: 
Cuadrorto 1

Perfil hidráulico del Parano

Iramo La Daz-San Pedino

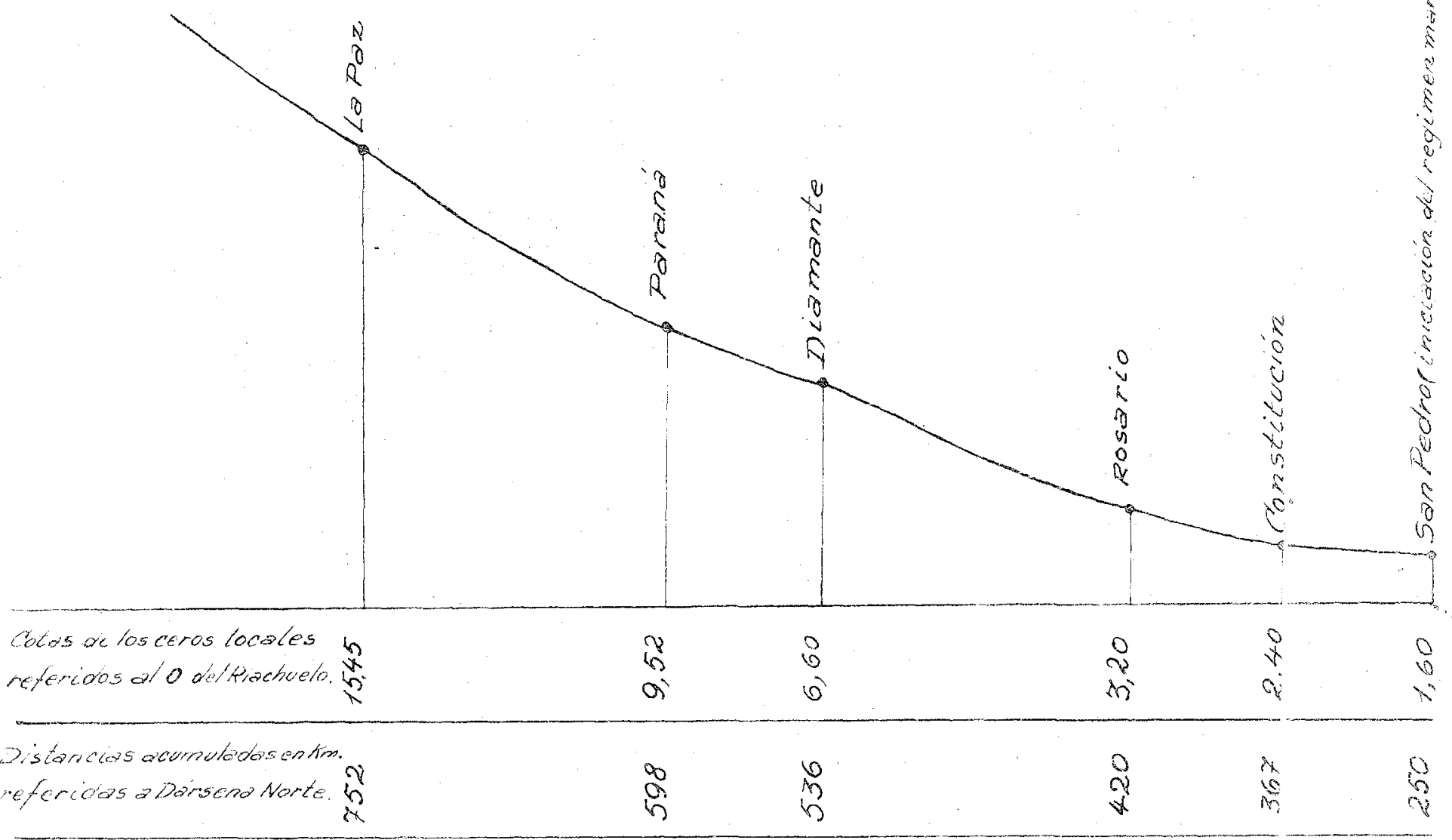




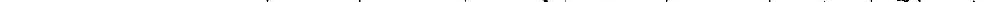


1) Un periodo de bujunte que so iniola pines ato otofio con ostajer minimos en tagosto $y$ setiombre, que veces ae prolon-

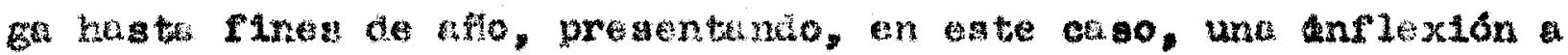
principlos to mireivera.

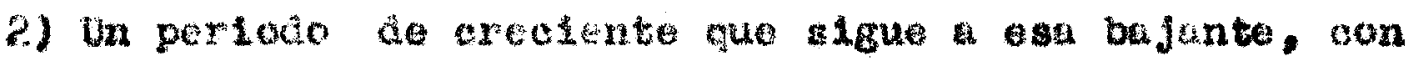

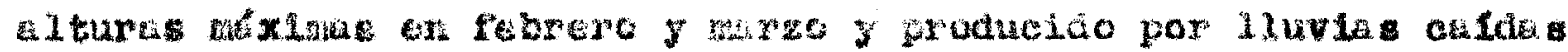

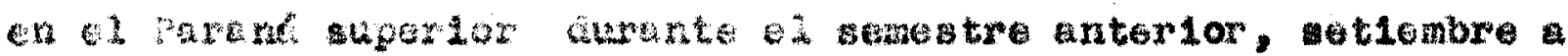

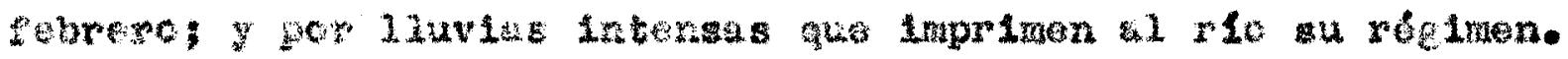

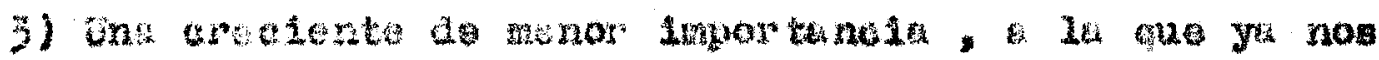

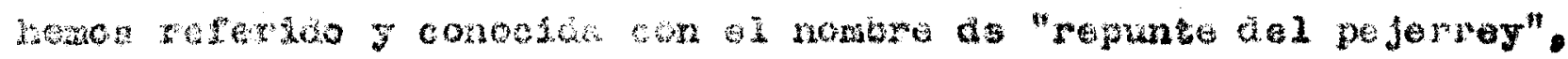

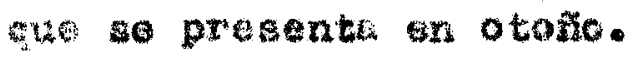

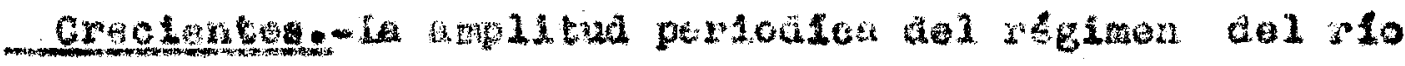

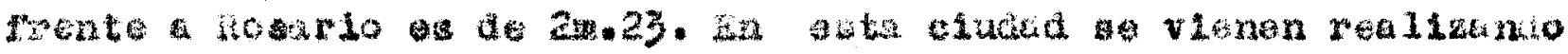

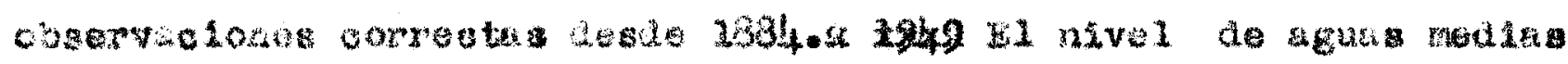

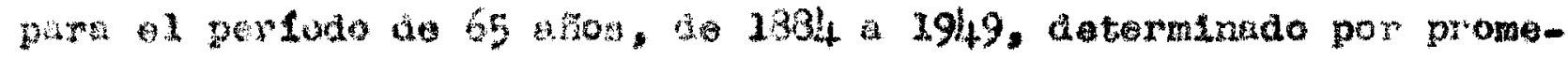

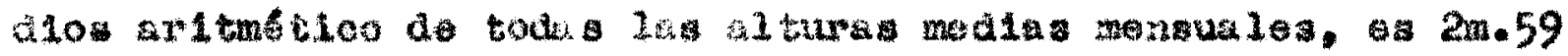

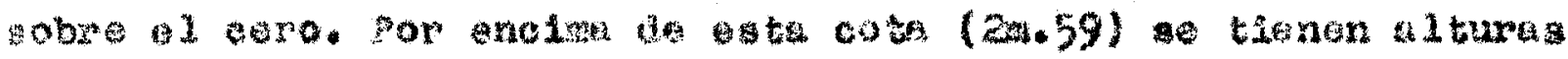

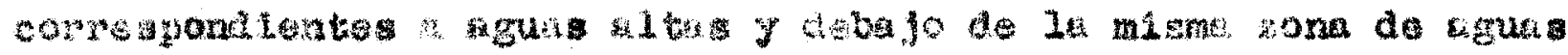
bugne.

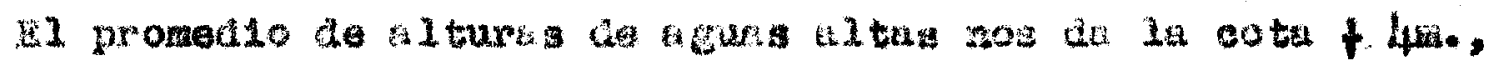

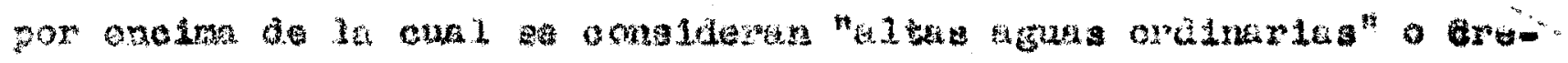
chas ordinentas".

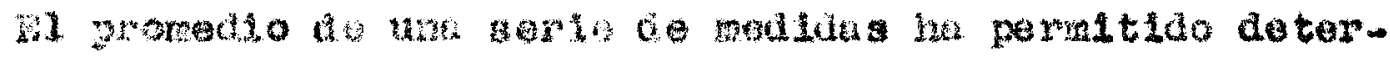

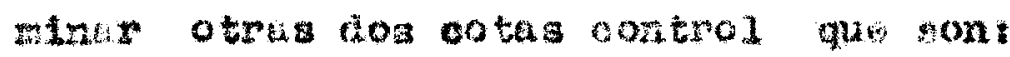

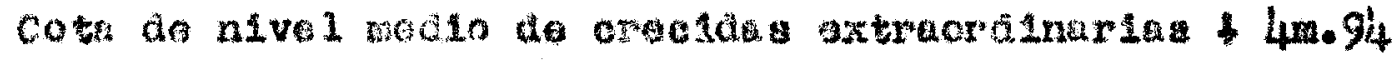

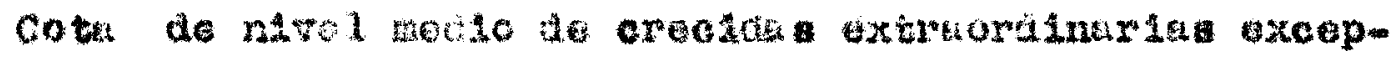
s.ond 1 a $+5 \mathrm{mat}$

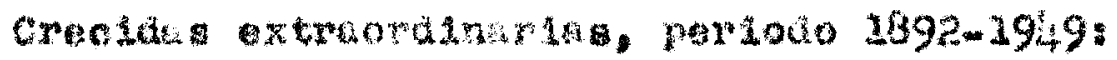

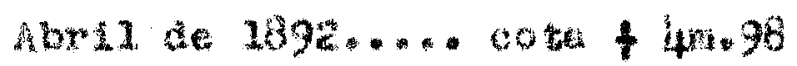

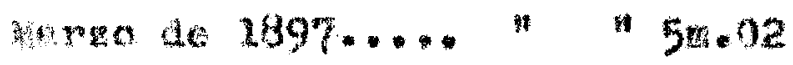

Tunio de $1905 \ldots . . . "$ "6m.22

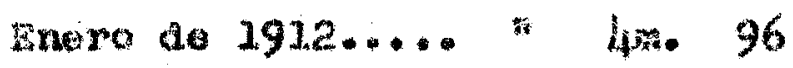




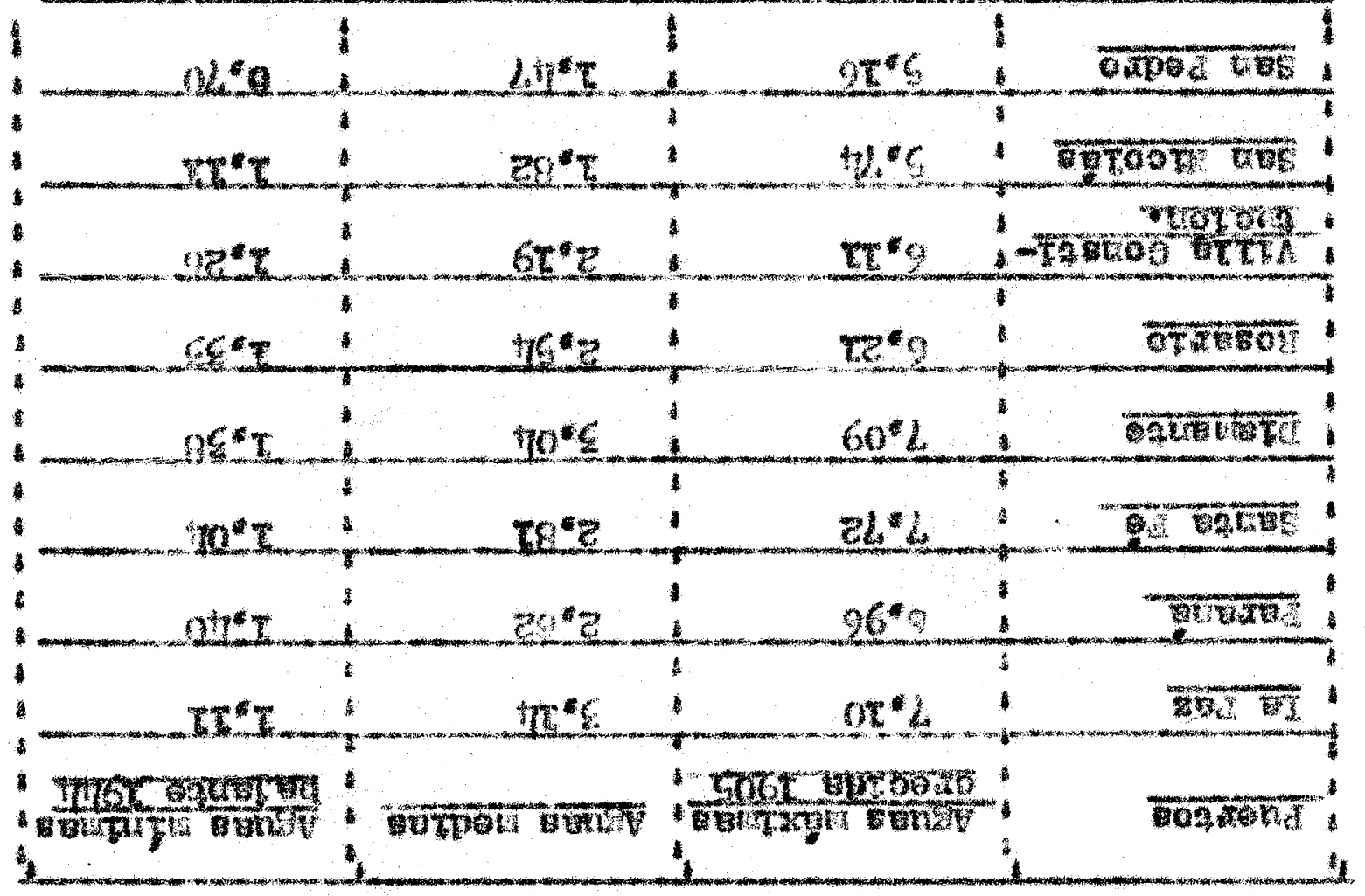

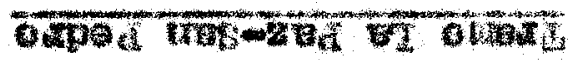

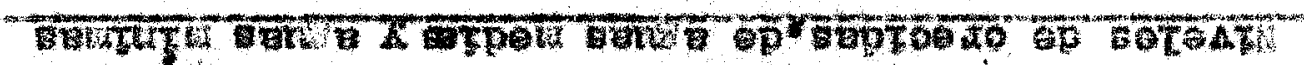

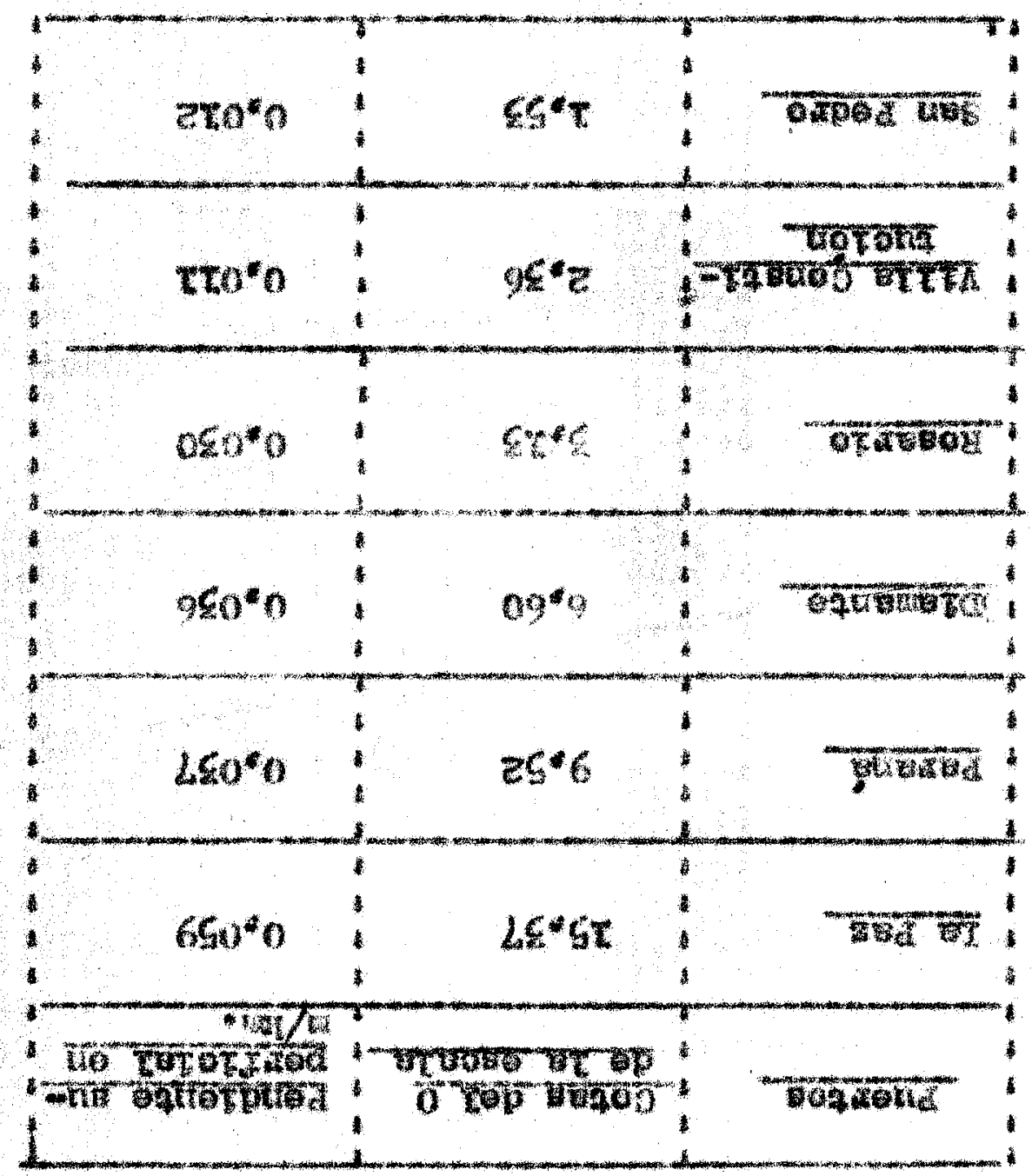




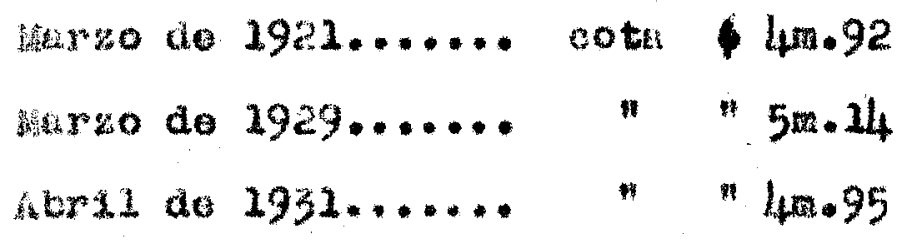

solumente la creciente de 2905, gue klexino en ko-

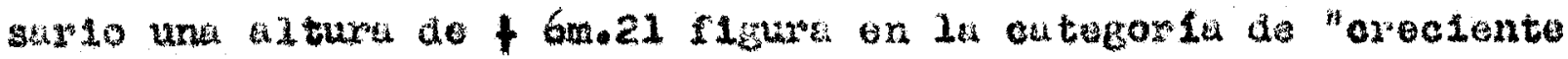
oxtraordinaria oxcopelond".

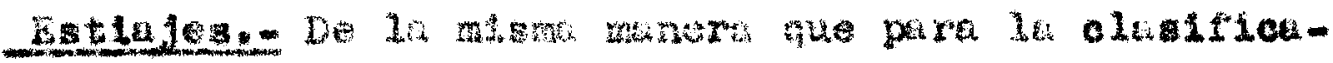

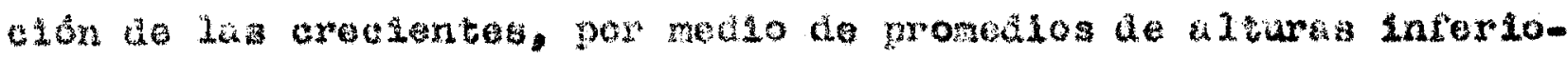

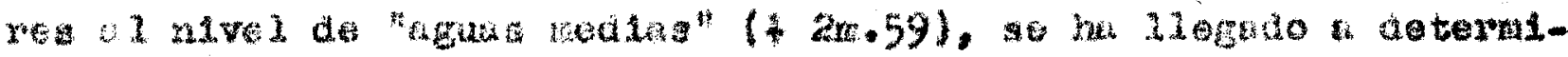

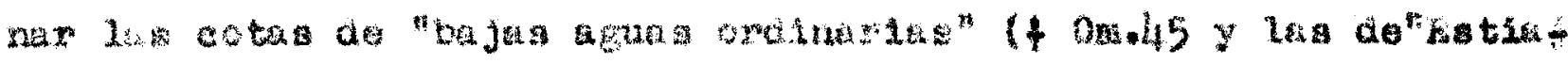

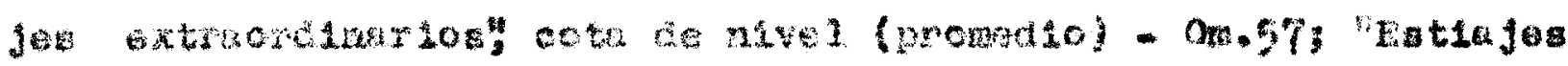

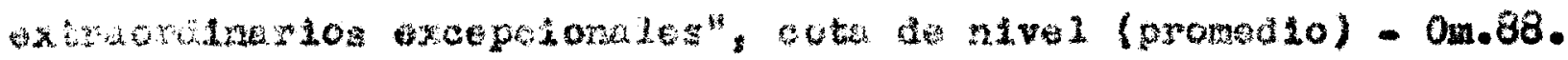

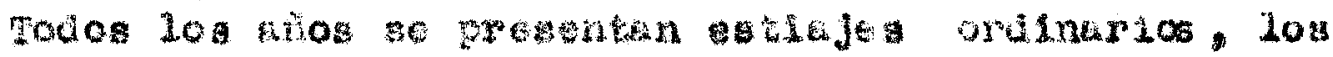

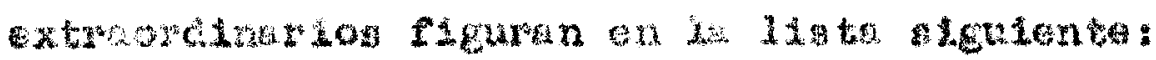

\begin{tabular}{|c|c|c|}
\hline Enoro de $192 \ldots \ldots$. & otet & $-0 m \cdot 74$ \\
\hline Wictembre do 1916. & $"$ & $-1 m .0$ \\
\hline 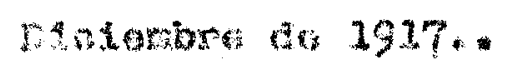 & $"$ & -0 r.os \\
\hline hoviembro de $19 \%$... & $"$ & $-0 m .86$ \\
\hline Seturnbre do 1935. & $n$ & $-0 m a 89$ \\
\hline 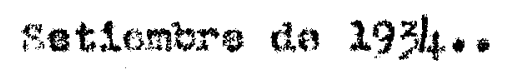 & $n$ & $-0 \operatorname{mas} 86$ \\
\hline octubre de $1937 . .$. & " & $-0 \mathrm{ar} .5 ?$ \\
\hline Cotubro do $194 \mathrm{~h}$ & " & \\
\hline
\end{tabular}

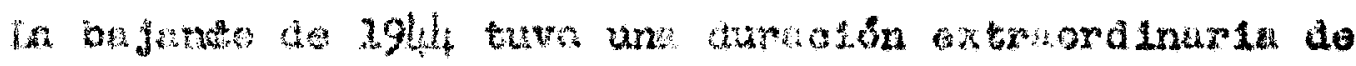

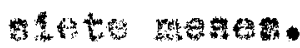

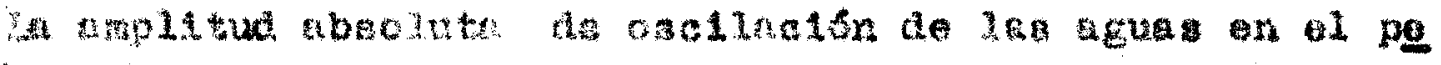

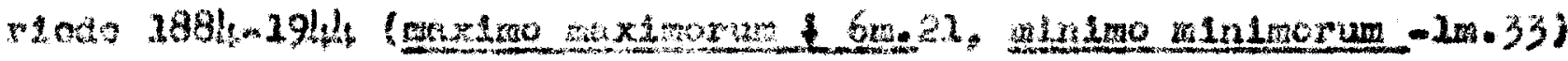
recult to de $7 \mathrm{~m} .54$.

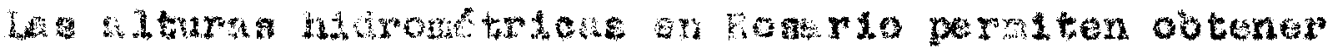

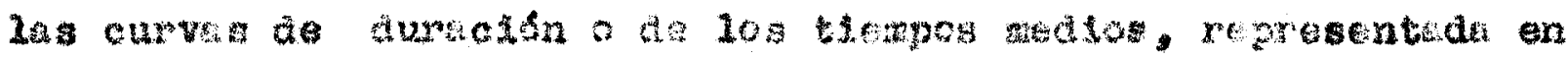
la pieng

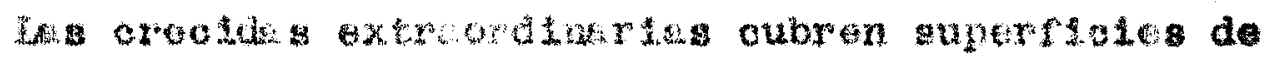

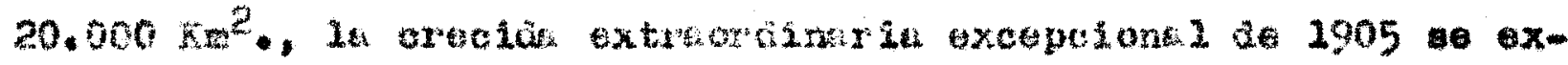
tends6 sobre $35.000 \mathrm{Km}{ }^{2}$, do $10 \mathrm{~s}$ cuileg 20.000 orar do ambiente 


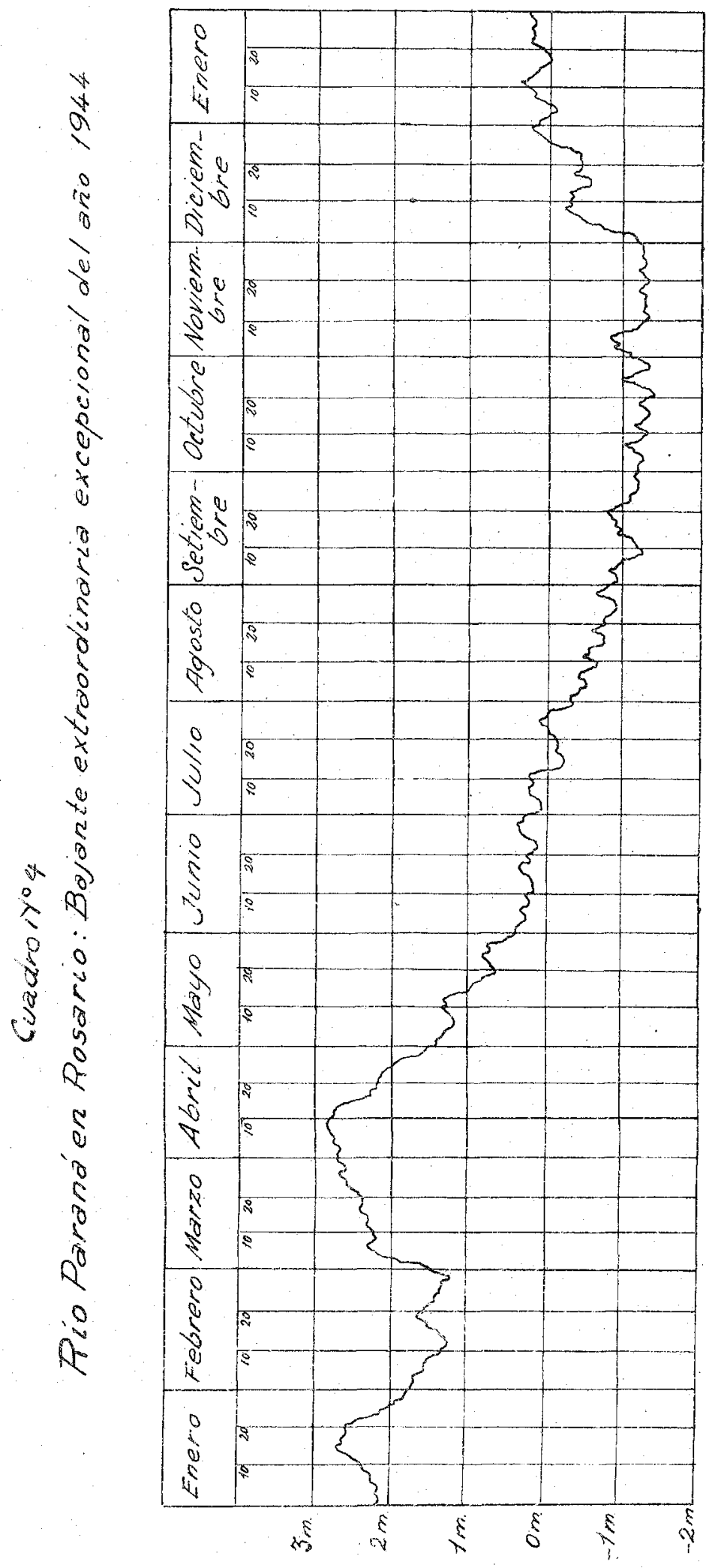




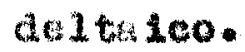

Cauda les - se hi convonido an obtener valores de derrane a-

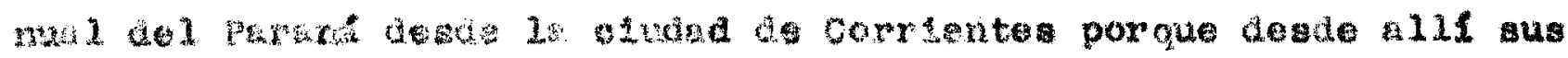

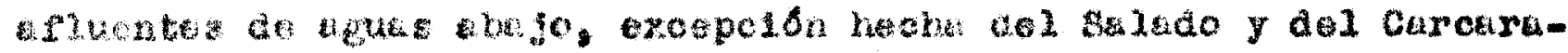

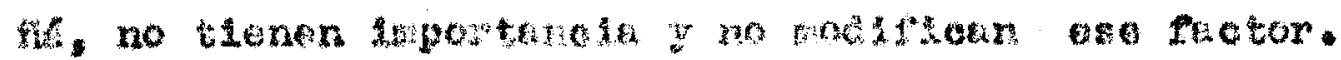

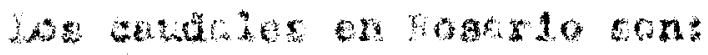

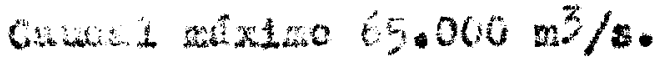

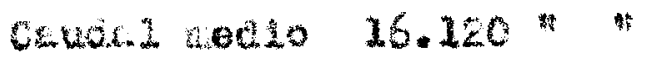

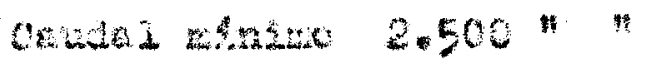

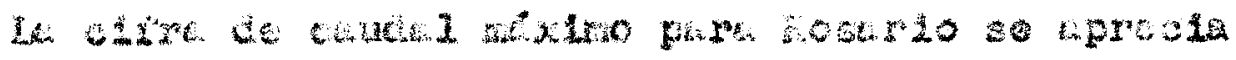

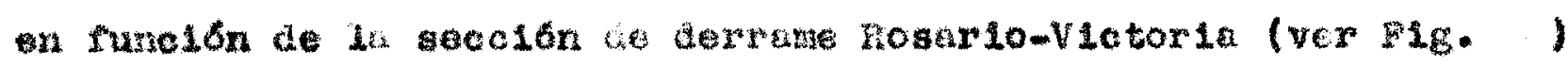

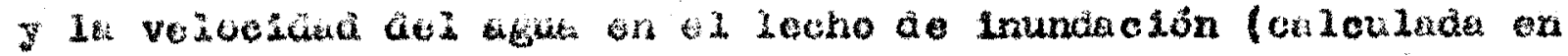

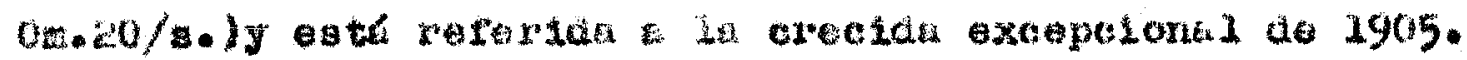




\begin{tabular}{|c|c|}
\hline Año & $\frac{\text { Denrame }}{\sin 2}$ \\
\hline 11901 & $: 416,3$ \\
\hline 1902 & 482,5 \\
\hline 1903 & $: 425.7$ \\
\hline 1904 & 1584,6 \\
\hline 1905 & 701,6 \\
\hline 1906 & 1498,3 \\
\hline 1907 & 514,0 \\
\hline 1908 & 1564,5 \\
\hline 1909 & 419.1 \\
\hline 1920 & 1406,8 \\
\hline 1911 & 411,9 \\
\hline 1912 & 1592,9 \\
\hline 1913 & .487 .2 \\
\hline 11914 & 1468,3 \\
\hline 1915 & 439,4 \\
\hline+1916 & 1384,7 \\
\hline 1917 & $, 378,4$ \\
\hline 1918 & 1450,1 \\
\hline 1919 & $, 573,9$ \\
\hline 11920 & 1611,8 \\
\hline 1921 & 547.6 \\
\hline 1922 & 1629.1 \\
\hline 1.1923 & .619 .7 \\
\hline 1.1924 & $14,27,3$ \\
\hline 1925 & 392.6 \\
\hline 1926 & 578,7 \\
\hline 1927 & $.469,9$ \\
\hline 1928 & 542,4 \\
\hline 1929 & 638,0 \\
\hline+1930 & 328,2 \\
\hline 1931 & $.671,7$ \\
\hline 11932 & .638 .6 \\
\hline 1933 & 1451,1 \\
\hline .2934 & 350,0 \\
\hline 1935 & 577.1 \\
\hline 1936 & 436,8 \\
\hline 12937 & 1447,8 \\
\hline 193 & 435.2 \\
\hline 1939 & $.473,0$ \\
\hline 1940 & 533,0 \\
\hline
\end{tabular}

Demrare total da el ponfodo 19012940 : $20.247 .5 \mathrm{Ku} 3 .-$

Dexrame promedito en el períndo 1901-1940 : $506,28 \mathrm{x} 013 .-$ 


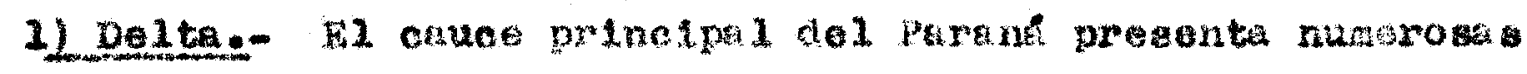

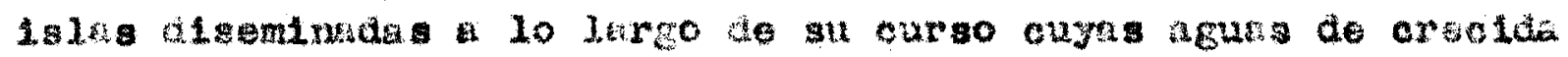
1 a cabren totamenta.

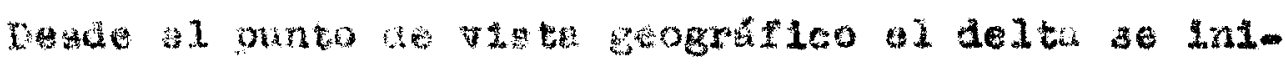

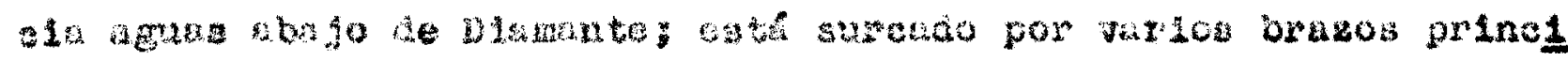

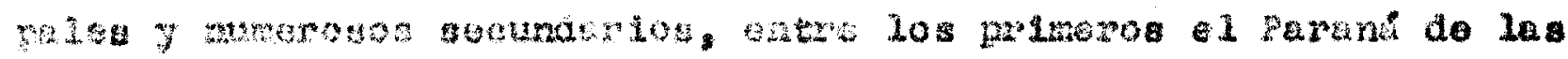

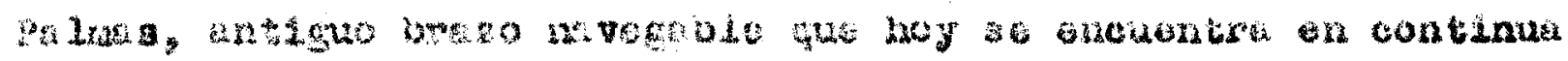

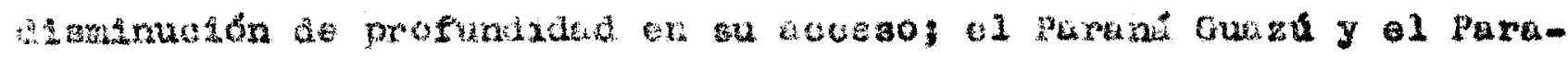

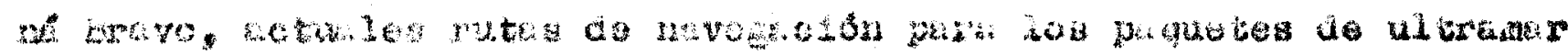

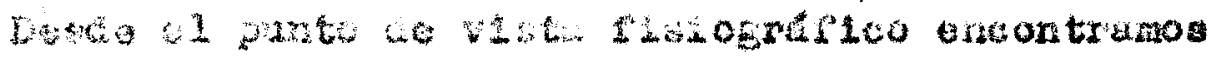

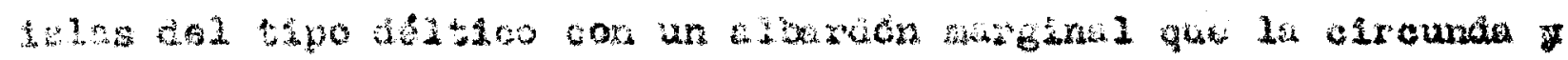

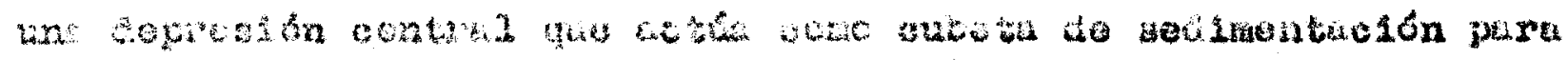

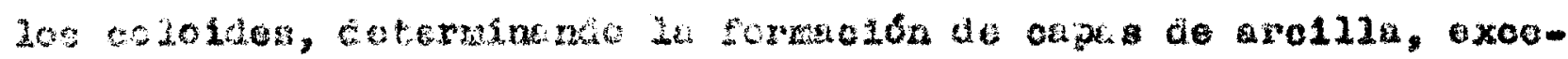

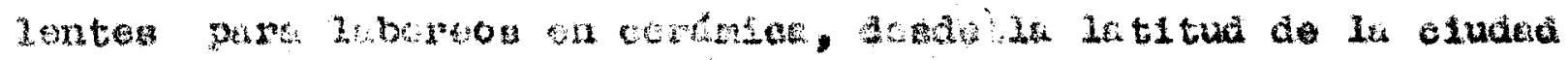

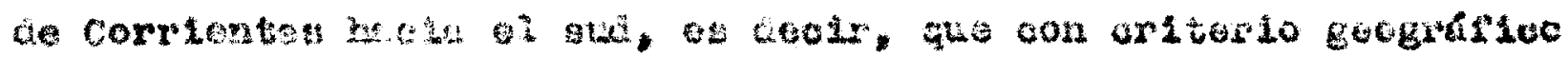

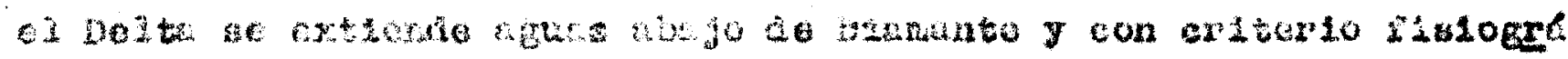

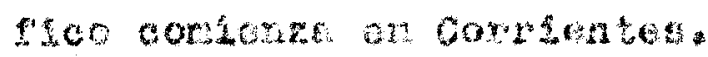

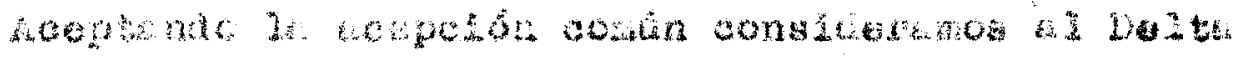

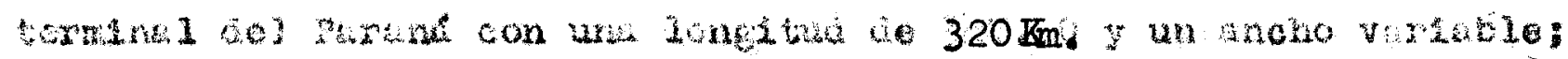

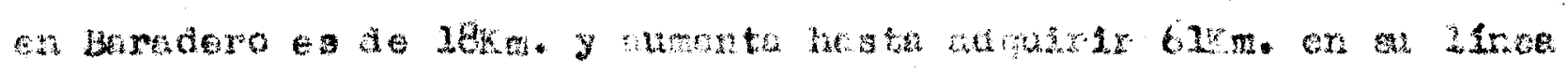

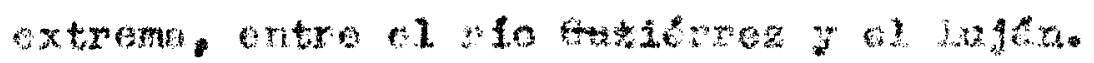

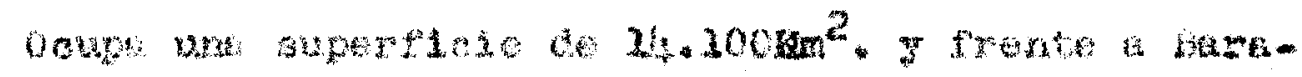

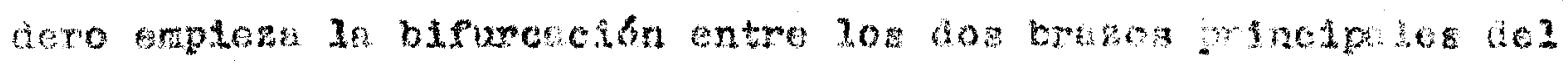

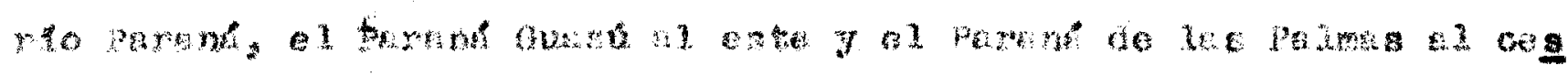
$+$

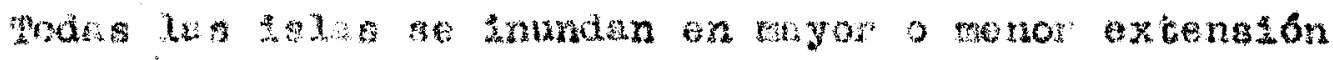

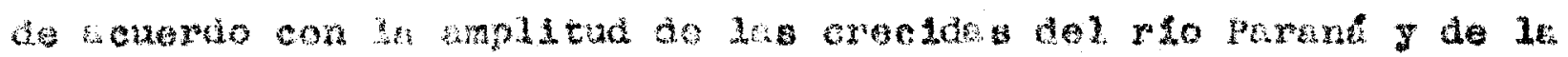

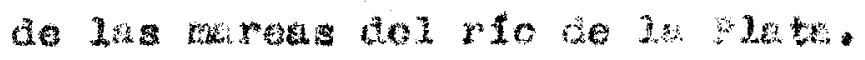

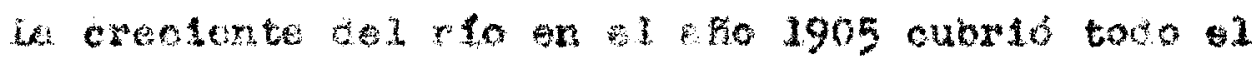
oolta.

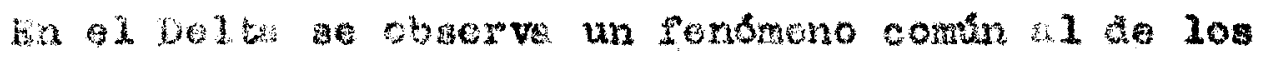

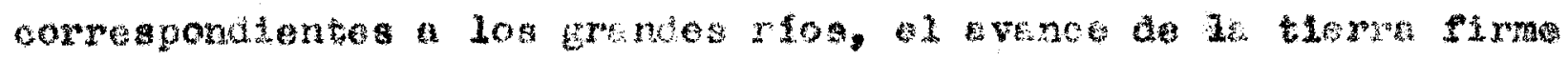




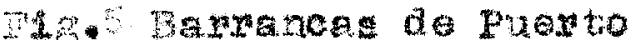
Caboto. $=$

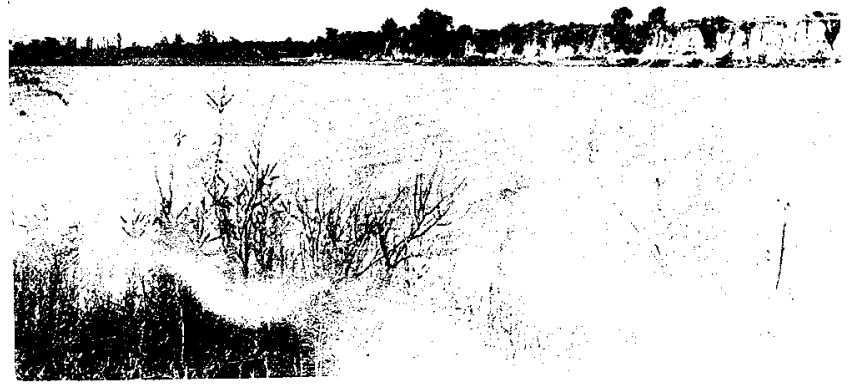

F4. Rosario..
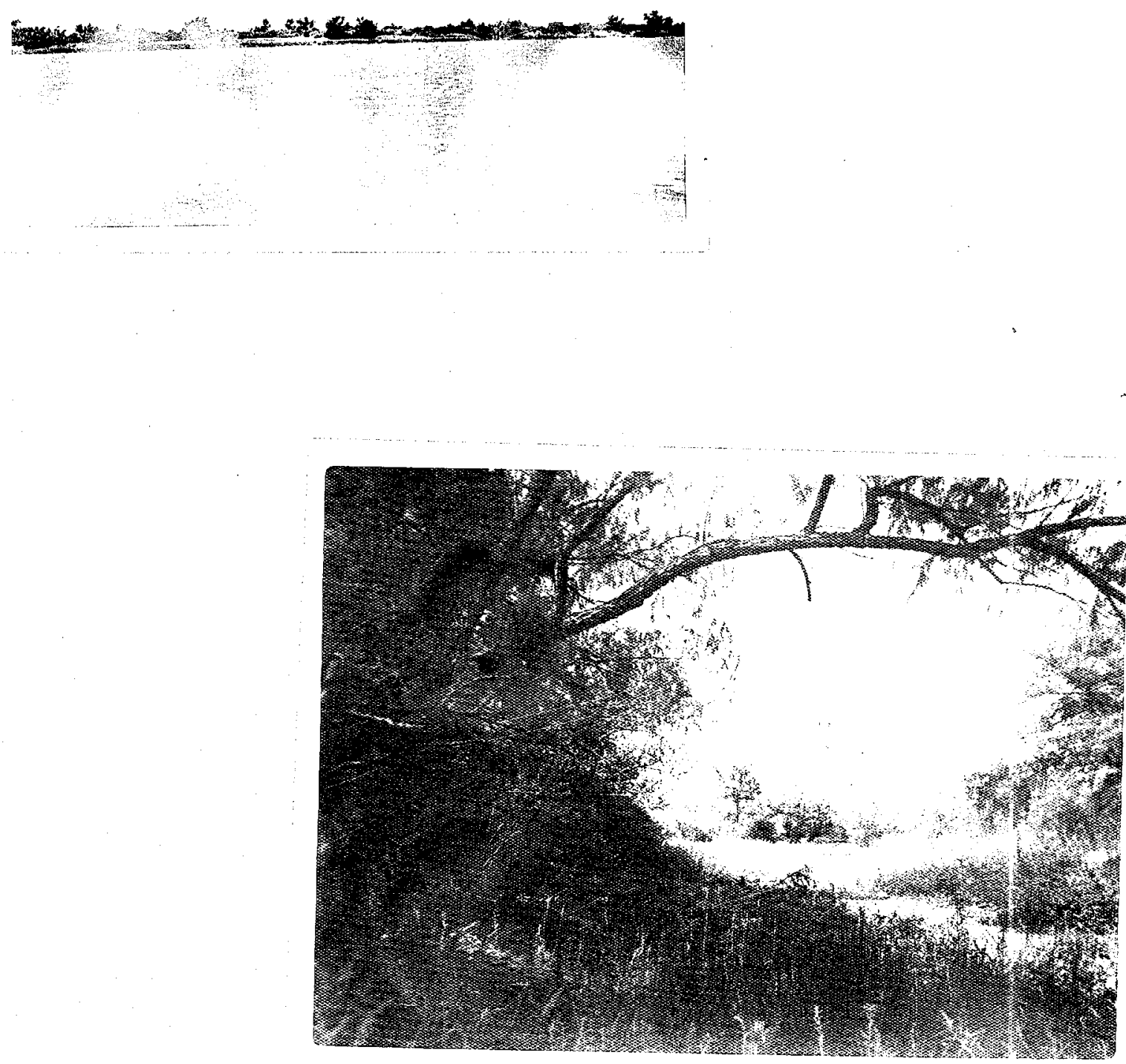

Pis. Paisaje do una "boca".- 
haola guas abejo, awertando constantenente su stuersicto.-

2) Aporte do matorlal Góllao.- Solo otudsos jooalos an al

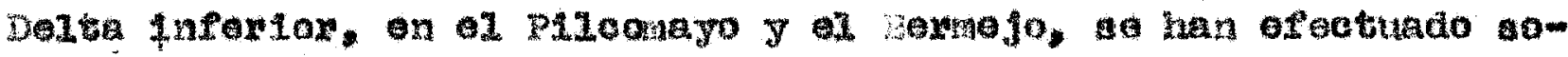

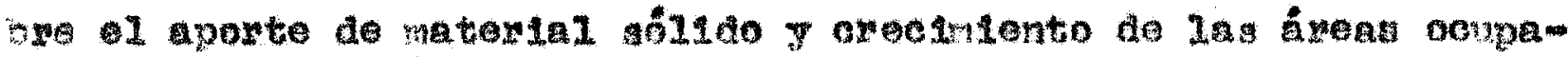

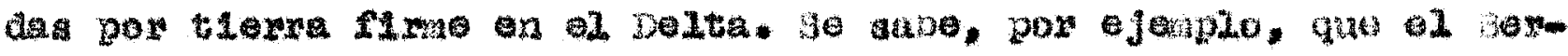
mojo aporta al Paxaguay 100.000 .000 de tonolada a amena y aros-

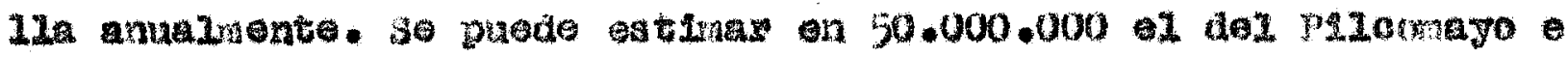

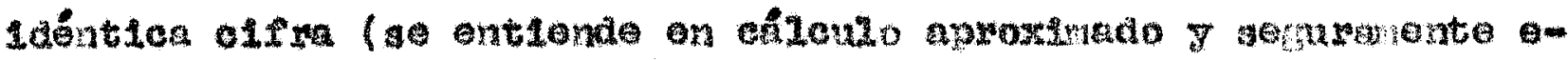

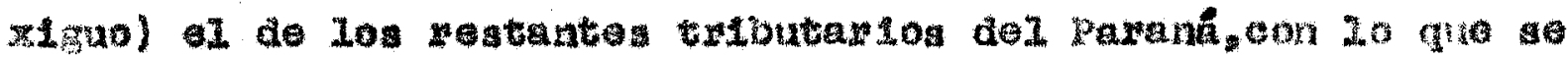

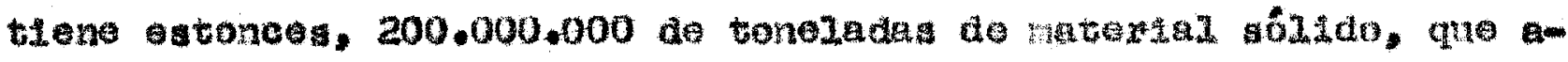
aualnonte baja hasta ol bedta.-

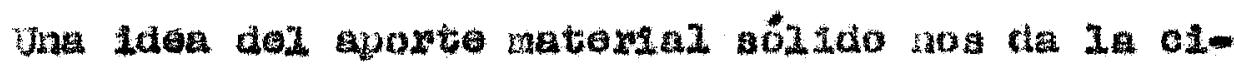

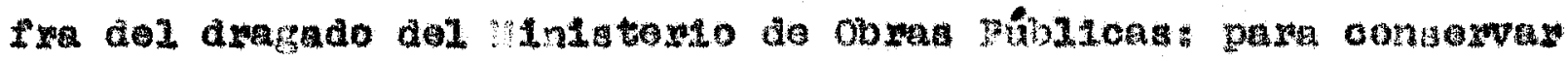

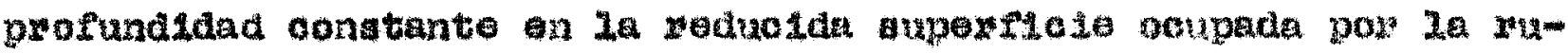

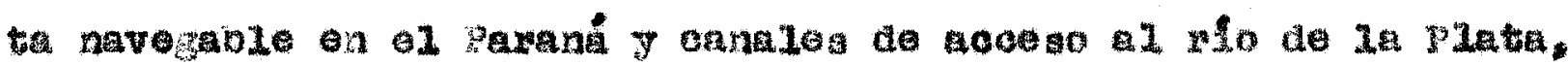

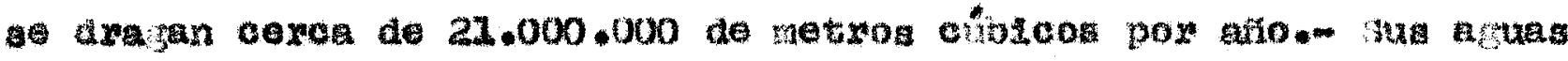

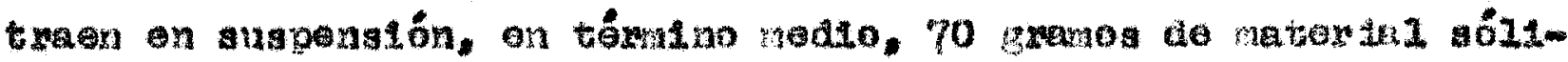

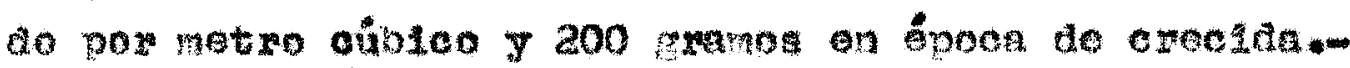

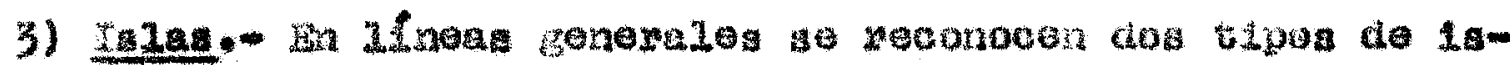
1a bion defindow, saber:

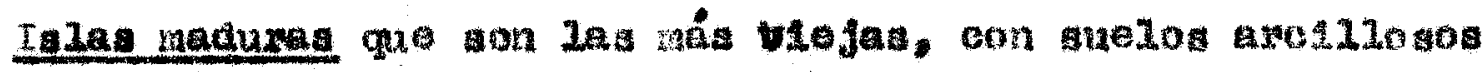

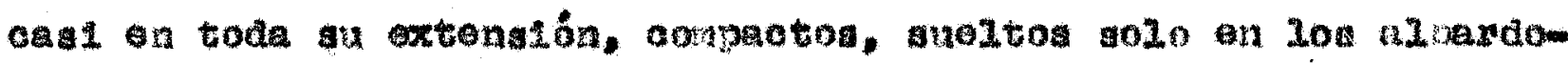

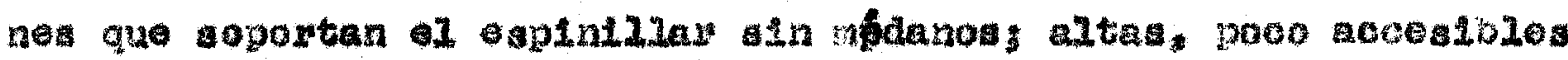

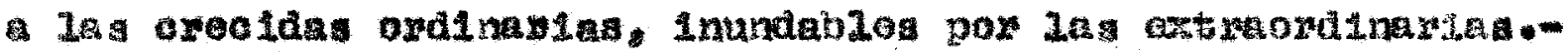

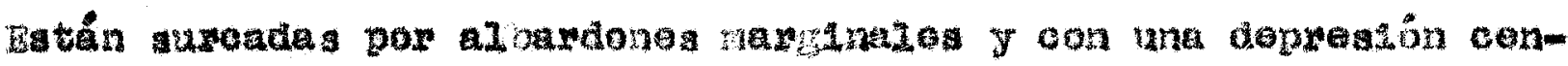

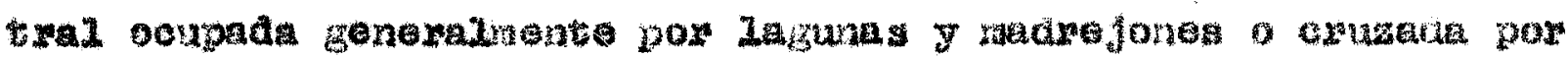

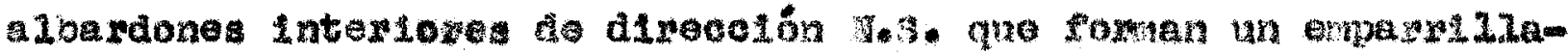

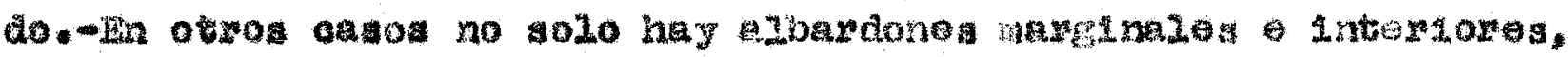

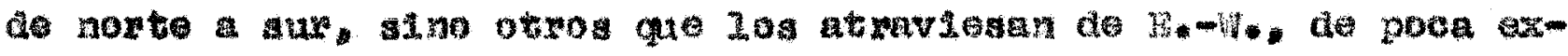

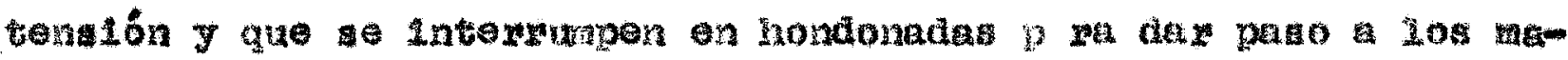

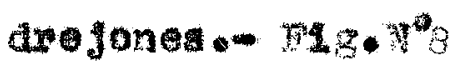

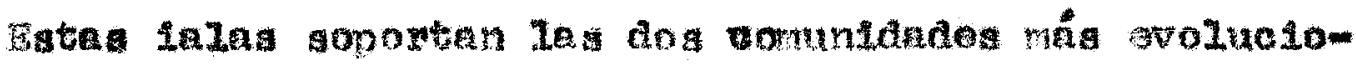

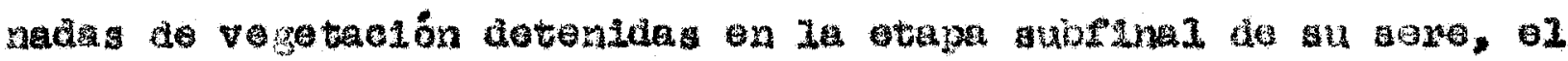


ESQUEMA TEOPICO DE UNA ISLA MADUPA

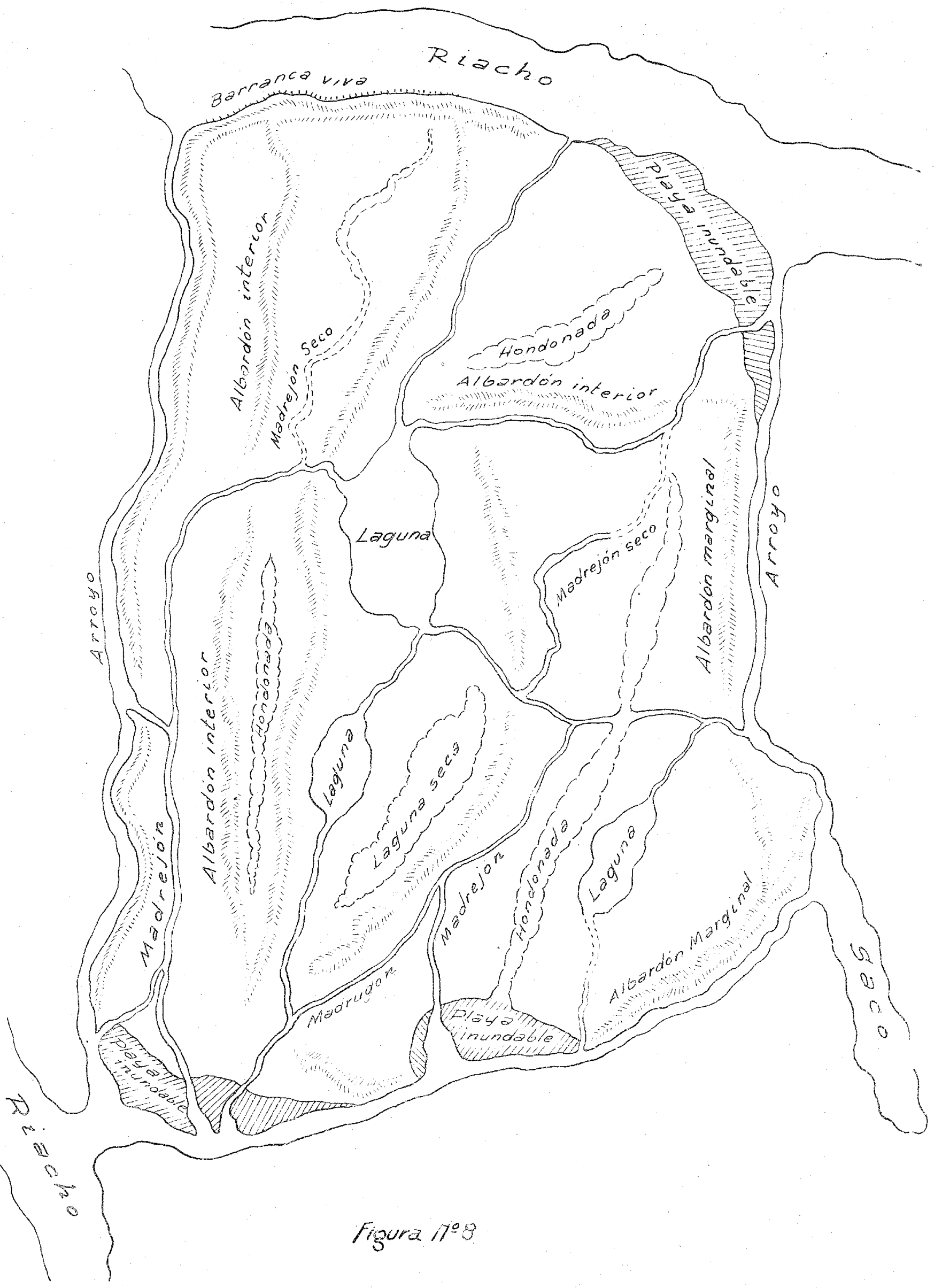



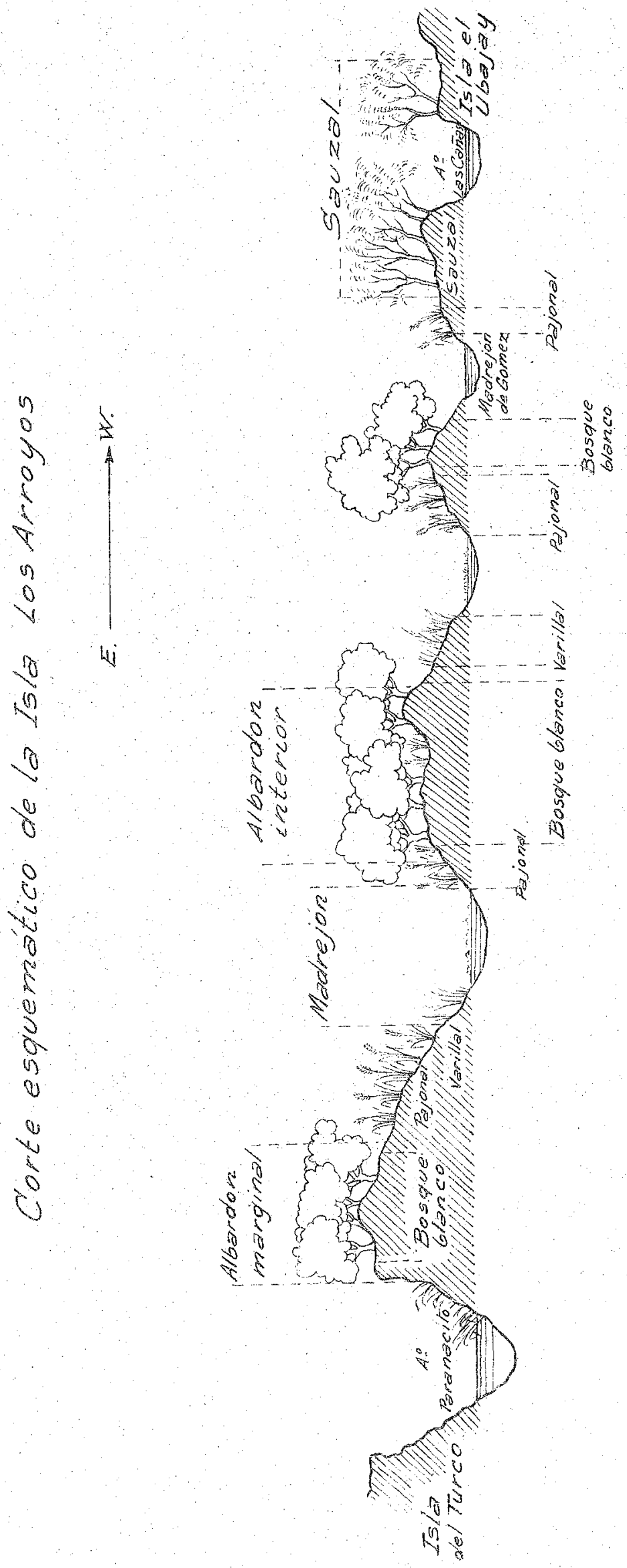


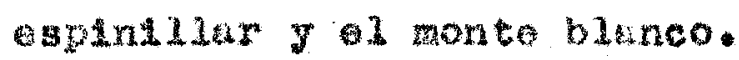

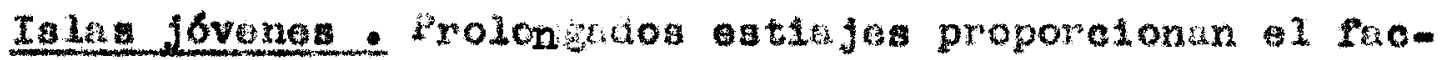

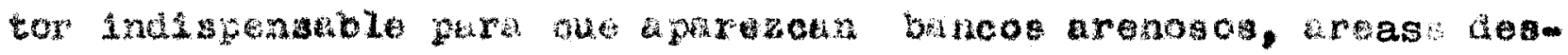

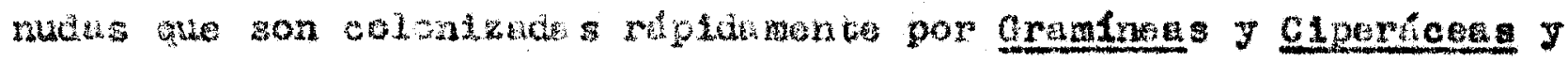

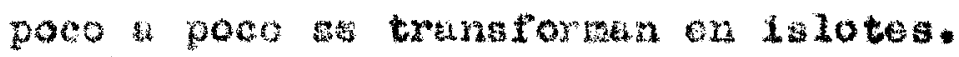

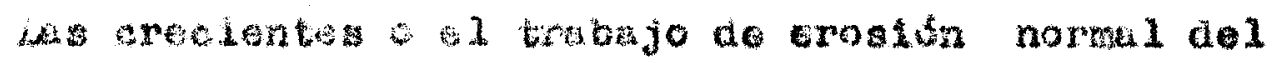

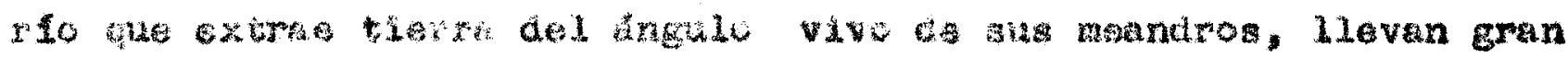

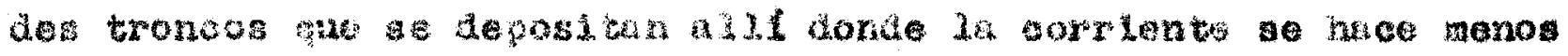

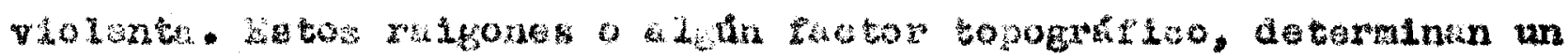

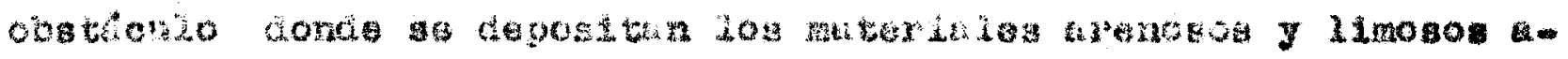

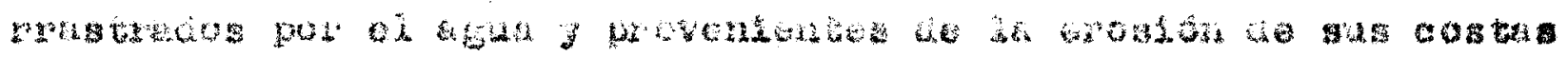

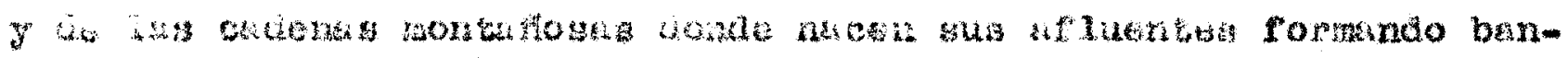

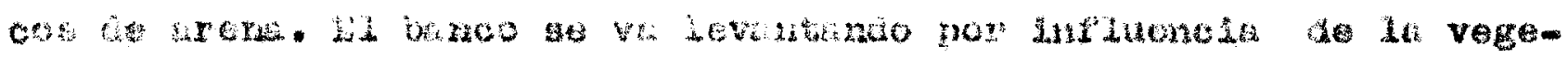

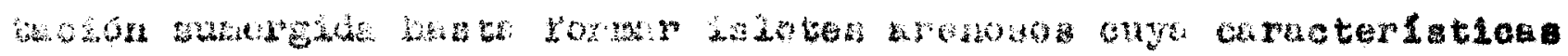

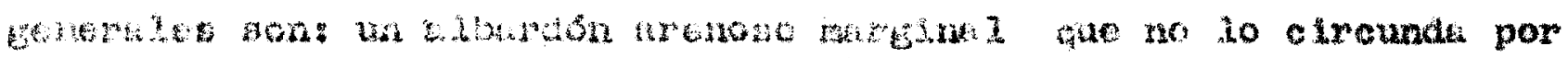

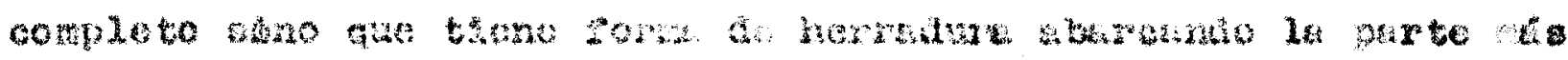

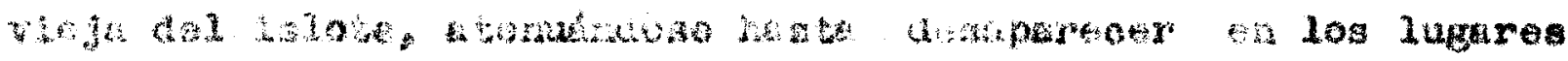

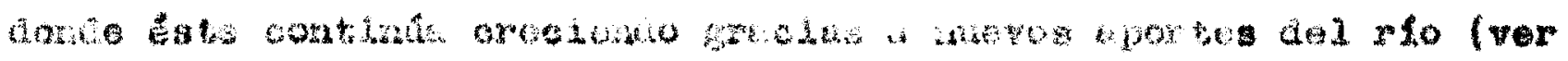

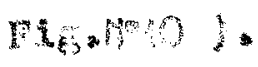

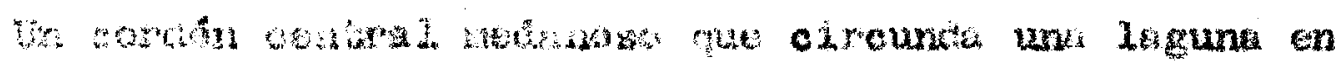

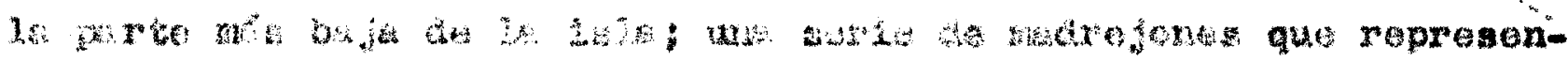

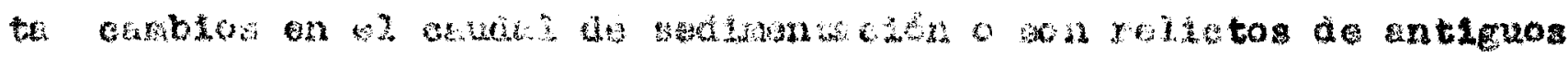

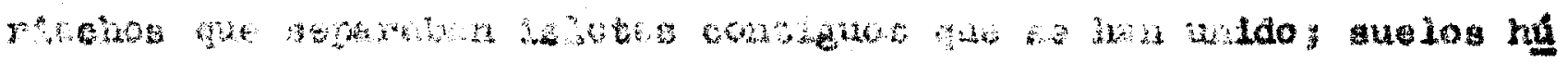

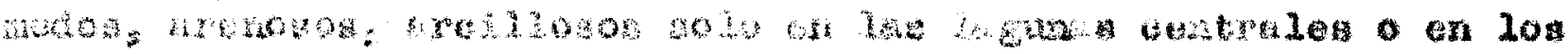

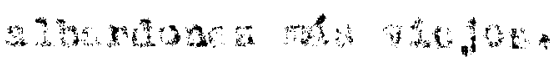

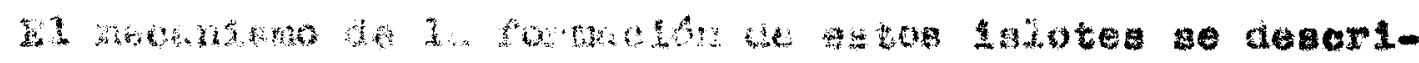

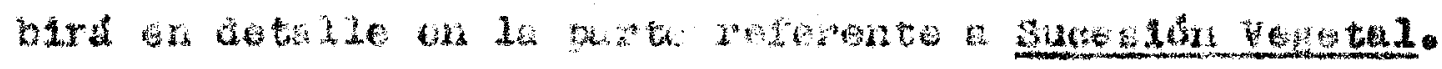

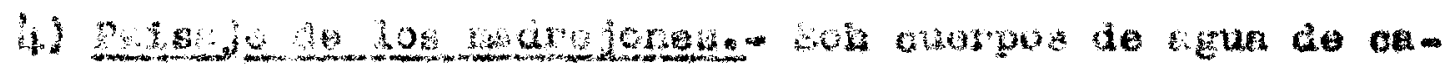

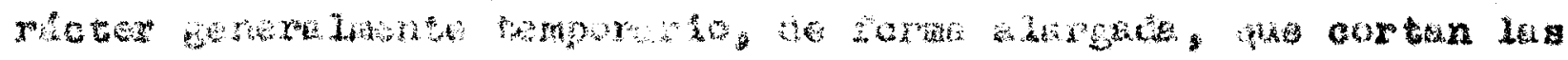

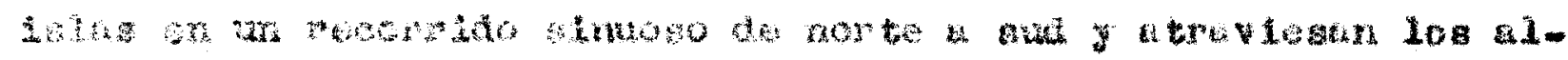

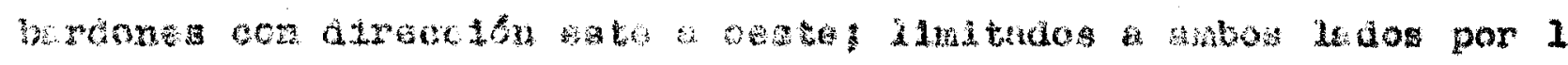

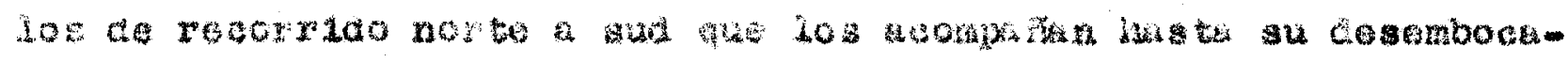

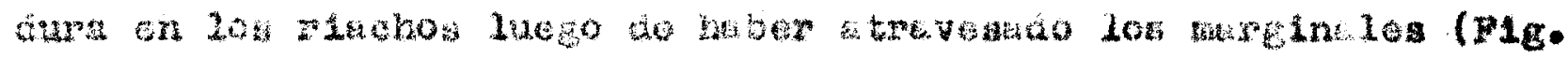



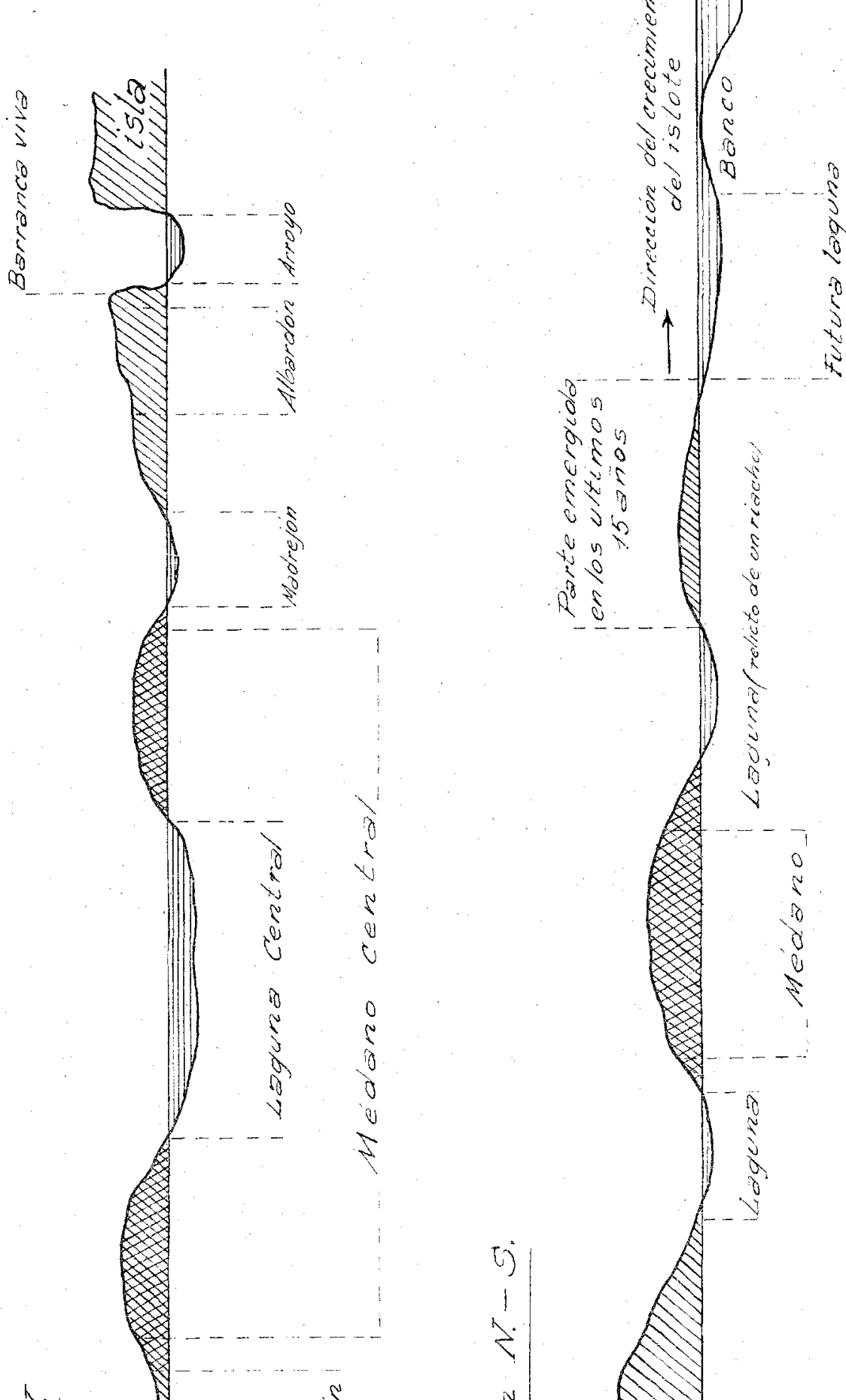

0
0
0
0
0
$j$
0
0
0
0
0
0
0
0
0
0
0
0
0
0
0
0
0

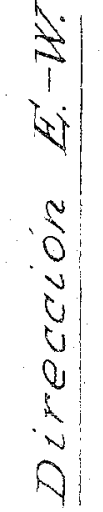

0
1
5
$v$
0
$v$
$u$
0
5
0
0

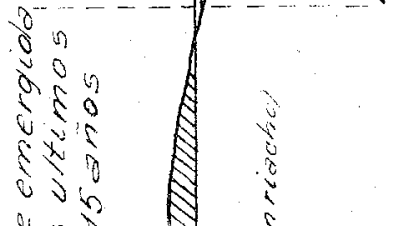

iv

$R^{8}$ ह

$\overbrace{0}^{0}$ 


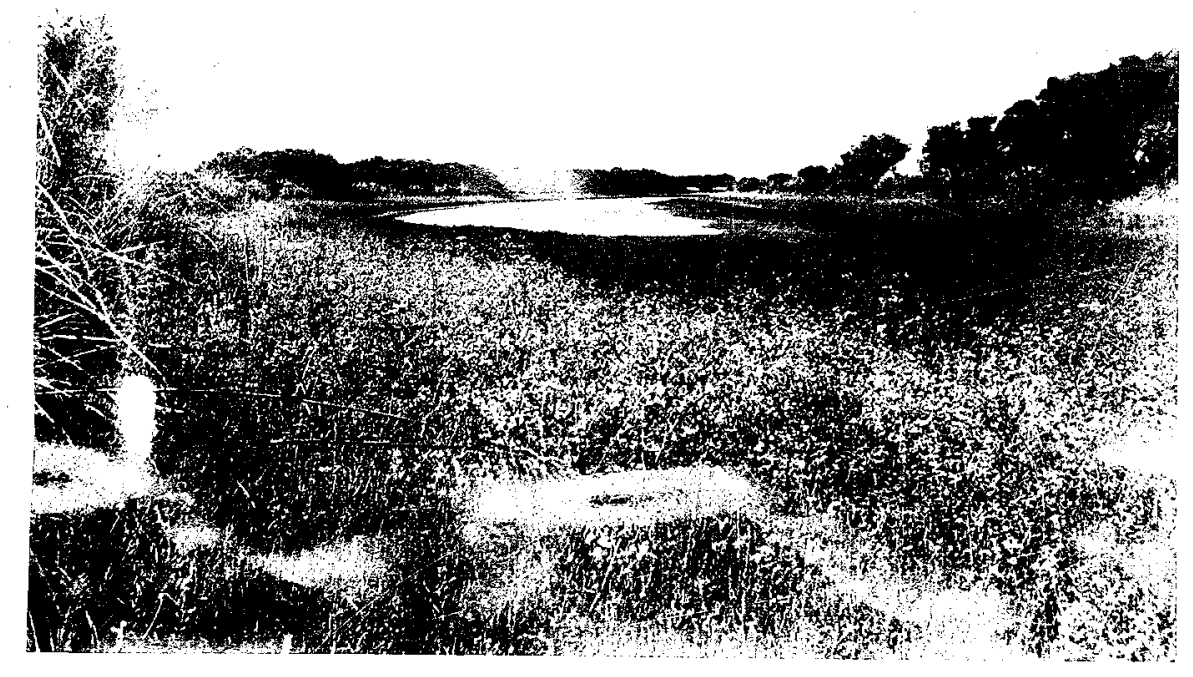

F18.11 Palaaje de madrejon boedeado por dos albardones interiores.-

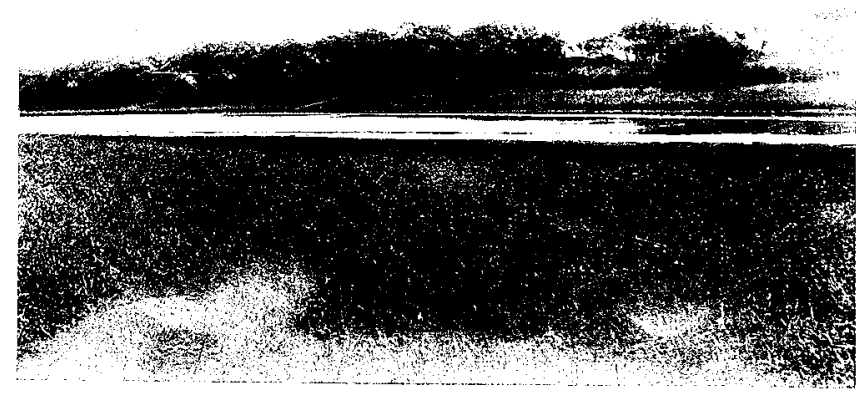

II: 12 Palsaje de madre-

Plg.to Paigaje de madrejón.-

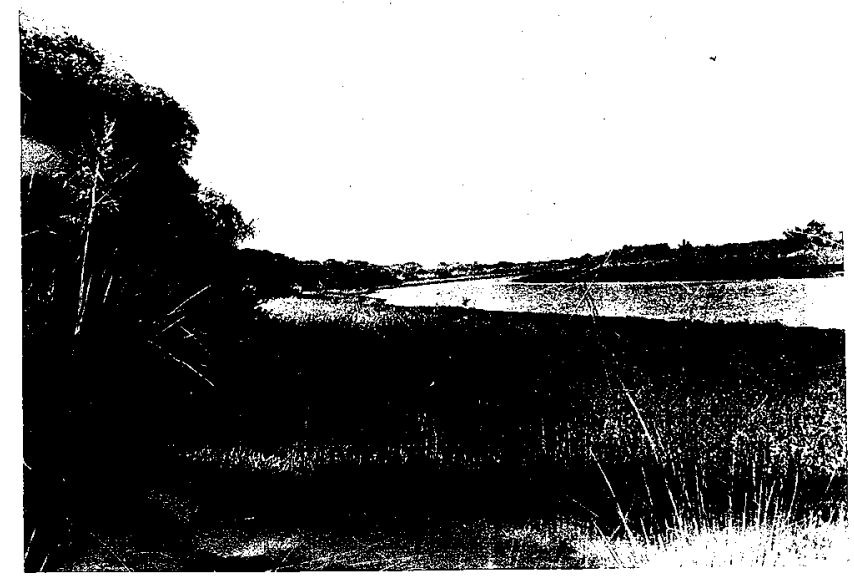




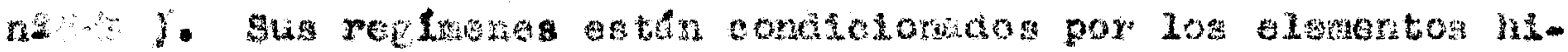

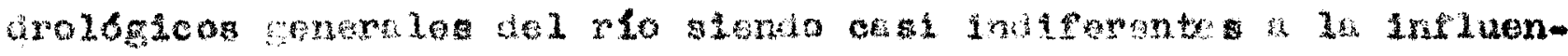

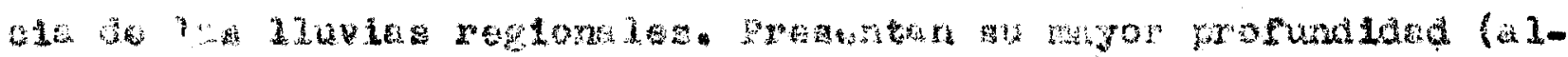

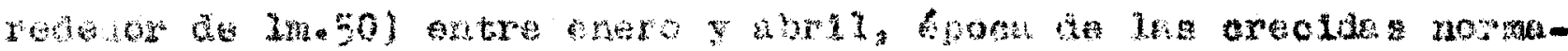

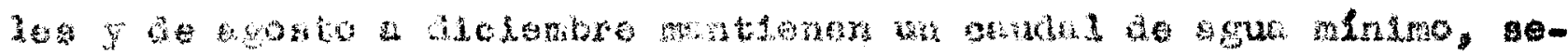

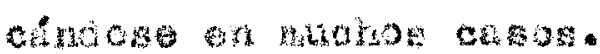

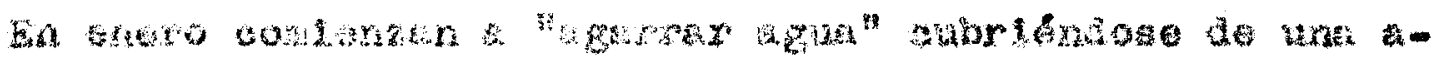

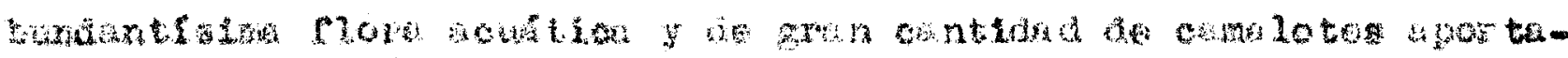

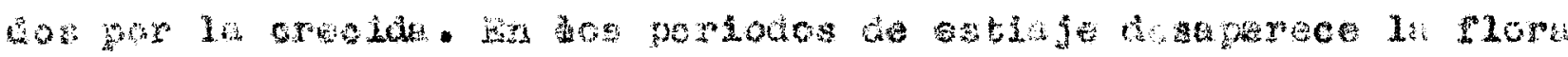

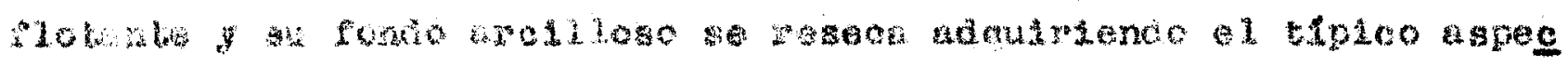

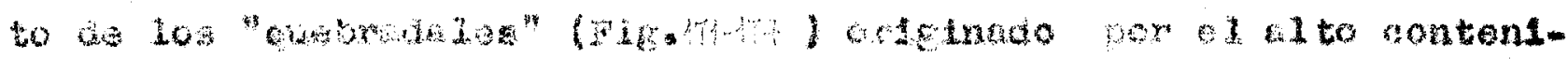

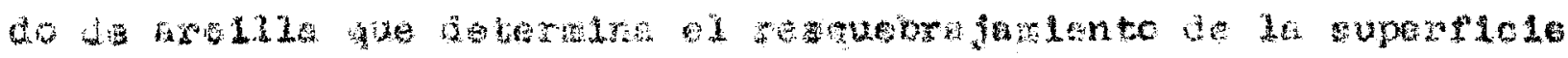

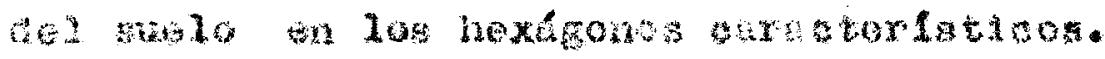

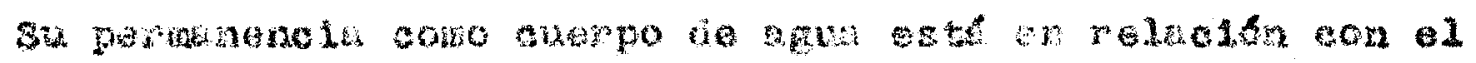

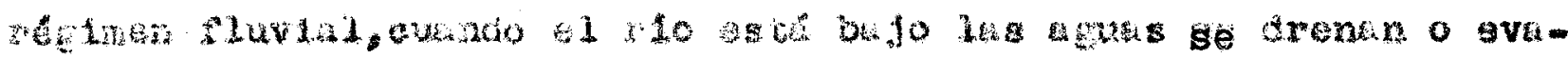

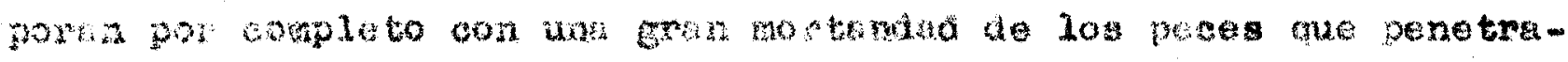

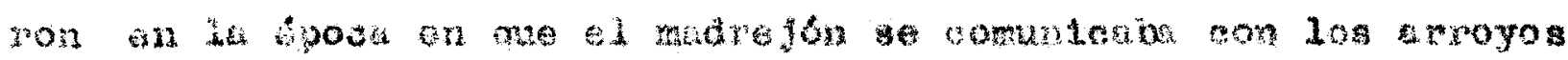

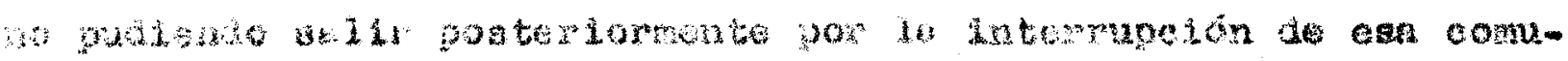
23.

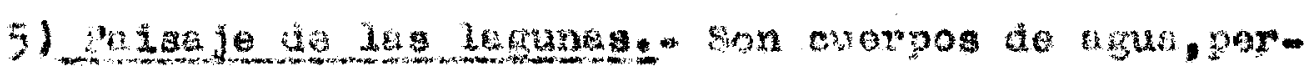

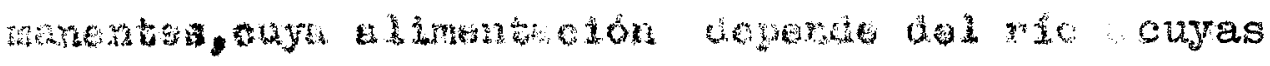
thes peing

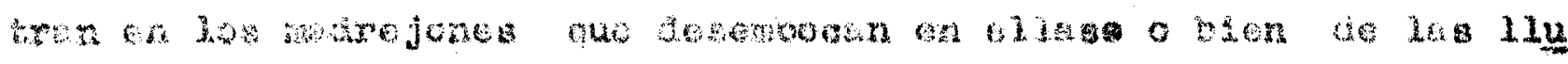

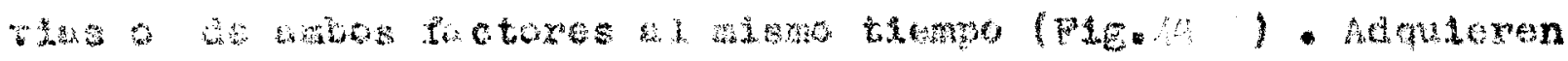

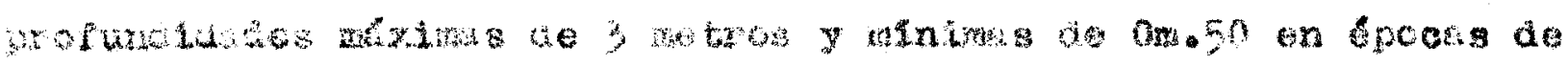

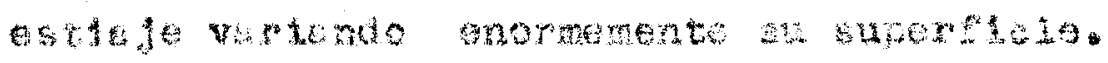

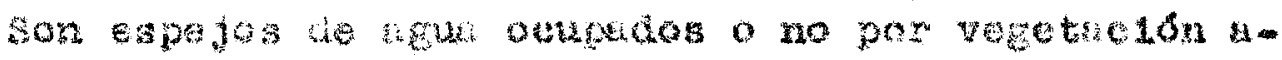

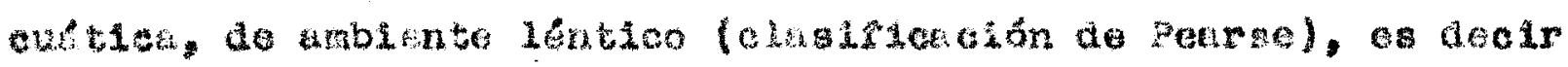

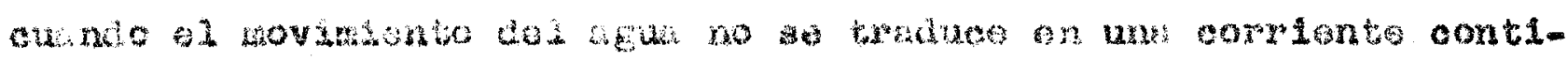

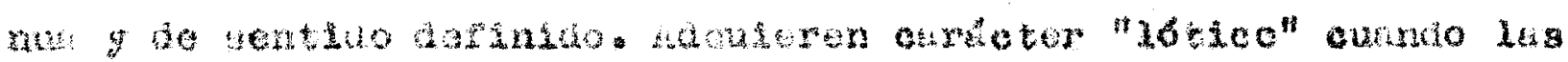

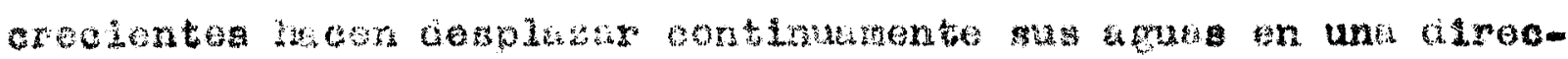
exsa deringe.

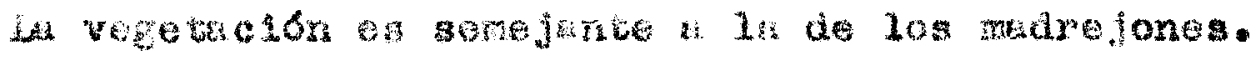

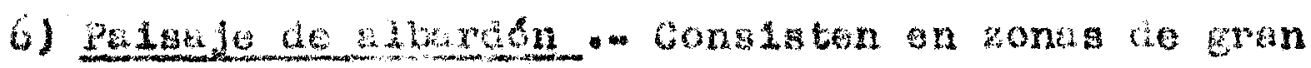




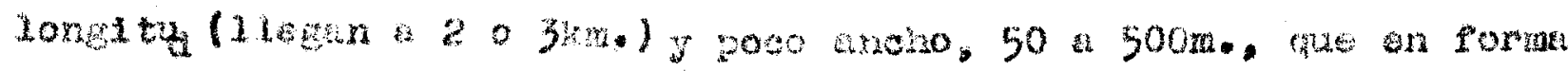

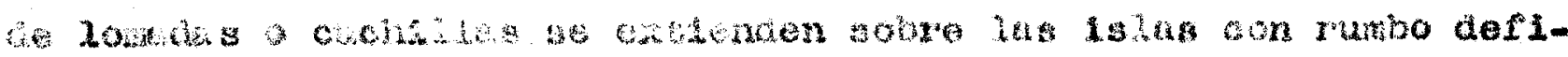

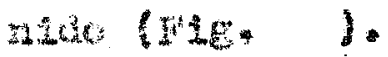

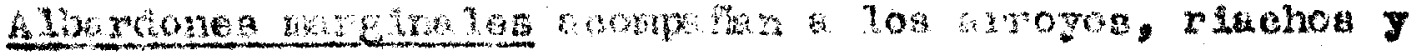

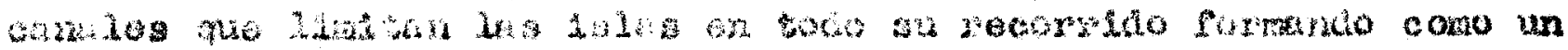

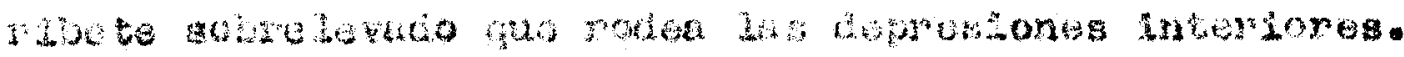

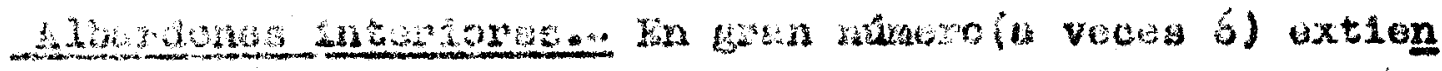

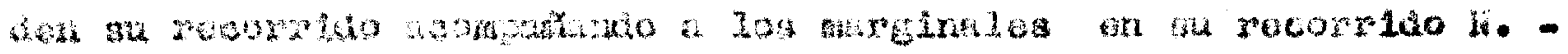

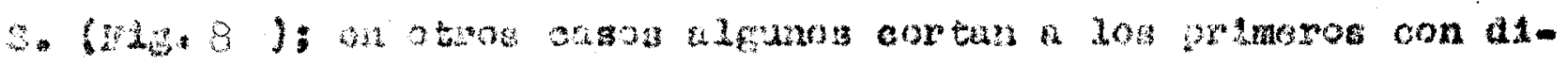

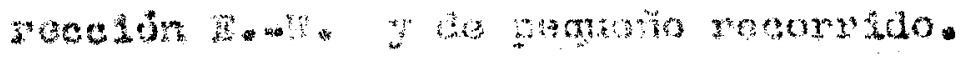

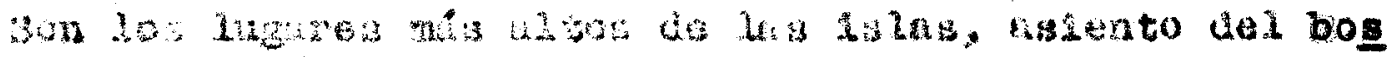

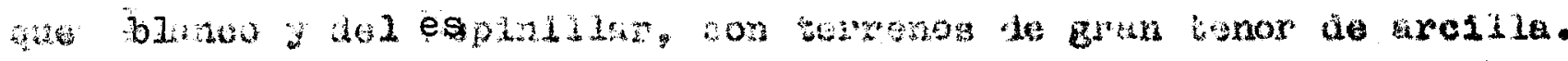

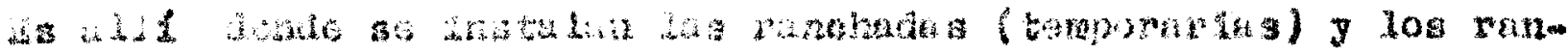

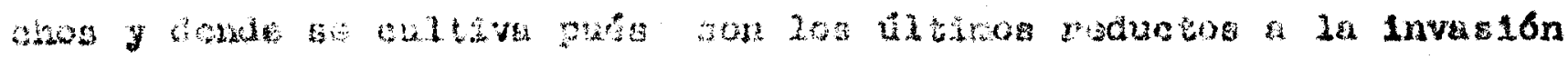

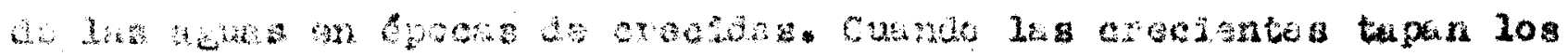

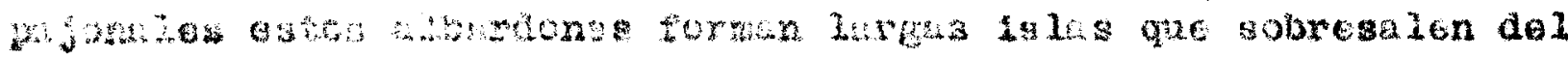
sigut 


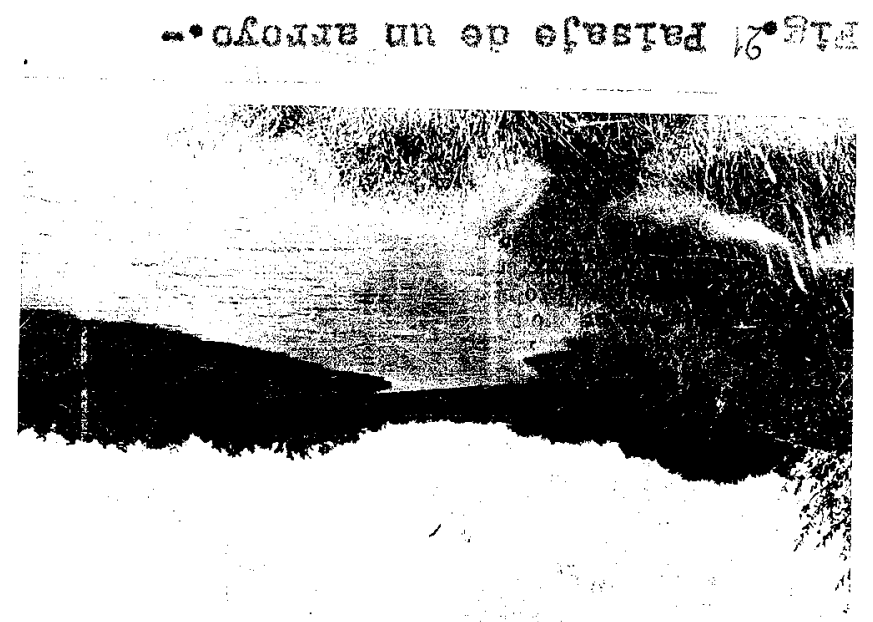

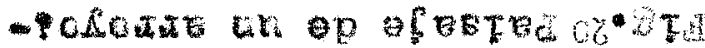

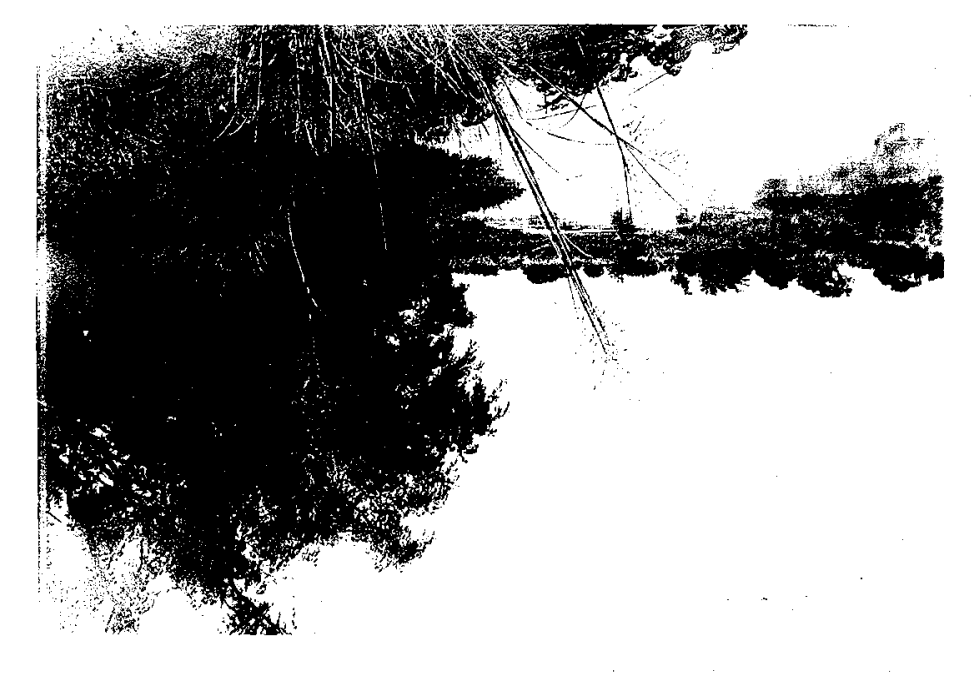

an op ofetrod or 


\section{1 - El sue10}

a) Geología. La escala cronológica en los terrenos de las islas los registra sumamente jovenes; en las más viejas el suelo puede es tar representado por el Platense superior; superpuesto existe un de pósito cenagoso gris negruzco que const1yuye el Aymarense y apoyan do en éste la tierra vegetal o Arlanense. En cambio, las barrancas de ambas márgenes del paraná son muy antiguas, habiendo sido estudiada en detalle por Enrique de Carles, Carlos Burchharat, Santiago Roth y Alfredo Castellanos.

Ia estratigrafía de ambas márgenes del rio, según caste1lanos, es la que se reproduce en la lámina no $2 \%$.

b) Caracterea fisicos y químicos.- Los suelos de le provincia de Santa fé han sido estudiados en el "Instituto Experimental de Investigación y Fomento Agricola-Ganadero" de la citada provincla $\mathrm{y}$ de los realizados por su Director, Dr. Josué Gollán (hijo) 6 transcribimos las principales caracteristicas de los suelos de las 1slas:

a) Agente de transporte de la roca madre: subacueo (en oposición al eblico que predomina en el sud y oeste de la provincia).

b) Procedencia del material de la roca madre,

la cuenca superior del paranó.

c) Ambiente de deposición de la roca madre, fluvial.

d) Roca madre de los suelos, arcillosa y limos palustres

del Paraná actual.

e) Unidad fisiografica, ambiente de islas.

P) Nomenclatura del tipo de suelo normal, ceránina (Ilamado asl en le nomenclatura universal).

g) Tipos de texturas: Arcilloso-11mosas, arenosas, arcillo sas, areno-limosas $\mathbf{y}$ arenas.

Los depósitos f'luviales vinculados al rio parané afectan 


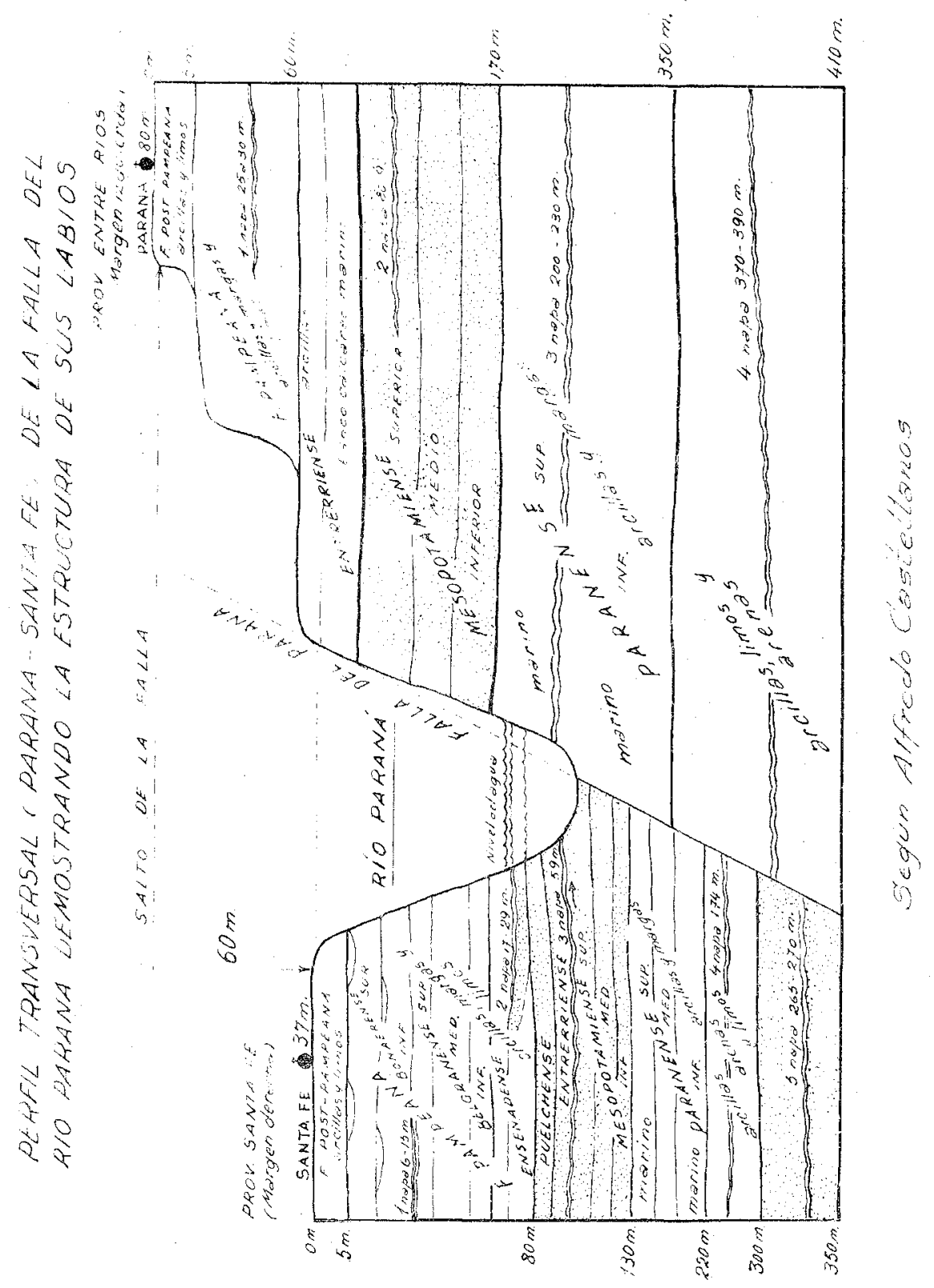

3
5
0
0 
1a. forma de extensas playas horizontales en la dirección este a oes te, con escasa pendiente hacia el sud. Suaves y a largadas lomadas cortan esta región de nor te a sud. Este ambiente de deposición posee también un albardón de varios metros de altura que bordea el le cho de inundación del paraná.

Las rocas madre del ambiente de lslas están constituidas por granos redondeados y exentos de seles, contienen micas $\mathrm{y}$ dan por el análisis mecánico curvas granulométricas de acumulación ablerta.El tamaño del grano dominante en este ambiente fluvial no es uniforme sino que se alternan rápidamente, tanto en sentido vertical como horizontal, estratos de granulometrlas distintas. 


\section{( 4 Muestras)}

\begin{tabular}{|c|c|c|c|c|c|c|}
\hline $\begin{array}{l}T \\
1 \\
1\end{array}$ & Análisis mecánico & $\begin{array}{l}1 \\
1 \\
1\end{array}$ & & & & 1 \\
\hline$T$ & & T & $\boldsymbol{T}$ & T & & \\
\hline 1 & Gr. P. 100 & 1 & 1 & i & $\begin{array}{l}1 \\
1\end{array}$ & ! \\
\hline$T$ & & $T$ & $T$ & $\mathbf{T}$ & & \\
\hline 1 & 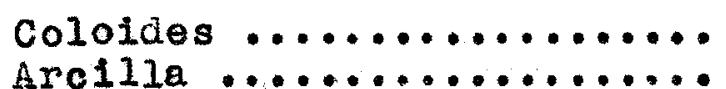 & $\begin{array}{r}8,5 \\
: \quad 17,5\end{array}$ & $\begin{array}{l}13,0 \\
30.0\end{array}$ & $\begin{array}{l}25,0 \\
34.0\end{array}$ & $\begin{array}{l}15,0 \\
1 \quad 27,5\end{array}$ & i \\
\hline i & Limo $\ldots \ldots \ldots \ldots \ldots \ldots \ldots \ldots$ & 30,5 & 26,5 & 33.0 & $\begin{array}{l}21,0 \\
35,5\end{array}$ & $i$ \\
\hline 1 & Arena flna $\ldots \ldots \ldots \ldots \ldots \ldots$ & 43,0 & 36,2 & & 33.0 & 1 \\
\hline 1 & Arena gruesa ............. & 9,0 & 7.3 & & 4,0 & $\mathbf{t}$ \\
\hline 1 & Gravas $\ldots \ldots \ldots \ldots \ldots \ldots$ & $1 \quad-\quad-m-$ & $-\infty$ & $-\infty$ & $\ldots$ & 1 \\
\hline $\mathbf{1}$ & 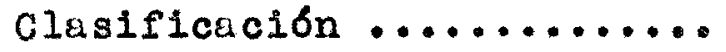 & 'Lozm ar & 'Arcilla & Arcil & Le Loam & 1 \\
\hline 1 & & $\cos 110-a$ & & 1 & - arci- & 8 \\
\hline $\mathbf{I}$ & & 'renoso. & 1 & 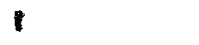 & 110 so & 1 \\
\hline 1 & & 1 & 1 & 1 & 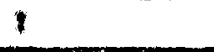 & 1 \\
\hline$T$ & & $T$ & & $T$ & & $\mathbf{T}$ \\
\hline $\mathbf{I}$ & & 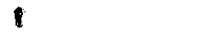 & & 1 & & ' \\
\hline 1 & Constancias hidricas & 1 & & 1 & & 1 \\
\hline 1 & & 1 & & 1 & & 1 \\
\hline$T$ & & $T$ & $T$ & $\mathbf{T}$ & & $\mathbf{T}$ \\
\hline $\mathbf{1}$ & $G_{r} \cdot p \cdot 100$ & 1 & I & ' & 1 & 1 \\
\hline 1 & I. & 1 & $\mathbf{t}$ & 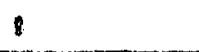 & 1 & 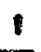 \\
\hline $\mathrm{T}$ & & 7 & T & $\mathbf{P}$ & $T$ & 7 \\
\hline 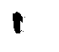 & Humedad $\ldots \ldots \ldots \ldots \ldots \ldots \ldots$ & $1 \quad-\infty$ & $-\infty$ & $-\infty$ & $-\infty$ & $t$ \\
\hline 1 & Humedad equivalente de cen- & 17,7 & 0,011 & 109,011 & 59,011 & $!$ \\
\hline 1 & $\operatorname{trifuga} \ldots \ldots \ldots \ldots \ldots \ldots \ldots$ & 1 & 1 & & 1 & 1 \\
\hline 1 & Humedad equivalente de cam- & 15.9 & 25.7 & 16,8 & 16,6 & 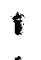 \\
\hline 1 & pa п̃a & 1 & 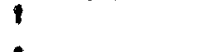 & 1 & 1 & 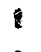 \\
\hline$!$ & Relación de estabilidad..... & -- & $--\infty$ & $--\infty$ & $-\infty$ & 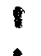 \\
\hline 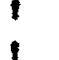 & & 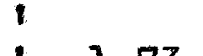 & 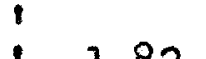 & 3 & 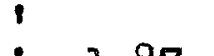 & 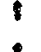 \\
\hline 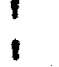 & $\begin{array}{l}\text { so especifico aparentel..... } \\
\text { lmite } 1 \text { lquido inferior..... }\end{array}$ & $1,1,73$ & 1,82 & & & i \\
\hline ' & Limite plástico inferior.... & $17: 9$ & $i 30,4$ & $1 \quad 4,9$ & $136 \%$ & i \\
\hline 1 & Indice de plasticidad....... & 1,7 & 120,9 & 124.7 & $11 / .2$ & : \\
\hline 1 & IImite de contraccion....... & 16.8 & 20.6 & 14.0 & N. 5 & 1 \\
\hline 1 & Cambio volúmétrico......... & $-\infty$ & -- & $i$ & 1 & $\mathbf{t}$ \\
\hline I & Contracción lineal.......... & --- & - & 1 & $\mathbf{v}$ & $\mathbf{t}$ \\
\hline 1 & 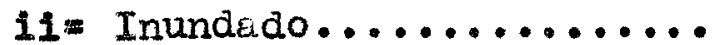 & ' & $\mathbf{I}$ & 1 & I & 1 \\
\hline 1 & & 1 & 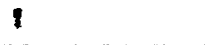 & 1 & 1 & 1 \\
\hline The & & 8 & & & & \\
\hline B & Determinaclones varias & 1 & & & & 1 \\
\hline 1 & & 1 & & & & \\
\hline ? & & 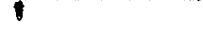 & 8 & 1 & $\mathbf{T}$ & $\mathbf{T}$ \\
\hline 1 & $g r \cdot p \cdot 100$ & 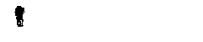 & 1 & 1 & 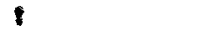 & 1 \\
\hline 1 & & 1 & 1 & 1 & 1 & \\
\hline$r$ & & $\mathbf{T}$ & $\mathbf{T}$ & $\mathbf{T}$ & & \\
\hline ! & cloruros $\ldots \ldots \ldots \ldots \ldots$ & ivest. & & $\begin{array}{l}\text { Cont. } \\
\text { ibast. }\end{array}$ & $\begin{array}{l}\text { Cont. } \\
\text { bast. }\end{array}$ & \\
\hline t & Calcáreos. & no & no & 'Regular & ivest. & 1 \\
\hline ' & Sulfatos ... & no & 'Cont. & Cont. & cont. & ' \\
\hline 1 & & & I basta & & I best. & $\mathbf{t}$ \\
\hline 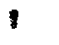 & Ensayo de floculación $\ldots . .$. & Disper & $(x)$ & $f(X X)$ & $1(x)$ & 1 \\
\hline $\boldsymbol{t}$ & & 'sa & 1 & 1 & $\mathbf{I}$ & 1 \\
\hline I & Ensayo de desleimiento ..... & 1 & $--\infty$ & $-\infty$ & $-\infty$ & 1 \\
\hline ! & Reacción pH en agua ........ & 15,4 & 7,7 & 8.3 & 8,2 & $t$ \\
\hline 1 & Reacción pH en $\mathrm{cI} \mathrm{K} \ldots \ldots .$. & $-\infty$ & $-\infty$ & $-\infty$ & $=-\infty$ & 1 \\
\hline 1 & & 1 & 1 & 1 & 1 & 1 \\
\hline
\end{tabular}




\section{$2-$ agua}

a) Agua subterránea.- Existen diferencias hidrologicas de acuerdo al tipo de islas: $19 \mathrm{~s}$ del rio tienen acufferos vinculados a les aguas del cauce, mientras las del lecho de inundación aguas de mayores concentraciones salinas $\mathrm{J}$ de otro carf́cter quimico dobico a las influenclas del agua salada del fondo y pobreza de acumulación de agua de percolación.

b) Arálisis de 6 meetras de agua del paraná extrajda en las "Cusitro Bocas", segín Jceve Gollán (h) y Déme.so Lachiga (1939);

\begin{tabular}{|c|c|c|c|c|c|c|c|}
\hline 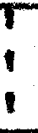 & Datos analiticos muestras ng & 864 & 865 & $\begin{array}{l}1 \\
: 866\end{array}$ & 887 & 868 & 869 \\
\hline $\boldsymbol{T}$ & & $T$ & $T$ & 8 & $T$ & 7 & $T$ \\
\hline $\mathbf{I}$ & Mgr. p. 11tro & $t$ & 1 & : & 1 & 1 & 1 \\
\hline $\mathbf{I}$ & & 1 & 1 & 1 & 1 & 1 & 1 \\
\hline $\mathbf{I}$ & & 8 & $T$ & $T$ & $T$ & $T$ & \\
\hline 1 & Sllice $\left(S 1 O_{2}\right)$ & 145 & 20,0 & 164,0 & 126,0 & 125,0 & 18,0 \\
\hline $\mathbf{1}$ & Hierro $\left(\mathrm{Fe}_{2} \mathrm{O}_{3} \ldots \ldots \ldots \ldots\right.$ & $--\infty$ & 19,0 & ivest. & vest. & vest. & \\
\hline I & Aluminio $\left(A, O_{-}\right)$ & 199 & 65.0 & 14,0 & 122,0 & 21,0 & 124,0 \\
\hline $\mathbf{I}$ & * 2.3 & 1 & & & 1 & & \\
\hline t & $\mathrm{Ca}$ lcio $(\mathrm{Ca} \cdots) \ldots \ldots \ldots$ & 1387 & 37.0 & 7,0 & 22,0 & 7,0 & 14,0 \\
\hline ! & Mronesio (Mo..) & 13935 & 1603 & 58.0 & 12230 & 139.0 & 1775.0 \\
\hline 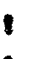 & & & & & 1 & & \\
\hline 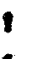 & Sodio y Potasio ( $\left.\mathrm{Ha}^{*}\right) \ldots . . .$. & 14438 & 1846 & 176,0 & 12434 & 167,0 & 1249,0 \\
\hline 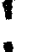 & & 120 & 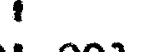 & & 1 & & \\
\hline 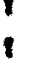 & clorhidrieo $(01) \ldots \ldots \ldots$ & 3789 & 991 & 135,0 & 1642 & 39,0 & \\
\hline 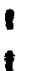 & sulfurico $\left.6.0_{4}::\right) \ldots \ldots$ & 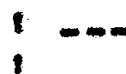 & $-\infty$ & $-\infty$ & $-\infty$ & +-- & $1 ;$ \\
\hline 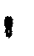 & $\operatorname{Nitrico}\left(\mathrm{NO}_{z^{*}}\right)$ & 118,0 & -- & & i & & \\
\hline 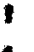 & & 1 & 1 & & & & \\
\hline : & Carbónico $\left(\mathrm{C} \mathrm{O}_{3} \cdots\right) \cdots \ldots \ldots$ & 1290 & 1199 & 162,0 & 154,0 & & \\
\hline : & Bicarbónico $\left(\mathrm{C} \mathrm{O}_{3} \mathrm{H} \cdot \ldots \ldots\right.$ & 1274 & 46690 & 290 & 3529 & 1223,0 & 1557 \\
\hline 1 & & 1 & 1 & 1 & 1 & 1 & 1 \\
\hline
\end{tabular}


El clima de la provincla de Santa Fé es templado en el sud $\bar{y}$ cálido en el norte, con medias anuales que oscilan entre 36 y $21^{\circ} \mathrm{C}$, máximas absolutas entre 42 y $46^{\circ} \mathrm{C}$ y minimas absolutas de -2 a $-10^{\circ}$ C.

En toda la provincia la primavere $\mathrm{J}$ el otoño tienen aproximadamente una temperatura media igual; la major diferencia entre el verano y el Invierno no pasa de $1^{\circ} 91^{\prime}$; la temperatura meata anual de la provineia es de $17^{\circ}$ para la zona sud y de $19^{\circ}$ para la norte (Carrasco 1884, pág. 17\%.

La temperatura media de enero, el mes más caluroso del año,oscila entre 26 y $28^{\circ}$ para la región norte y entre $10 s 24 \mathrm{~J}$ $26^{\circ}$ para la sud.

En tierra firme esté sujeto a variaciones bruscas, con sequias Intensas que producen grandes pérdidas en las cosechas y épocas lluviosas que anegan las zonas de desagthe dificultoso, co mo la del departamento San Gerónimo entre Maciel y Puerto Gaboto. En estas épocas solo en bote se puede establecer contacto entro ambas poblaciones.

Las lluvias son abundantes y permiten la instala ción de cultivos que no requieren riego artificial. En las arroceras se aprovecha el suelo bajo inundable del Rincón de Grondona $y$ la zona de Puerto Gaboto y para mantener el nivel del agua en época de sequla se eleva la del rlo y se derrama sobre sus campos.

En el ambiente Insular la influencla del Parané se hace sentir creando un microclima más húmedo y cálido, con cambios menos bruscos de temperatura y un régimen pluviométrico más regular. Como no existe ninguna clase de registros climáticos en las islas y como el observatorio del servicio Meteorologi co Nacional, en Rosario, está situado unos $15 \mathrm{kilómetros} \mathrm{al} \mathrm{W.} \mathrm{de}$ la costa, en Fisherton y reglstra condiciones muy distintas a las de las islas, hemor preferido referirnos, en lo que respecta a régimen pluviométrico, a Vilia Constitución, donde se deja sentir més 
Ias isoterma del mapa de Davis para la zona estudiada son: verano 22 a 26 ; otoño 16 a $18^{\circ} \mathrm{C}$; máxima meala 23 a $25^{\circ} \mathrm{C}$, minima media 8 a $12^{\circ} \mathrm{C}$, máxime absoluta $42^{\circ} \mathrm{C}$ y mínima absoluta -6 a $-10^{\circ} \mathrm{C}$. Temperatura.- La media anual promedis durante el perlodo $1928-1937,17,6^{\circ}$ en Roserio.

En el invierno la temperatura desciende, registrándose muchas heladas; en otoño y primavera la temperatura es suave. La estación de Piscicultura del Ministerio de Agri cultura de la Nación, establecida en Rosario, lleva registros diarios (sin sacar promedios), a unos 50 metros de la costa, que dan diferencias de hasta 5 y $6^{\circ}$ con las obtenidas en la Oficina MeteoroIógica de Fisherton y coinciden con las que pude obtener durante 36 alas con un termómetro de máxima y minima instalado en la is1a Los Arroyos, frente a Gaboto, en el albardón marginal, a $1 \mathrm{~m} .50$ sobre el suelo debajo del bosque blanco. Estas últimas observaciones por ser tan reducidas no permiten sacax ninguna conclusión ni hacer comparaciones.

Lluvias.-Fl promedio anual de liuvias varia entre 800 y $1100 \mathrm{~m} . \mathrm{m}$. correspondiendo la mayor cantidad a los meses de setiembre hasta abril, los más secos de abril a set1embre. La distribución de las lluvia es irregular habiendo años liuviosos y otros muy secos.

En la zona del Paraná las lluvias son més regulares y erecuentes, en cumbio, hacia el Vi. se hacen más irregulaxes $y$ hay prolongadas sequias, sobre todo en los meses de invierno.

$$
\text { Compárese en el euadro ne las precipitaciones de }
$$
Rufino (oeste) con las de Reconquista y Villa Constitución, vinculadas a la influencia del Parana.

Humeda -- La hunedad relativa del aire es de $75 \%$ en Rosario (promedio anual. Este promedio es muy elevado comparándo10 con el de otras regiones secas del pais. 


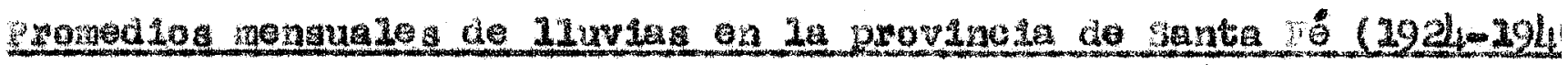

\begin{tabular}{|c|c|c|c|c|}
\hline ses & Moga: 10 & paaba & meno & Roopngusatse \\
\hline 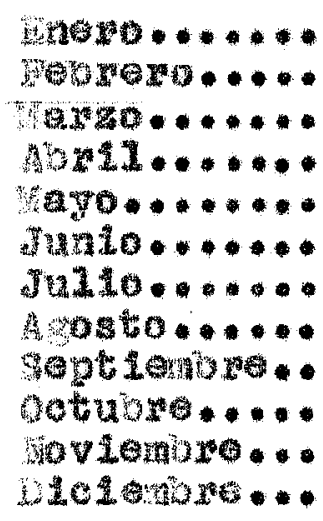 & 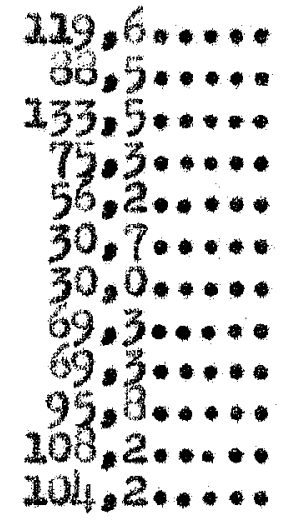 & 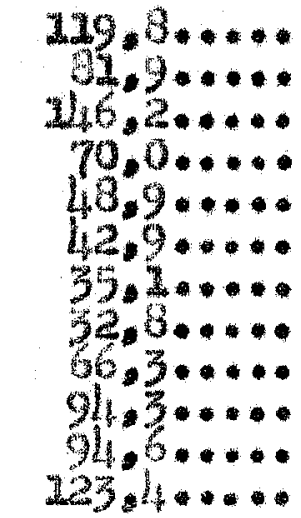 & 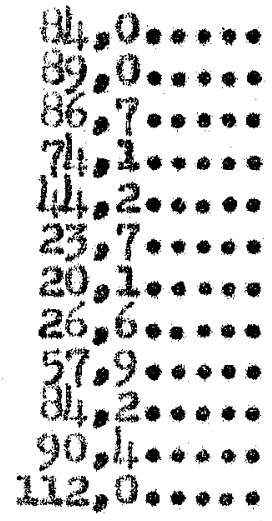 & $\begin{array}{r}240.2 \\
72.9 \\
245.6 \\
202.7 \\
52.3 \\
37.6 \\
35.5 \\
45.2 \\
52.3 \\
109.0 \\
235.3 \\
455.2\end{array}$ \\
\hline
\end{tabular}

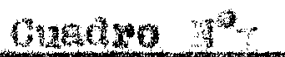

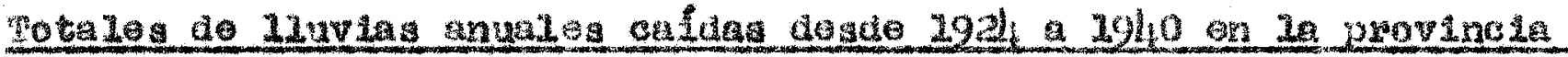
de santa 16

\begin{tabular}{|c|c|c|c|}
\hline Año & Sosag 10 & Earra & recosqua \\
\hline 1921. & $769,0 \ldots$. & $909,0 \ldots \ldots$ & 2126,0 \\
\hline 1925 & $2043,0 \ldots \cdots$ & $04,0 \ldots \ldots, 0,0 \ldots$ & 932,0 \\
\hline 1920 & $2013 \cdot 5 * \cdots$ & $99.0 \ldots \ldots$ & 2126,0 \\
\hline 3927 & $377.0 \ldots$ & $512,0 \ldots \ldots 60,0 \ldots$ & 724.0 \\
\hline $2920 \ldots$ & $992,0 \ldots \ldots$ & $052.3 \ldots \ldots .2003 .0 \ldots$ & 2152.5 \\
\hline $1929 \ldots$ & $780.5 \ldots \ldots$ & $570,2 \ldots \ldots 7,72,0 \ldots$ & 823,0 \\
\hline 2930 & $992,0 \ldots$ & $1091.9 \ldots \ldots$ & 2299.0 \\
\hline $1931 \ldots$ & $2176,0 \ldots$ & $1279,0 \ldots \ldots$ & $24,2.0$ \\
\hline 1932 & $932.3 \cdots \cdots$ & $395.5 \ldots \ldots 663.5 \ldots$ & $3575 \cdot 2$ \\
\hline $1935 \cdots$ & $976,8 \ldots \ldots$ & $761,5 \ldots \ldots, 1250,5 \ldots \ldots$ & 37.5 \\
\hline $1934 \ldots$ & $146,5 \ldots \ldots$ & $1193,0 \ldots \ldots$ & 2120,0 \\
\hline $1935 \ldots$ & $730.5 \ldots \ldots$ & $2224 \cdot 5 \cdots \cdots$ & 2000,0 \\
\hline 1936. & $1222.5 \cdots$ & $1256,0 \cdot \cdots \cdot$ & 305.0 \\
\hline 1937 & $779.5 \cdot \cdots$ & $429.5 \cdots \cdots$ & 305.0 \\
\hline 1938. & $903.5 \ldots$ & $2030,0 \ldots$ & $96 x, 0$ \\
\hline 1939. & $2027 \cdot 5 \cdots \cdots$ & $2073,0 \ldots \ldots$ & $254 \%$ \\
\hline 1940 & $32,6,0 \ldots$ & $1255,0 \ldots \ldots 1087,0 \ldots \ldots$ & 2365.0 \\
\hline gea 10. & $959.9 \cdots$ & $94,2,3 \ldots \ldots$ an, & 1062.6 \\
\hline
\end{tabular}


Promedios menguales de 2 luvias caldas on Rufino Vilia Congtitución durante o1 perfodo 1924-1944.-

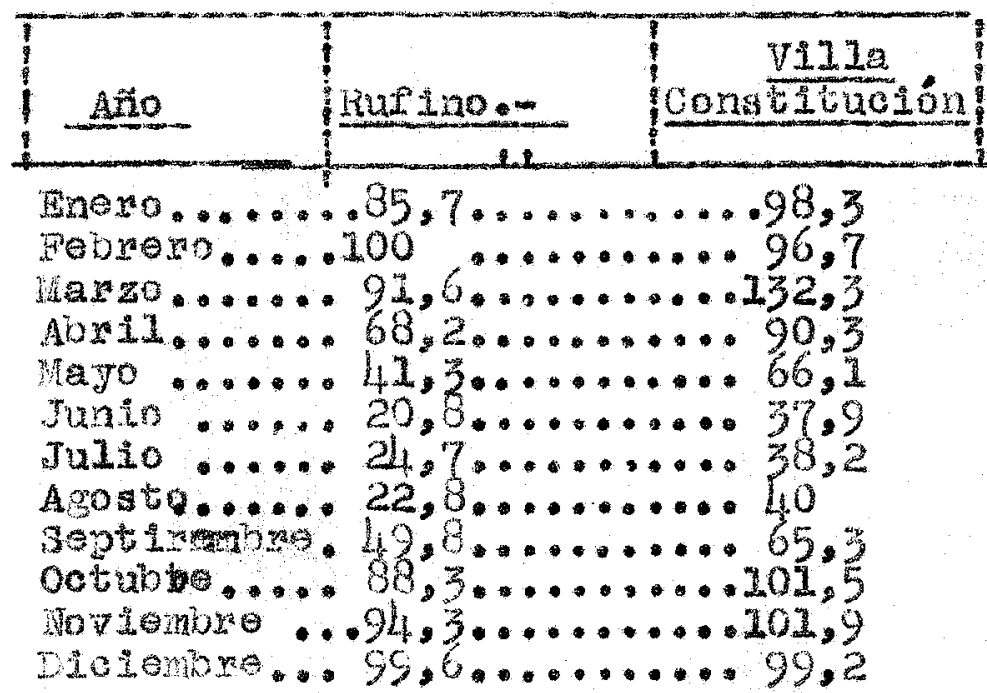

\section{Guadro $\mathrm{NO}^{9}$}

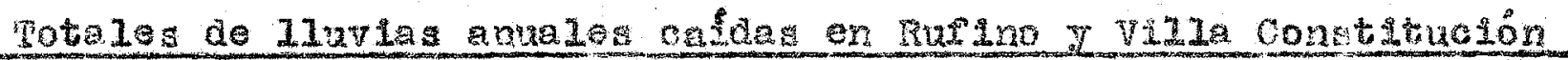
- argante el pertodo $1224-1244-$

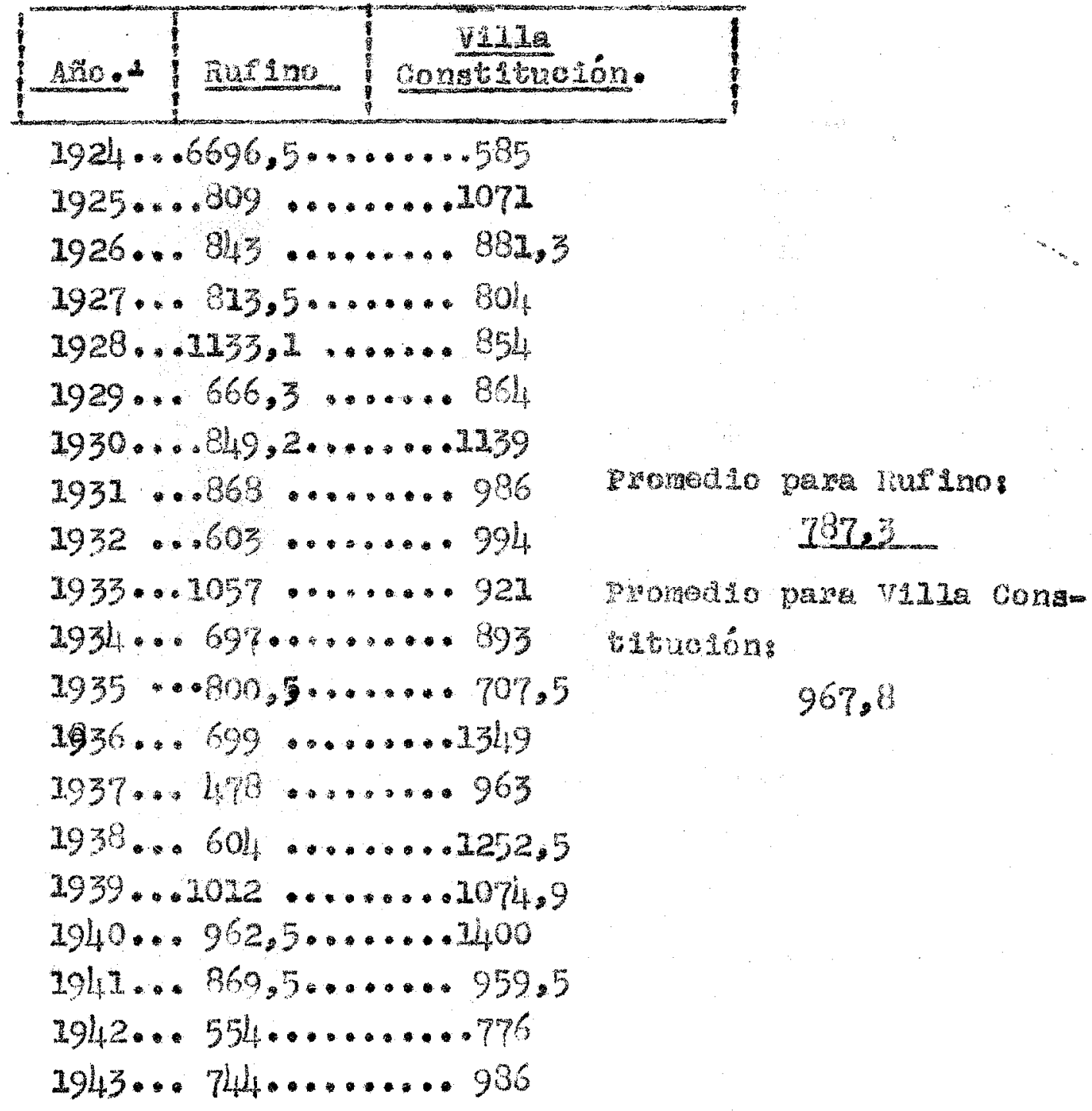




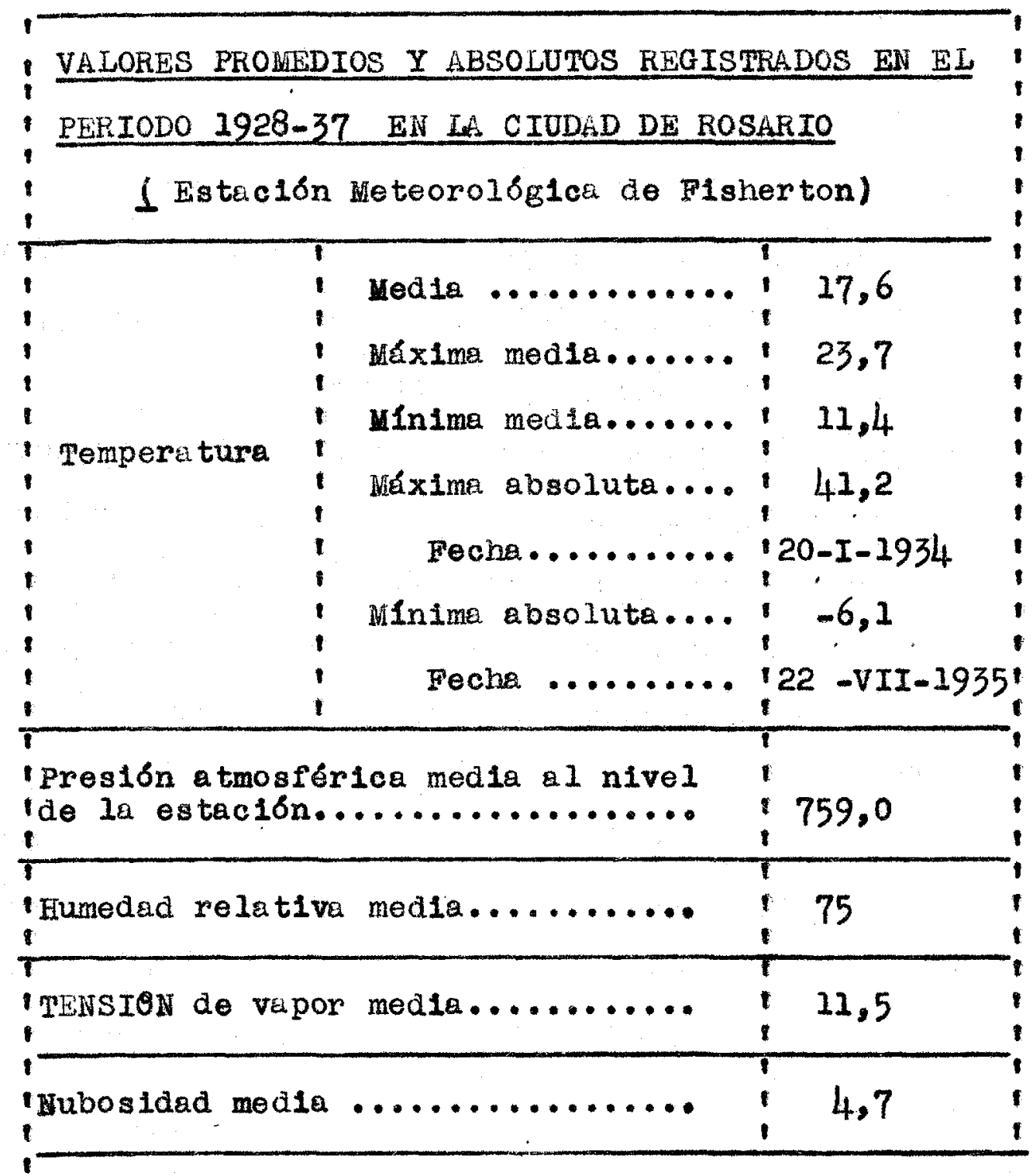

Eeladas - El Paraná influte también en les heladas que suelen cier en los meses de mayo a setiembre, pero aumenten en frecuencia $\theta$ intensidad on las zonas del oeste que se encuentran alejadas del ro.

Empiricamente los cltricultores $y$ viñateros saben que el ries go de las heladas para sus cultivos so atenúa enormemente en las vecindades del Parana. Asf vemo casi toda la costa, desde coronda a Puerto Gaboto, cubierta por cultivos de citrus y más al sud por viñedos. 


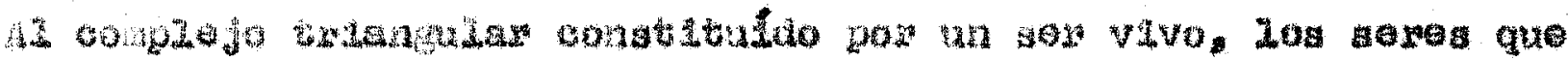

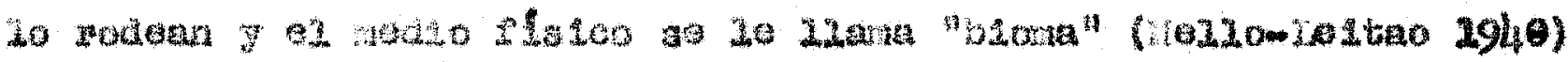

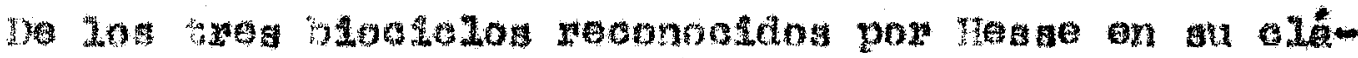

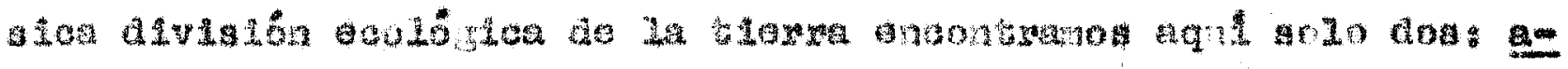

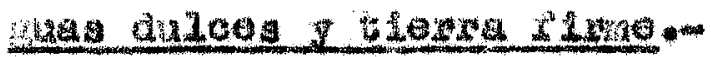

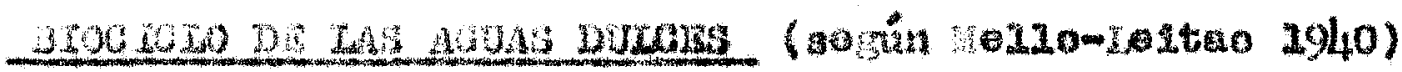

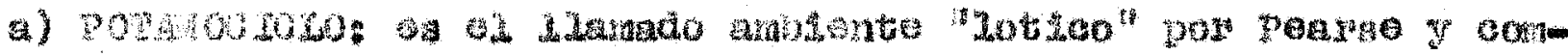

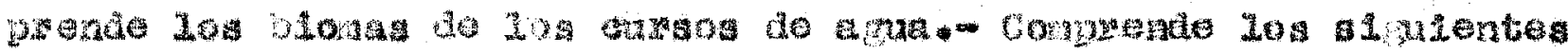

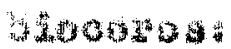

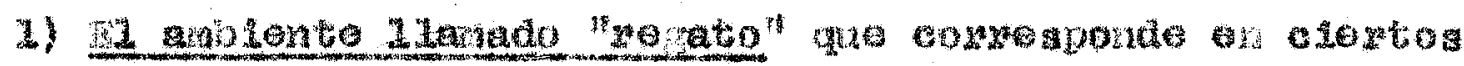

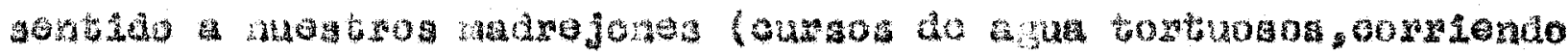

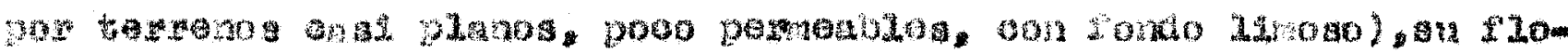

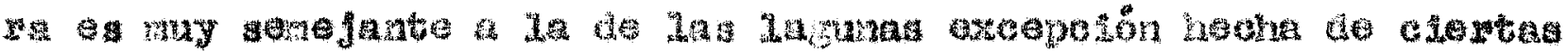

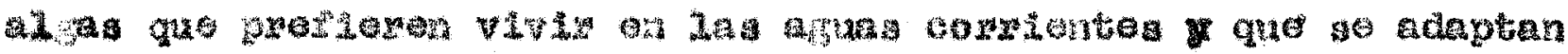

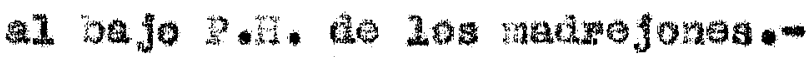

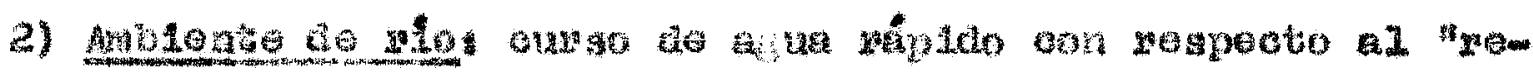

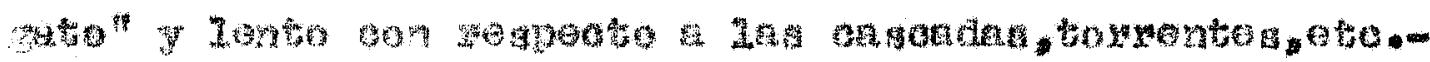

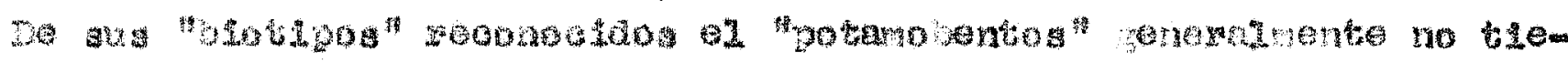

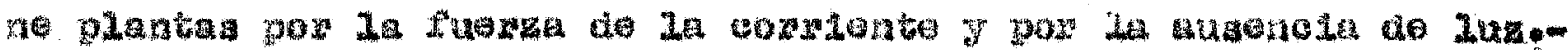

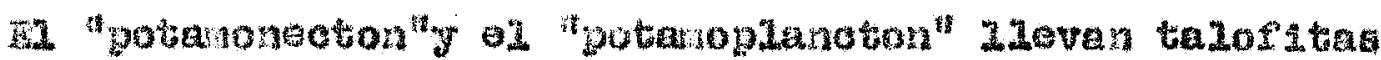

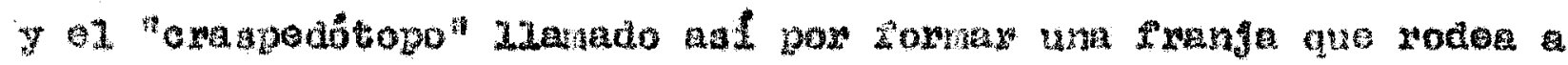

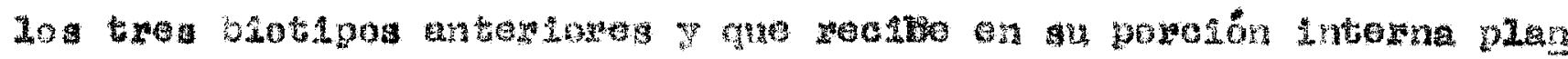

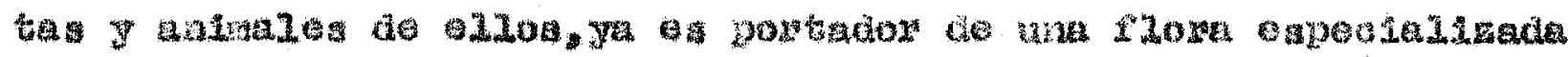

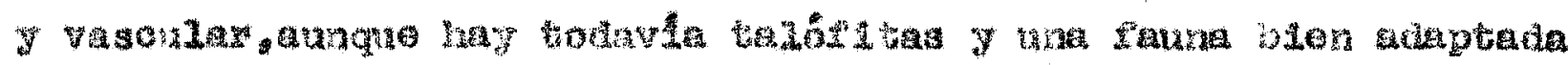

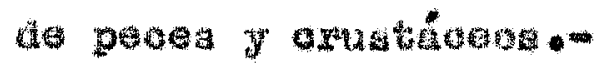

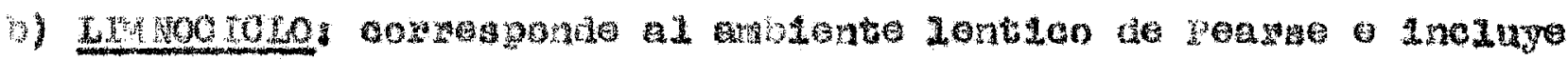

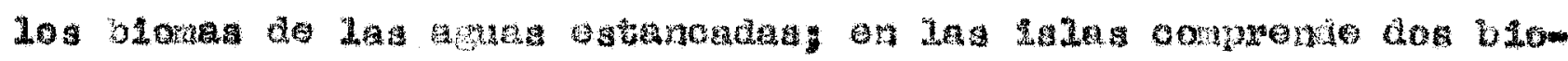
coros:

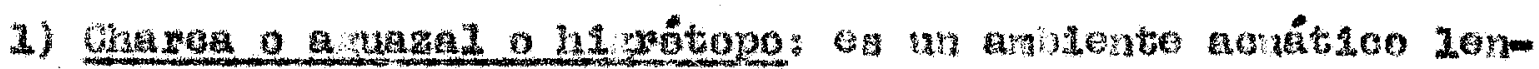

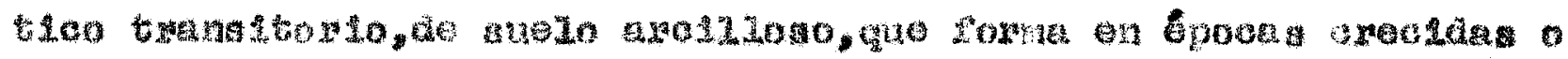

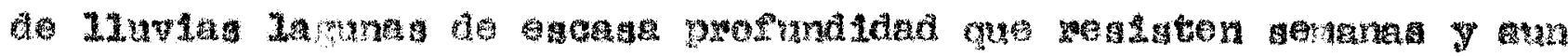


xase sin secarae en las ếpocas de prolongados esthajes.- Tlane al t1po de vogetactón acuâtica de las lagunes aunque senoralmento aus plan

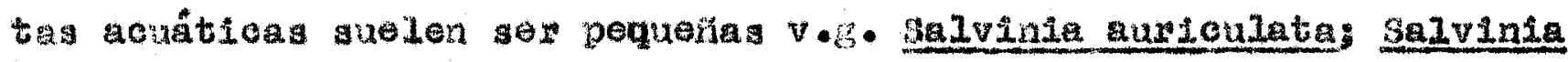
rotundirolla: Azolia flliculojaes; Pristia stxatiotos, otc.-

2) Lagunas: amblento acuático de escasa profundiad con ol fondo cublerto do vogetación $\mathrm{y}$ a supenflele cublerta casi en al totalidad por plantas Plotantes o por hojas $y$ tallos flotantos de las arradgada en el fondo.- Sus blonas constituyen el "eullnnotopo"

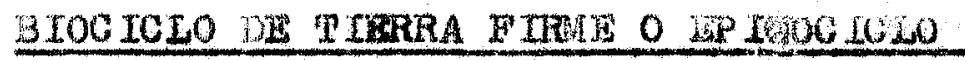

a) hastukopoposes el blotipo de reglones que se secan y anden peMódicamente pregentando una vegetación partioular helofita o anfi$12 \cdot$

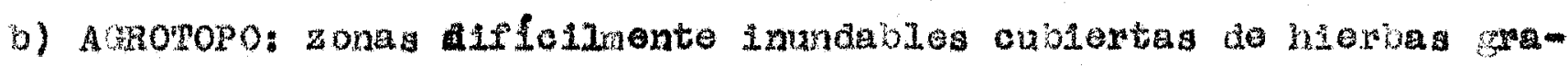
minlfomea cono ol pajonal.-

c) FLORESTA: comprende tros blotipos:

1) Esclatopo: a el arbiente del sotobosque; sombifo, sco en hurnus.-

2) Grerotoporconatituldo por ma flora oplaendrica y una fauna más o menos adaptada a una via dendricola,pasando toda au vida,

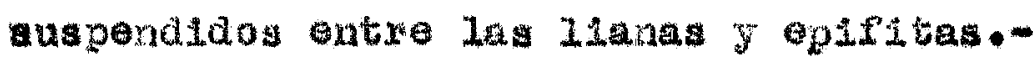

3) Acnepodo: 6 a el anblente de las copas do los árbole donde

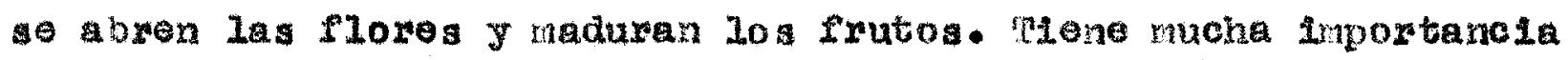
en Ia selva y cas ningune an al bosque donde no ge nota o a ia tri-

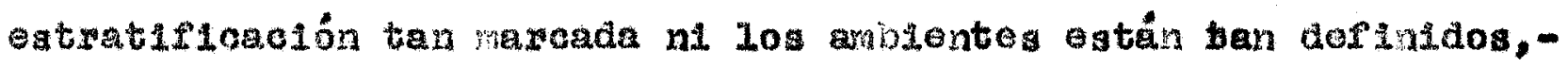

Brocorosison las subdivistonea nayores de los tres bivelelos de Mesge: tan, aguas duloos,y tionras fimos.-

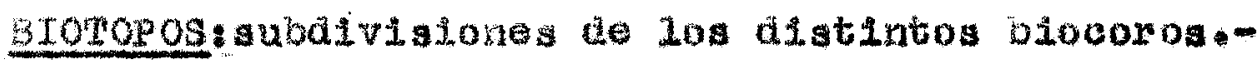


1 - Acejón del hombre sobre la vegetación

La activiad humana como factor controlante y alterante de la cubierta vegetal se ha hecho sentir hace relativamente poco tiempo ( 60 affos más o menos), cuando el consumo do esenclas maderables por parte de las grandes cludades $\mathrm{y}$ de la población rural de las provin clas de santa Fe y Entre Rios exigio el acereamiento del hacha a 1 10: bosques fác1lmente accesibles y transportables que poblaban los albardones isleños.

Hil exiguo porcenteje de hebitantes, la falta de cond1ciones apropiada pare los cultivos y la lejanfa de las zonas urbanas, son factores que han contribuldo a la mejor conservacion de las islas alejade de Roser1o, Victoria, Puerto San Martin, Puerto Gaboto, La Cuevas Y Diamante.

Las causas humana de alteración son múltiples $y$ van descle la destruoción de la vegetación sin alterar el suelo o camblar su contenido en agua, hasta la desertización o la producción de un suelo más húmedo o un érea de agua.

Las activiaides primordiales mediente las cuales el hom bre da lugar a la formación de áreas desnudas aon 108 incendios 7 . $1 a$ tala.

las modilicaciones producidas por la civilización en la cubiexta vegetal pueden ser directas o indirectas (Hauman, 1928). En el primer caso ol hombre destruye siembra voluntariamente, en el segundo, su Influengta es pastva y no proviene de sus actividedes relacionadas directamente con las plantas.

$$
\text { Acción directa }
$$

a) Destrucción de la vegetacion sin aporte (Explotación).Esta actividad esté perfectamente caracterizada en la explotación de los bosques. La intensidad o la minuelosidad del desmonte determine que el resultado sea un cambio de regetación o la inioiación de une nueva sebe. Esto ritimo no ocurre on las 1slas, alvo el ca so que a la tala suceda un incend1o que produzce una destrucción 
completa de los tocones.

El desmonte es la actividad económica més importante de las 1s las.

Desmonte.- En pocos lugares se realiza una explotación racional de los bosques. Algunes medidas de preservación forestal se refieren :

a) Suspenaer el talado de noviembre a marzo, pués los troncos cortados en esa época no retoñan, reanudándola en abr11 pare continuar la hasta octubre.

b) En lugar de hacer hachar a 30 o 40 centimetros del suelo, como es costumbre, se corta el árbol a los $2 \mathrm{~m} \cdot 40$ o $2 \mathrm{~m} .50$ de alto (seria como une intensa poda a baja altura); con ésto se consigue que el árbol retohe con mayor facllidad y rapidez. Este procedimiento no es eccnómico pués se pierde la parte de tronco de mayor valor, por eso se usa poco.

Las tareas del desmonte son:

al Limpieza: se corta a machete las zarzas " "csipos" que se apoyan en los troncos e impiden el trabajo del hachero.

b) Hecheo, generalmente a dos hachas.

c) Corte: se corta el tronco en las medidas comerciales exiglás que son la "pleze" de 2m.20; "meala pieza" de lm.10, ambas de mayor diámetro que $10 \mathrm{~cm}$. J"Lefa" del mismo largo que la media pieza, pero de menor diámetro o muy retorciá y tortuosa.

a) Acarreo: para acercar le madera a la costa se usa el acarreo a hombro cuando es liviana, en caso contrario en dos medios de transporte primitivos, la "angarilig", especle de camilla sobre la que se aplian atravesados los troncos, manejada por dos hombres desde sus extremos, y el trineo o rastrin, armazón sin ruedas, con dos barres de acero pare que se deslice sobre el pasto, tirado por dos o cuatro caballos.

-) Apliada : se forman las pilas en le costa de los canales y riachos, a la espera de tiempo propicio para construir las balses. 
1) Embe lacao: Unc bclak conalste en un corral de 10 a 20 troncos de sauce orlollo (se los elige porque flotan con sumu faclilada), unlalos entro si en aus extromidades por cadena formudo un ampl10 afroulo 1 Iamado correl an cuyo intertor ae arroja la made ra (el suce ar 10110 desemperí la misma función que el ceclro (Cedre-

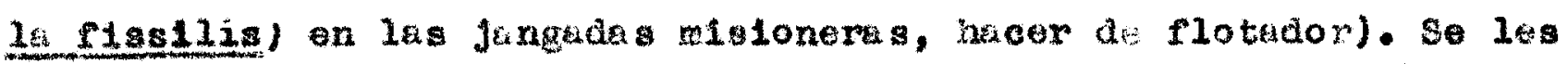
suele agregkex"plohones" que son "corrales" wá ch1cos que llevan la madera sobrante y se atan a le balag.

g) Trangpor te de lag balag: Tales bilsa, a lmpulso de In corriente, culdadas por tres o cuktro axnoas o tiradus por lanchas so llevia a destino.

otro medio de truasportar las plezas es construir un

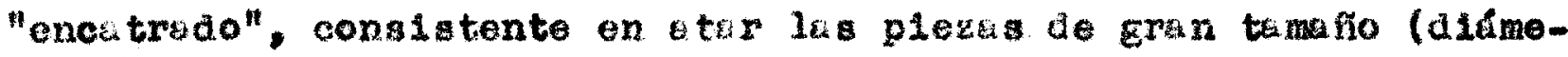
tro) con sogar. Ho se usa la Jungude del norte, dado el escaso dLa metro de los troncos, mi el trensporte bodegk, por resultar demas sado costoso.

EI tulado de los selbos. se realiza con ol método del Delte, seckndo primoro las plentas por medio de und tncisión anuler

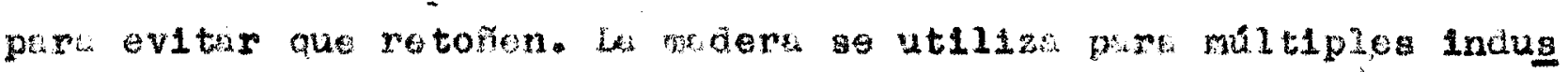
$\operatorname{tris} 3$.

L1 curupi $\$ 01$ t1mb6, "pelsaos", es decir descortezados,

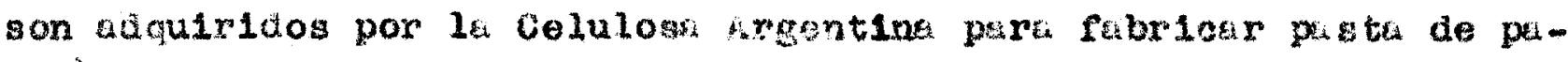
pel.

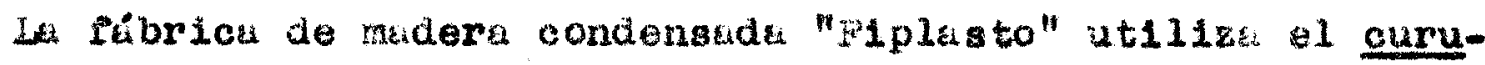

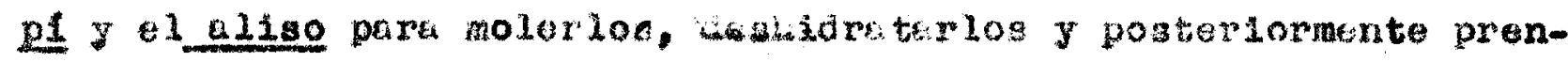

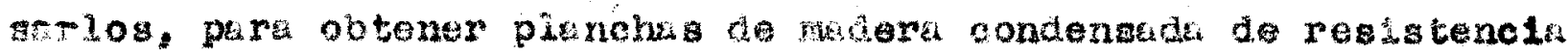
semejante a In do In indere texclede.

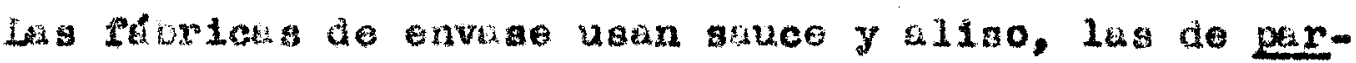
quets madera de espinilio.

IL seibo sirve ptru hacer tamagos destinados a plaos

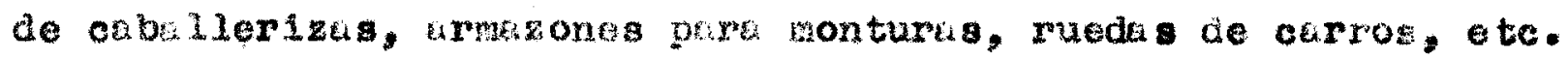
El resto de li madere es absorbláo por los serrade- 
pera construir cunota, remos $y$ botadores son te selbo; on los ranchos los "princlpales" y le "eumbrerc" de tirabó, los norcones de

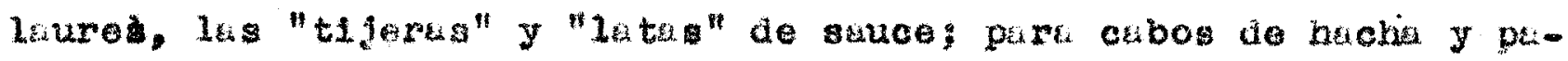

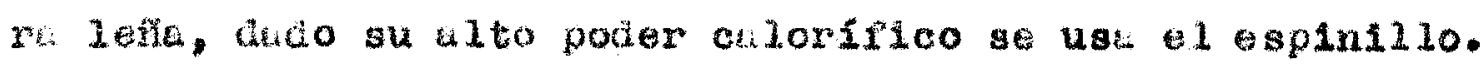

Corta de paja.- Incluimos en 24 destruceion sin aporte

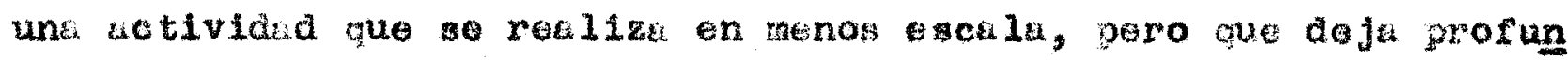
dis hus 1 las en el pujonal.

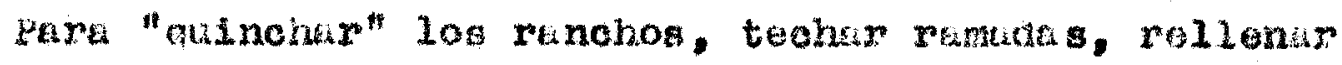

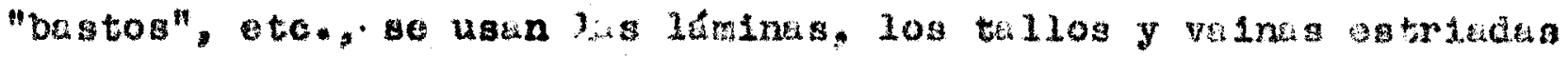

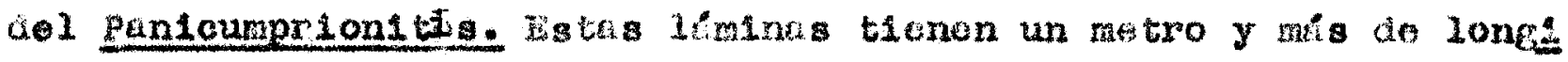
tud por 5 a 8mem. de ancho, un atraen denticulado y cortante. Se

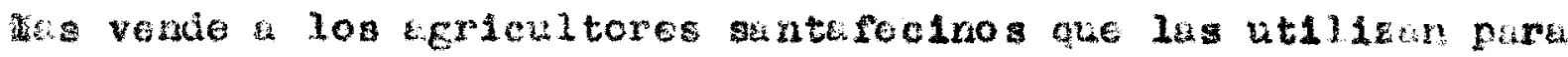

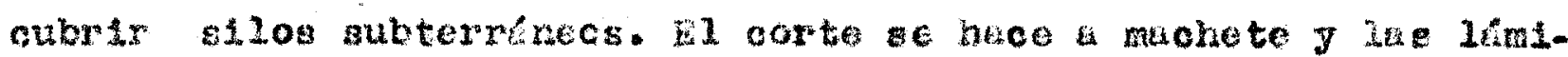
ne se reunen an gruegos heos. Cunmo el corte interiorize los macoliog de esta hlerbi, la planta se leajona y moro.

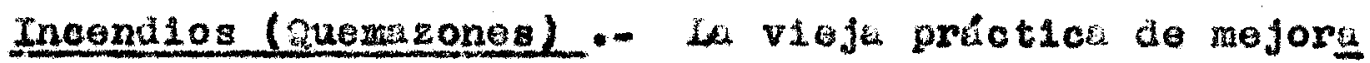

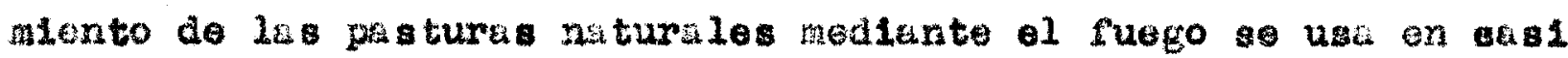
todes las igles por arversos motivos:

a) "para linplis el amo". Los terronos con colonias

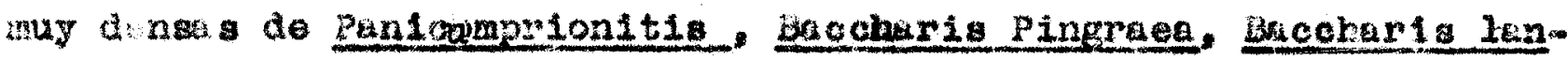

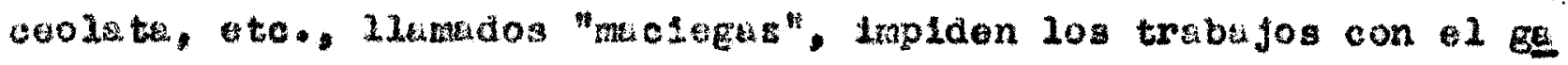

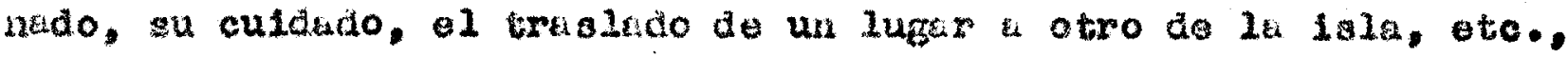
y 20 quema.

b) Para mejorkr 10a pustos. Cuknao a la quemión

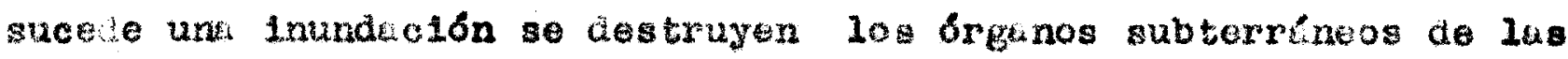

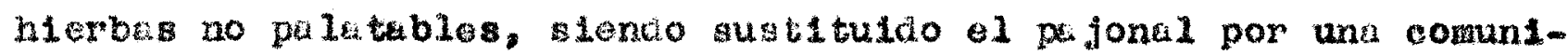

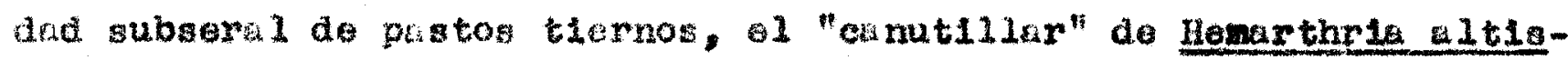
olma y setaris genlculata, especies muy apetecidis por el garado a Igur 1 que otra subdominantes o acompintantes, como plg1taria euyzbens 18, Eohinochlog polys tachye, etc.

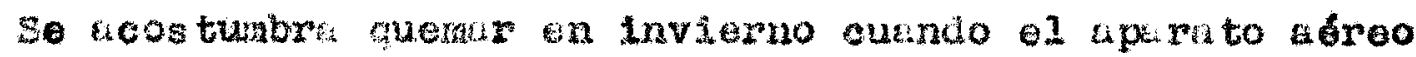

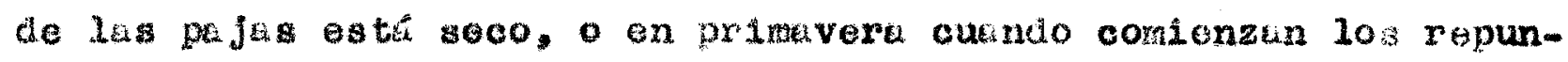
tes obtenléndose alversos resultados: 
1) La destrucción de los órganos aéreos del Panjcumprionitis y de los de Eryngium eburneum del cardal y la invasión del área del pajonal por hierbas palatables anuales que al ter minar el verano ceden ante la influencia de los renuevos de aquél.

2) La destrucción total de la vegetación de las islas, excepto de las plantas acuáticas y la creación de éreas desnudas donde se producirá un subsere que rápidamente cubrirá de terofitas la zona devastada.

El viento suele extender el fuego del pajonal al Bo sque Blanco producléndose incendios que destryen las esencias boscosas. En general, podemos cecir que los Incendios, en la précilca, nunca producen áreas desnudas para la colonización, salvo el caso que a éste le suceda una prolongada inundación que complete su accion destructore.

Ut1lización de otras egpecies vegetales.- Los funcos (Scirpus californicus) se cortan para fabricar esteras, cortinas, sillas, ete; los canutillos (Hemarthria altissima) so emparvan para forraje seco invernal; las varillas (Solanum glaucum), para cabo de latigo y para las "latas"de los ranchos; el Cyporus giganteus pera Idéntioos fines que el junco: la carda (Exyngium eburneum) para engorde de cerdos.

b) Aporte sin destrucción (Plantaciones)- in este caso las comunidades no son destruidas paro se las altera agregándojes nuevos elementos.

El único aporte realizado en ese sentido, en las islas, son plantecionos aisladas de Sauce álamo, sauce llorón (Salix babylonica) y mimbre (Salix viminalis) que a titulo de ensayo se hacen sobre los arehales ribereños o en los islotes jovenes, desde hace 8 años, más o menos, con óptimos resultados.

c) sporte despues de la destrucción (reforestación

I cultivos) - En la reforestación como en los cultivos es previa una destrucción casi total o total de la vegetación que se sust1tuye por comunidades inducidas por el hombre.

Reforestación.- En pocos lugares se sustituye lo des- 
montado por sauce alamo, alano mussolinl o con estacones de sauce coloredo y allso.

Las sustituciones tienen buen 6xito, pero se prefiere otro sistema de trabajo para reforestar: se ralean los densos renovales de aliso (Tessaria integrifolia), sauce (Salix 槅boldtiana) y cuxupl (Baplum haematospermum), que crecen en los buncos jovenes cubriendo amplias superficies, con altura y àistribución tan uniformes que perecen cultivaios por el hombre $y$ las plantas jovenes extralaas se lievan a los lugares desmontados, prendiendo con facilidad.

Estoa renovales son tan densos (hasta 55 plantas jóvenes de aliso por metro cuaćrado) que liegada una determinada edad (má o menos ln.50 de altura) la competenola elimina muchisimos individuos que ceden ante la prosión de población de los que llegan primero a la napa de agra $y$ a sobropasar la altura media.

También se plenten estacones obtenläos de plantas viejas, con resultado satisfactorio solo en el selbo.

Cultivos -- Para realizkrios es necesario, primero, aes truir en forma total la vegetecion existente; fales tareas previas son may costoaas pués cono solo piede sembrarse en los albardones a cauda de las frecuentes inundeciones $\mathrm{y}$ estos son asiento del $\mathrm{kcg}$. que lanco, debe primero destroncarse, es docir, extraer el árbol con sus ralgones para que no impidan estós las labores del arado. Un paso posterior es la queme de la vegetación herbácea para limpiar el Éree; se rotura Iuego con aracio a mansera que entraña menos peligro s d choce con ajgün resgón, pués alte en vez de volcar se y por bilino se viembra.

Ninguna isla he siojo sometida a cultivo extensivo de biảo a las creclentos temporeris que cuda dos a tres años, en marzo abril, las Invaden y llegan a lapar los aloardones. Sin embargo aprovechando los largos estiajes se jealizan con singviar éxito clertos cultivos de poca duración.

En la isla "Los Arroyos", frente a Puerto Gaboto, 
sobre el albarán marginal, en una extensión de 10 hectáreas, se siem bra toda clase de hortalizas, malz y varios erutales (éstos ya han resistido varias crecientes).

Es notable el vigor con que se crian el bananero correntino $y$ el nogal.

\section{fecion indirecte.}

a) Animales doméstlcos - La ganadería practicada en campos neturales trae aparejada una serie de alteraciones cuya intensidad depende del grado de patoreo. Su Influenela se hace sentir de vaI ias meras:

Utiliasr veg6tales pare su subsistencia, quo en el caso de ser dominantes los colocan, al ser maltratados, en satuación de inferlorided frente a los subdominantes gue llegan a a sumir el control de la comunidad.

Ademés de comer pisotea haciendo més compacto el suelo; los comederos o revolcaderos se transforman rápidamente en áreas desnudas, lo mismo que los corrales, bebederos, etc.

Sus dejecciones fertilizan los campos y su influencia see extiende a la composición floristica de las comunidades que frecuentan acarreando semillas de especies de otras áreas.

En la islas tal tipo de Influericias se reduce a la ". presencia de dos especies, el cbrojo (Xanthium Cavanilles11) cuyos falsos frutos vienen enredados en el pelo y la cepa-caballo (Xanthium splnosum) .

La abundancia de pastos tiernos pa latables, entre los que se destacan Hemarthria altissima, Paspalum repens, D1g1taria cuJabensis, Echinochloa holodes, ote., contribuyen a gue estas islas sean muy estimadas para la cria do ganado.

In époces de grandes sequlas; cuando las pasturas de las costa santefecink $\$$ entrerriana desaparecen, es cuando ellas adqule ren su máximo valor pués es dificll gue en el" ambiente is las "se sientan los efectos de la proiongada sequla que afecta tierra firme. 
de ganado famélico, sobrecargándolas, pero normalmente el número de cabezas que soportan es exiguo.

Las crecientes, al tapar completamente las islas, crean al ganadero un serio problema, produciéndose entonces una migración a la inversa, es decir, de las islas a la tierra furme.

El ganado caballar no resiste las inundaciones pués necesita suelo seco y sucumbre con gran facilidad; en cambio, el vacuno sobrevive aún teniendo agua hasta el vientre, slempre que encuentre algo qué comer.

En los ultimos años, un nuevo peligro para la haclenda ha adquirido desarrollo casi a stronómico, la presencia de la piranha o palometa (Serrasanus), que en el afán de la persecu ción y destrucción de su enemigo natural, el yacaré, ha tomado enorme incremento.

Las vacas ya no penetran a comer la vegetación acuática de madrejones y riachos, pués las piranhas llegan a amputarles los pezones de las ubres, to que les acarrea serias afecciones. Los mosquitos son también un enemigo del ganado, observándose a vacas y caballos buscar alivio al anochecer en los albardones y las "Iimpiadas", evitanào los lugares más frecuentados por estos dipteros, en los"bajfos" y el borde de las lagunas, madrejones $\mathrm{y}$ arroyos.

6) Flora adventicia.- Las labores humanas, eapecialmen te los cultivos, dan lugar a la introducción involuntaria de algunas malezas. Como le agricultura casi no se realize son pocas las especies ptesentes en caliád de adventicias.

Se han anotado solo jas siguierites: Gardo de Castilla (Cyrare carcuneulus), Caränus nutars ver. mierocephelus, achicoria (cichorium Intibus), trébol blanco (Irifolium repens), ataco (Amaran6 tus hybridus), verdolega (Portulace oloracea), Chenopodium ambroslolaes, Oirg ium vulgere.

c) Modificaciones del ambiente.- Tales tipos de modificaciones indirectas no se hacen notables en el ambiente isle- 
So por la exlguk denglada de 1 a población, la falta de construccio Les de envergadurk, ausoneia de caminos, de industrias, etc. Hebjtucion - Puejo ser de dos tipos, temporaria, 21a-

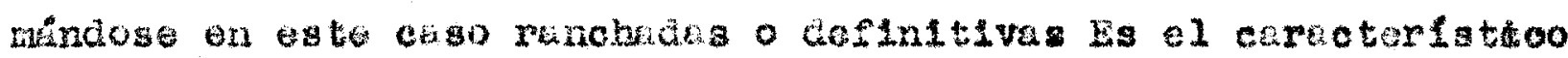
rancho de paja, de paredes at quincho, que se efectín con paja bra-

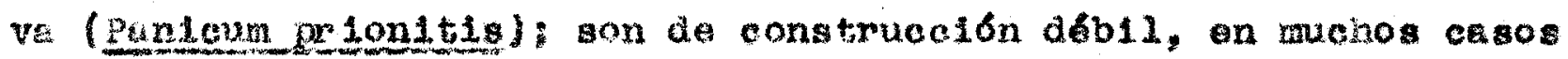

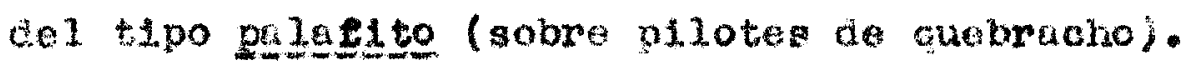

Las renehudus son construccione casi sienge Incompletug ado su ofracter aflmero, 1 a construyen los hacheros, cerca

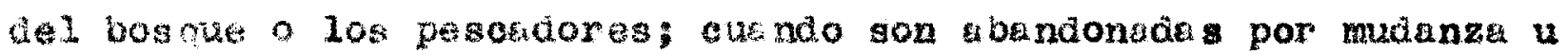

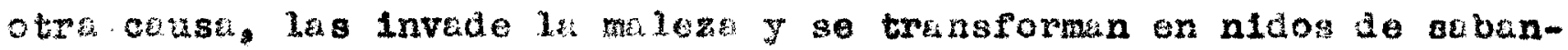

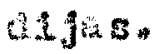

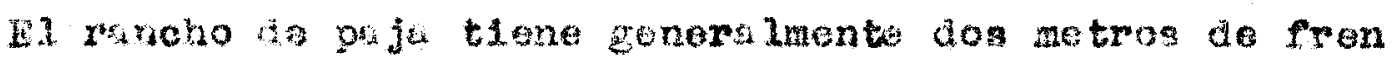
te por treg o cuxtro de fondo: gu tipo general at armazón consiata

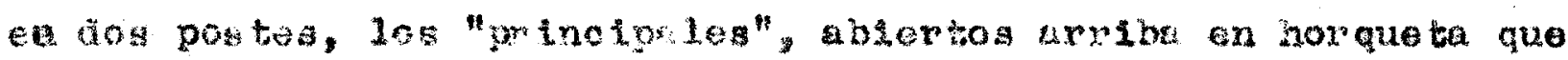

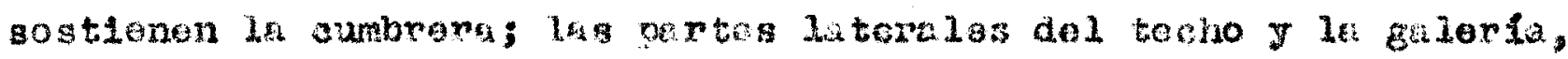

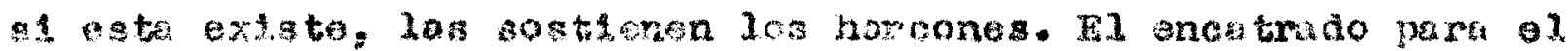

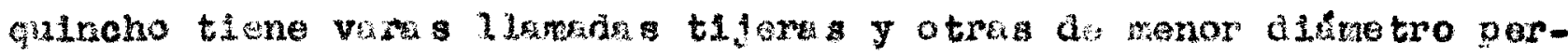

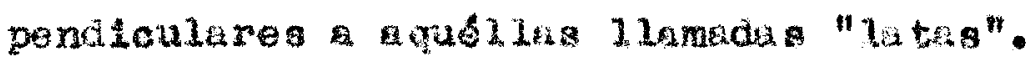

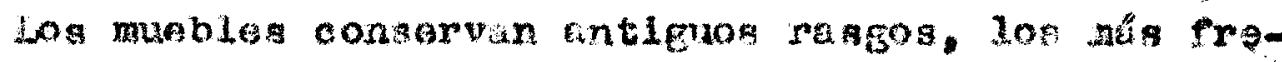

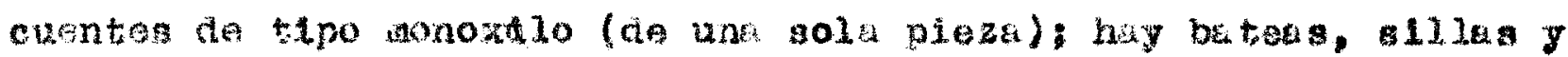
bancos monoxilof, las segunas fabricudes con troncos de selbo al.

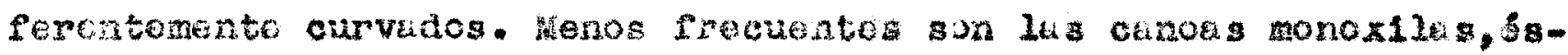
tus pequeria se prepuran con troneo de aejbo excavado y correspon-

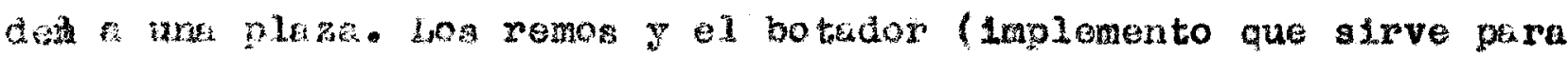

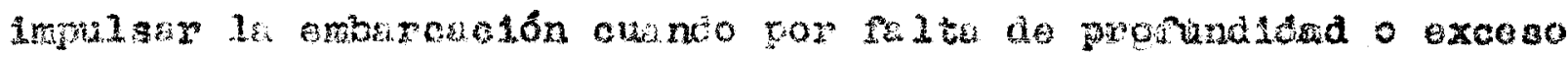

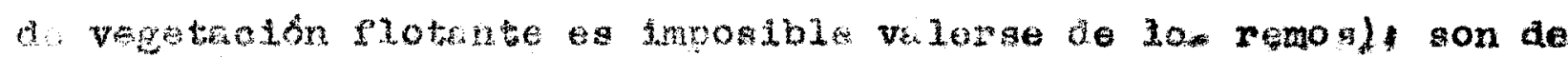
madere do sotbo.

\section{2) Actividedes teonóráloas.}

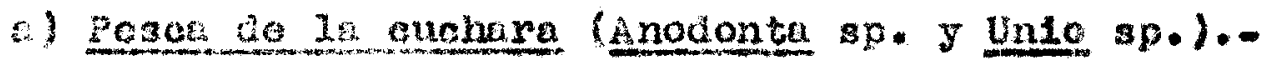

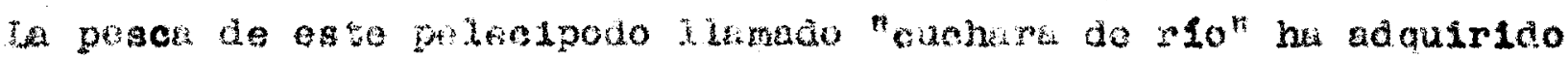

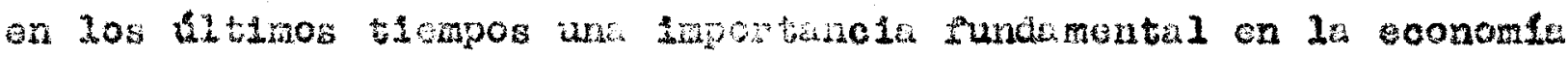
de lus 2slas, dudo los altor preclos que por ella se paga (W2.500 
por tonolads) a los encriguaos de proveorias a lus industritus del. nicar con que se pabrican botones.

La cuchera (hnouonte y Unio) vive enterrada a unos 10ea.

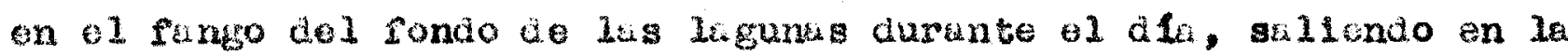
noche. rezón por la que se pretiere la pesca nocturna. Los medis de recolección son:a meno en las lagunas do pock profundidad on las

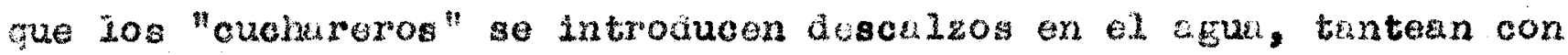

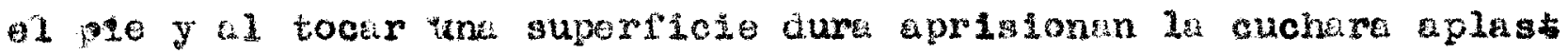
tundols contre ei fango. Iuego to extraen con la mono y la colocin en un morral que llewn colgkndo. sos cuchereros prícticos, al tookr le cucher, con un movimiento mpialsino del ple la montan

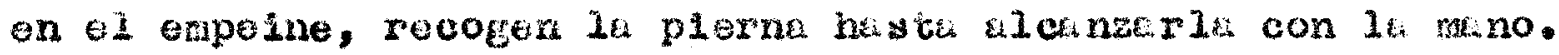

El o tro prodedimiento es con rastri12o eralesao cuando

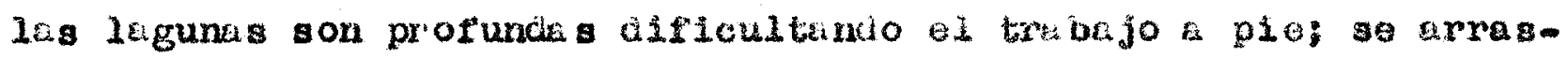
tra con ese implenento por el fango que levanta el limo y si enouen

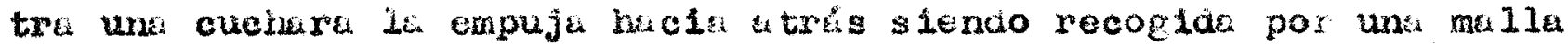
en forma de embuclo alrectarente utada al ratrillo. El arrastro so hace a cunos o desá ia costa.

Los dog alstemas de recolecclor son muy penosos, en el priner caso por tenet que permanecer el cucharero hasta diez hora dentro del aguk y $\mathrm{s}$ se trabeja de alis soporter el reflejo inkguin tablo del sol en el ague, 10 que true sus consigulentes afectones oculares, $y$ on el segundo porque el trabs jo de los remos pura tirar el rustrilio so hace muy posado deblendo turarse los remerog cuda quince minutos.

Una ves rocoglda le cuchara as necesara abrirla para extrea las purtes bandes incluyendo el tunto, este trabajo ge hace a cuallio.

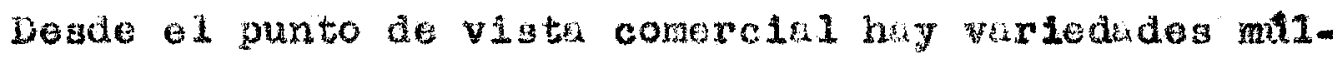

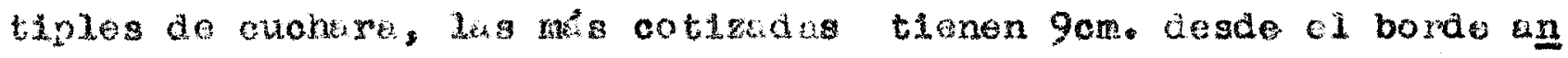
terior al borde posterior $y$ su nacan es tailterale.

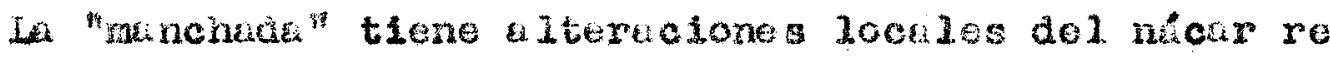
presentada por muchus de color aurillento y por consleutente su 
valor comerciel disminuye. Las vilvas de los animales muertos susren un proceso de alteracion de $\mathrm{O}_{3}$ da que forma como un talco aue cubro el nicur nitorado. Miles habitsoulos no tienen valor comerchal y as les liama "cuchara poarda" pero los lugarefos 10-

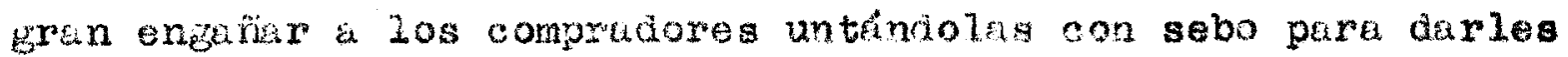
a bri110 coractontatios.

21 "boto"es obu especie de gran adinetro antero-possentor we trinbler 30 compa.

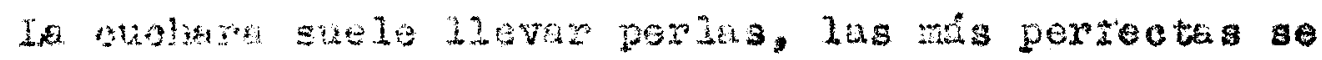
Yenten a 20

b) Pegea.- Los islebo a teran sus actividades de hacheros, warores, cuchareros, ete., con la pesea, Ja para in-

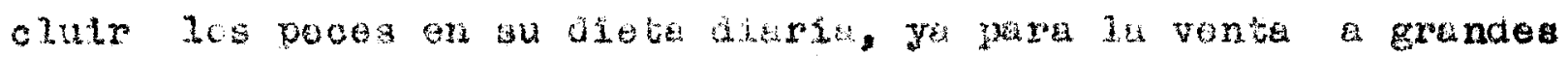

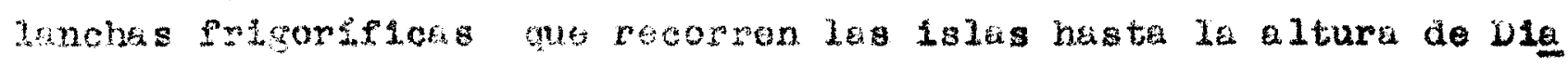

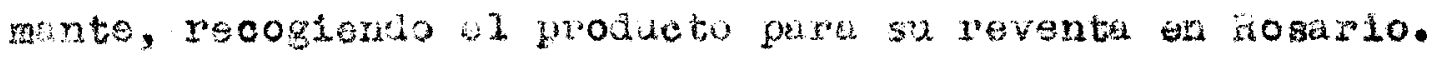

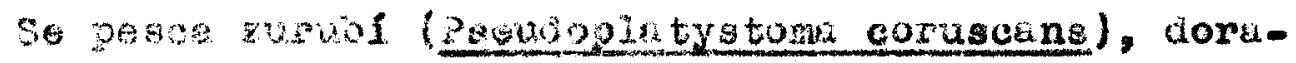
do (Salminus maxilagsog), pojerog (Augtromeniala (jasilichtys)

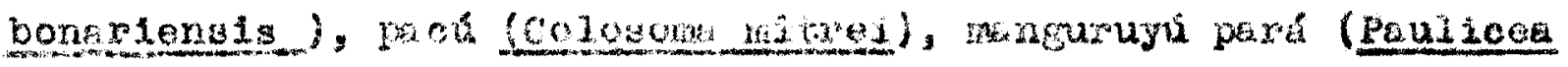

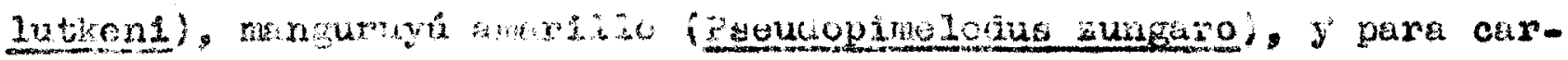

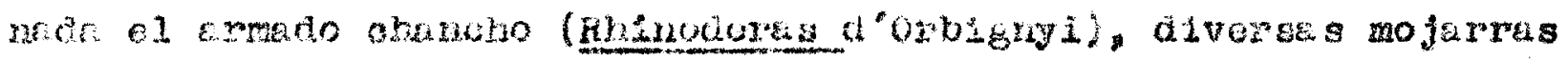

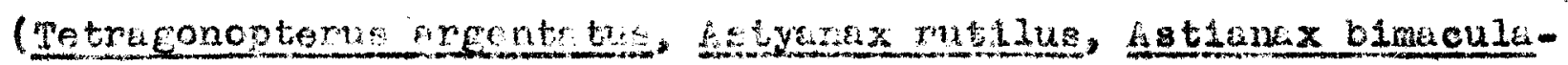

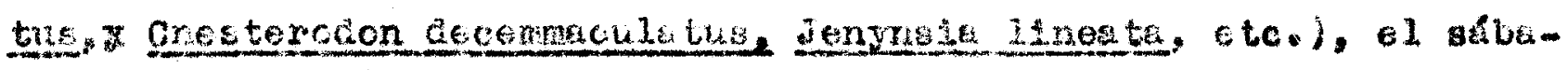
20 y la tarerira o taruche.

Los elstemas de pesee son los generilizados en el Parand,

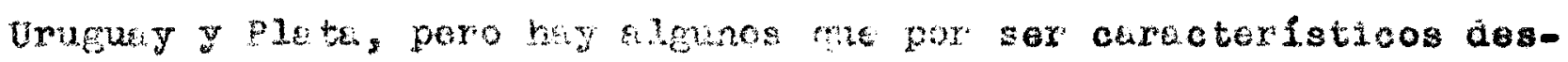
cribiros a continucten:

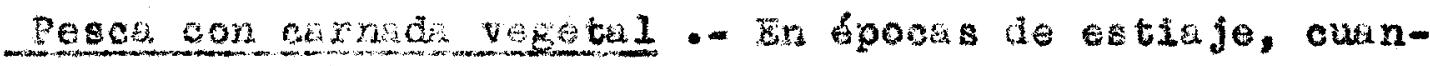

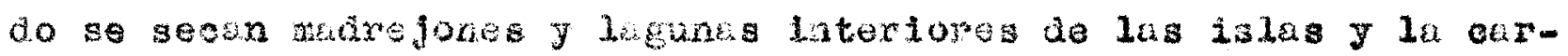
nudi escasea, por ser catos lugaxes los prinolpulos provectores de

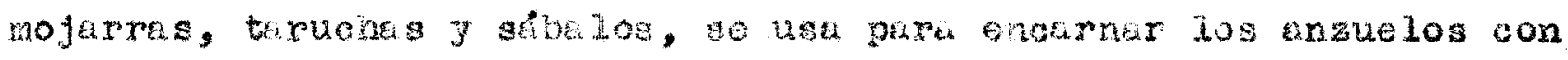

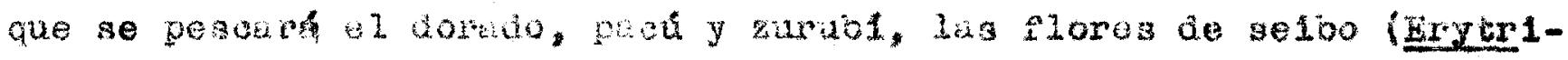
na erigtagi11) gue por su color y apecto suplen con efleacla la 
¿i It csmo. Para pascar a zurubl thmbién so usan los frutos de

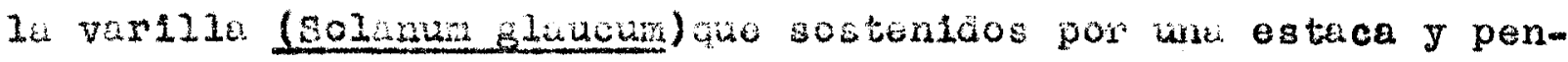
lleates de sin plolin, se colocun a unos 40 o $50 \mathrm{~cm}$. por enclma de La superficie del aguk, el pescador coloca su cunoa entre los came 1otes, ceres ae la carnada y cuando el zurab1 salta le aplica un "bieherazo" y

Eegck en los comeáeros - La mangas de langosta saltona avanzan on las islas J Ilegadas a una barranca comienzan a caer al agua. Tales lugraes se liaman comederos pués son los preferiaos por una abundantisima cintidad de peces que comen langosta los poscadores se instalan all con $10 s$ bleheros lis ios y apenas asoma

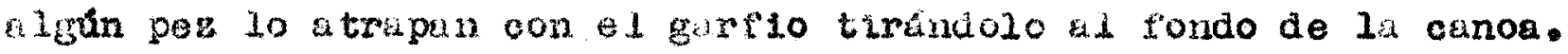

\$30s lugares propornsonan pesec mu abundante $y 10818$ Lenos oe ingentan pera hacer avanzar la jangosta sobre la costa aarupia, generalmente prendiendo tuego a los pajonales cuando el vien to sopla hade la berranca. En otros casos pocogen langostas y las arrojen on lots liagres que dica anteriores hablun sido comederos Ltrageno ast la posca.

pesca a necineze- in las zabunas y madrejones de aguas trenquiles dendo $\$ 6$ ve le presk, se introcucan descalzos (stempre

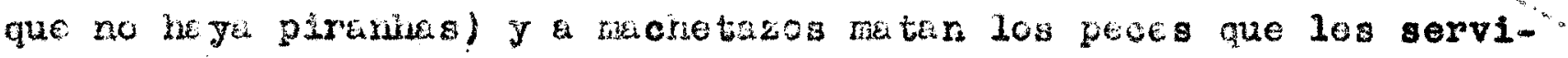
red de cernadia o purti comer.

CL caze - vaza de animales plifferos. La apreciadis1.

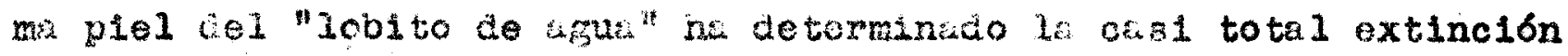
de esta espocie (Lontri paranensis) or las isias vecinas a los Extandes centros pooledos; nés cowunos, pero tumb1én muy perseguidos son el quiyé (uyocastox coypú)y ol curpincho (Hiarochooris marochoeris) aste ultimo muy apreciaco por su curne, siendo la paleta un manjar exgatsito pare los ialehos. Inotdentulmonte, por su plet, 30 cara tambien el aperer (Cavia parparom), pero su valor es reucido.

otros andmales.- se persiguo ed yearé con icentica Pinalidad que el lobito de agua y para comer tode clase de aves a. cuéticas. 


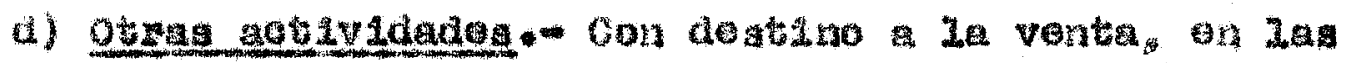

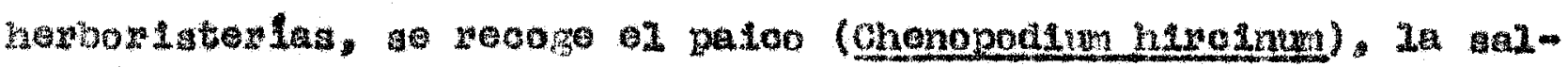

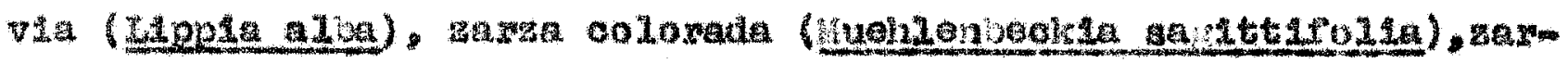

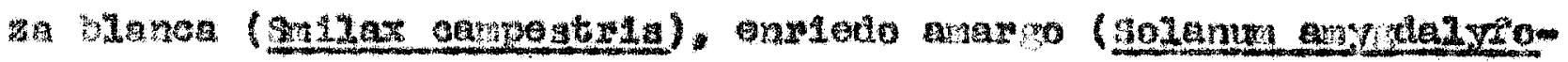
Intate 0

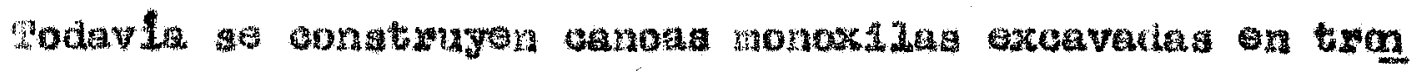

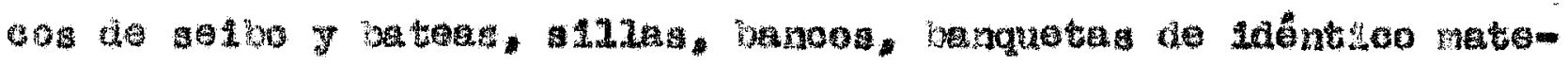

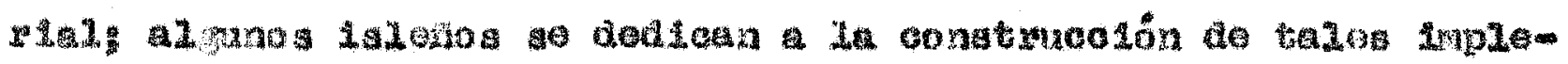

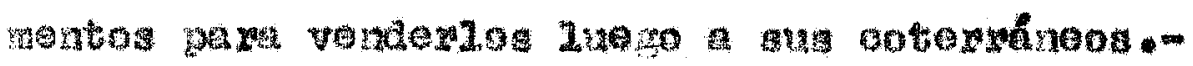

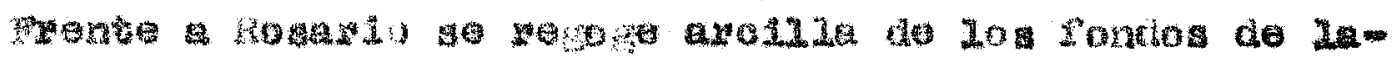
Sมas 1. 
VECETACION DE LAS ISLAS

I-Metodo empleado y definiciones

En el estudio de la vegeteción se ha seguido un sistema mixto ut1lizando métodos de afferentes autores que han demostrado su efi cacia al haber sido empleados ye en nuestro peis por varios investigadores, especialmente por cabrera, Ragonesse y Covas, en este ti po de estudios.

Para los inventarios se tuvo en cuenta el sistema de Braun Blanquet, simplificado. Los censos graficos se han hecho con el método propuesto por Olenents y weaver (1944, págs. 24-27). A ellos he segulao también en el empleo de la nomenclatura de las comunidades y de su evolución.

Se hicieron censos en cuadrados de 1,25 y $100 \mathrm{~m}^{2}$. En ellos se estimuron valores de abundancia y sociabllidad para cada especie, altura de la vegetación, cobertura $y$ composición del sue10.

En cada comunidad se trazaron cuadrados gréficos que dan una idea mís objetiva de la vegetación, generalmente estos se realizaron en el mismo, lugar y en la misma superficie que su correspondiente inventario de abundancla y sociab111dad.

No se ha estudiado la estratificación de las rafces ni realizado transecciones, ambas inconvententes para este tipo de estudios, por impedirlo, on primer lugar, la falta de una barrance donde pueda hacerse una sección y en segundo la abundancia de suelos movedizos que imposibilitan el trabajo de extensión de las cintas slguienáo una feja que abaxca varias comunidades cortándolas transverse imente.

La sección tiene mucha importancia en la estepa, por ejemplo, donde la compotencla por el agua es notable y donde la pom sición relativa, la profundidad y extensión de los órganos subterráneos, nos dan uni laea de la estructura y economía de la comunidad vegetal y no en el medio insular donde el agua empapa todo el ambien te subáreo. 
La transecoión es de vilor cuknóo hay irregulixidades on Ia topogrufia o en el suelo, en las 1 lag solo ea titl para determinar cómo una comunidad cede luger a otra.

Se han confeccionado 60 Inventarios de abundane1: y soclabilidad y 25 cuadredoa gréficos. In 103 primeros se da uní clfru de presencla que indica el núnero de invantarlos an que figura una especie determinada.

Se han tomedo fotograftas vertickles, pero careciendo del dispositivo apropiado se ut1lizsron alturas naturales o se sacaron directamente desde la alture del peoho.

En las fotograflis se ha procurado obtener una imagen de cada comuniala en su const1tucibn mís tiplca, de 10 ocotonos: las diversas etapas de la evolución de la vegetacion, sus dominantas la corteza de lis osencla erbóreas.

No se hatizizado en ell andisis fltosociológ1co pué no os ol objeto de este trubajo $y$ porque para ello os imprascind1ble el estudio de cade comunlada en sus variaclones estacionales y anuales durante un perlodo de varios años, 11 levando d control de la vegetación por medio del uso de cukarados permenentes, cukdrados denudados y serles de fotograflas o tristudos.

sumado \& 10 anteriormente expuesto el conocimiento rudimentar 10 que todavic so tiene de nuestras comunidades vegetales y el escasisimo adiestramiento dol observador on tales tipos de estudio, se tendra el motivo de las grandes lagunas que presenta. pués no constituye sino une visión pinorimica do la vogetación que pourá servir pura postertores trabujos de detalles.

Le circunstancla fuvorable del deamonte ha permitio renlizar reouento de an 110 que en el cuso de "El Islote", pueden ar algura luz sobre el camiro que ha seguldo la formacton del mismo. En los árboles de 1sles viejas ea de ut1lidid mínima, pués no se han hecho observiciones gue permitan deduclr de su desigukl espesor, cembios olináticos, inundaclones, oto. 
Comunidad.- Téralno amplio que dosigna cualquier agrupación definlăa de vegetales.

Comunlakd ollmax.- Is el hitimo grado hasta el que puede 11 e gar a evolucionar una sere bajo el clima de la región en que vive. Algunos autores consideren que hry elimax edafiog, sin embargo aaul se la tiene en cuenti como determineda por el clims $\$$ no por ef suelo. Hsta vegetación estab121zeda en equilibrio con el elima. En las isla la vagetacion detiene ou evolucion en la etapa subfina 1, no hay ontonces olimax.

Comunidad seral - Son las comunidades no climb́xicas que representan una establlizacion mis o menos eflmera de las sucesivas olas de vegeteción que conaucen a la climax.

Comanidad priseral -. Son las anteriores a li elimax J se desarrolian sobre áreas primerias, es decir que no han astado ocupadas anteriormente por plintas.

Comuniad subseral.- Se desenvuelve en areas secundarias que han soportado vegetacion, posteriormente deseparecida por quema, talado, linunda ofon, eto.

Comunlada subelimáxica.- Inmediatas anterlores la cli max que no puelen evolucionar hasta elia por estar controladas por la repetiolón de tulas, incendios, pestoreo, inundaciones; o como ocurre en las is las, par encontrarse fuera de su área climitica y estar determinada por condicionos microclimáticas y edéfices. Ea la tepa subrinal de la sere.

Sere o serie - Conjunto de comunidades serales. Hiarosere - Sere que tiene por área desnude pera su inl ciación al gua.

Sammosere - Sere que se Inlcia en la arena.

Serclimax - Cuando is evolucion os contenida y prolongada Inderiniamente en Igunas de lis primeras otapas. Subsere-- Sere que se origina en un firea secundaria anteriormente ocupada por vegetación.

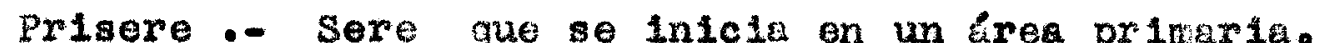


Asocies.- Conunidad no olimixier, earceterizkdk por dos o mís especlos dominuntes. Se designa con el nombre de/lominantes, por ejomp

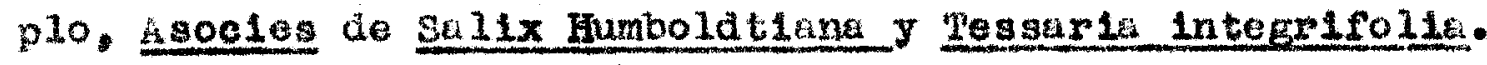

Consooles - Comuniata no climixica con un 3010 domineinte, consocies de Acucia cavente, por ejemplo.

Fecies - Nodiflación de la socies determinade pax

14 Corme de reunión de 10 dominantza.

Soc1es - Modificuelón de la asocio determinada por el papel do dominantes que esumen las subdoninantos on ciertos lugares.

\section{2 - Invente $10 \mathrm{~s}$}

Se hi uscio el o1steme de Breun-Blanquet(1932) dindose un vilor conveneional paru la bundanole y la dominunoid en conjunto, de acuerdo a esta escala:

\$: Individuos rnxos, superficle y volumen ocupados muy escasos.

1 = Ind1v1uuos abundantos, espac10 y eupest1010 ocupados pequeños.

2 - Indiviaius muy tabundintes o cubriendo 1 meno $1 / 20$ de 12 auperfiole.

3 - Wúmero cua lquier de Individuos cubriencio de $1 / 4$ $41 / 2$ de 14 supertato.

46 Nunaro cus 1 quibera de individuos cubriendo de $1 / 2$ a $3 / 4$ de le suporficle.

5 = Numero culaplera de indivicuos, ote. más de $3 / 4$ de la superficie.

La sociblitda se indici con otro numero, colo. cacio continuación del que indiea zbundineli y separado de 61 por un punto o guión.

Le senit 98 tsta:

1 Ind1viduos a Is Iados.

2 - Plantes en pequeños grupos.

$3=$ pluntus on grupltos reuniaos.

4 - Pratas formano pequefia colonla o manche

$5=$ Plantas formendo grandos manchas.

Un punto alsido o un guión Indican que la espocie filts on 


\section{3. - Precuenola}

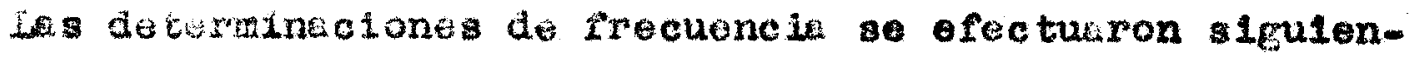
do el. nétodo adopitado por kagonesse y Cova (1.947).

En algunos casos las misma parceitas que alrvieron para Inventar 1ar bundanoli y octabilidad, se uaron pta frecuenota cuando el número de censos ere menor de 10 ; se marcaron percelas hasta completar esta cirra $y$ al ellas solo se anoto, presencia. Se ut1lizaron alempre 10 paredas por consejario la reducción de frocuencla absoluta a porcentum alar por lo monos 10 lugares pira que 10 porcentijes pueden ger tomados consideracion (Braun-Blanquet, 1932, pug. 53).

Wucha veees el tamefio de las parcelas para anotar proDencita no colnolde con el timato de los inventarioa do abundencla Y soolabilidad.

Los resultados se expresaron an por clento peris oada espeole y se confeccioneron lom diagrama correspondientes, anotaindose en las abolsas las clasea de frecuencio y on las ordenada el número de espectea. 
Degae el punto de vista fitogoogrufico, el ambiente in sulax de la maxgen derecha del Parank, comprendido entre Rogario y Puerto Gaboto, osté Incluido en lo que se 1lama Delte superior.

\$1 delta del parané se divide on dos secciones fitogeo graficas (Elawan, Burkert, Parodi y Cabrera, 1947, págs, 140-142): Delta superlor, desde Dicimante a Ibleuy $y$ el Delta inferior, desde

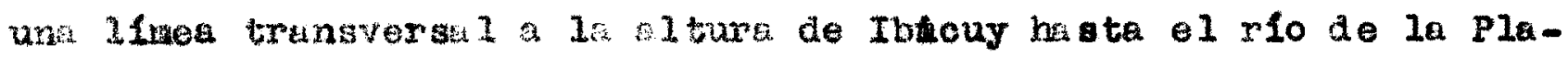
te.

A Vogotacón bsmanguexa.- Bl delta tiene limites perfec temente definias en los flancos donde esta circundedo por las baprancas de Entre Klos, Santa Fe y Buenos Alres, barrancas que soportan una vogetacón caracteristica que se le suele llamar Galeria parunense.

Eata guierlo se extiende por amba orillas del rio, desde el Iimite sud on el territorio de lisiones, con la selva subtropioal orlentul o selva migionete, hasta penetrar en territorios do otras forma clones, cono el bosque chamufio, bosque xerbfilo con predominto do Ecacia y Frosopis región de las sabanas y praderas del centro $y$ sua de Intre lilos y por último en la estepa de Gramineas ha ta el audeste de la cludad de la plate, conde ya no prosperan sus esencias arboreas debldo a la influenolas del ambiente marino. Sus esencies caracteristioas sufren veriaclones $y$ ge sustituyen de norte a sud. Su composición floristica, en sentido latitudinal, se puede establecer gracias a $10 s$ trabajos de Burkart (1947, pags. 130-131), Earod1 (1934) y Berez (1942) de la siguionte manera:

En las regiones de Empedrado, San Ambrosio y Derqui, hry bosques de selbos con picus lonckij, Schinopsis ba lensae. A-

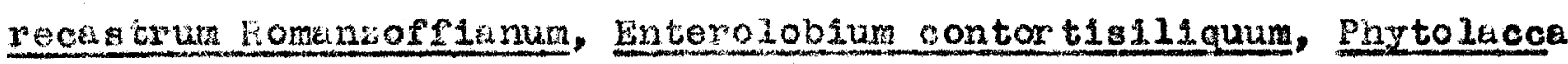

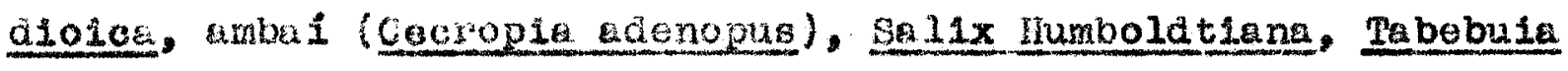
1pe, Geltis splnosa, Scutik buxilolta, Acacia aroma, Saplum haomatospermum, Lippla Iyelo1des, Cereus sp., Opuntia Bromelie. La vege tación herbacea esté representade por: Verbene lacinluta. Aclaurpha 
tribuloldes, Nicotiana longiflora, Heimia salicifolia, Senecio braSiliensis, Solanum sisymbriffolium.

En Reconquista (Santa Fé), sobre un albardon elevedo y arenoso aparecen grandes seibales costaneros y una flora rica en elementos misioneros con precominio de lecherón (Sapium haematospermum), Ingḱ (Inga uruguensis), sauce (Salix Humboldtiena), timbó blanco (P1thecellobium multiflorum), chilca (Baccharis lanceolata), duraznillo negro (Cestrum Parqui1), etc.

Desde la cludad de Santa fé al sud, comienzen a eleverse los albardones que antes estaben cublertos por bosques de sauces solbos, sarendis, laureles, etc., y hoy han sido reemplazados por la agricultura; sin embargo, restos de ellos se ven en la desembocadura del arroyo Frlas, isveer, y entre santo momb y las "Cuatro Boces".

En Rosarto aparecen chañares (Gourliea soinosa), ombú y algarrobo. En Baradero Lippia Lycioldes, Opuntie, Caesalpinia Gilliesi1, Berberis ruscifolie, Ehedra, Sohinus polygamus, Porlieria microphylia. Acacia atvenia, Acacia bonariensis, Cassia corymbo sa, Grabowakla y Holmbergia.

Ya desde el sud de la provincia de Santa fé se agrega a la parte alta de las barrancas del paraná, el bosque xerófilo llamado talar, Asocies de Celtis spinosa + Jodina rhombifolia + Acacia cavenia.

En Campana hay talares y chañarales.

En la ribera argentina del rio de la plata quedan todav1a algunos reaictos de selva maxginel "subclimaxica", especialmente en Punte Lara. Su Ilmite sudeste no puede ser delimitado (Cabrera y Dawson, 1944, pág. 267), pues en las riberas de Palo Blanco y La Balandra he siajo destruida $y$ suplantada por bosques artificiales de sauce, minibre y álamo.

En este sector finci la galeria tiene rucha afinidad fioristica con la selva subtropical oriental, pero aumenta su complejidad por el aporte de esencias austrobrasileras que bajan por 
la galerfa del río Uruguay. Esta vegetación se extingue cerca de la ensenada de samborombon.

Del lado entrerriano encontramos una vegetación semixerofile hasta cerca de Gualeguay, que habita la barranca alta sin tener alspersión hacia el interlor de la provincla. Esta zona es llameda por Beez subregión Paranense.

A la altura de la paz este bosque costanero tiene la siguien te composicion: Acacia cavenia, algarrobos (Prosopis), tala (Celtis splnosa), quebracho blanco (Aspldosperma quebracho blanco), caranday (Irithrlnax campestris, Seutia buxifolia), sombra de toro (Jodine rhombifolia), Acacla bonaeiensis, Salix Humbolatiana, Cephalantus sp.

Le vegeteción barranquera de Paraná y Diamante (Baez,1923) acusa el monte costanero con unos $10 \mathrm{kil}$ (bmetros de ancho formado por quebracho blanco, chafiar, ñapindá, esplnilio, ñandubay, algarrobos, tala, palma caranday, Schinus polygamus, Ephedra Twerdiana, SaDium heema tospermum, Jodina, Lippia Lxo101des, Acha tocarpus praecox, Bumelia obtusifolia, Schaesseria argentinensis, Ximenia americana, Conaalla, etc.

En Victorla, Burkart (1944, pág. 133) anota las siguien. tes especies de este monte semixerófilo: ombú, Prosopls nfgra, Celt1s spinosa, Lippia Lyc101des, Schinus polygamus, Jodina rhombifolia, Acac1a cavenia, Caesalpinia G111iesil, etc.

Este bosque barranquero se extlende, en la margen 1zquier da del Baraná, desale Gualegukychú hasta Corrientes y a meálda que avanza hacla el norte aumento la densidad y porte de sus dominantes, hasta formar una verdadera selva costanera o selva en galeria. La galería Paranense tiene un desarrol 10 de $1200 \mathrm{Km}$. Y se la considera como une entidaa fitogeográfica continua que forma una faje cuyo ancho oscila entre 10 y $40 \mathrm{Km}$. 
Donde existen barrancas la delimitación lateral de la vegetación es bien definida, pero donde el cauce de intndactón no encuentra vallas en sus flancos, los limites son muy imprecisos.

Consideramos delta desae Diamante a la desembocadura del parana, pero con la salvedad de que islas del mismo tipo, es docir, planas, surcadas por albardones interiores, por madrejones cegacios en determinadas epocas y depresiones contrales en palangana que so portan laguna: las encontranos desae corrientes al sud.

El rio regulariza la calda de las iluvias actuanào como gran cubeta de evaporación, aumenténdolas en relación con el interior de Santa fé y Entre Rlos; atenúa el efeoto de las heladas hacléndolas casi desaparecer; disminuye las diferencias de temperatura entre el dia y la noche $\mathrm{J}$ entre las distintas estaciones; aumenta $3 a$ humedad ambiente y construye terrenos jovenes que se vincuIen con diversas comunidades edfficas. Tales son las causa por las que la vegetación dética es distinta a la de las formaciones porque atraviesa y an a la de los bosques costaneros.

Fn su alstribucion latituainal hay observaciones aisIada que permiten reconstruir, en parte, ans cambio floristicos.

a) Dolta superiof - En las islas próximas a Corrientes (burkart en Hauman, Burkart, Parodi y Oabrera, 1947) pkigs. 130131), la cublerta arbores este representada por Nectandra membranacea, Ocoter acutifolia (laureles del paraná y Uruguay), sause (Sa11x Humboldtiana), Ingé (Inga uruguens1s), curupi (Sap1um haematosperaur), sengre de drago, Eroton urucurana, Geoffraea striata y Bergeronla sericea.

Entro los arbustos y gufrutices se destacan: Solanum Elaucua, Solanum angustifoldun, Mimosa pigra j entre les hierbas aversos polygonum, el helocho mrismexis trifollata, Eupatorium hecatanthum, Lathgrus nigrivaivis, Echinochloa cruz-ga111, Cuscuta, 
ete..

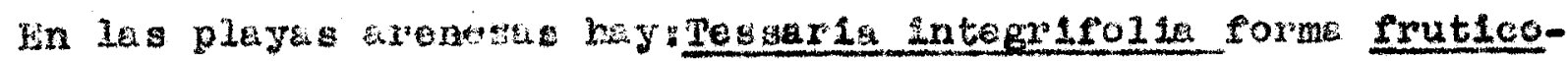

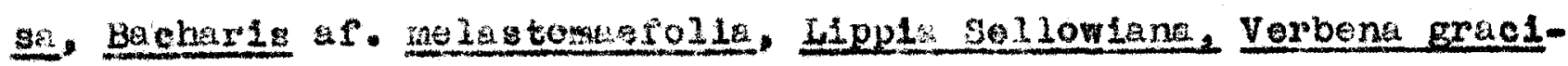

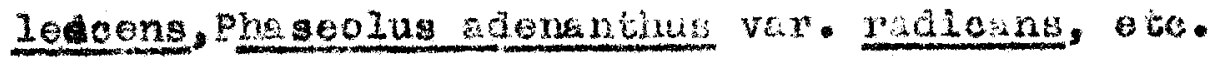

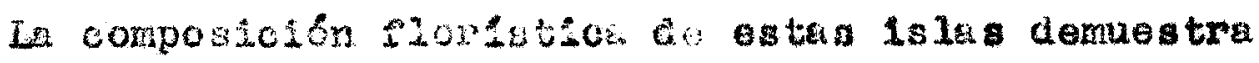
su. arinidad con ol chaco oriental.

En la zone de Dleminte apriecen bosques fluvialo en gran cantidad bosquecilios de acuce y also en les partes areno-

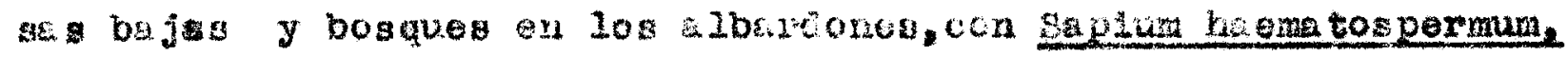
Nectundre nembranacoa, Plthecollob14r multiflorum, Erythrina oris-

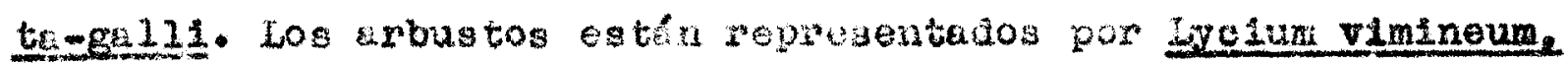
Aesenynomene nontevideng1s, Cephalutuus glahretus, Sesbania marg1-

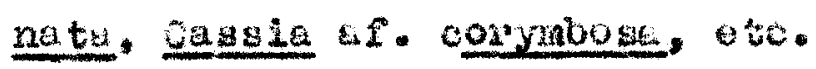

In la latitud de Fosizio tenemos vegetacion insular

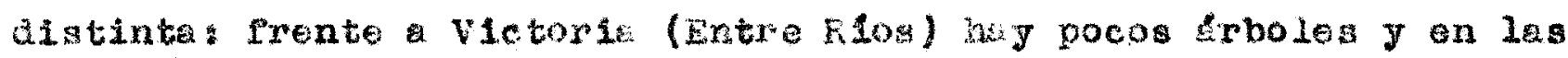

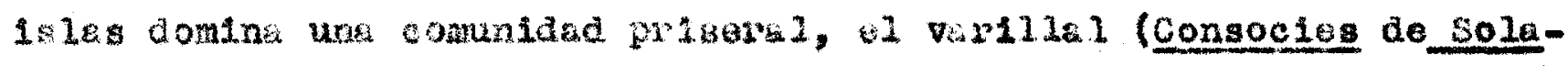
num glaucum) y frente a Foes 10 bosques de timbo blanco. P1thecellobium mit1elorum on ourupl, selbo y laur 1 ; montes de hcacla cave-

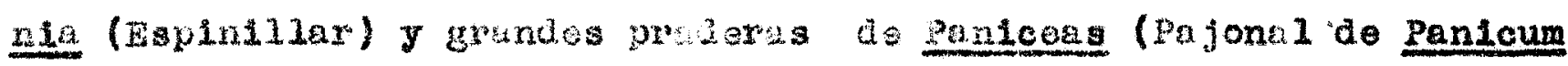

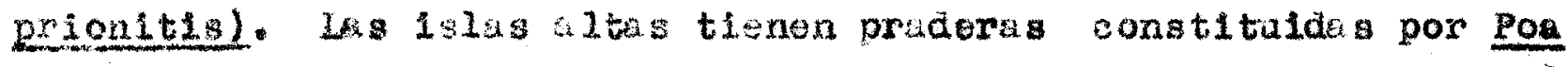
p11comayens1s. Briga, Seteris, to.

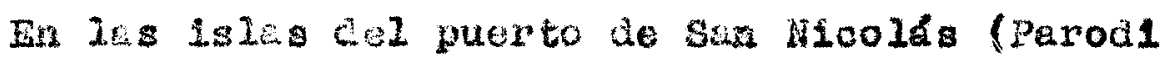

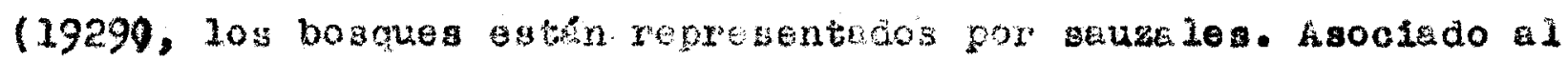

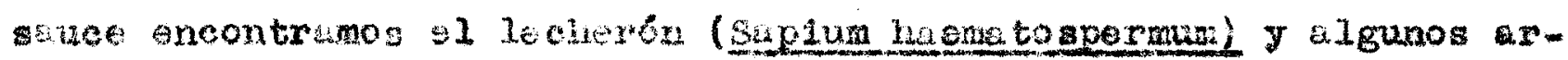
bustos como el gersnd1 (Gephajantrug glabratugl, sggbania marg1nata, ete.

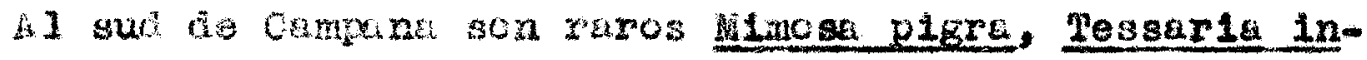

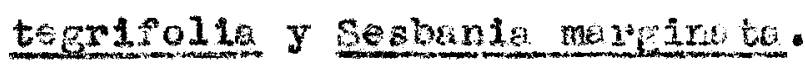

b) Delta inferioz- Es mucho menos extenso que el su-

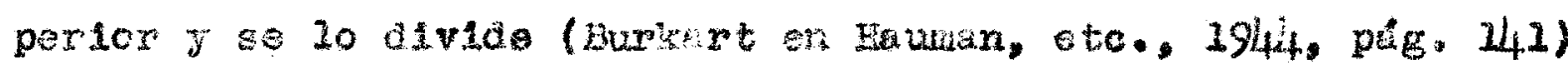

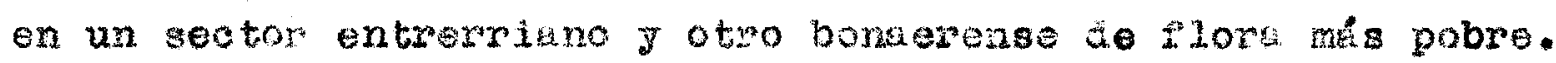

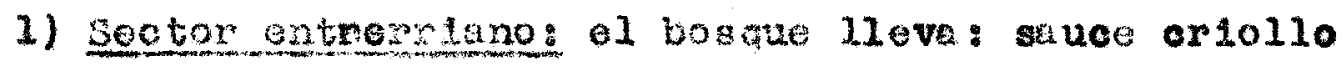
(Sa11x Humbolatiana), selbo (Erythrina crista-ga11i), timbó (Entero- 
loblum contort1a11iquum), cunejón (Rapanea laetevirens), sangre de ärago (Croton), matiojo (Lucuma), Laurel (Nectanara membranacea), blanquilio (sobastiania brasilionsis), pitingas (Eugen1a), amarillo (Merminalia), aliso (Tossaria integrifolia), surand (cephalanthus gabratus).

En este region insular se rusionan las dos corrientes de vegetación del Urugary y del parane (Baez, 1942), prevaleciendo $1 a$ primere por el considerable numero de especies de origen austro-brasileño.

2) Sector bonaejense - Las 1s lis $30 \mathrm{ri}$ bajas, on forma de palangana, con albardón meginal y depresibn centra1, ocupada $p$ por densus comunidaces de helofites, especialmente pajonales de Seirpus giganteus. Su monte bianoo se compone de jos siguientea árboles: setbo, Ingá, lapachilio (Lonohocarpus netldus), mata ojo, lau rel, canelón, blancuilio, curupi, Blopharocalyx Tweodiel, Eugenia Giacescens, antrlio, azahar del nonte (3ymolocos uniflora), eto. Los brezos extrenos del delta interior son los ros lauJu $\mathrm{y}$ Paramecito Martinez. 
In la sección del Delta superiox, on la zona de la mergen derecha del Paraná corprendida entre Rosario y puerto caboto, se distinguen dos comunidades subclimáxicas, el bosque fluvial o bosque blanoo $\mathrm{y}$ el espinillax,detenidas inderinidarente on la etapa subfinal de su evolución debido al microclima creado por el hóloEstas comunidades evolucionarian de no mediar esos factores climáticos 7 edáficos hacia asociaciones do dos formaciones (cilmáxicas): la selva subtropical oriental y el bosque xerófilo peripampeano,respectivarnente.-

Se describen también varias comunidades higrófilas que evolucionan hacia la subclinax y algunas comunidades subserales creadas directa o indirectamente por influencias humanas.-

A - COMUN DADES SUBCLIMAXICAS

1) Bosque fluvial o bosque blanco o bosque Insular

(Asocios de Saplum haematosperruun; Erythrina crista-gali; Hectandra membranacea; Pithecellobium multiflorum:Figs . N29:38

Es el equivalente del "rante blanco" del belta inferior, dificilmente adquiere el carácter de gelva en raleria siendo sus características las de un bosque higrófilo, constitufido por fanerofitas no ruy densas ni altas, escasez o ausencia de epifitas, con un solo estrato arbóreo.-

Cuando estos bosques se alojan on los albardones marginales de islas contiguas separadas por un arroyo estrecho, su aspecto recuerda el de las tipicas selvas on galeria.-

Es recuente oir Ilamar a ese bosque "monte blanco" quizás por difusión del nomore local de la vegetación selvática del Delta inferior, o simplemente monte.-

Aquí se usa el término "bosque blanco" porque la madera de sus dominantes es lgual a la del "monte blanco", blanda, de colores claros hasta blanca y pulposa, salvo la del timbó blanco (Pithe- 


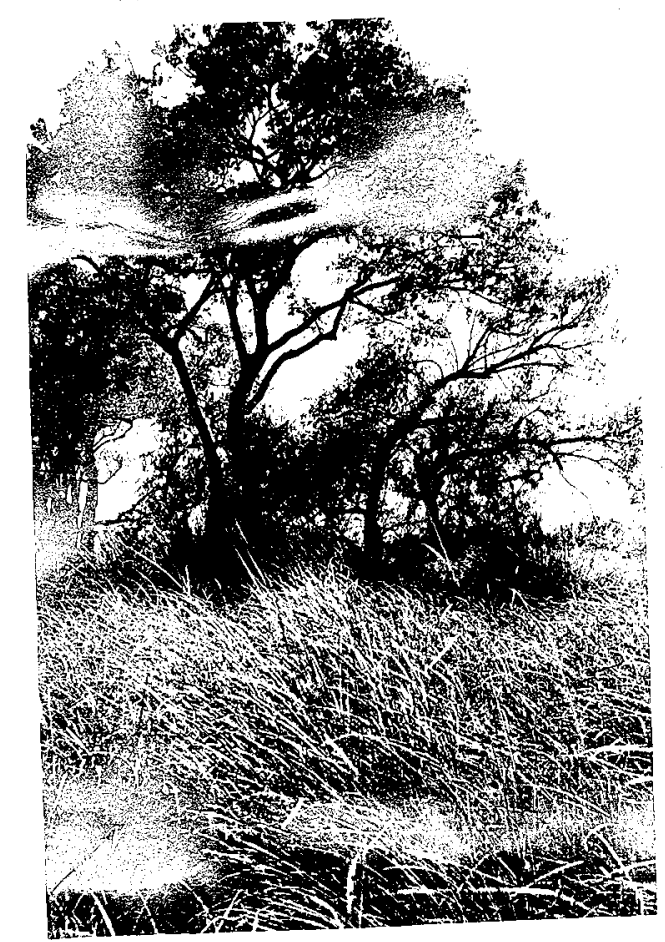

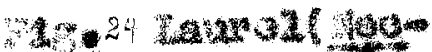
tagy
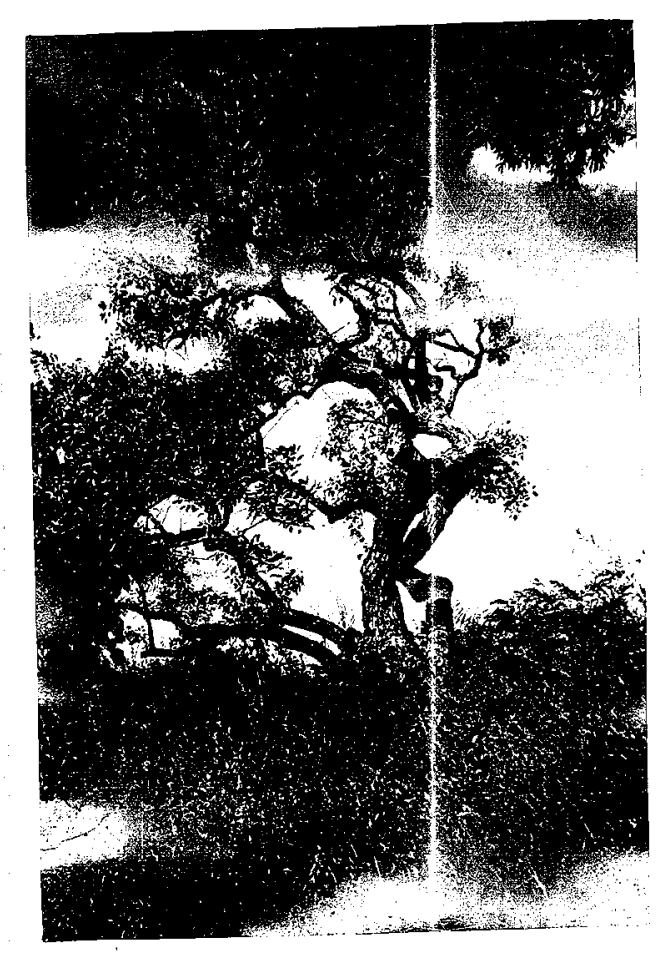

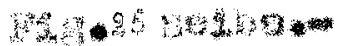

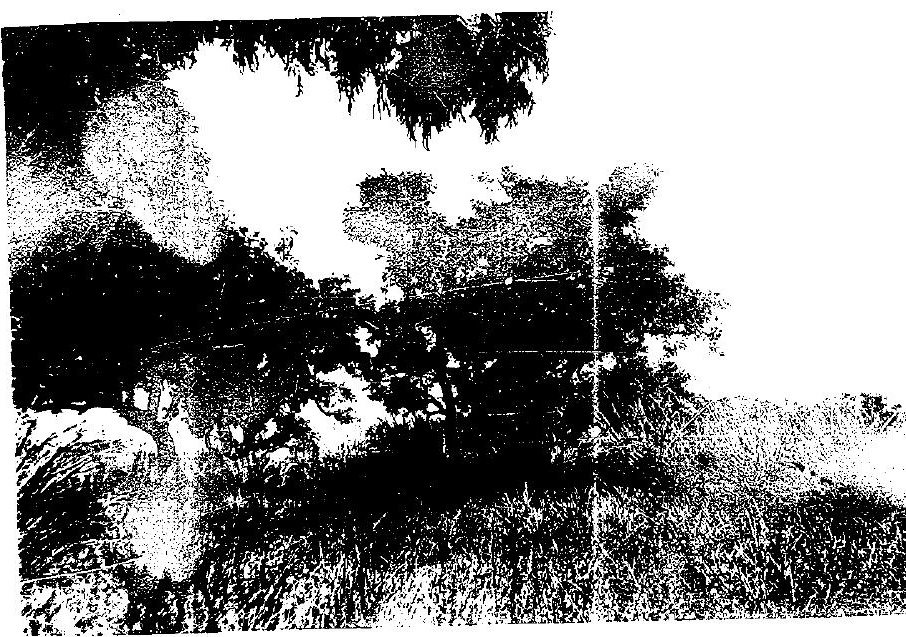

H.

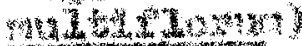


ce11obium muIt1florum). dura y peade que flota dificilmente en el agua.

otro carfoter comin a 1 bosque fluviel y monte blanco del Delta Inferior son las hojas de los Érboles, todas grandes y brim 11antes.

El. bogque blaneo se desarrolla on los alolos arcillosos de abundante contenido orghico y nitrielcaclon normal de los alm berdones de las islas mós antiguas, meduras y altas, indicando con \$u presencia una de los lugares donde el factor controlante de la sobrecarga de hunedid del suelo se hace menos sicentuado permitiendo una más fácil oxigenación, y al mismo tiempo sitios donde norm malmente ao liegan los repuntes peribalcos del rio. Constituyo unka de las etapas sueesionales más elevadas del ambiente insular y con ella se interrumpe la sere que más al norte, la altara del parale 10 28, conduce a Jas asocisciones de be formación climácica de la gelva gubtroplcal orientai.

El thicroolima del "ambiente lelag" os meis hímodo, més oxlico $\mathrm{y}$ con menos fluctueciones diarias y estacioneles que el clime estepa" del sua santafesino; ol "clima bogque xerófllo" del anillo peripampeano, $¥$ el "clirts perque" de la megopotania, gracias a ta Influencts tempersine del rla, pexmite el dearrollo de ano vegetacion tipo bogque higrofilo en una región de bosques xerofilos, de estegus y de parques.

Como en las islas, esta comunidad no puede evolucionar por hallarse en una latitud donde la selva subtroples l no prospora; conalderamos entonces are se trata de una subclimax determinada por factores de compensactón edélicos y climúticos.

En la zons que nos ocupa, entre Rosario y Puerto Gaboto, la vegetación no es muy densa, hay pocas epleftas J Iinas, tefiendo les caracteristica a un bosque conststulio por un estrato superiod de megatanerofitas peremifolias,1atifoliadas, de 10 a 12 metros de altura, que crecen a veces reunidas $y$ otras en forma espaciada, constituyendo con sus copas un dosel discontinuo e Invadi- 


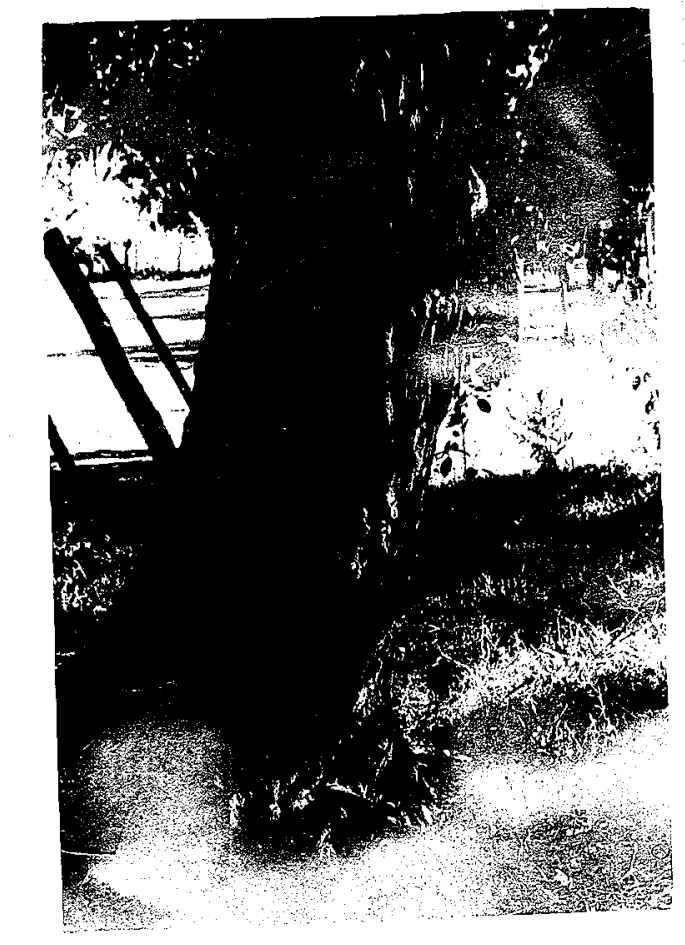

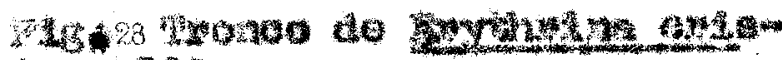
by-12a214

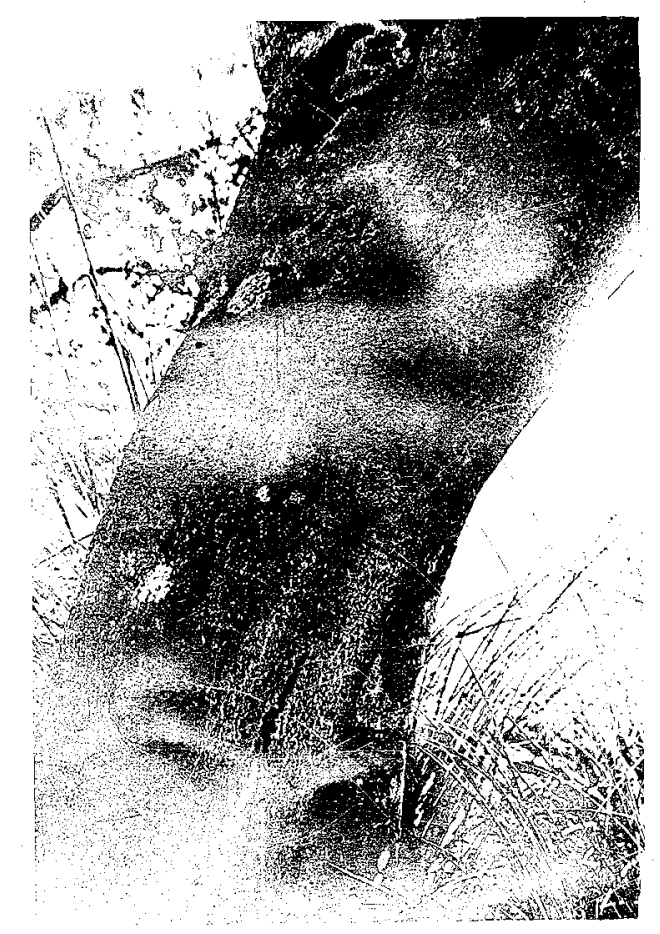

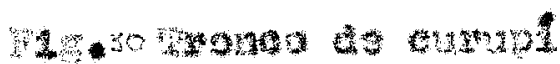

(3)

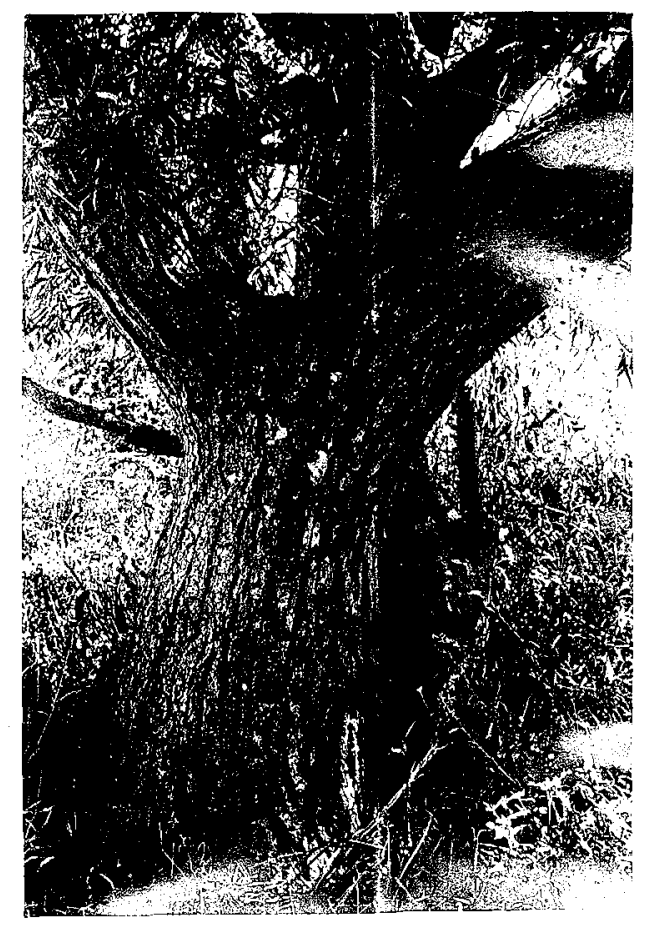

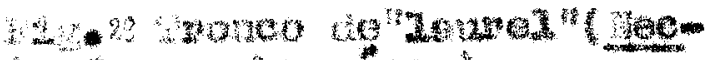

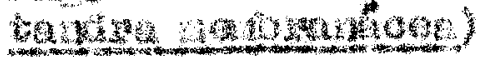

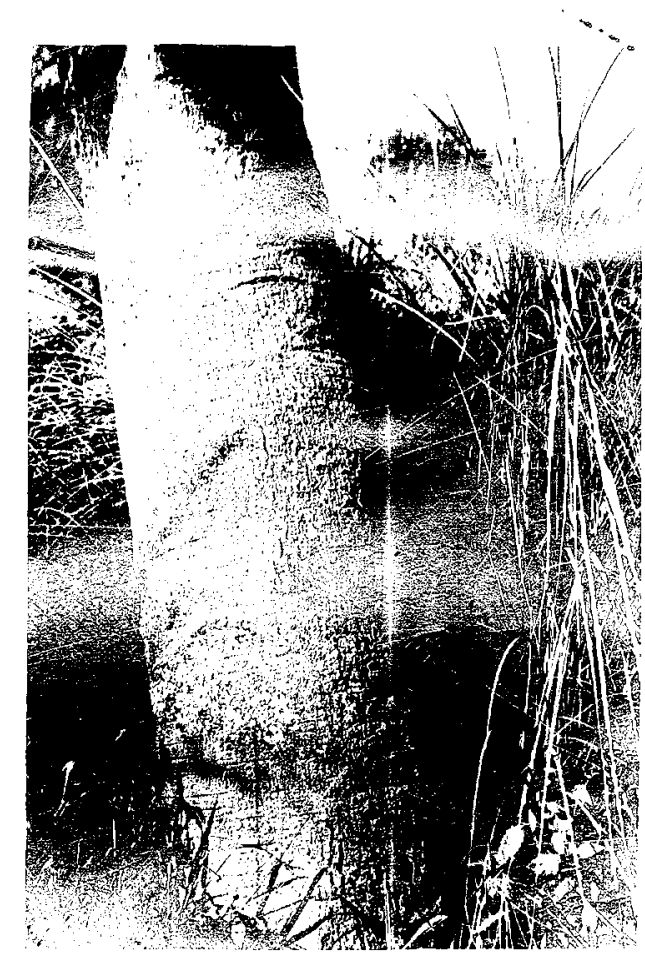

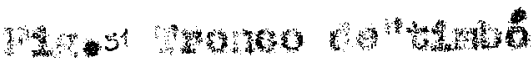

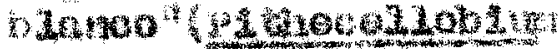

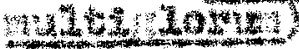


witiforum, Nectandra membranacea \& Sapicin haematospermum I

Superficie estudiada en $m^{2}=100$

Fecho: $5 \cdot 2 \cdot 49$

Coberturd: $90 \%$

Bosque hidroficio abierto

Altura de lavegetación 10-15 metro:

Suelo:arcilloso-limoso, humedo

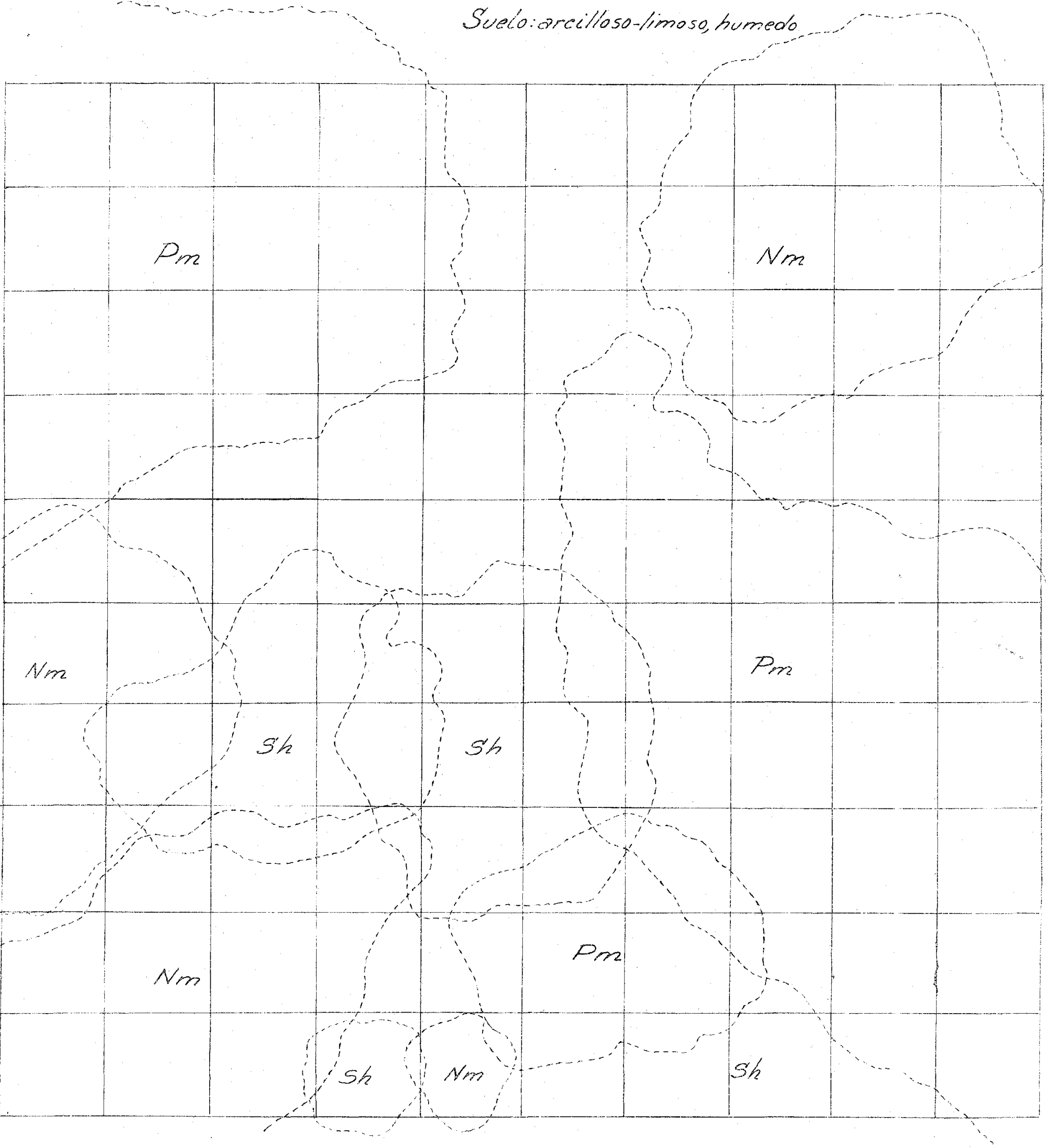

Nm Nectandra menbranacea

$P_{m}$ Pithecellobium multiflorum 
Fay muy pocas microfanerofitas, nanofanerofitas, lianas y eplf1tas.

En el estrato mas olto encontramos las especies dominantes que controlan 1 s comuldad mediante la sombra que proyectan sus copas, las mos importantes son: el curupl (Sapium hamethos -

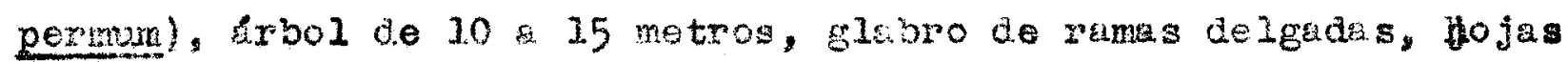
lanceoladas de borda serrado y base tenuada, cípsula lisa de color rojo $y$ gran polimortisno foliar y floral; ol laurel (INectandra membranocea var. Fakjfolis) con hojas lineales urvas, que junto con otre Lauracea (Oeotea acutifolia) del belta inferior son los aos representantes de este familia en el amiente de lslas; el seibo (Exthrina crista-ealli), de poen altura cuando crese solo (4. a 8 metros), pero vegetando con otras especies 11 ega a 20 m., de tronco cublerto por gruesa corteza rumosa (F.g. ); rames delgadas, hojas alterna, caduefa, pinaticompuestes y germosas flores rojas solitarias o en racimos de 2 o 3: el timbo blanoo (Pithecellobium multif flomul ano do los dos que existen en el belta, careterístico del chaco que tiono su Ifrite nustral on las islas frente a josaxio $y$ que se afferenta del timbó colorado (Enteroloblum contontigiliquum) por su menor porte y cuando no está florecido (época en que es fúcil confundirlos) por el número de pinas, nunea más de cuetro pares; una Mirsinceea de hojas persistentes, el canelón (Rapanea laotevirens) de 7 a 12 metros $a$ alto, con follaje verde oscuro y mu denso I el timbo colorado (Enteroloblum contortisiliquum)más grande gue el timbo blanco, de cope hemisférica y vainas negras en formo de oreja.

De menor importuncia es el ubajay (Eugenis Myrelanthes) de grandes frutos amarillos comestibles.

Estos firboles se estén utilizendo hace unos 70 años sin que la vegetación indigene muestre slntoma de degradación, ga lvo frente a pario donde el hecha ha destruido muchos de estos bosques. 
Perful sobre la barranca del Pananá en el Bosqueblanco

Canalue los Reyes

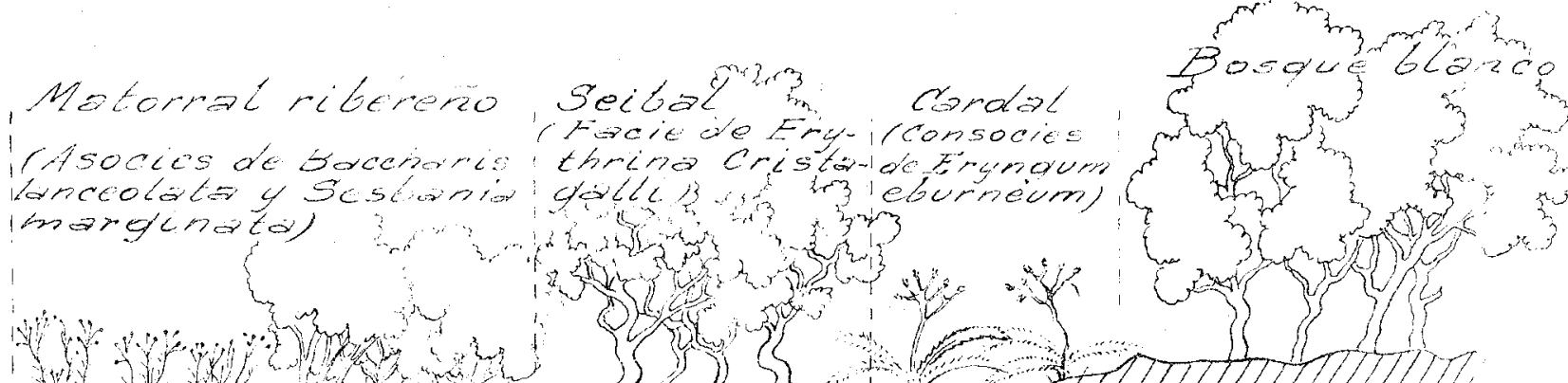

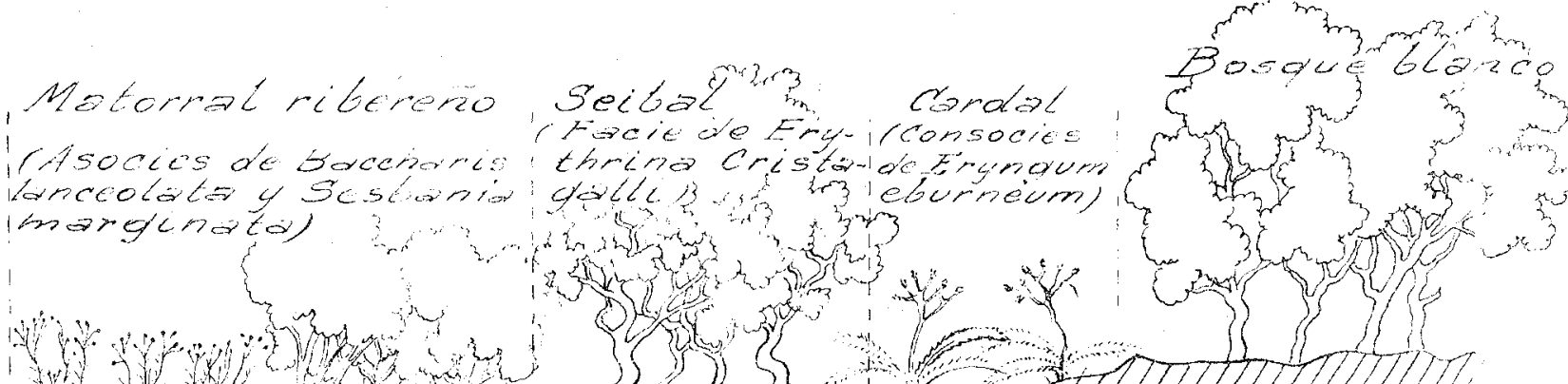

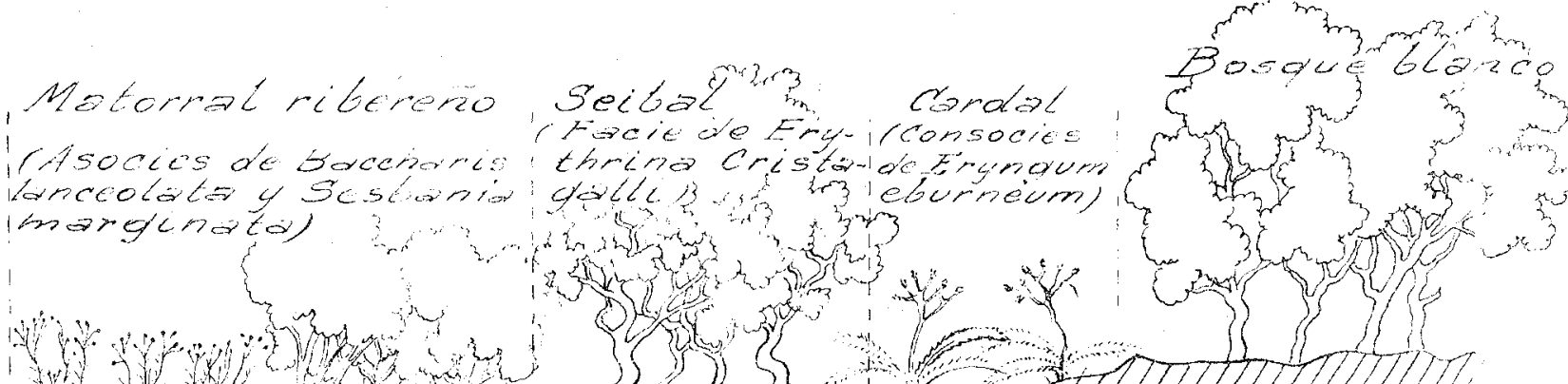

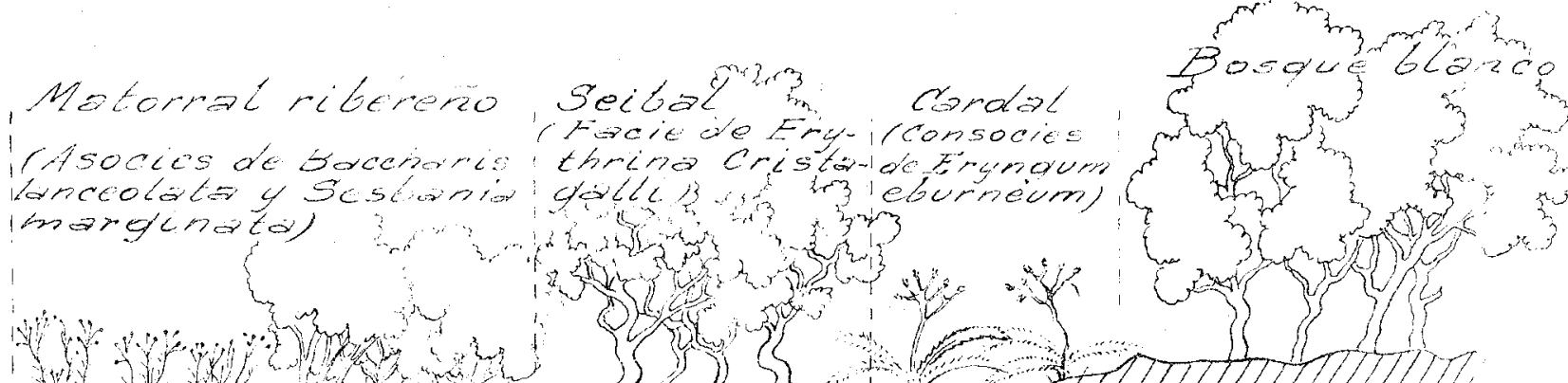
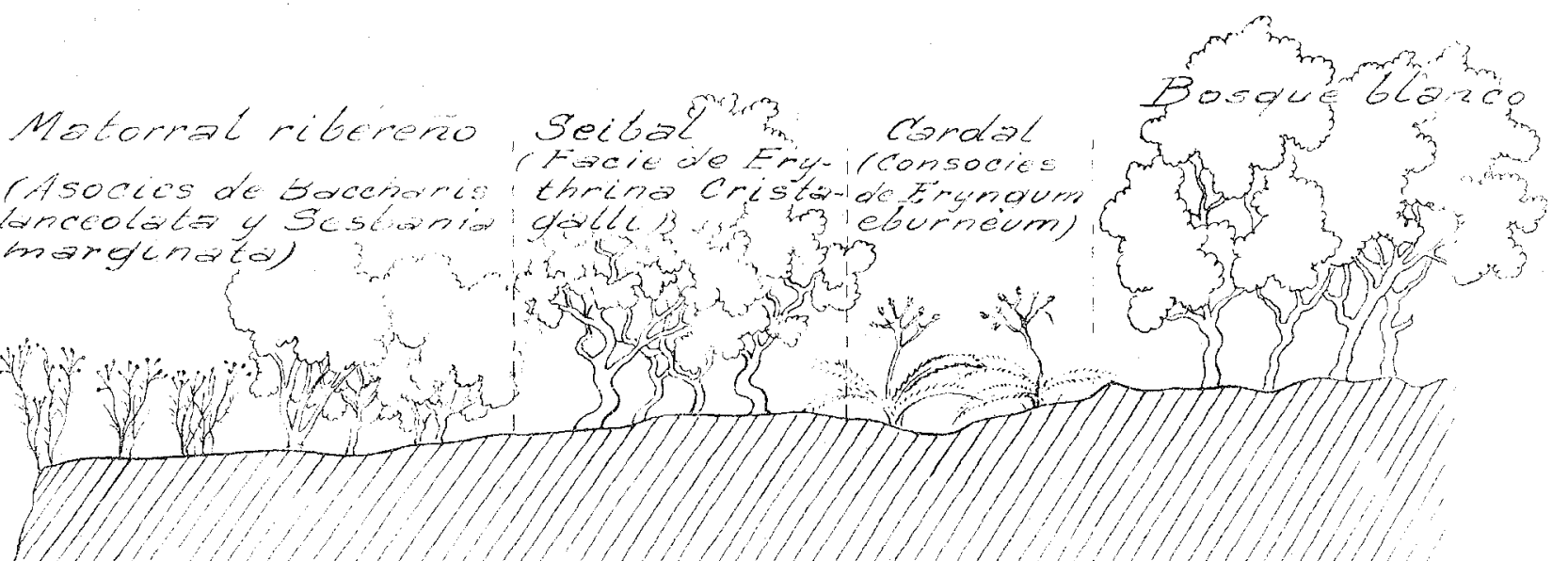

Matorral ribereño

Monte de Carelon Asocies de Baccharis

lanceolatay sesbanio

Canalót

los Reyes de Panicum,

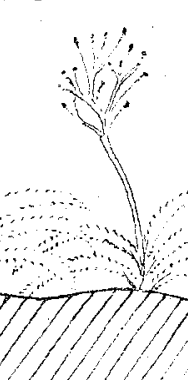




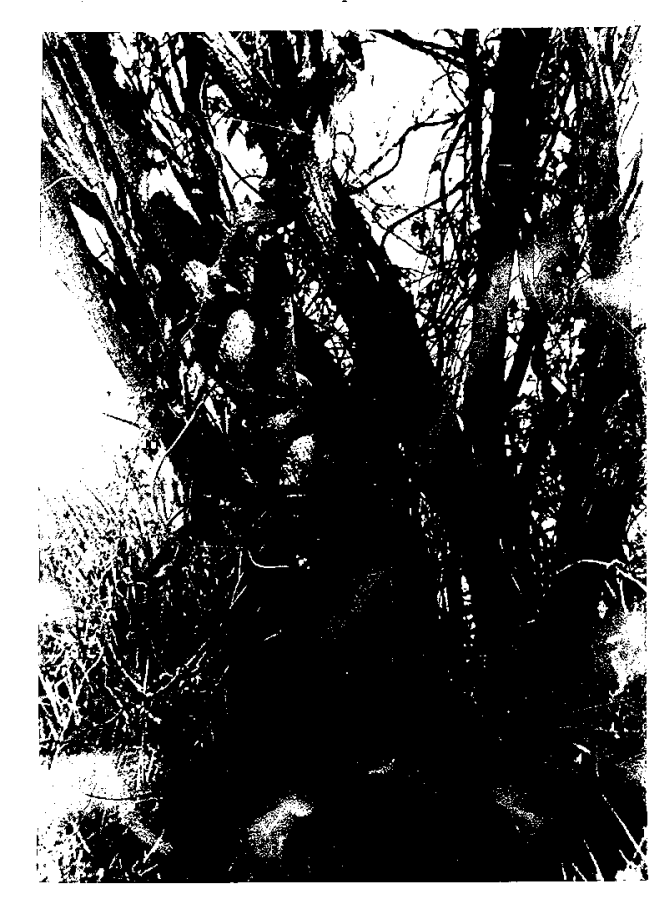

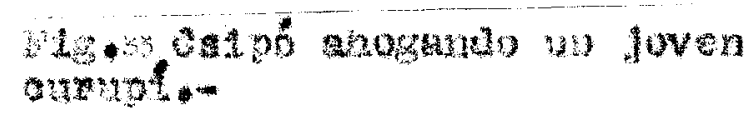

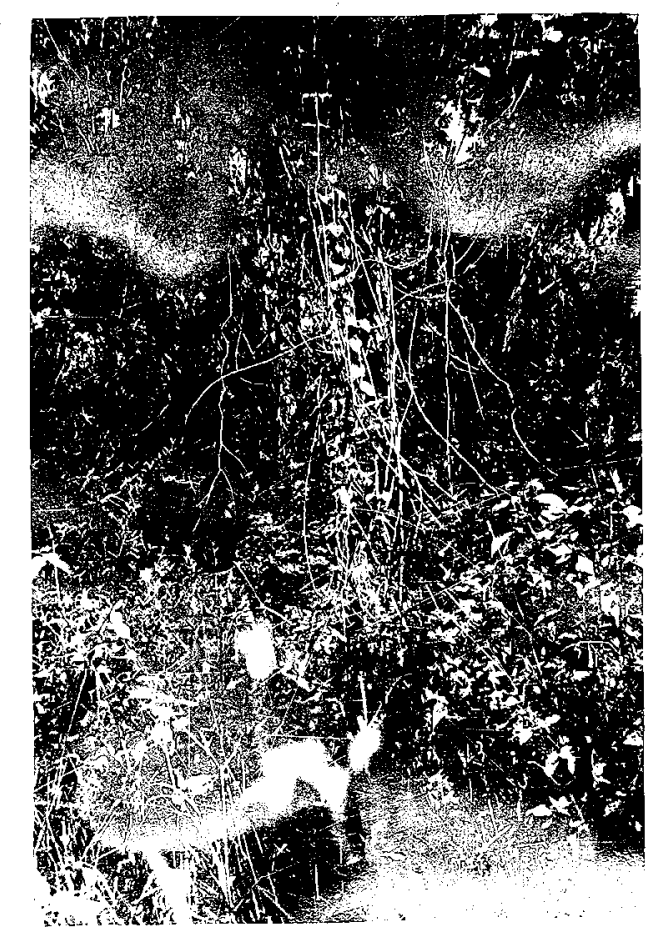

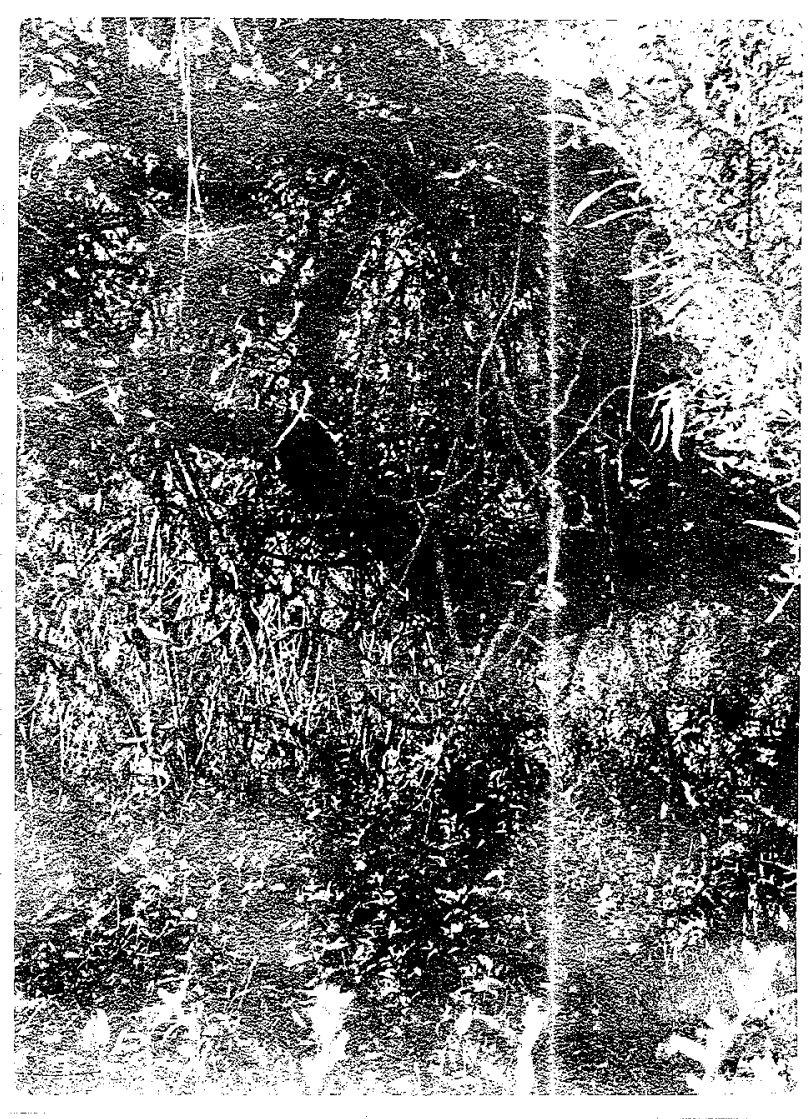

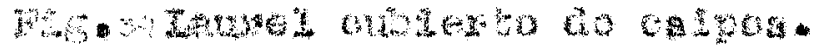

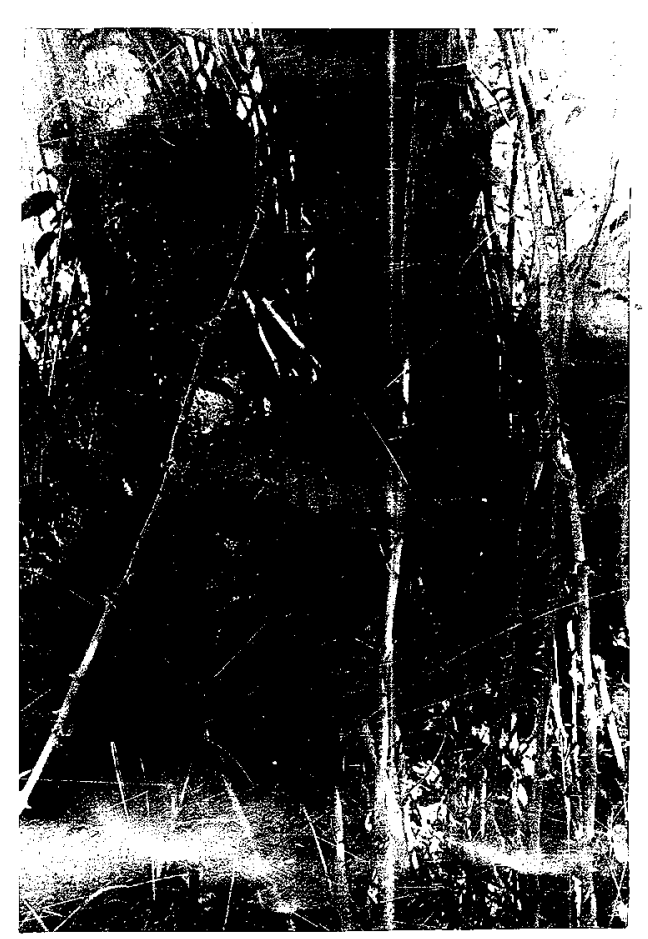

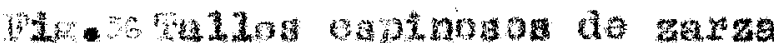

$32 \mathrm{an}$ a

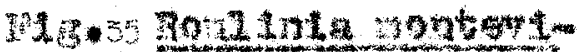


ños grupos de sarand1 (Cephalanthus glabratus), que en muchos casos forman socies, adquiriendo el papel de dominantes por la desaparición del estrato ae megafanerofita. Otro arbolito es cassia af. corymbosa, de flores anaranjadas.

Los arbustos Icanzan alrededor de un metro ochenta centimetros de altura $y$ en êl predominan nanefanerofitas umbrofilas, como Cestrum gellowlanum, la cerqueja (Beccharis Penningtonil), Acalipha gracilis, el duraznillo negro (Cestrum parqui ), y en los lugires más sombrios granảes colonias de un sufrutice, Sida hastata.

Las enredaderas y lianas (Csipo e Isipó) no abundan; las hay con gnuesos tallos leñosos, como la zarza o zarzaparrilla blanca (Smilax campestris), zarza colorada (Muehlembeckia sagittifolia). C1ssus palmata, Caralospermum grandiflorum, etc., o débiles trepadoras como Mikania periploc1folia, Mika nia micrantha, Cardiospermum halicacabum, Calonyction aculeatum, Cajaponia flcifolia, Passiflora coerulea, ete.

Las epifitas son muy poco abundantes, se reducen a una cacm tácen, Ia "suelda consuelda" (Rhipsal1s lumbricoldea) g el clavel del alre (Tlilandsia aranthos), ambas viven sobre el principa portaepifltas del monte blanco, el seibo (Erythrina criste-gal11), y son muy comunes observarlas sobre seibos viejos $y$ aún secos.

El estrato herbáce perdiendo su carácter selvático de ser pobre en densidad, se hace extraordinamiamente tupido, existiondo coberturas de noventa y más por clento. Este carḱcter de bosque y 1a uniestratificación de las copas, aiferencia de los dos o tres estratos de la selva y sumado a la escesa flora epidénarica, da la tónica este paisaje boscoso de albardón.

Il estrato herbaceo es pobre en densidad solo en los lugares muy sombríos, pero donde penetre la luz soler directa el s suelo se cubre de un tapla continuo.

En 20 s lugares sombrlos vegetan colonias de sida hastatata sobre el estrato herbéceo, constituido casi exclusivamente 


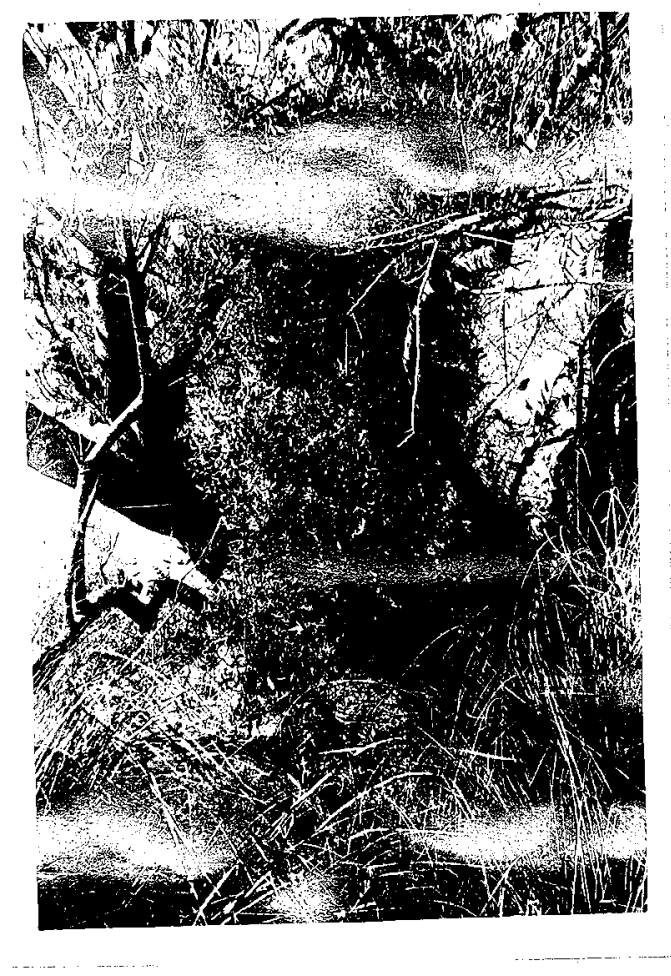

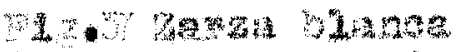

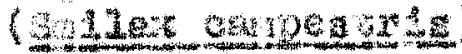

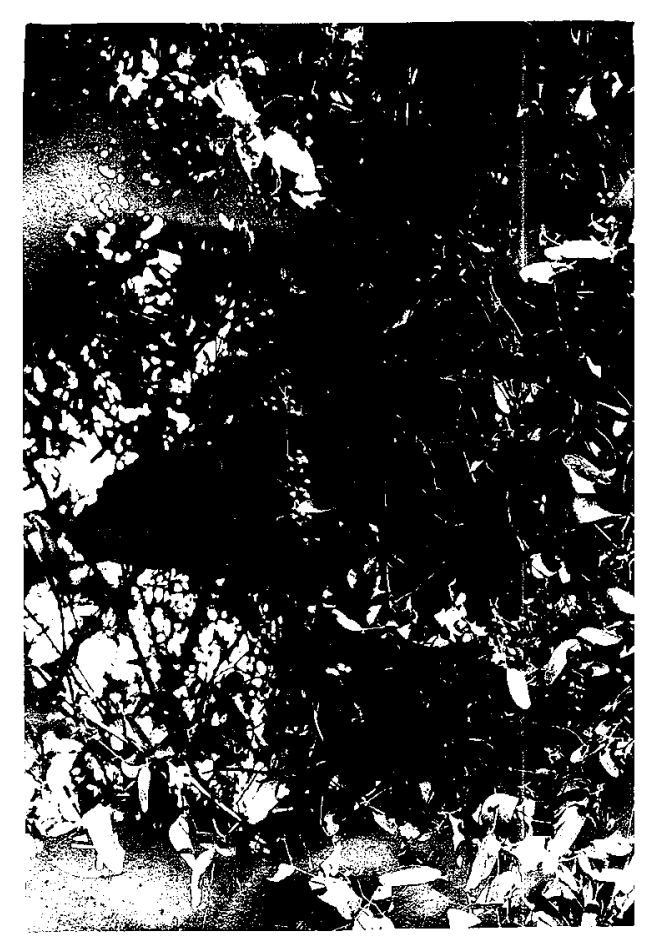

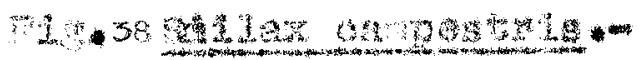

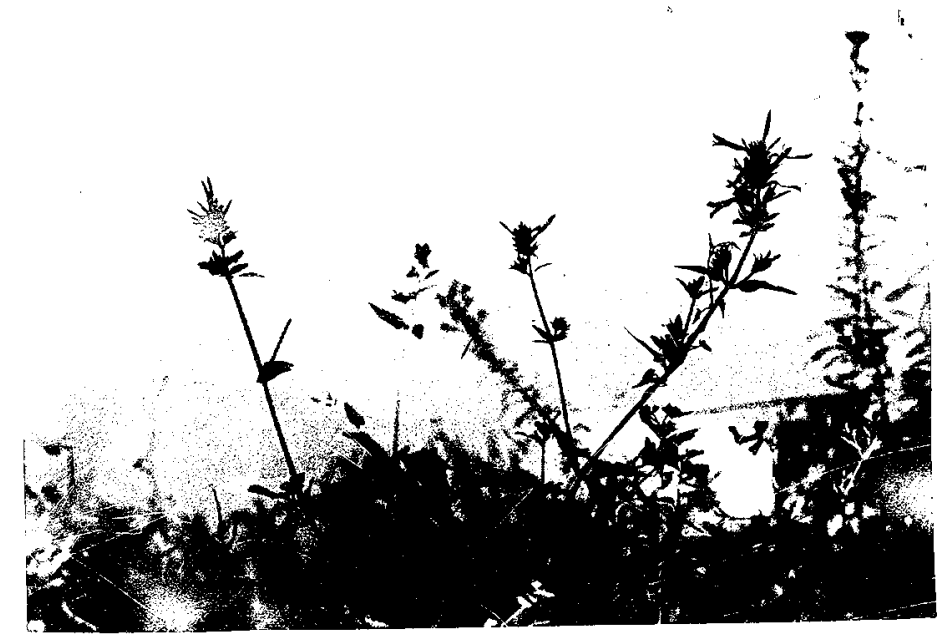

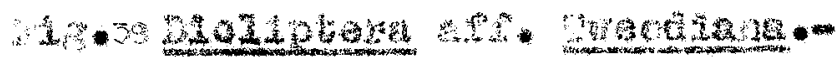


Fig. $N=40$

Corte sobre la Garranca del canal de los peyes Endirección $N$ - S.

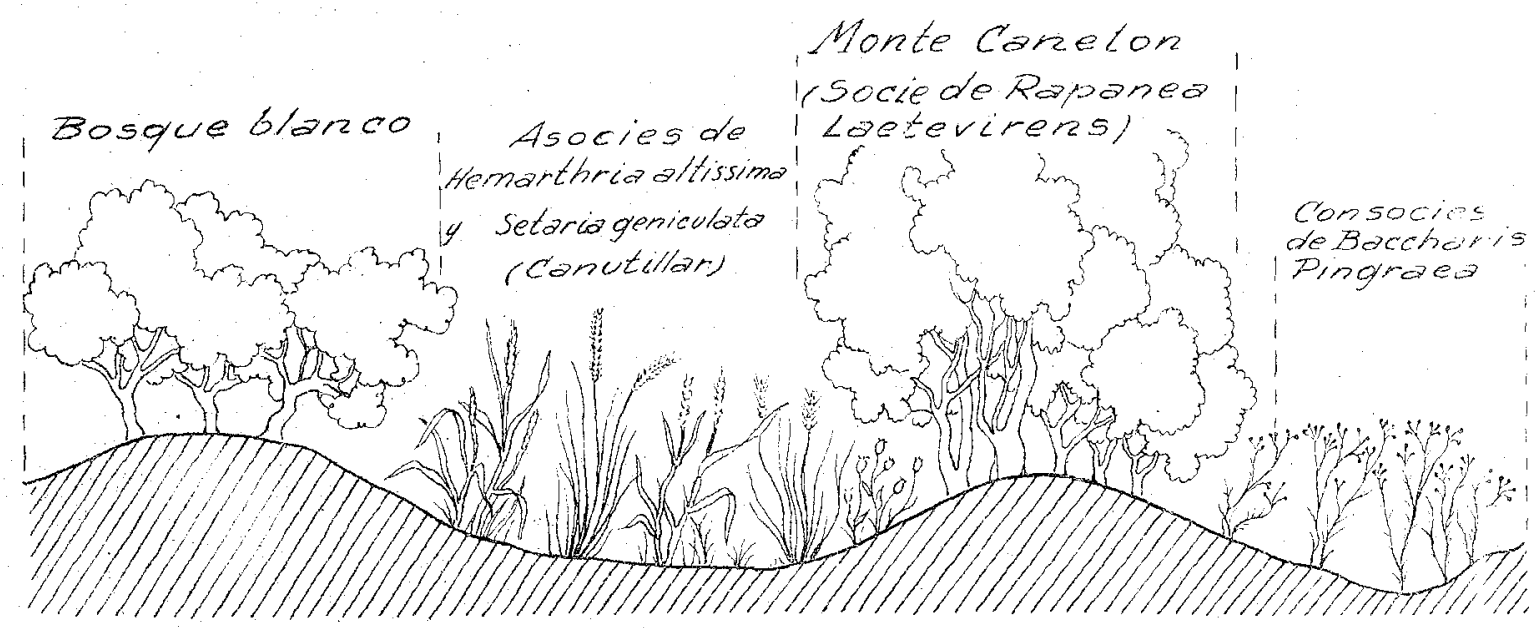

Eg. $N^{\circ}$

Conte sobre Laborranca del canal delos Keyes er Madrejón seco

rorte de direcciór tivit)

Chilcal: Asocies de Hemanthria altssi. Asacies de Paspalum repens,

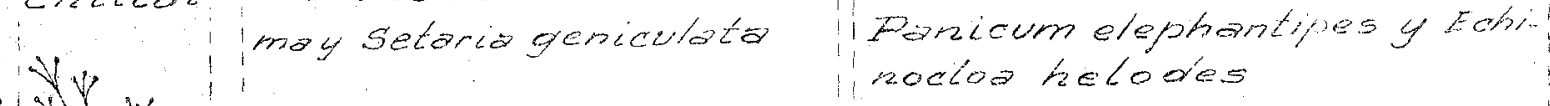

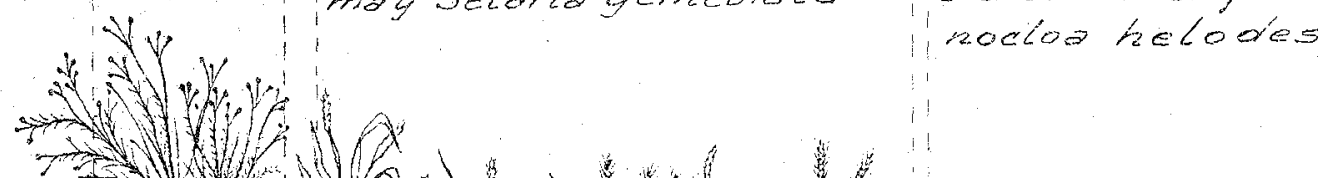

canol de

rospeyes

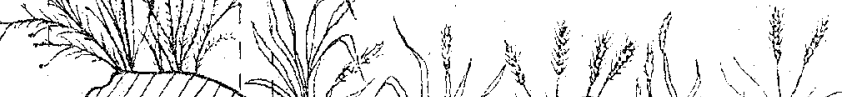

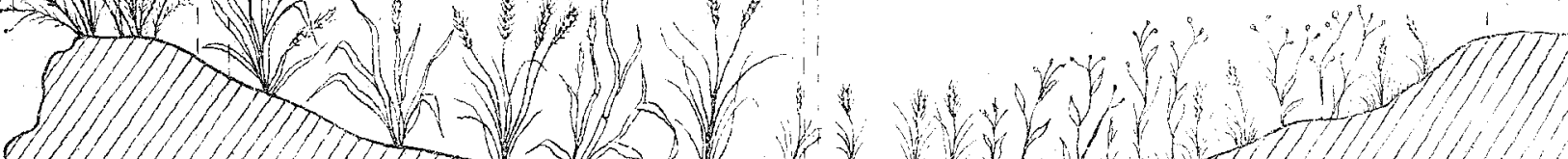


cantia elongata, Erigeron Garanexi, Cynodon dactylon, Digitaria laetevirens, Paspalum Hieronymi, Paspalum repens, Digitaria cuyabengis, $\theta$ to,

No los claros lnvade el pajonal de Penicum prionitis con Vorbene 11ttora 11s, Verbena bongriensis, Cyperus 1aetus, Panicum aebulorum, Pagalum detichum, Setaria genjeulatg, etc.

In 19 hondeneds gue oruan los albardones sirviendo de drenaje auxiljar s los marejones on époes de creciente, encontramos Ambroeja tenulfolis. Frjochlog montevidensis. Echinochloa ho1odes, Echinochlos cruz psvonl, Eehinochlos polystschya, Baccharis Plngrees, Seteris globulifere, Diplachne uninervia, etc. Sobre un césped de gnapholjum purpureum e Hypochoer is m1crocennala var. Aluflorg sobresalen las esplga florffera de dos

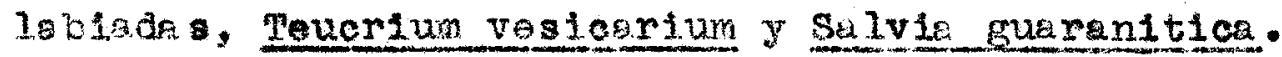

A veces y manchones de oxilis cordobensis con ScutellaIa platensis..

En muchos lugares es diffoll el acceso por la presencia de an vordadoro onrejado entre los fuboles, formado por los tallos espinosos de la zara blanos (SmIlax egmpestris), due enredándoso en los seibos 1 laga hasta secarlos, slenó más resistente a esta kocion el curups y el laurel.

El ocotono entre Dajonal monte blanco alcanza una anchu-

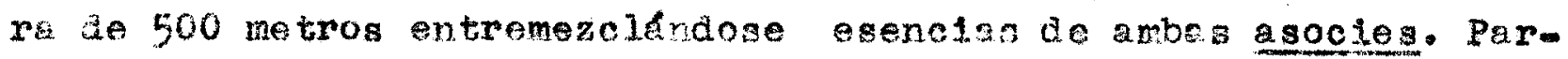
ticulemente atritente es el aspecto que eduioren en tales zona

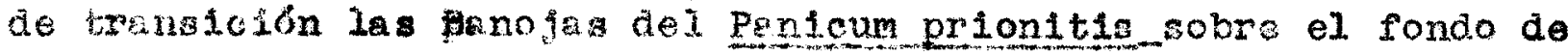
Ios selbos que penetran como curfe del bosque on cl pajonal. Estos ecotonos, conde los arboies se alternan con prederes de altas Penfceas tienen todo el apecto de un perave neturgl. Los albardones porta. dores del bosque son los lugeres más altos de la isla; no los anegan los repuntes y las erecientes los cubren temporeriamente hasta una alturg de Om.80 a lm. como meximo y 3610 en essos excepcione1es, steno fólimente facimente dstinguble to parte de los tron cos que he eqtero sumerclat on el ggua, puss la oorteza en esos lu- 


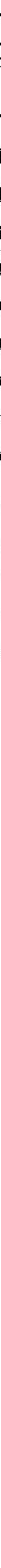




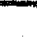

onsis.

$1: 1$

2

2

2

1

2

$I$

1

1

1

1

1

1

1

1

1

1

1

2

1

1

1

I

1

1

1 
Plg. Interion del posm che de canelond.
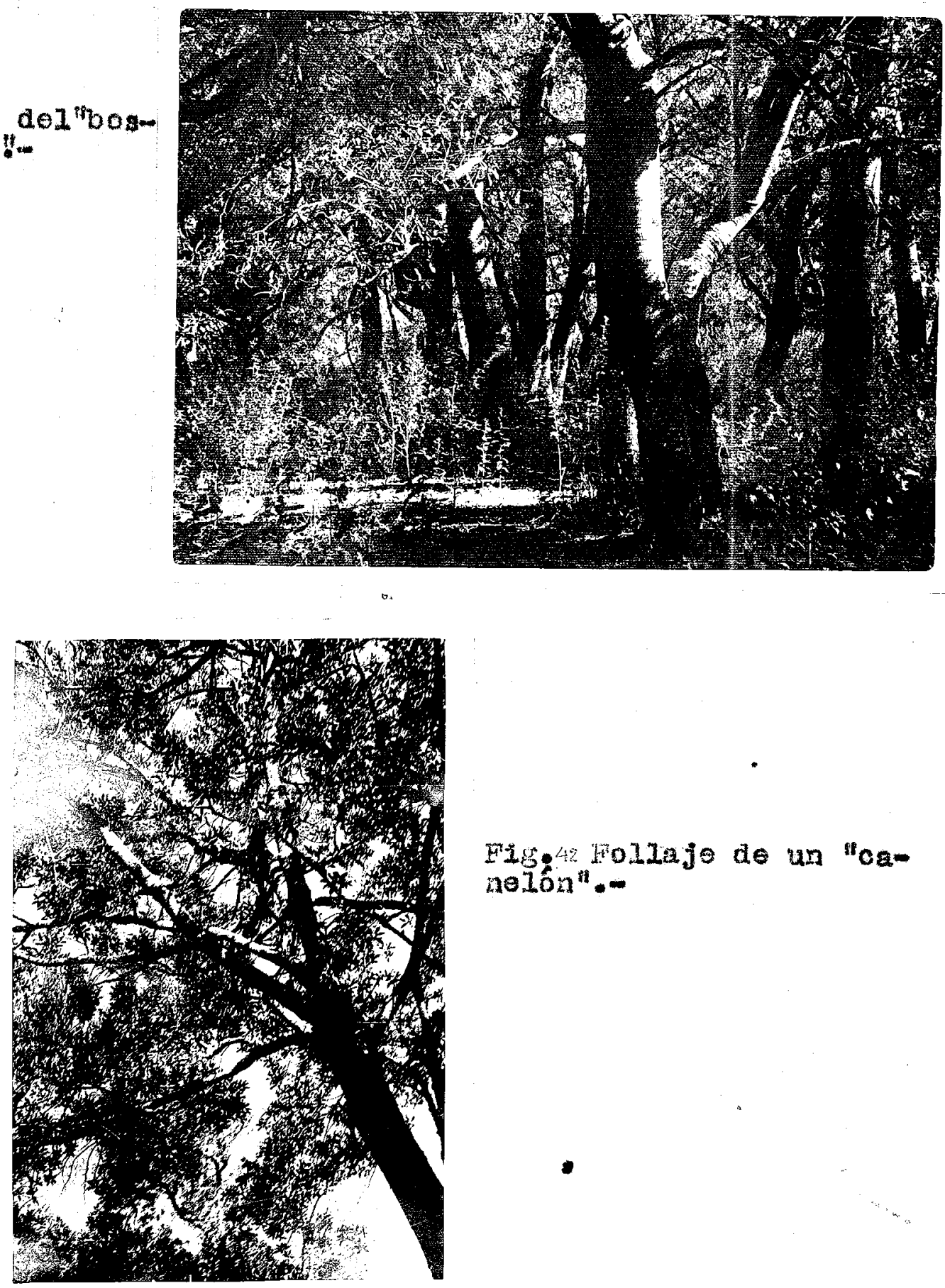

Elige Hollajo de un "cano.16n".-

Ig.45 Intertor dol"bosque de canelonn"..

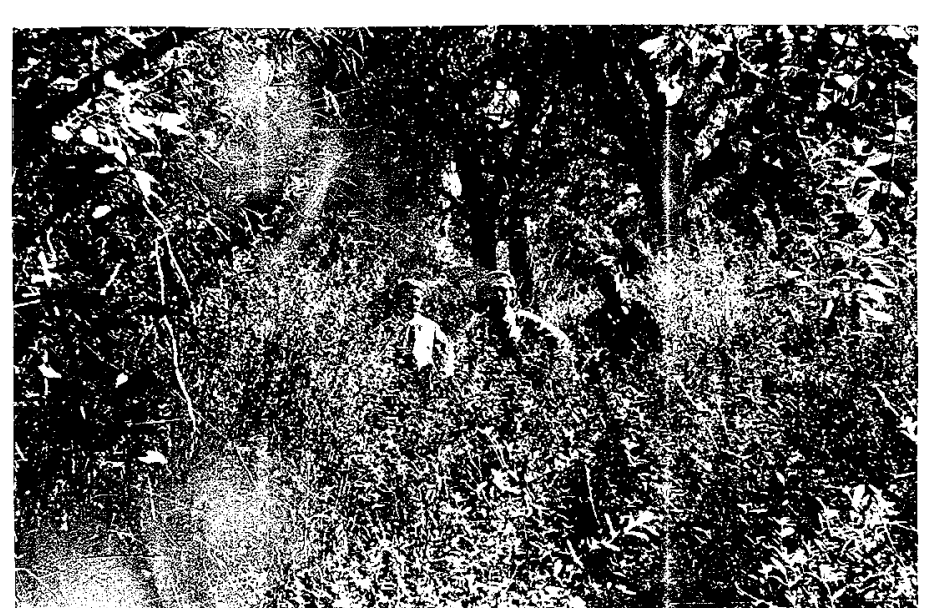


res está desprovista de los liquenes que en el resto del tronco le dan un tinte verde grisáceo. Como su suelo es el más apto pará los cultivos va siendo destinado $y$ en algunas partes suplantado por plan taclones de sauce, álamo y frutales.

\section{2 - Unidades menores del monte blanco}

a) Socies de Rapanea laetevirens (Bosque de Canelón)-(Figs. ) - Con criterio provisorio incluimos como socie del monte blanco, los altos $\mathrm{y}$ extensos bosques que tienen como esencia arbórea fundamental une Mlrsinacea de hojas oblanceoladas, obtusas, brillantes on $\theta 1$ haz $y$ flores pequeñas dispuestas en glomérulos, el canelón (Rapanea laetevirens).

Dentro del trea de vegetación bajo control del Saplum ha ematospermum, Erythrina crista-gall1. Nectandra membranacea var. falcifolia y Pithecellobium multiflorum, hay un subdominante, Rapanea laetevirens, que ejerce un control local adquiriendo el carácter de dominante.

La circunstancia de que algunos dominantes del bosque fluvial estén esparcidos en el bosque de canelon, como el seibo, el timbo blanco y el laurel y que el estrato herbéceo tenga ana composición floristica semejante, caracterizando los lugares sombrios, a Igual que en el bosque de albarán, las grandes colonias de sida hastata, nos induce a incluirlo con carácter de socies de la msocles subclimaxica, pero la persistencia de ciertas especies que son raras debajo de los seibos, curupis, laureles y timbb, como Valeriena scandens, Acalipha gracilis, Iresine celosia, etc, la continuidad y exclusividad del único elemento arbóreo $\mathrm{y}$ la falta de árboles de canelón en la totalidad de los lugares donde el albardón soporta el bosque blanco típico, son motivos que podrian, previa investigación en otros lugares, determinar la existencia de dos comunidades distintas, el bosque blanco y el bosque de canelón. En su estrato herbáceo se han anotado las siguientes especies: 


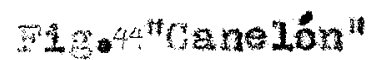

(Menanoa laotovinonu)

n.
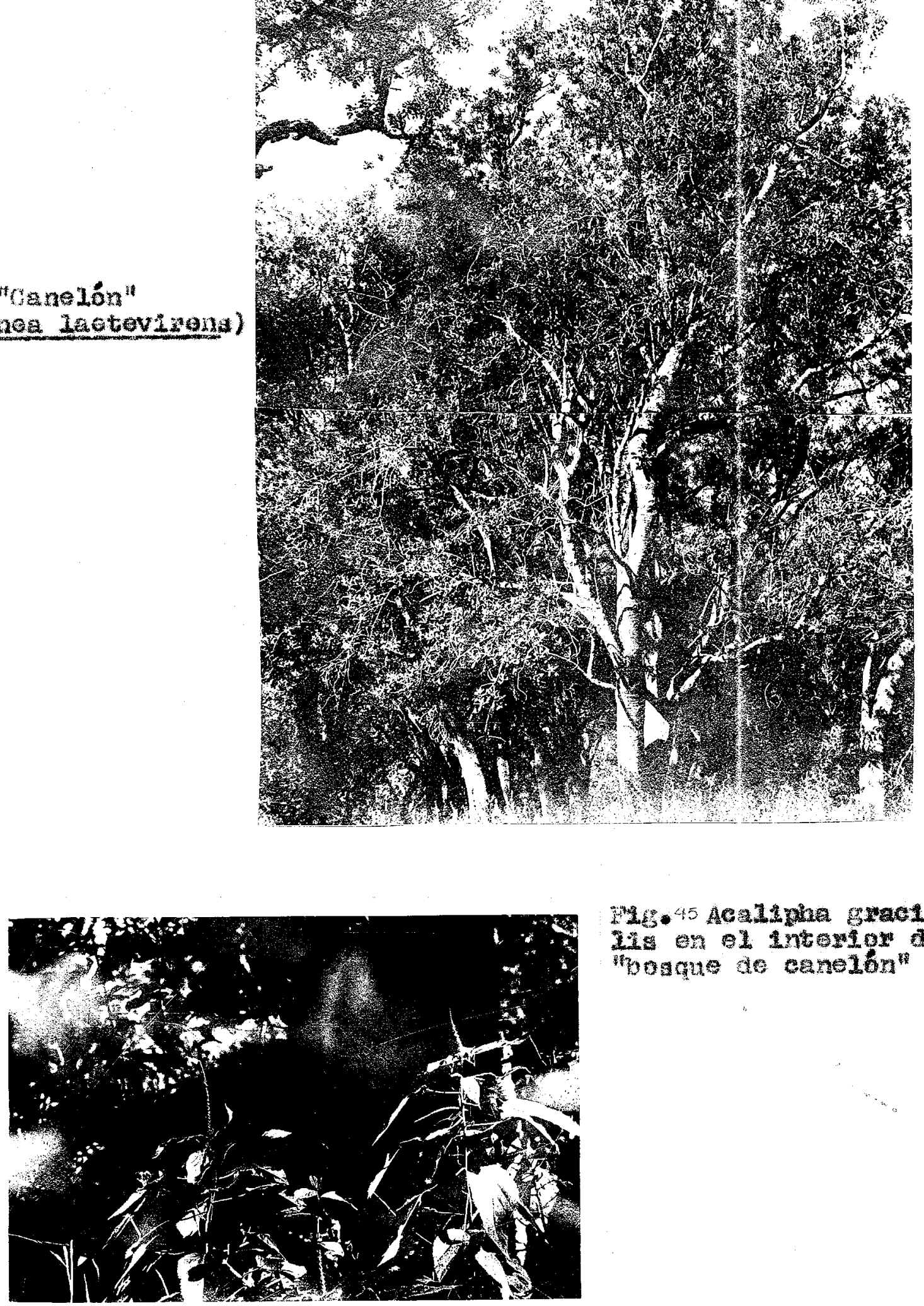

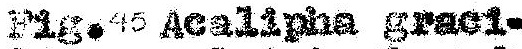

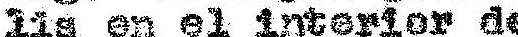
Hog ane de cenelbn

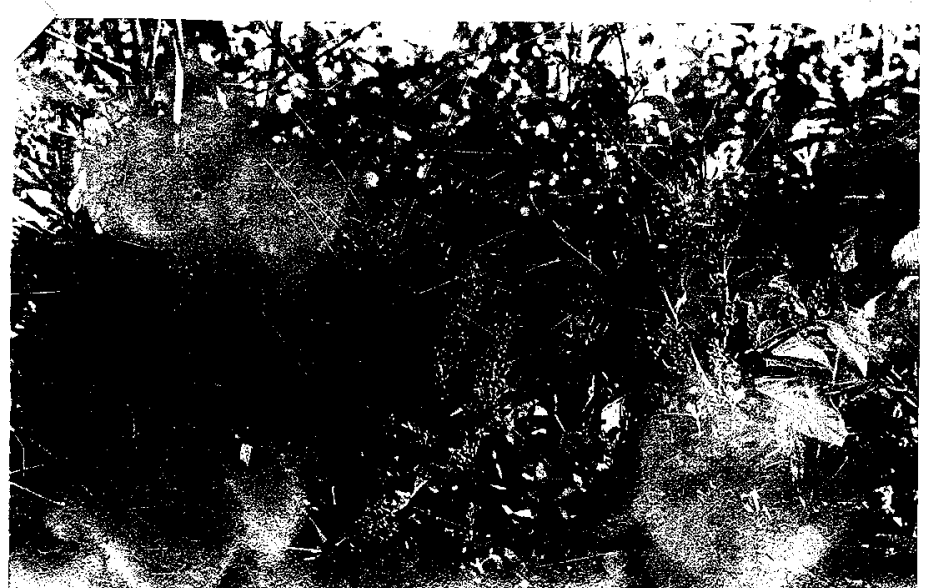

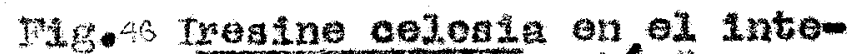
mor dentbogare de canolón" 
Censo grafico correspondiente al Bosque de Canelón (Socie de Aapanea laetevirens).

Superficie estudiada en $m^{2}=100$

Fectio: 25-1-49

Cobertura= $95 \%$

Altura de la vegetacion $=12-1.5$ metros

Bosque higrófilo denso

Sueto: arcilloso limoso, humedo

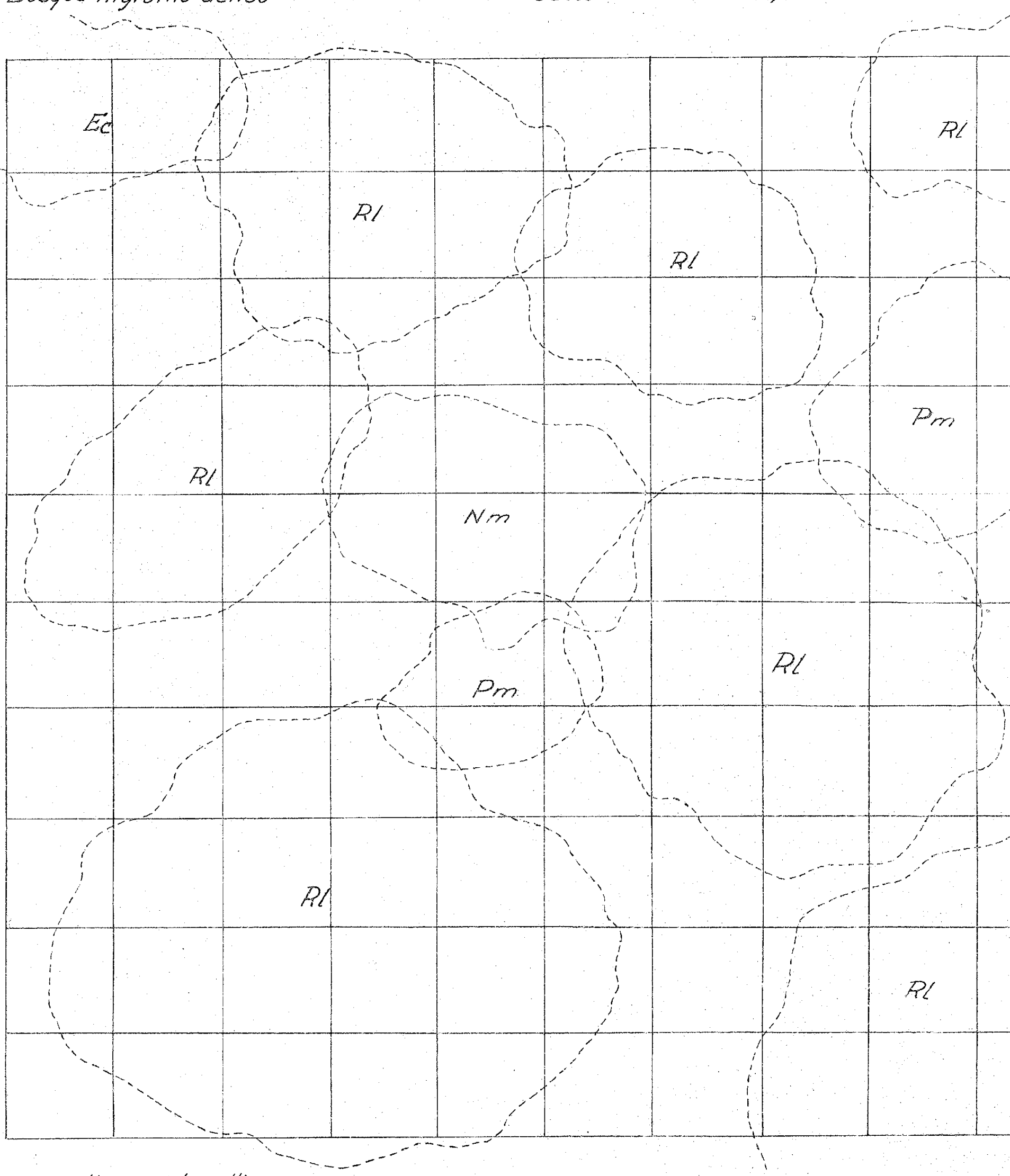

Ec= Erythrina crista-galli 
Iresine celosie

Pfaffla stenophy1la

Tradescantia elongata

Acalipha grac111s

SIda hastata

Teocrium vesicarium

Verbena brasiliensis

Modiolestrum geranioldes

Panicum prionitis

Setarla genioulata

Setania globulifer

Hemarthria altissima

Centaurea Tweedie1

Dieliptera Tweediana

Bacharis Pennington1

Smilax campestris
Solanum $\mathrm{sp}$.

Cestium sellowianum

Passiflore coerulea

Cyperus laetus

Heleocharis viridans

Gyperus 1mbricatus

CJperus vireng

Cyperus a lbomarginatus

Axonopus compressus

Digitarla laetevirens

Paspalum Hieronymi

Diplachne uninervia

Eragros tis hypnoldea

Eragrostis af. flaccida

b) Facies del Seibal - En los abardones marginales son muy comunes las colonias puras de seibos (FIgs. )$(\operatorname{Er} 1-$ thrina crista-gal11), que con sus troncos rugosos, ramas divergentes, muchas de ellas secks, que sostienen un follaje poco denso.y sus hermosas flores encarnadas, dan caracteristicas inconfundibles 21 palsaje.

Como $10 \mathrm{~s}$ exigencias ecológicas de este árbol son muy amplias, se adapta a diversos suelos, constituyendo una a vara del bosque blanco en el ambiente del pajonal e inclusive en zonas pantanosas como las ocuptidas por el varillal.

En estos suelos sobrecargados de hmmedad forma bosques ablertos, casi puros, en 208 que los froboles están a 15 o 20 metros entre $\mathbf{s}$.

Estos seibos eatán casi siempre cubiertos cuando son viejos, por las únlcas eplfitas de la zona: RhIpsalis lumbricoides y Tillandsia adranthos. Según Burkart (en Hauman....ete., 1947, pág. 108) esta caracteristica se debs a que la corteza fofa del sel. 

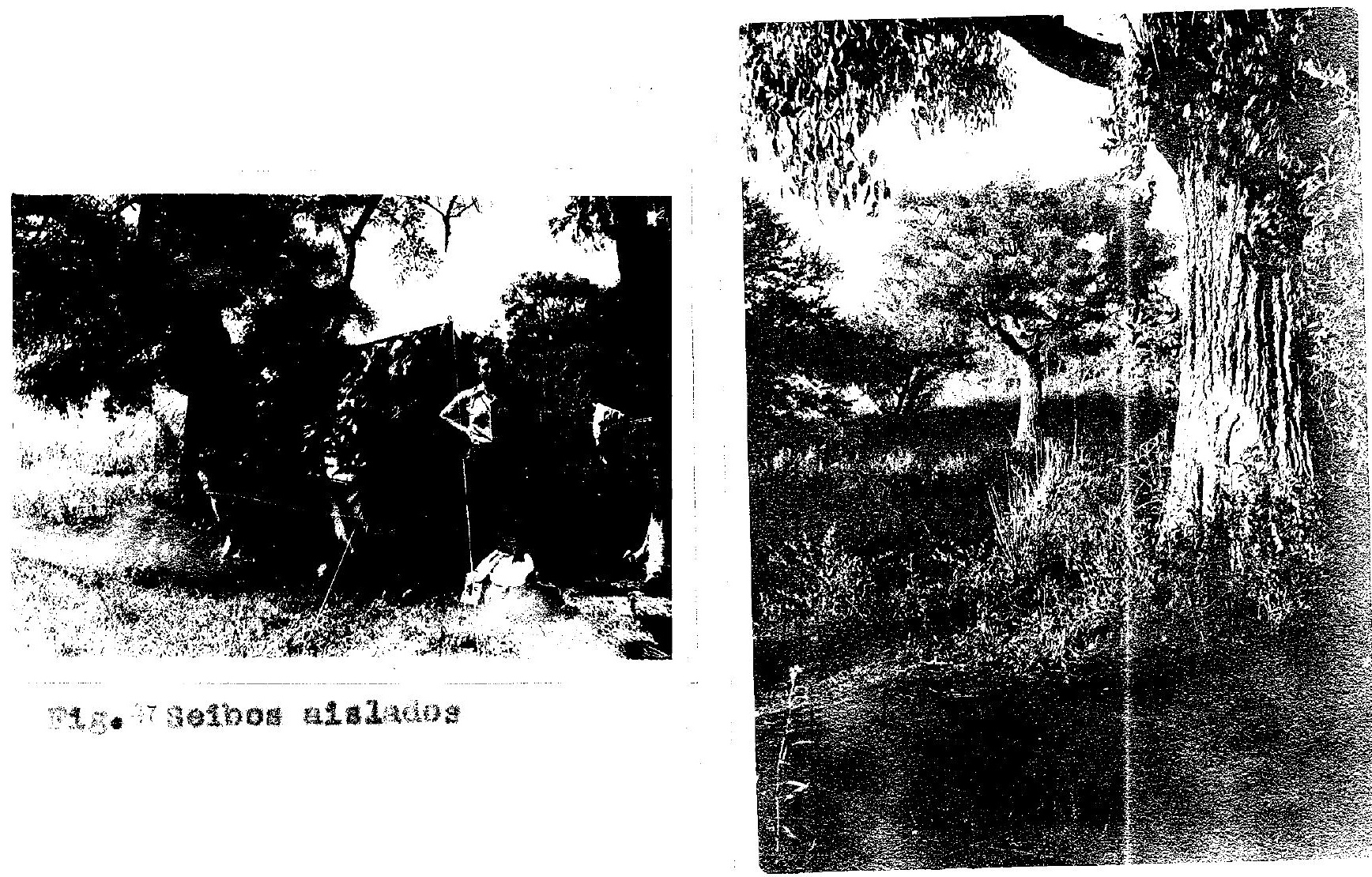

13.

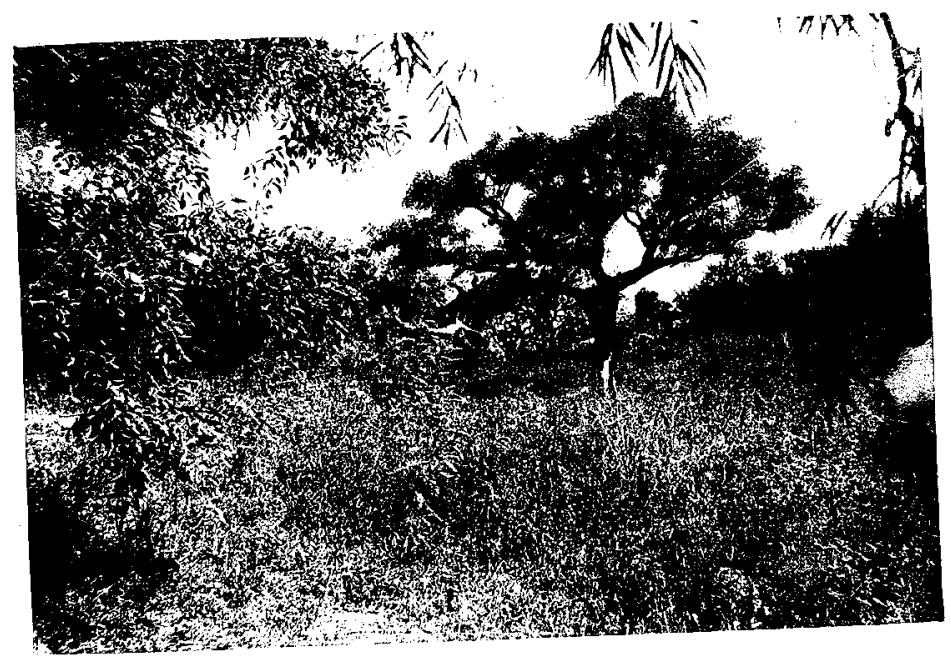

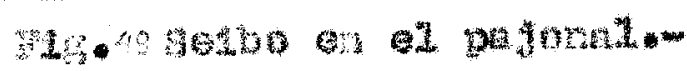

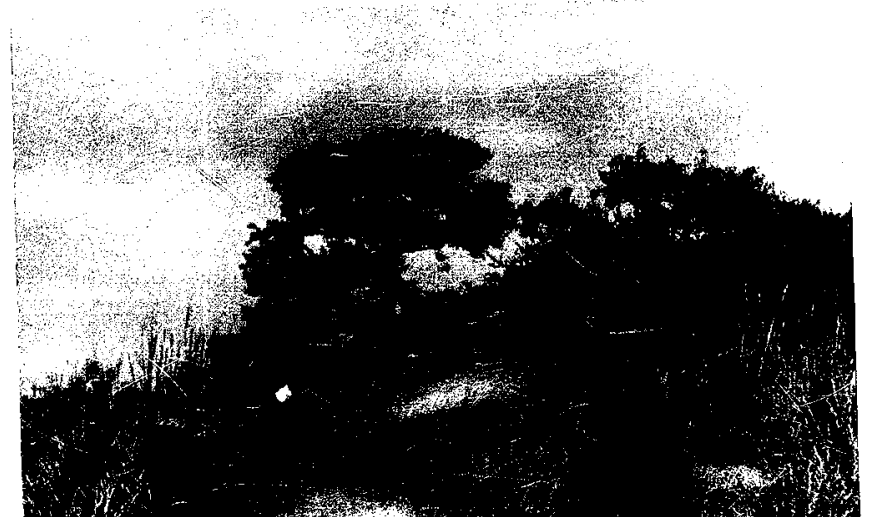


c) Facles del Timbosal o Timbusal -- En los albardobes interiores de las islas el timbo blanco (Plthecellobium multiflorum) se reu ne en comunidades puras, más o menos extensas, creciendo a veces entre cada arbol algún espinillo (Acacia cavenia) a islado y un arbo11to de llamativas flores anmanjades, Cassia af. corymbosa. Alterne también con el pajonel de Panicum prionitis.

d) Foc1es de Sapium haema to spermum y Erythrina crista-ga 111 -En los islotes, en la sere que se inicia en el arenal, son muy frecuentes bosquecillos claros con solo dos especies de árboles, el curupl $y$ el seibo, suceden al sauzal o al alsal y poco a poco so van transformando en el bosque blanco por la adquisición de nuevas esenclas arbóreas; tienen los mismos elementos que este último mezclados con especies del sauzal. 


\section{$\alpha^{1}=$ \\ th \\ $\rightarrow+\infty \ldots+\infty$}

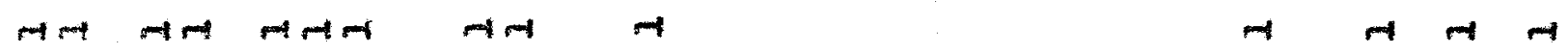

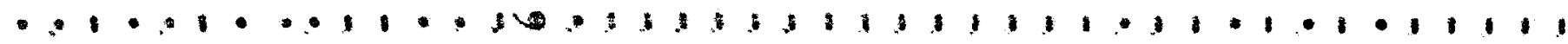

$-4+4+4+4+4+\infty$

0

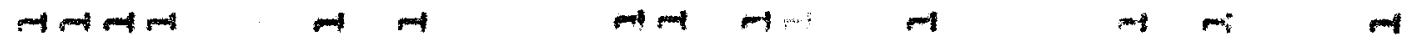

$\prod^{\infty} 0$

1

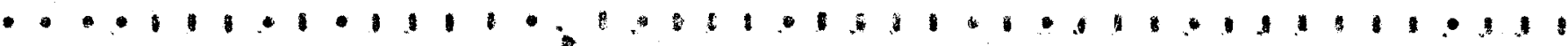

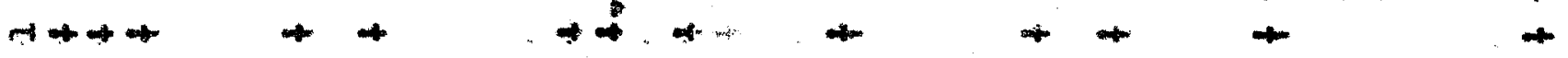

$-\infty-\infty$

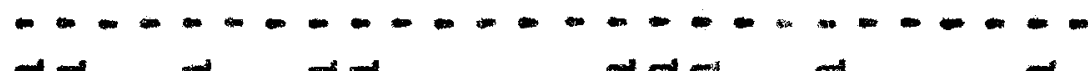

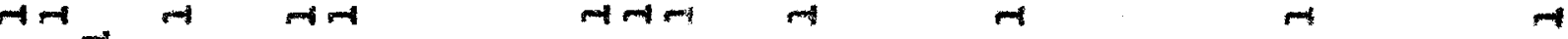

Hing

n.

$+m i+\infty$

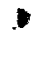

†용

ญे

$-2$

$+m i+\infty$

$+4+\infty+\infty$

1.1

111

.1 .1

m

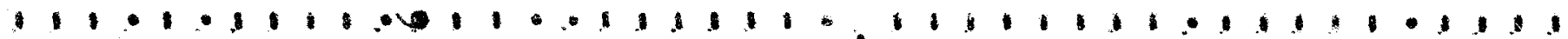
$\Rightarrow$ L

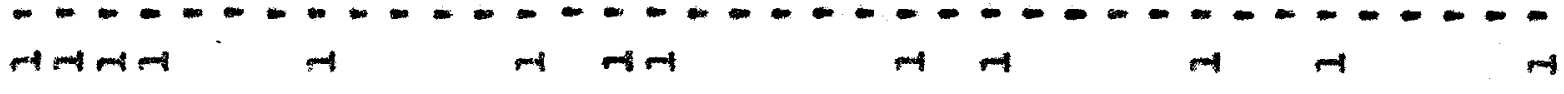

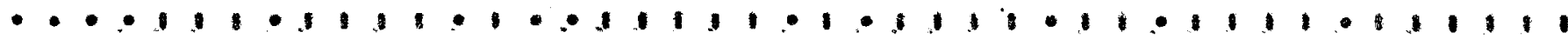

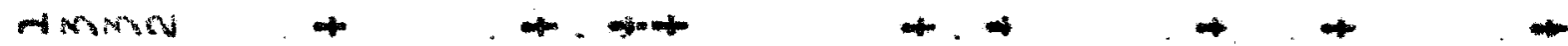

$\operatorname{li}_{-1}^{-1}$

$-\ldots-\ldots-\ldots-\ldots$

至

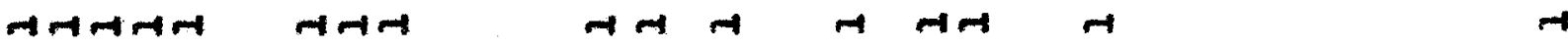

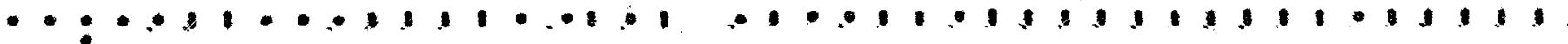

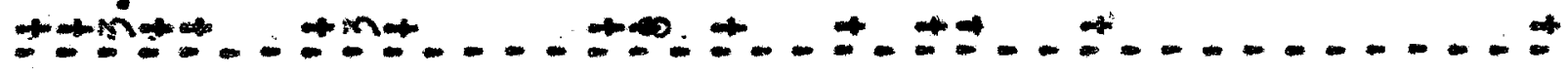

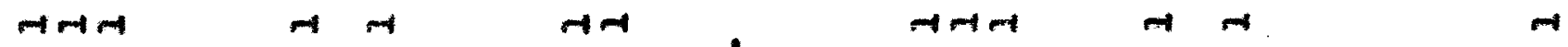

not

tac

$-\ldots-\ldots$

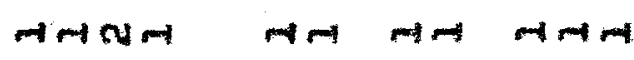

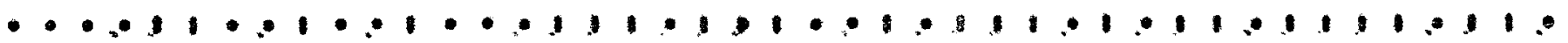

$n+\ln 2,+\infty+\infty$

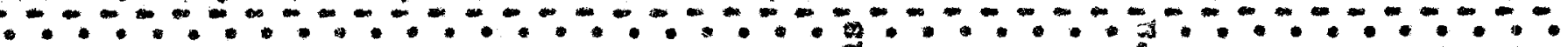

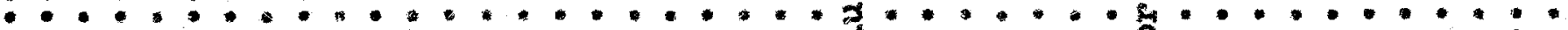

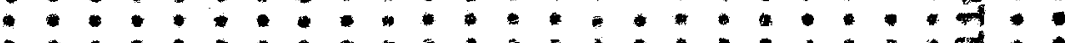

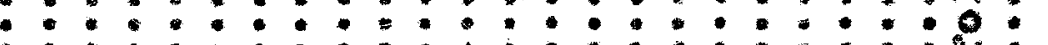

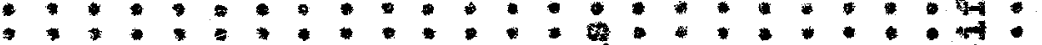

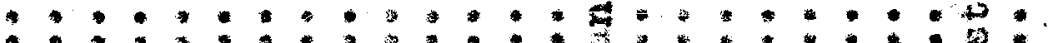

: : : : : : : : : : : : : :

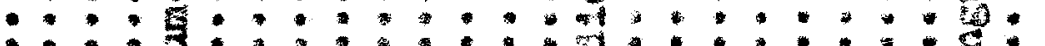

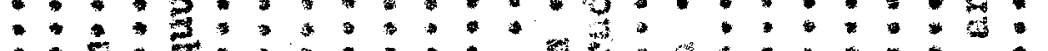

at

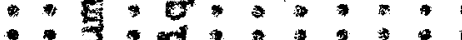

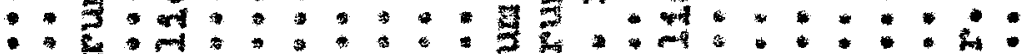

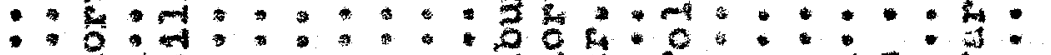

34

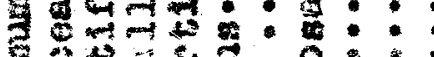

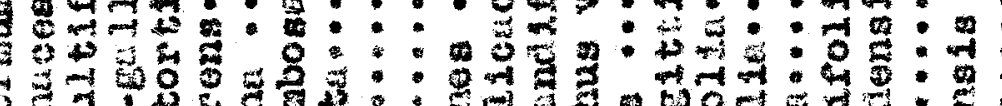

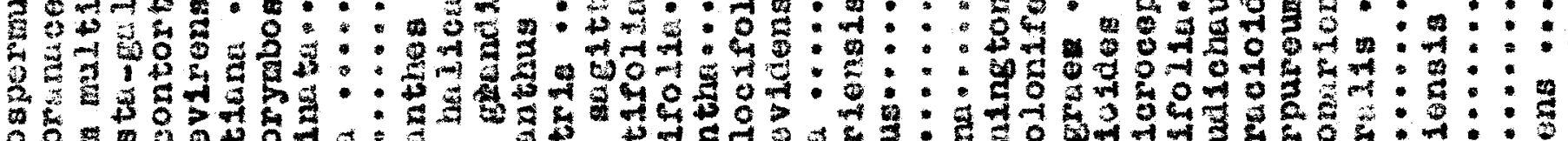

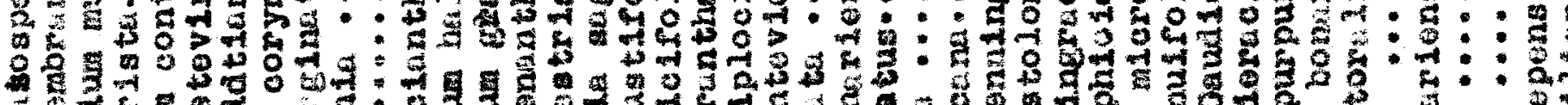

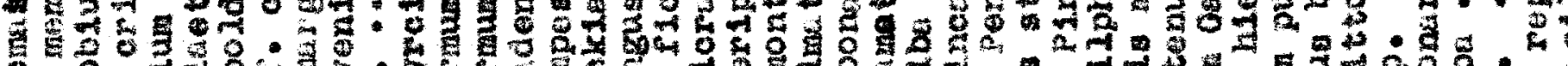

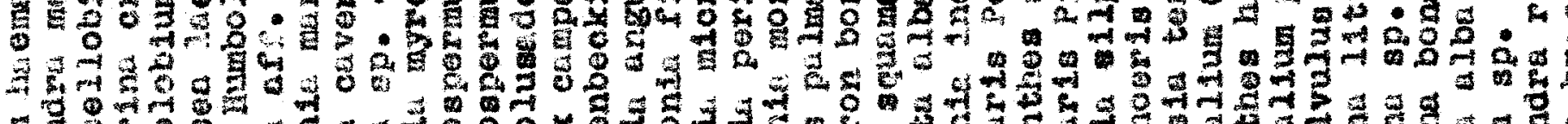

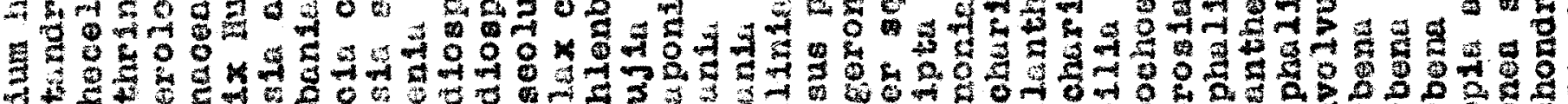
14 1. W 


\section{3 - Espiniliar (Consocies de Acacia cavenia) (F1gs $5 \%$ ph)}

Esta comunidad, que tiene por dominante a una faherofita xerbfila, de escasa altura, el espinilio (Acacia caventa), de posición sucesional dudosa. Aqui so la considera como una subclimax detenida Indefinidamente por la humedad del medio $\mathrm{J}$ que tiene como factos de compensación al suelo suelto, senoso, que permite el desarro110 de una comunidad de fanerofitas xerofilas en un clima de bosque higrofilo.

Estos espinillares evolucionan en tierra firme hacia la climax que es el bosque xerofilo, con predominio de los géneros Aca Q12 I Propop1s y otras fanerofitas xerófilas de escasa al tura. Este espinillar de Acacla y Frosopis, penetra desde el nor te de santa Pé como una cuña entre la galerla paranense y la estepa graminosa en su distrito subcalchaqueño del sud $\mathrm{y}$ centro de esa provincia, acercándose a la costa y teniendo sia extremo sud en el llamado "Rincón de Grondona", comprendido entre el r1o carcara. ñá y el Parané. Forma parte del anillo de bosques xerófilos que rodean la estepa pampeana circundándola completamente.

Los espinillares de la isla (Consocies de Acacia cavenia) Ios consideramos a qui como una comunidad evolutiva anterior - Ia final que culminarla en el bosque zerofilo peripampeano o periestép10o.

En los lugares mis altos $\mathrm{g}$ secos de los alberdones, coin cidiendo con los últimos sitzos que quedan a lvo durante las crocientes periódica, sobre suelo arolilosomarenoso suelto, crecen 1 los esplnilios formando bosques claros de aistribución muy irregular, que dejan grandes espacios cubiertos por un césped de Axonopus compressus, Geraraia communis, Ps spalum distichum, u ocupados por islotas del pajonal de Panioun prionitis. Estos espiniliaros son liamados por los lugareños. "Isles de creciente" por ser $10 s$ únicos lugares que no se an egun en épocas de lnundiciones y donde el ganado busca refuglo seco y alimentación. 


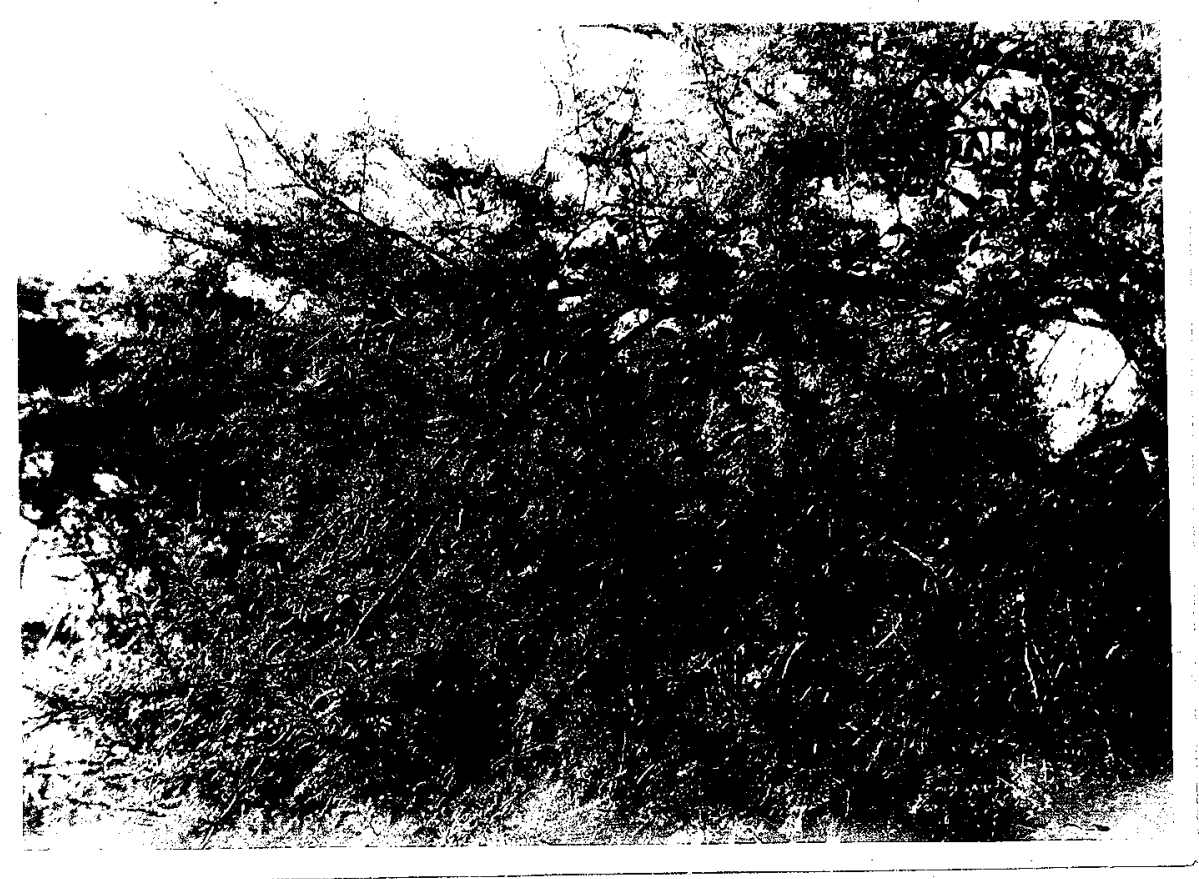

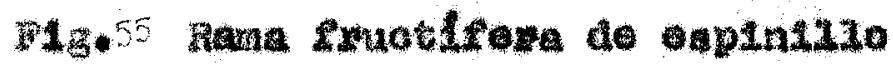

(Adacia oavensa)

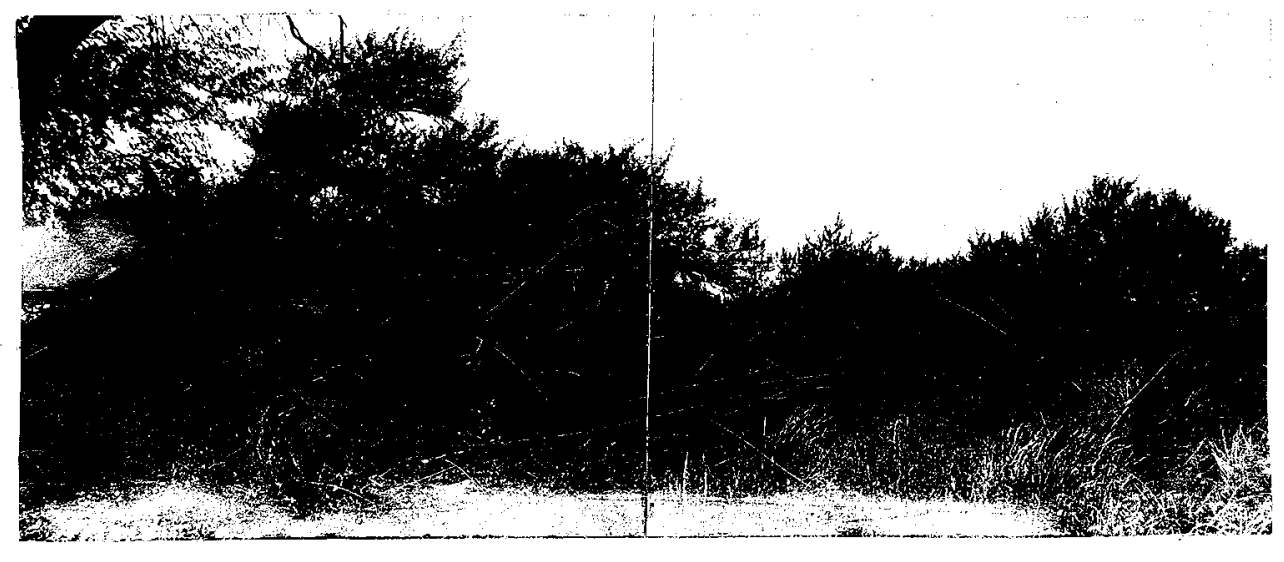

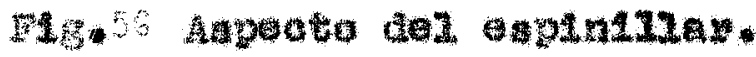
(Comoolea de Achela oaventa) 
Censo grafico correspondiente al Espinillar (Consocies de Acacia cavenia)

Superficie estudisodo en $m^{2}=100$

Fecha: $9-1-49$

Cobertura: $60 \%$

Monte xerófilo espaciado Altura de la vegetación: $3-5$ metros

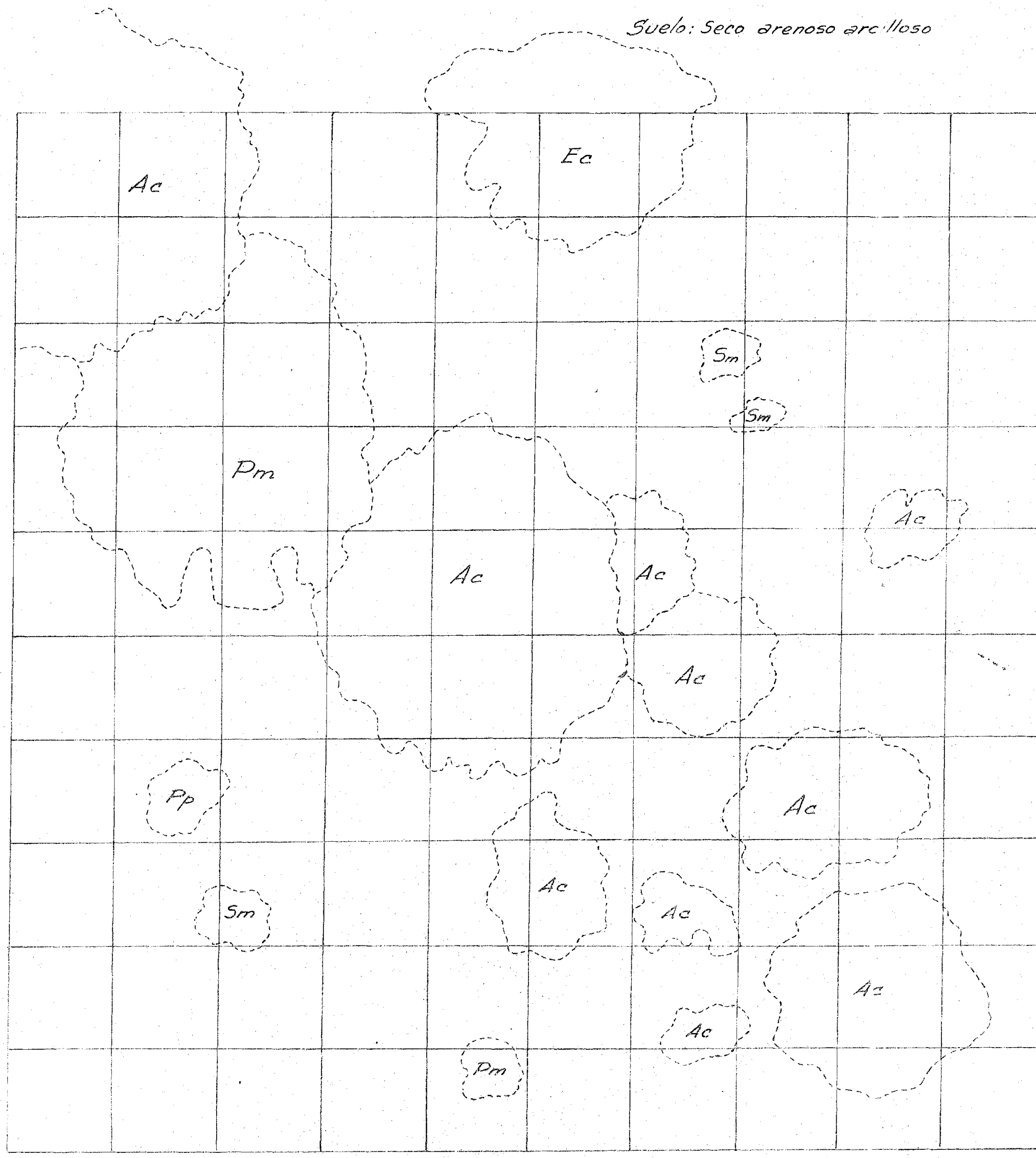

Ac. Aracia caverio

Eo- Erythrina cristogalli 
La dominante ebsoluta es al eapinillo (Acacia cavenis) arbol1to mimos6ideo, de hojas compuestas, flores grupadas en cabezuelas de color amarilo anaranjadas que aprocen 2 final del invierno, maders dura, ratorcida, tortuosa, de 5 a 8 metros de alture, valna gruesa y corta. Fste arbol, 1 gual que el selbo, tiene escasas oxigenolas ecologica, aunque no 1 lega a restsit muehe humedae en el suelo donde vegeta. Le oreciente oxtracránuxia de 1905 , según datos de los bicheros, destruyo ceal todos los espiniliares. Eh su conquista de habltats más secos, lo vemos cubriendo totelmente los cerritos artiflelales consiruldos por los indios como habltáculo permanente al resguardo de las crecidas.

Su madera es codicinda, por su poder calorifico, cono lefia; también se emplea en postes y parquets, lo que contribuye a que sus bosquecillos vijan desapareciendo bejo los efectos del hacha.

Como compañantes arboreos en los sitios hưmedos suelen verse algunos seibos (Erythrina crigte-gal11), laureles (Nectanara membranacea var. falcifolia) y timbo blanco (Elthecelloblum multiflorum). Los arbustos mis comunes son: Sesbanla marginato, Cessia ff. corymboag, duraznillo negro (Cestrum Perqu1), ete.La rama negra (Sesonia marginata) formi colonlas dentro del espinlliar.

Eh el eatrato herbiceo predominan Axonopus compressus, Cardionema remossisimum, Setaria geniculata, Cynodon dactylon $y$ debajo de $10 \mathrm{~s}$ espinillos se desaxrollan grandes colonisas de jerba del sapo (Marrubium vulgare) y stak hastata.

Son camunes, por Influencla del ganedo, 12 coloniag de Carduus nutans var. microcephale, adventivia, igual aue el Chenopodium hircinum.

Sobre las rumas de los apinillos ge apojan varias en-

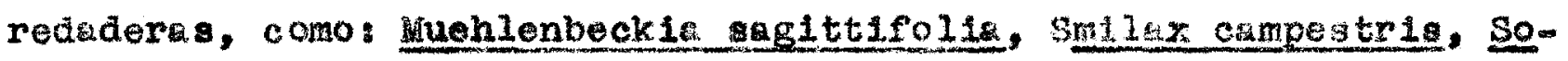
1anum amygalifolium, ete.

Lo Invaion por carduus nutans sueje ser tan grwnde que forme colonias densas y continuas debajo de los esplnillos. 


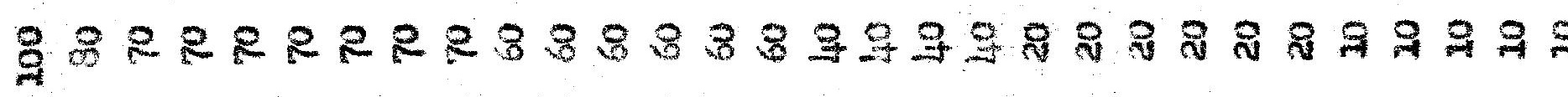
$9^{0}-5-N-\infty$ -

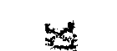

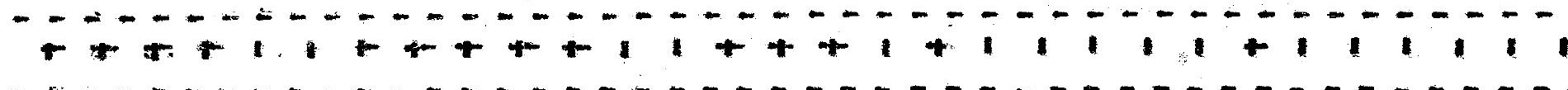
(1)

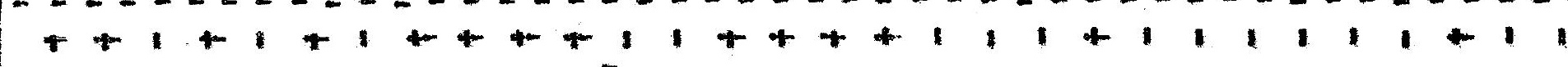
(- - - - - - - - - - - - - - - - - - - - - - - - - - - - - -

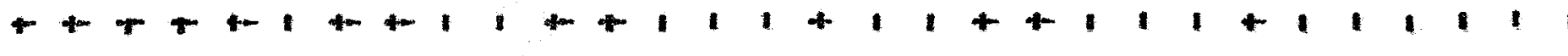

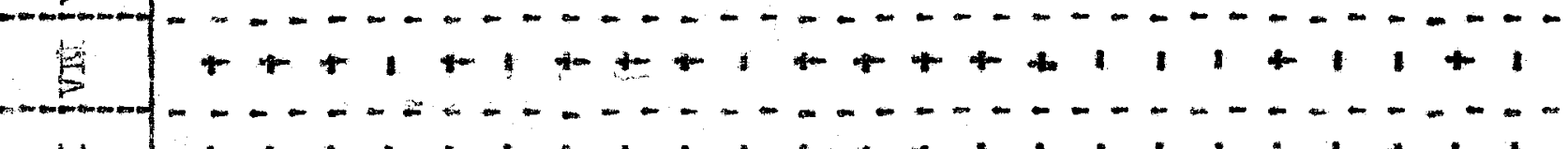

$-$

$=$

$-1$ $++++\ldots+1,1+1,1+1$

$-9$
$-\cdots$ 
Cuadrolto17

Diagrama de frecuencia-Espinillar

(consocies de Acacia carenic)

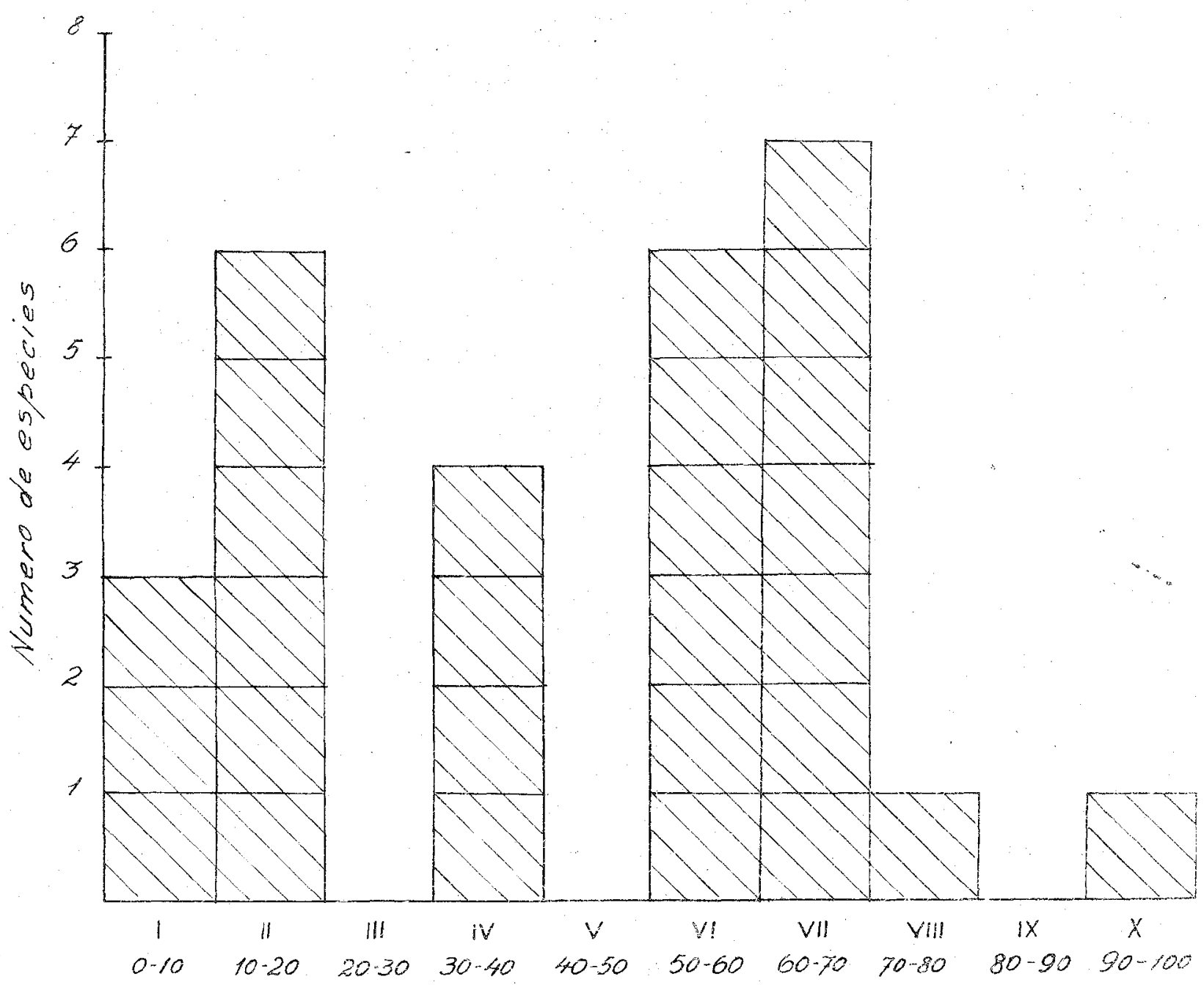

Clases de frecuencia 
El ecotono o zona de transiolon 1 pejonal está representado por una faja do Benicum priontis, con Krboles 1s lados o 1sleta de Acacia cavenia.

Desde ol punto de vista aucesional colocamos 1 espinillar como une etspo ovolutiva del misho rango que el bosque blanco, sucediendo como sato 1 pajomal on un nedio edáfico relativamente seco ¥ precediendo a 1 bosque zeróf110 perlestépico olimáxico. Le diversiflctaion aucesional serla as:

Comunidad seral Pajonal (Arocies de Panloum prionitas y Sehaef ferla uruguayens 1s)

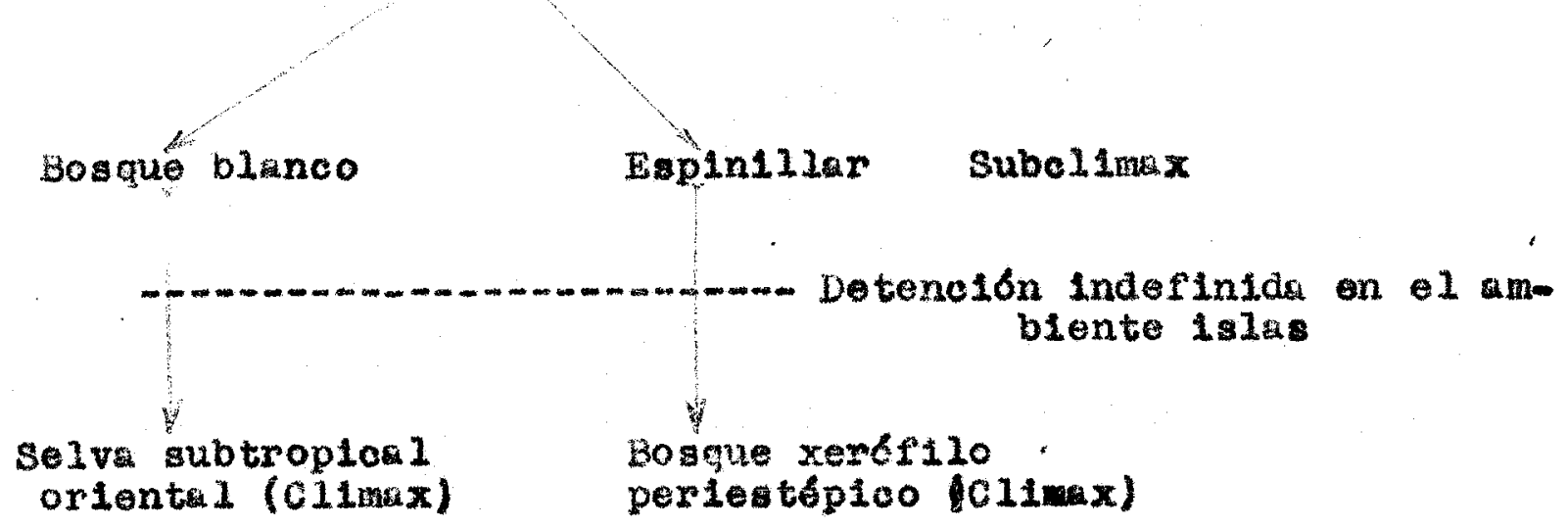


Numero del censo .........

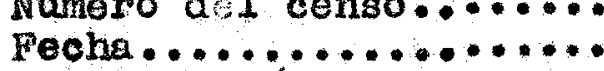

II II 8 III $: I V$

Sobertura of e...

da en $m^{2}$

$12-\frac{1}{90}-49 \cdot 16-1-4$

$6-1-49: 7-2-49 ! 8-2-49$

$v \quad v z$

VIX VIII $6-3-49136-3-49:$ $70: \frac{10-2-49: 24-2-49}{70}$ 70,90

- Nectandra membranacea ........ 4 . 1

PS thecelloblum

Erythrina crista-gall1............ 1

-Acacla cuventa................ 14.2

cassla af. corymbosa............. -

Sesbanda marginata............. 14.1

- Cestrum parqul................ ! : 1

Jaborosa integrifol1a ......... It 1

- Heotiana longlfiora ..........

' golanam boerhavifolium..........

'clssus palma ta ................

- Card1ospermam grandiflorum.... 14 . I

- Huehlenbeckla sagittifol1a.... If . 1

- Smilax campestris .............

'Araujla angustifolia..........

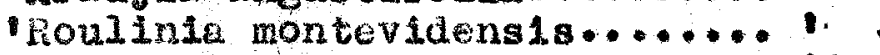

likania periplecifolia.......... it: 1

- Cardiospernum halica cabum .... -

isida hastata ...............

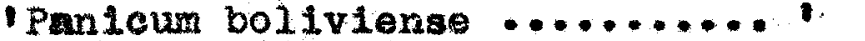

- Paspalum Hieronym .............. . 1

Axonopus compressus ............ It. 1

- Cardionema ranosissimum.........

- Setarla geniculate............ if is 1

Hod lo la trum geranioldes....... -

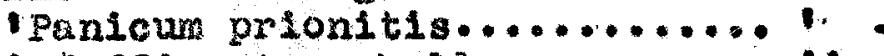

- Pfaffia stenophylla .......... It: 1

'Bachar 1s Plngreea ............... -

'Cynodon dactylon .............. if 1

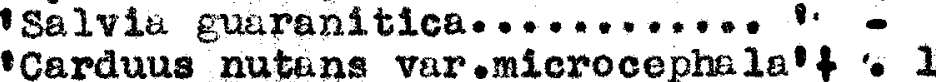

Chenopodium hireinum ..........

-Erigeron bonar tensis ..........

Aster af. squamatus ............ if: I

Eclipta albe ..............." -

- spergularia platensis ........

- eenotheria indecora............ if . 1

Heleocharis minima

Juncus tenuis

! $\quad$ i

$5 \cdot 2: 3: 2$

::1:

$1: \frac{1}{2}$

$2 \div 2:$

$-\frac{1}{2} \div 2: 3=$

$+\cdot 1$

1

$-13=2$

$-10$

: 1

4.1

$1: 1$

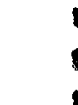

$-$

$+.1,1.1$

11.11

$\div: 1: 4: 1,1: \frac{1}{1}$

4: 1

$+$

\& 2

$-1.21$

$3: 2 \div+1 !$

$2 \div 2$

$2 \div 2:-1=1$

$4.1 .2,1,1=1$

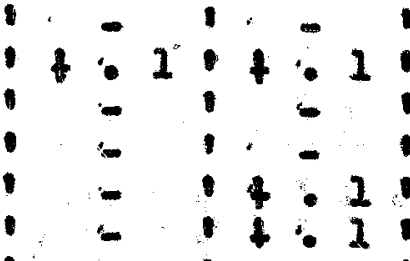

$: 2: 2$

,

$:-1: 2:+-1$

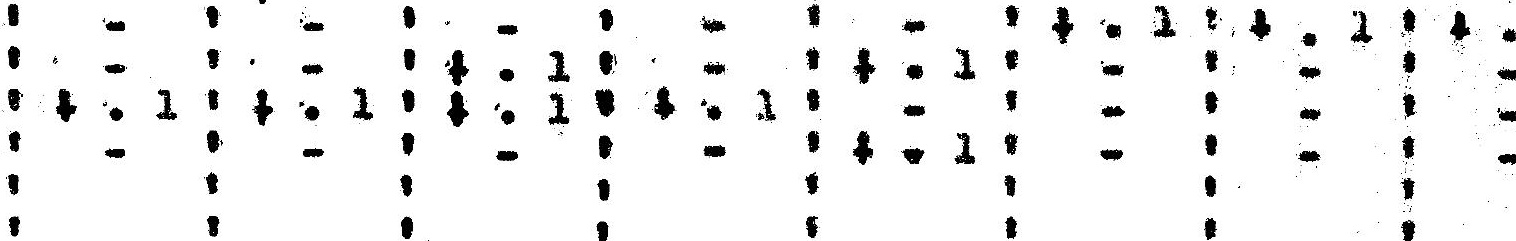




\section{B.- COMUNDADES SERALES.}

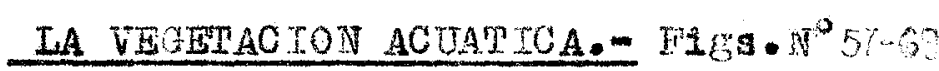

La fundanental caracterlstica de la prisexe del anblente insular reslde on que se orlgina siempre en un área desnuda representada por el agua, sus alversas etapas se desarolian en habltats cara vez menos himedos hasta Lzejar a las dos comunidades subclináxicas que representan las etapas más elovadas à la sucesión vegetul on esta negión.-

por consiguiente la vegetación acuética tiene rucha inportancia por la aoundancia de egtaciones apcopladas que le ofrecen las islas.- Unas veces se trata de laguars de agua tranquilas y per manentes; otras de charcas temporarias; otras de rachos: arroyos; madrejones; sacos; bocas, atc.-

Dosdo el purto de viata del lugar en que regetan $\mathrm{y}$ de sus peculiares adaptaciones al medio podenos distinguir los silulentes tipos de vegotación acuática:

a) Vegetación de las lagunas y madrejones: eulimnofites

b) Vegetación de los riachos,arroyos,sacos 7 bocas: potamofitas

c) Vegetación palustre proplamente dicha: helofitaa o plantas

anfiplas.

a) VEUETACION SUISERGTDA.

Cuando los distintos medios acuáticos pasan del ambiente lotico al lentico,es decir que pierden su comunicación con los riachos trams formandose en ague estancada, o en cualqujer lugar donde la volocidad de la corriente se atenúa conienzan a desarroliarse vesotales sumergidos.-

Iatas plantas presentan una serio de adaptaoiones caracteríticas. Sus tejidos neónjoos son oscasos, el xilema es muy atroriado,las hojas son delgadas o disectas,falta la capa de cutina en Ia epiderinj: los estonas ostán siempre abiertos, etc.-

En este redio hay.algas filamentoses verdes,y son muy comunes Elodea catradenais y myiophyllum brasilienge; en menor 


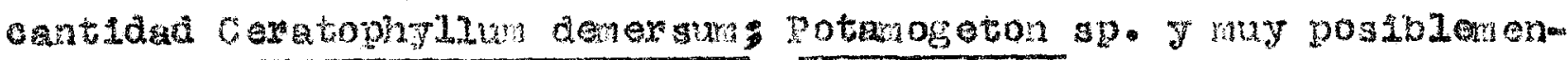

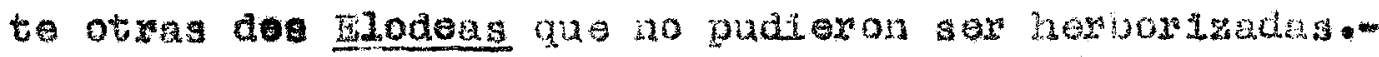

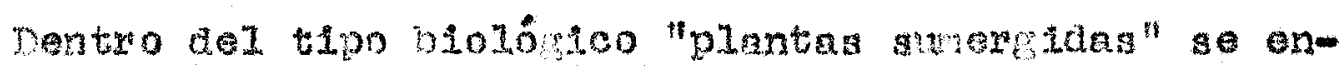

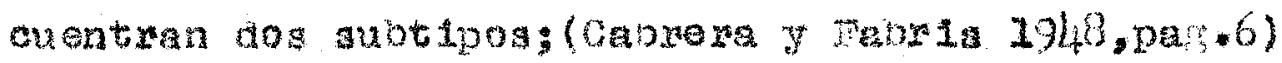

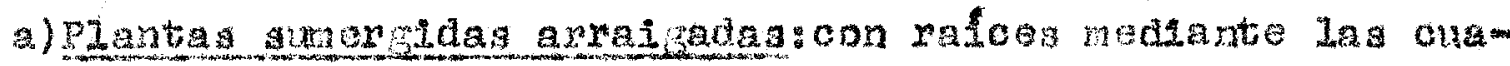

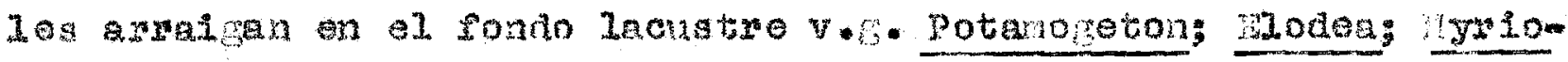
Dhr12ram.

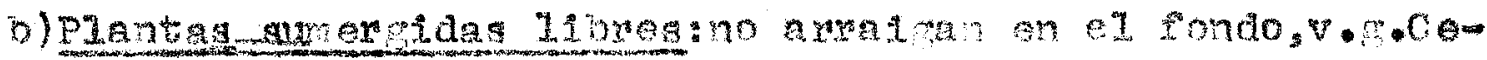

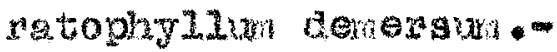

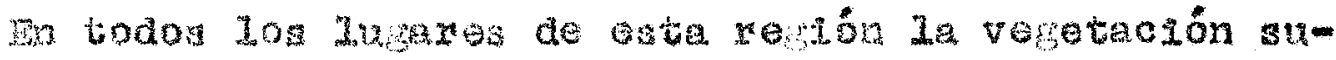

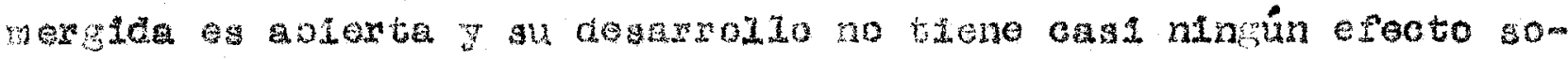

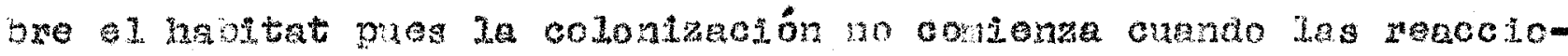
nes ontro las plantas sunergatas han logrado reductu la protundidad de la lagunas ano cuardo una prolongada bajanto deja sin alumen-

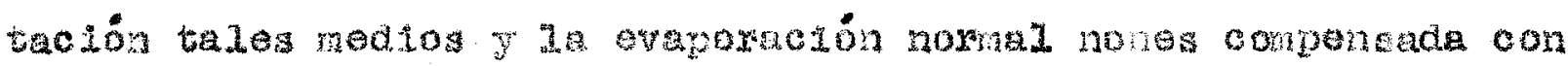

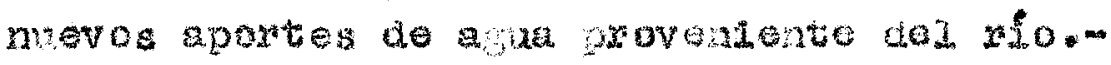

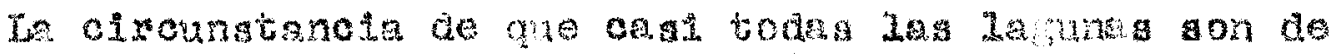
muy pock profundidad aurado a La pooa denatagd to la poblaclón vo-

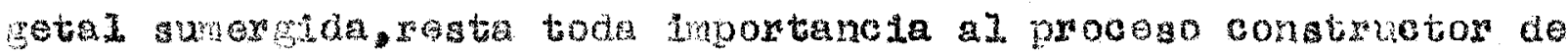

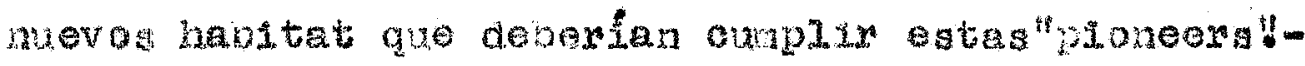

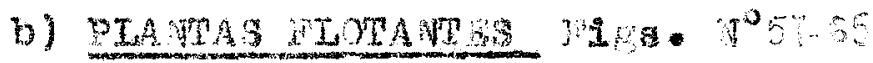

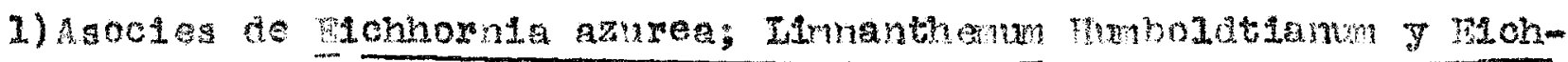
Dorria onasaspes.

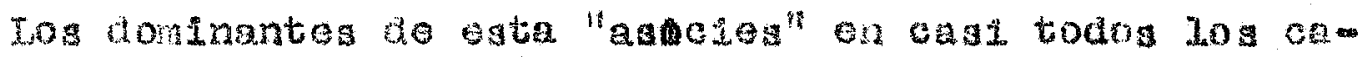

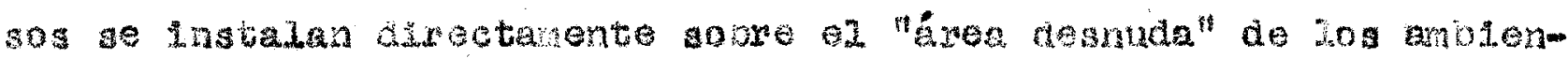

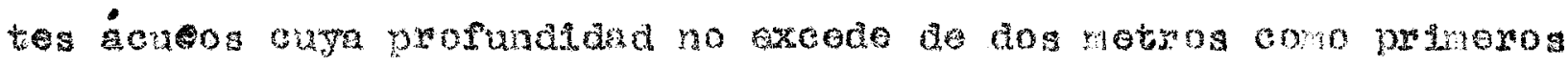
colonizadoses.-

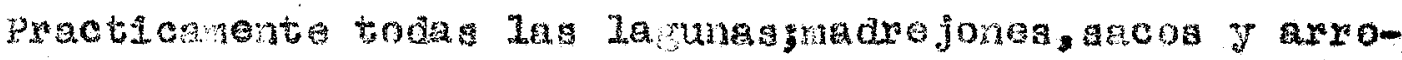

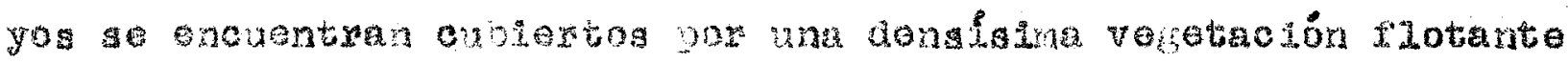

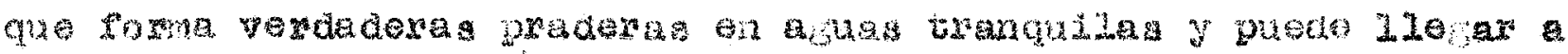

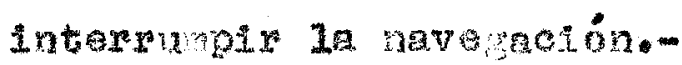

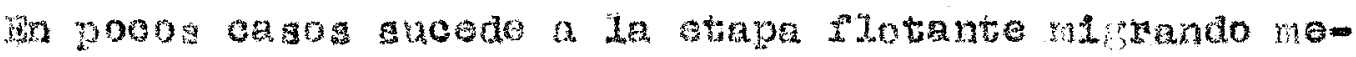




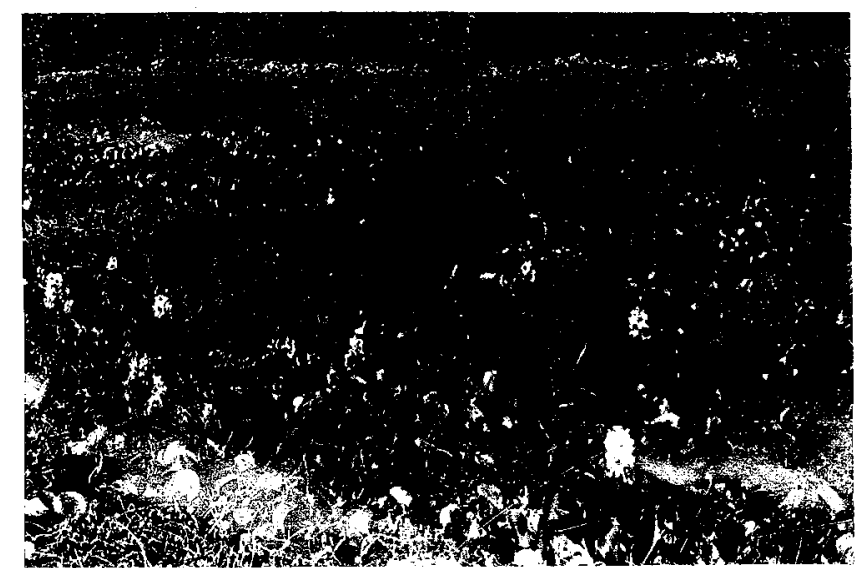

219.57 Aapooto de la otapa flotante cubriendo totalmonte una Iaguna.-

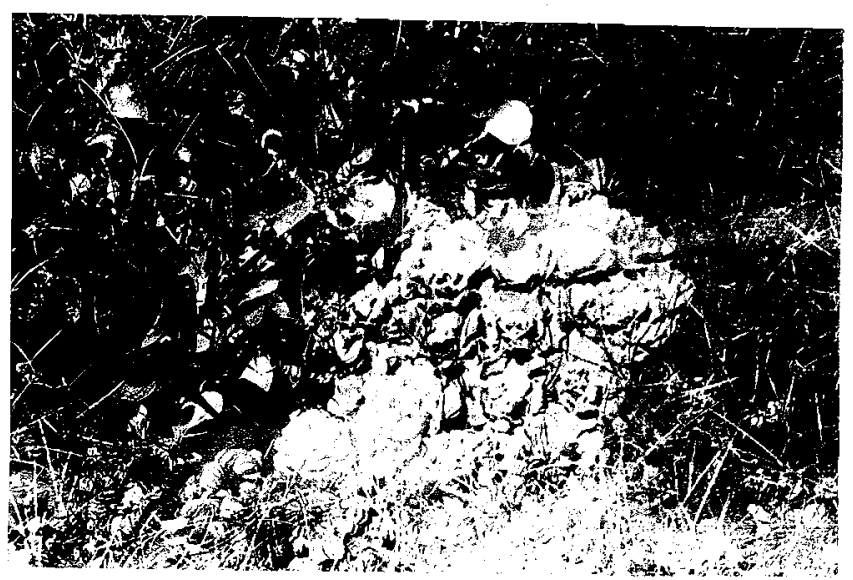

14.59 colonta de "yopoll1to de agua" (platla stratiotes)

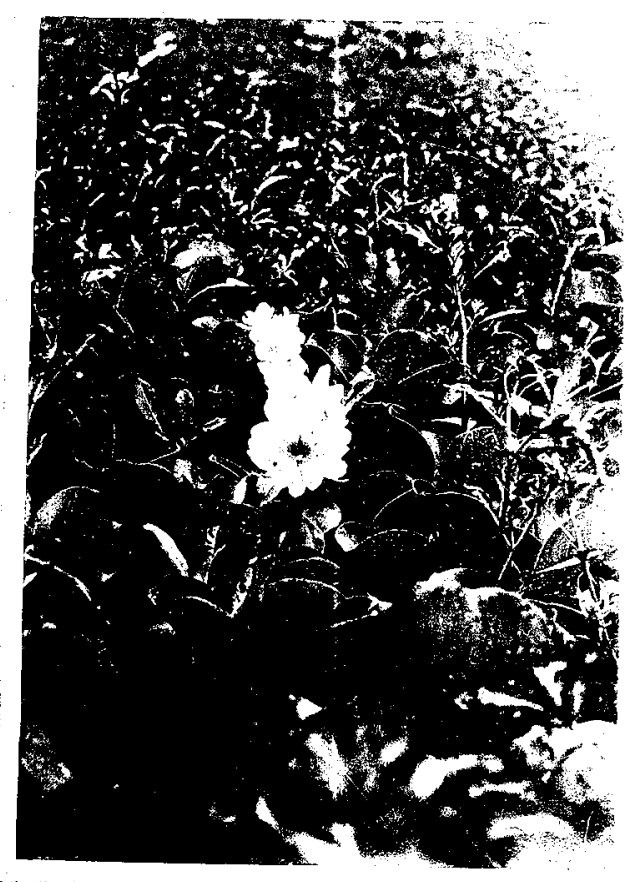

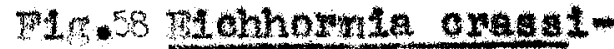
pes:-

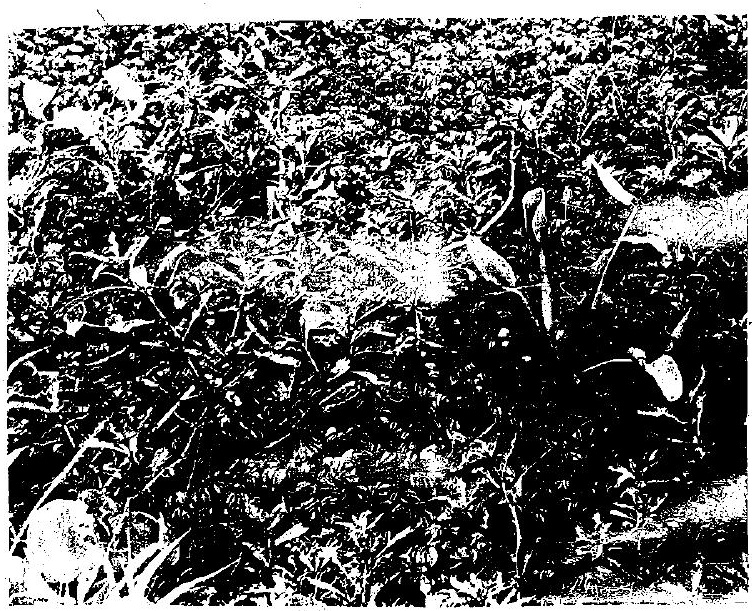

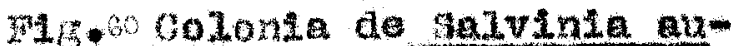
nevata.-

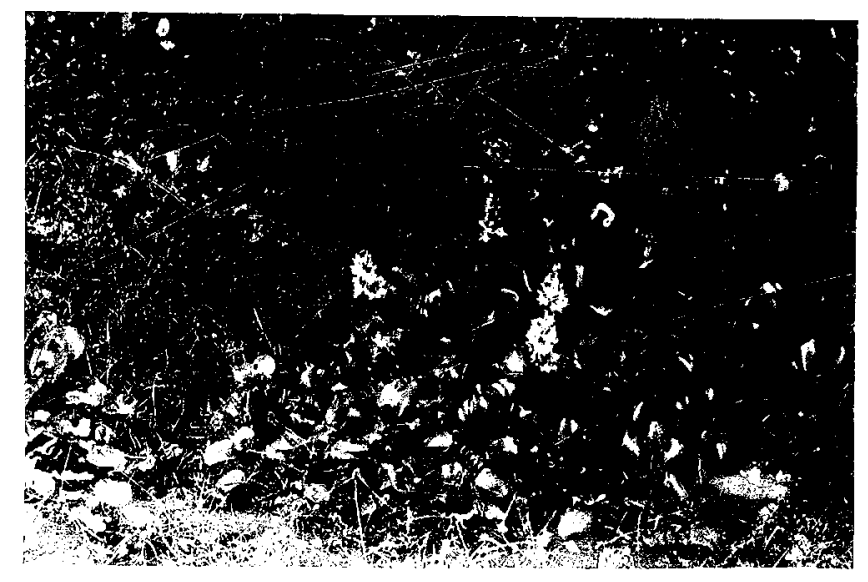

19.61 Btro a apocto de Ia votapa ciotante"- 


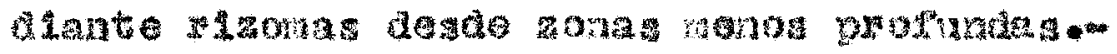

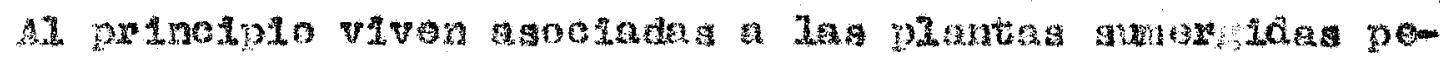

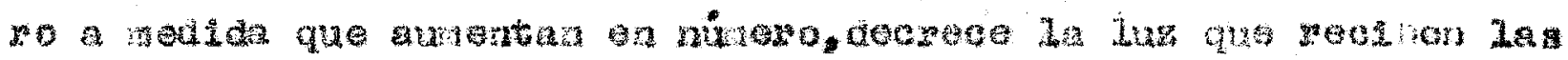

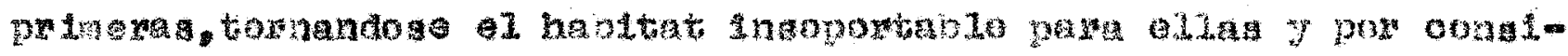

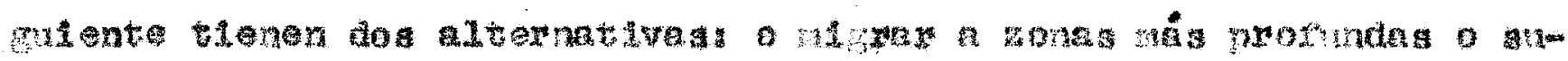
costatis.o

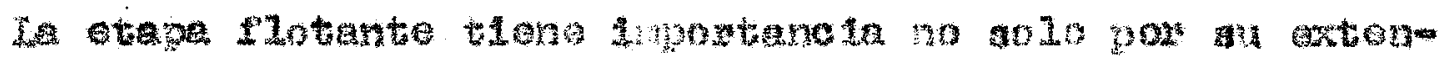

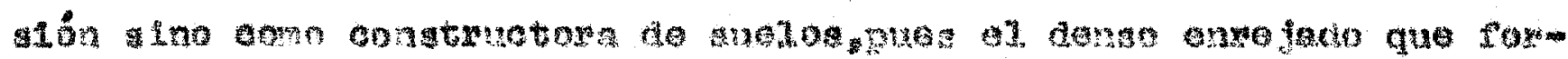

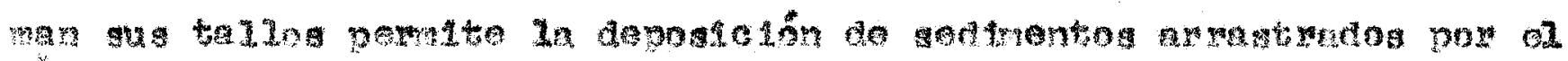

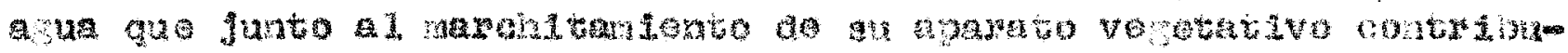

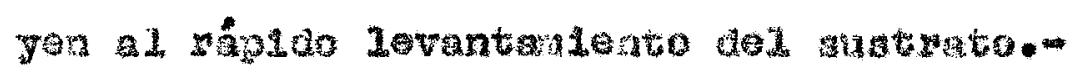

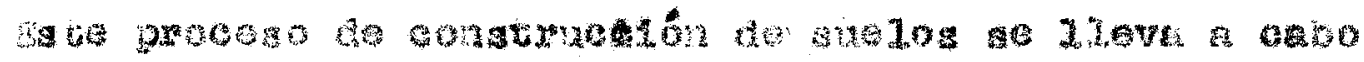

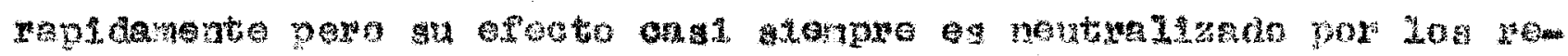

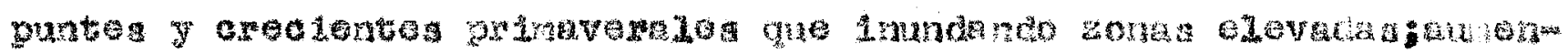

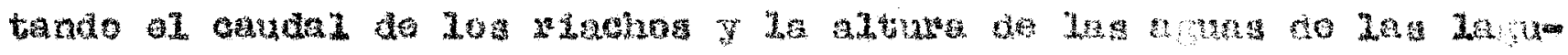

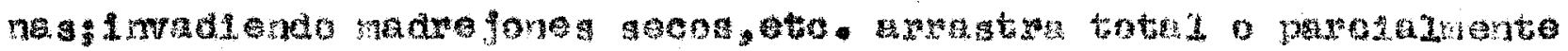

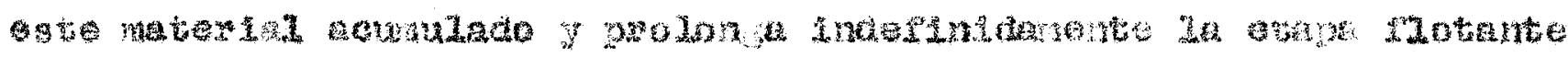

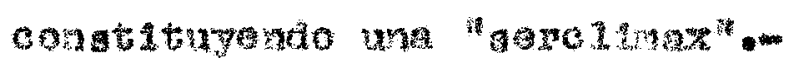

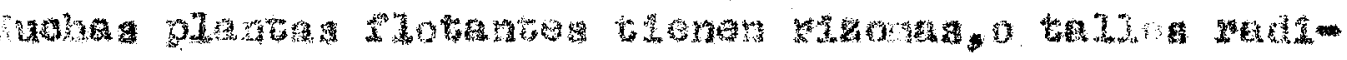

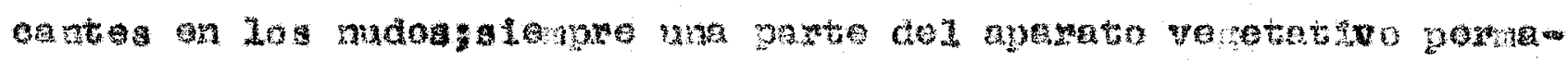

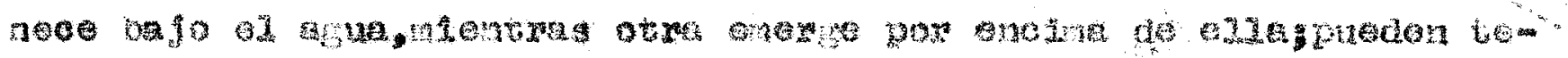

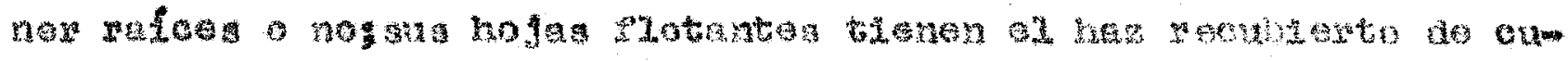

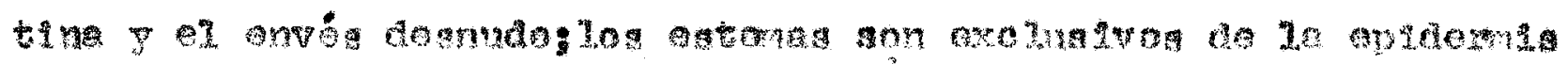

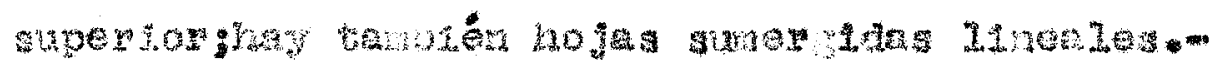

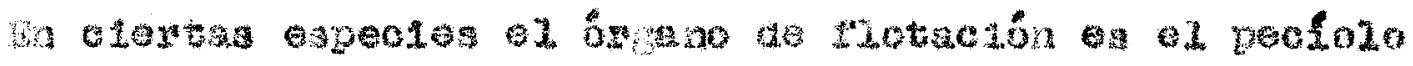

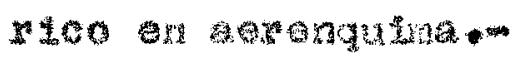

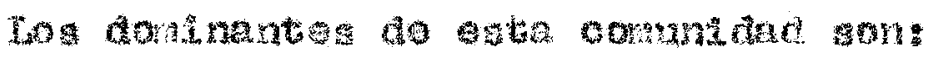

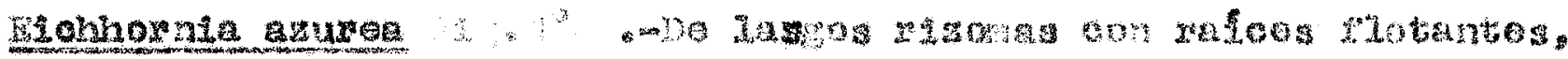

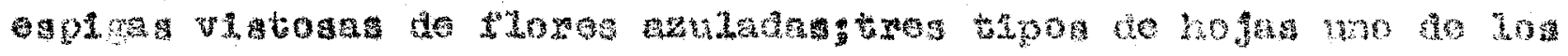

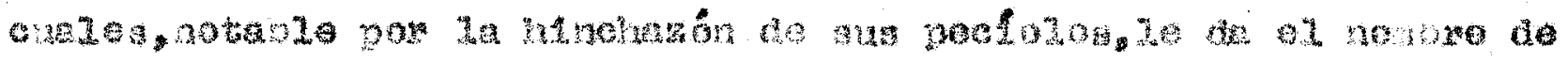

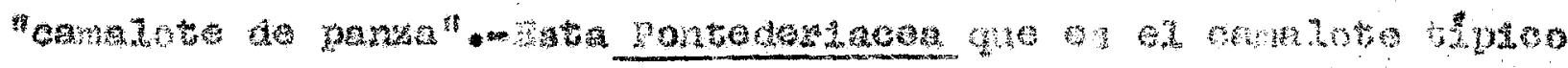

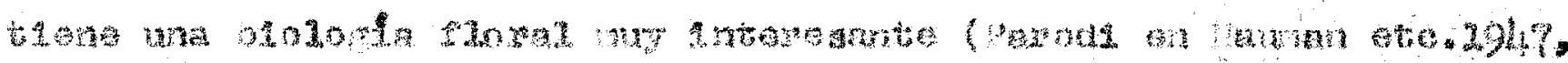


pag. 87) semejante a La de Elchhornia crassipes y Pontederia rotundifolia con floros heterostiladas trinorfas que degpués de la antesis encorvan sus pedúnculos,por una zona de flexión, sumergiendo los ovariog y madurando los frutos oajo agua (hidrocarpia).-

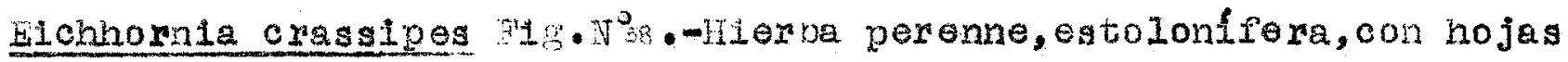
en roseta, de peciolo vejigoso y hoja rlorifera reducida; inflorescencia en espiga de duración effmera (dura un dia); tépelos de color rosado 1ila.-

Ilunaathernum Fumblidtianum Fig. $\mathbb{N}^{\circ} 36$ - -Genclanacea perenne, flotante, con hojas cordadas orbiculares $\mathrm{y}$ flores blancas exinera.-

Acompanan a los doninantes otras dos pontederiáceas:

Pontederla rotundifolia, de tallos ruesos horizontales tondidos sobre el agua que alcanzan hasta tres metros de largo y hojas de lámina orbicular o nenifome, caracteristica esta lítima que le ha dado el nombre vernáculo de"canalote de oreja" Fontederia cordata, rizomatosa, con rafces adventicias arraigedas on el lodo y hojas de Iánina Ianceolada elíptica u ovada,cortada en ia baso -

Con Igual Impontancia deben mencionarge el Hydrocotyle ranunculoides de talios fiotanteg, audos radicantes t hojas largamente pecioladas; suraneate comin en los madrejones contribuyendo a fomar conjuntamente con Azolla, Salviaia, etc . Las Lagunas esteradas; Nasturtiun palustre, hieroa pexanne de tallos tiernos; la pequeña Arácea compoolita Pigtia gtratiotes, Fig. No $N^{\circ}$ Iamada "ropollito de agua" las poqueñas Dericolitas, Salvinia auriculata; Salvinia rotundifolia

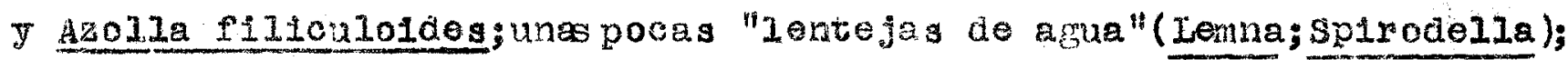
una Hepatica, Ricclocarpus ar. natang y en las partes más protundas encontranog los últimos ejomplares en su distribución hacia el sur de una Minfácea de extraordinaria belloza, Victoria cruz Lana; cuyas ho jas iedondas tienen un metro y nás de ajánetro simulando con su borm

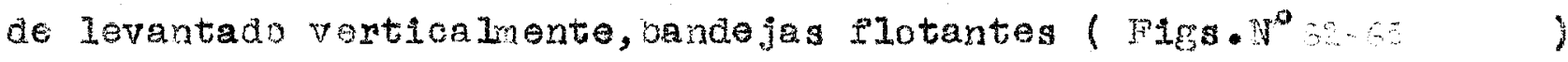
entro las que aparecen sus enomes floros rosado.s.- 


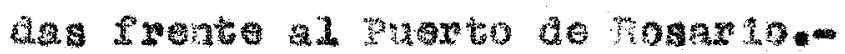

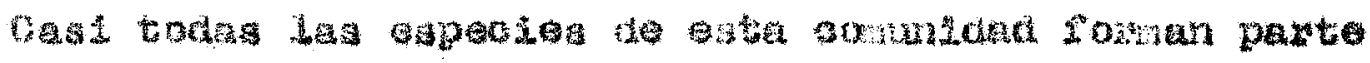

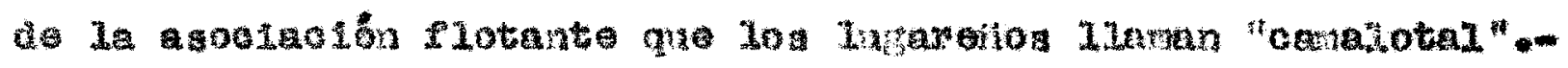

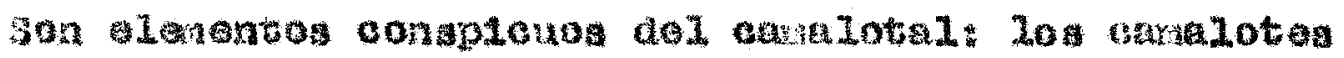

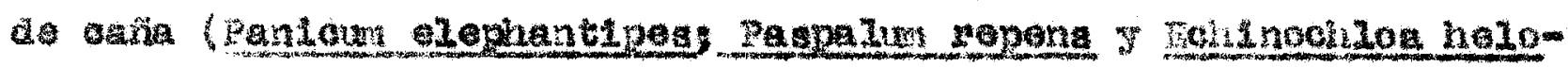

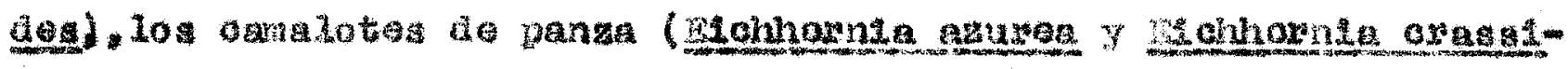

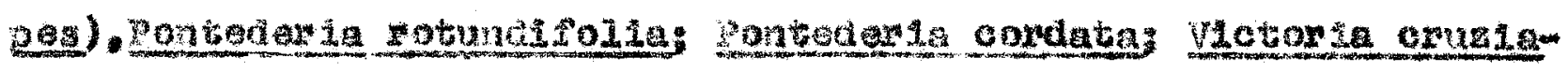

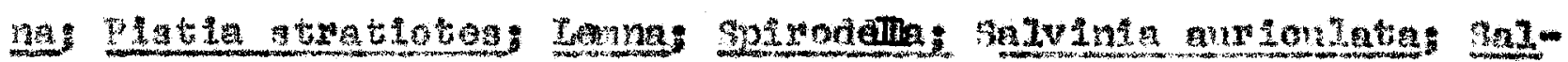

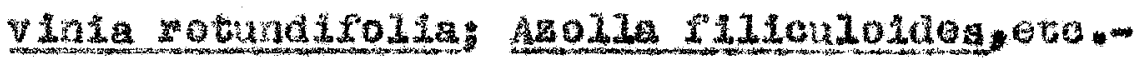

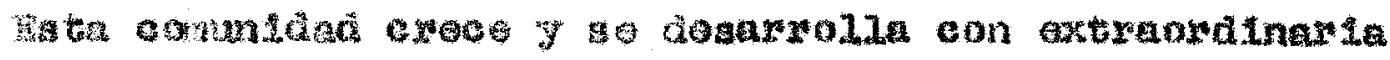

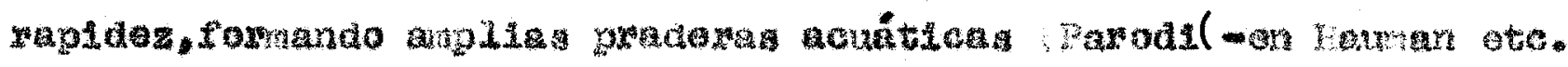

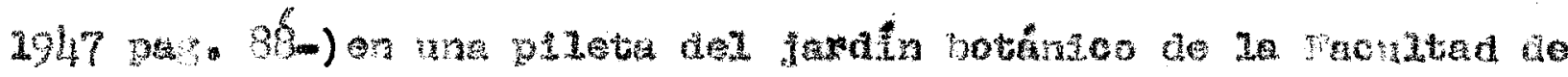

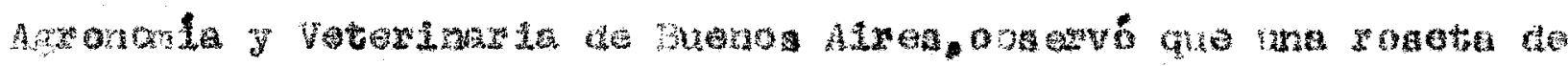

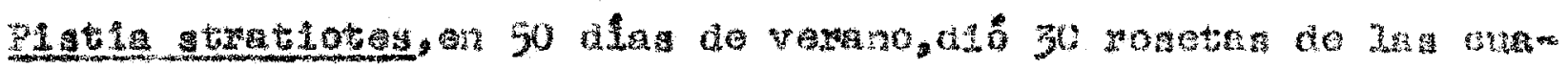
Ias 25 or

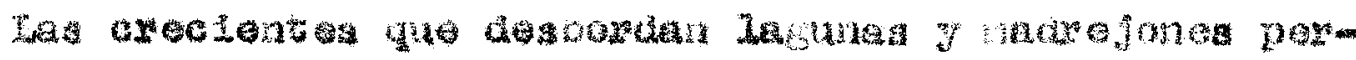

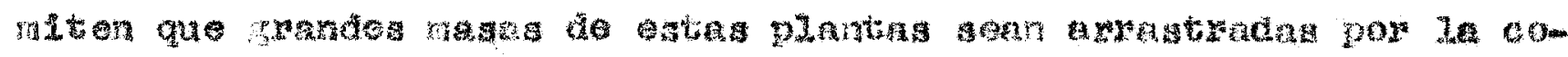

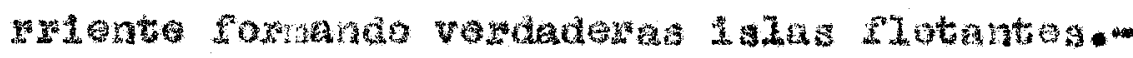

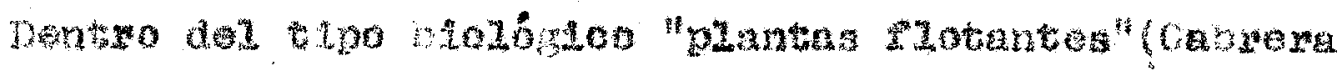

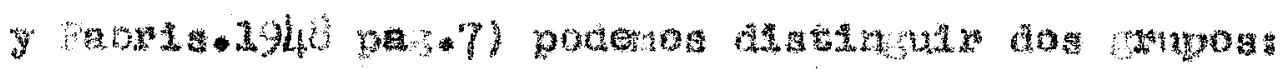

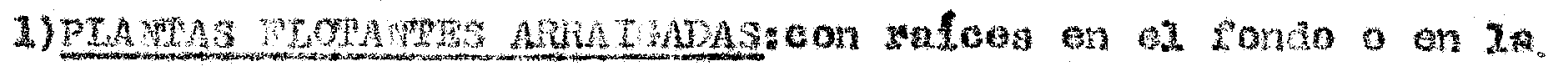
3.122.-

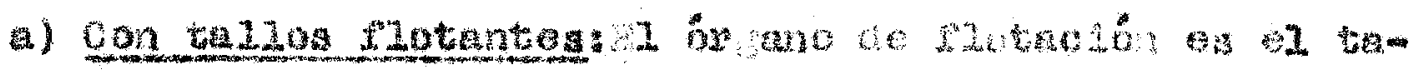

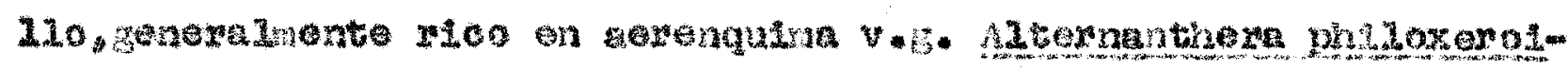

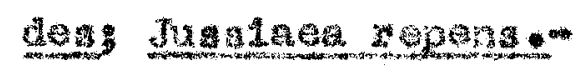

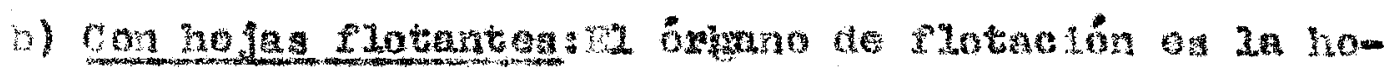

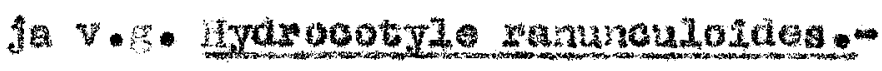

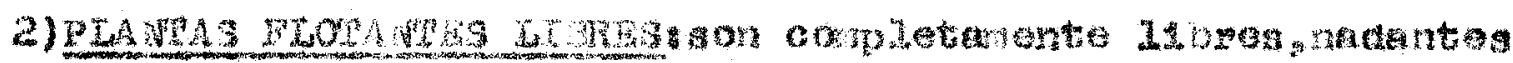

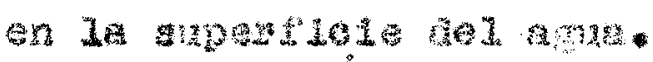

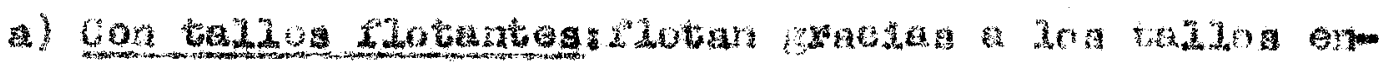

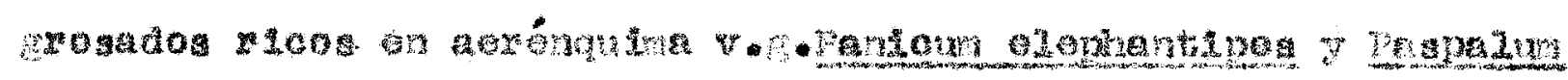
1.epen: 
Composiclón de la Asocles de Fichnornia azurea: jichhornia crasalpeg I LImnanthemun Irumbold Lamun--

Stapa flotanto on las larvuas, nadrojonas, sacos, bocas y charoas. Altura de la vegetación 0,50 xa * suolo paranoso, roo en detritus or șántoos.-

\begin{tabular}{|c|c|c|c|c|c|}
\hline 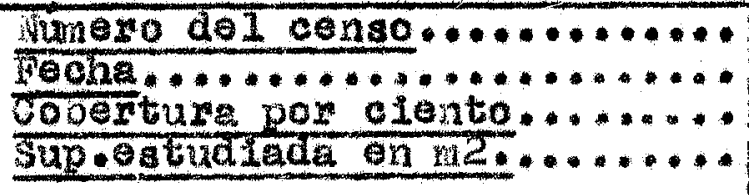 & $\frac{7-3-49}{200}$ & $\frac{1 T}{20-1}+19$ & $\frac{1 \pi T}{90}$ & $\begin{array}{c}20-12 \\
200 \\
1\end{array}$ & $\frac{22-149}{90}$ \\
\hline 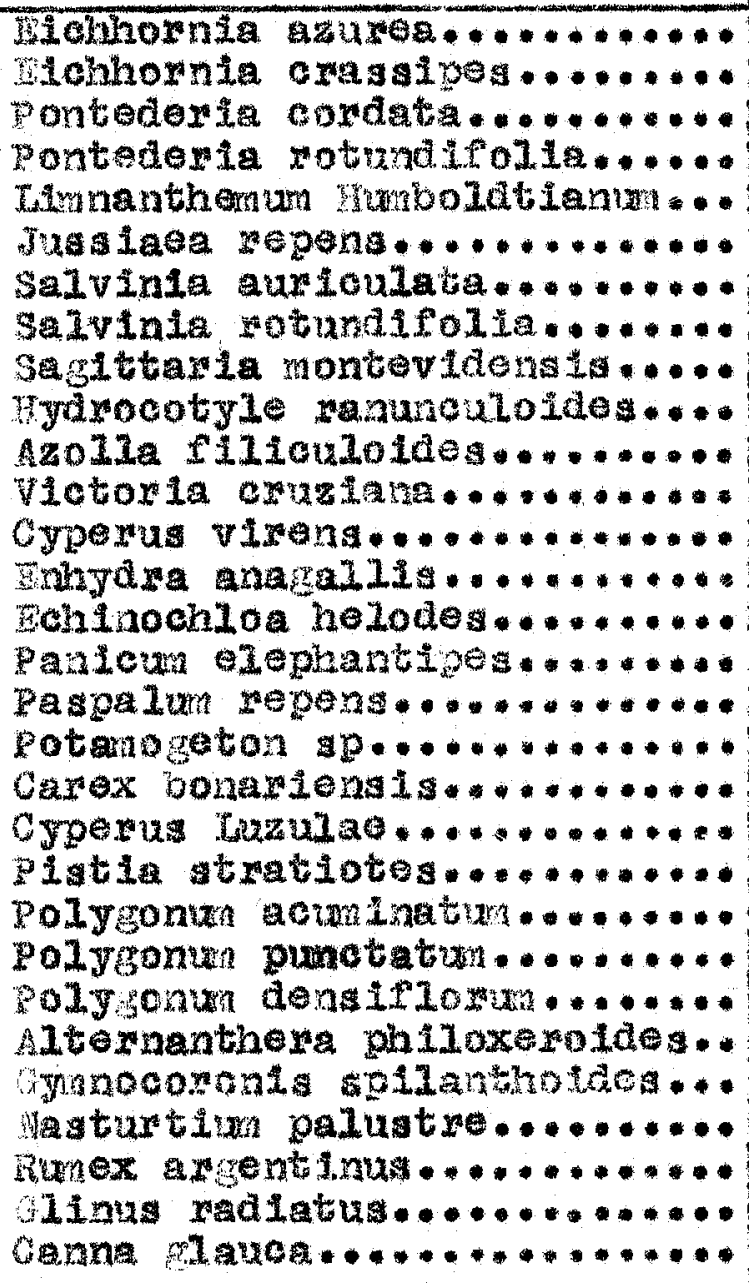 & 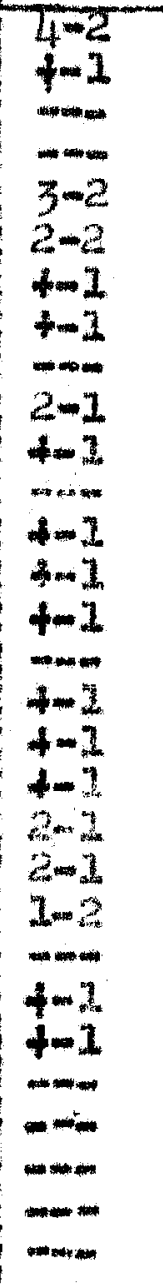 & 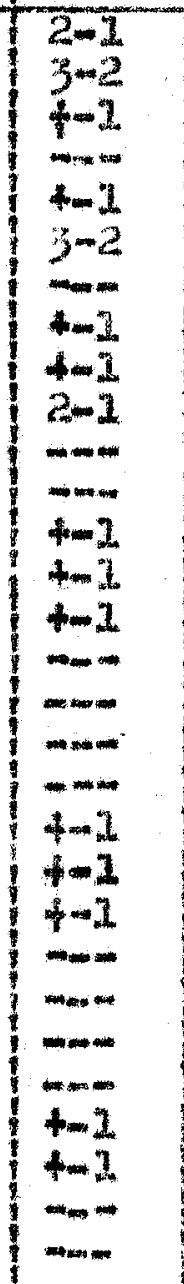 & 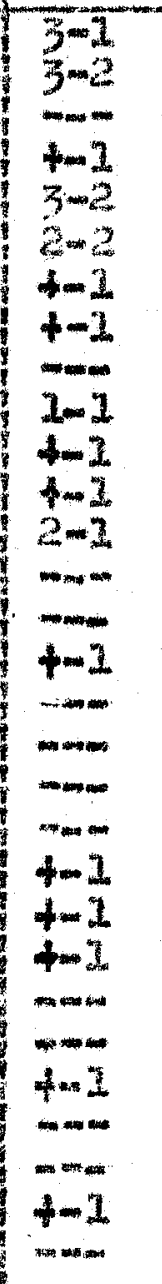 & 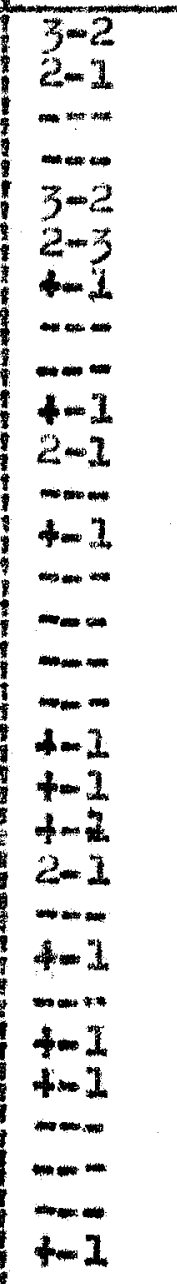 & 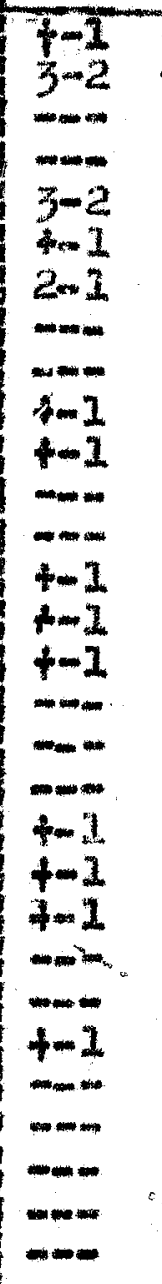 \\
\hline
\end{tabular}




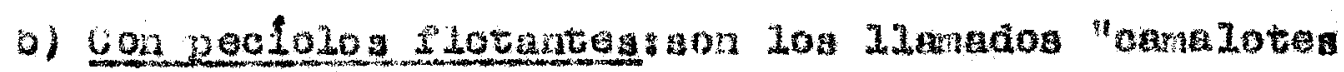

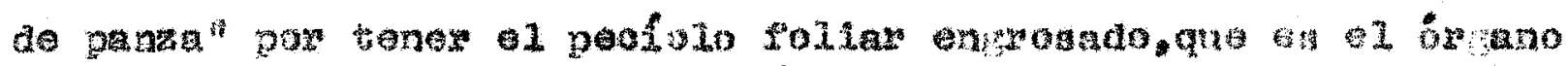

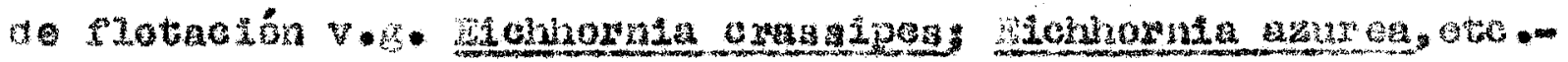

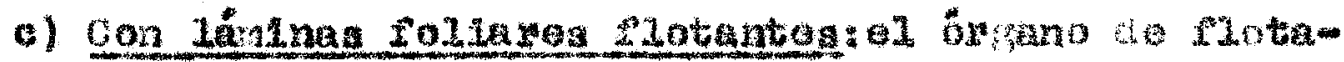

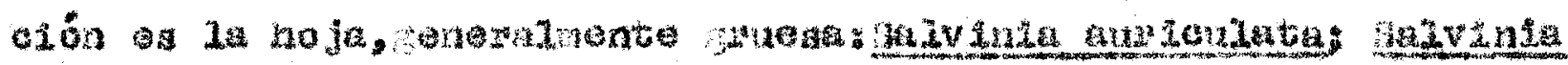

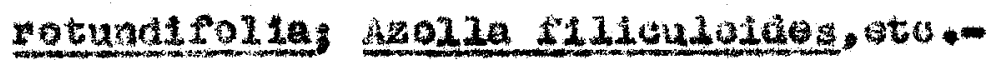

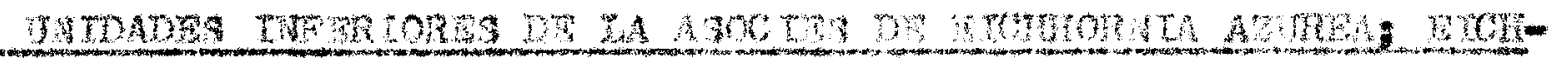

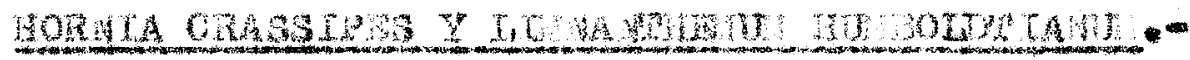

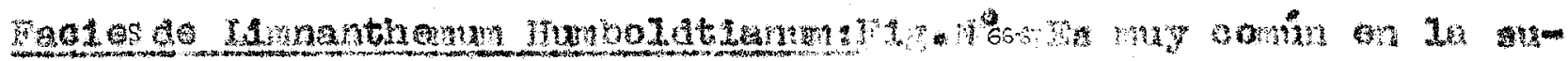

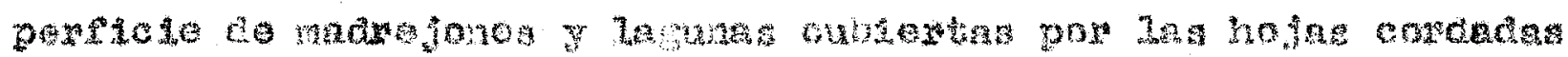

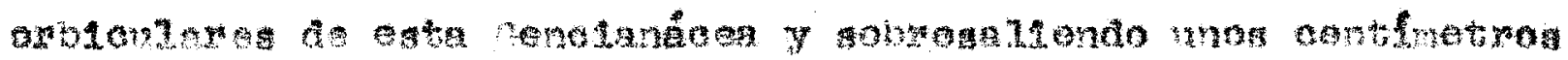

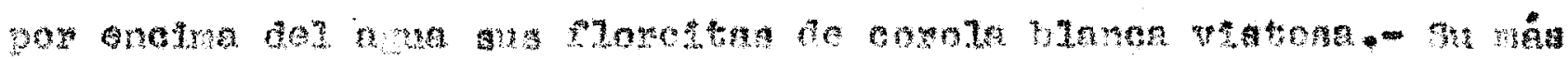

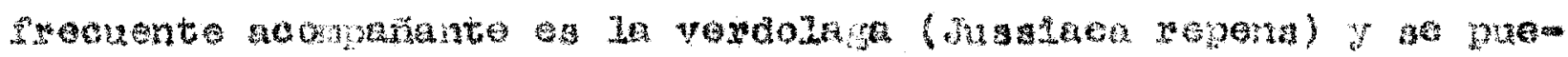

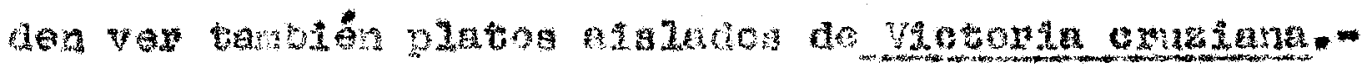

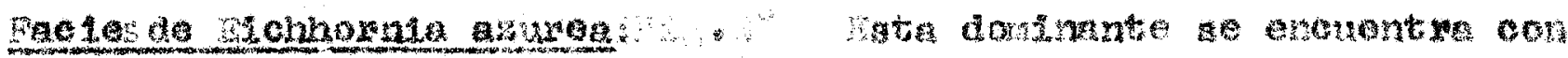

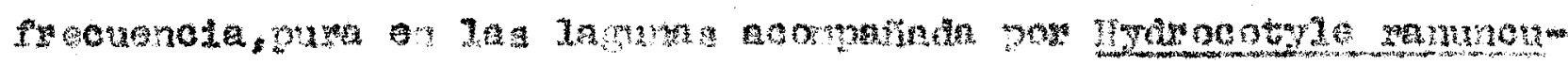
101093 5.

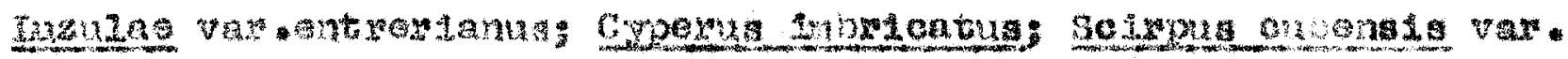
paranguman

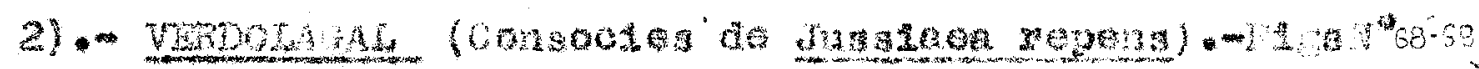

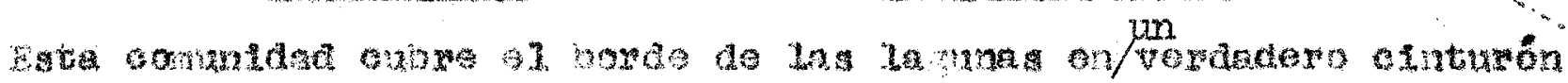

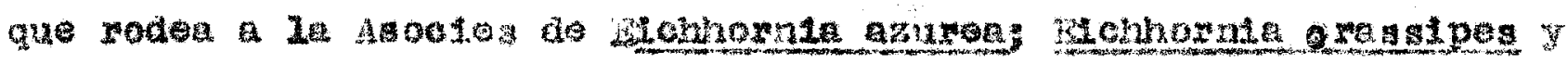

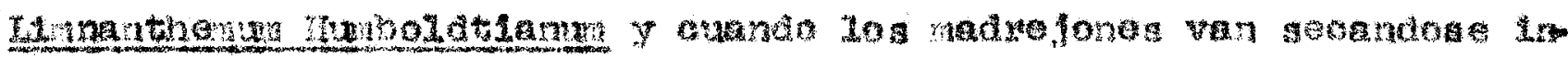

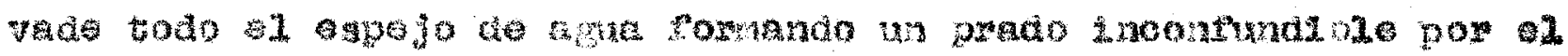

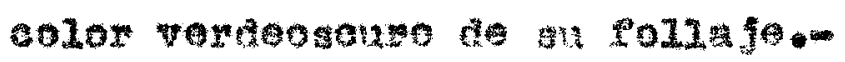

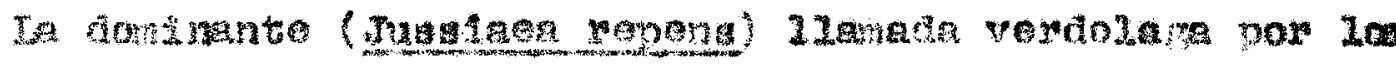

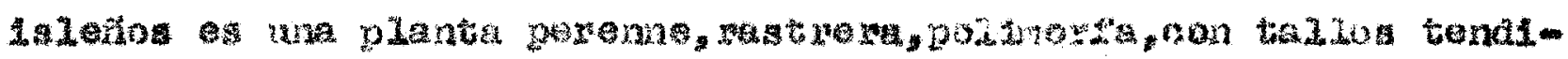

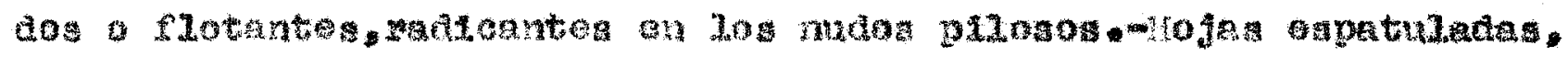

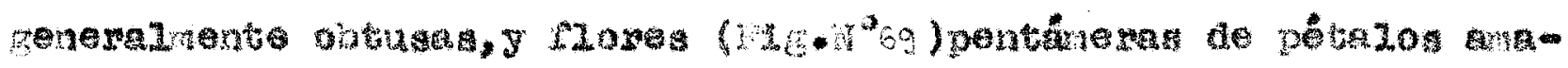

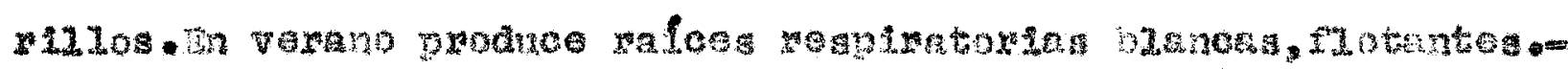

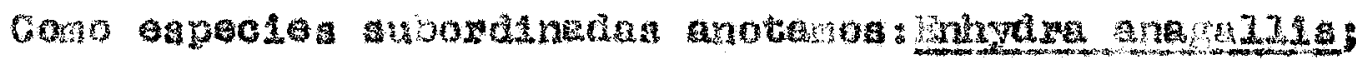

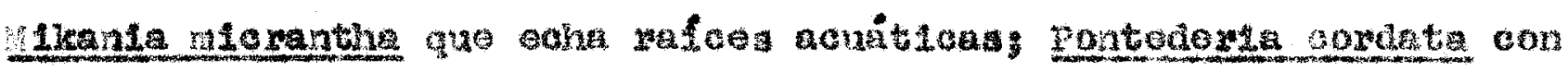




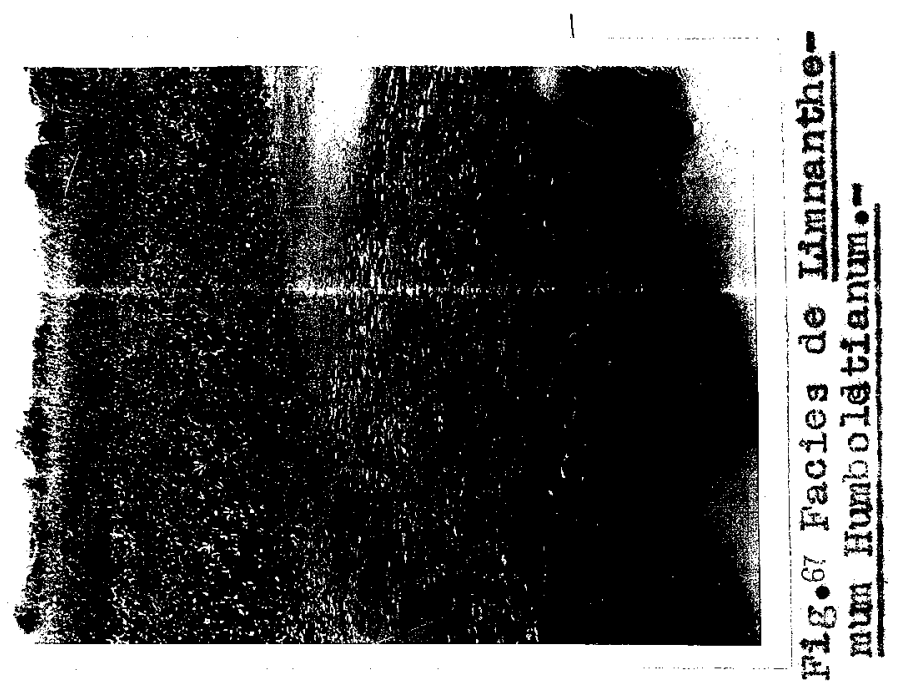

4
5
5
5
5
5
5

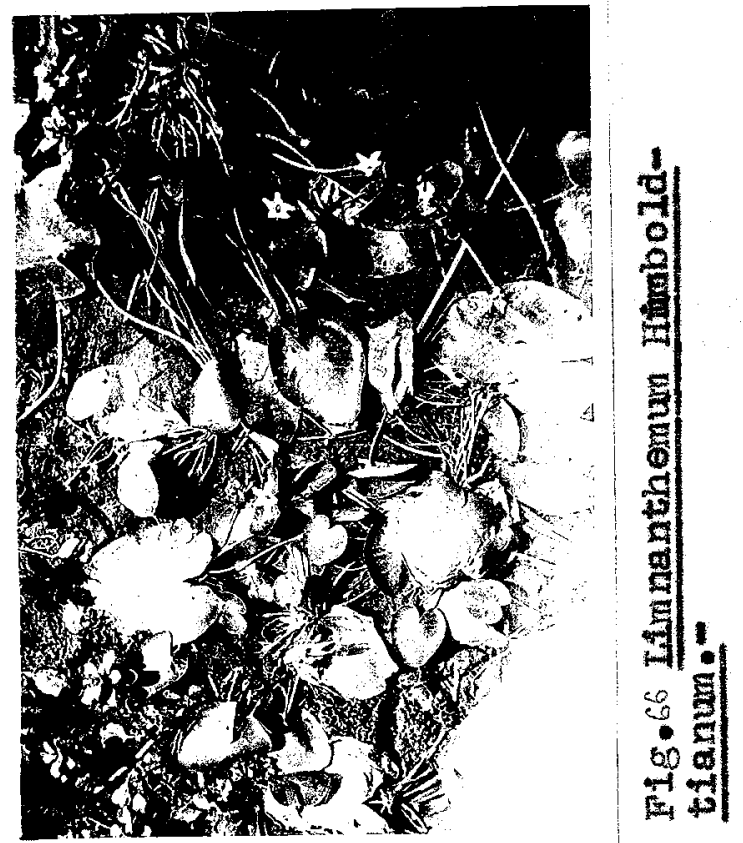



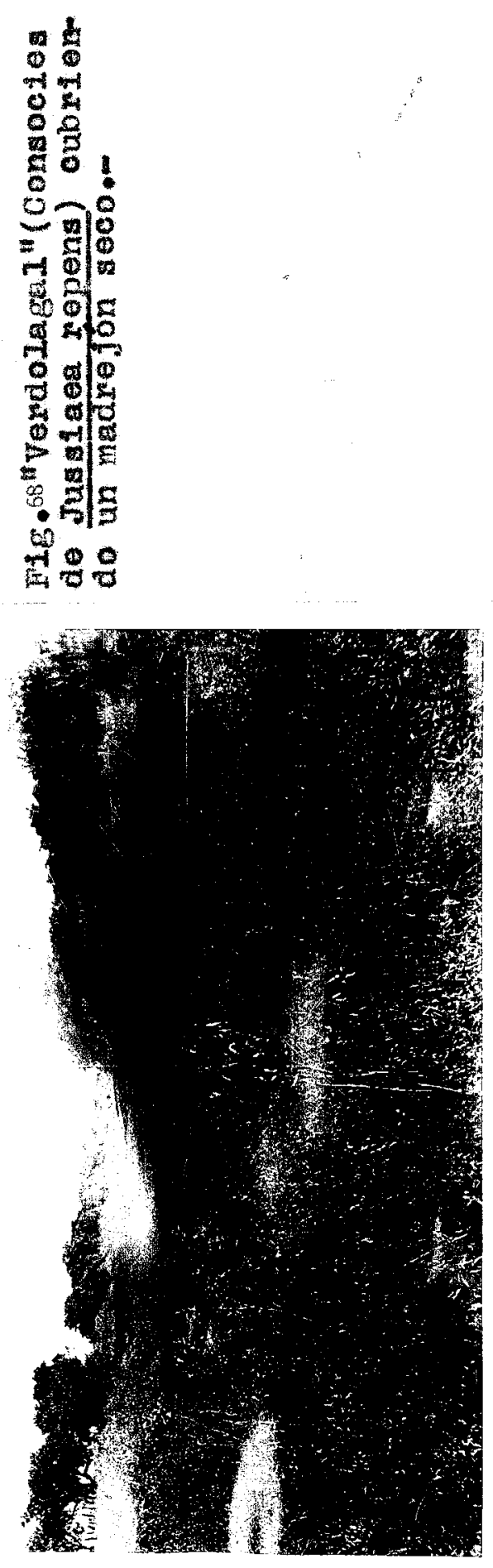

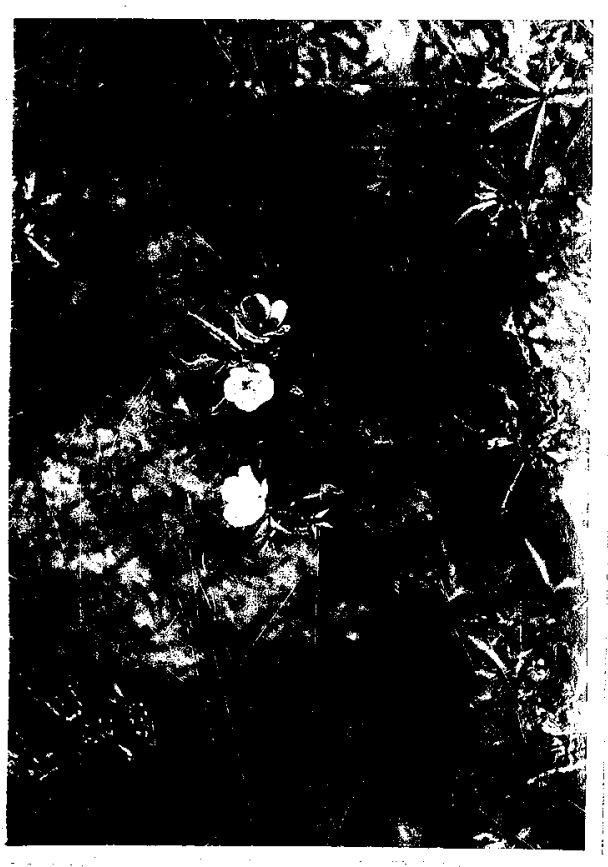

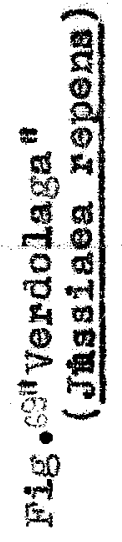




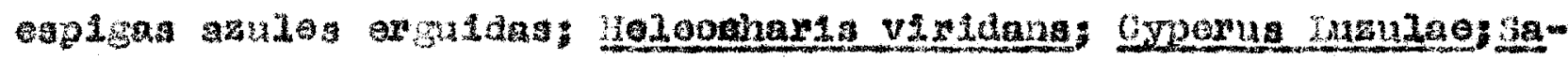
1ttar $1 \mathrm{a}$ montovidansta. oto

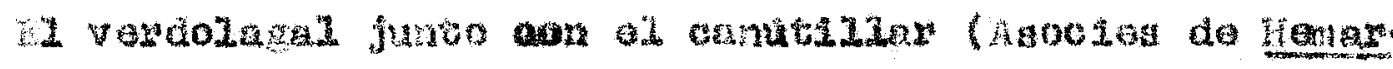

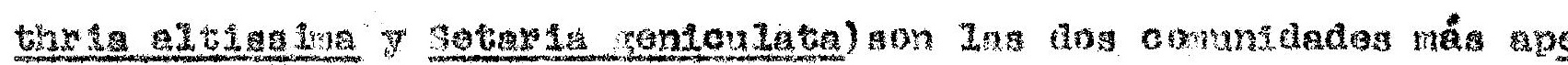

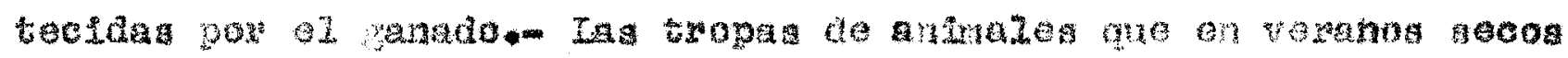

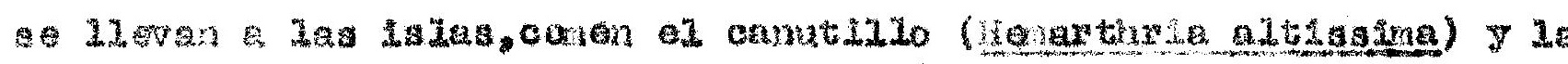

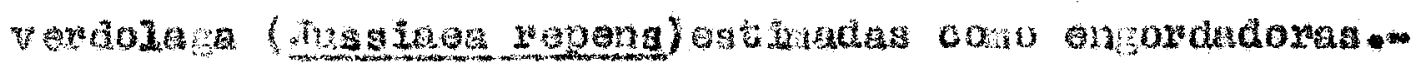

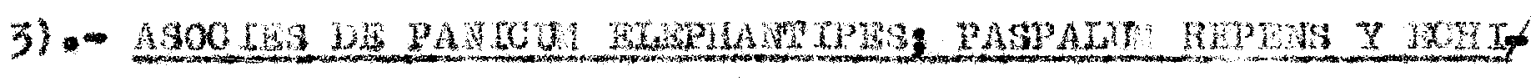

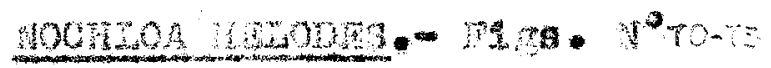

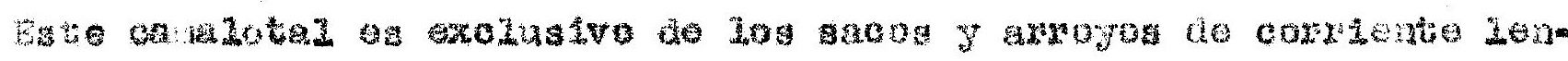

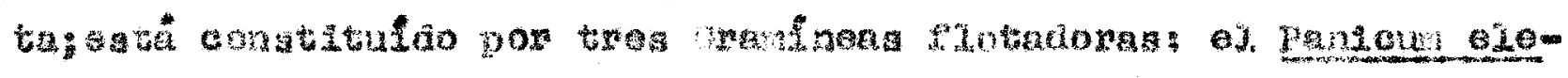

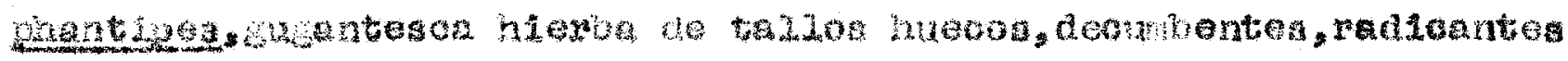

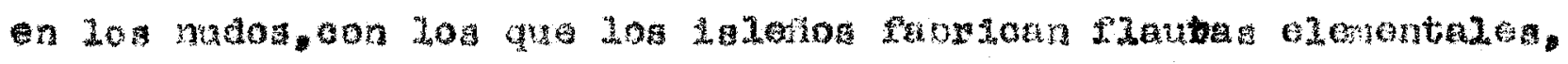

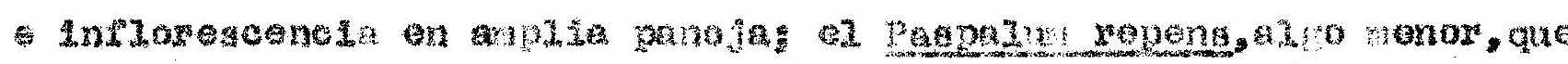

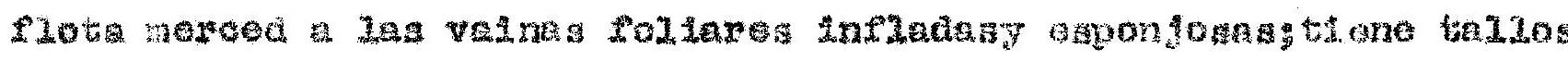

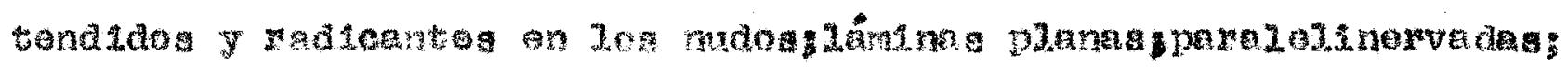

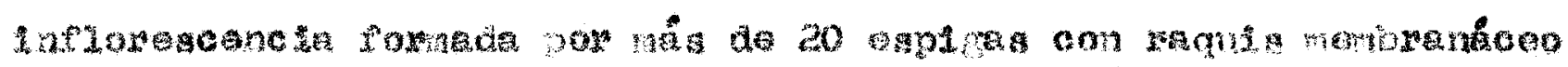

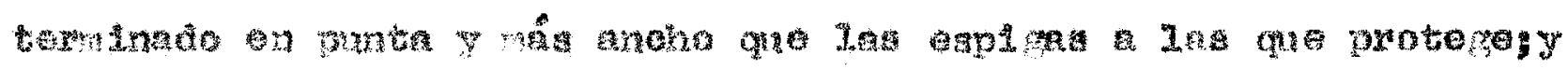

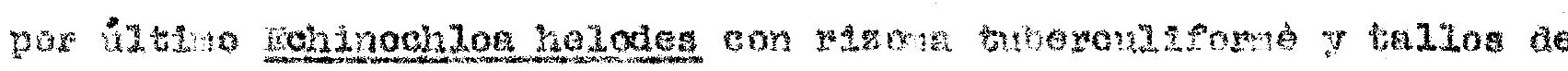

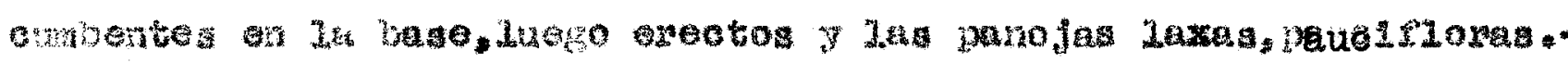

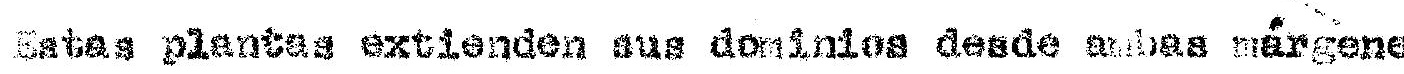

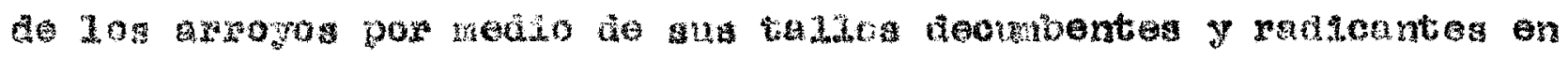

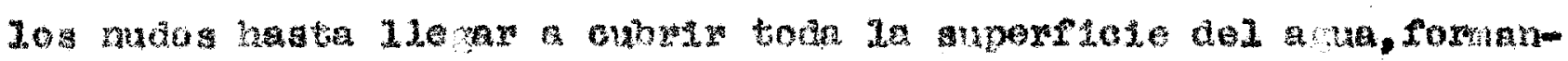

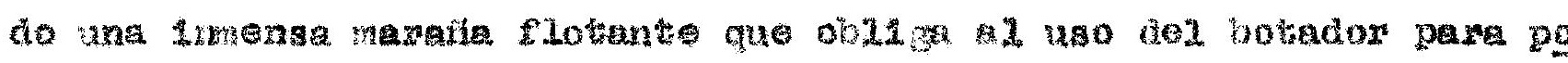

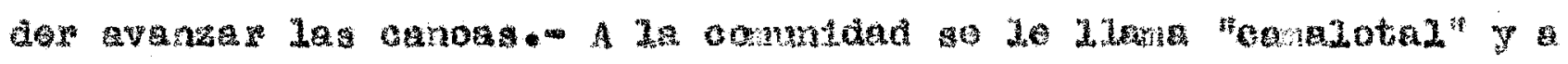

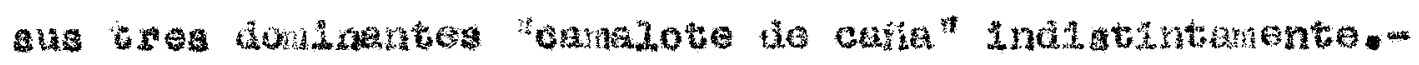

Wa

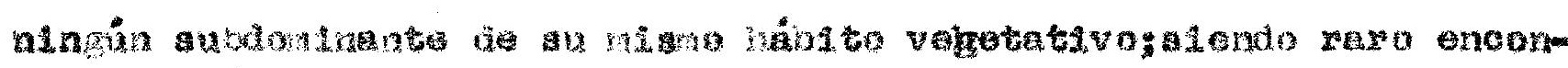

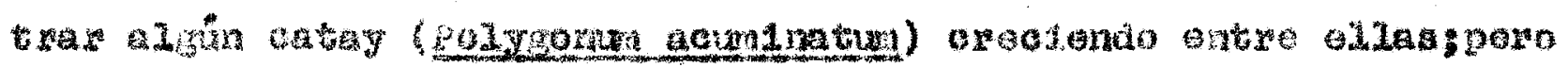

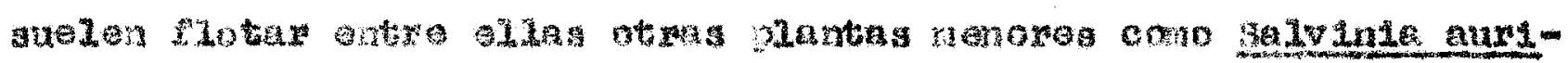

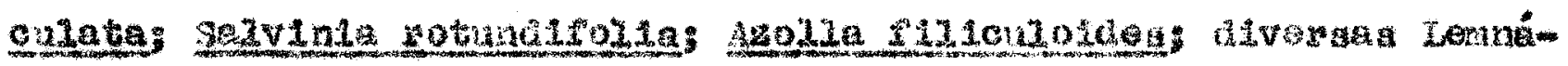

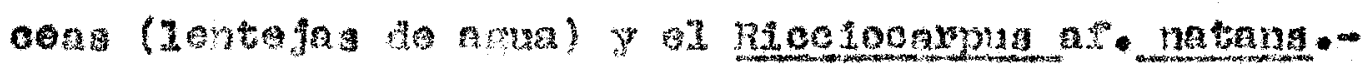




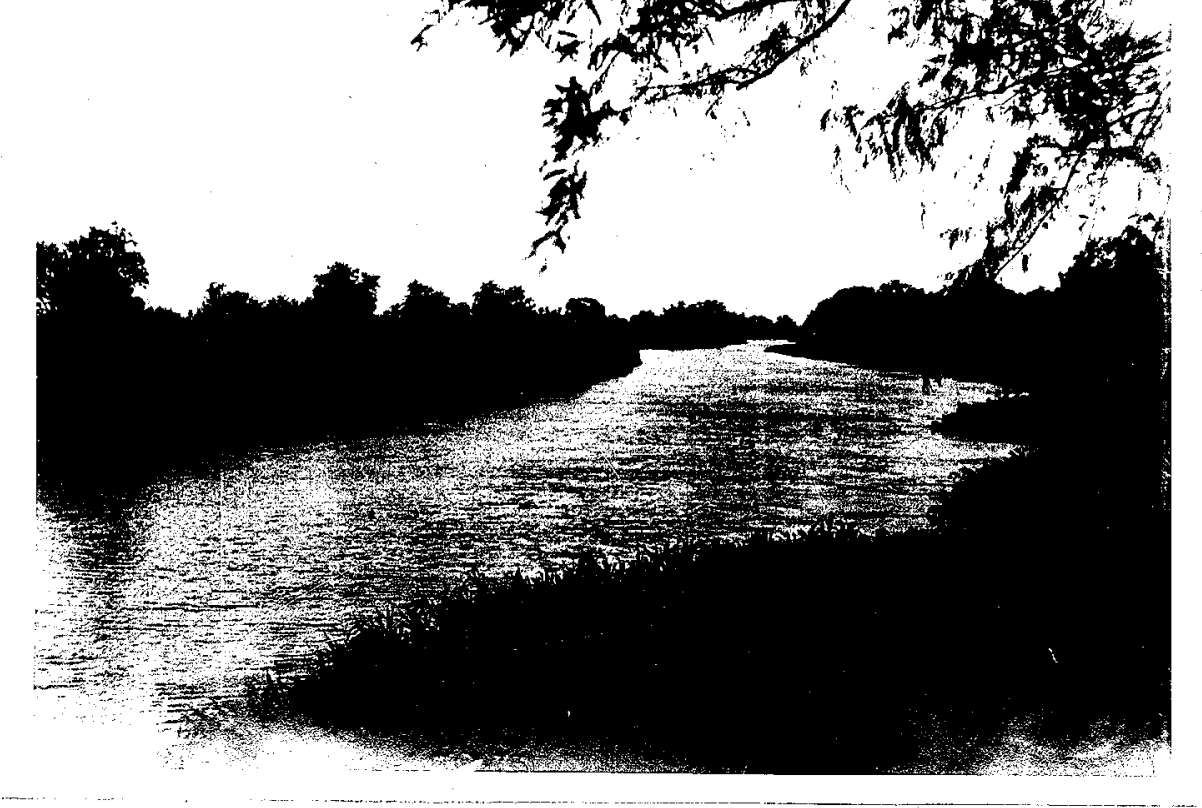

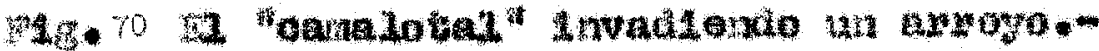

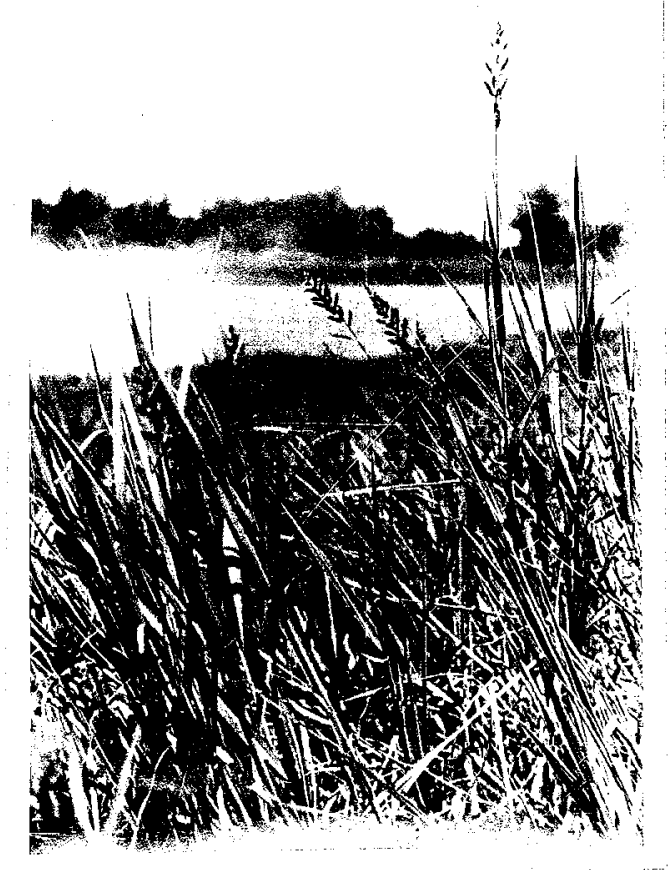

1. hazodeso=

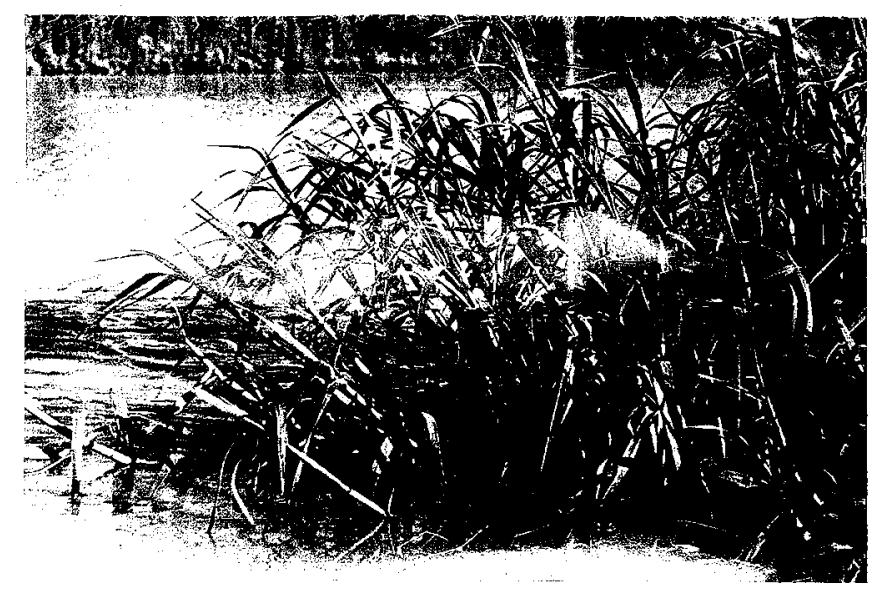

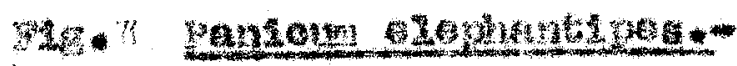

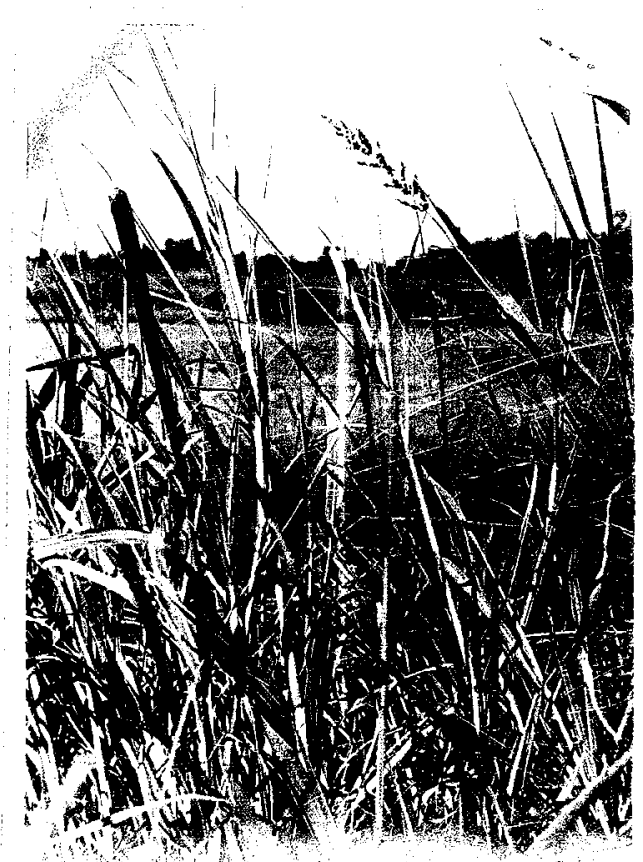

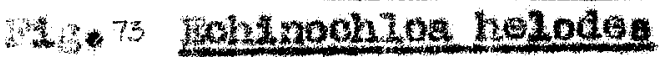




$$
\text { Hig. Nor }
$$

Perfil del Madrejón de "Funes"

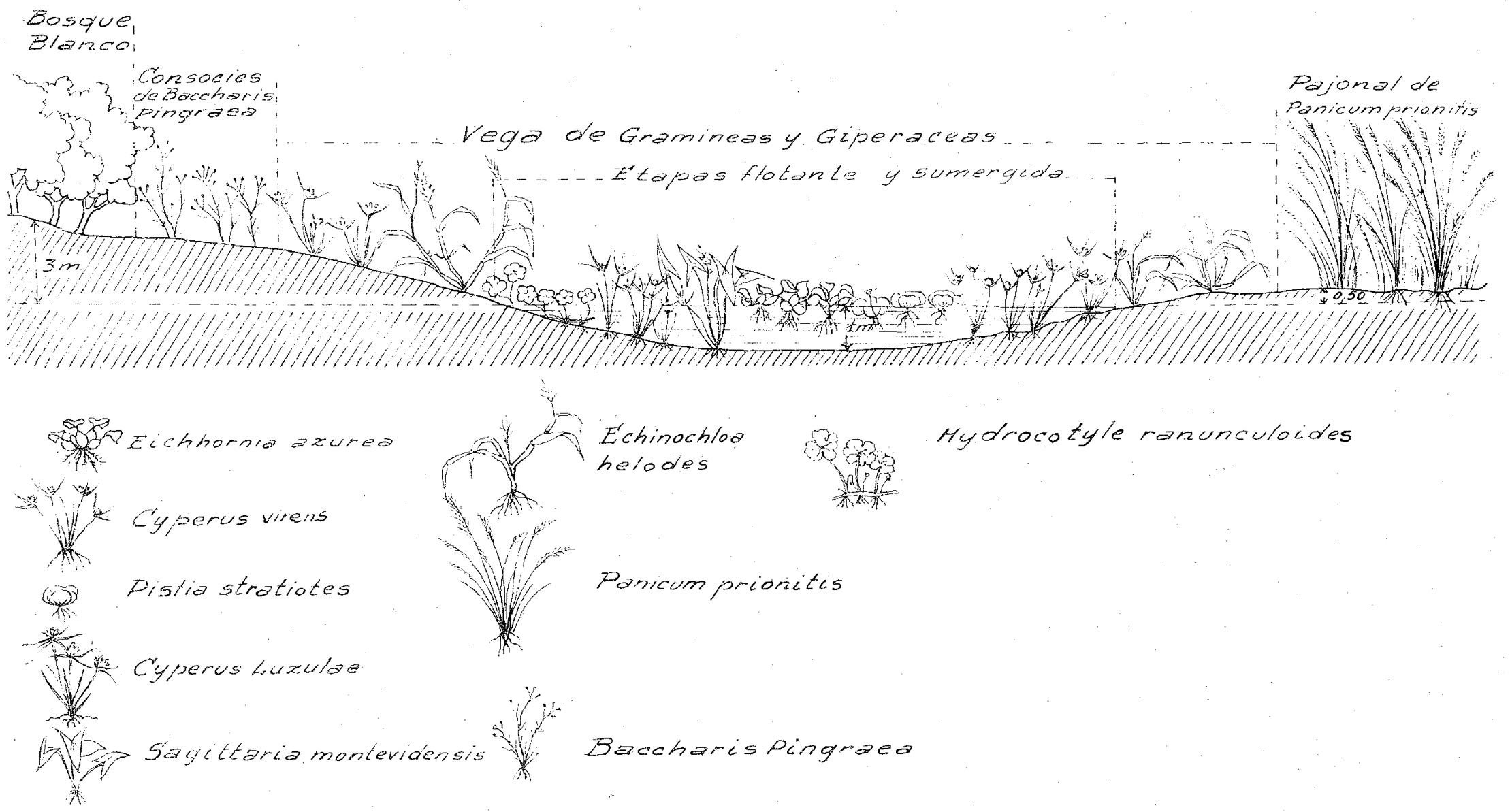




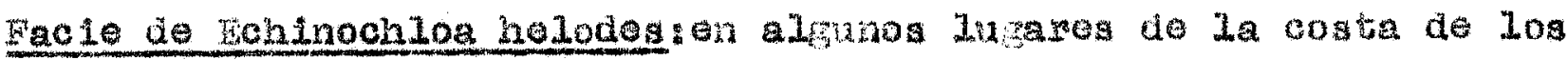
arpoyos $y$ en determinadas lagunas asume esta Garinea ol antrol absoluto de la comaldad, faltando jas otxa do dminantas - -

c) PLANIAS ANETIAS O MDLOFTIAS.

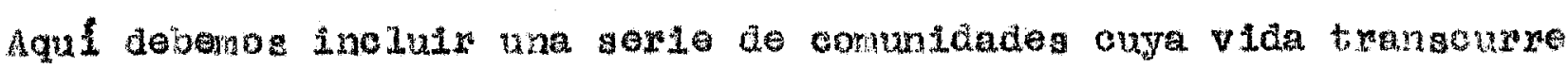
alternabivanonte dontco y ruera del agua.- Tales t1pos do comunda-

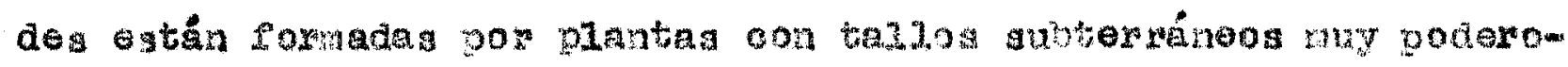
sos, de Ins que nacen váatagon yooa on tejloos de soutón.-

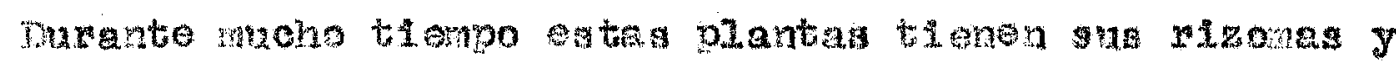
ralces on un suelo gooresaturado do huredad y gran parte del apara-

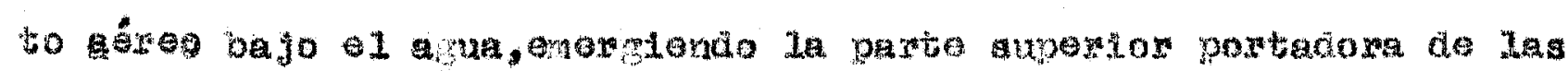

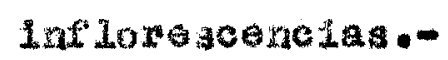

Al tipo biolóstoo "plantas anfiblas" Cabrena J.Mabris, (1948,pas.8) las han dividalo semin ins canotemations de las hoJas on:

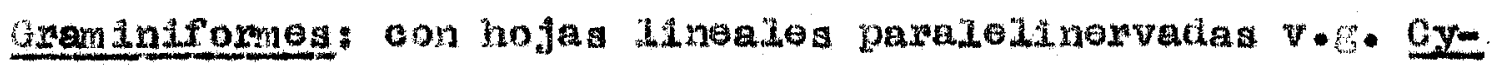

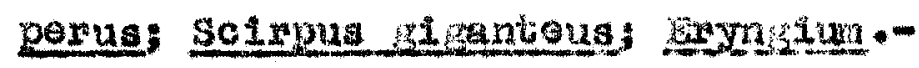

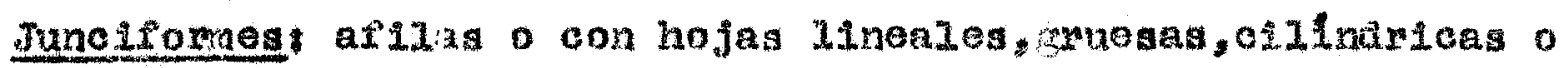

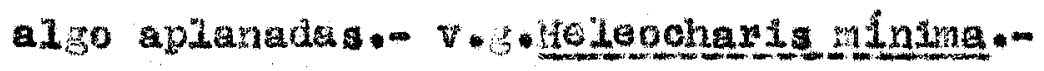

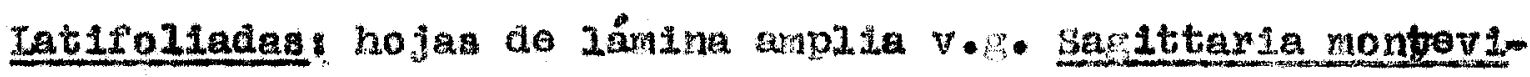

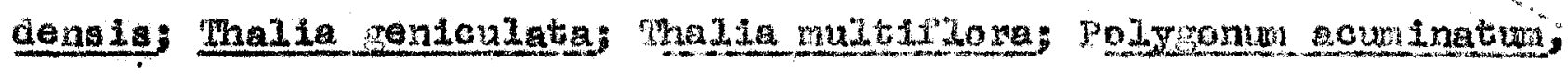
eto.

Deade el punto de vitu suoentonal las helofitag letifom Liada repreantan la etapa de tranafición entre las plantas fyotento y 1 a veretación de $20 s$ pajonalo o pradenes hajas.-

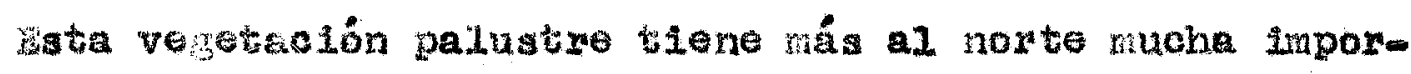

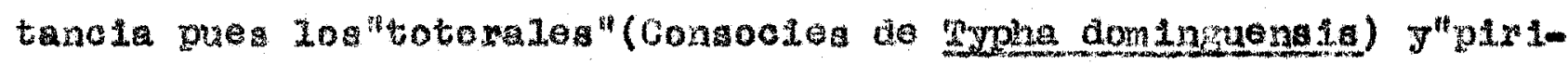
2219:" (colon

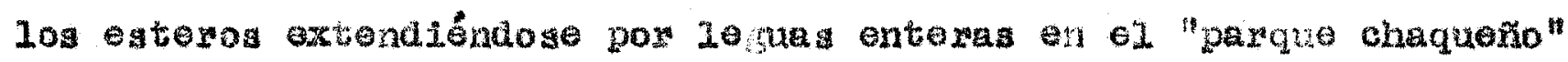

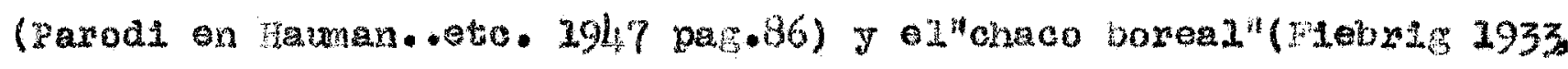
$\operatorname{pat} \cdot 7) \cdot$

Ta 21 note 20 cmponentes princtpalos de ata vegeta- 


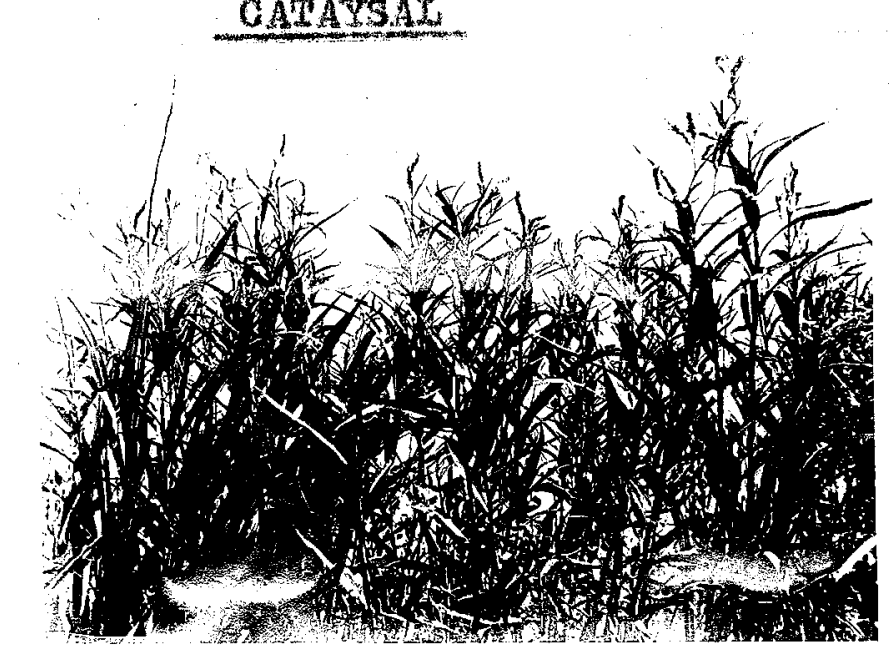

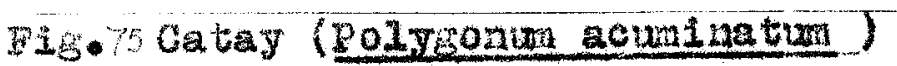

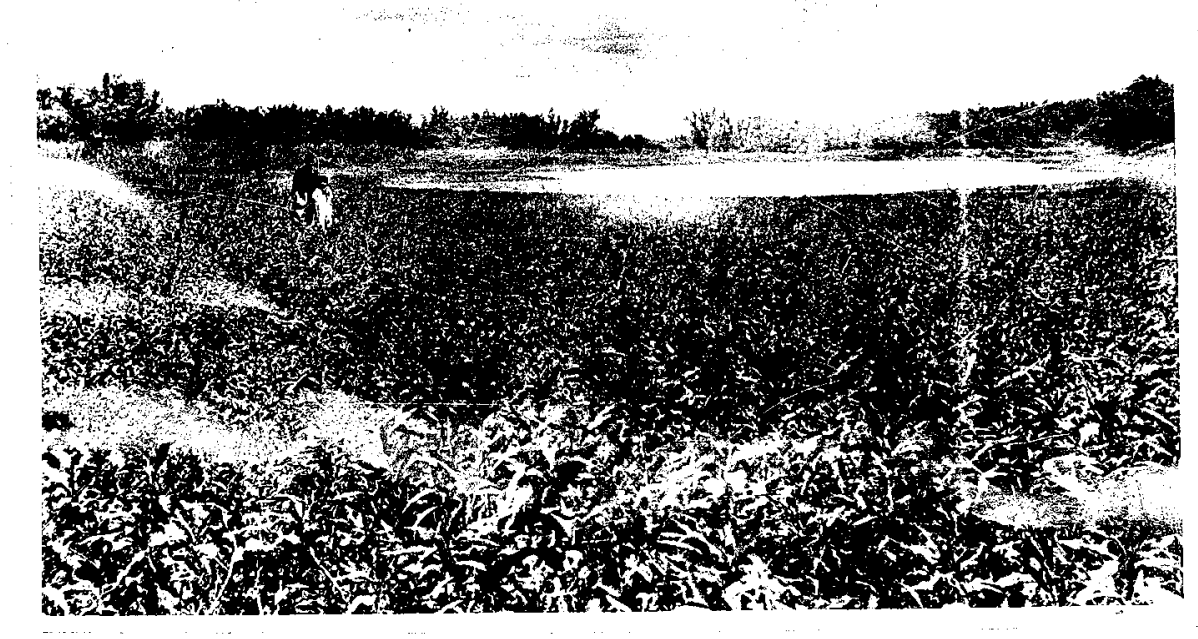

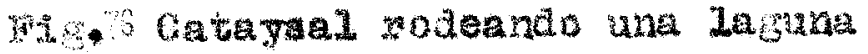

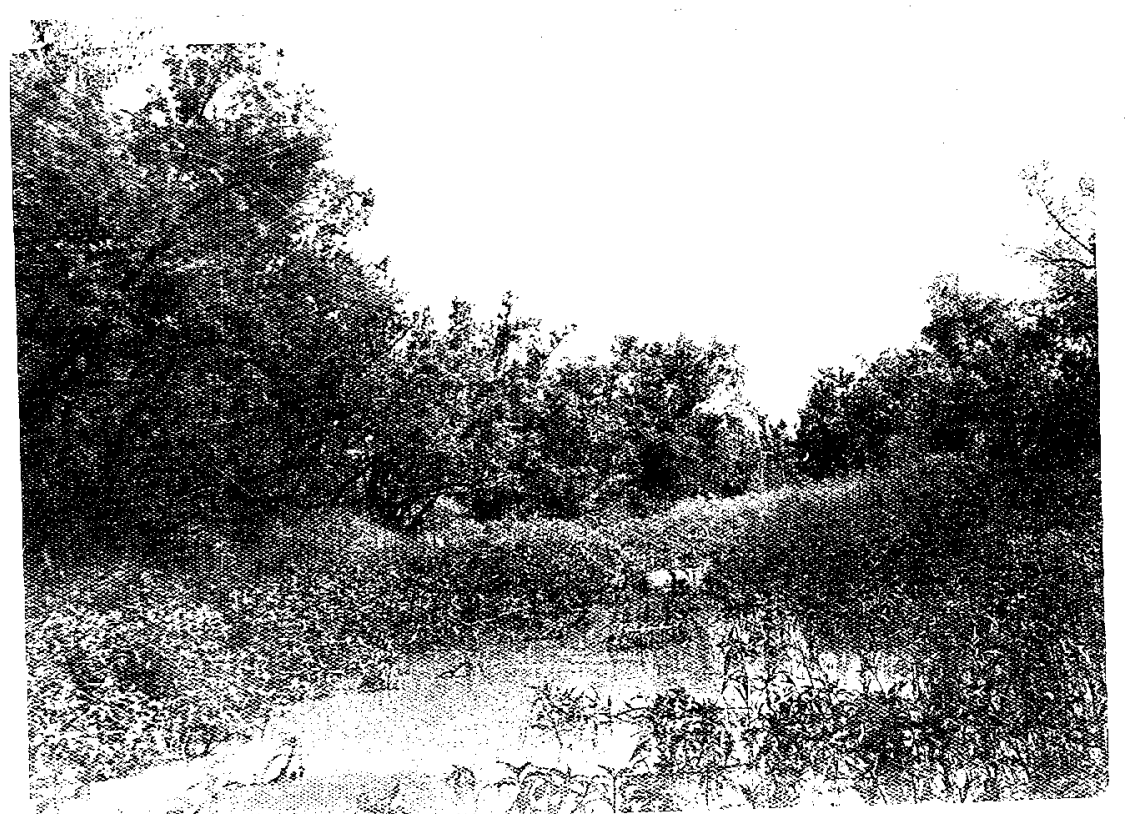




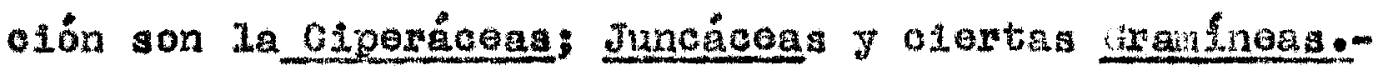

$$
\text { 4) GARAYSAL (Congoetes de Dolugonum acuninatum) }
$$

Rodeando las comunidades flotantes de las lagunas de playe arenosa, on un faja que guede alcanar 200 netros de ancho, se encuentran colonlas puras de esta hierba pereme, de tallos ascendente y hojas cortanente pecioladas, oval-lanceoladas,portadoras de un principlo acre que las hace no palatajes y dol que provione au nombe vulgar Gaá: Jerba; pay: picanto,agrio.-

ocupan taiblé las xiberas do los arroyoa de max aren aro-

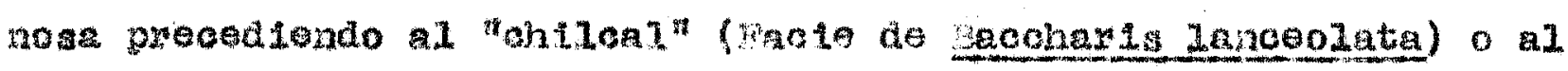

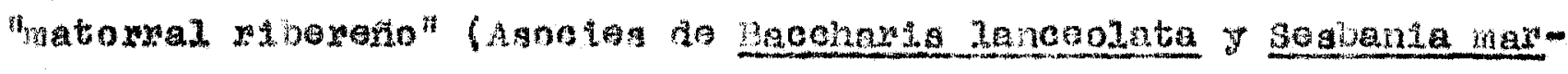
ginata)

Acmparian as. polyonnum goum tnatum las simulentes espe-

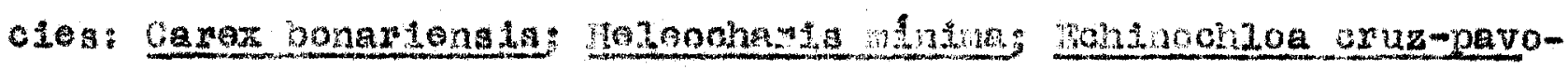

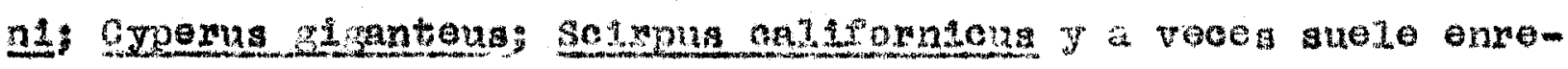

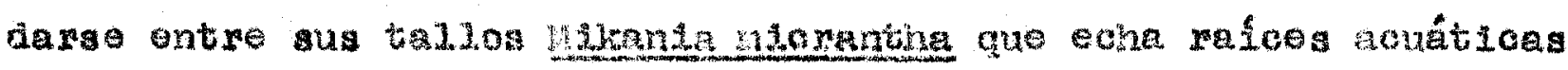
Y vive sobre log catay.-

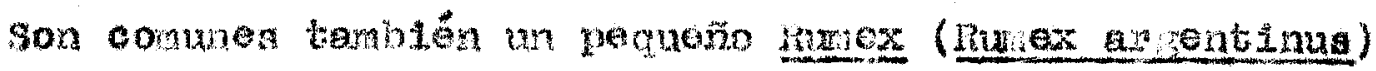

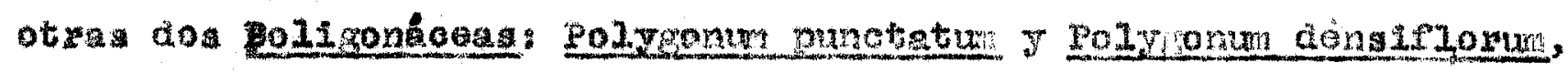

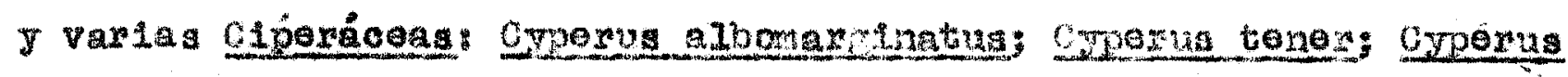

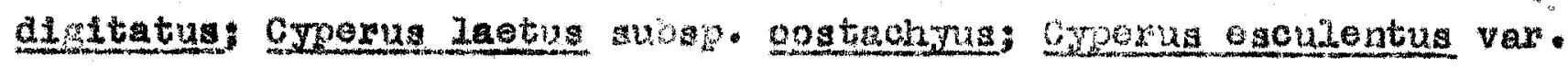
Leptostachyus: selrpus oubong is, ote.-

Durante la wayor parte del año esto comuntad astá cubienta por unos 30 a $20 \mathrm{~cm}$. de agua 7 en fpocas de bajante invade hasta el fondo de los radrejones secos..-

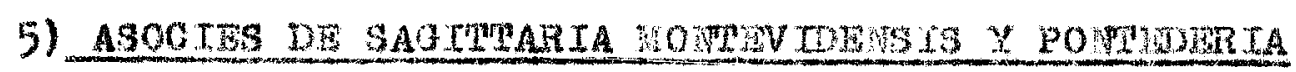
OORDATA. -

W I fondo de madrejones y lamunas chando tionen menos de $30 \mathrm{~cm}$. de agua se vo invadido por esta comunidad constituida por la "pata de 10ro" o "sqeta" (Sarttaria nontevidensia), haver peremo, nobusta, Nzomatosa de hasta un retro de altura con holas largamente pecioladas y sagtadas; riorea blanoas, crandes, dispuestas on verticlios 


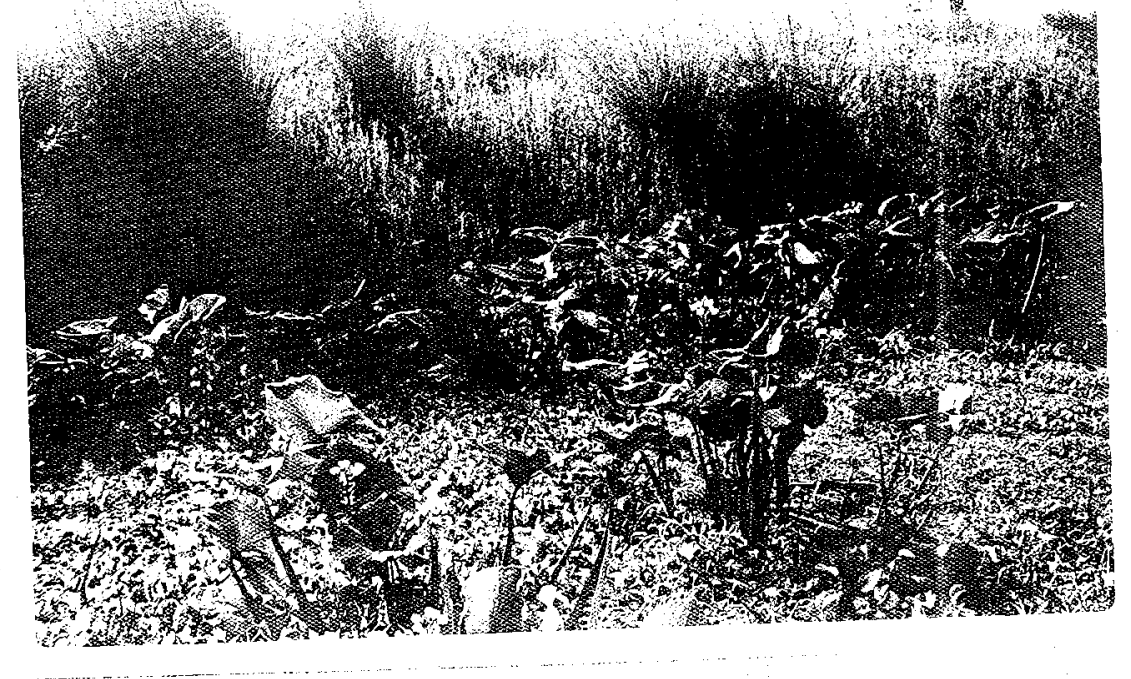

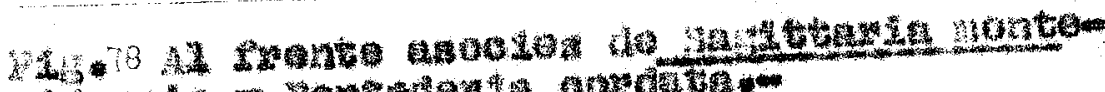

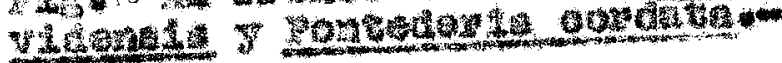

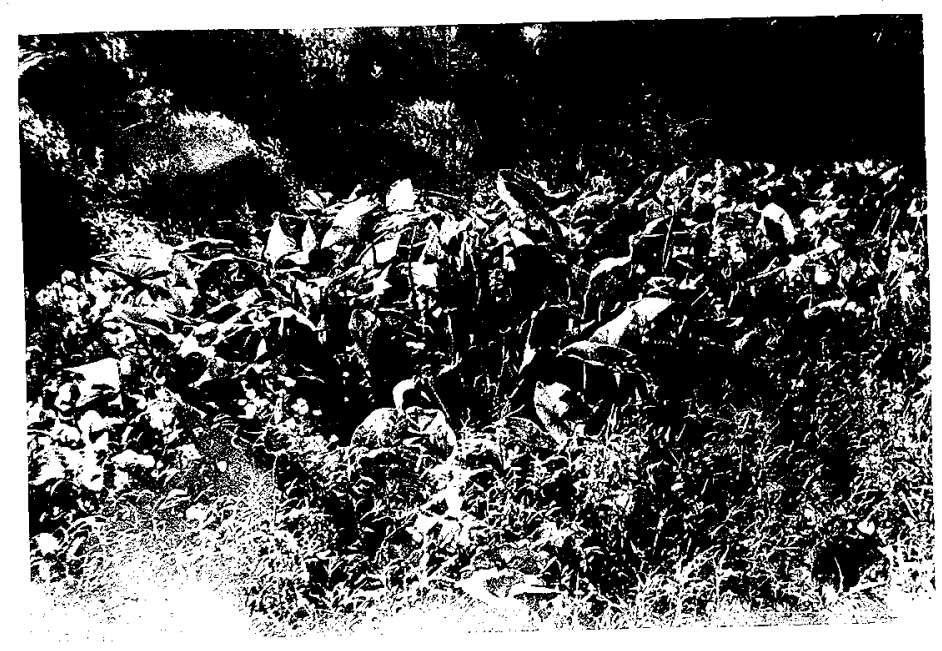

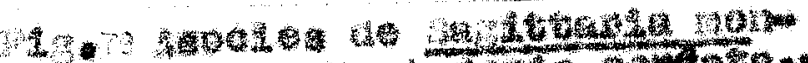
*

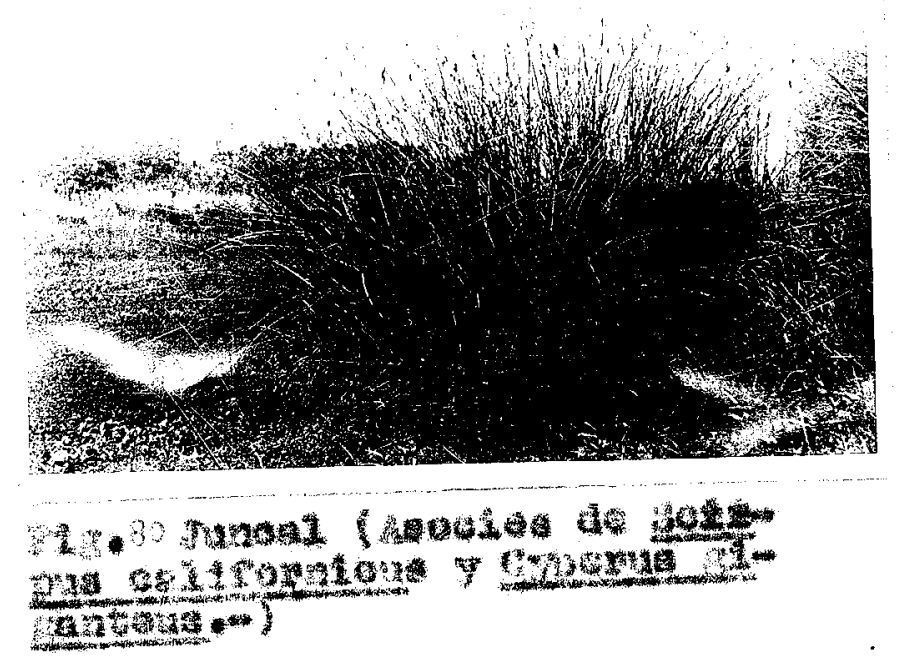




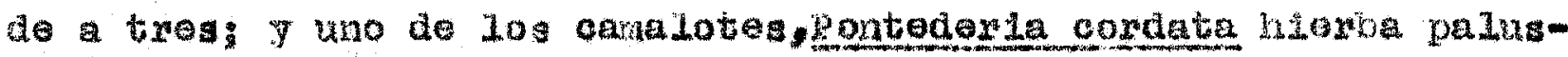

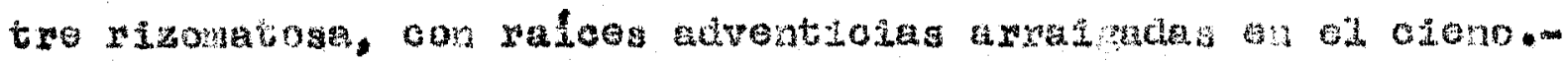

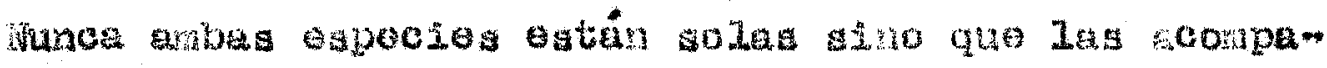

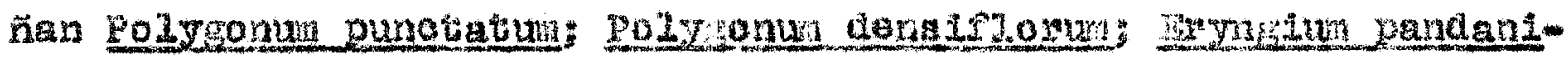

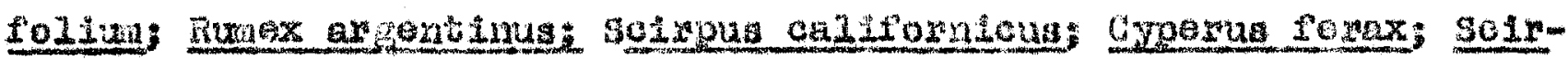

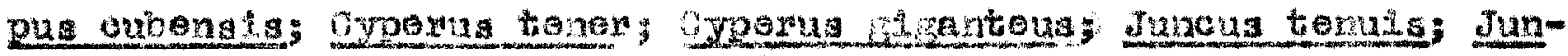

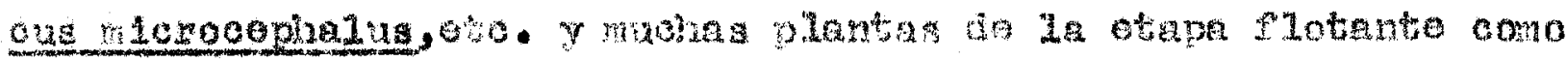

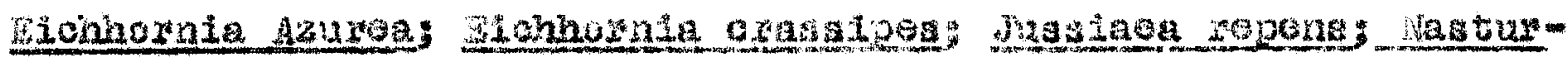

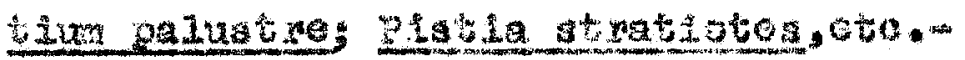

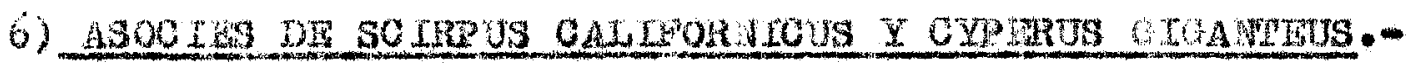
Fina

Estr comundad es la aquivalents de 10 "platzales" del parque che-

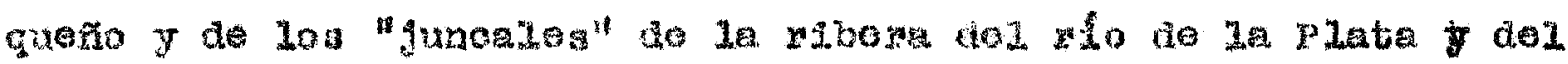

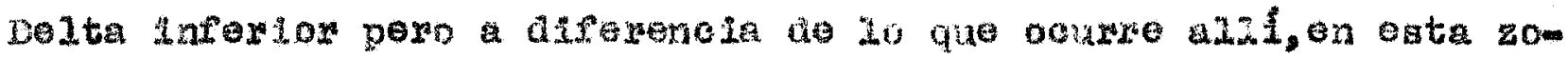

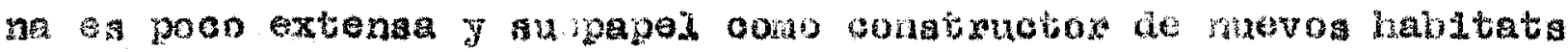

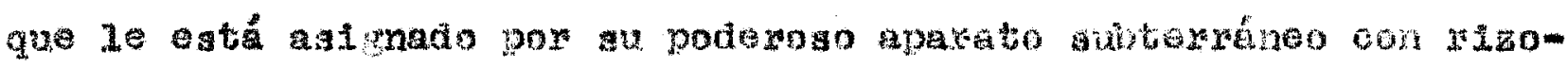

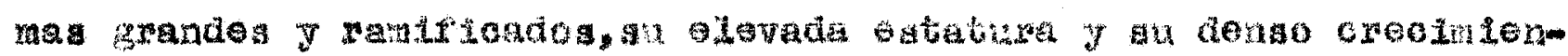
to on metas, aqui se te neutmalzado pon 1a poca superticie que acu$p a+\cdots$

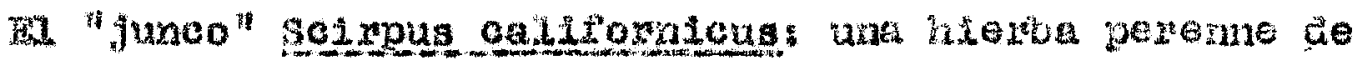

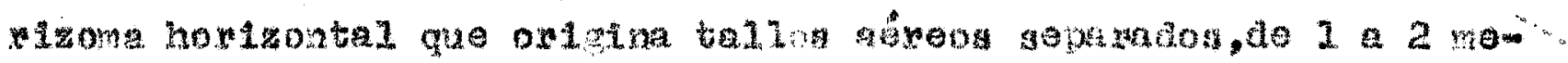

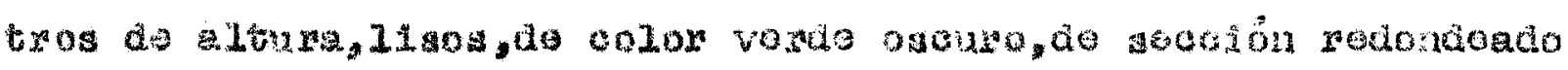

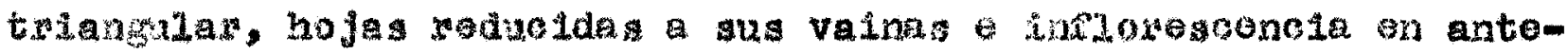
1a compuegta, laxa.-

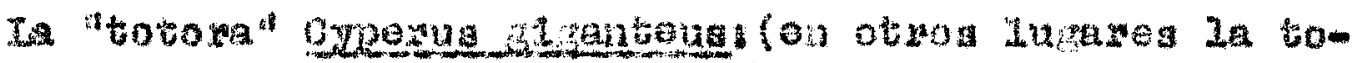

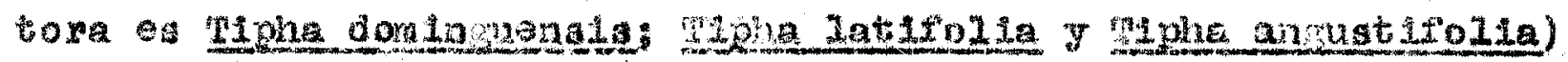

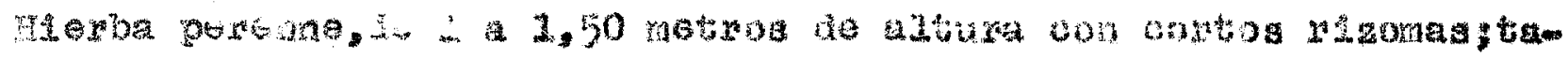

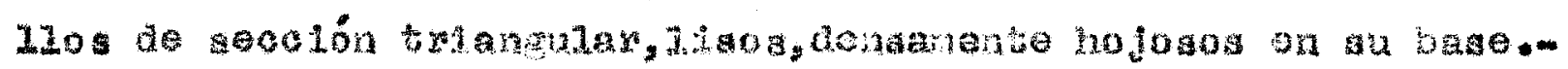

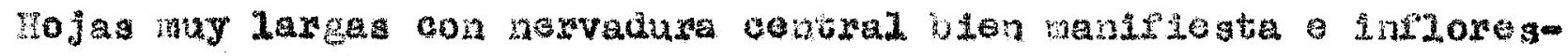
cencla amplia, terminal. gabel tforme...

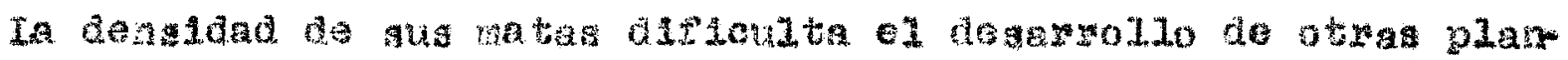

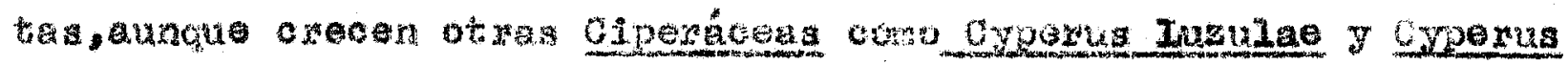

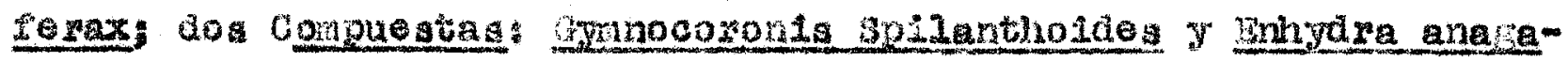


Pepresentacion esquemática de un madrejoin temporariamente seco

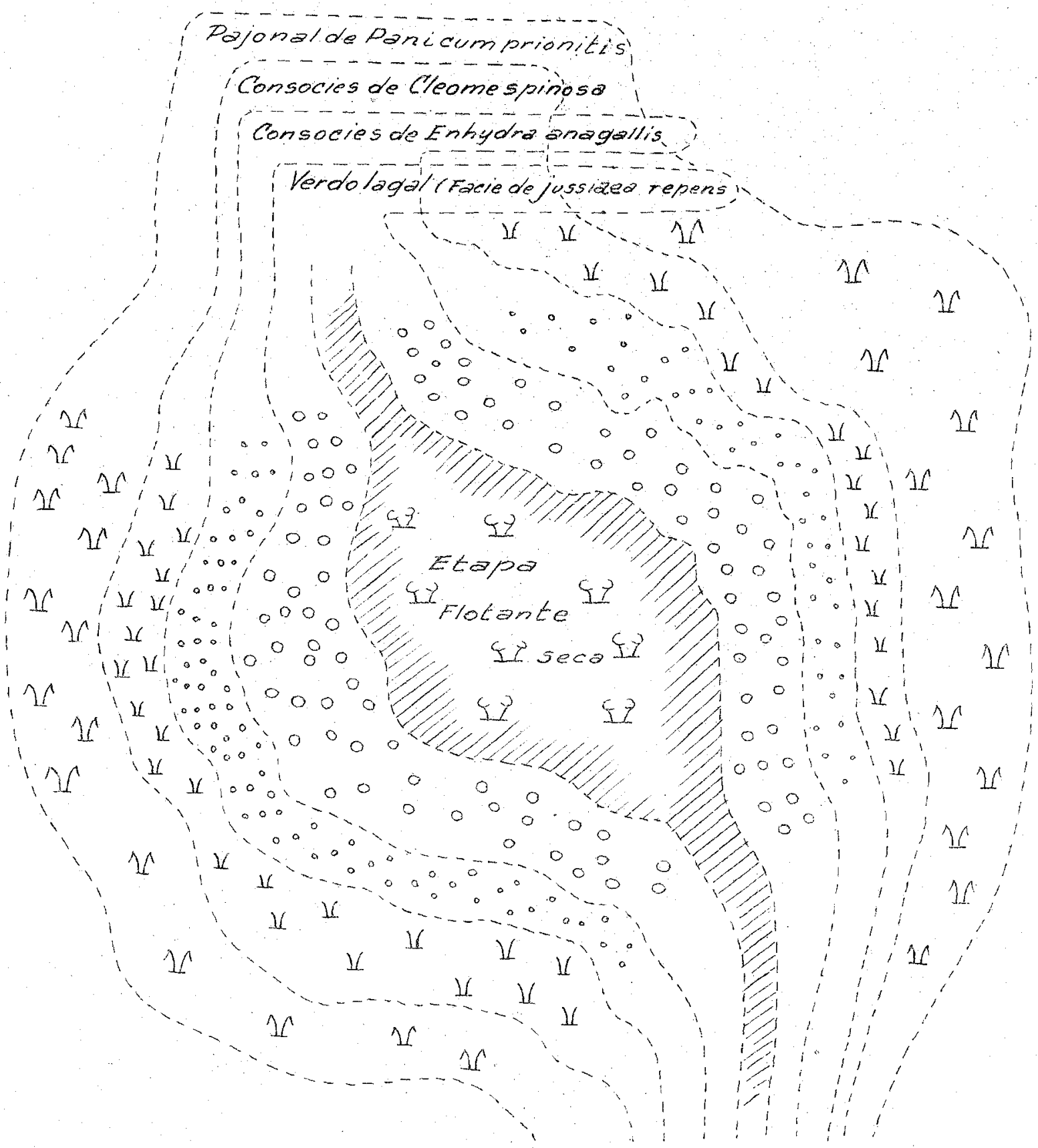




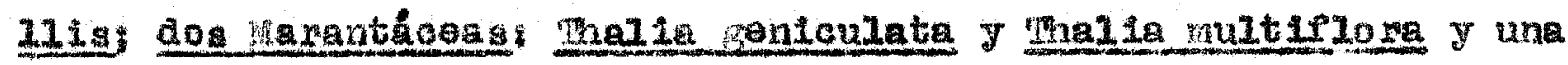
Gannácea: Canna Lauca.-

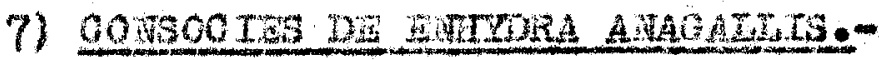

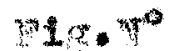

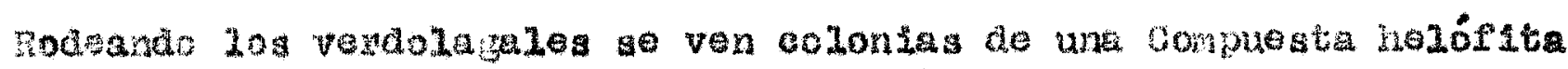
parano con talios grosos carnosos, tenaldos, extriados; hojas om

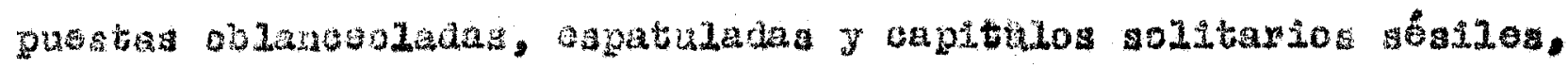

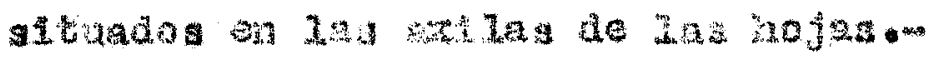

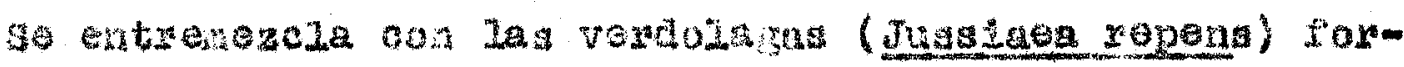

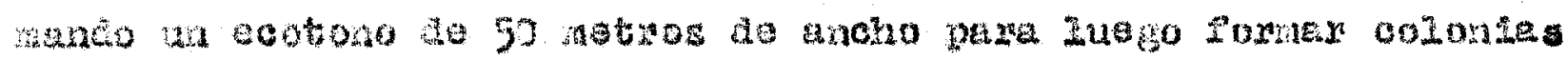

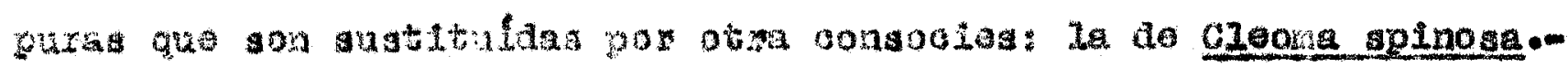

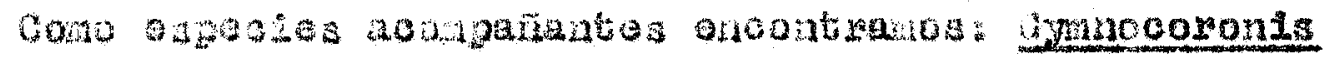

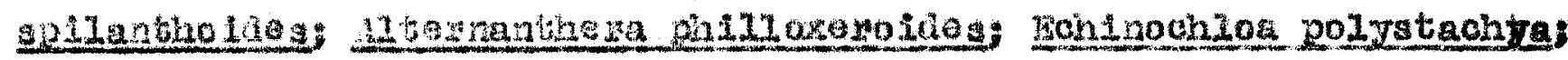

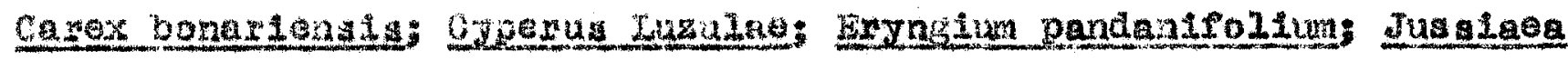

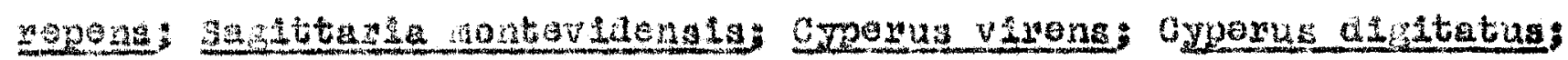

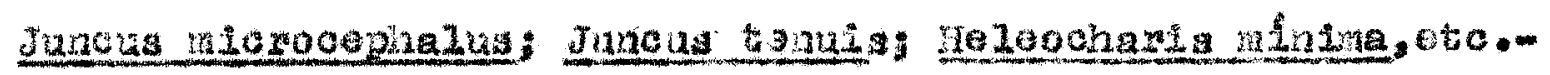

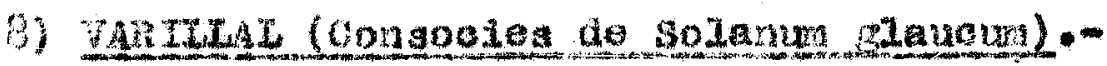
$7+3 \cdot 8-8 ?$

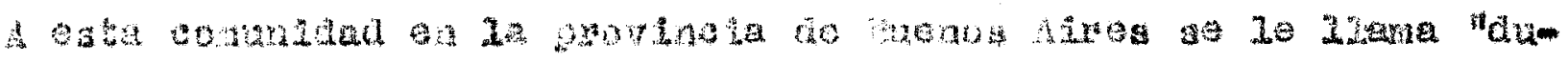

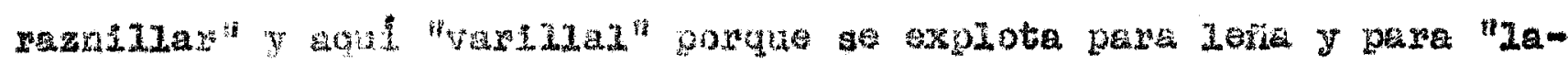

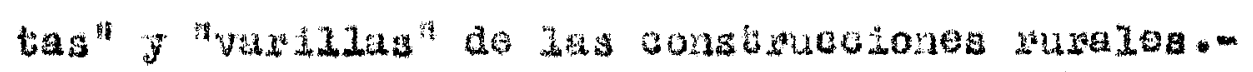

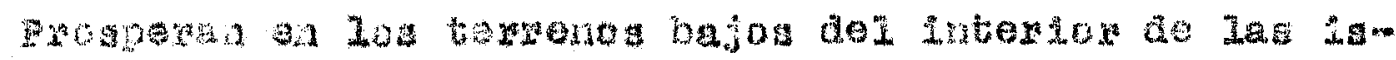

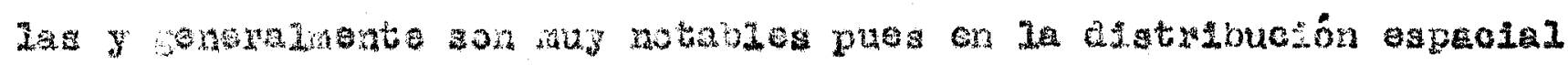

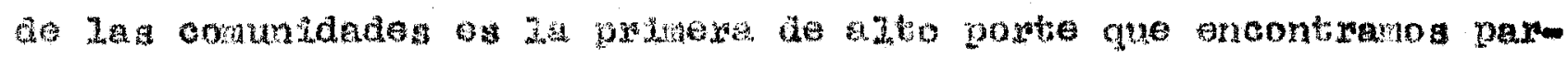

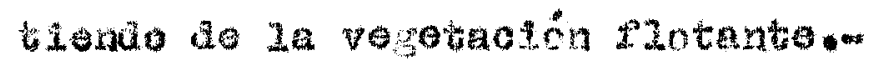

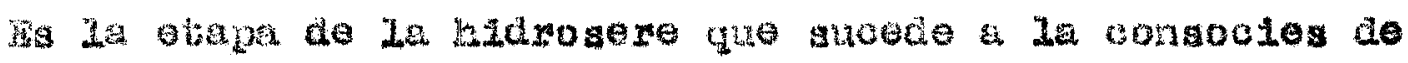

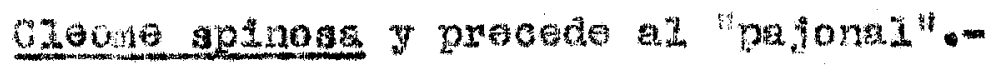

is una comunided de almededox de un metro y rodio do al-

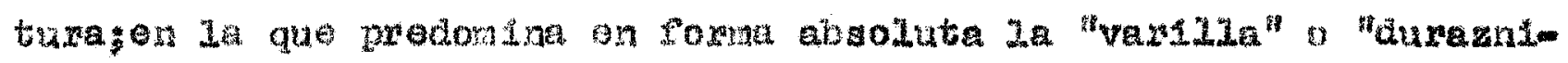

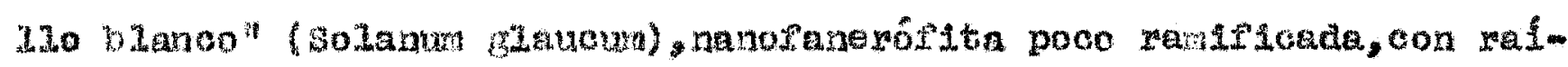

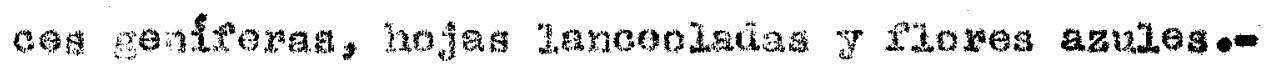

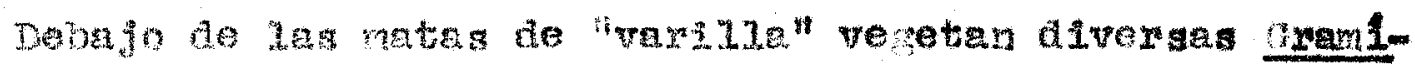

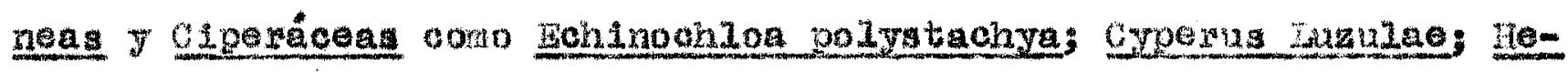



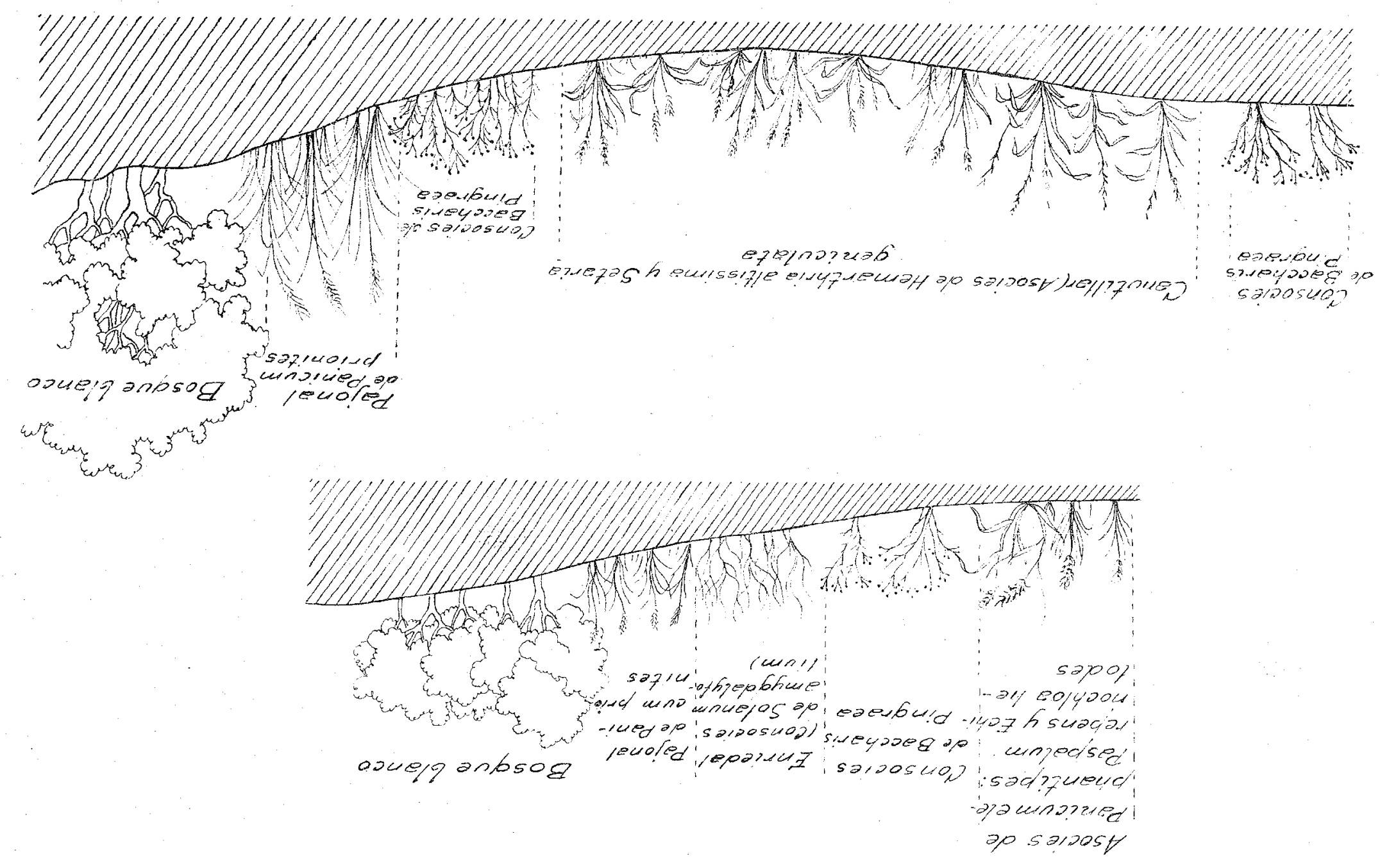

opas upapou un 


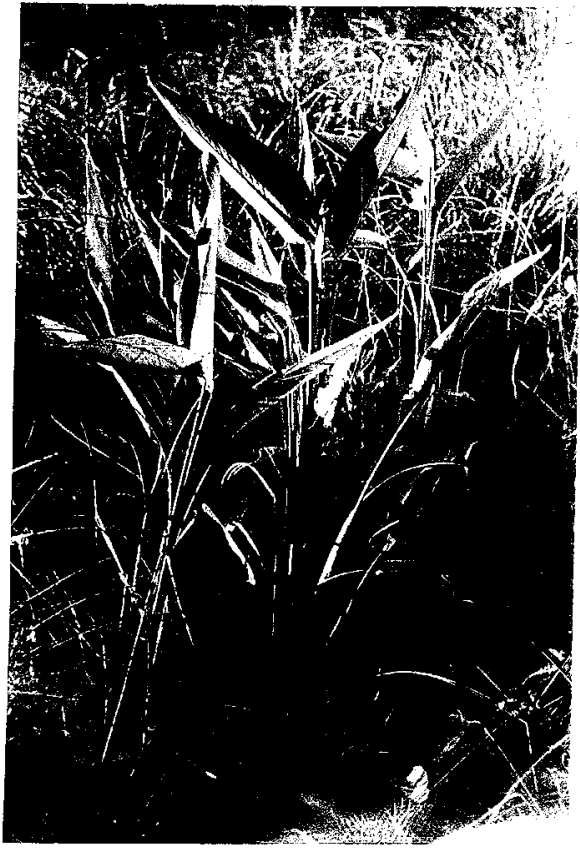

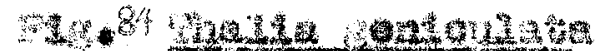
syow

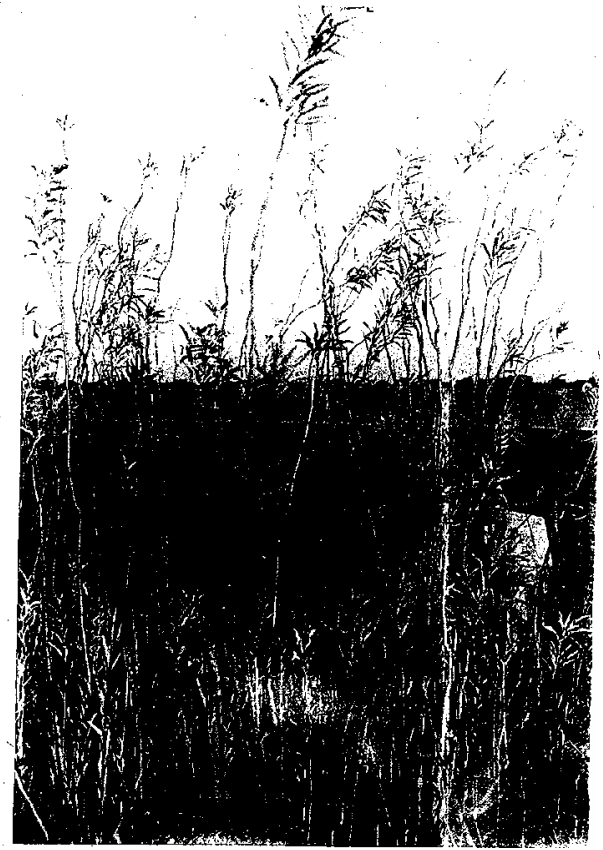

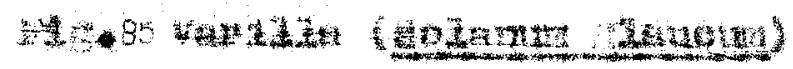

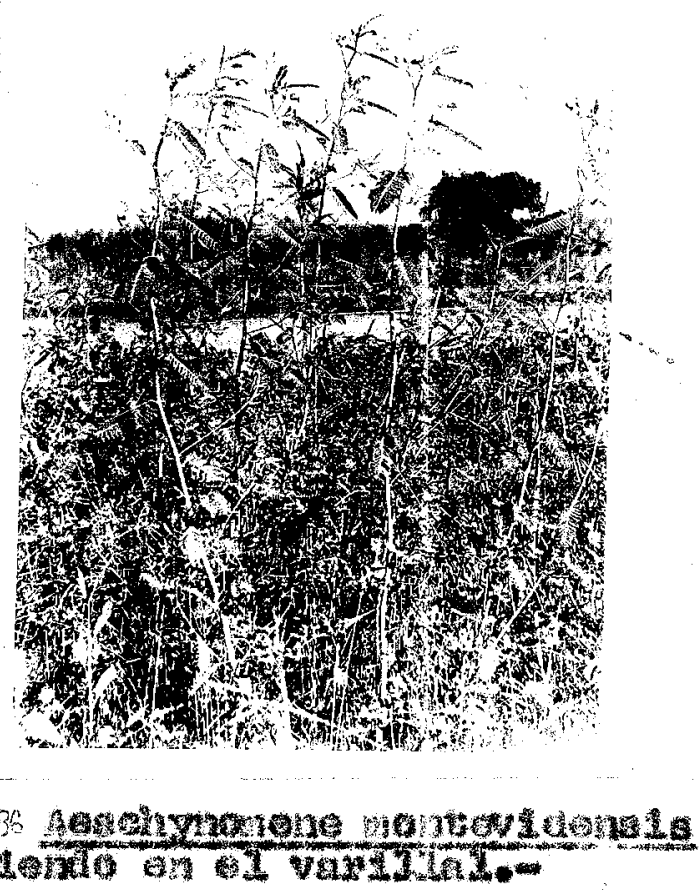

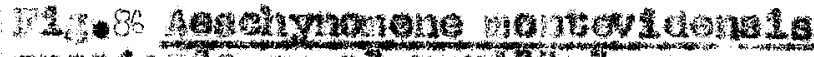
6ot

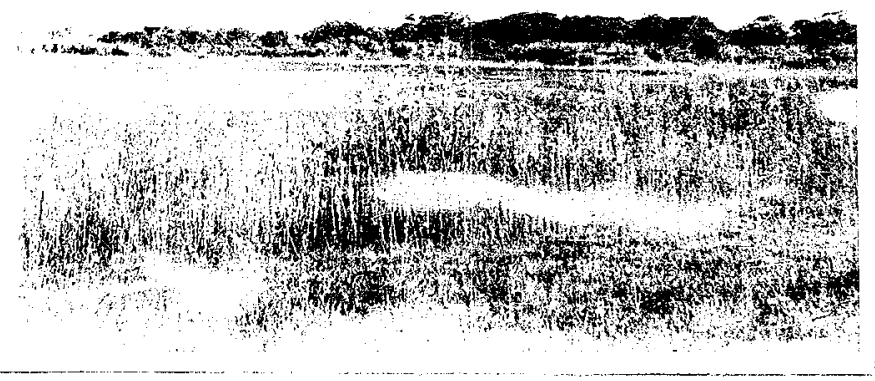




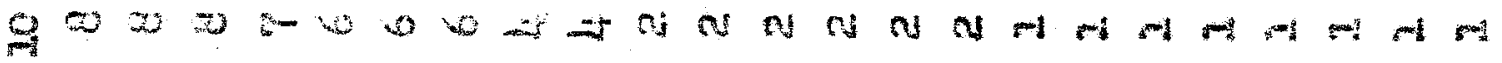


世? 200000-f ap sasep

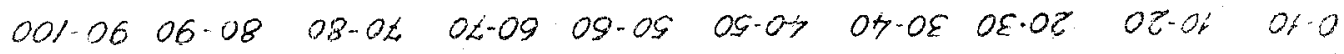

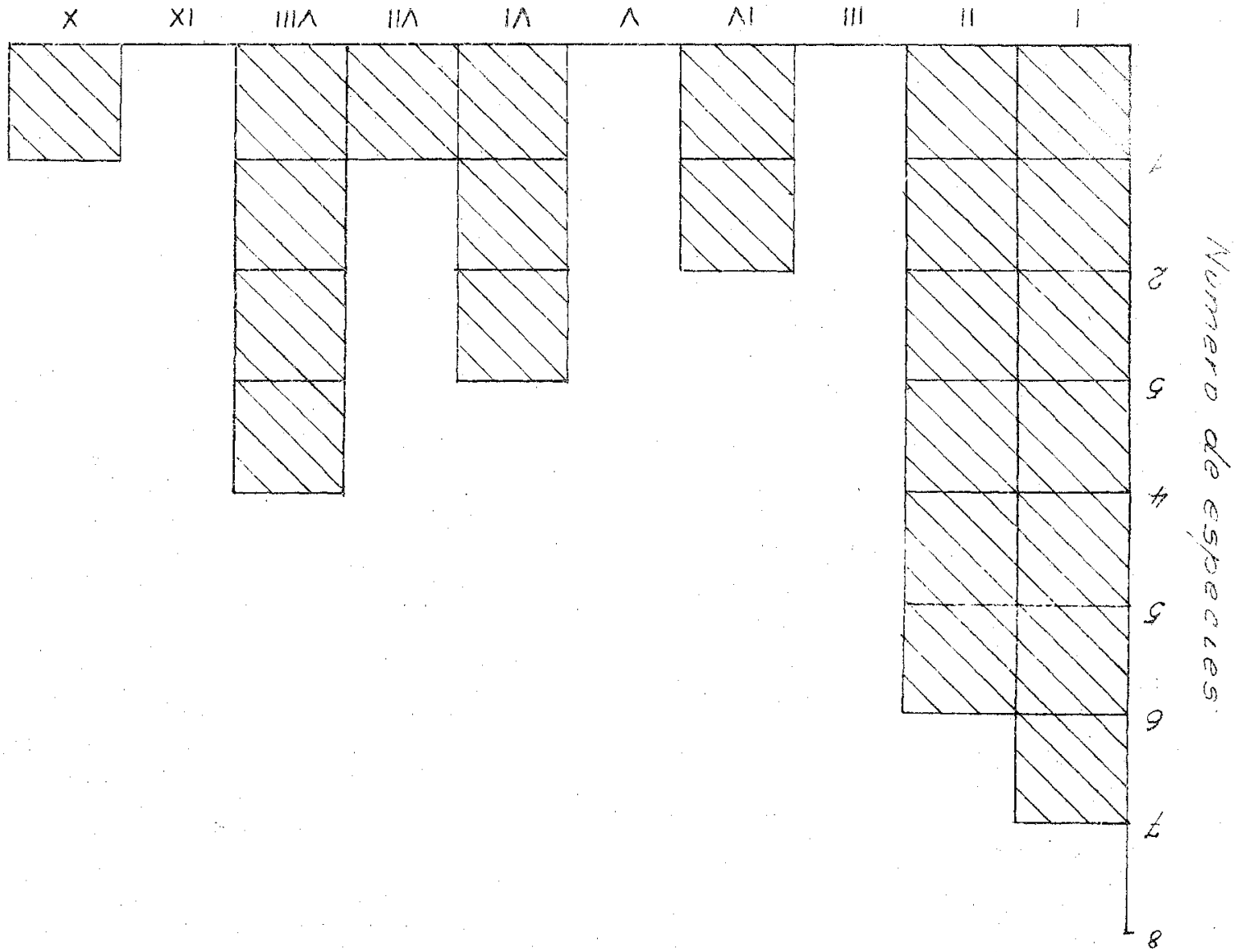

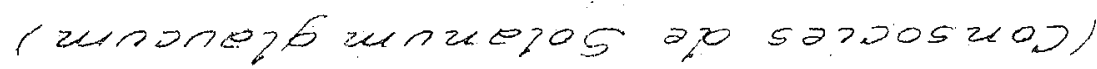

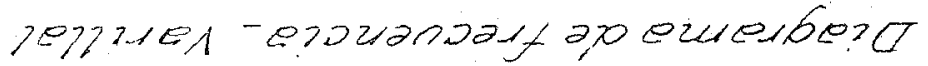

Hö $\mathrm{N}$ ONpon 


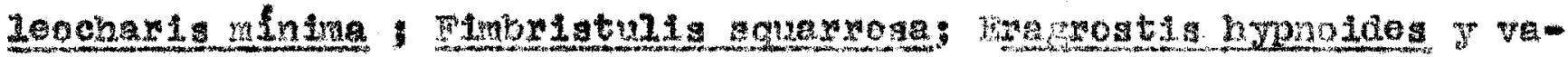

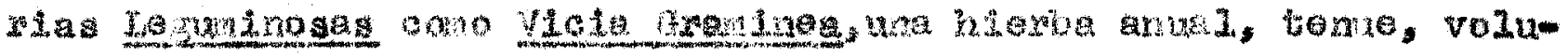

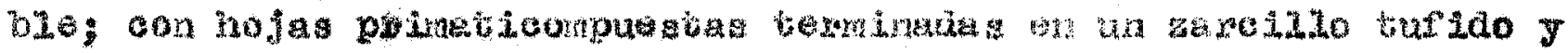

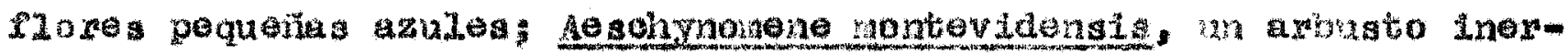

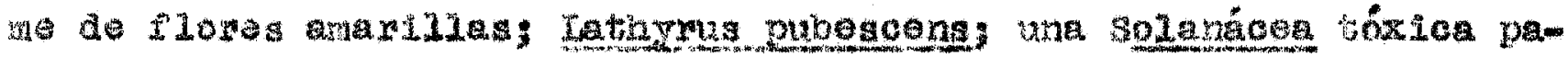

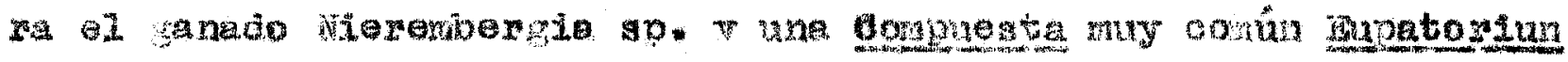
Cagrollearmis:-

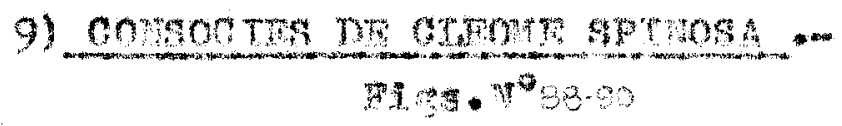

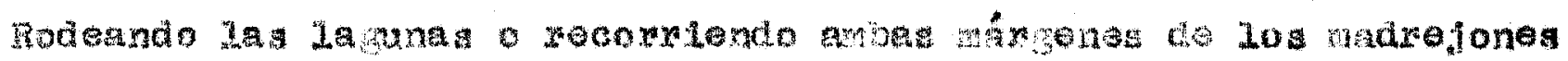

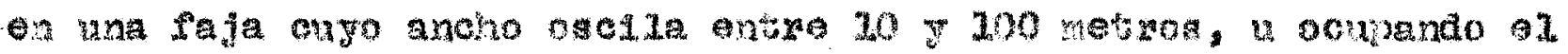

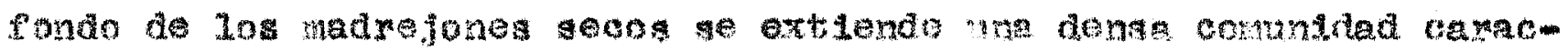

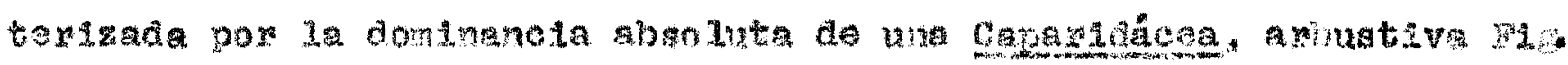

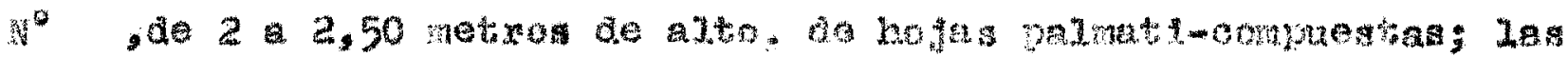

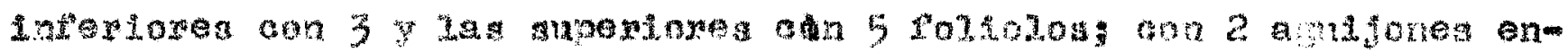

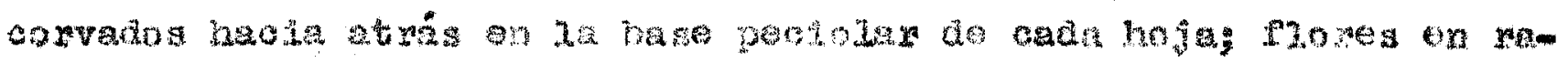

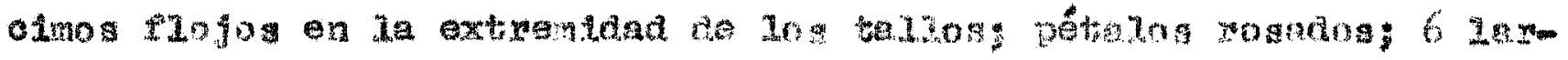

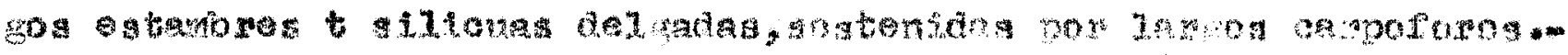

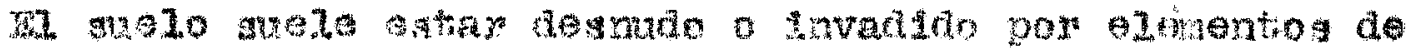

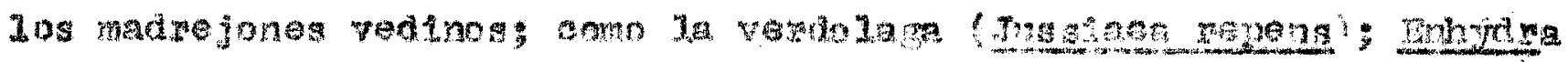

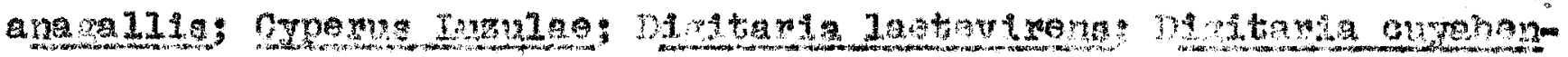

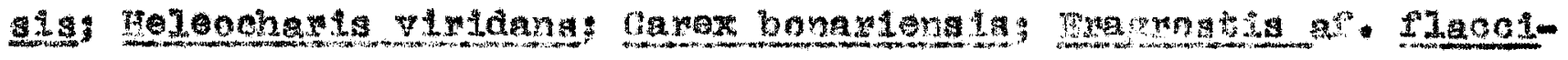
dat,, 0

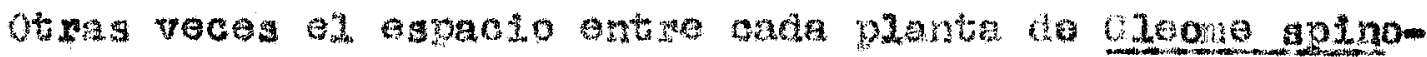

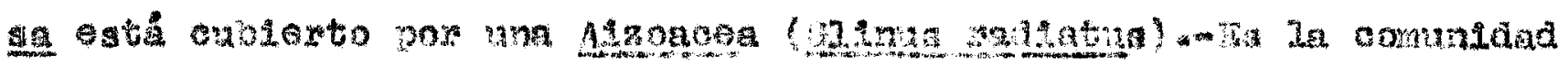

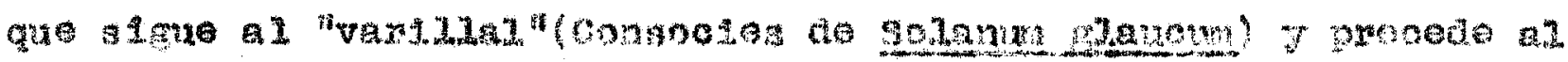

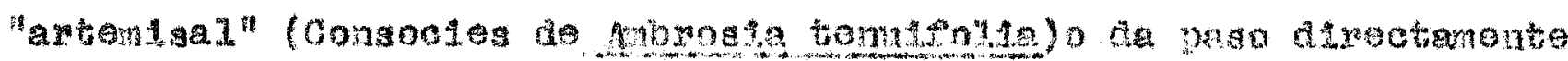

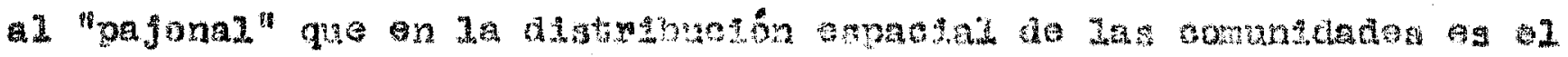

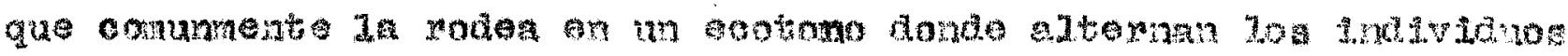

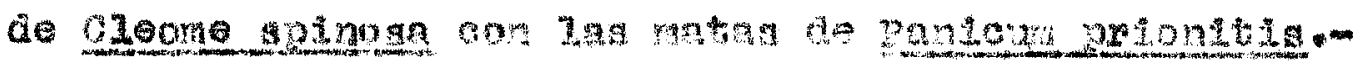

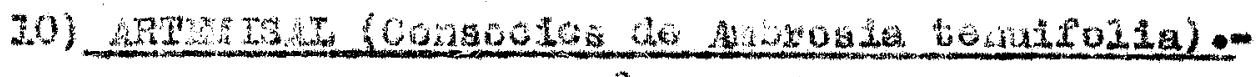

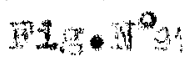

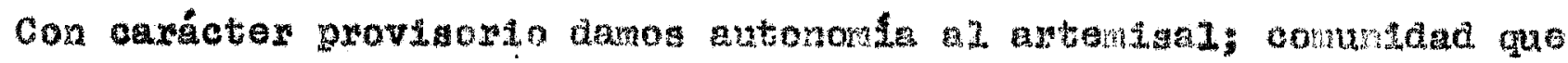


5 - 88 n

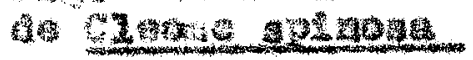
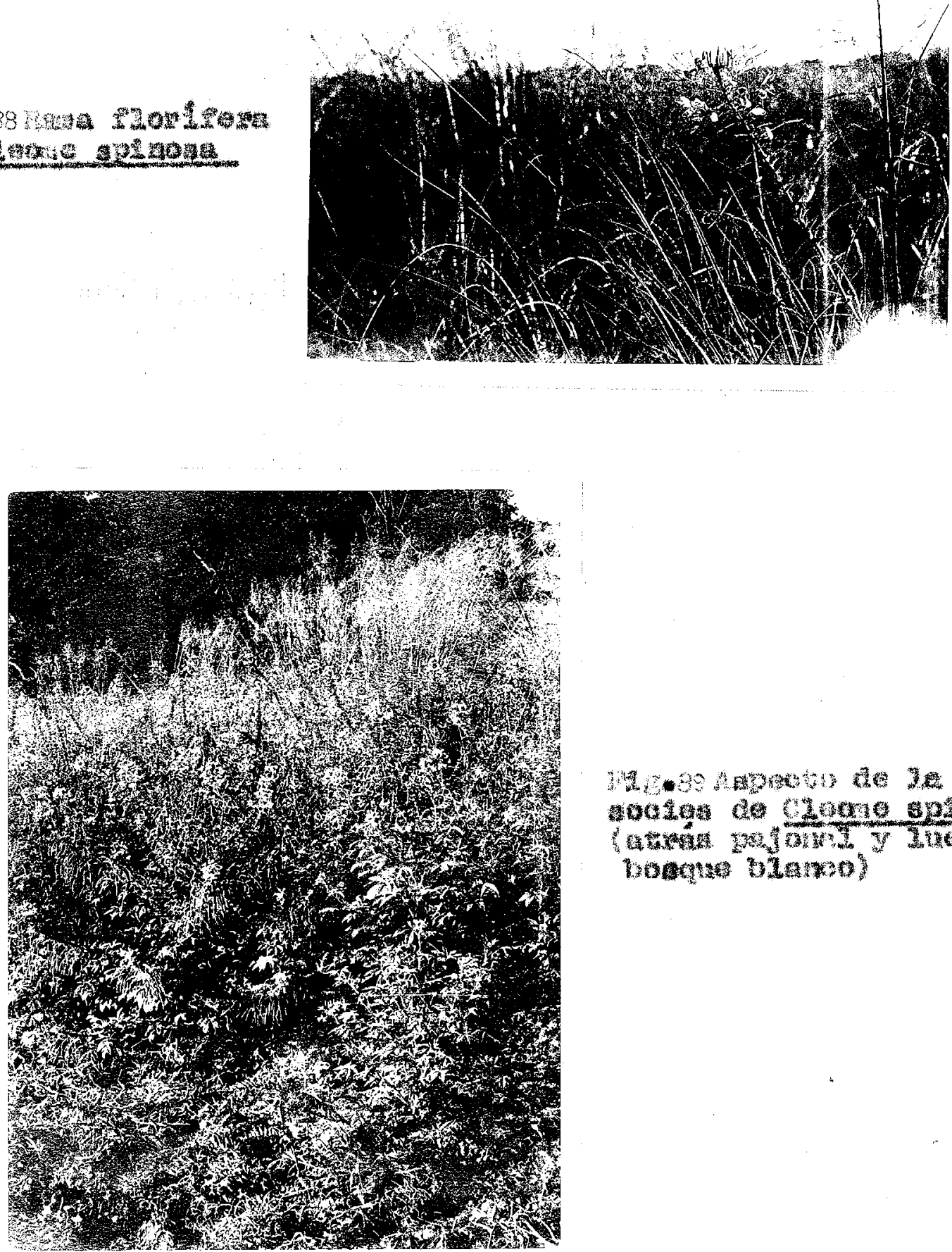

Y4. 30 A

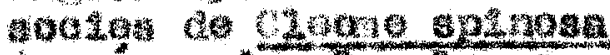
(1)

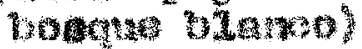

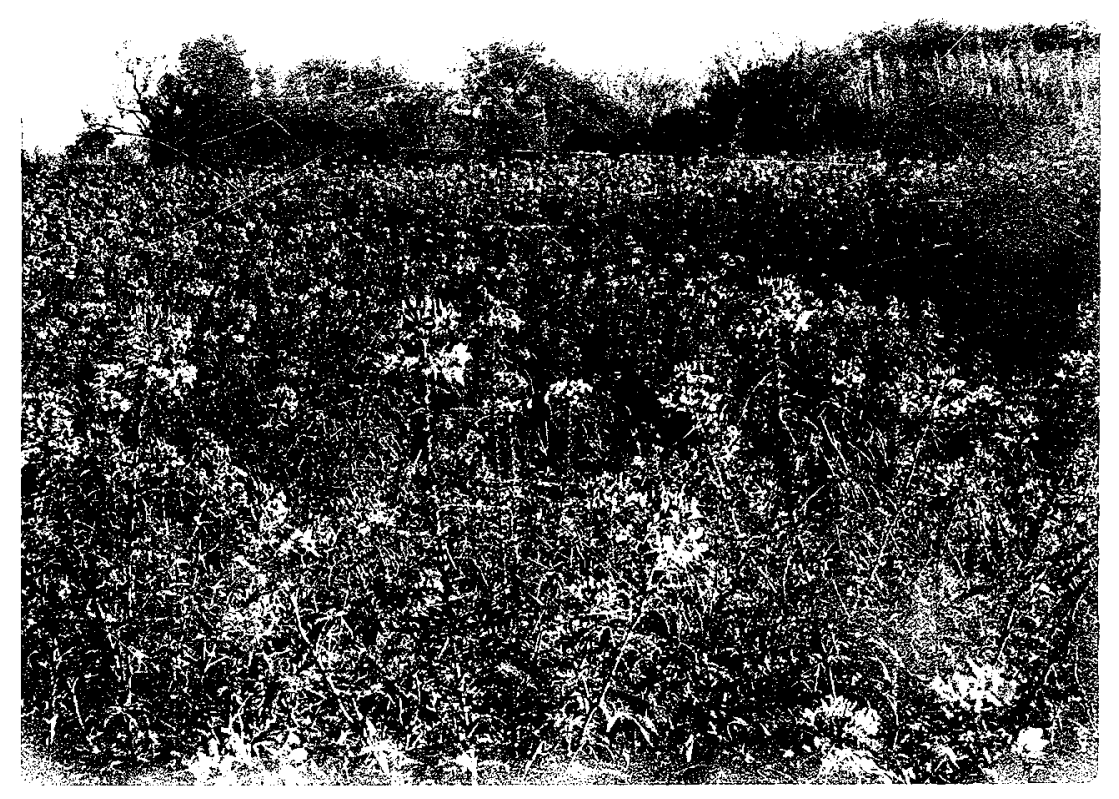




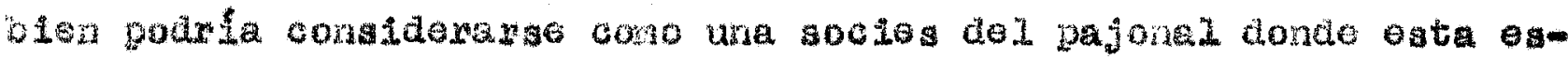

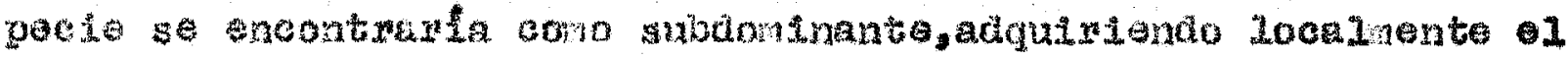

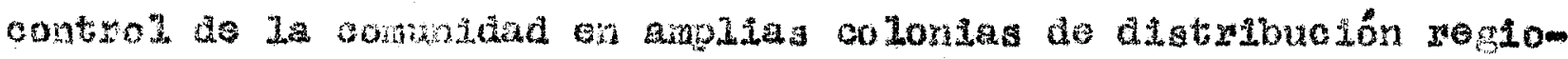
ala 1 Jovajoada.

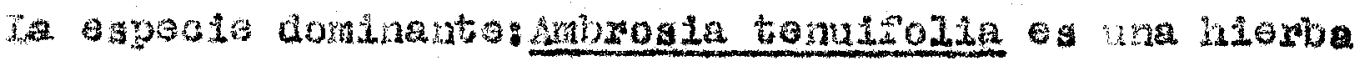

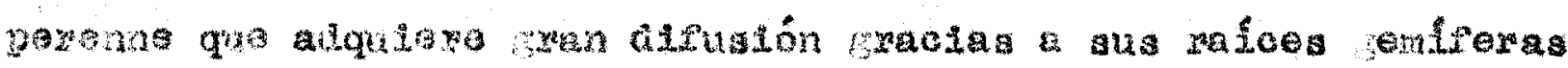

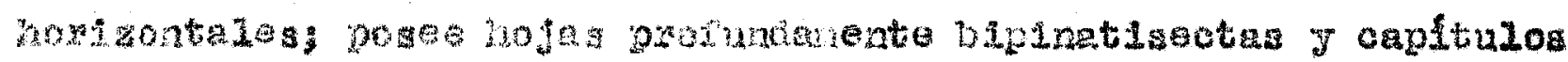

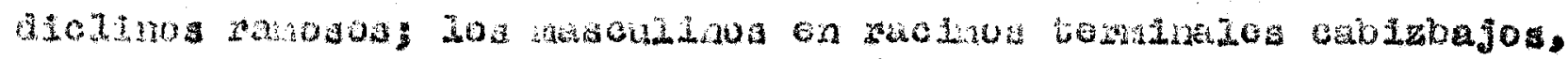

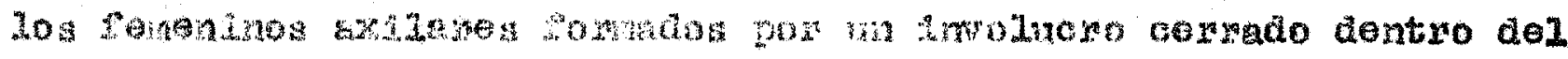

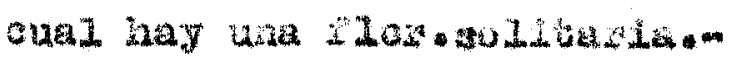

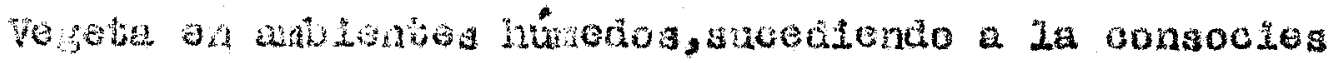

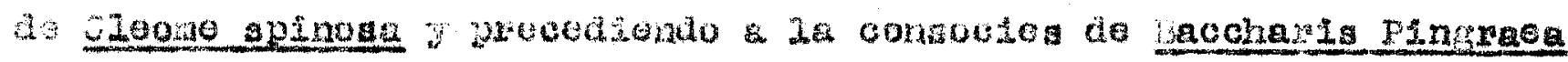

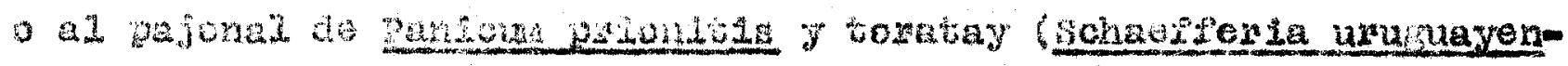
ind.

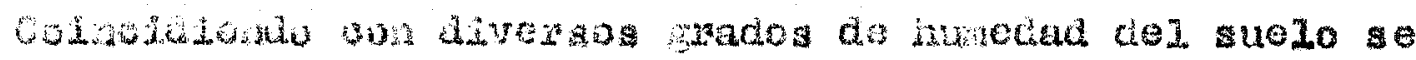

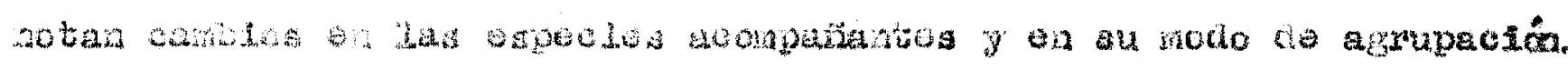

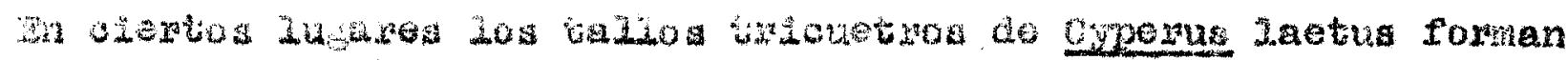

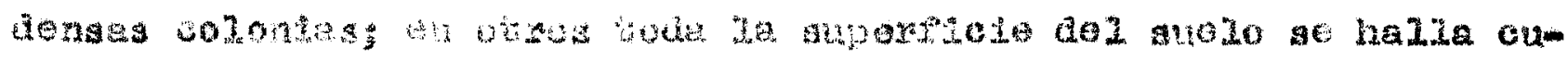

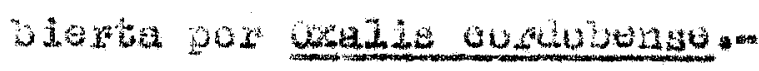

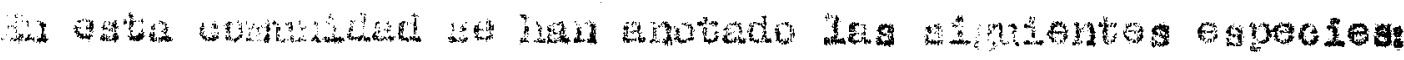

2012pta sing

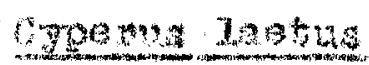

gapatoriun hecabagthum

Gechangs ingats

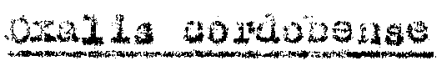

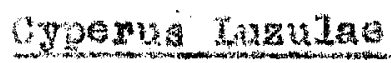

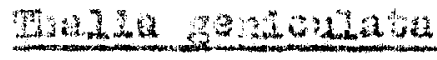

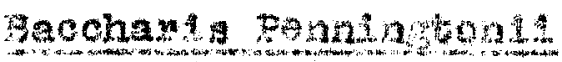

Juncus merocephandus

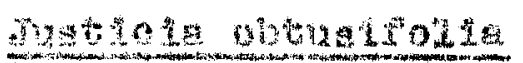

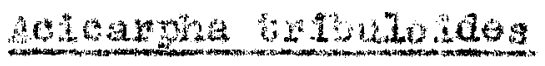

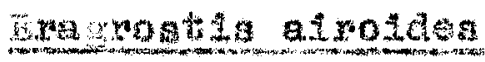

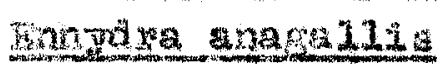

1011450 vertact2ets

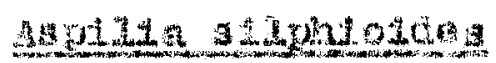

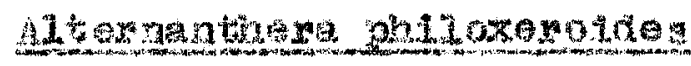

40nopus congresone 19apezun repens

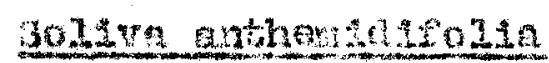

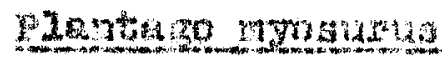

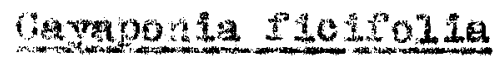

Vennoria Lagane

Aestinnouene mentovidenas

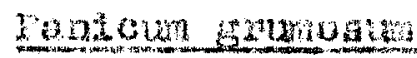

garegr prangte

cleome gpinoga

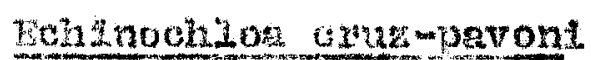

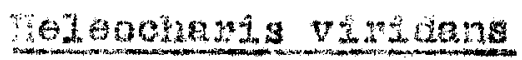

Mnnocorona aguanthoides

11niss majatus

Manjenoorg Ia Inar1oldos

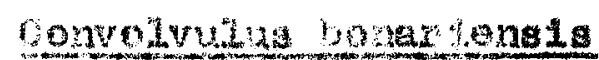

Hydroogtrie manumouloldog

14starla Laetevingas 


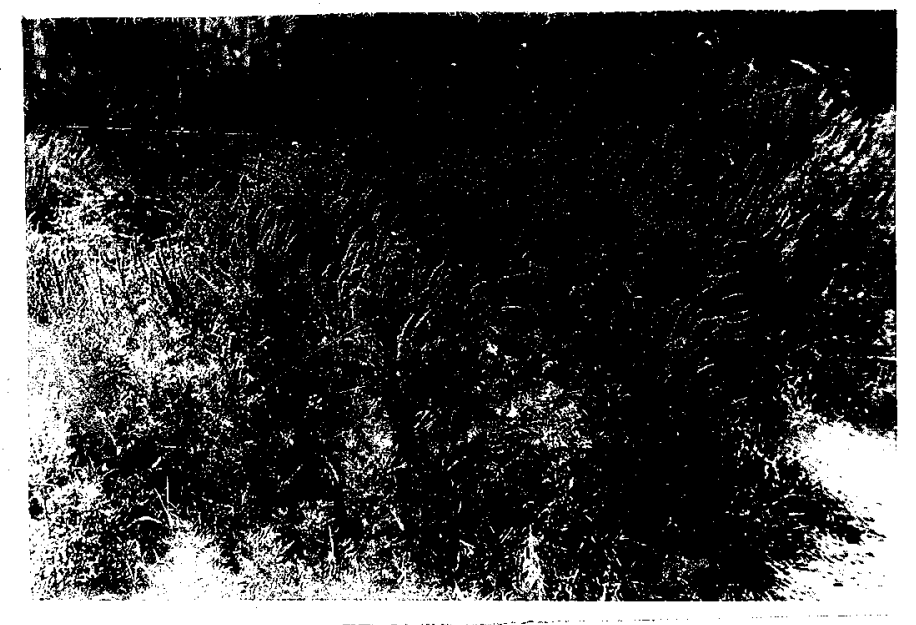

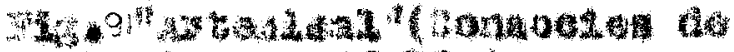

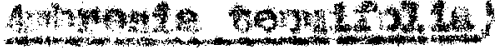

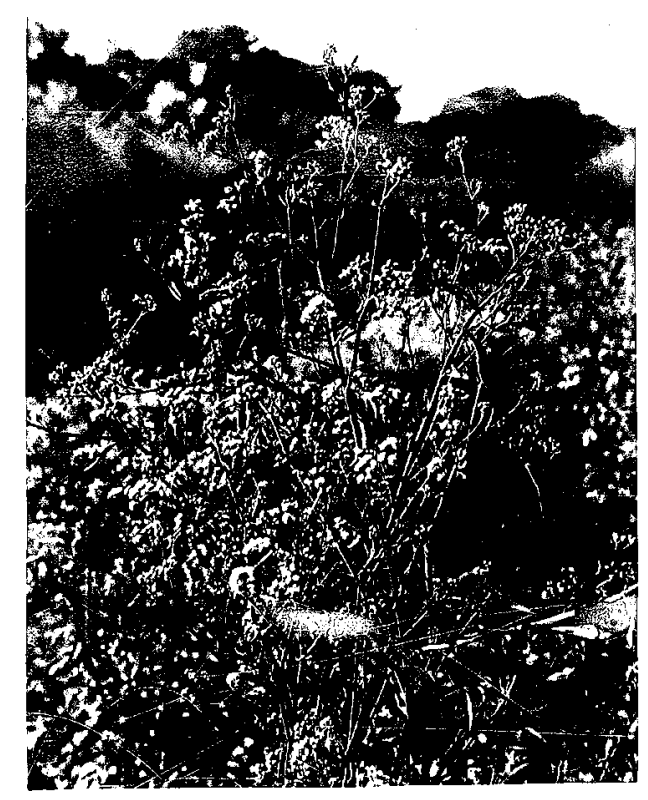

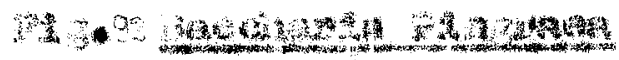


Paspalum Hieronzmi So irpua cubonsts var. pasazuazens 19

Cyperus 1noricatua
Alochloa montev1damals Gaperue gurinamonsis Groerus netloxu van. Araternus

\section{2) CONBOC IES DS BACGHARTS PIVIRATA $F 1, \cdot N^{\circ} x$}

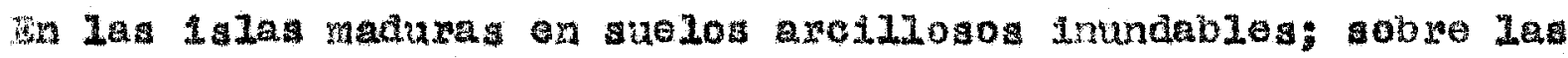
mágenes levada de los madre jones, precodiondo a pajonal axisten extensas colonias de una compueata sur ticosa porenne de I a 1.50 metros de atura, de talios ascendentes o erectos, slabros, de

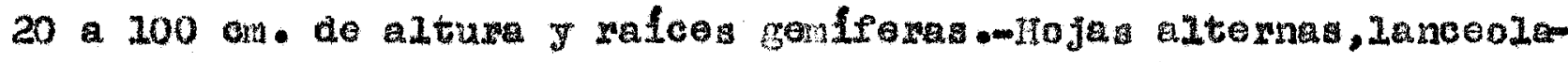

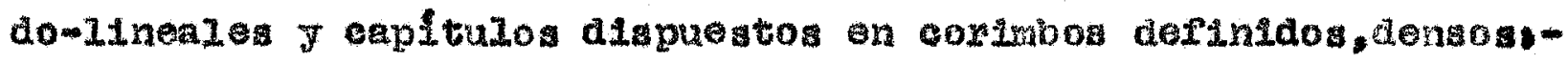
Bacoharis RIngraea

Se reconocon en osta comunidad tres estratoa: nao

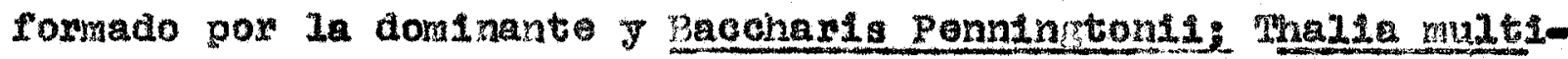

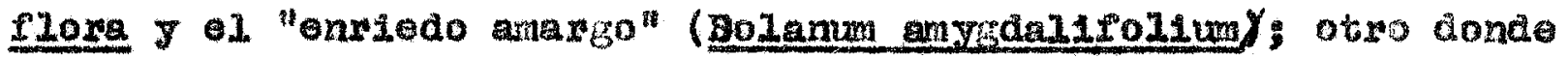
conviven varias fanerógama onanas cono plantago mrosurus; So 11-

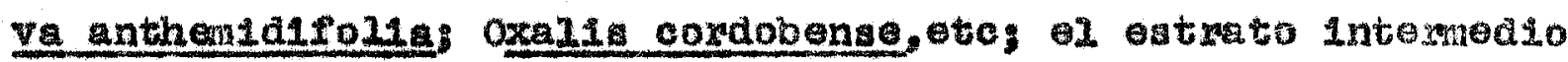
presenta colonias tiplcas de una fcantácen perenne de tallor ereco

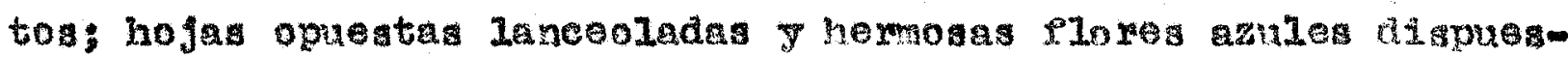
tas en esplgas tominales: Jugticia obtusifolia y una sedo de Gl-

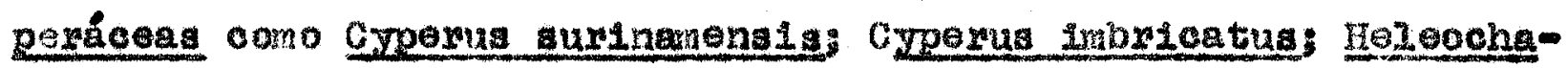
No minira, ote. que atestiguen el grado de hunodad de su sustratoEta comunidad Invade zonas vocinas extendiéndoge con suma rapidez gracias a Ia safces gentromas do la ospocie controm lante.-

\section{2) GAROAL (Consocies de Buyglum obunnoum

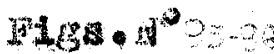

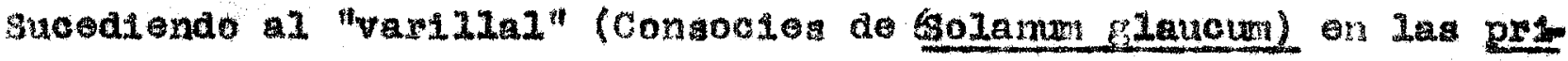

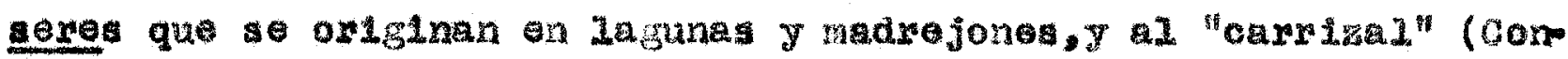

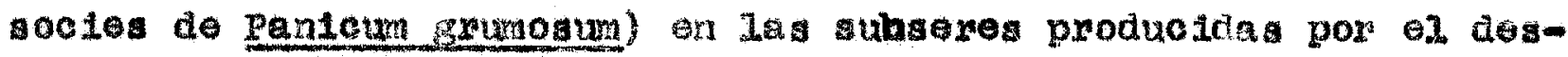

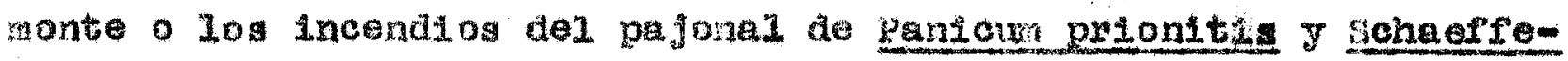

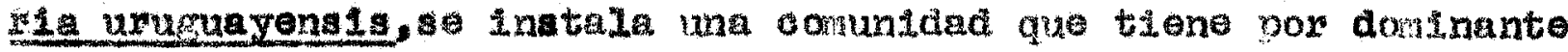




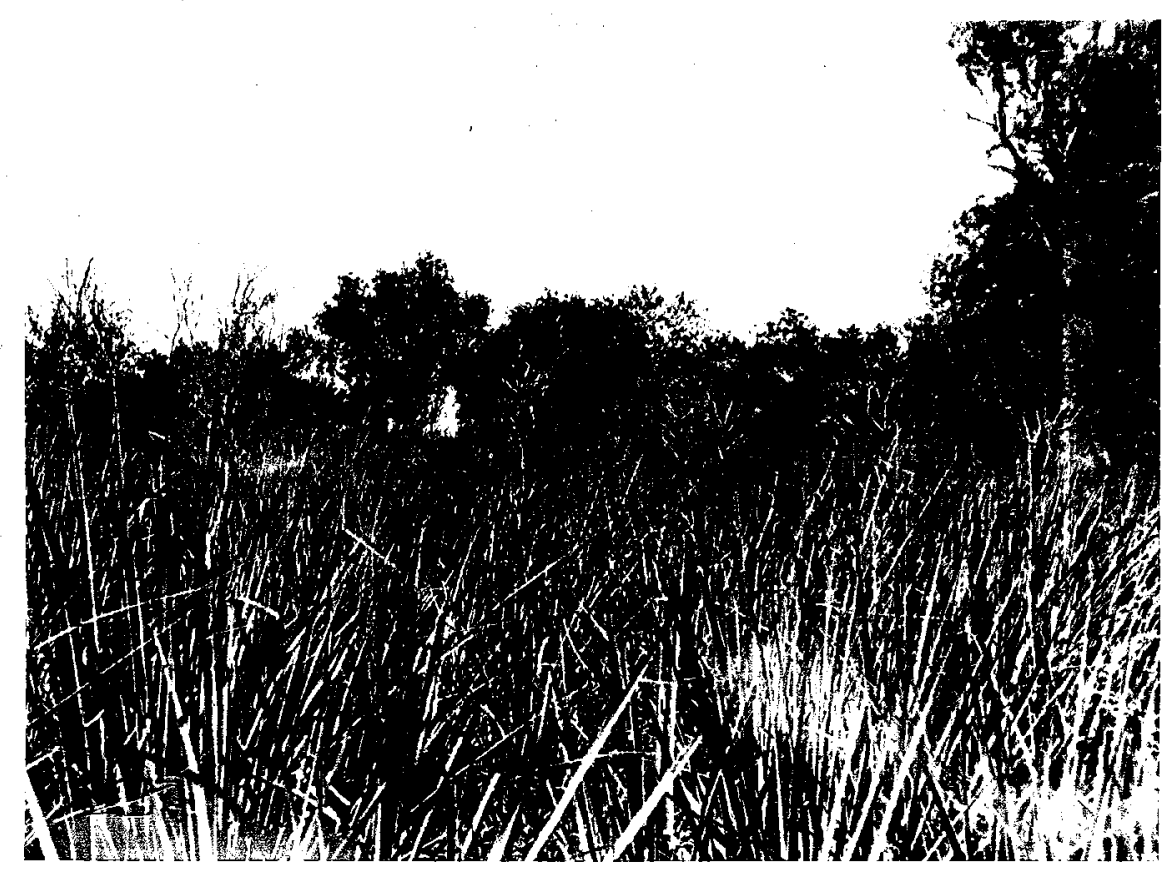

F1. 93 Aspecto del "cardal" (Consocies de Erynglum eburneun) -.

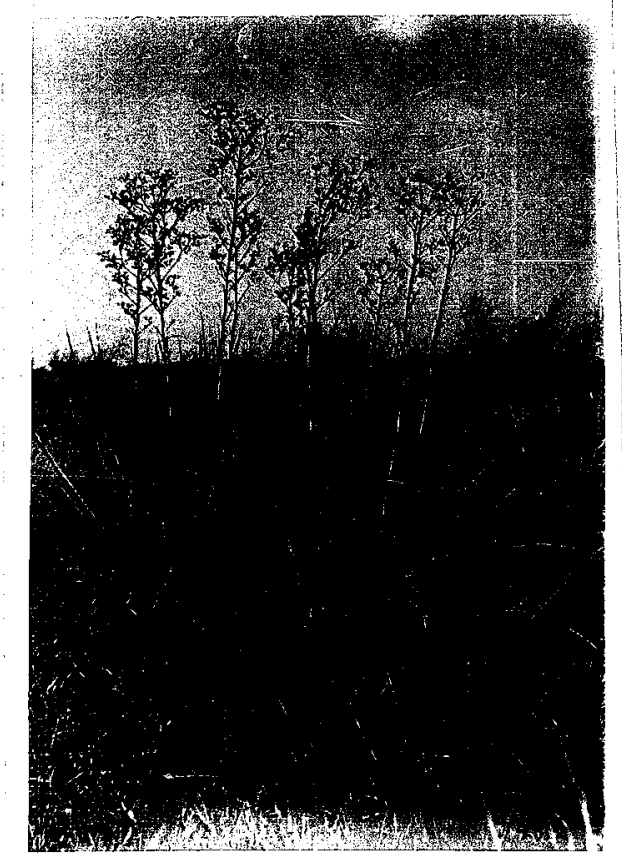

\section{F1g. 94 Carda (Erynglum oburnoum) .-}

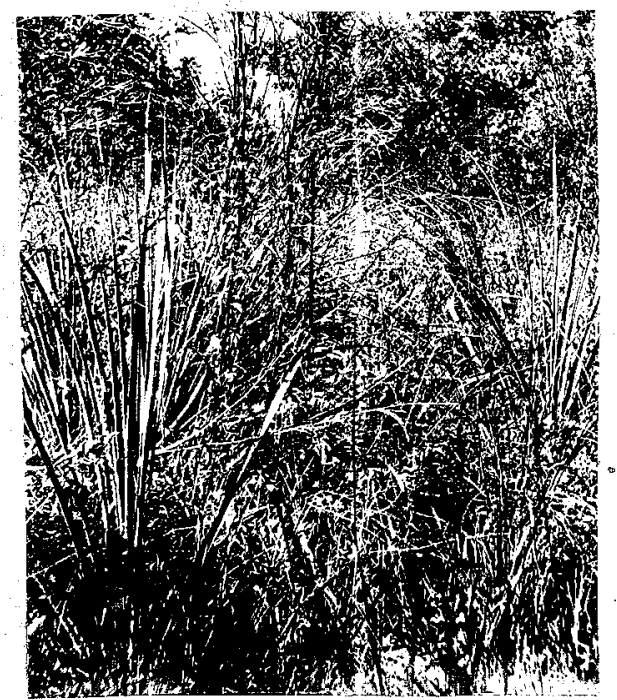

Plg.95 Cardal

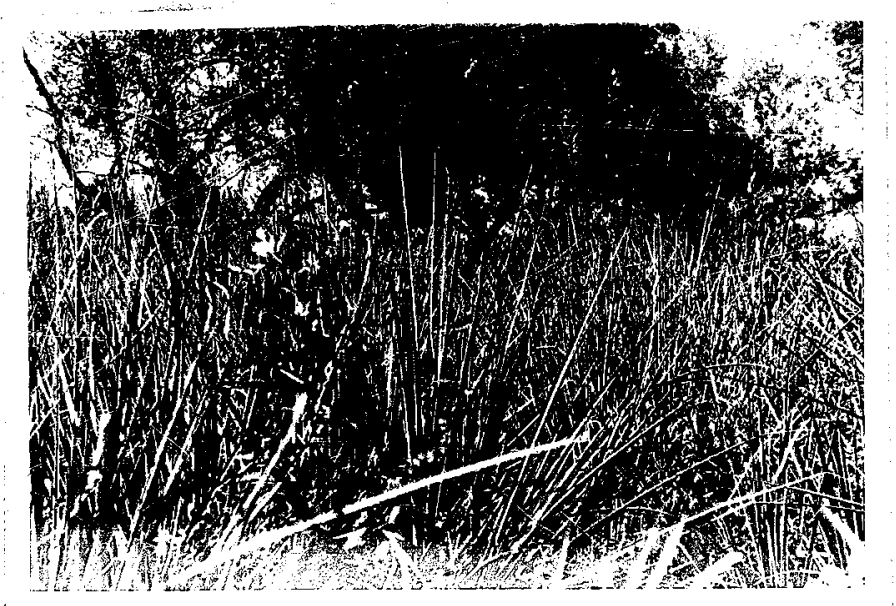

F1g.96 "Carda1" desarrollandose debajo del bosque fluvial.- 
una Wabelffera bronellfome, con hojas proviatas de aguala eaplnas

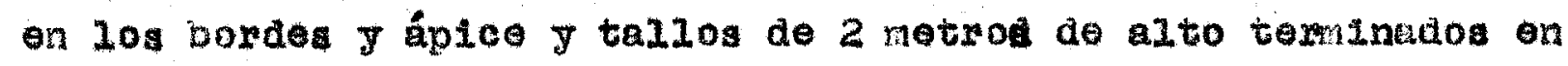
una penoja de capltulos ovoldeos esplnosos: Ia"carda" (Erymálum oburneum)

Sistos densos candalos son practicamentes impenotrablea salvo a caballo, por las esplnas de sus nojas.-Vegetan on campos bajos Inundados perlodicanentes pudiendo vivir debajo del bosque blanco depradaco por la tala.-

La "oaxda" auele 1 acomparieda por otra eapecie del mism mo género pero de nenor porte g oppltulos más chloos: el Erynglum pandanifolium; apareciendo ontre sus matas las aguientes aconpanantea: una graralnea tiexna de 1 a 1.50 notros de altura, Hemarthrie altissima; varias Verbenas (Vervena 11ttoralls) Verbone boneriensis: Yeroena mejapotanica); una Amarantácea apojante de 2 a $2.50 \mathrm{~m}$ de altura, Pfafela atenophyzla; 19 "paja brava" (Panicum priontt1a); Ieucrium veglearium Vernonia inoana: unaccompuesta de herrosos capltulos amar1110a Aap111a g11phiojdos: Convolvulus bonarieng1s: A-

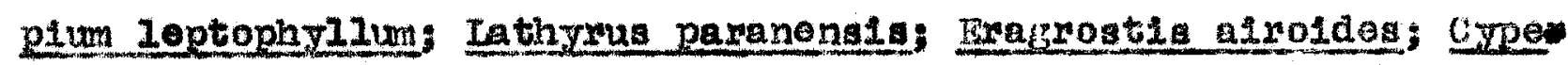
rus abornarglnatus var. pachyanthemos: Grpenus neflexus vir. fratexris: Grerus esculentug, to.-

\section{3) CARRIzAT (Consocios de Pantcura Emuosura)}

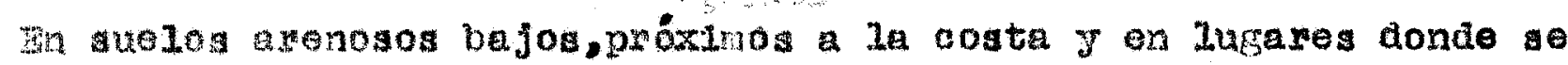
ha taleco el boque blanco encontranos densos pejonelea de una hierba ponemne, Hzomatosa, de 2 a 2 metros de alture; hojag duraa glabras panojas arectas amplias,foraada por numeroaos raciros compueatoa. densos; ej "corrito" Pantoum grumosum -

Este conunidad no tiene predilección por un determinado tipo de suejo; so la encuentiva en la vooinded del. "natorral im beneño" aobre me1o areneso húmedo, Imandable, en lo médanos inte-

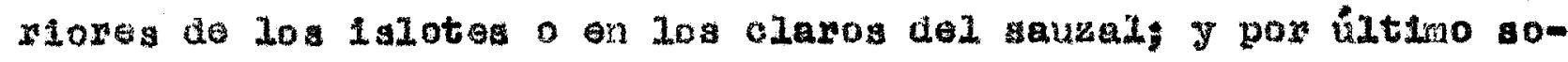
bre aueloa arciliosos-Itmosos como son los do los aluardonos portaderes del bosque blanoo.-- 

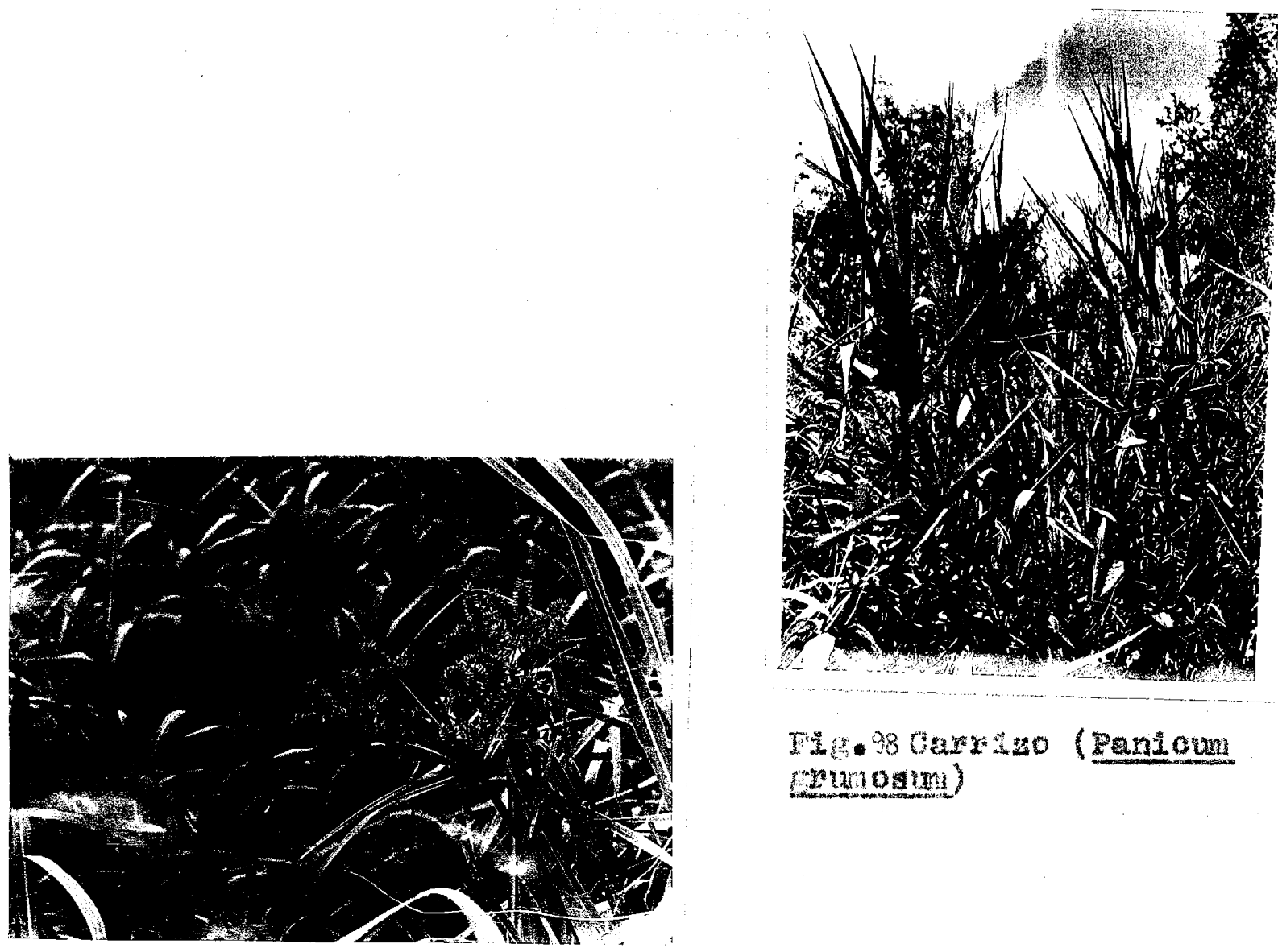

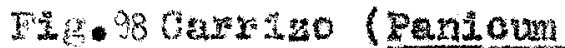
Pumosini

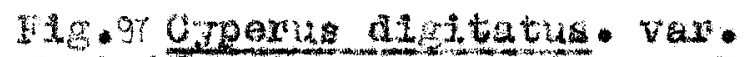

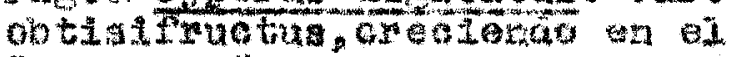
"dariz La"
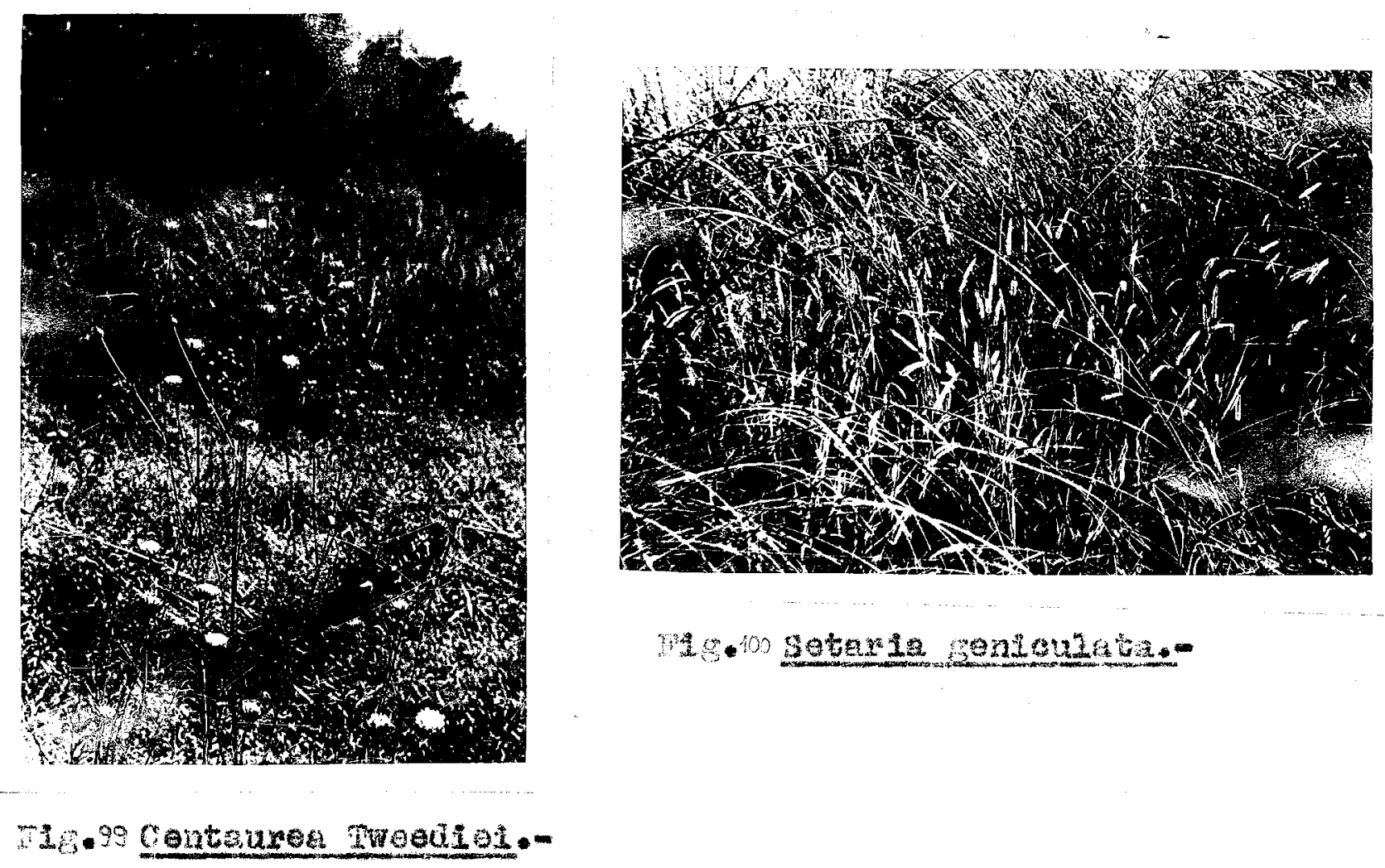

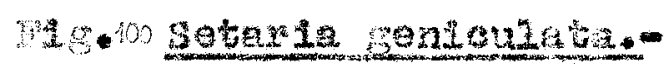


Acompañan a1 "canxiz" Setaria genloulata 3alv1a jua-

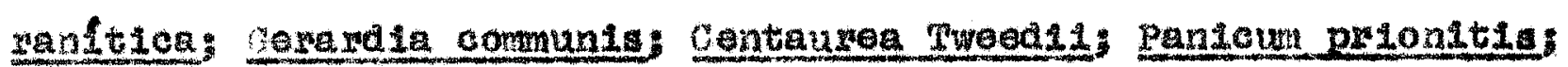

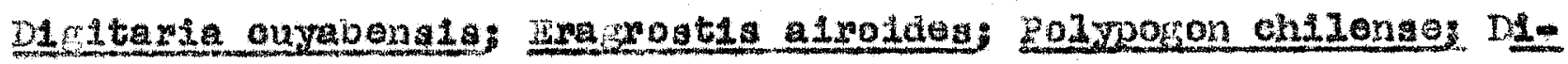

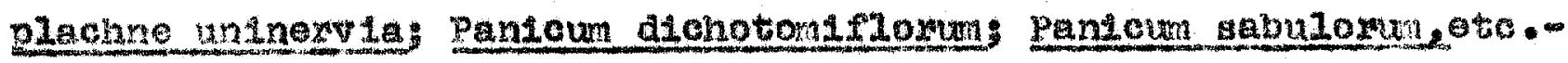

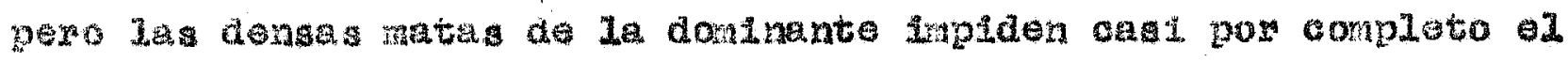

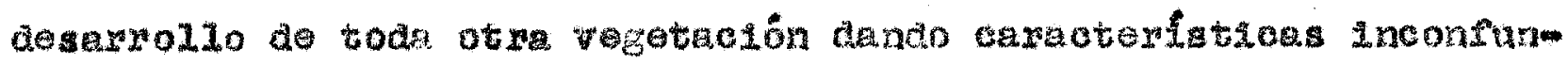
aloles asta comundea que se astingu a larga alatancia pon el colon vorde gnisáoeo de gu xoLlaje.-

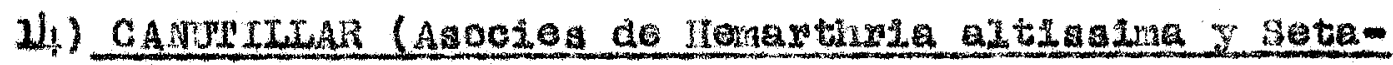 ria gemoulata- - Fopto}

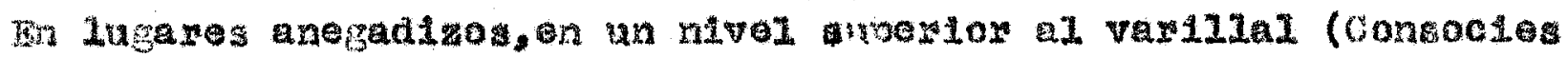
de 3olanug glaucua) y sobro gualos no tan himedos a extence el camutilax cuya dominante. donjuna hlerba perenne de caria acon-

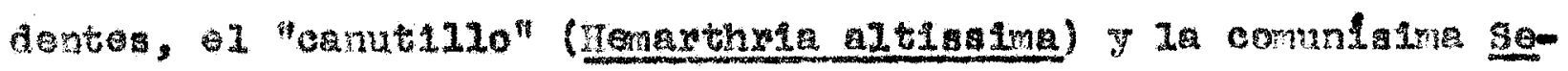

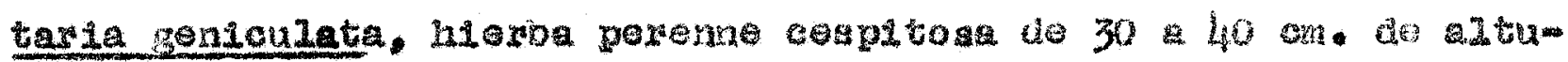

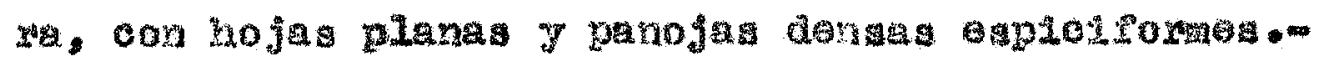

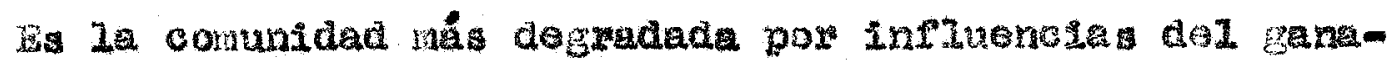

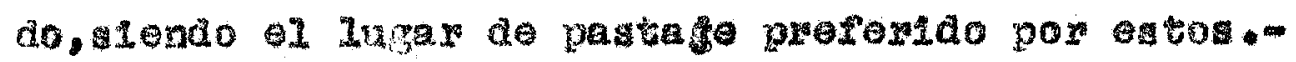

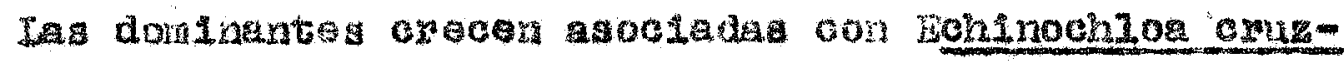

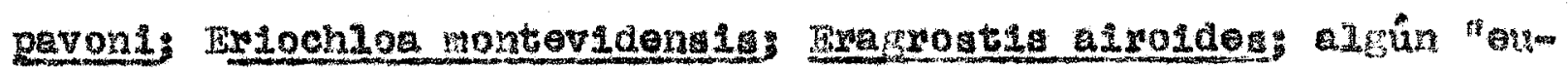

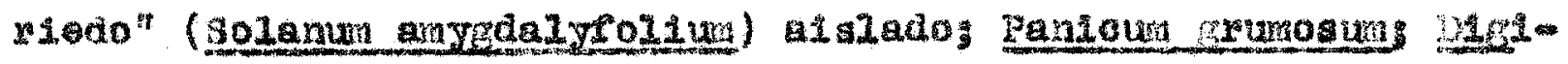

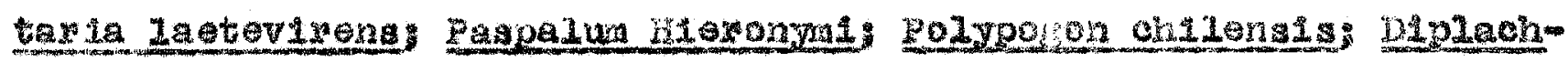

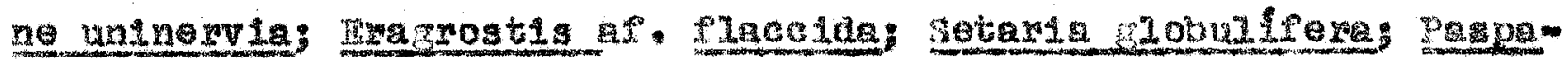

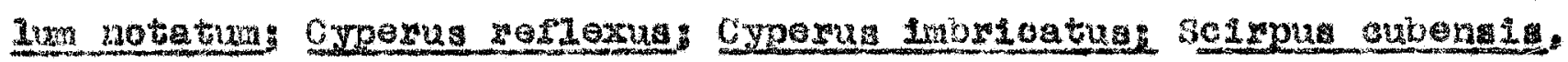
ets.-

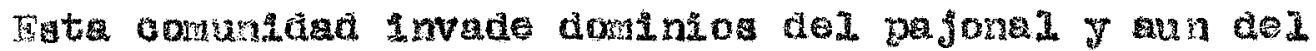
bosque blanco slgulendo el curen do las hondonada quo aryan de de-

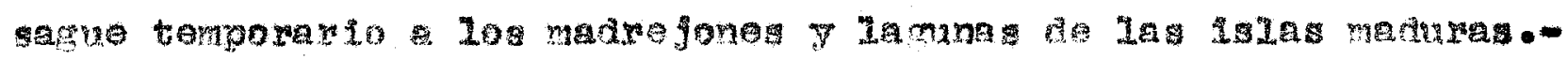

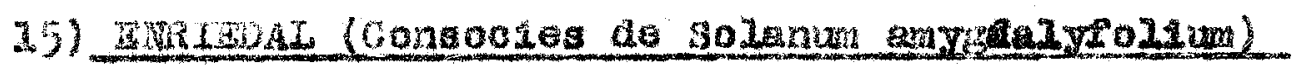

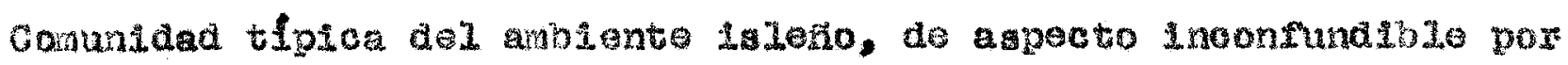
el color (verde oacuro) y el hábto de la donnante gue se onsoda

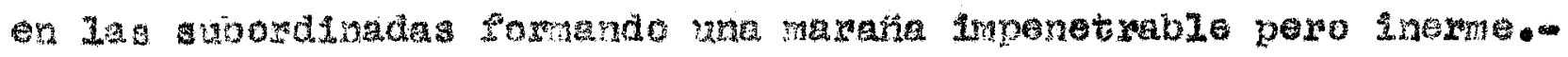




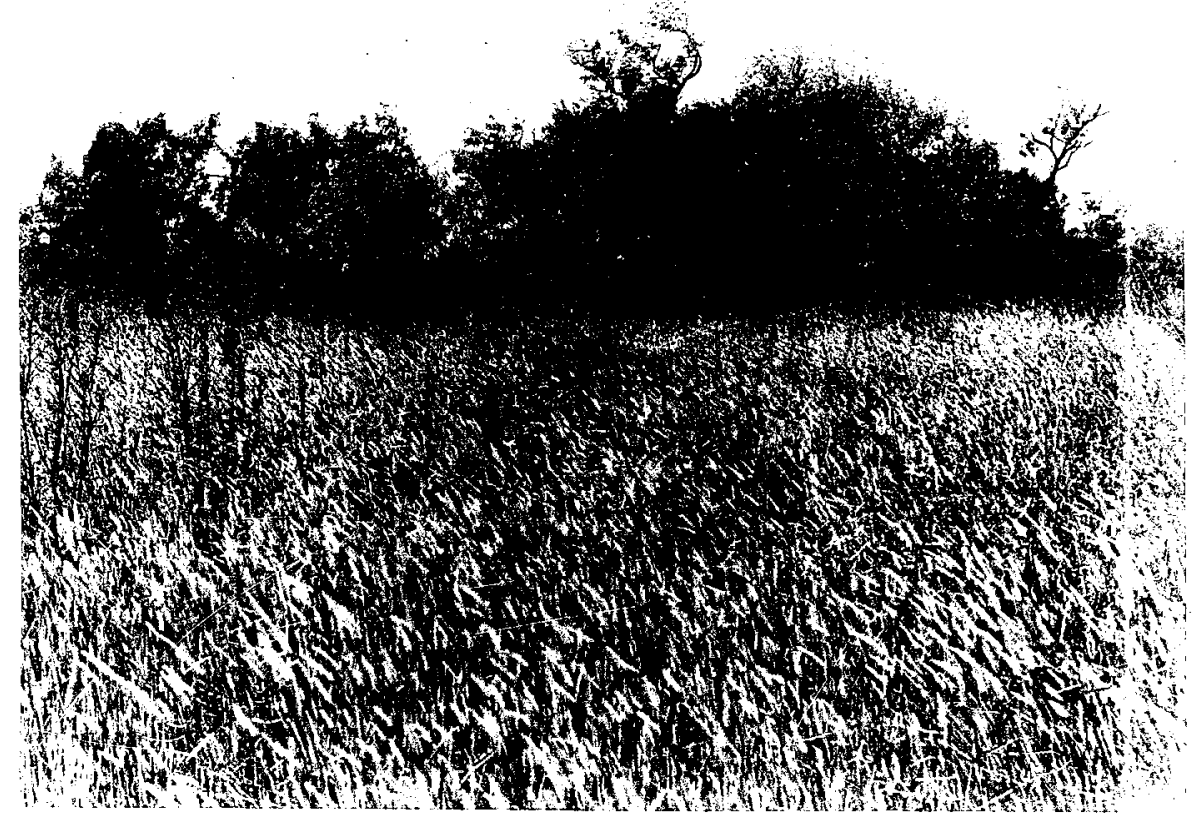

Fig. 100 Aspecto del canut11lar (Asocies de Hemarthria

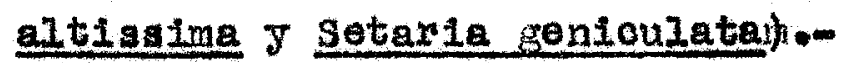

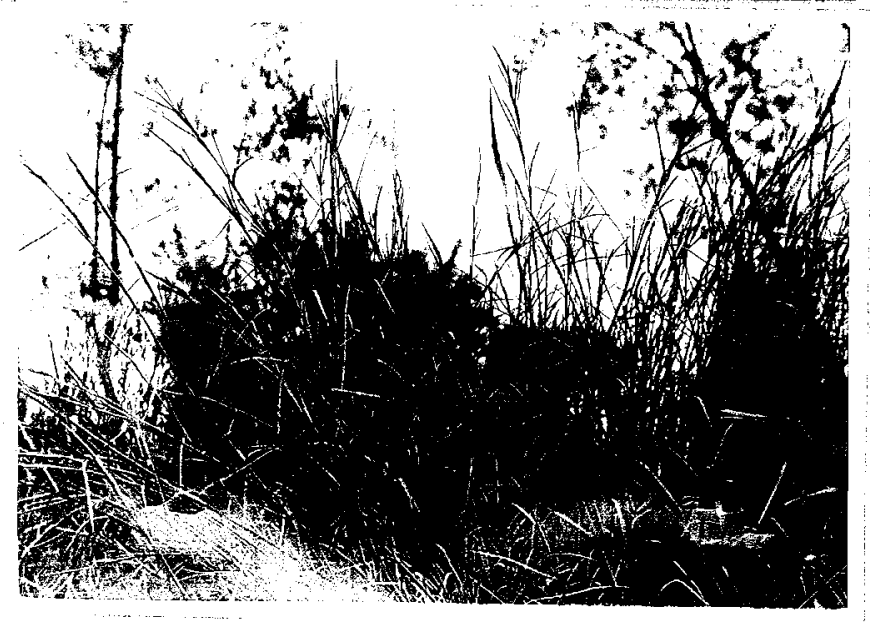

Flg.to: Hemarthria altiasima

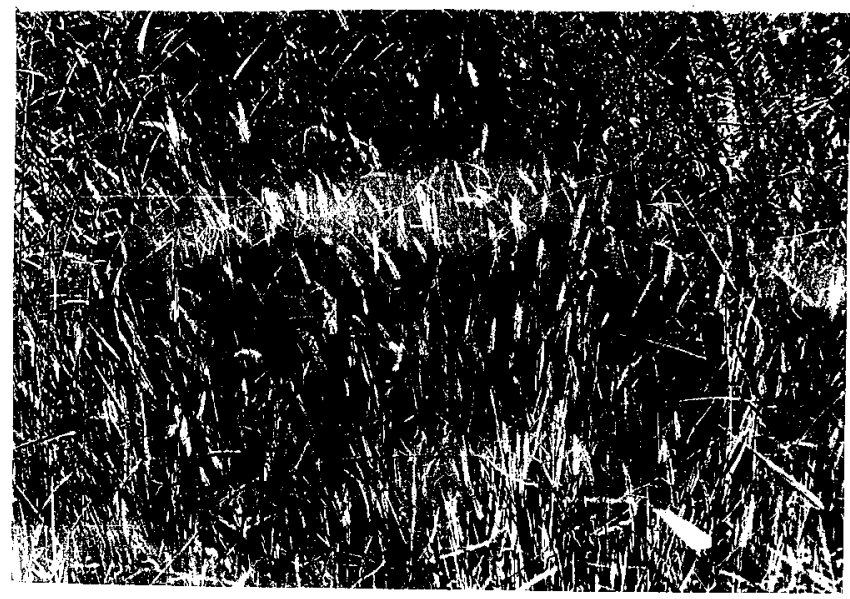

Fig. 102 setaria genlculata

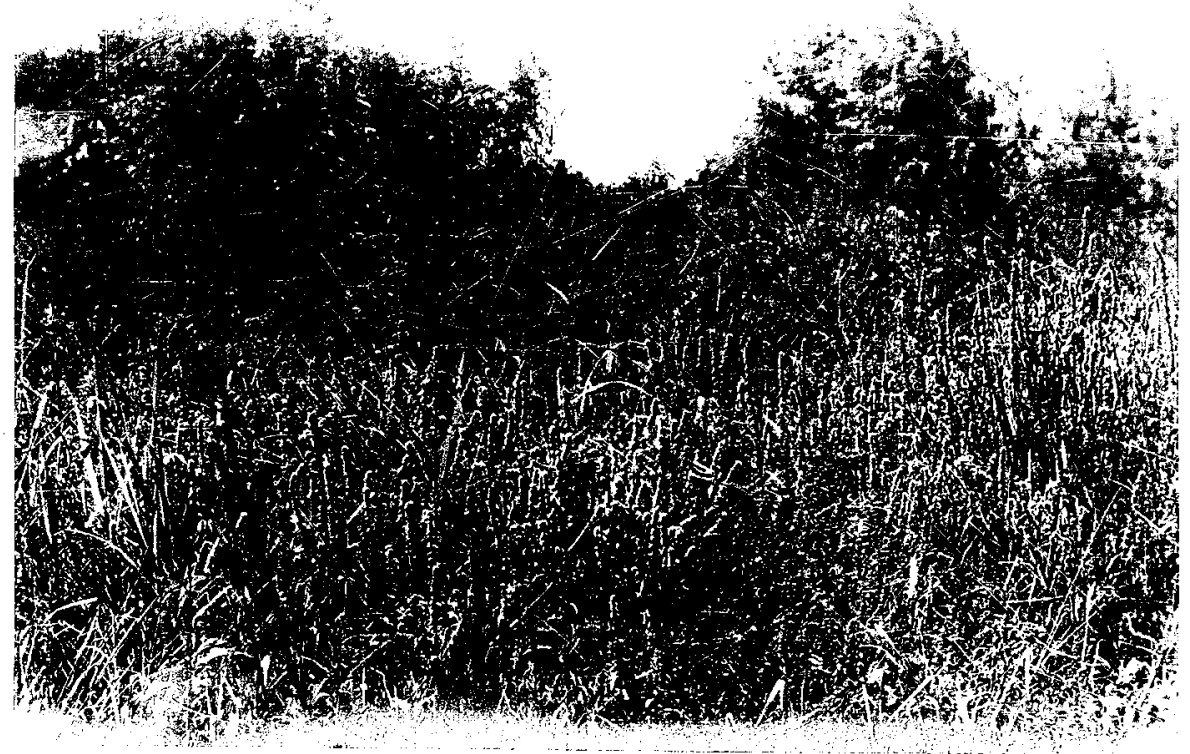

Flg. 65 Colonie de Bao charis Penningtonit on -1"canut111ar" 
El control de ota comuntad 1o ejence una entededere perene con naval thexuosas; hojas ovadas, glabras y sores azules

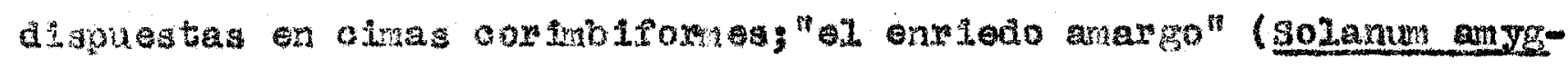

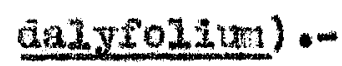

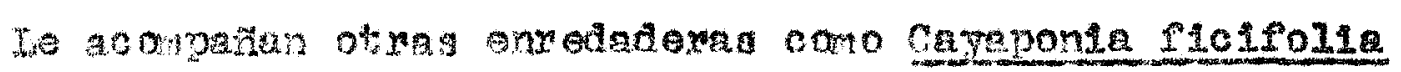

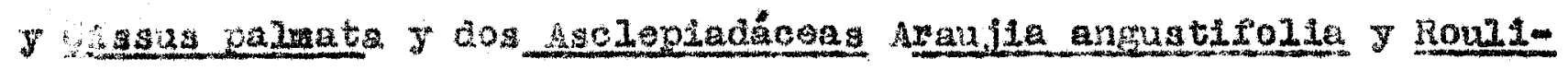

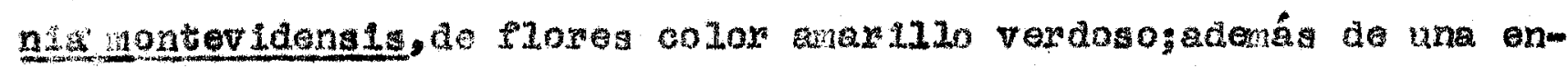

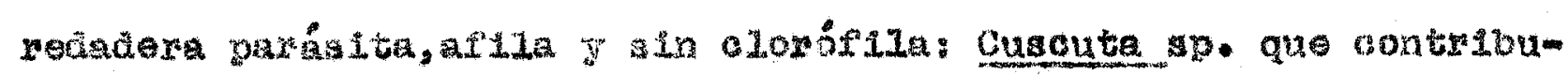
Jon hacer más attell ol accoso a esta comundad-

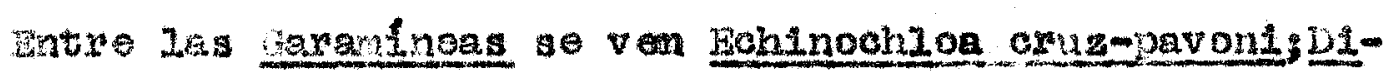

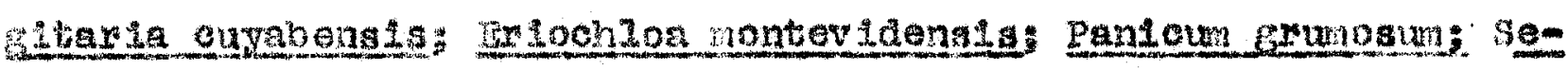

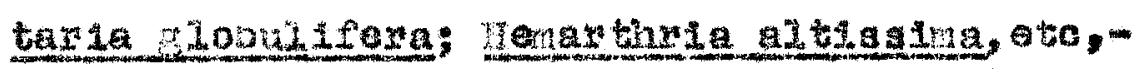

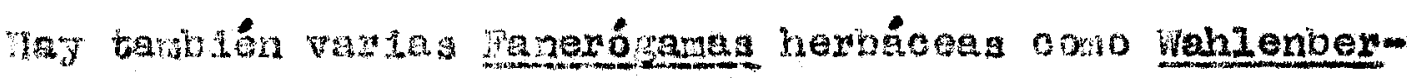

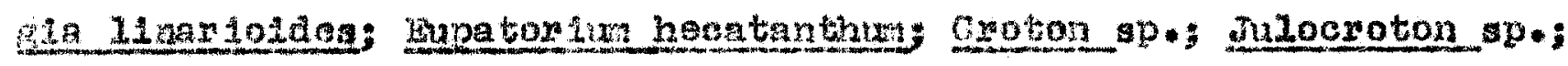

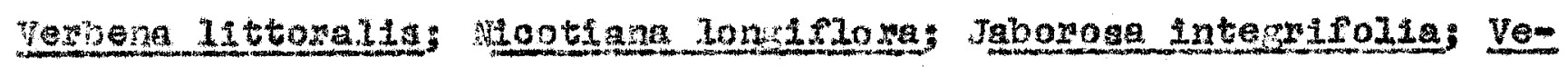

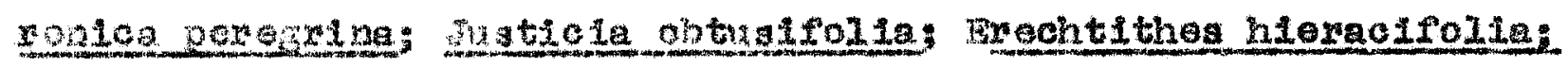

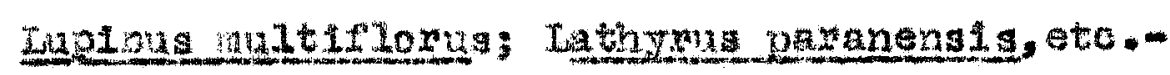

whtre en i edal y la consoctes de Jaccharis Pingreo

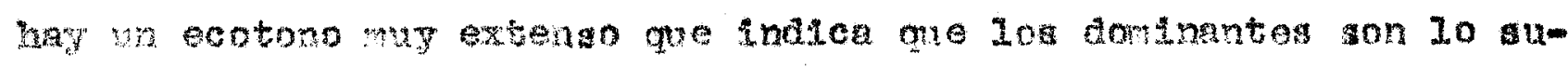

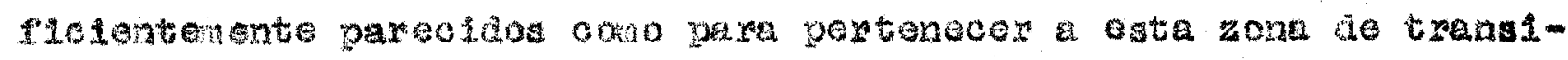

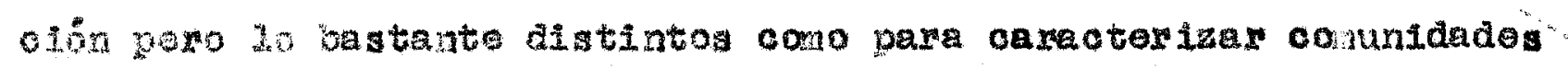
alforentes...

Gaso lántico fource entre el "oanuti21ar" (Agocies do

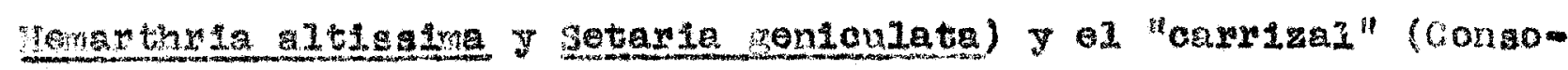

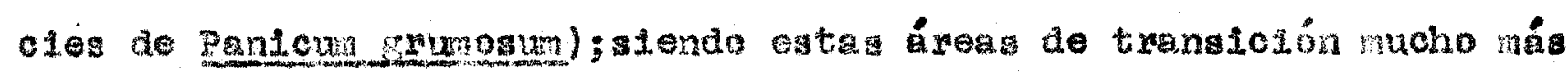

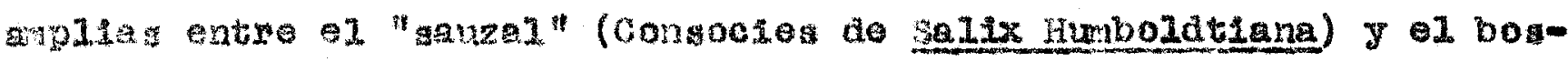

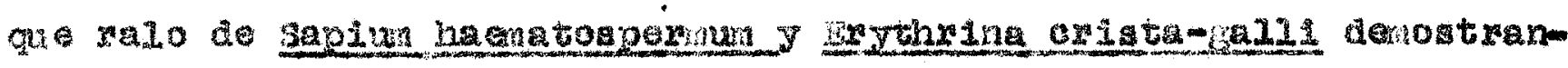
do que los dontnantes serales o terporarios muestran un srado do oqulvaloncta crando se oncuentran en el ecotono.-

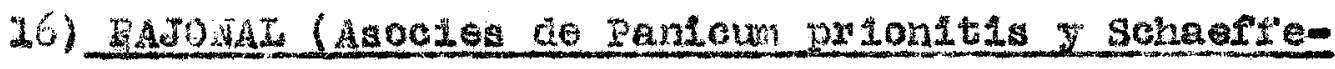

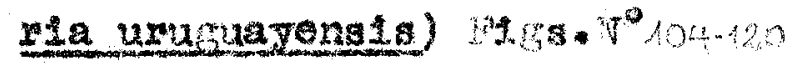

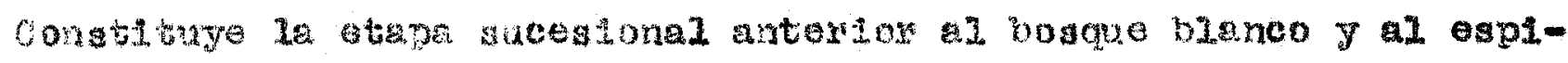

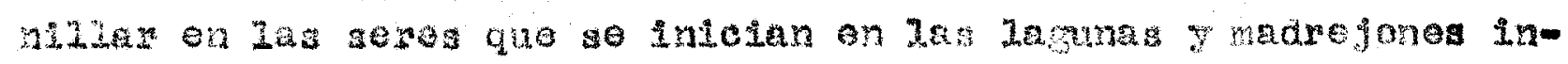


Fis.104 Los dominantes del "pajonal" : Pentcun prionitis y schaefrerie uruguayens 1s:-
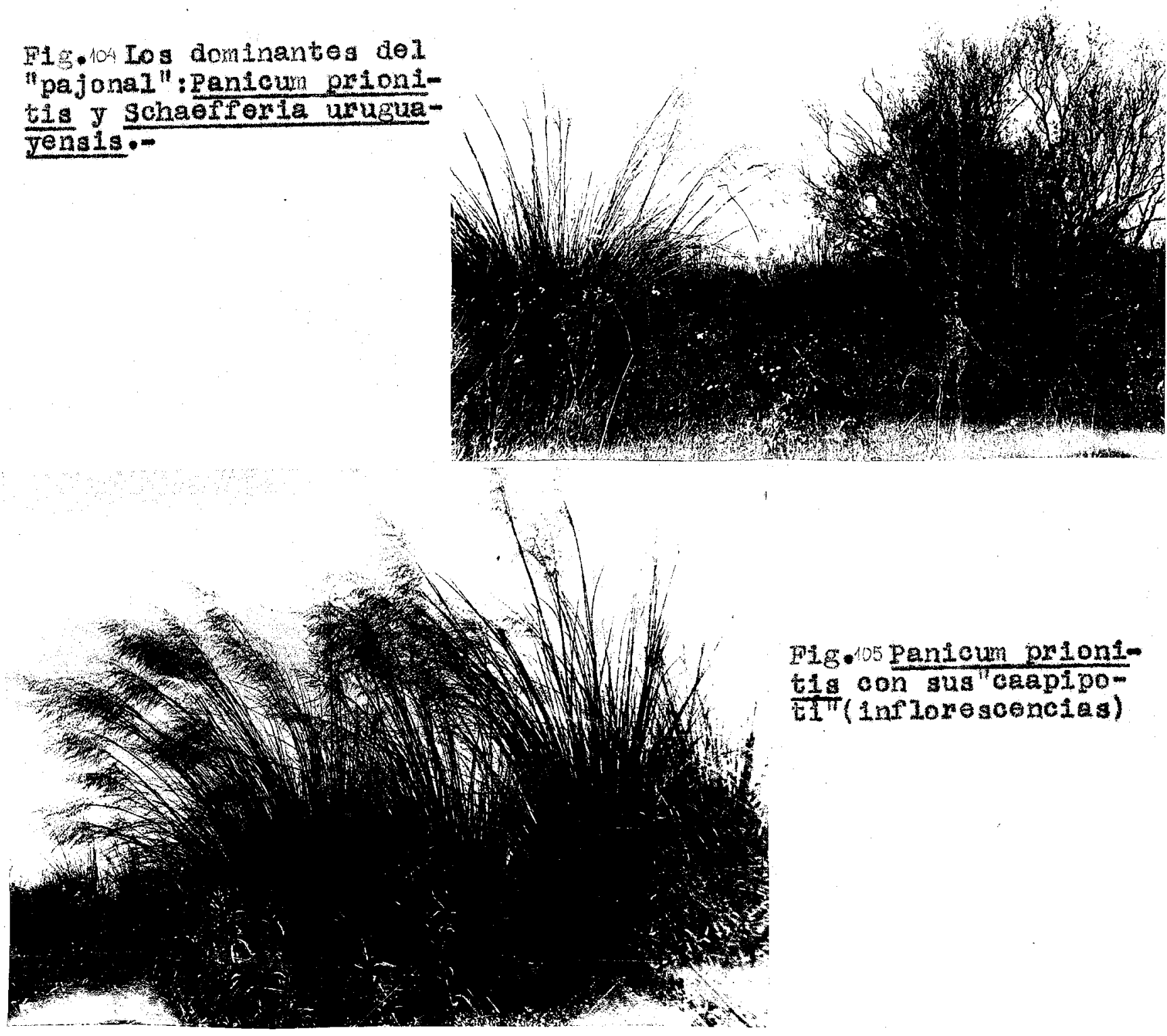

Eig.105 Panicum prion1tis con sus capipoil" (inflorescencias)

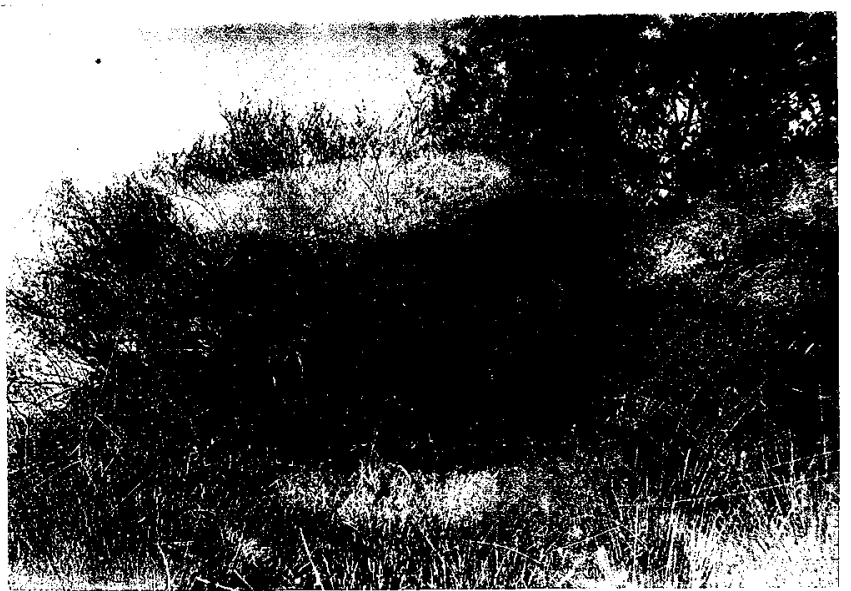

PL. 10 Toratay (Schaefferla uruguayens is) . -

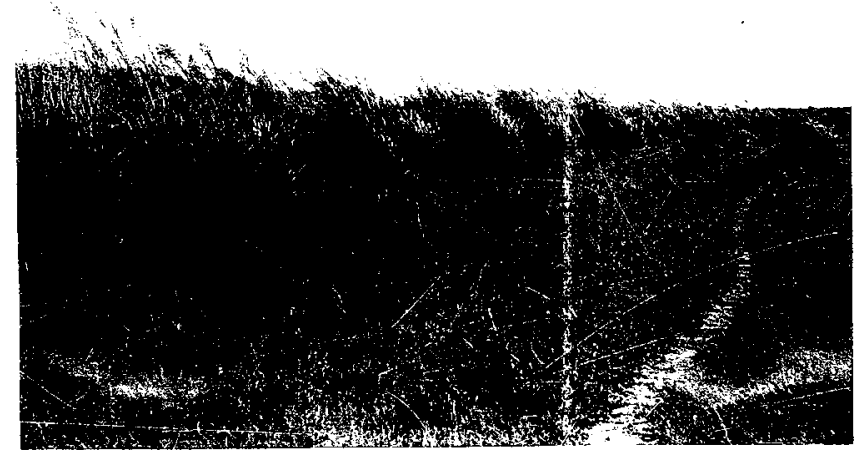

Fiz. Pajonal.- 
terlores de las ialas; 10 preceden el "cardal" (Consocles de Erym-

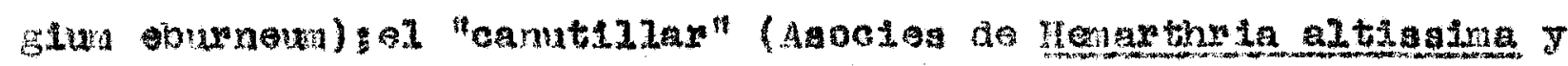

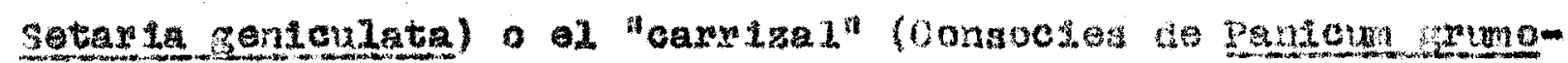
$\sin 1$.

Por Ia mpexfiolo due cuoro es una de las comuzdados náa irnoortantes de la nogión.- octhpa terrenos anegadizos curanto Ia orecientea $\mathrm{y}$ on cas todos los casos so encuentra en imenas bolanes redeadoa completanente por low albardono que soportan el "boaque blanco".-

tu las islas del tipo deltáloo non una deprasión con-

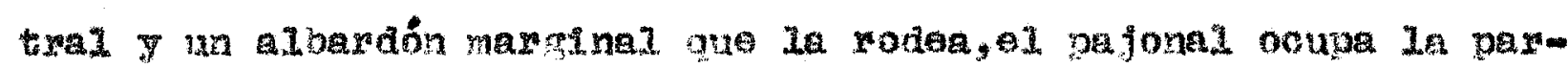
te má alta de djcha hondonada recotandoge sobro las altuza cubiertas de esoneins arbóreas.-

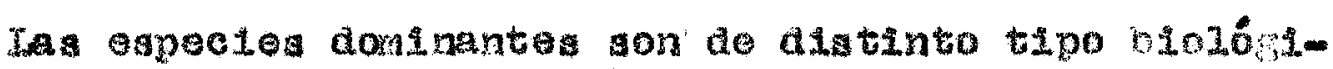

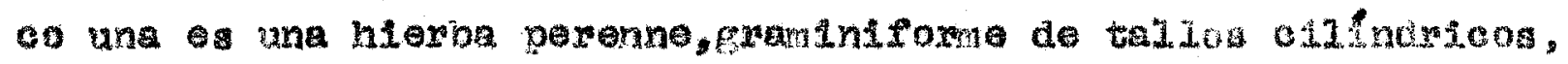
eatrlados, de 1 a 2 motros de alto y valnas follares ostriadas con

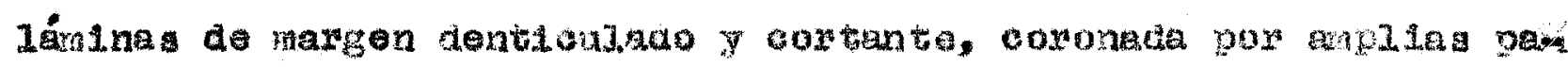

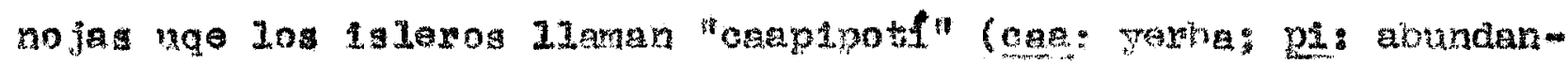

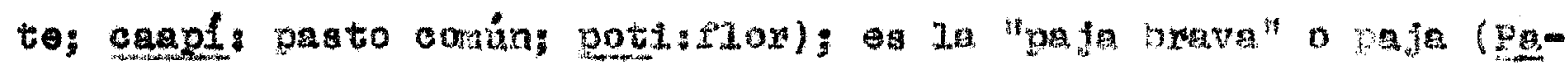

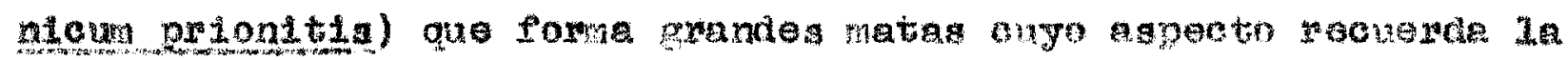

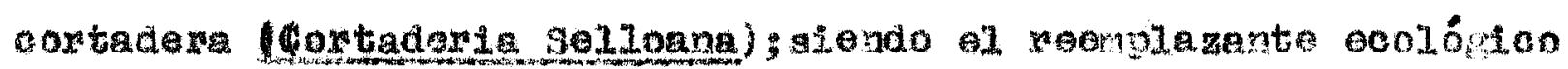
de estr empecie en el amblente de lajas.m

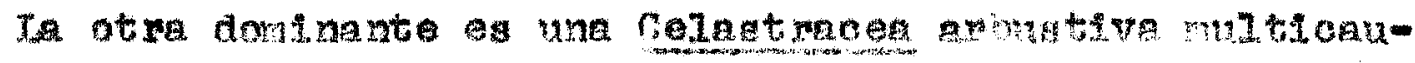

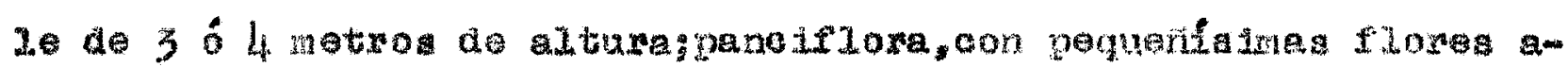
campanadas, blanquecinas : Sohaefferta uruguayens19.-

Cuando el noute ha alao talado el pajonal invade sua domintos, fomando un denso tapla oon almmos ámboles alaledos que ole-

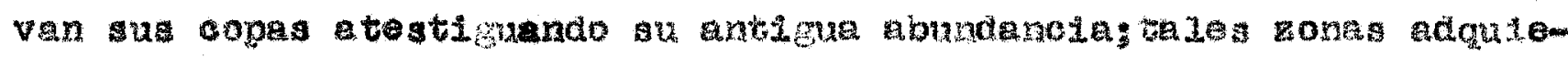
ren ol aspeto tipico deI "paraine".-

Dentro del pajonal colnoldendo con matovariac:ones

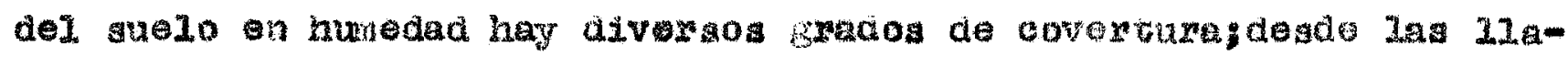
mada "haclega" o"campos suclos" donde on Panlex? prionte is ooupa 

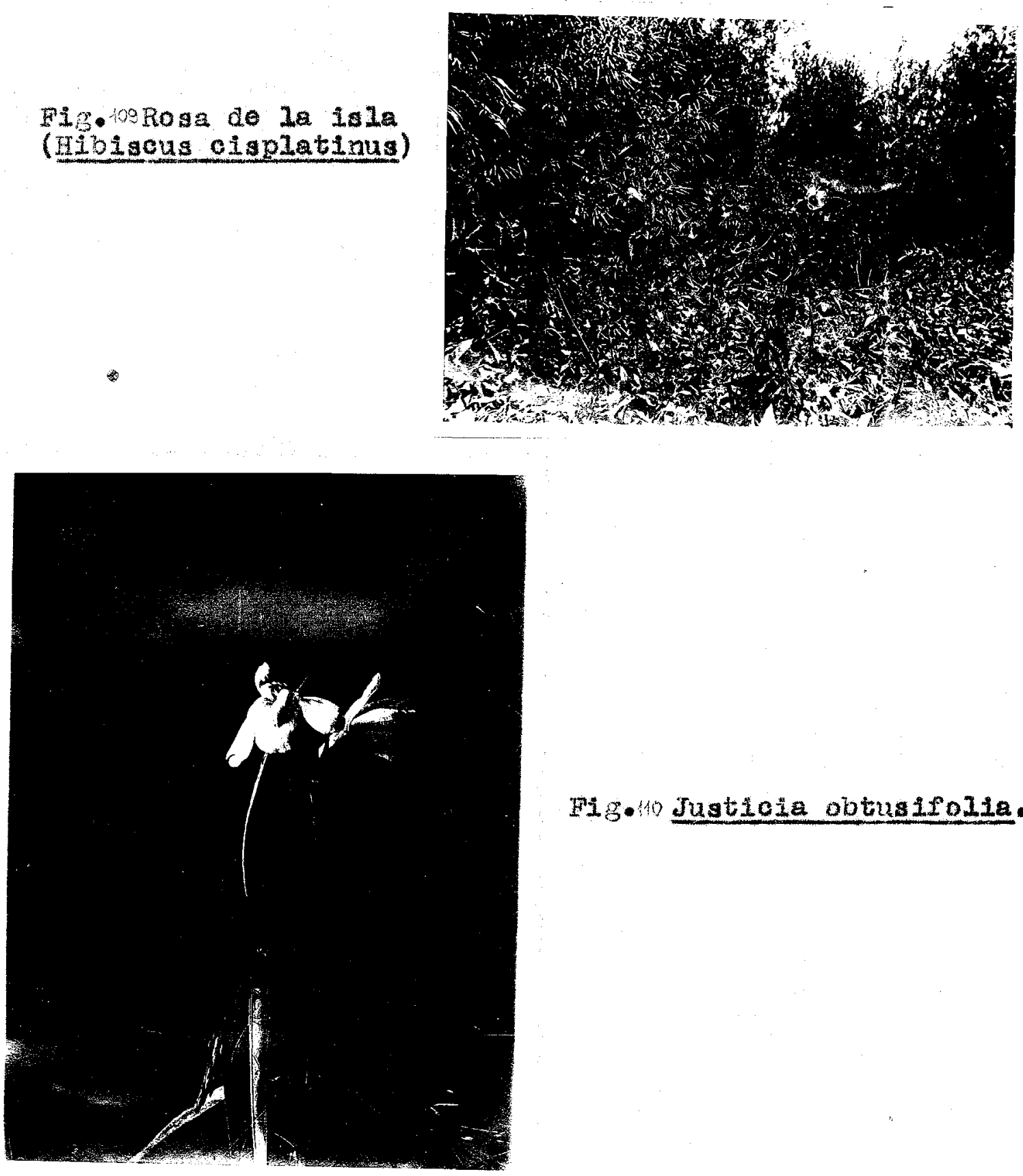

Fig 10 Justicia obtusifolia.-

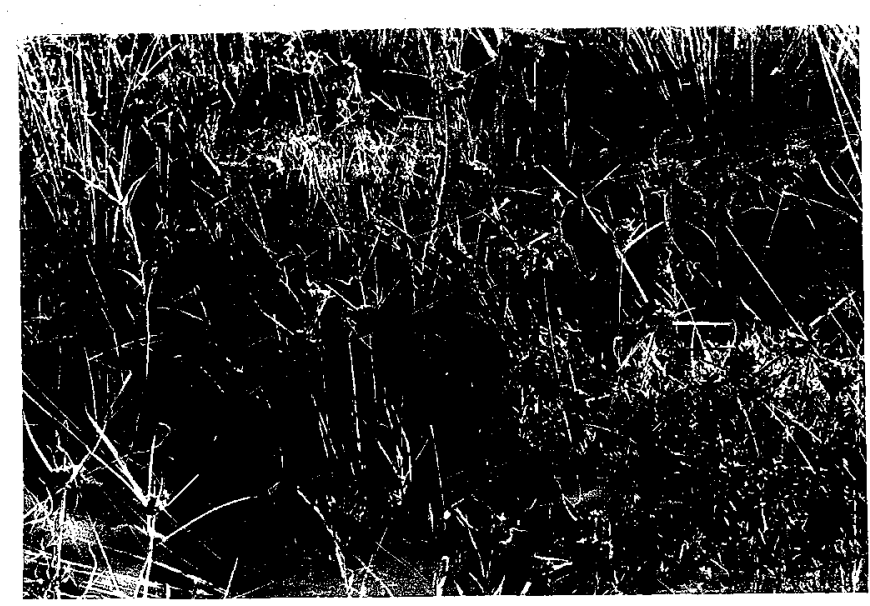

F1g. III Cyperus 1aetus--

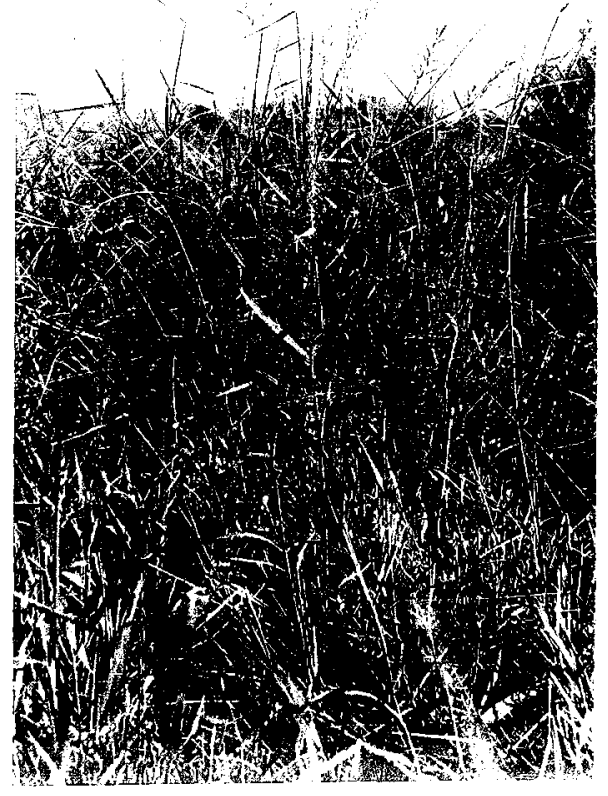

D1g.12 Ertochloa monteviaen- 
Censo grafico correspondiete al Pajonal (Asocies de Panicum pronctes y Schaefferia uruguayensis) superficie estudiada en $\mathrm{m}^{2} \cdot 100$.

Fécha: 5-1:49

Cobertura: $70 \%$

Altura de la vegetación 2-3 metros

Suelo: inundable arculloso

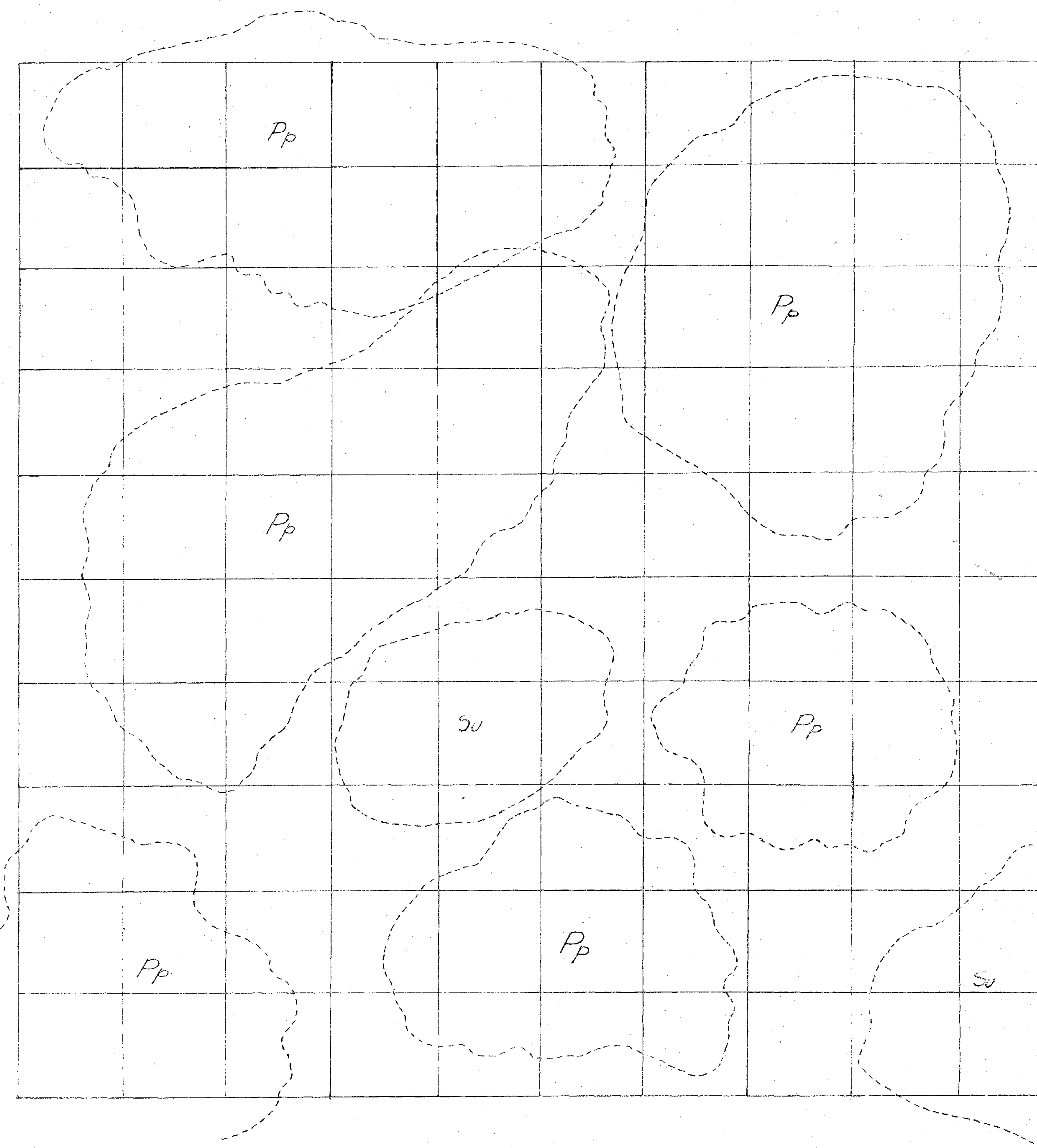




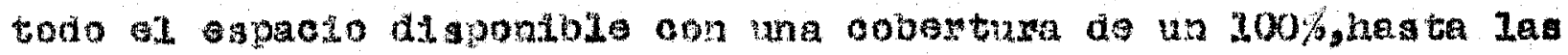

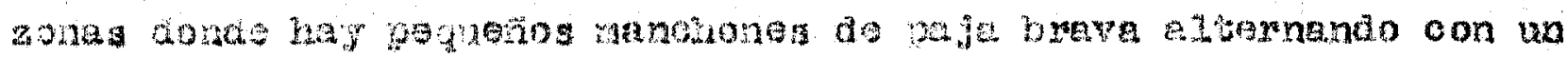

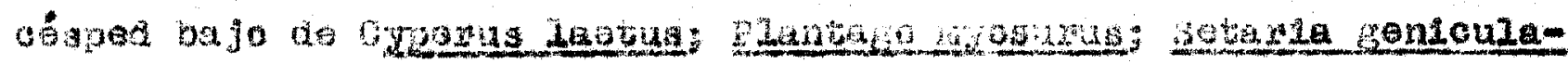

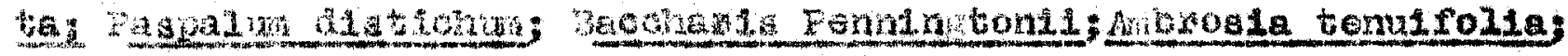

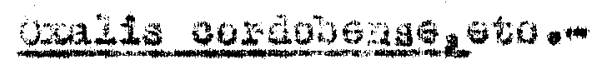

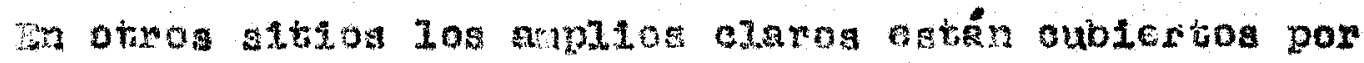

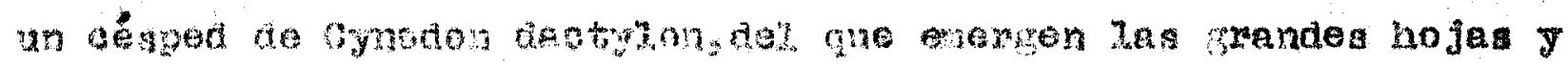

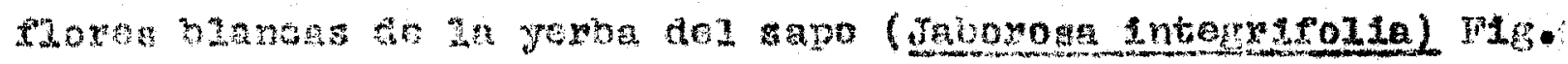

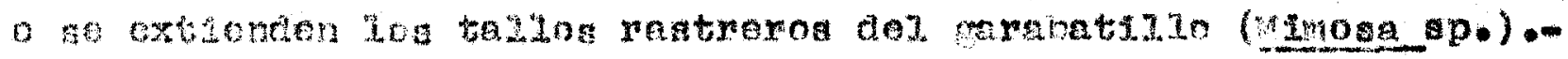

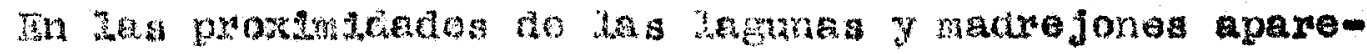

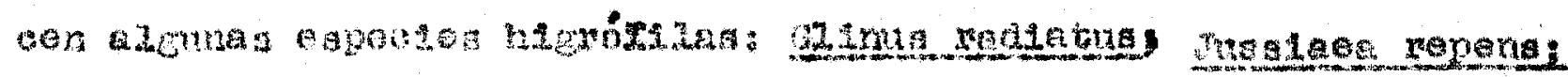

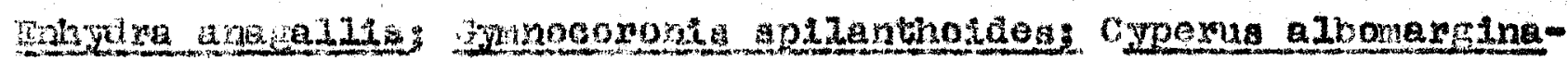
tis

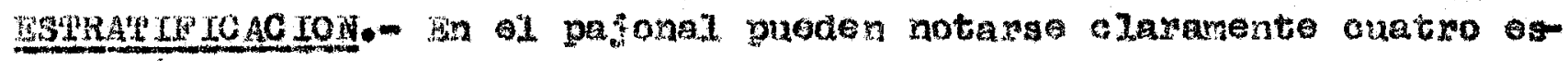

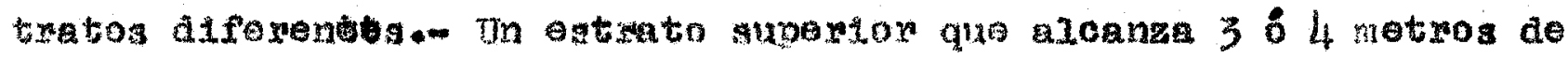

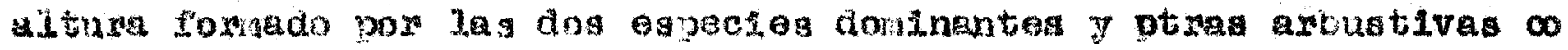

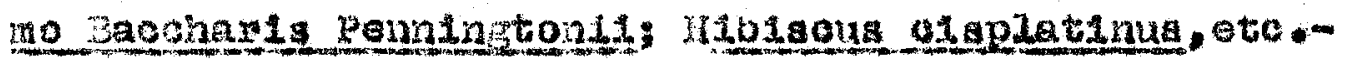

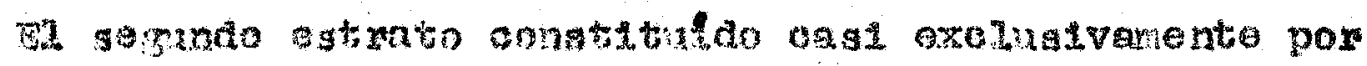

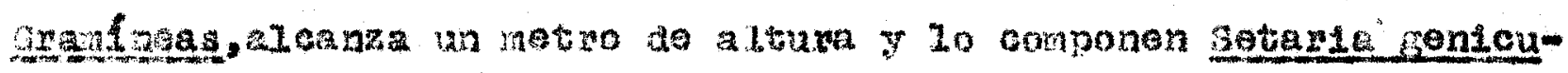

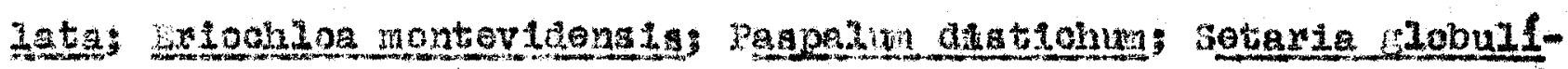
teng, oto...

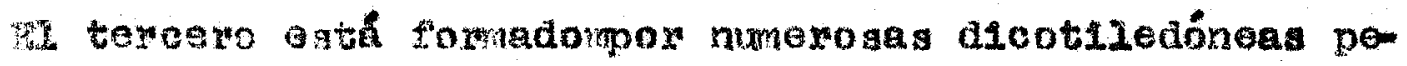

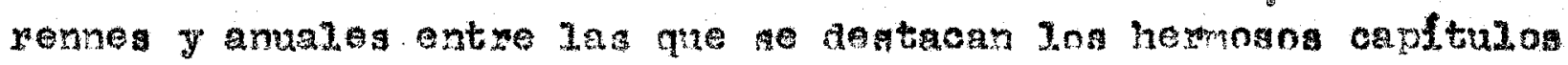

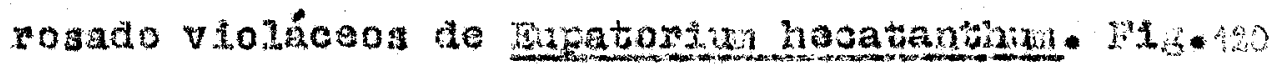

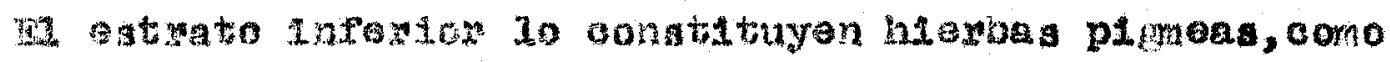

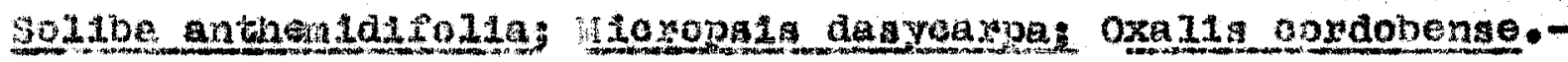

Ina areadaderas son muy commes yintiluzan como apoyo al

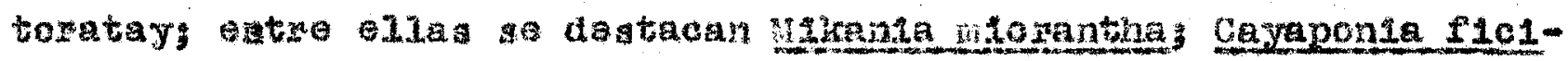

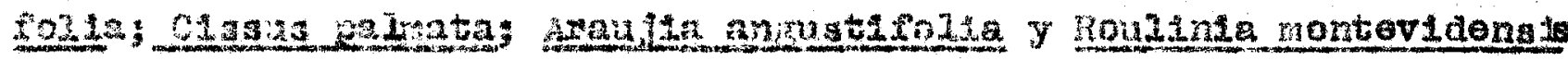

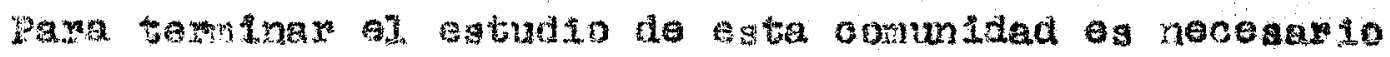

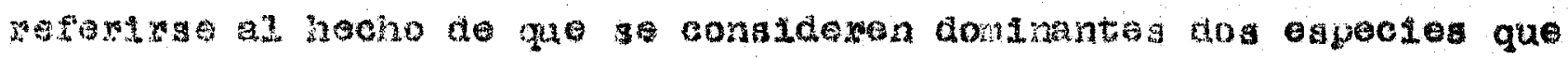

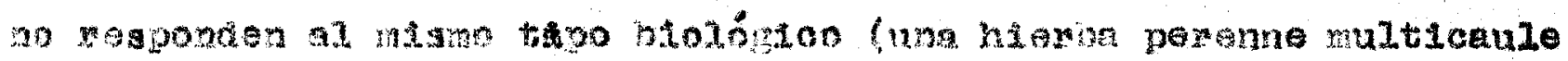



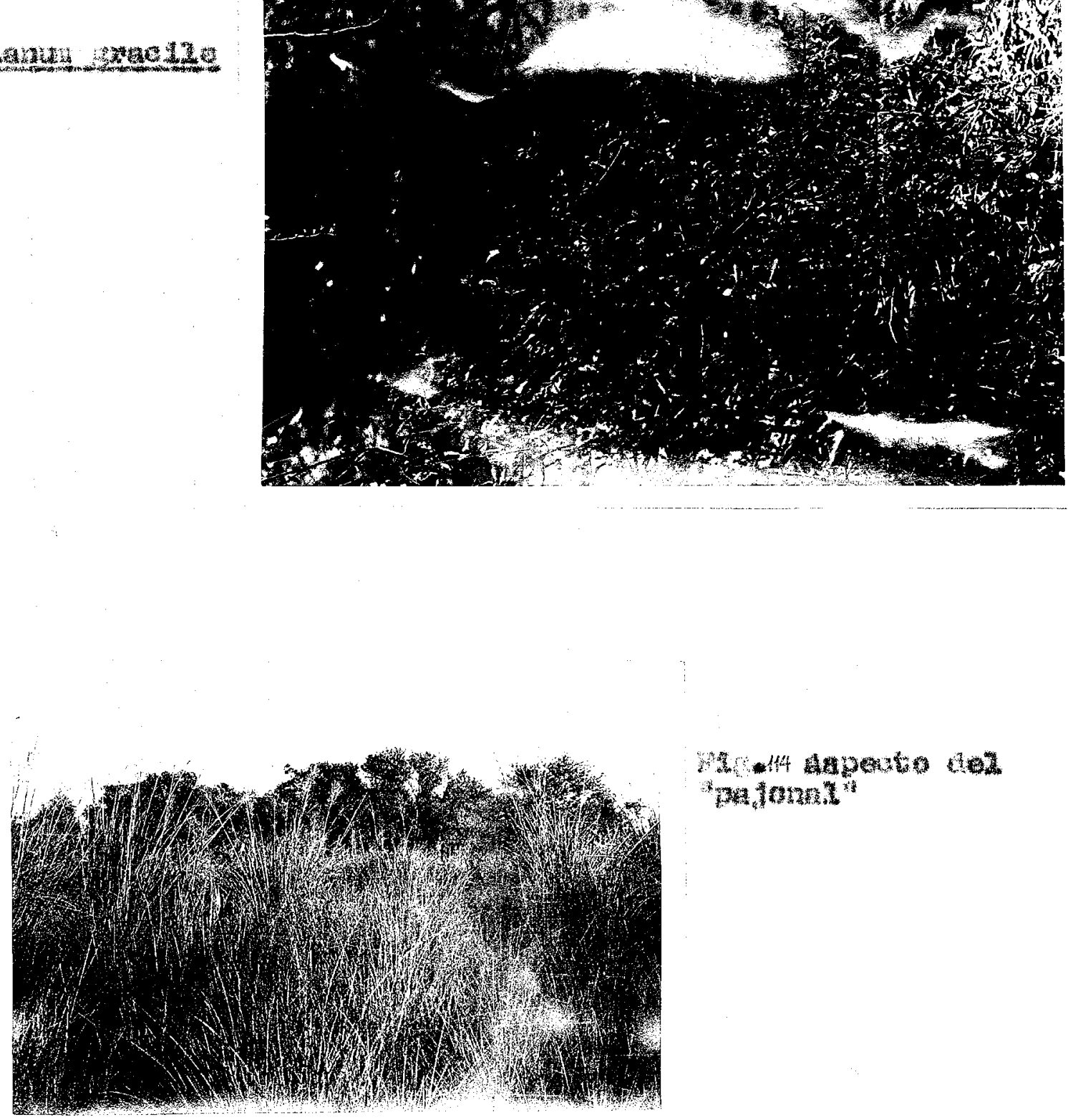

7. "jस
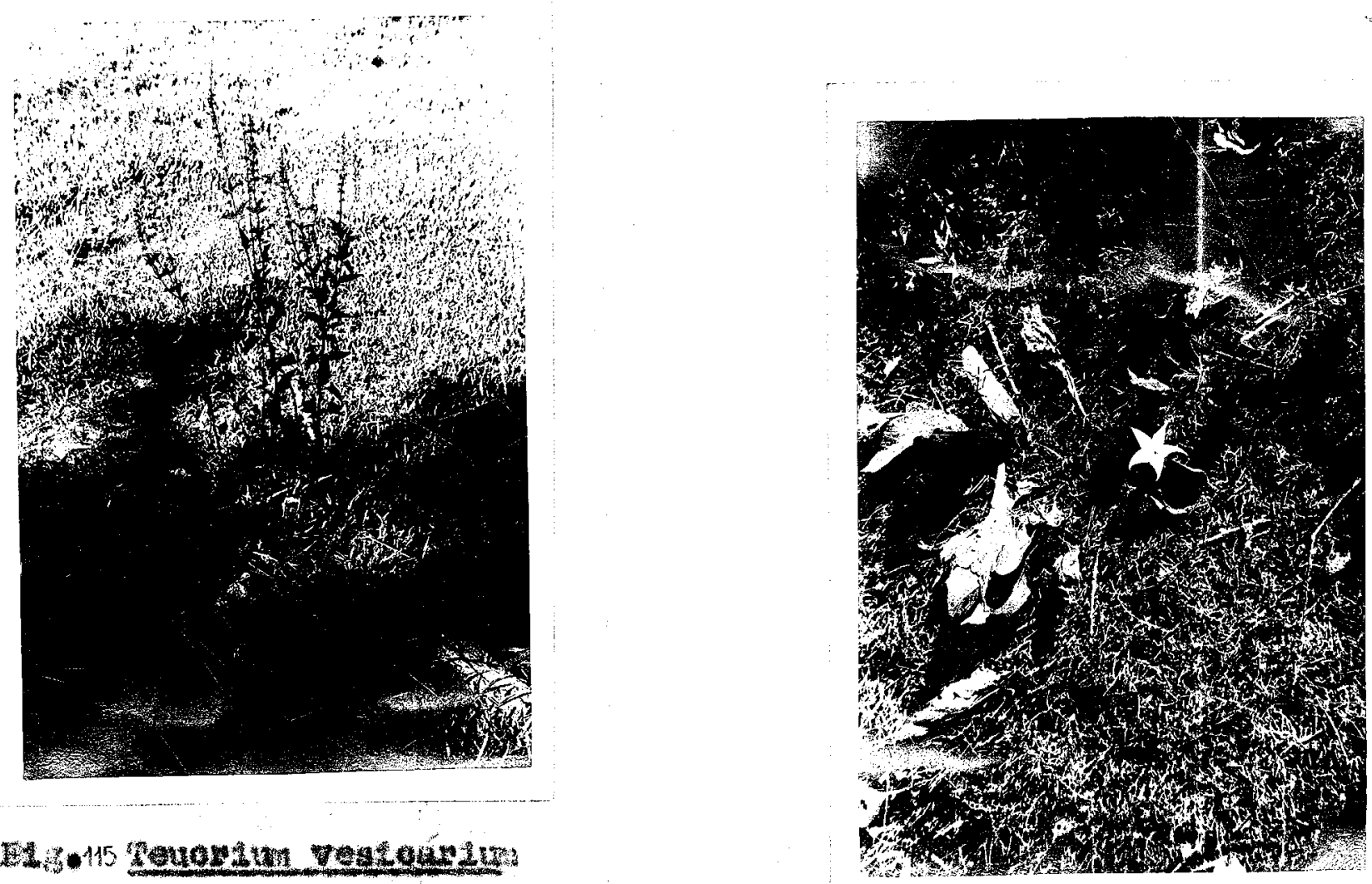

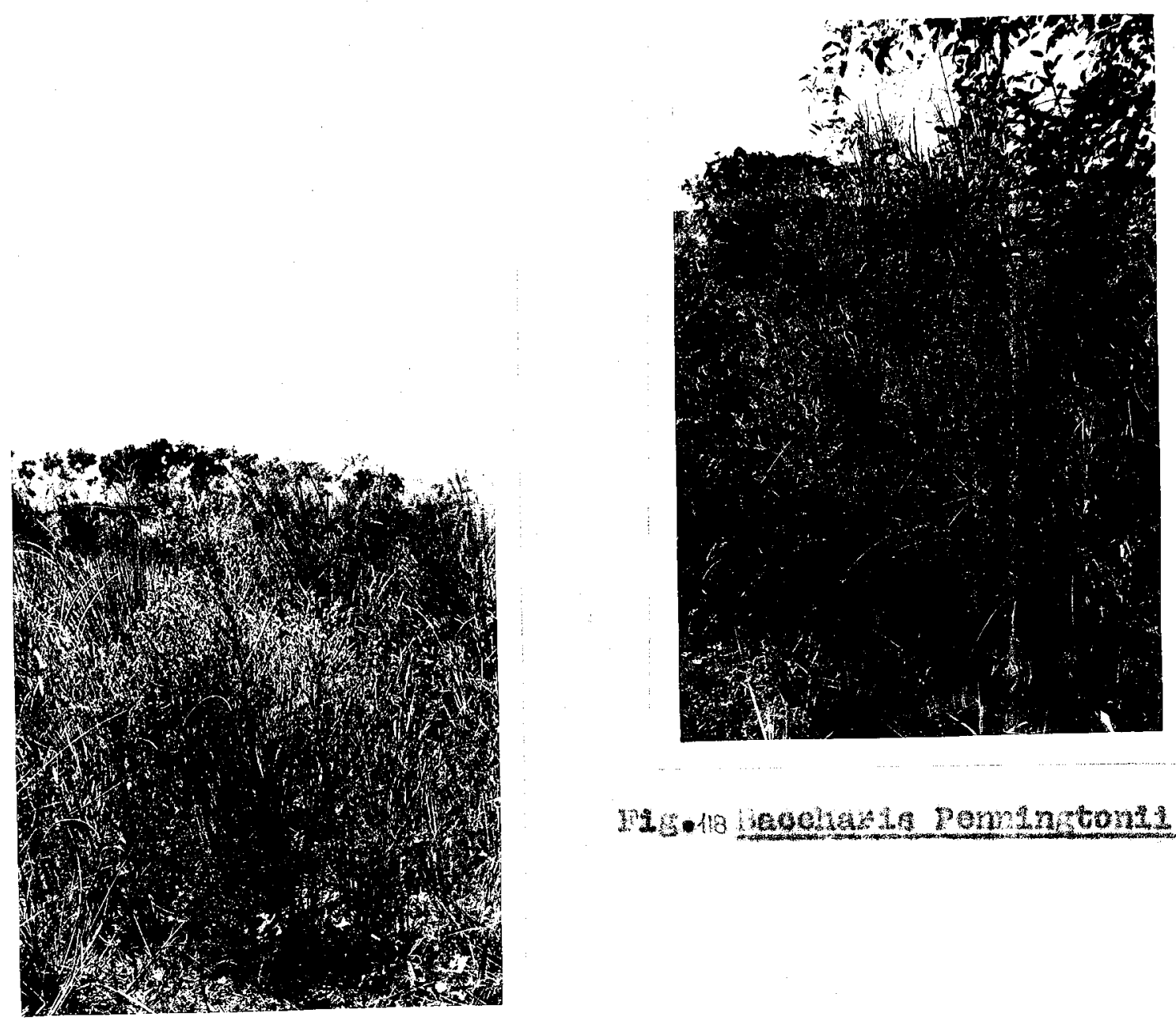

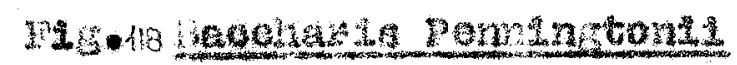

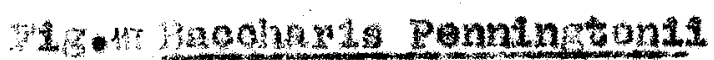
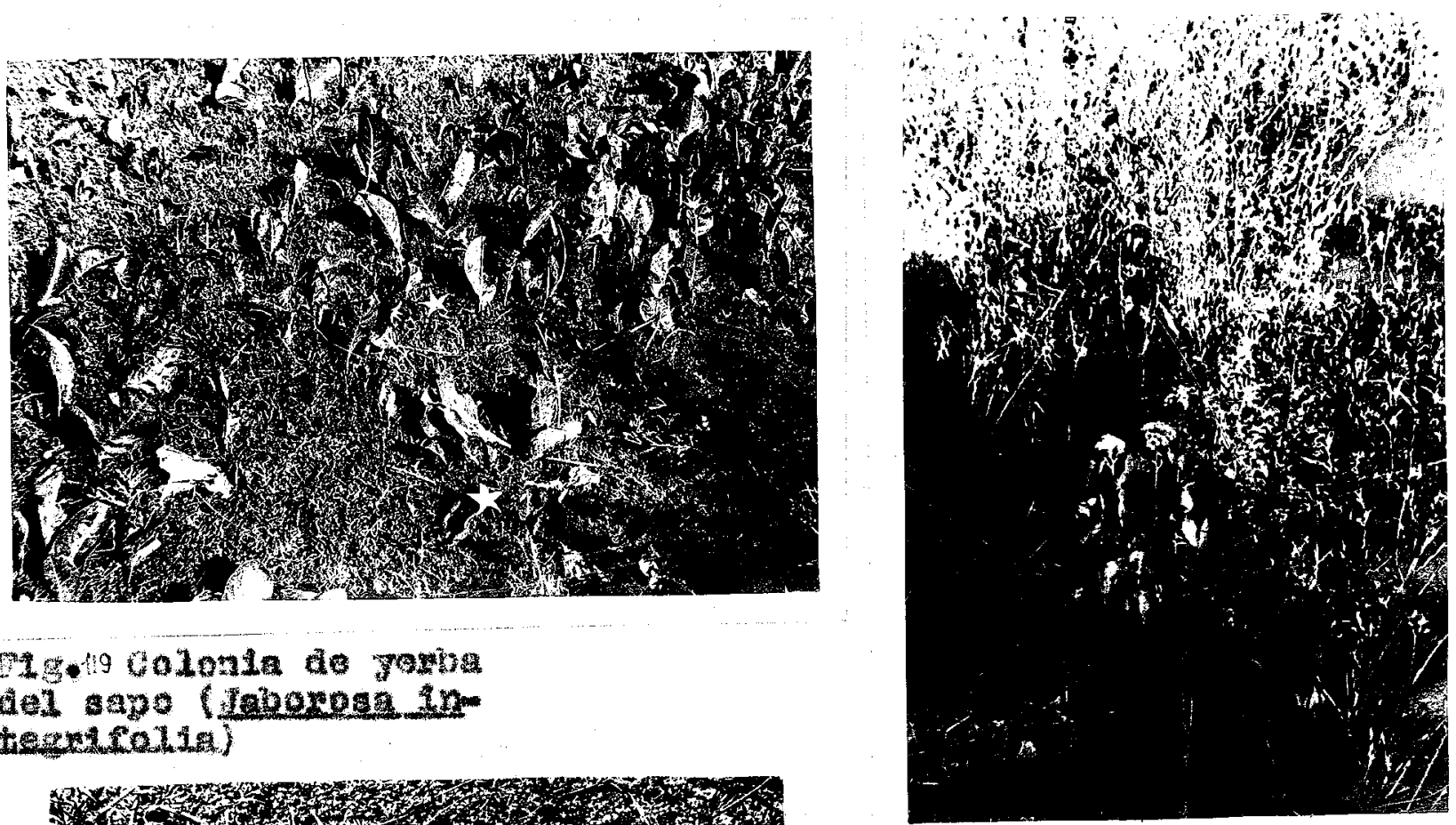

Dig. Colonia de rayba

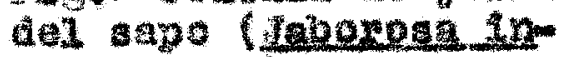
tegetrould

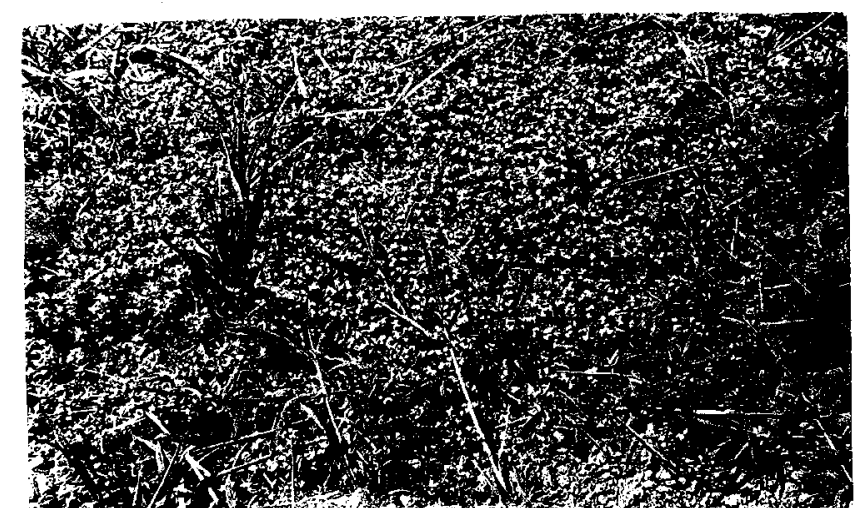

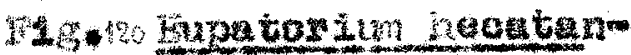

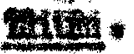


y un arousto), romplendo as una loy cati axionéton on ecologla que dice: Modos Ios doninantes de ma comniard depen pentenecer a la

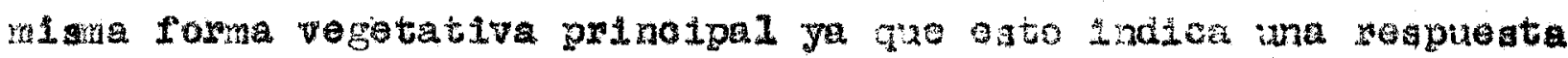

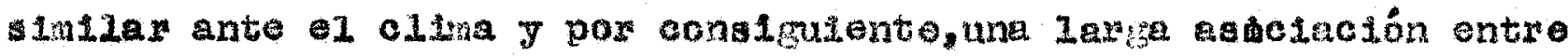

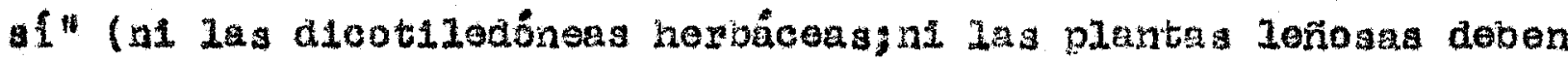
sor conslderadas domlmatos on 10: pastizales). ( Hozver y clenents $\operatorname{pag} \cdot 573 \cdot-19447$.

So ha condidexado que ambea ospecled ojercon ol control de la comuniad porque cuplen lad axigencias neceserdas pera donlinar ol área que son:

1) Tanañ: au estatura as agor que if de sua competidobas.-

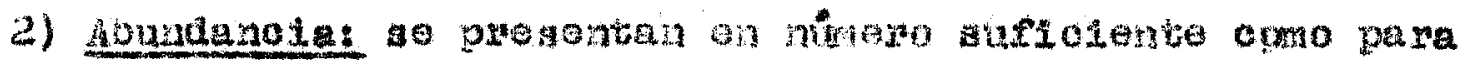
controlar el área.m

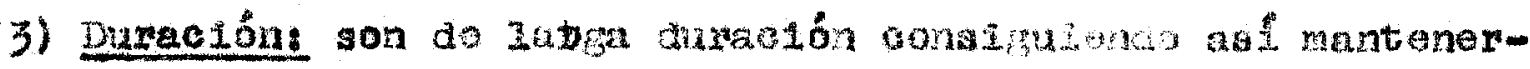
Se contra los invasores.

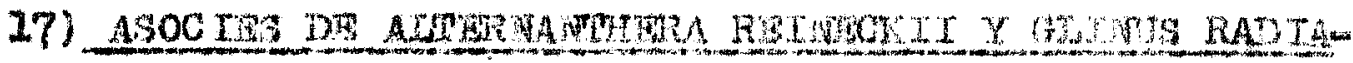

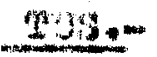

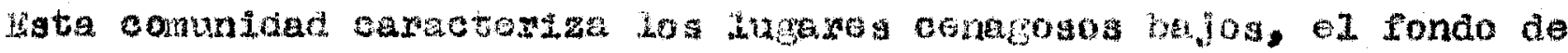

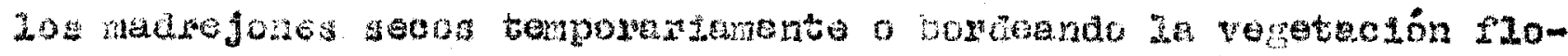
tance de Ias Lagunes.-

Gu espedes controlantes son: una Aresantácea perenne

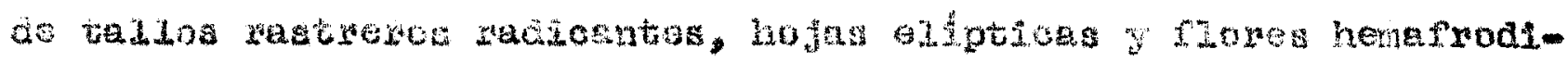

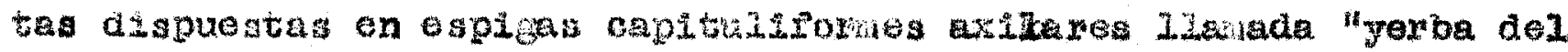

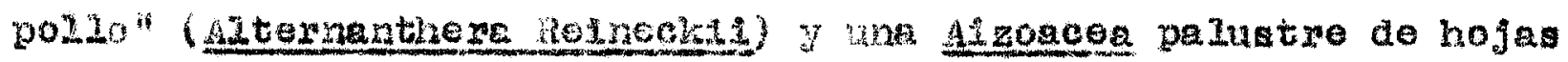

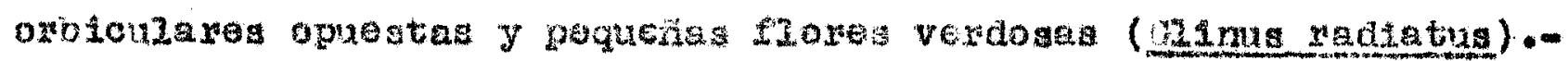
Se Introdicon en sata comnldae alonsutos de le vecinas

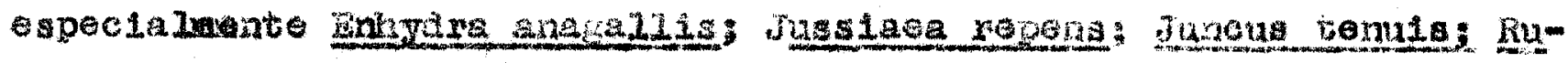

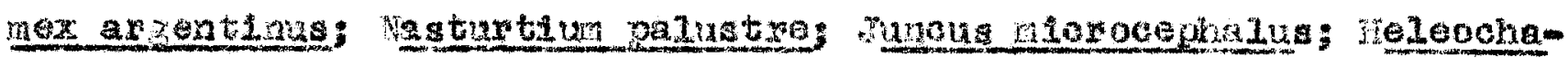

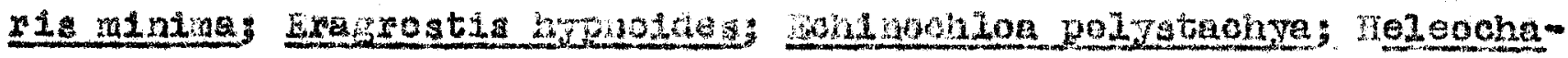

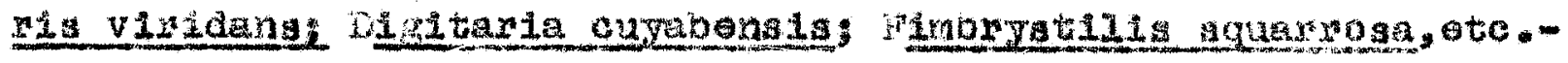

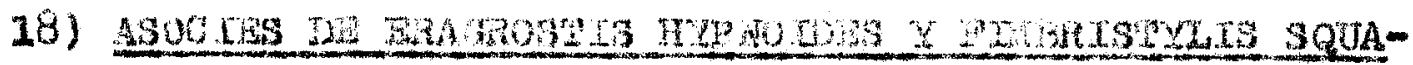
Betse-

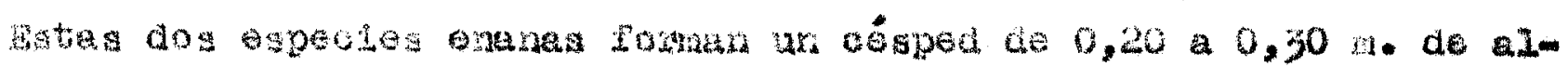




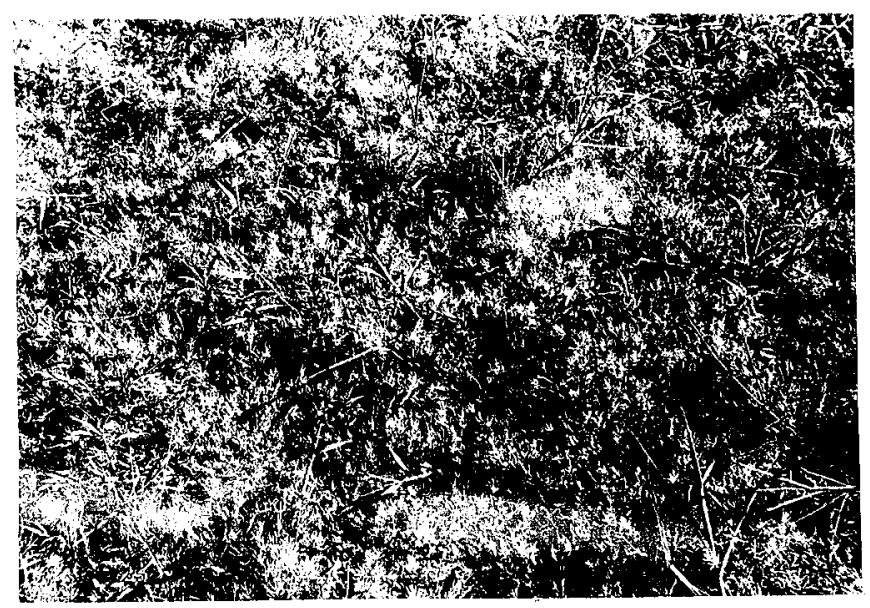

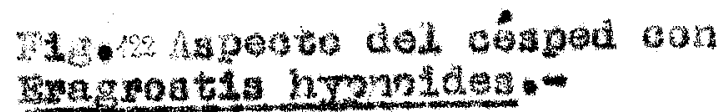

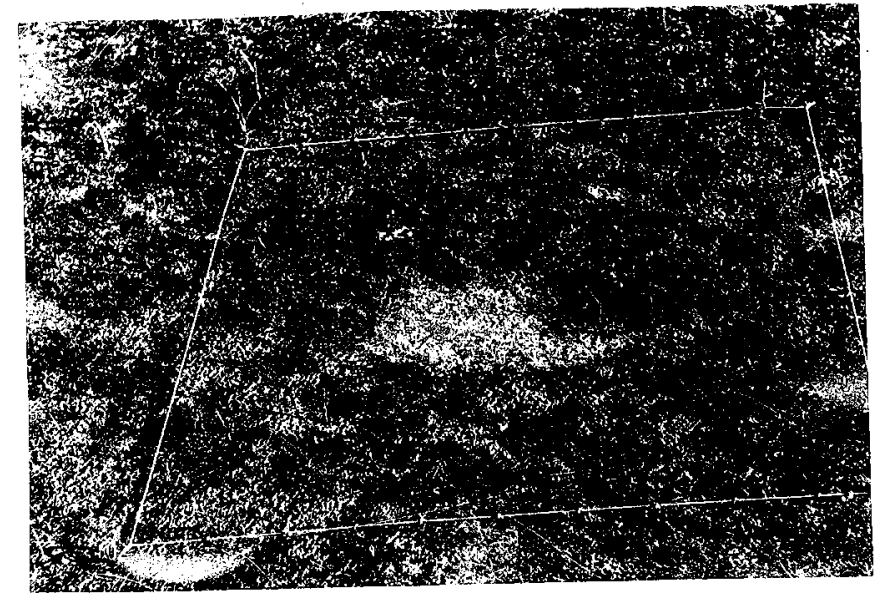

3.5.

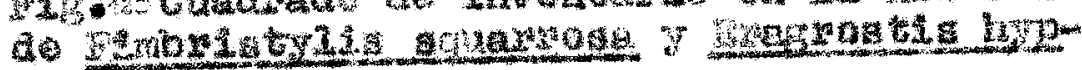
not dxse- 
tura que cubre on una anplia faja de 50 a 150 m. Las nárgenes arow

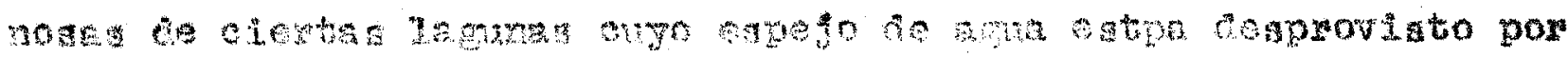

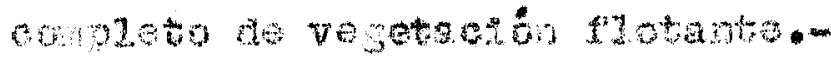

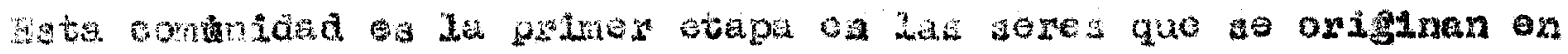

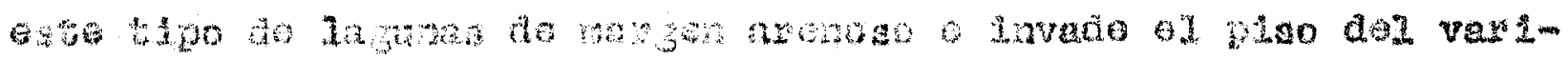

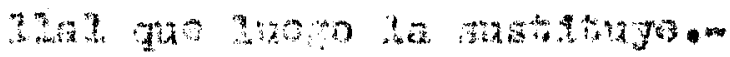

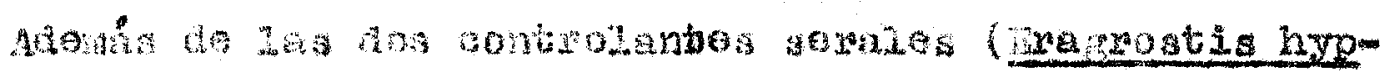

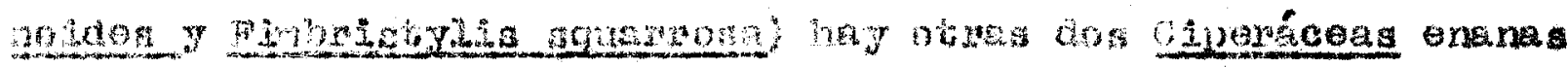

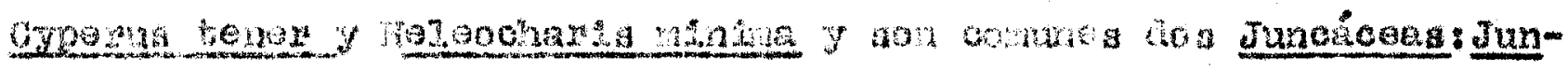

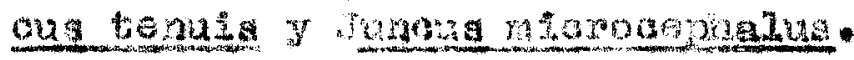

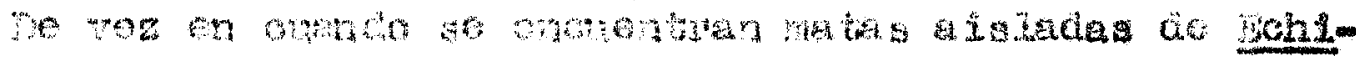

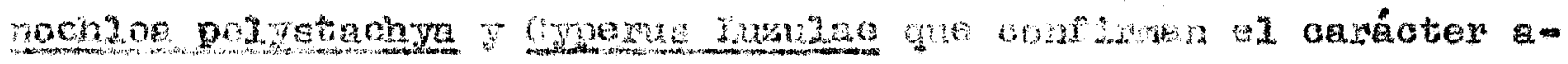

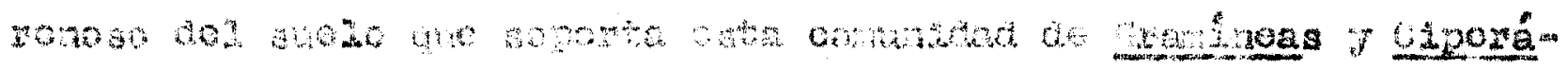
cosin-

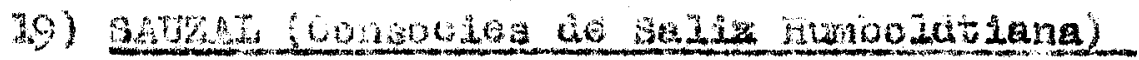

1240.1245

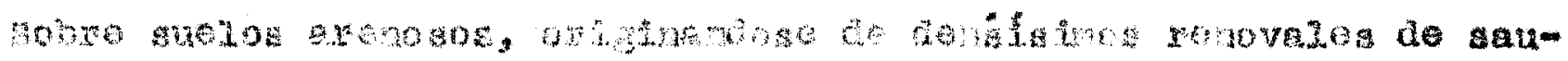

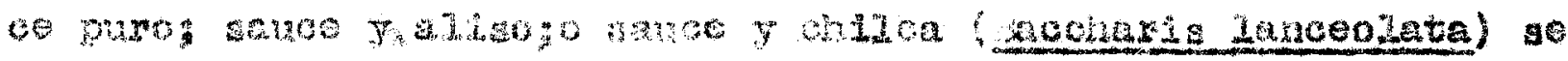

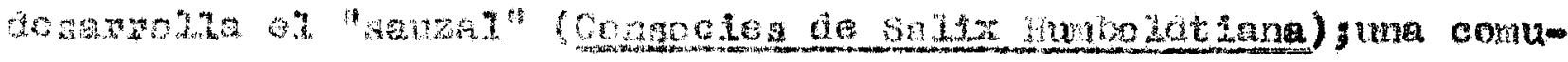

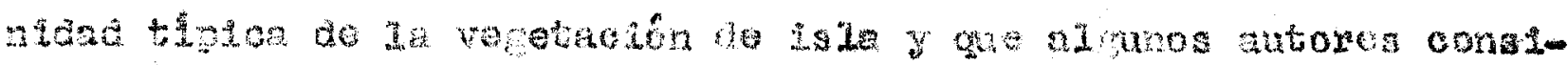

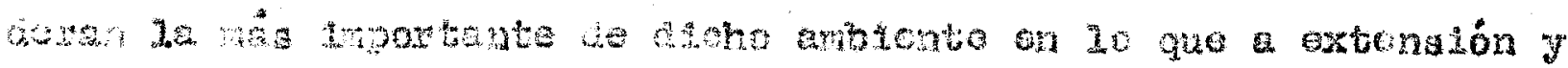
eroluclón de neflere.-

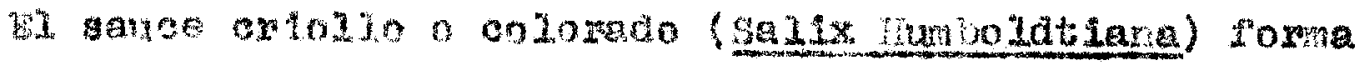

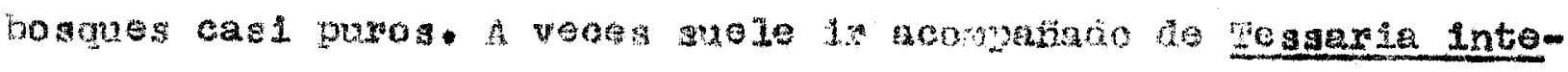
molla.-

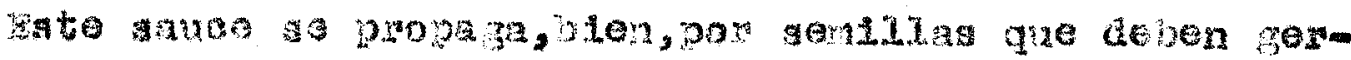

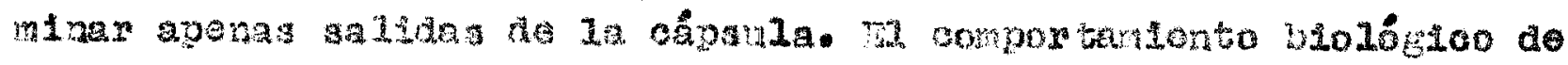

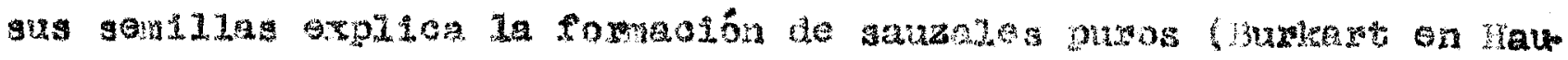
$\operatorname{man}$ eve. $2947,02,3081 . \cdots$

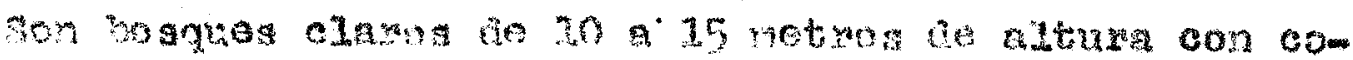

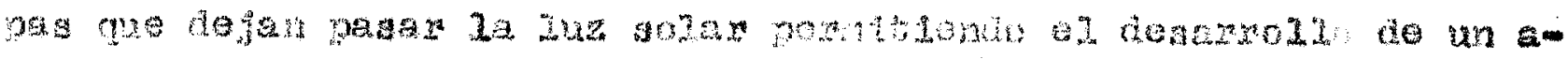

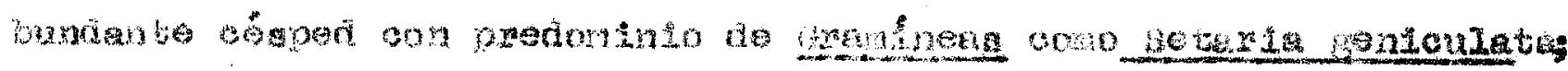




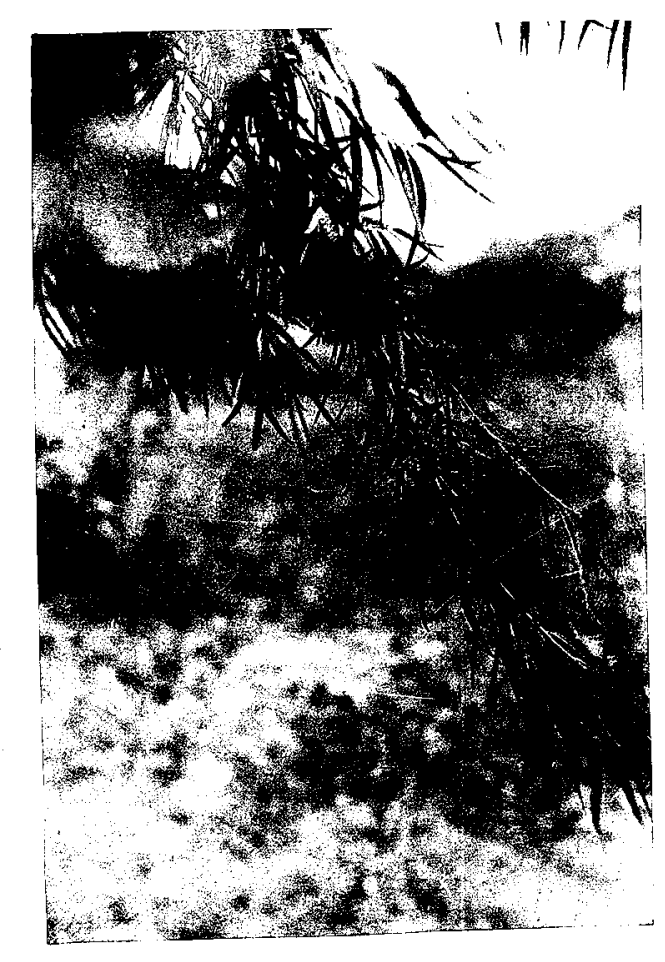

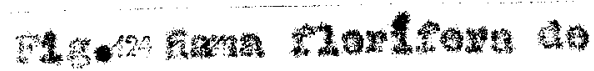

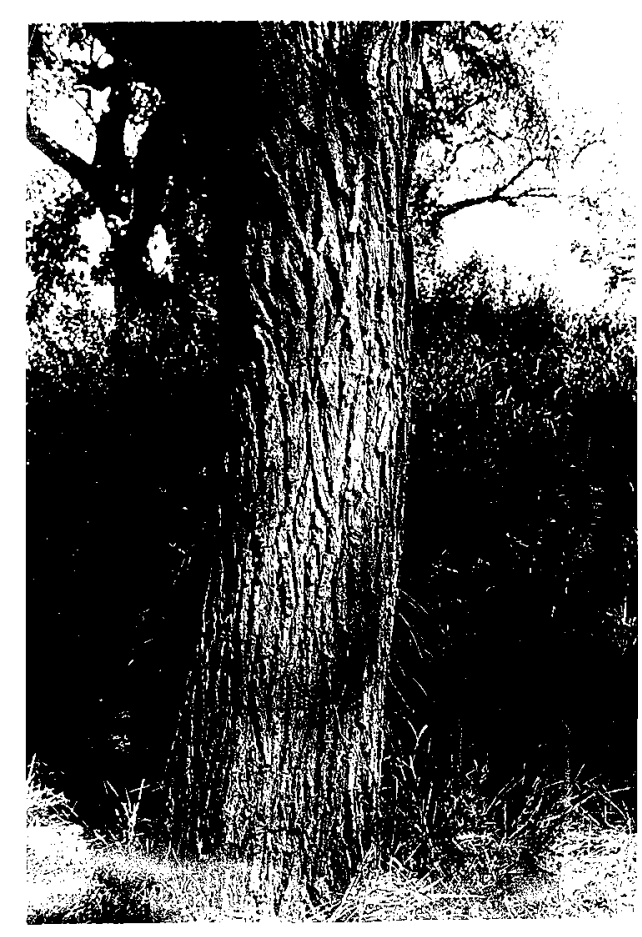

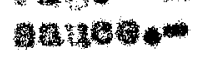

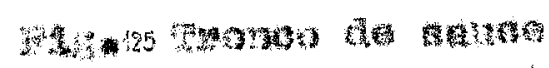

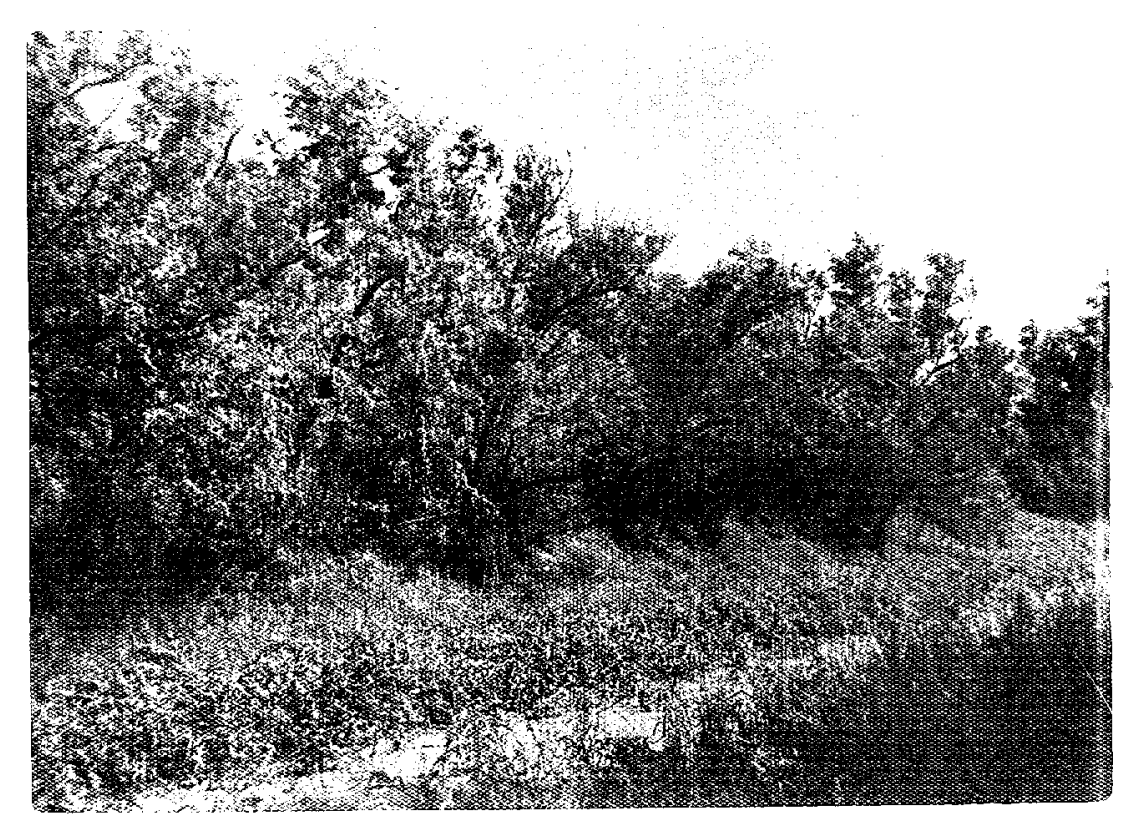

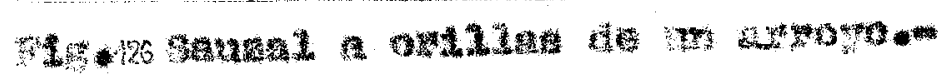

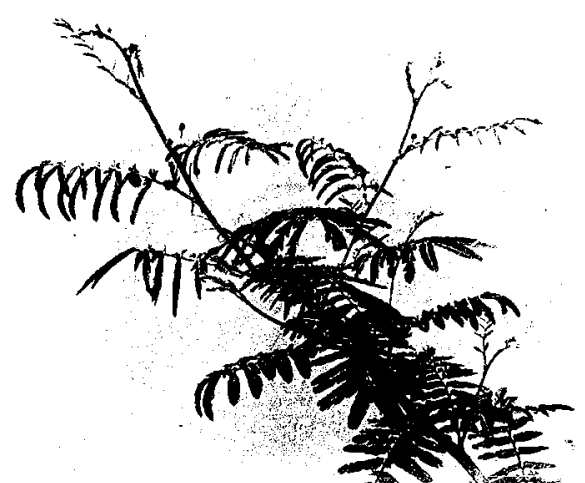


Superficie estudiada en $m^{2}: 100$

Fectad 11-1-49

Altura de la vegelacion: 10-12 metros Cobertura: $80 \%$

Bosque abierto

Suelo arenoso humedo

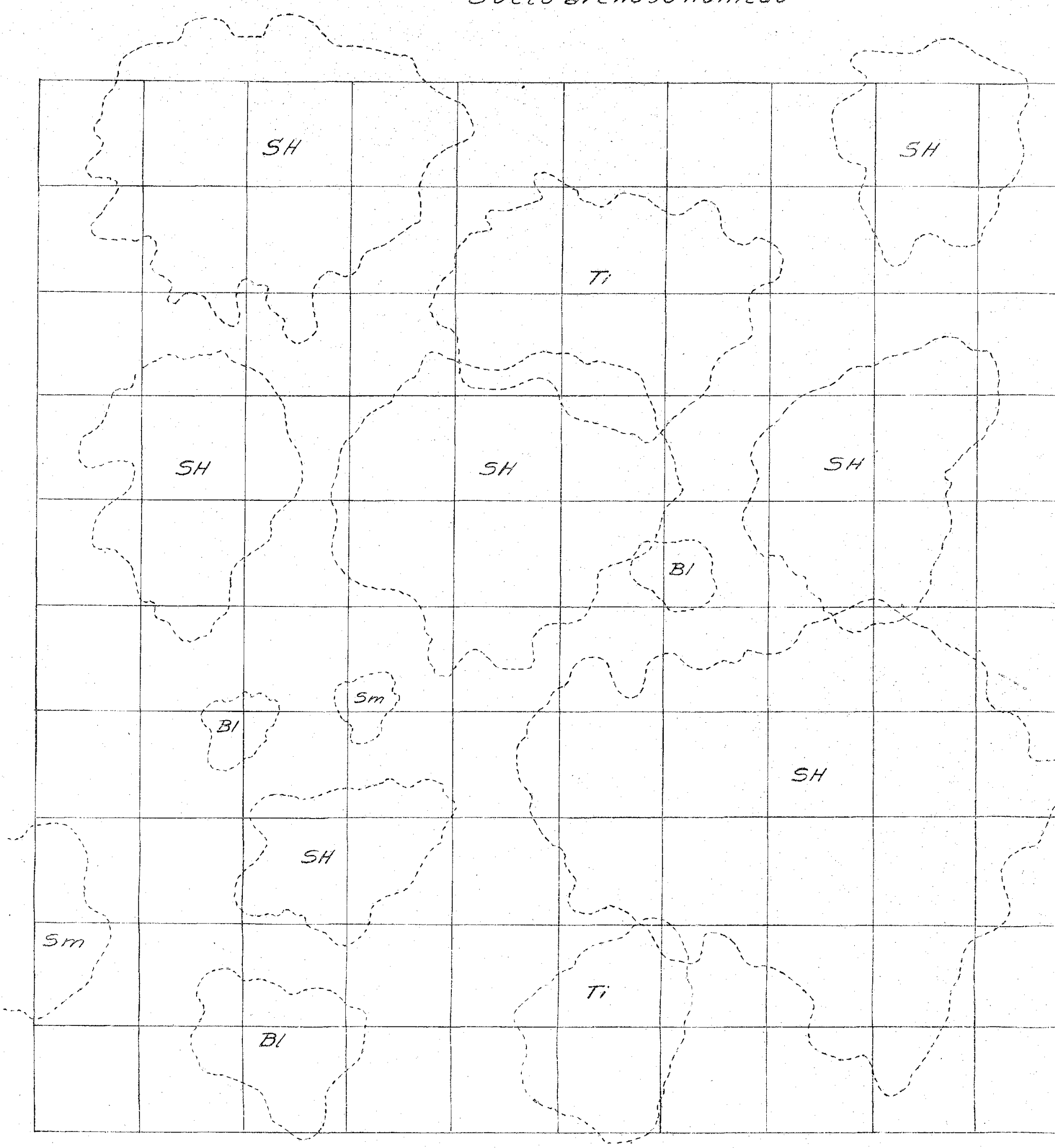

B/: Bacchanis lancroolata

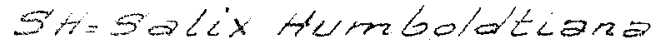

sm = Sesbariom margunatio 


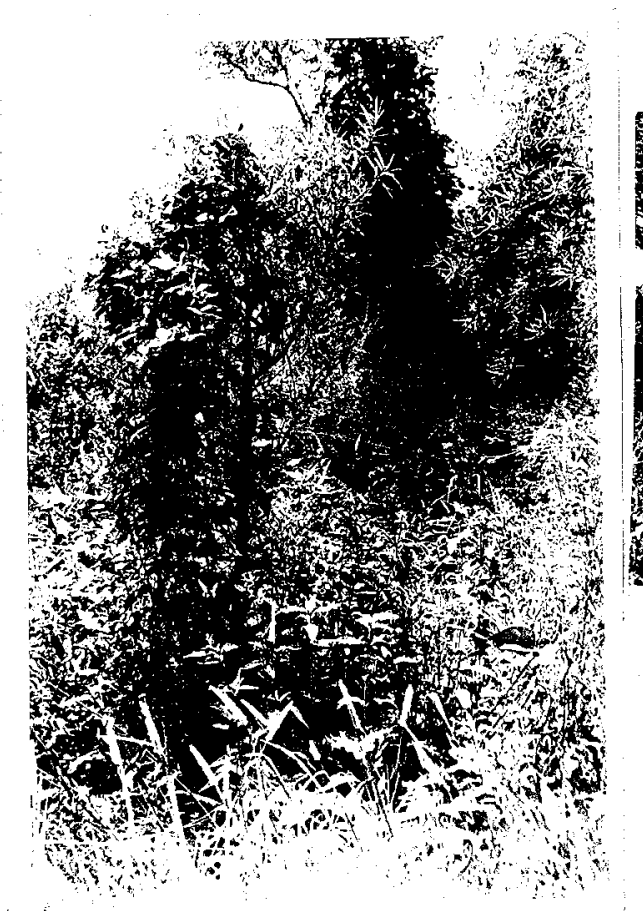

F18. Calometion aculeatum cubriendo un joven ourupi.-

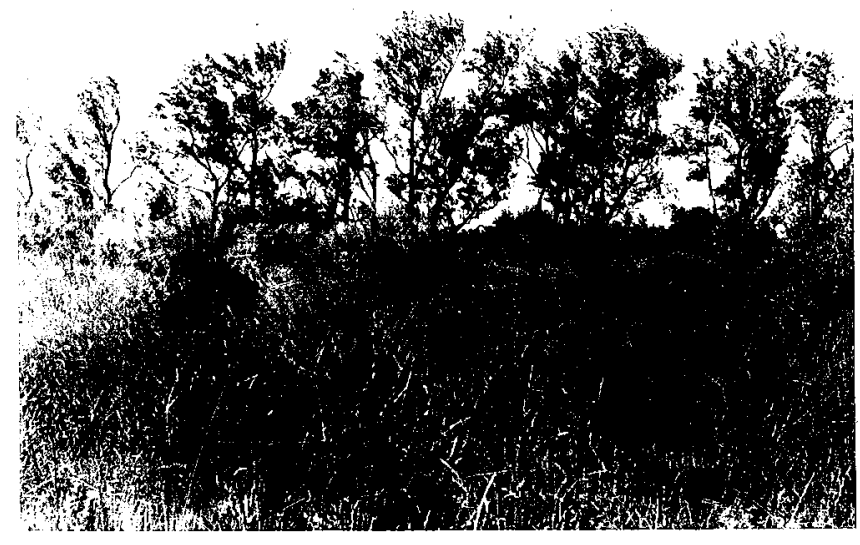

Flg. "gauza1".-
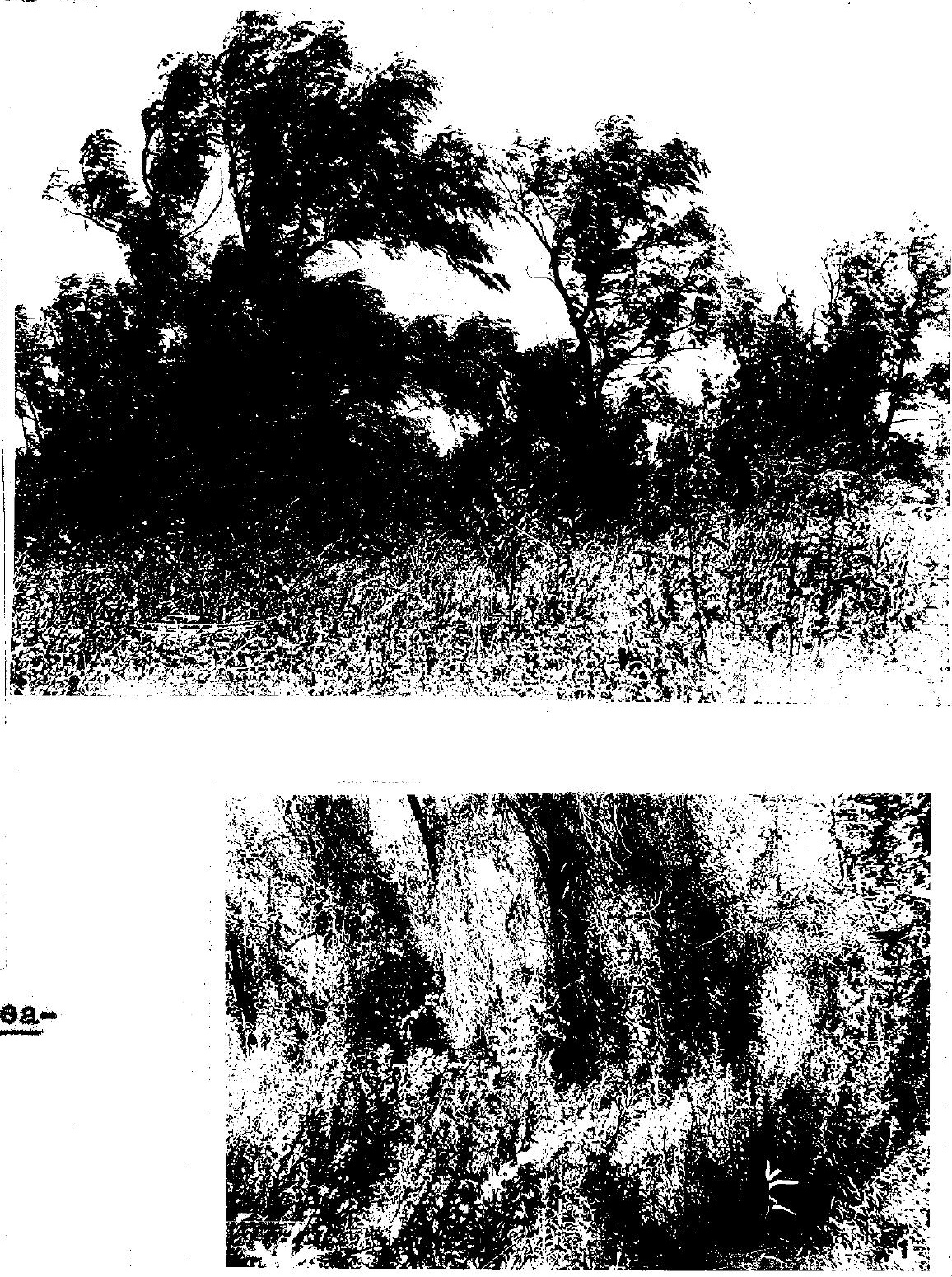

W18.180 Troneos de "sauce" comp1etamente cublertos por Ia dama de noche (Calonyetion aculeatum)

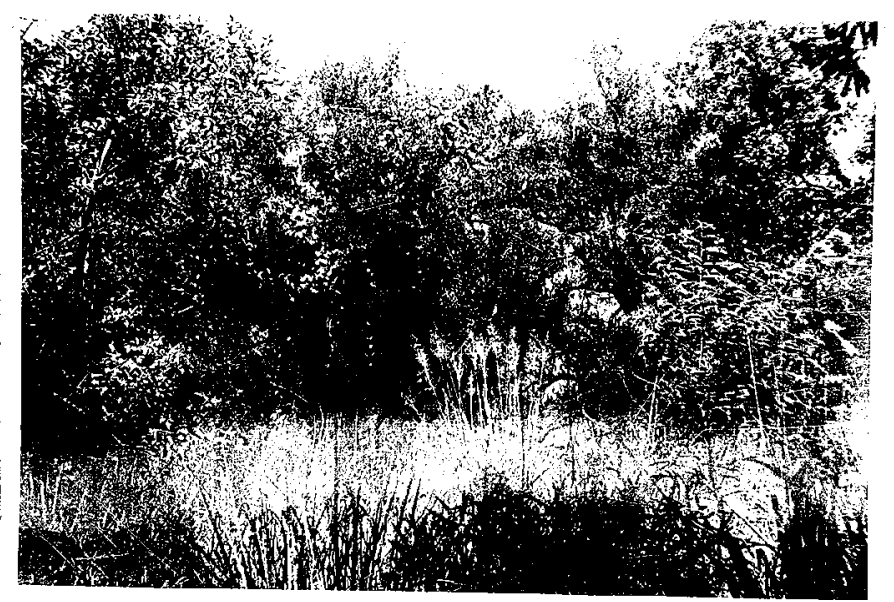

Flg.32 Interion del "aauzal".- 


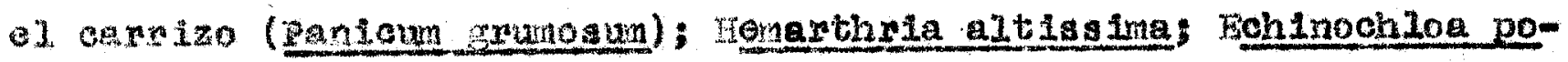

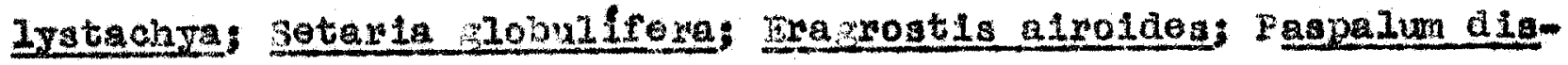
tLcium, etc,asocledas a varlas compuestas. Iupatarlum hecatanthum:

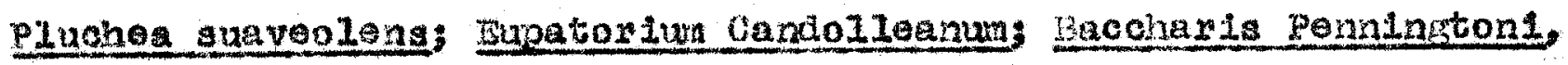

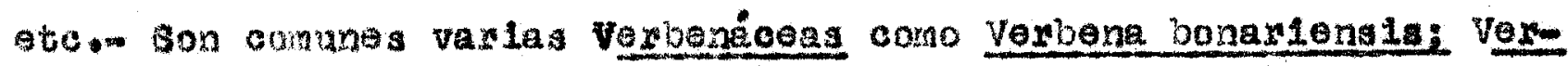

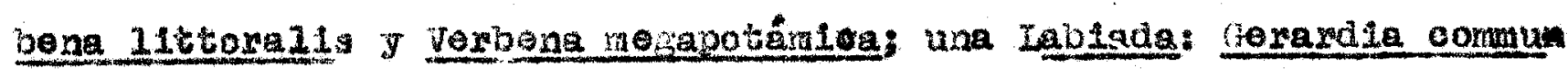
nis y ua Le

Ios aroustos eatrix pepresentados por casi todos $10 \mathrm{~s}$ -

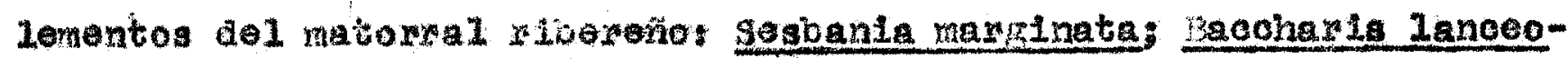
1ata; toratay, obc.-

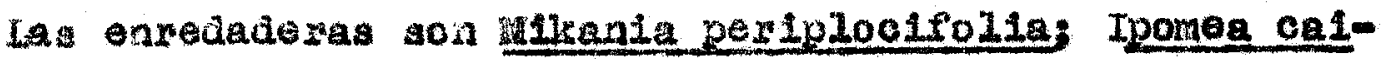

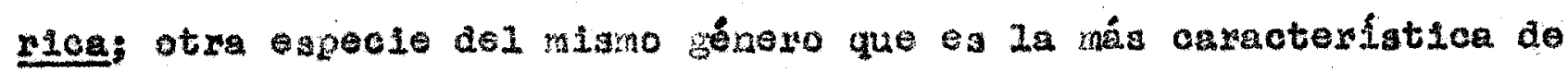
osta comunlaad y $116 \mathrm{ga}$ a curlu completamento loa troncos con su fo11ajo: Inprea aloa; una Iezuninosa con floxes de estandarto onrolla-

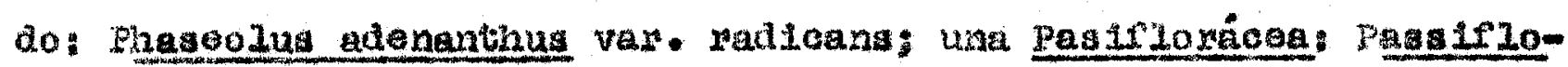

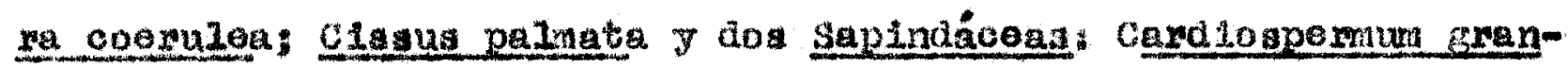

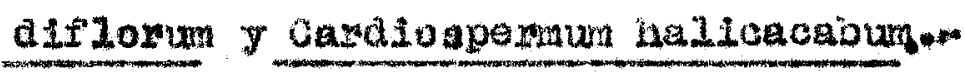

4ta comundad ha ldo aotivo de vaxias interpretac lonea. Alrunos autores (parod 1929) la considoran cono ia gáa impor-

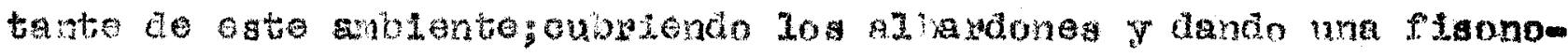
xunta propie a las 1alaa.m

Sn Reconquista, ( Parod 1934) ae dan como jacompañanto del sauce al

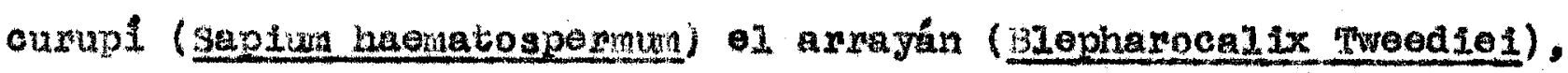

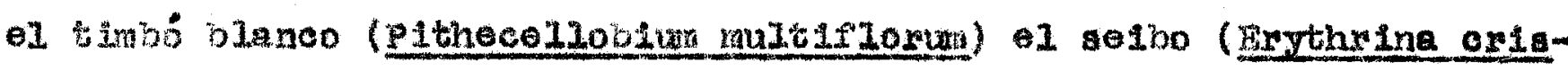
ta-ge 111): Hinose 12 gra 7 X120ana venogum.-

Gu san Neolás (randi 1929), so clta el sauzal como 1 a couvuidad néa Importante de las la las.-

Pa la zona que nos ocupa ocumo todo lo contrarios el sauzal no convive nade nás que con una le la ospeciea cltada pare Reconquista; os una hemoan gengitiva con floxos woadar y vainas enizadas de pelos castafio que 21 ga a formar matorrelos de dos me-

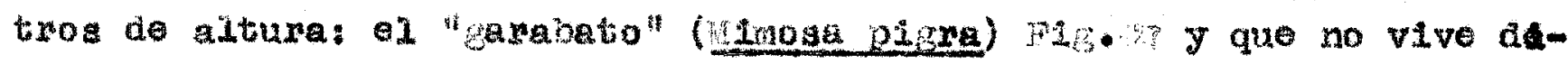



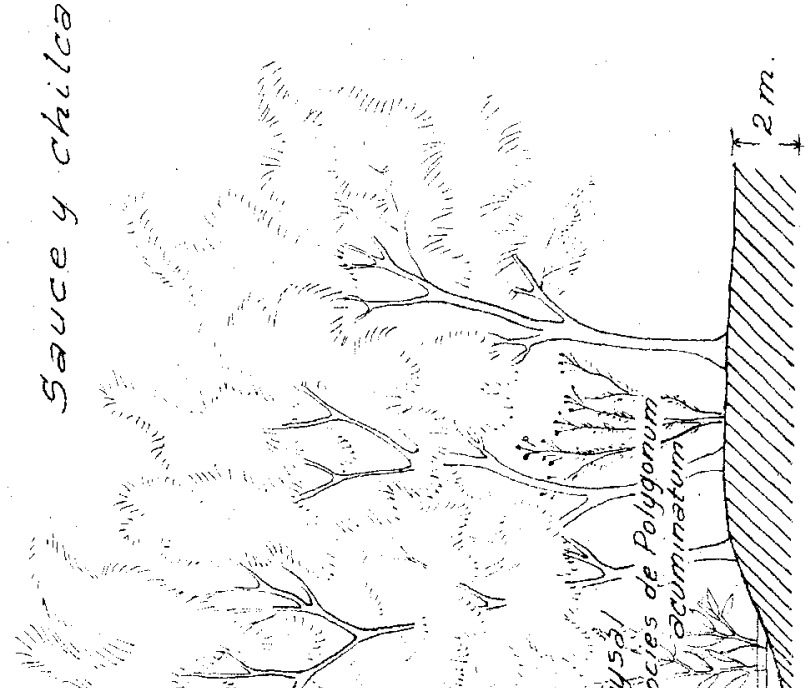

$\therefore$

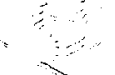

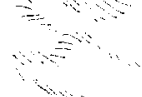

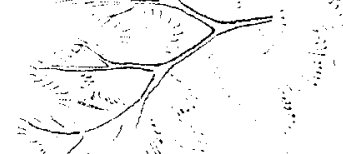

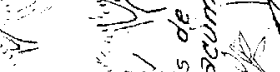

$a^{2} y^{2}=1$

0

0

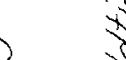

0
0
0
0
0
0
5
5
$x$
0
0
0

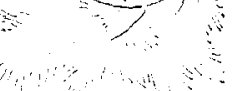

$\because$

की

5
0
0
0
0
0
0
0
0
0

ह

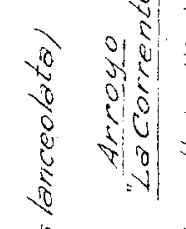

2. है है

5

0

i

2

is

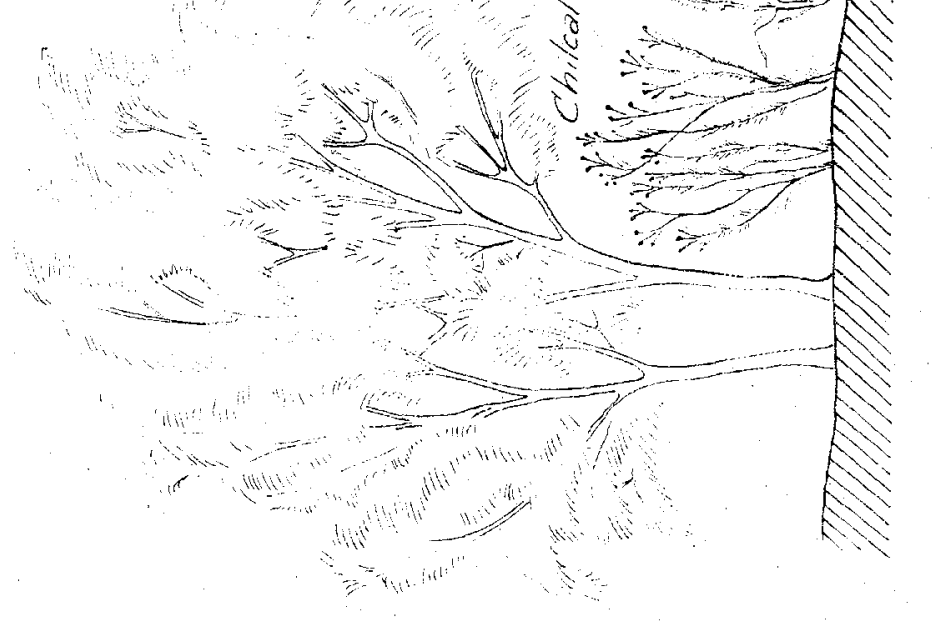


Cuadrolye26

Diagrama de frecuencia-Sauzal

(Consocues de Salix Humboldtiana)

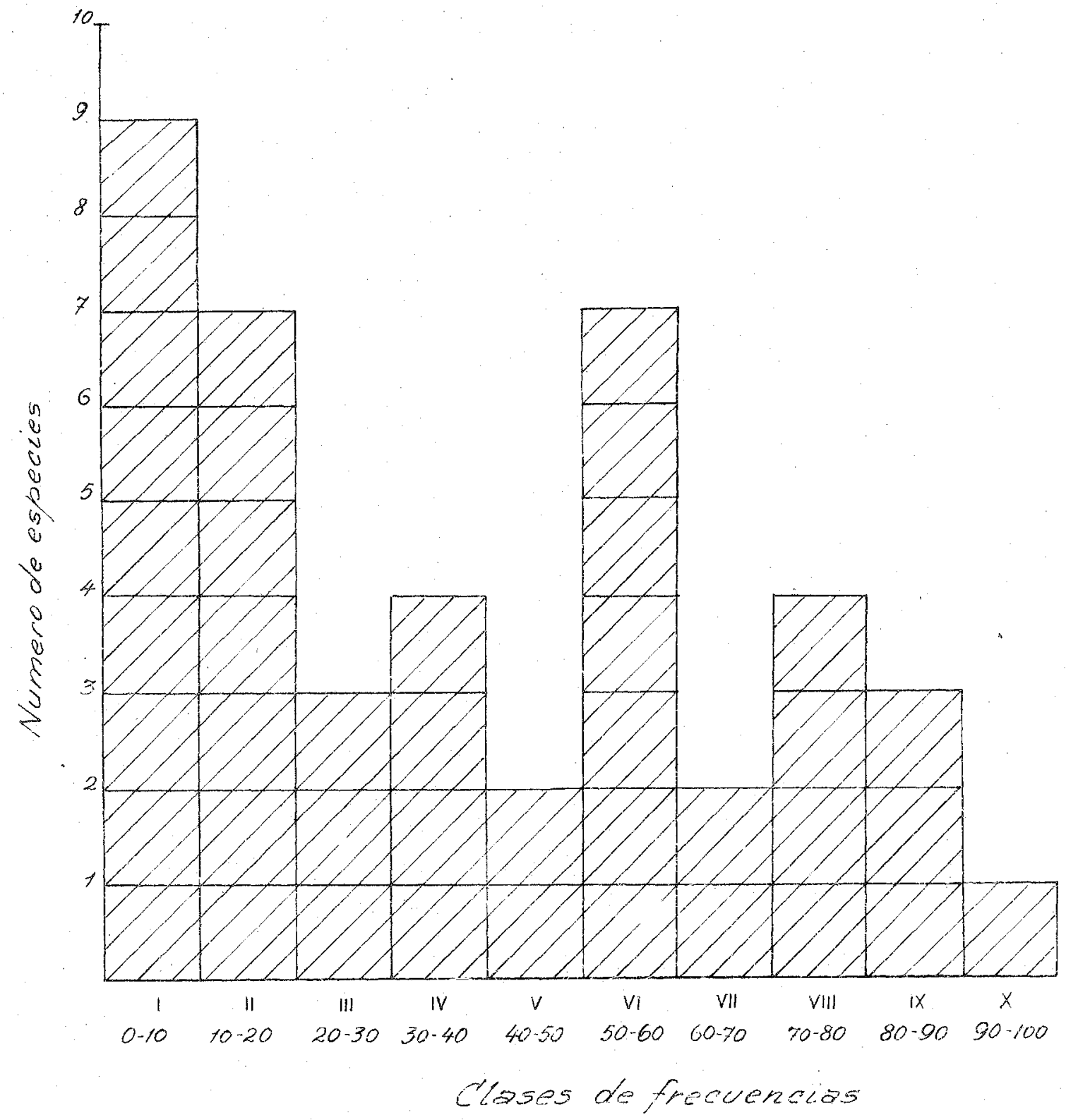




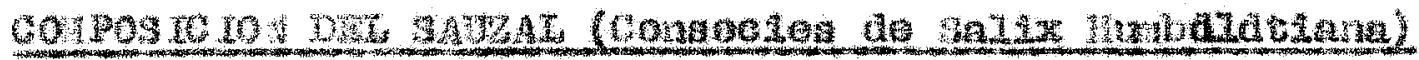

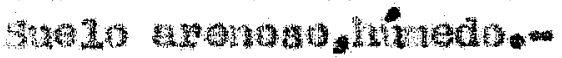

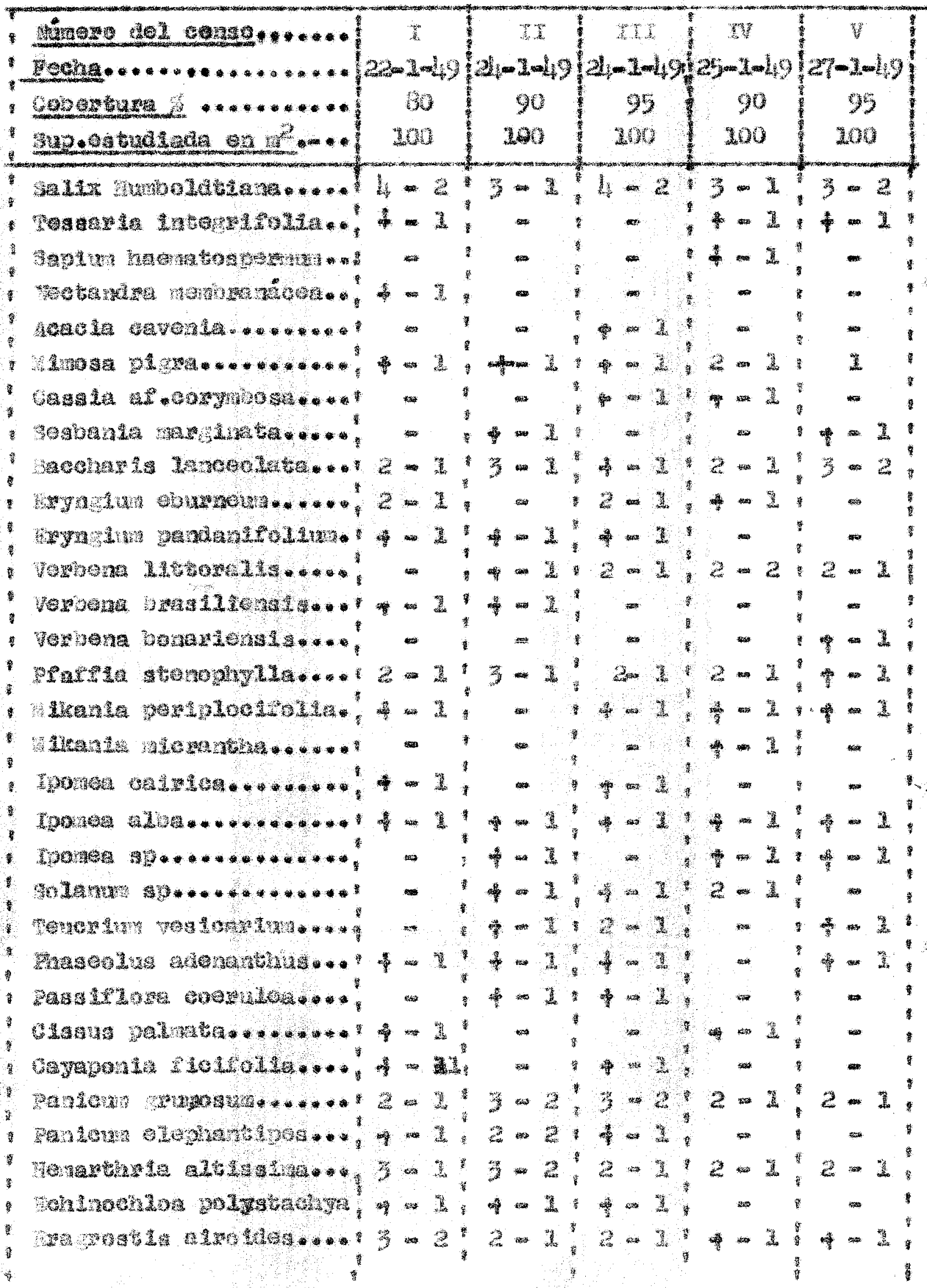




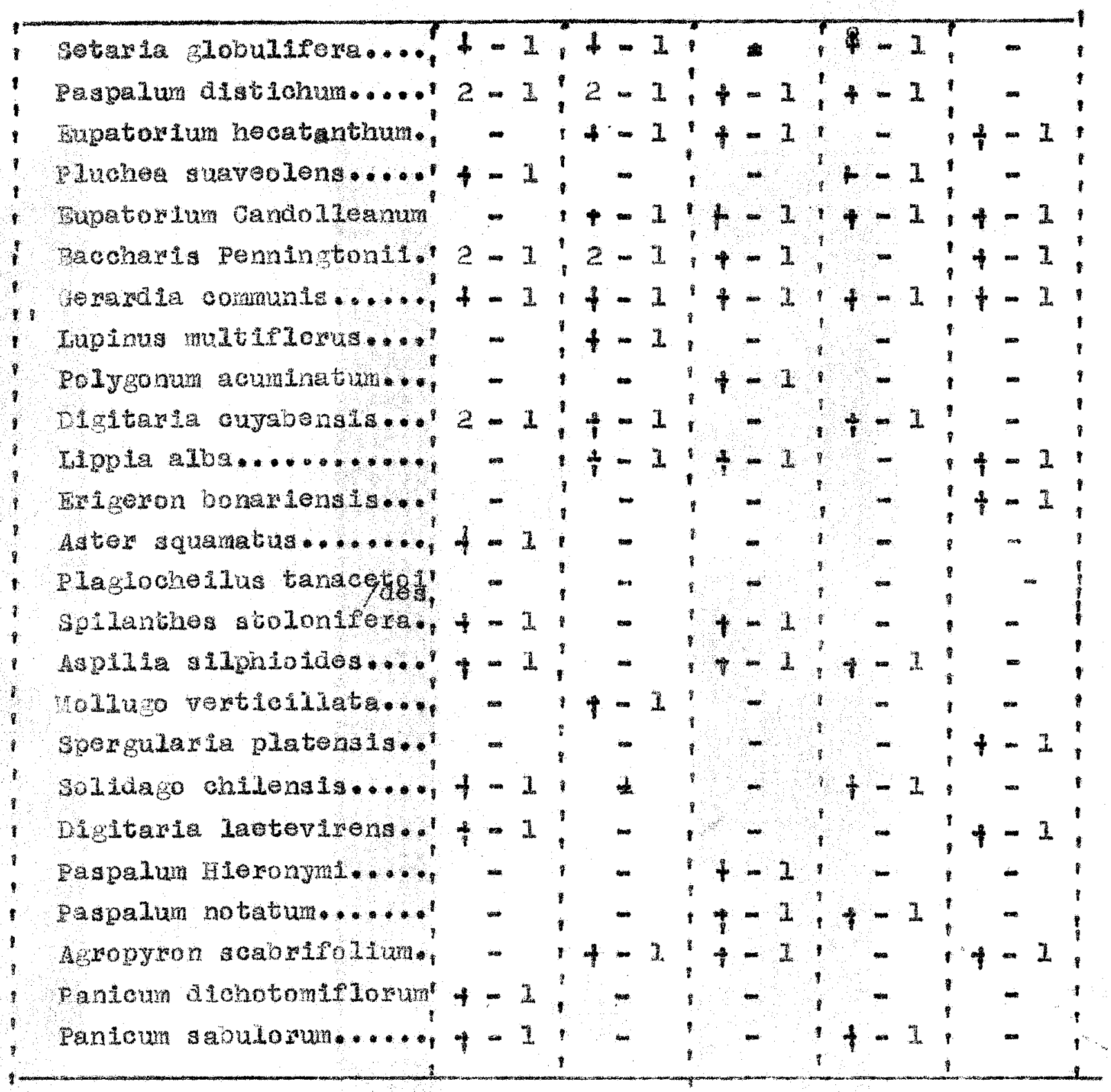


rectamente debajo deI sauzal sino en los claros $y$ on la costa arenoaa.-

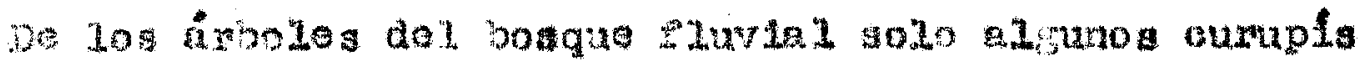

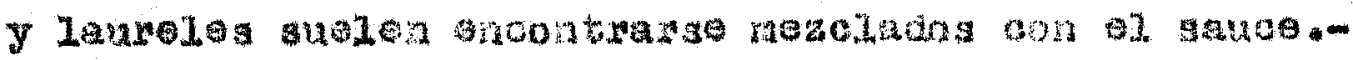

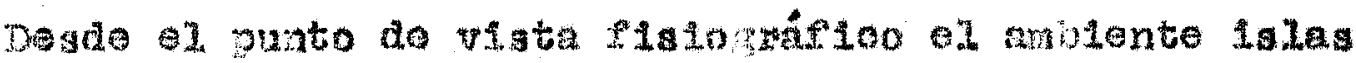

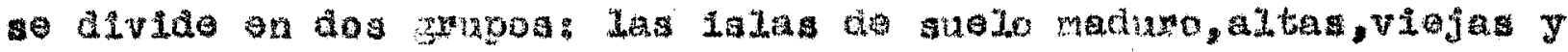

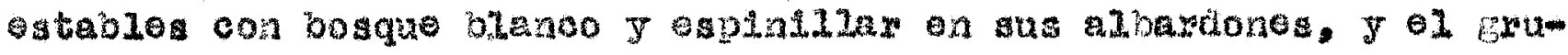
po de las ialas y bansos de pachente tomación con abundanto hume-

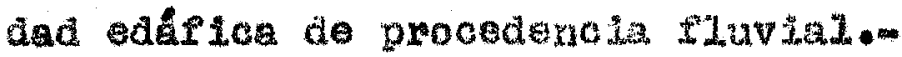

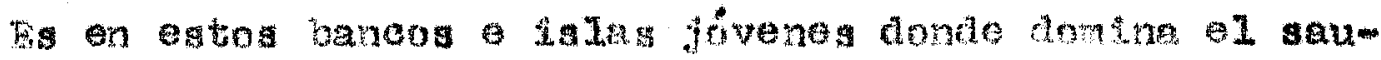
2al (Consocter de salix hugooldtiana) que creco puso,donso g vigono-

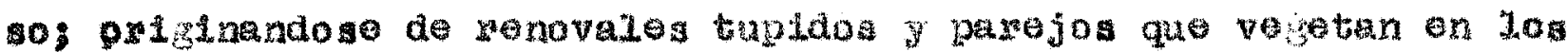

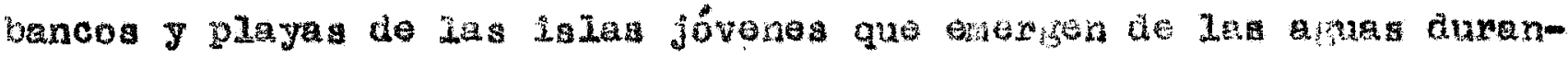
to prolongadas bajahtos.-.

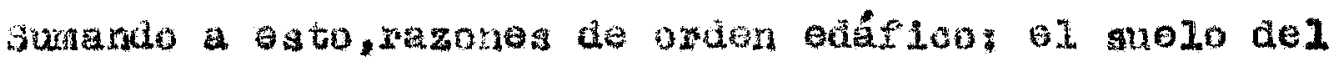

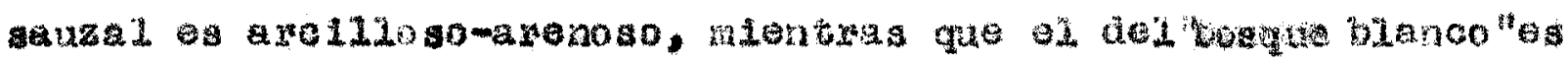

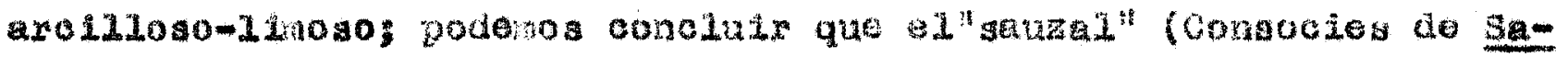

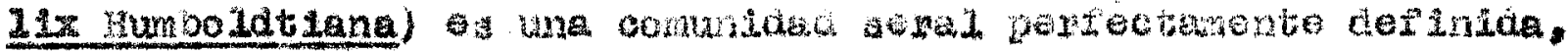
cuyos doninios se extienden solo en las lazas $y$ bancos fóvenes form

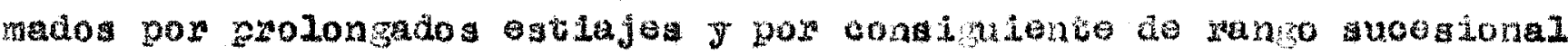
anterlor a nosque blanco.-.

20) ALISAL O EOBADL (Comaooles de pessania Internifo11a) isigs.

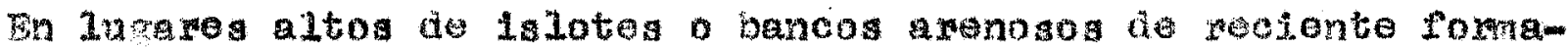

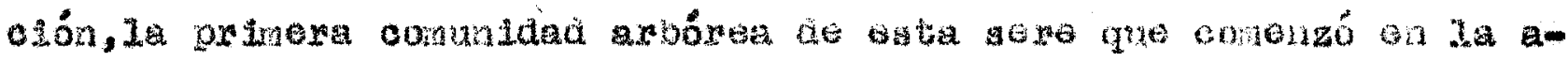

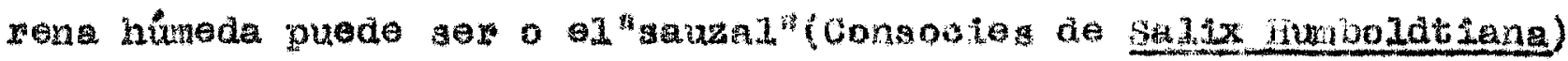

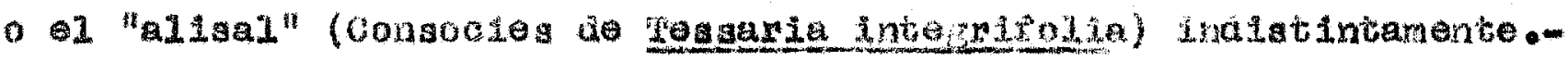
Ambas comuldades ocupan el miano rango en la escala

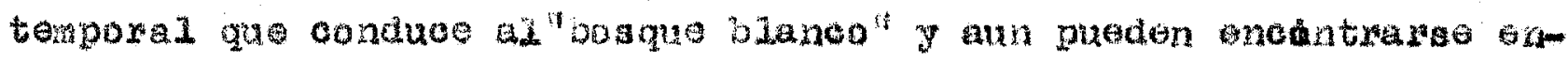
trenezcladas sus osencias doninanto en una poblaclön que polw la-

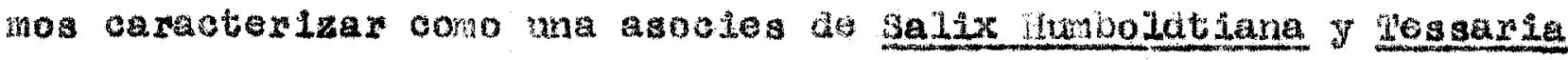

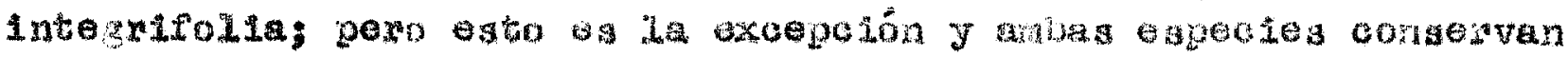




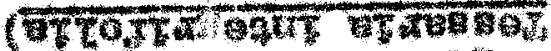

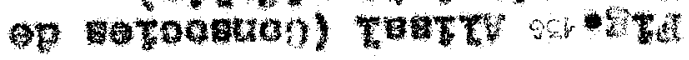
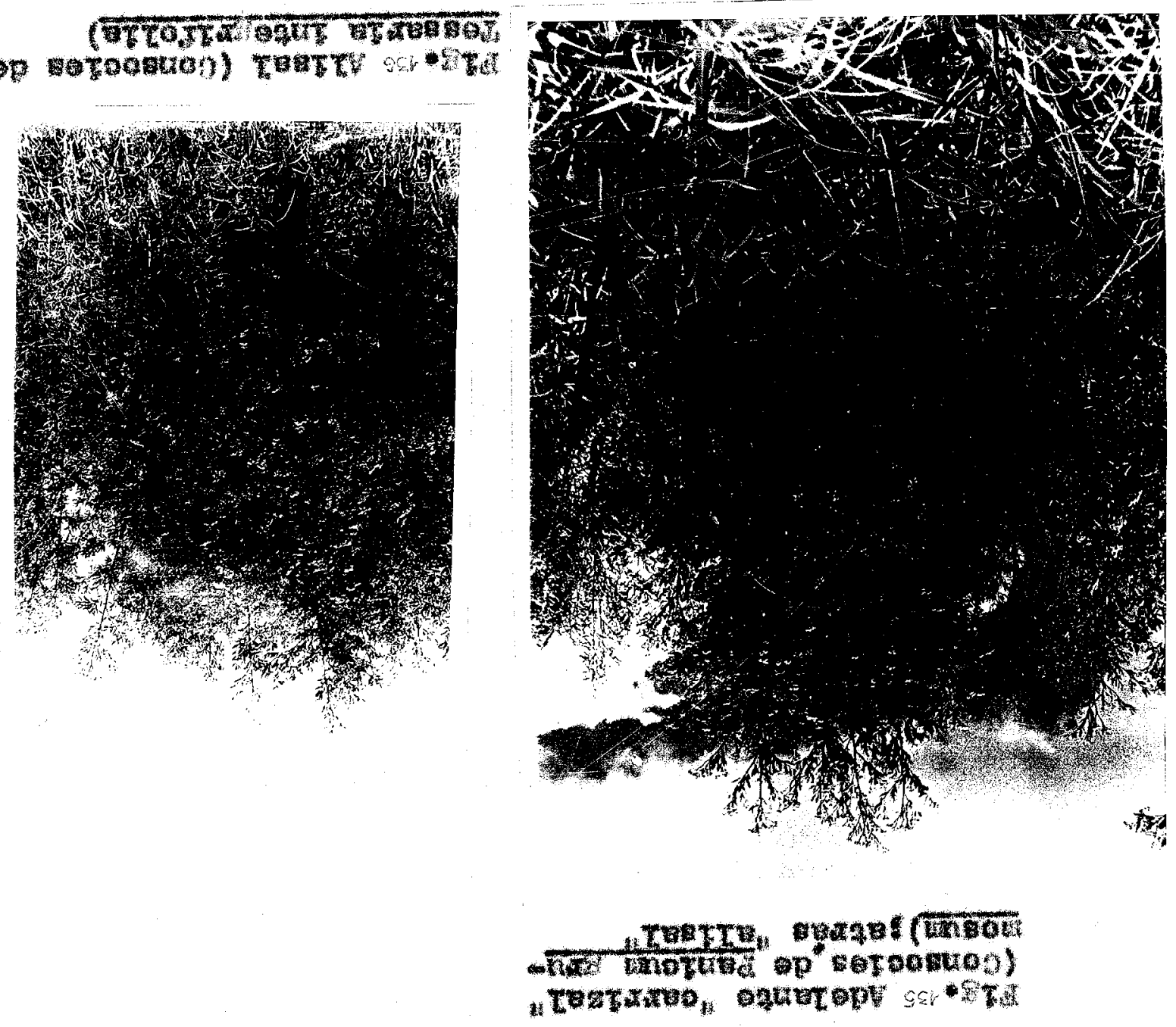

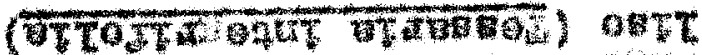

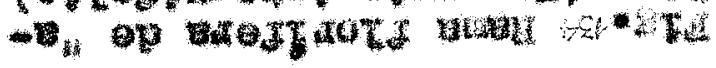

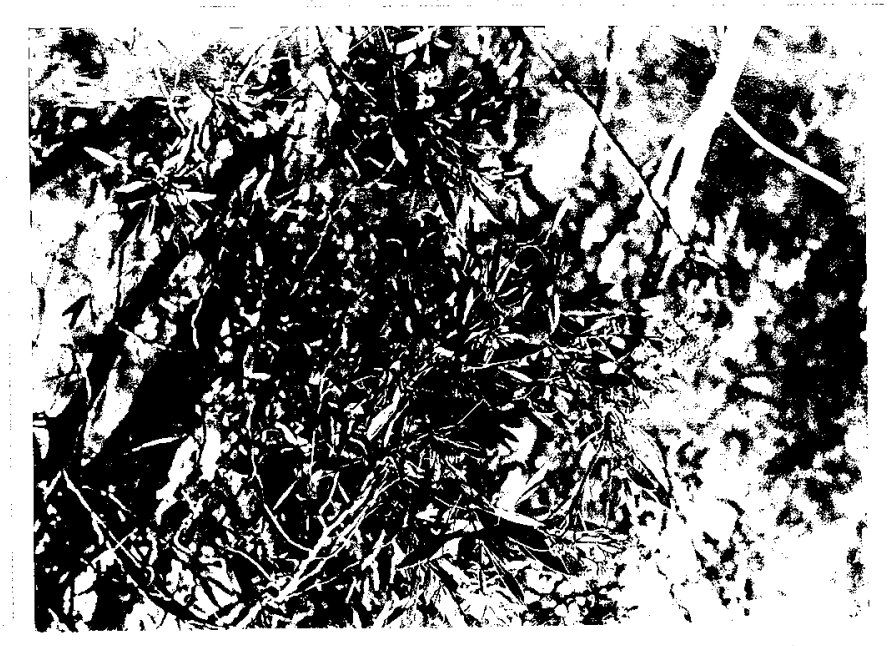


generalnento su autononla. as por ello que preferinos estudiarlas a Ia Iadas :-

Mata conuntad tiane pox dom thante a. "aliso" o pájaro bobo (Tessarta integrfolia) una hewrosa complosta arborescente de 5 a 7 metros de altura; tronoo de 30 a 50 cm. le ádánetmo; capltulos rosados y un follaje azulado que rompe la monotonía de 1 coloraclón verdeascura del regto de la vegetación haciendolos olutingulores a large djatanolan-

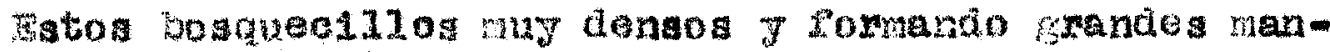

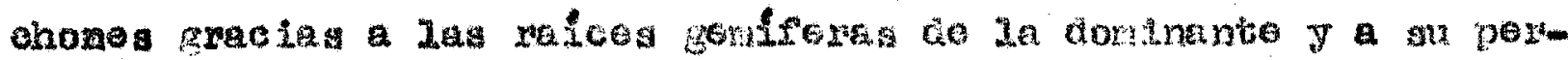

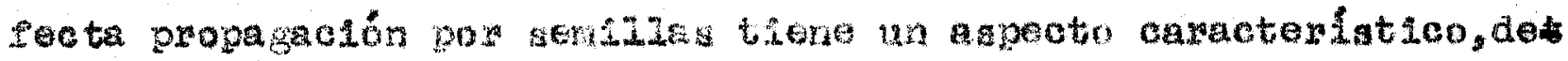

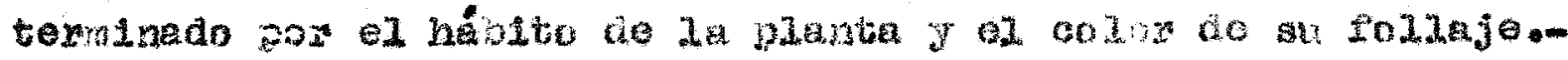

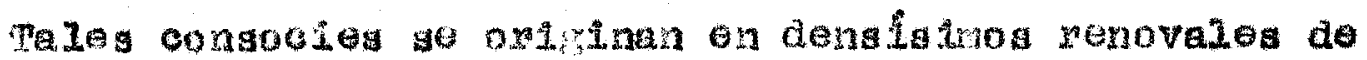

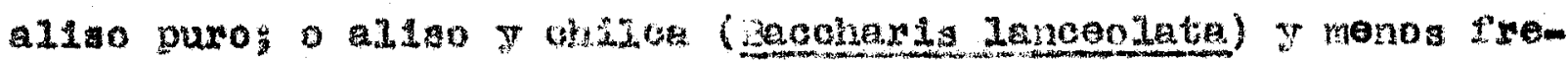

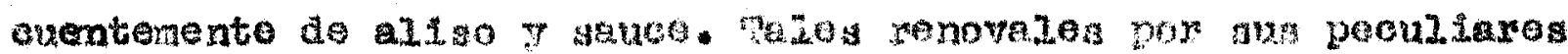

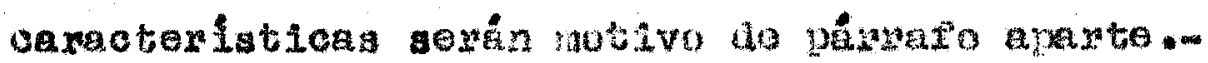

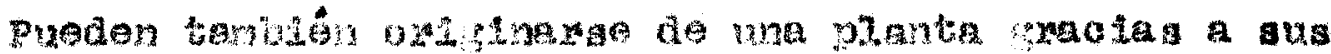

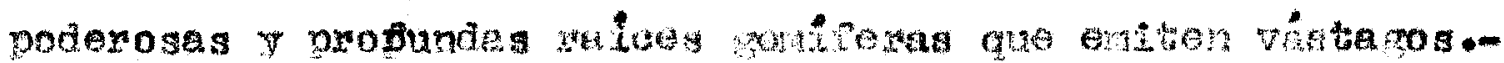

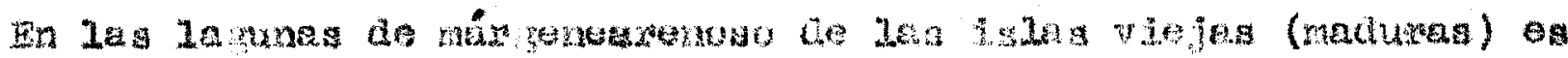

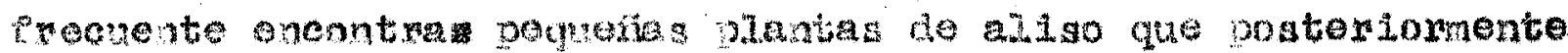

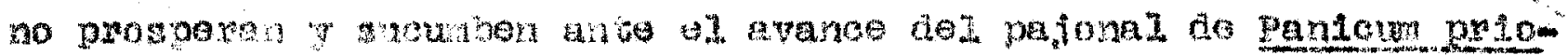

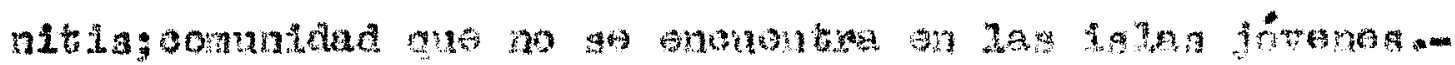

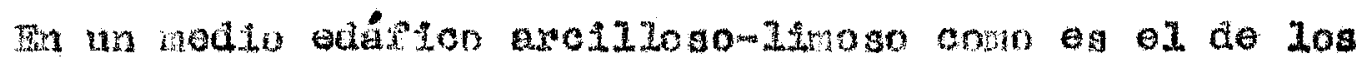

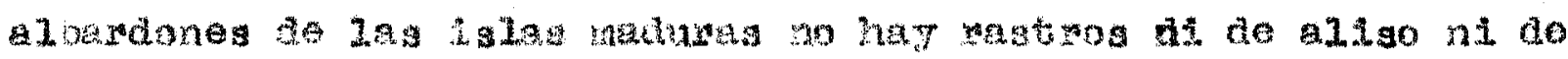
sance.

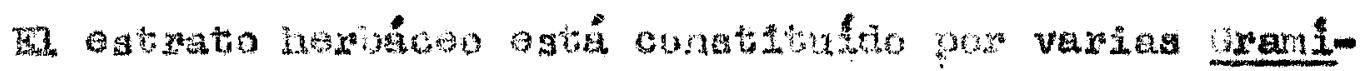

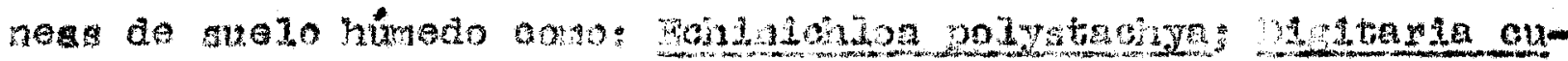

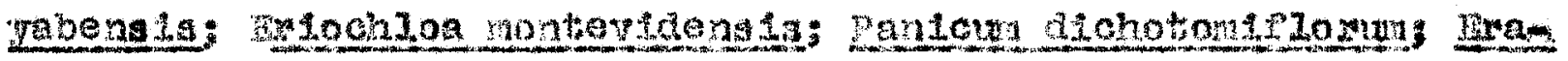

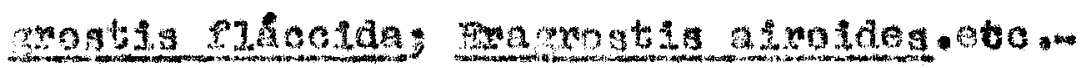

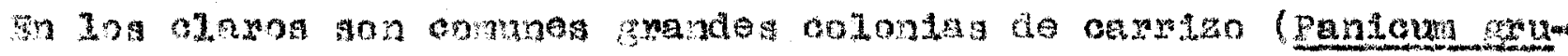

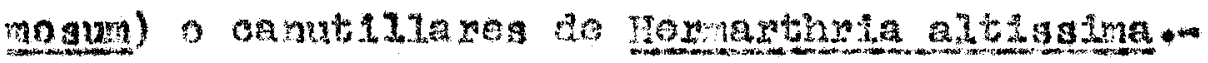

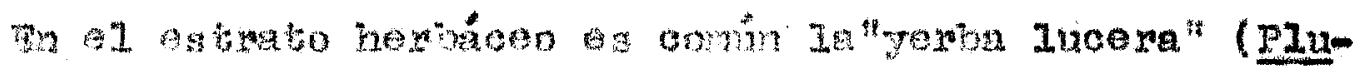


chea suaveolens) y geraxdia comunis junto a.1 "garabato" (Mimosa 1-

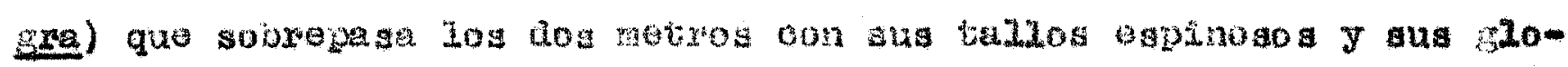

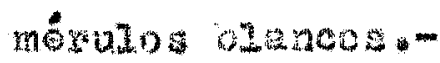

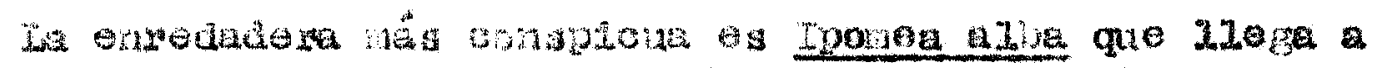

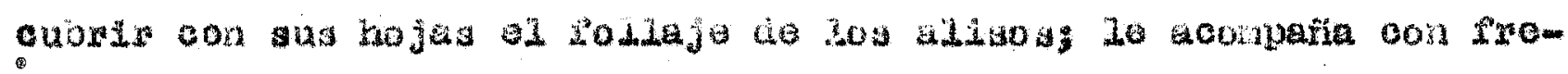

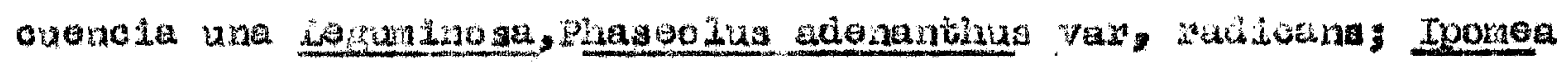

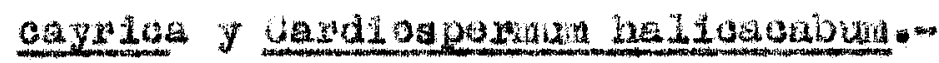

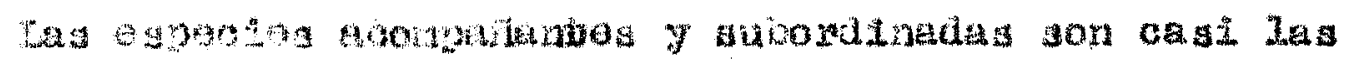

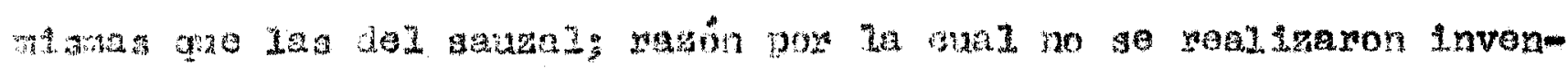

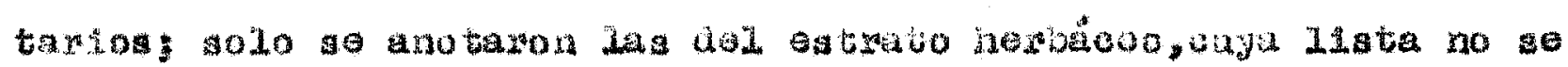

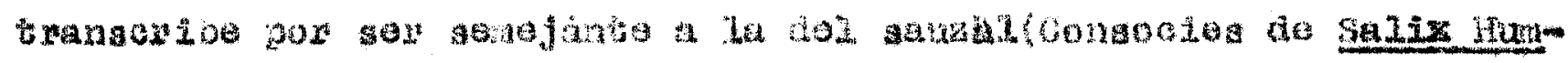
boldolanal.

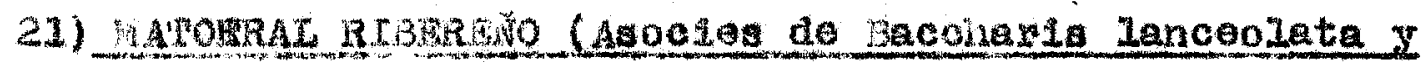

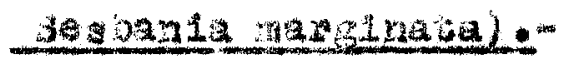

B.

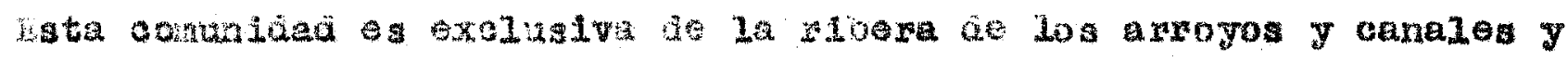

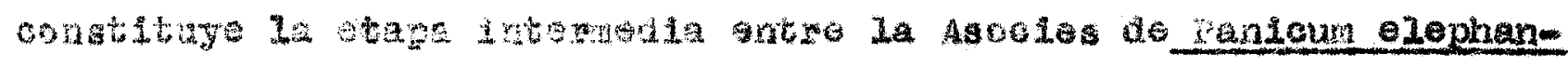

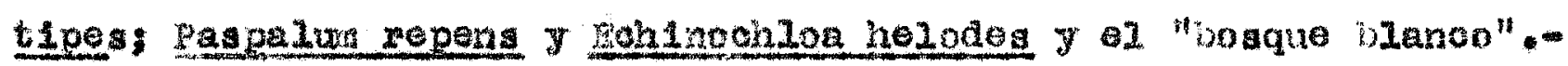

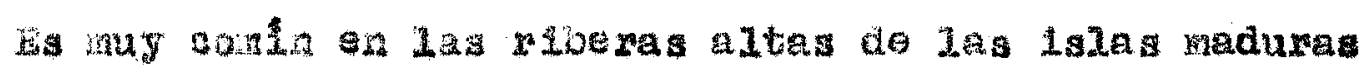

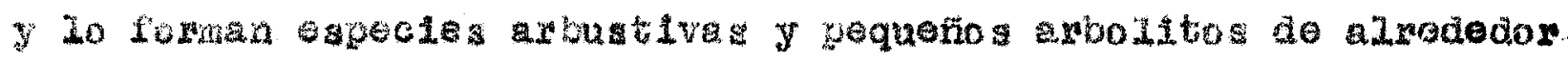

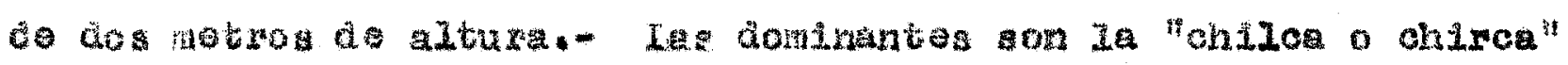

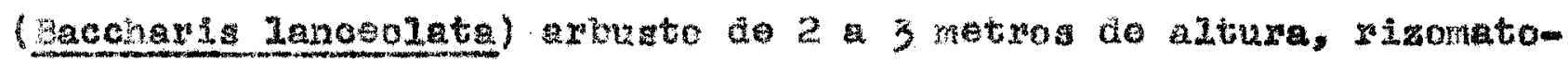

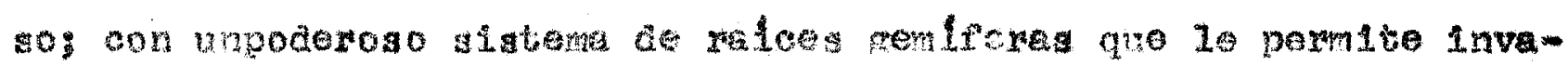

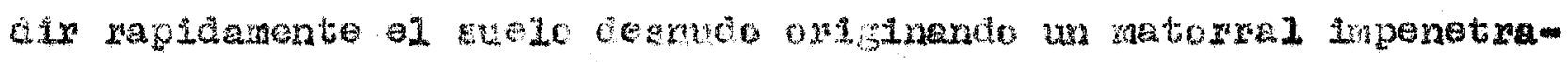
be, su tal1o principel es 16 toso y low seoundarios do todo los ta-

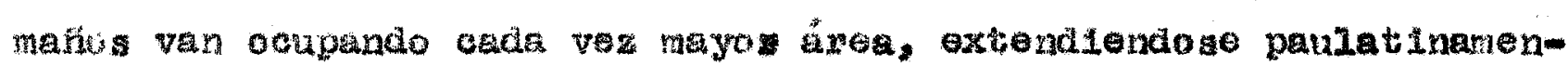

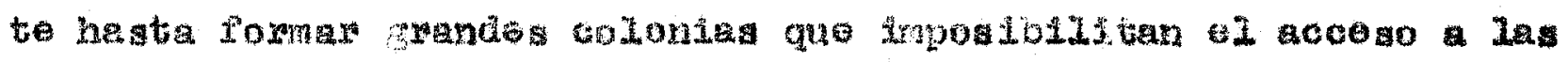

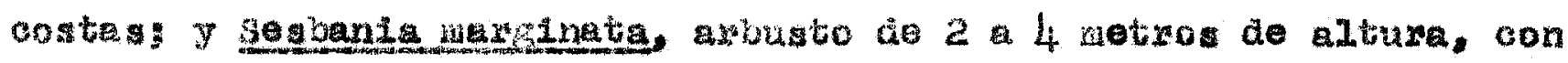

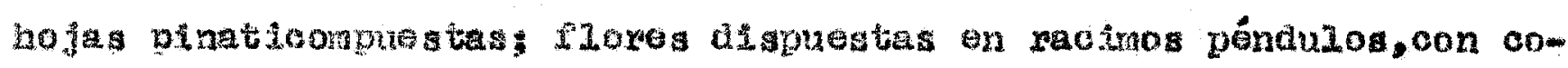

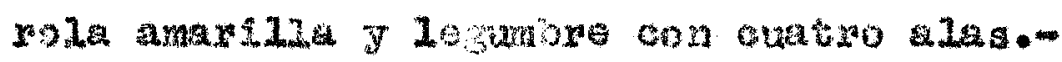

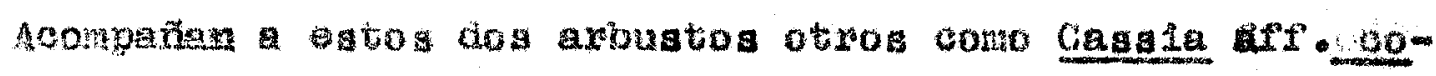

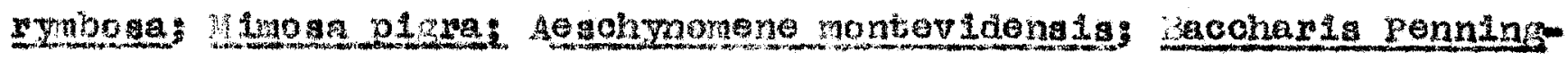

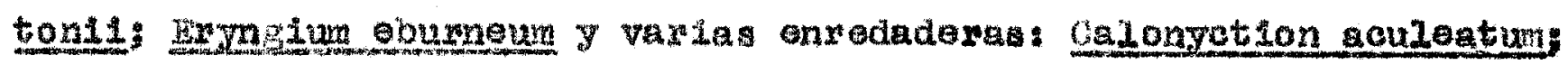




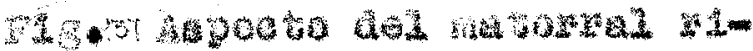

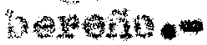
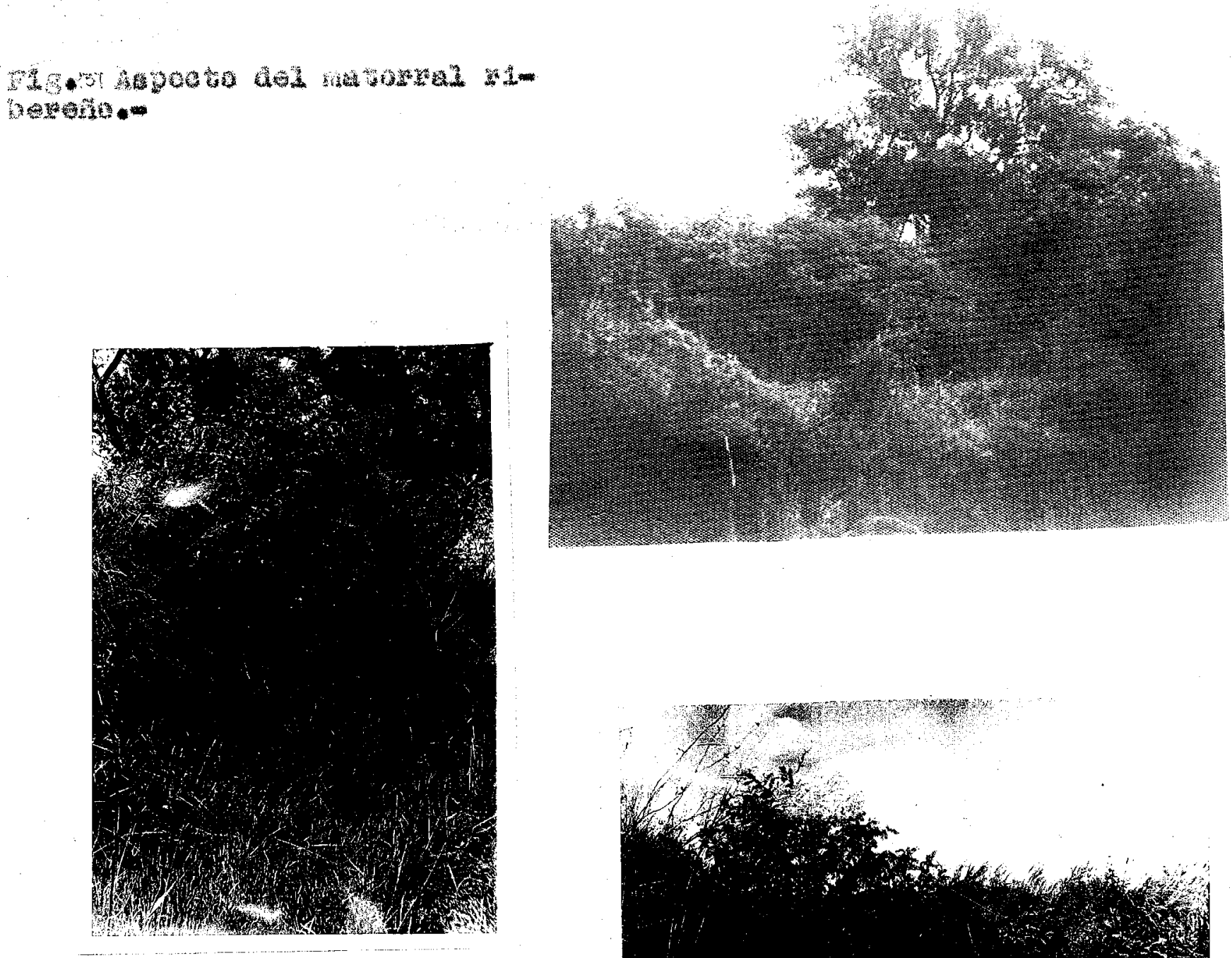

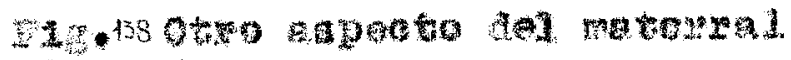

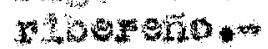

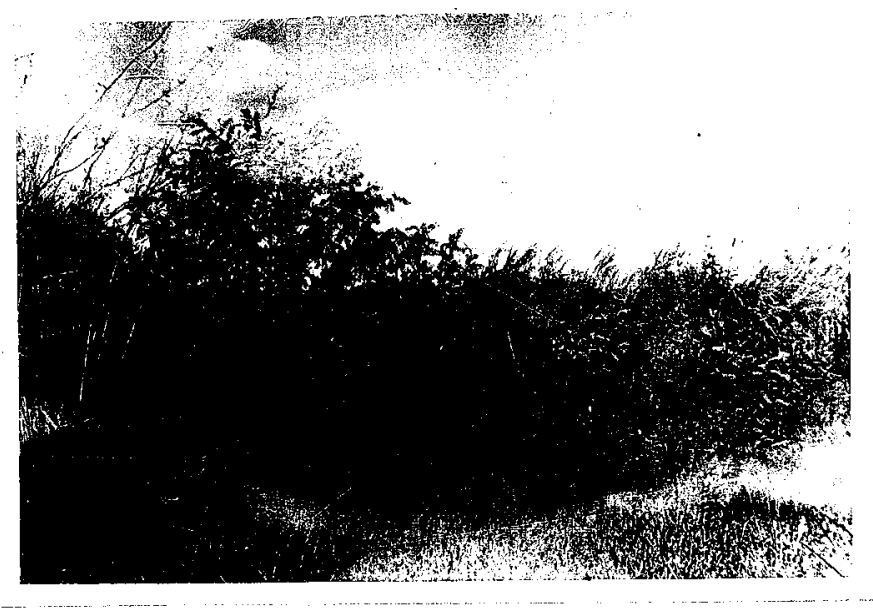

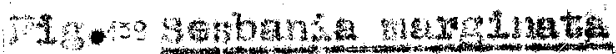

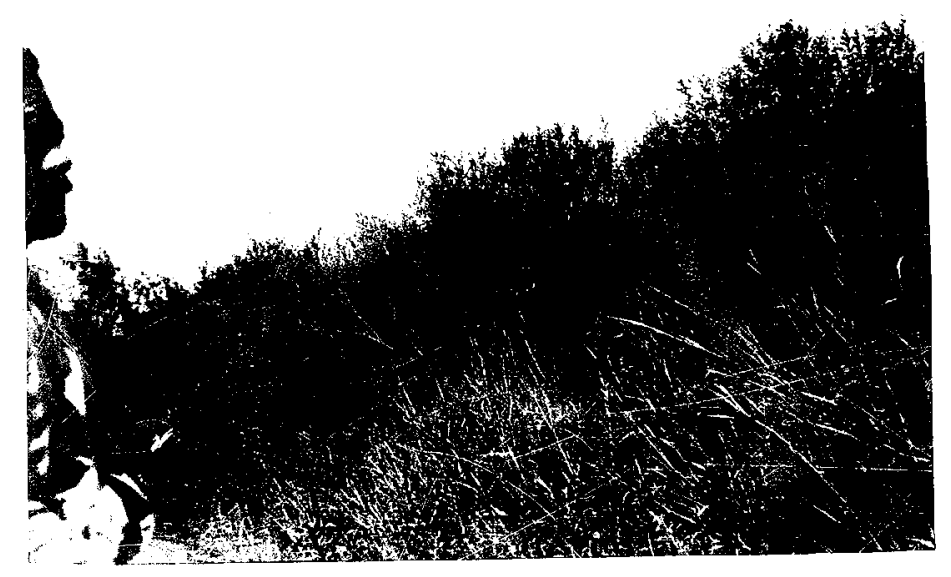

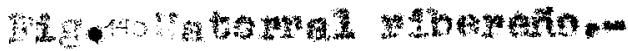

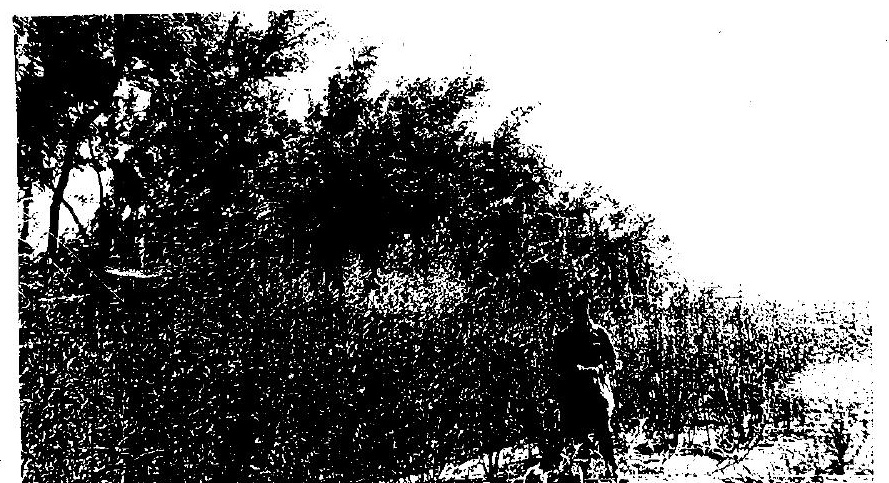




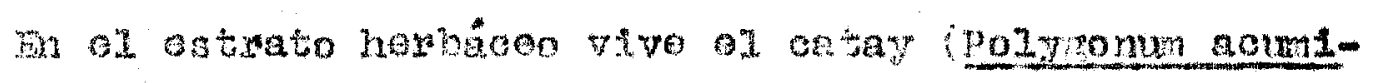

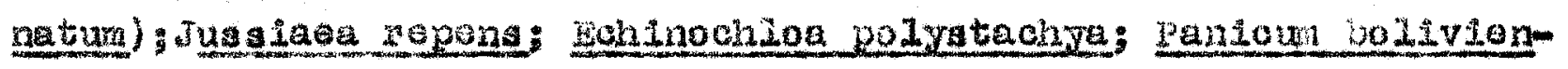

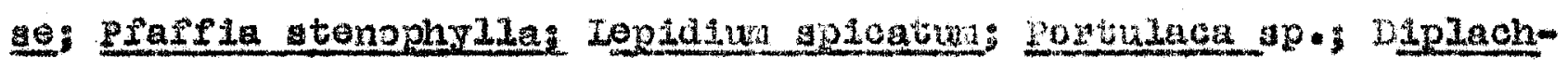

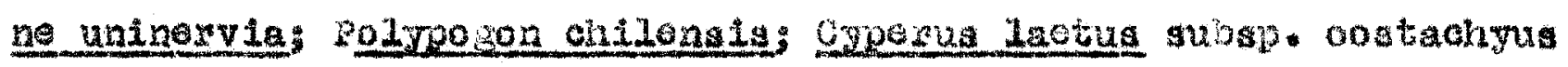
otco

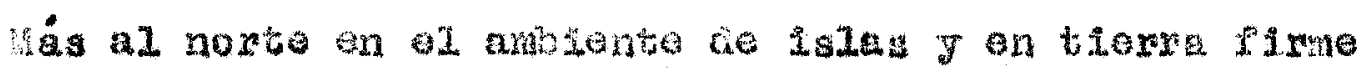

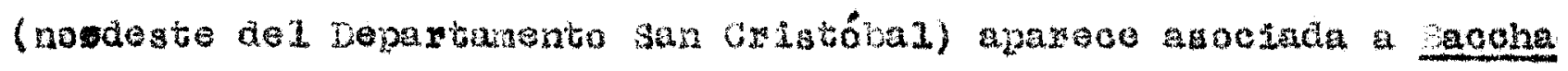

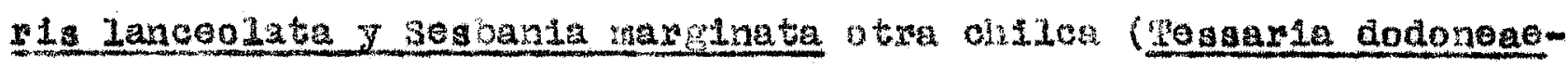

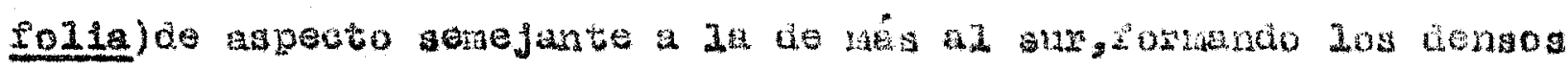
chilcales que caracterizan las mámgenes del kerrojo y el pulconayo. OGITCAL (Factes de Baccharis Ianceolata).

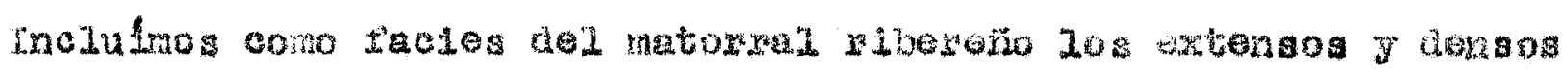
chlicales que formen colonia os los temonos anomosoa y bajos de

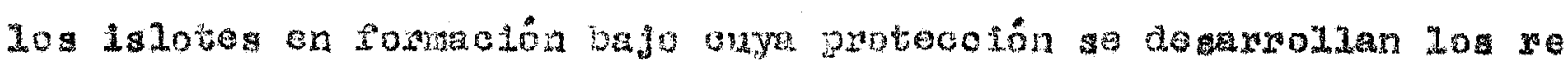
novales de aliso y gaues.*.

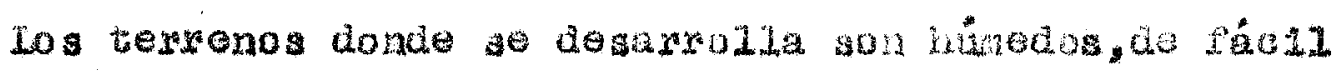

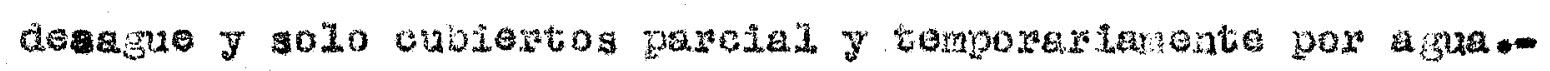
Le suelen acoupanax; Ghenovodiura hircinum; 21,1taria cuyabensis; Pa

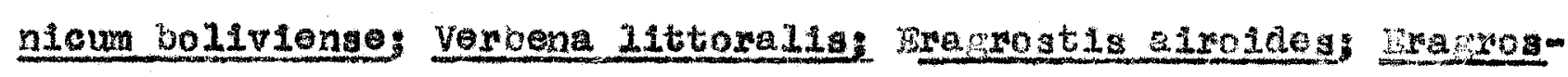

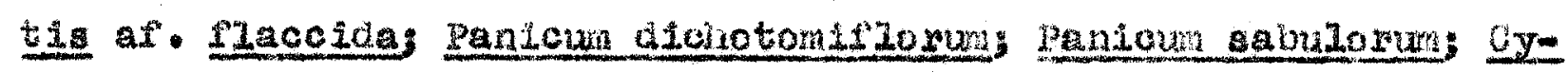

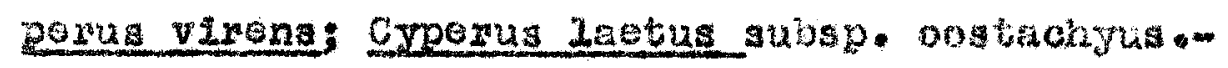

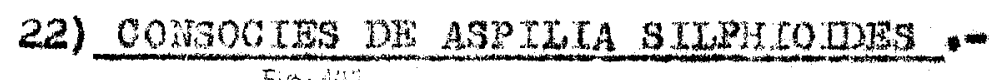

Comunidad que inelulnos provlandamonte an haver podido determinax

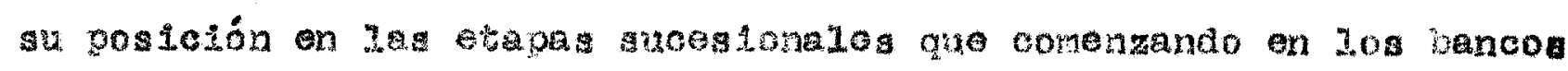
arenoso conducen al "bogare blanco".-

Su posición espactal es duffold de detexnanar a vece

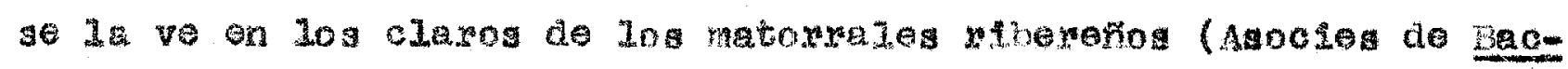

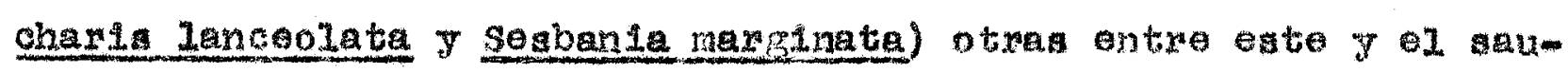

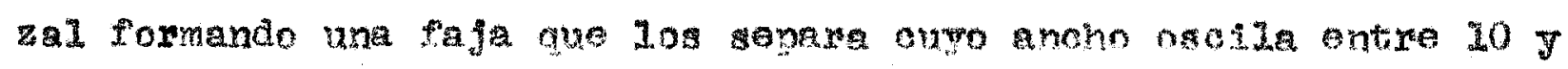

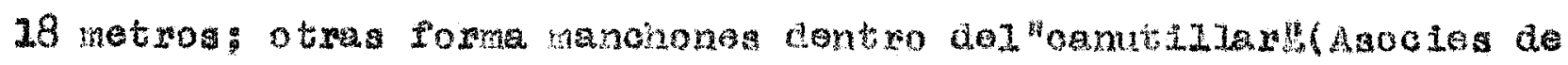
Honarthrie altiagina J Sotaria jenioulata).- 


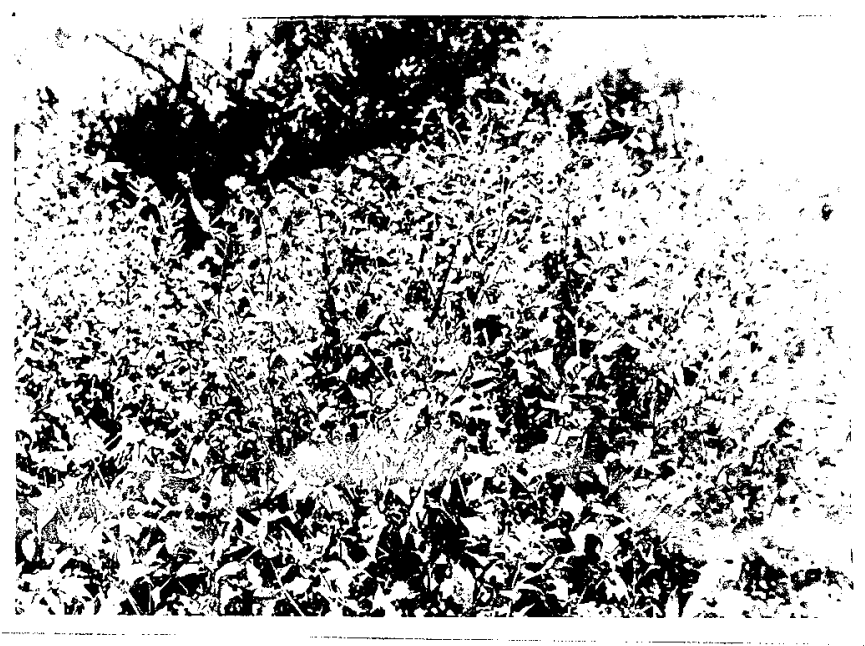

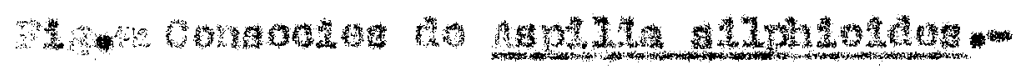
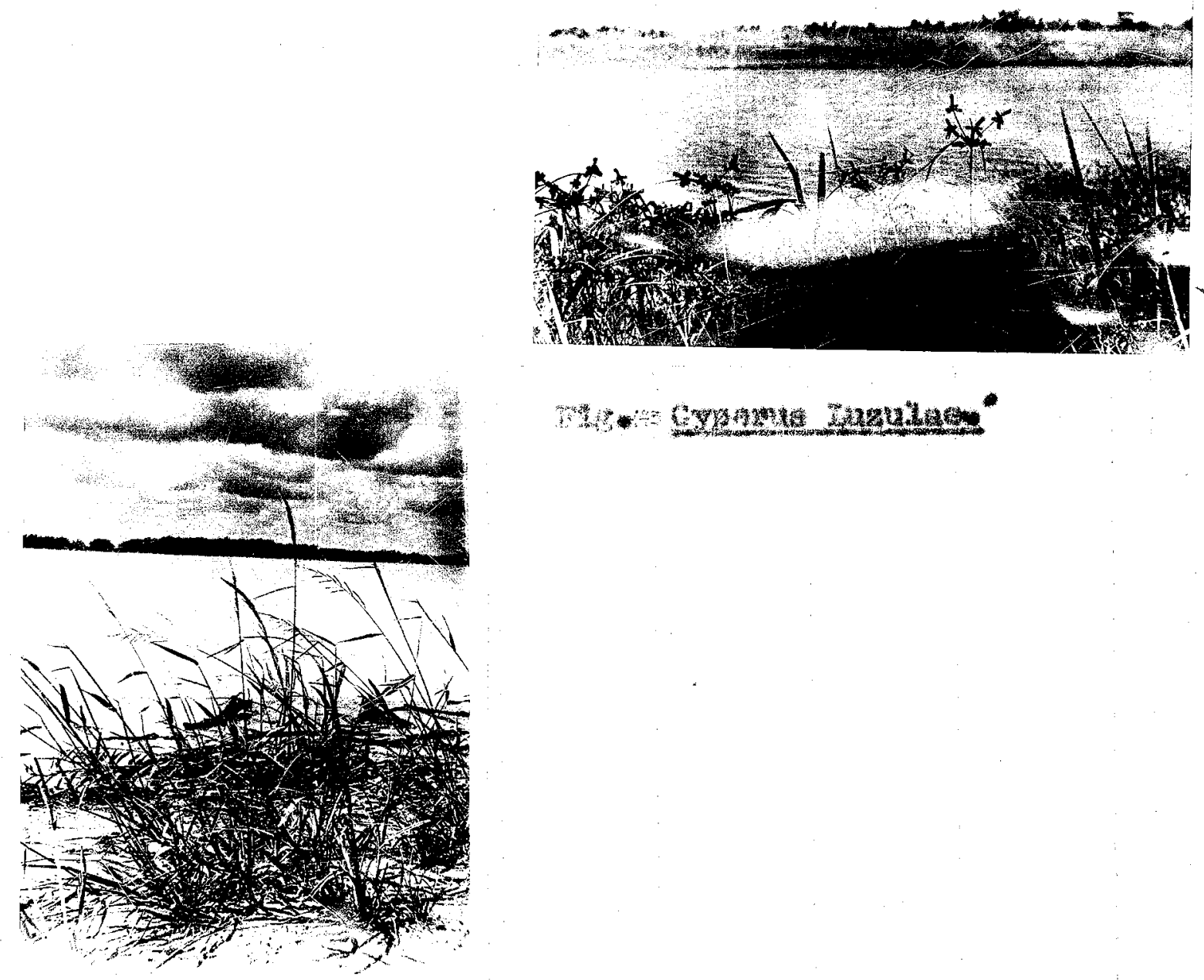

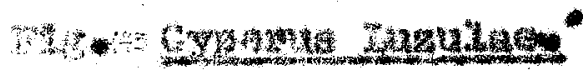

10.144.

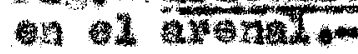


del aqua.

(Asocies de Cyperus Luzulas: y Echinochioa polystachya)

Superficie estudiada en $\mathrm{m}^{2}=25$

Fecha: 5.3 .49

Cobertura: $30 \%$

Altura de lavegetación $50 \mathrm{~cm}$.

Suelo arenoso-humedo inurdable

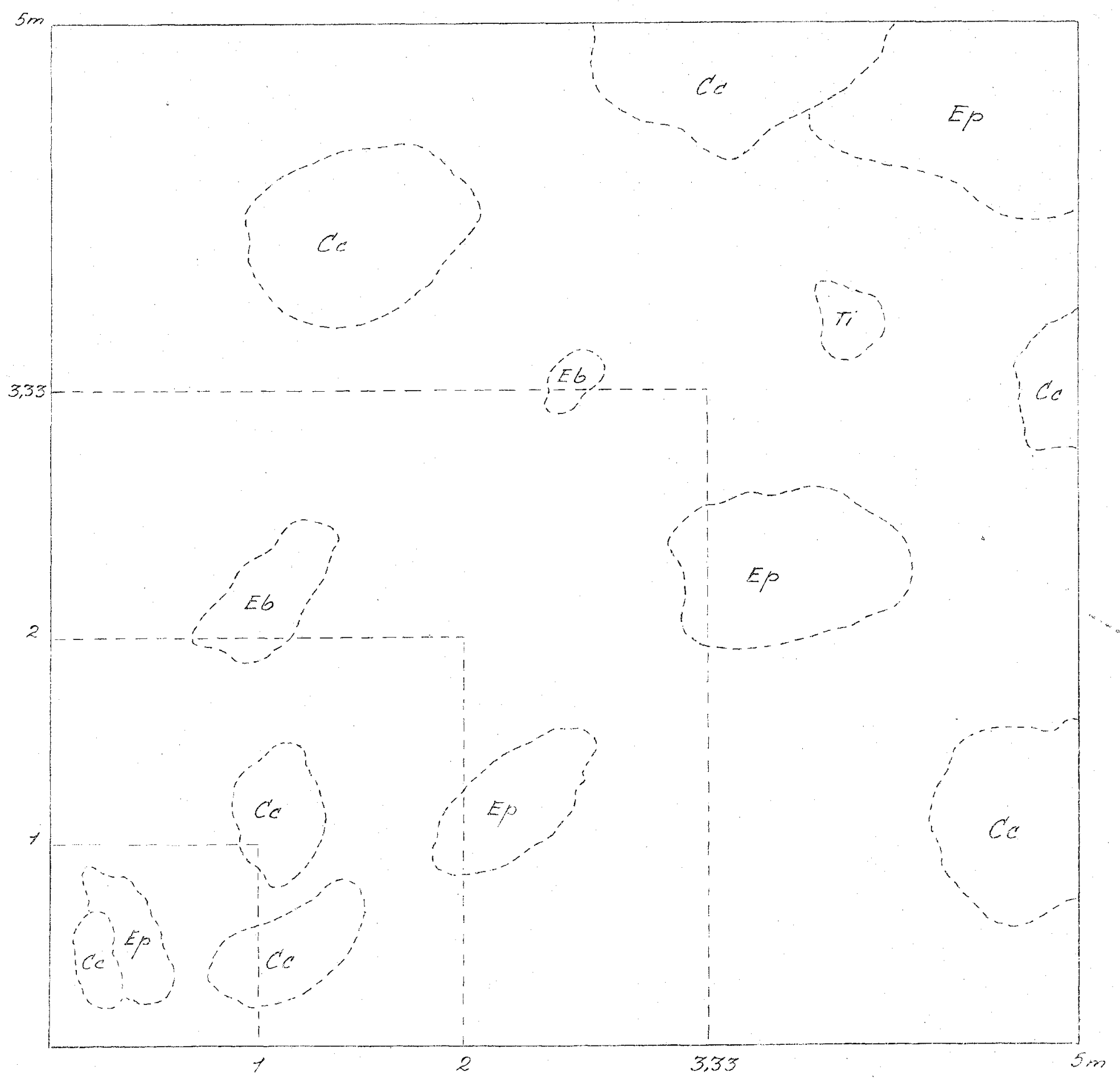

$C_{C}=$ Cyperis Luzulae

Ep: Echinockice polystaorya

Eb = Eragrost tr airoides

$T i=$ plantulas de Tessarca integrifolia 
\$u Laen 1 fleación cono conunlad autónoma tarbién os du-

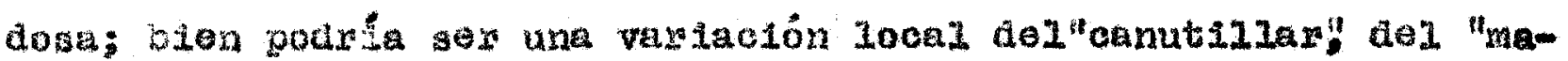
torral ribenerio" o dol "aguzal" que adqulere localnente el control de la comunidad fomando una wocles dentro de la unidad mayox: 1a ascetes o consocies.-

La dom Inante de ogta commidad og una compuegta sufru-

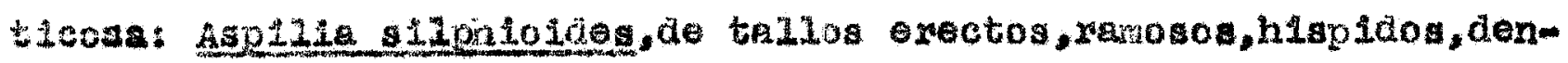
samente hojosos de 1,50 a 2 metros de altuma. hojas opveatar cap1tulos solitaros y forlos domatas atmonfas.-

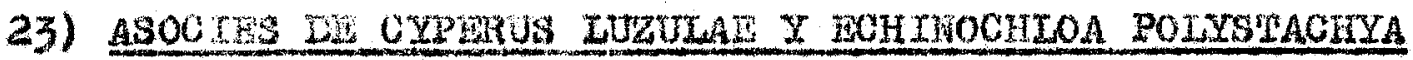

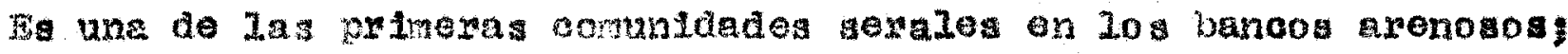
aus doninante s on Lns veruaderos "pioneers" o grineros pobladorea

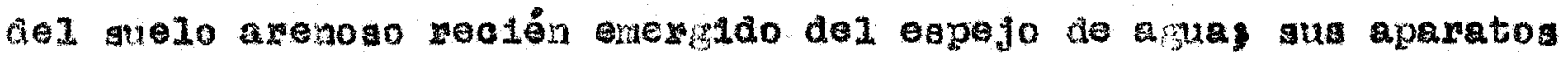
de propagación. Hzones $\$ 0$ tolanes permiten a dosernolio y la for-

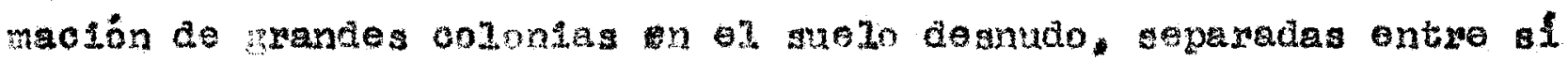
por espacios deaprovistos de vergetación*m

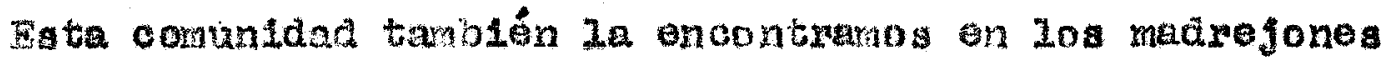
F Laruna de mérenes arenosos en ato ceso la cobertura os mayor oacliando entwe 50 y 70 , gen cambio en los arenajes zecién omerstdos y oublento temponandanete pox al agua, ia conerture no pase. de1 $30 \%$

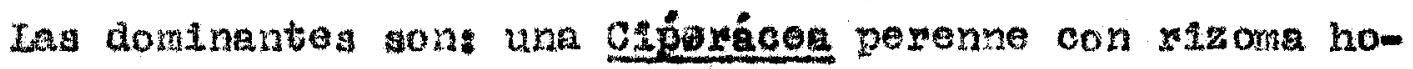

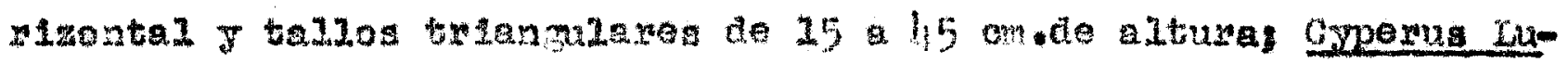

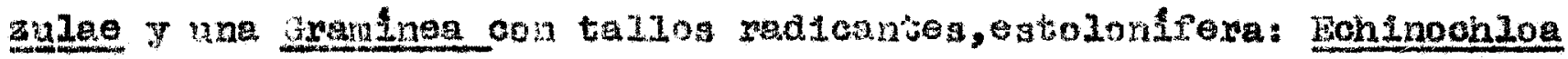
po1zatachye--

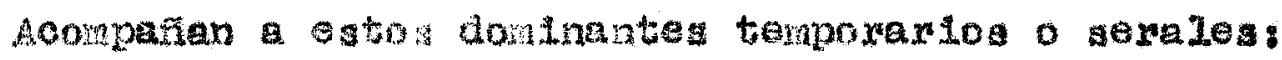

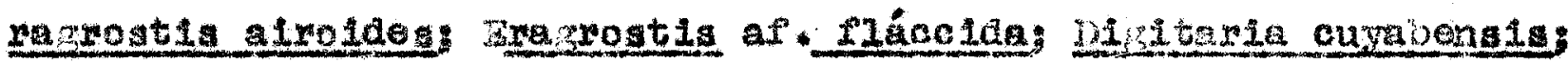

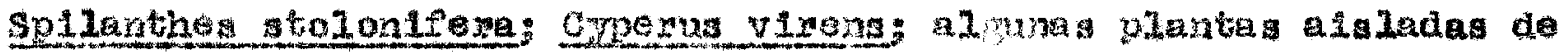
Eluchea guarealens: Convolvulia sp. I Lipla alba.- 
del agua.

(Asocies de Cyperus Luzulae y Echinochloa polystachya)

Superficie estudiada en $m^{2}=25$

Fecha: $5-3-40$

Coberturo $=30 \%$

Altura dela vetacion $=50 \mathrm{~cm}$

Suelo arenoso-humedo inumdable

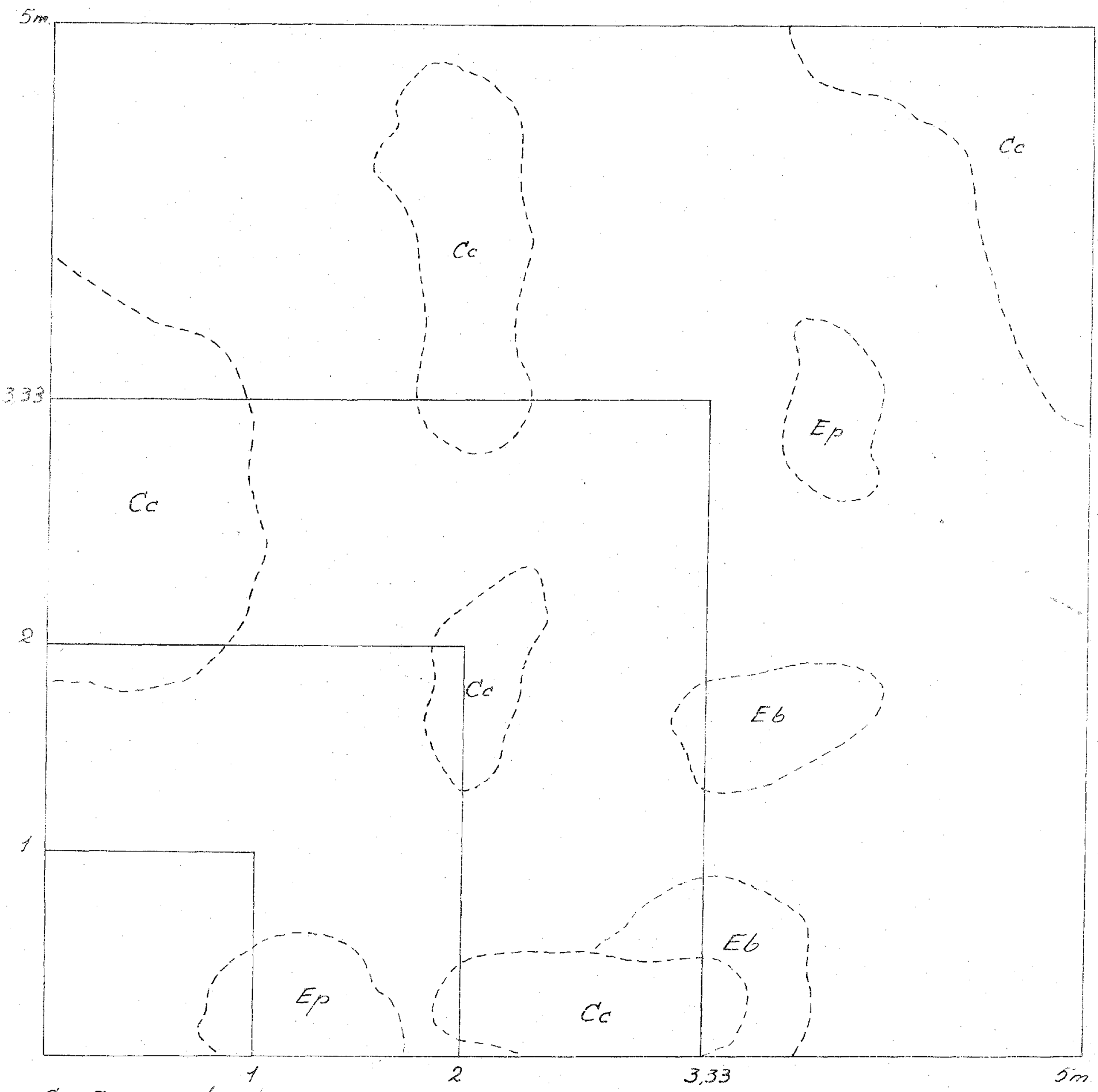

$C_{C}=$ Cyperws Luzulae

$E G=$ Eragrosicis acroides

Ep=Ectinoctioo polystodyo 


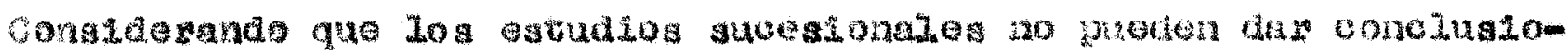

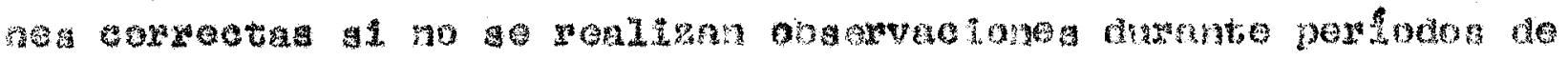

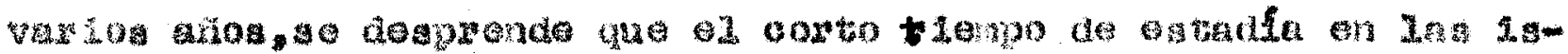

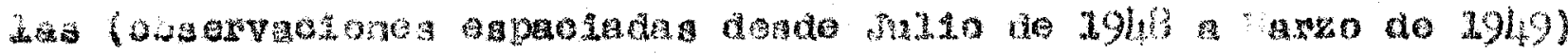

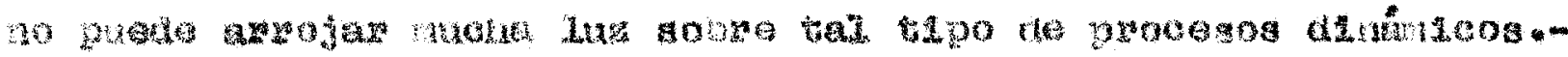

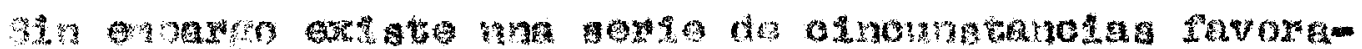

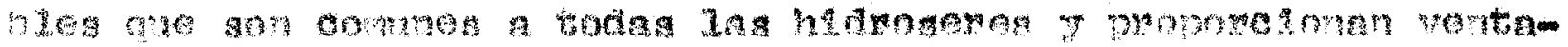

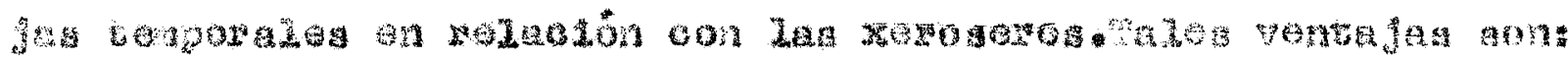

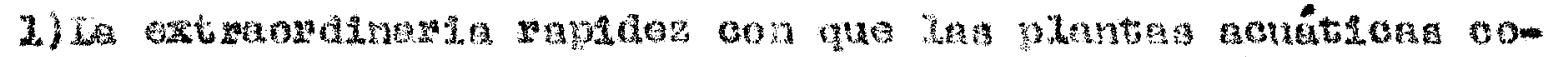

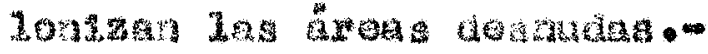

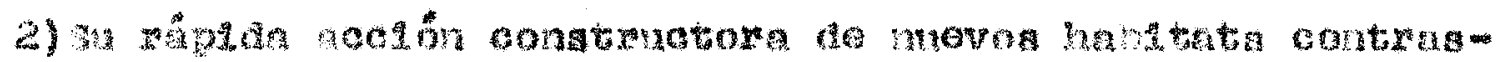

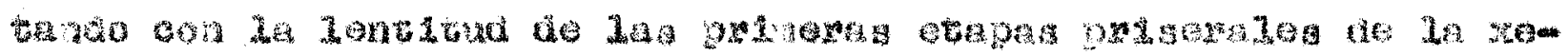
soneso.

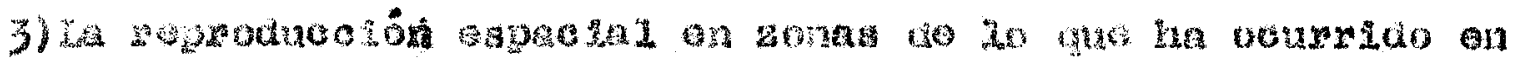

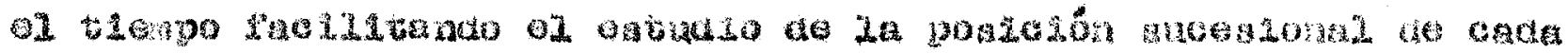
comalada.-

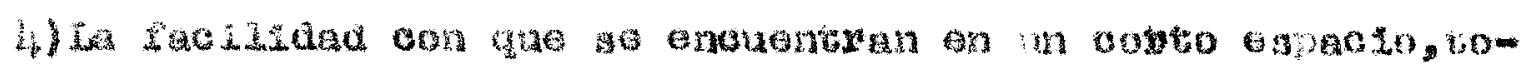

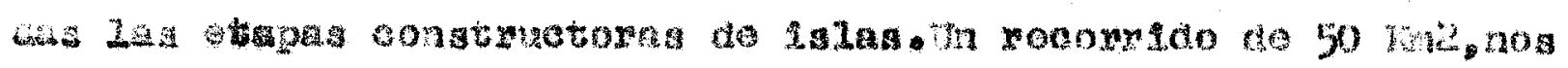

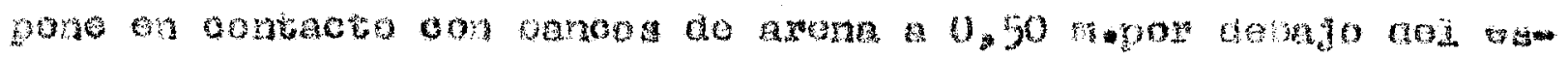

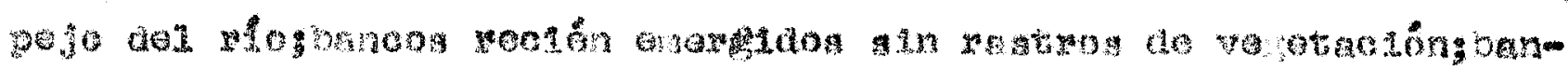

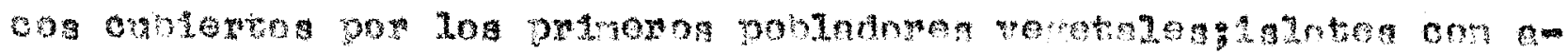
9

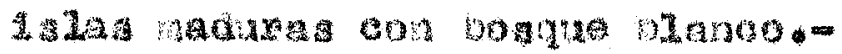

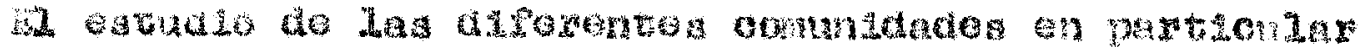

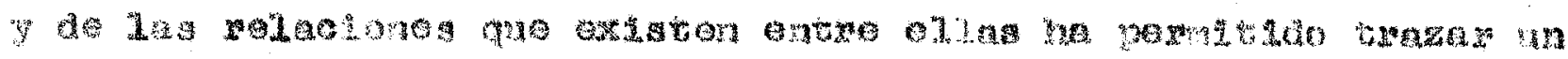

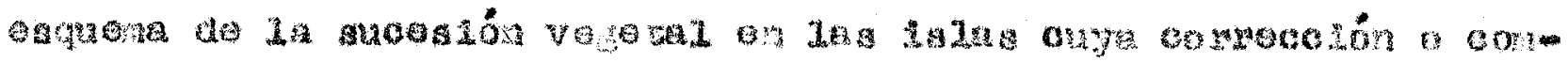

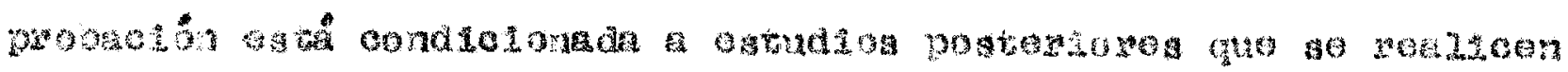
9u

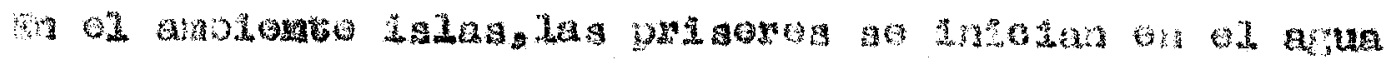

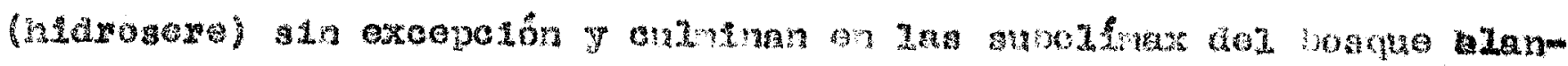

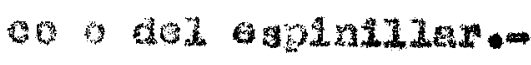

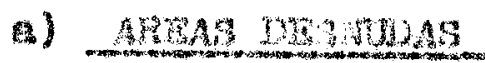




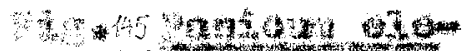

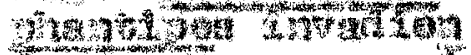

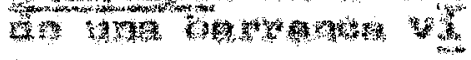
tat
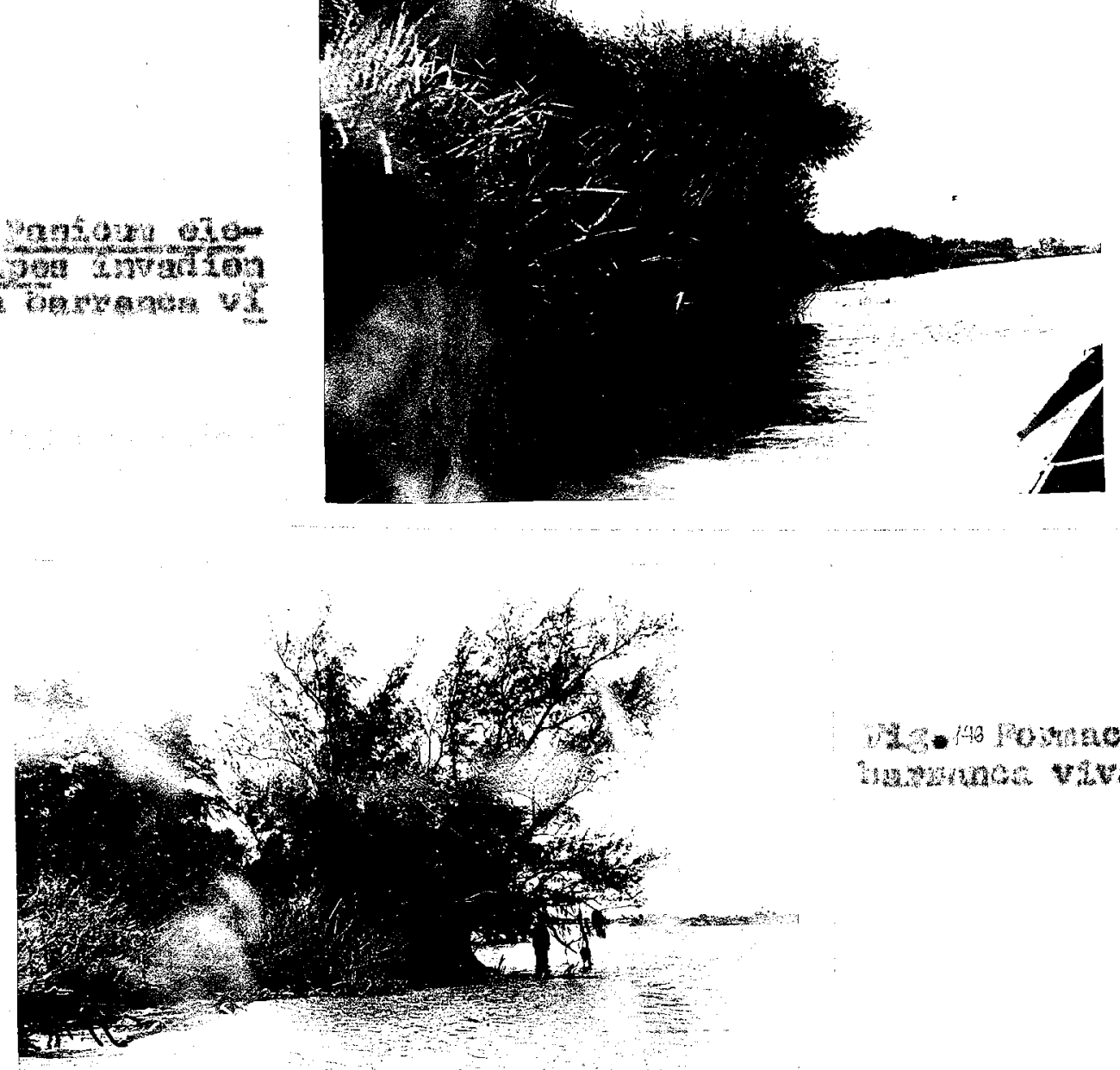

F)

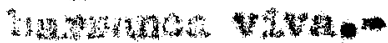

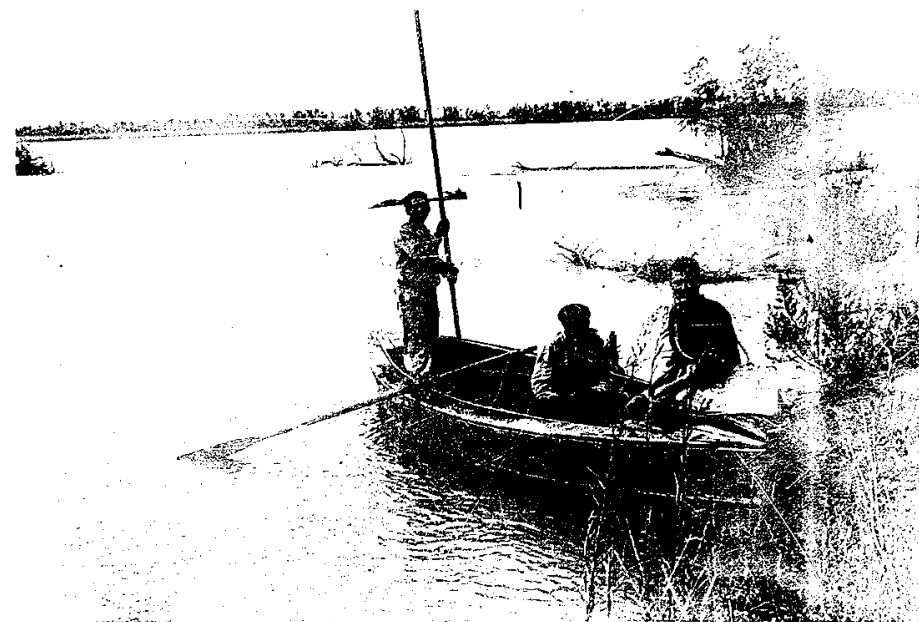

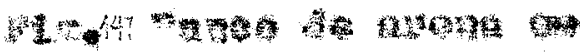
mats

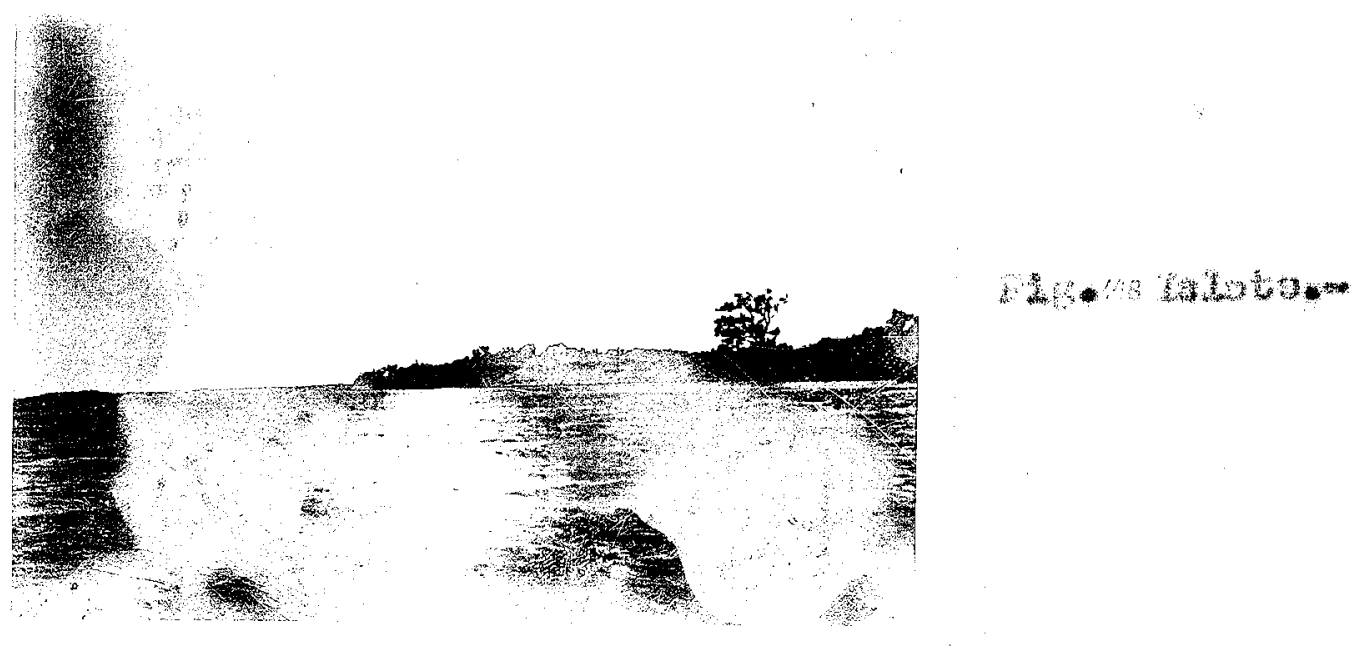




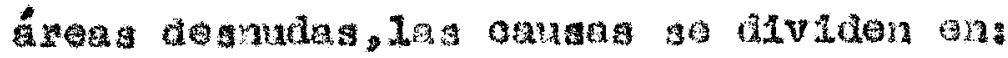

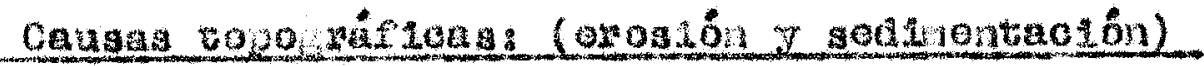

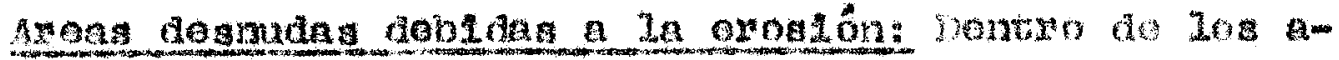

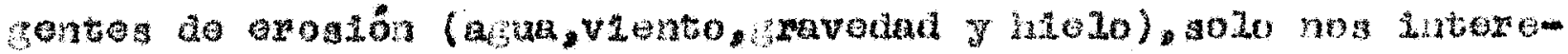

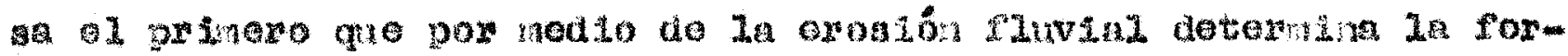

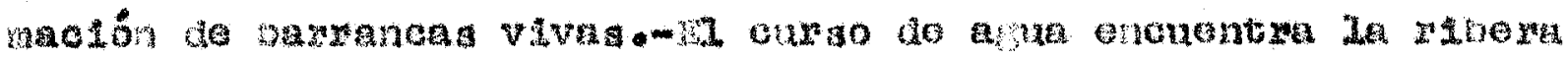

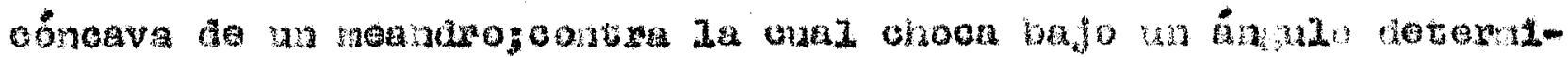

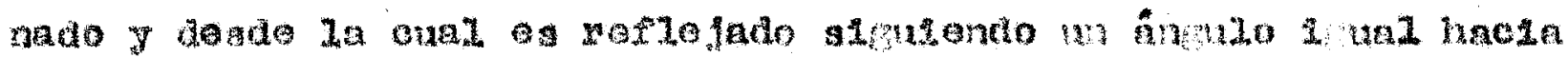

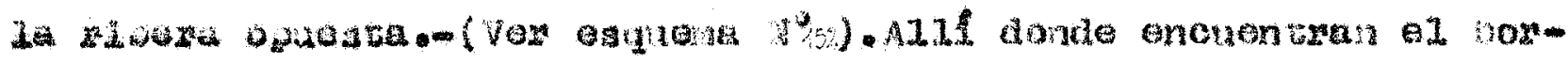

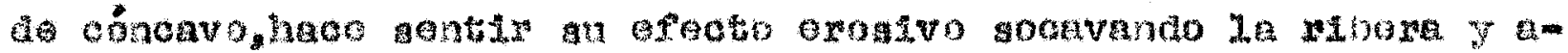

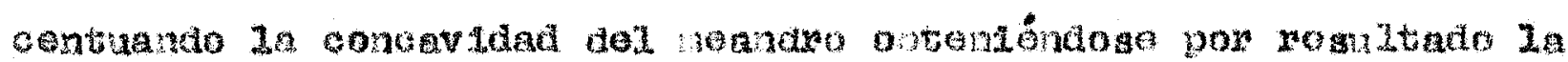

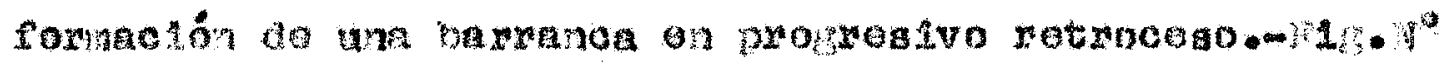

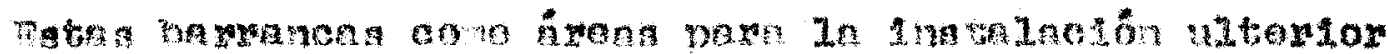

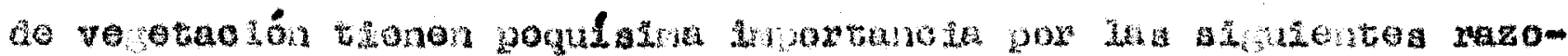
Hes:

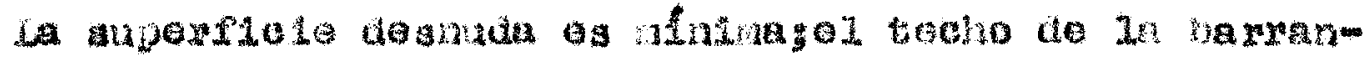

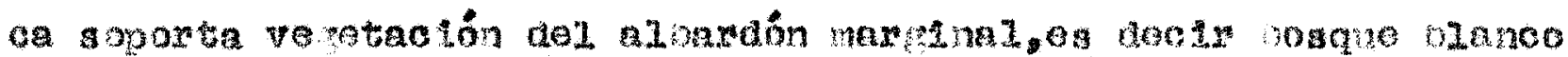
y st baso ea Landa constantomento pox a1 a

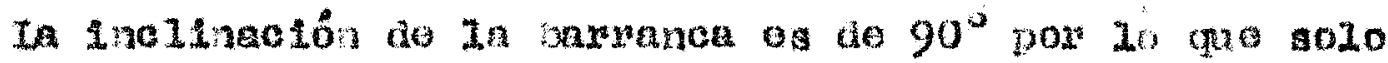

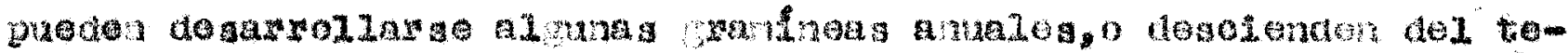

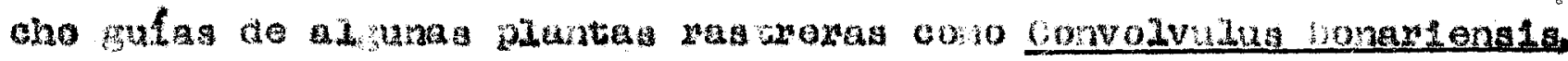

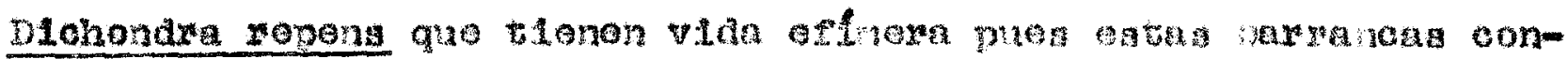
thatad an zotivo wetrocoso.-

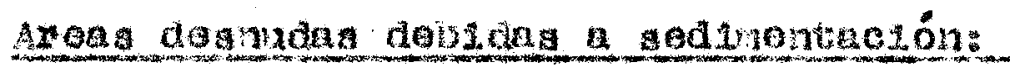

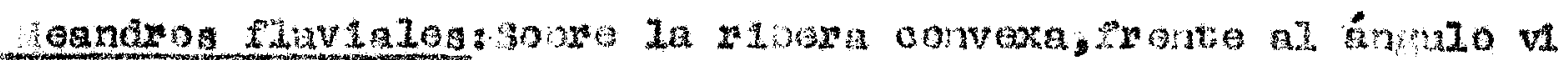

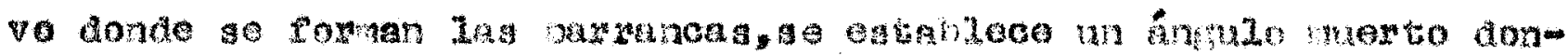
do 19 a ya gode

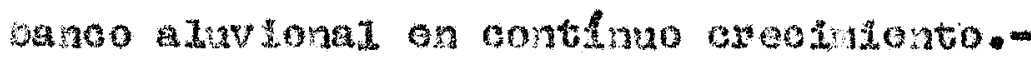

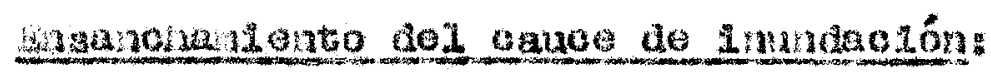

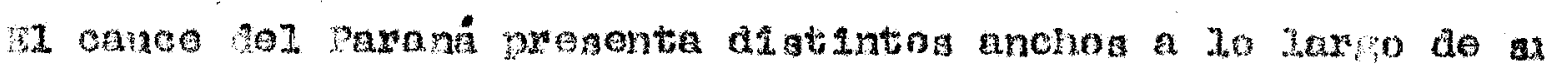

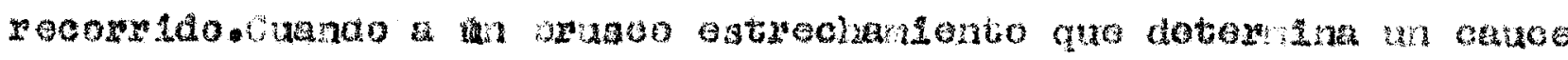




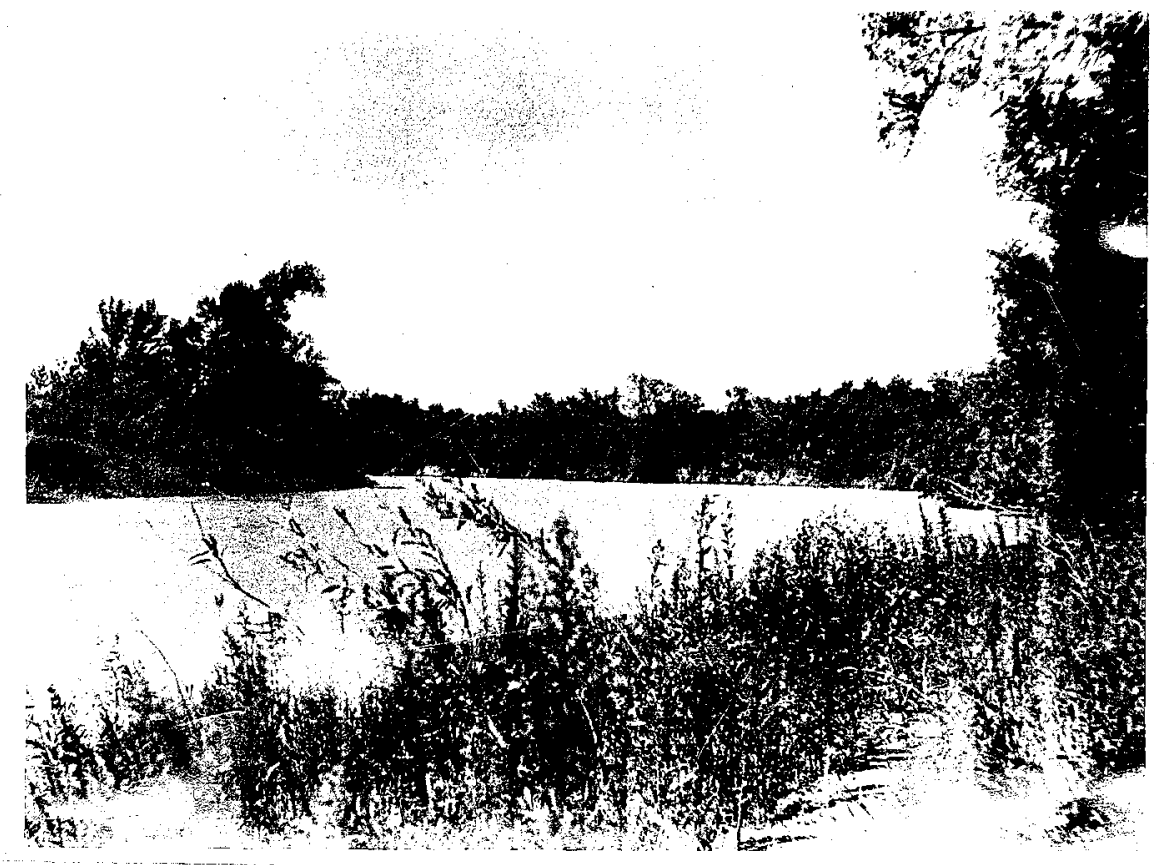

\section{P15. 149 meandwo fluvial: la dowocha anguzo vivo con

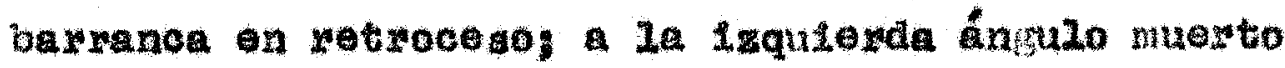 con activa sedimontación--}
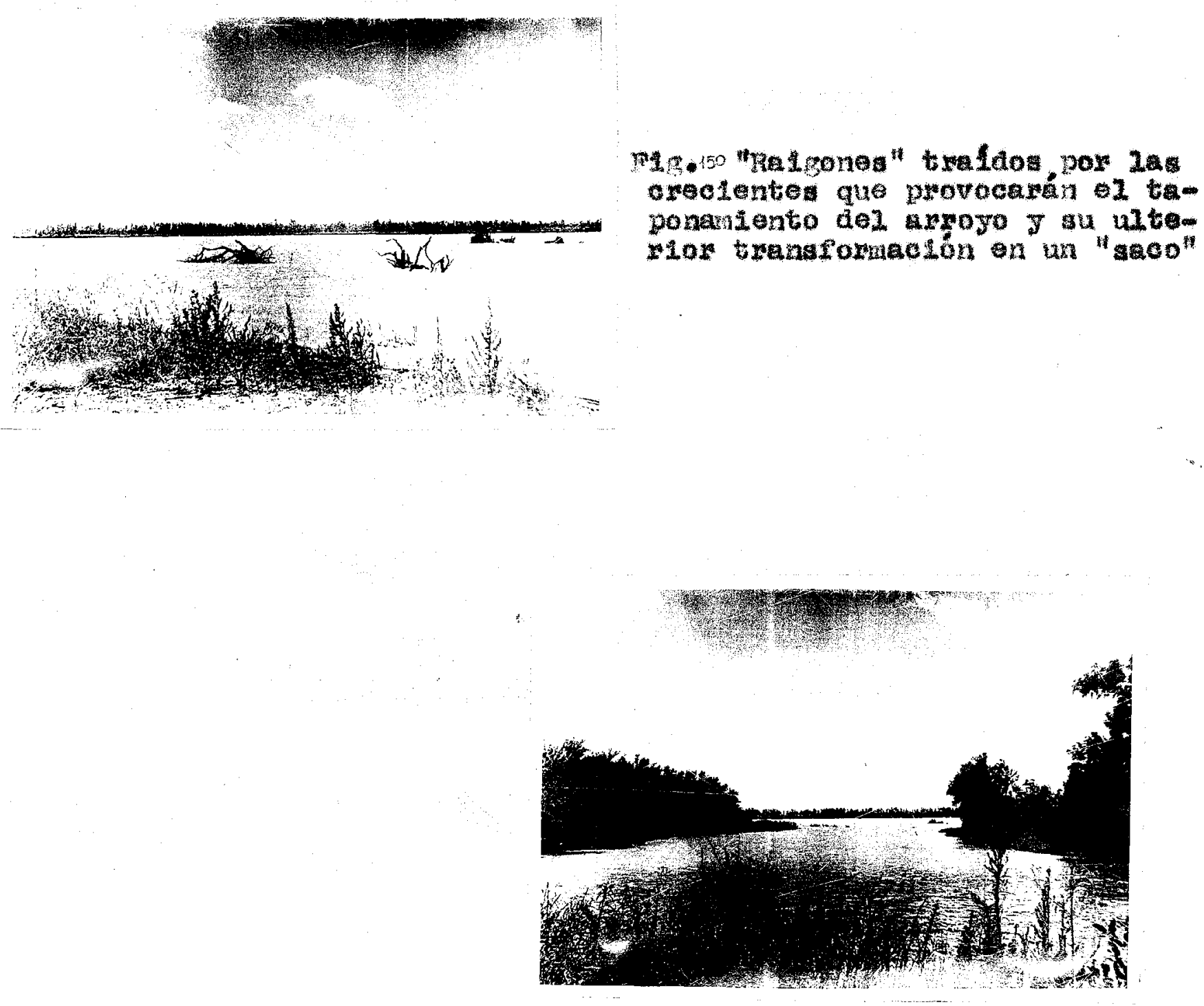

Fing A 6eponam Lonto - 


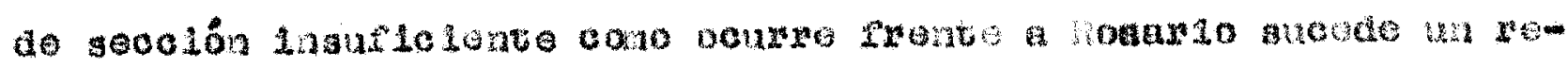

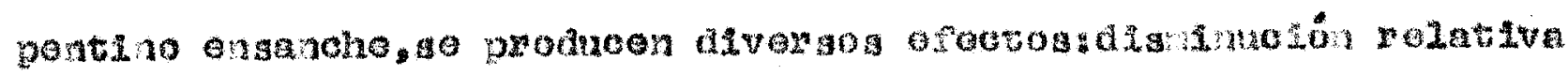

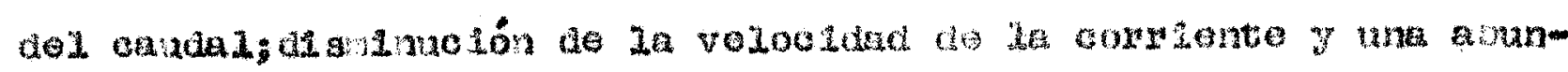

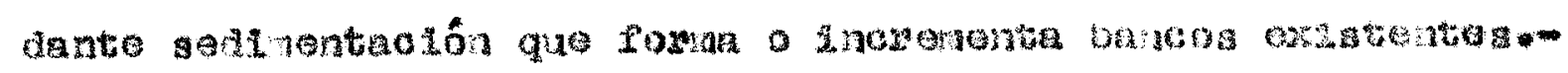

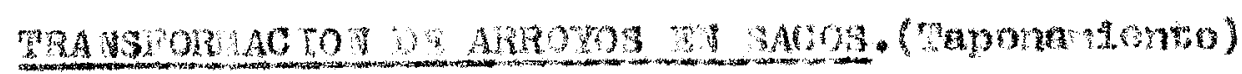

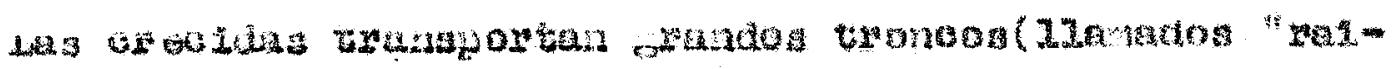

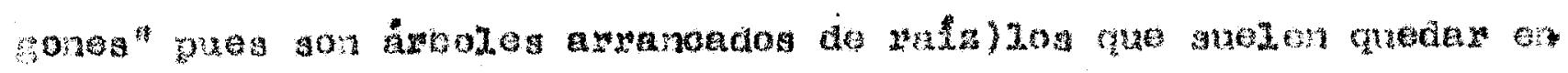

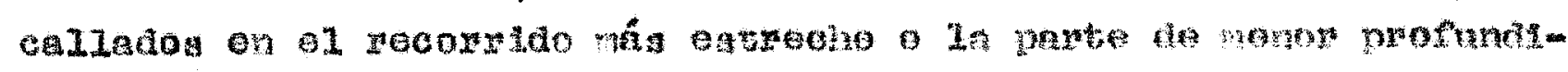

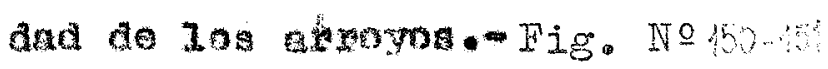

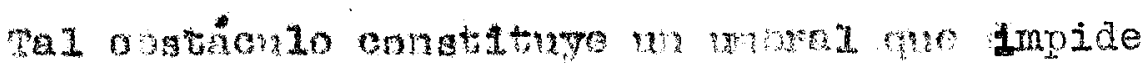
is

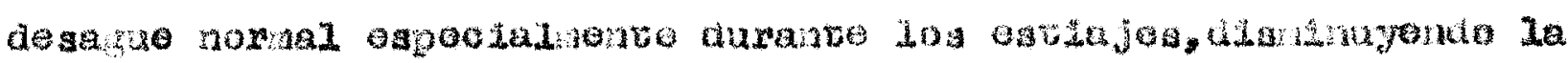

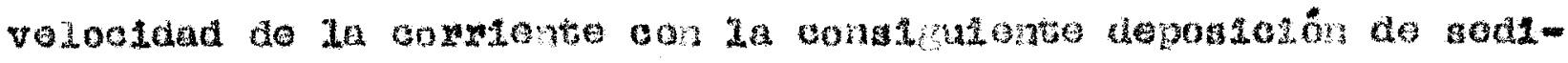

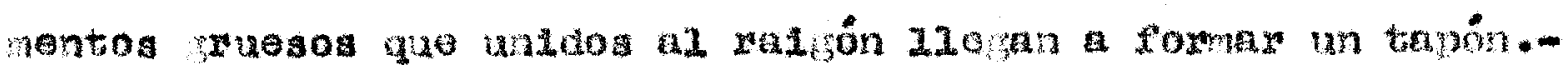

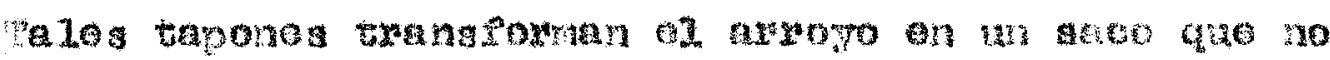

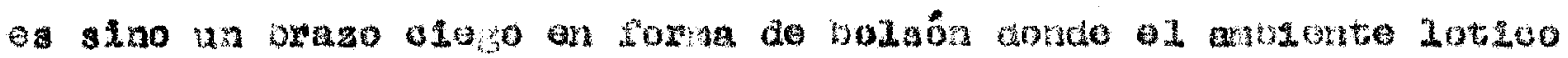

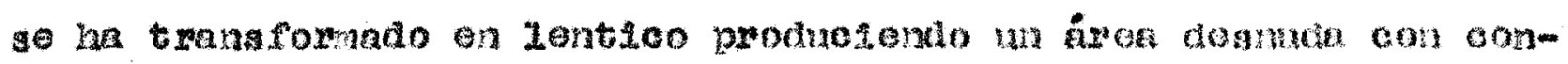

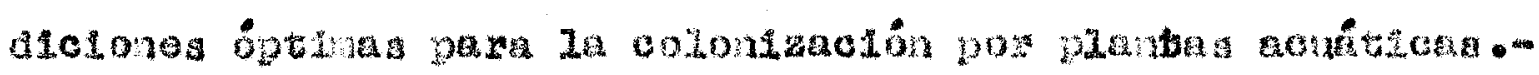
QATSA3 QLIARICAS:

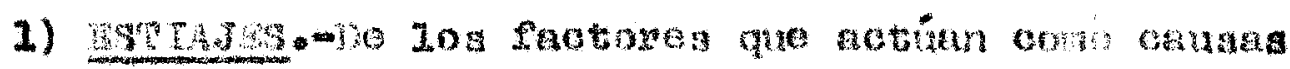

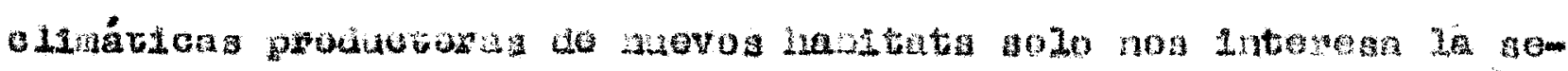

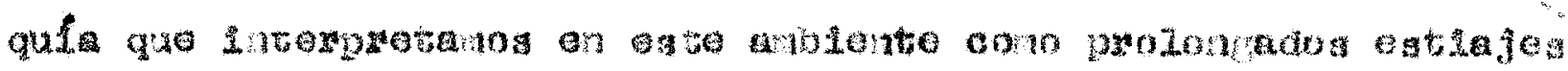

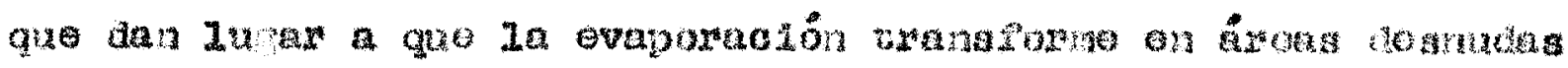

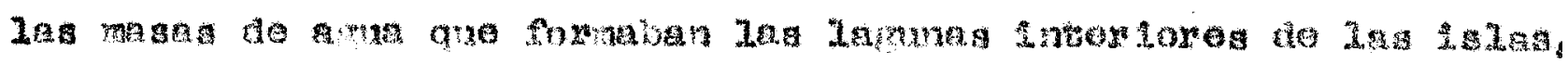
Y te

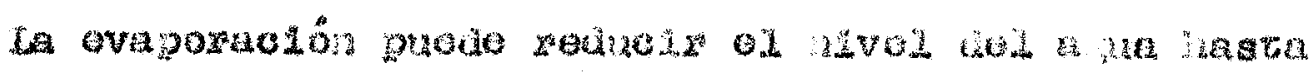

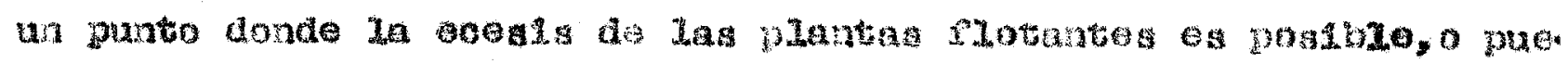

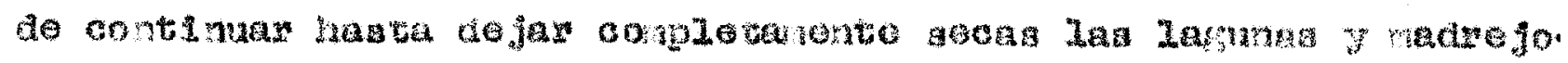
no: -

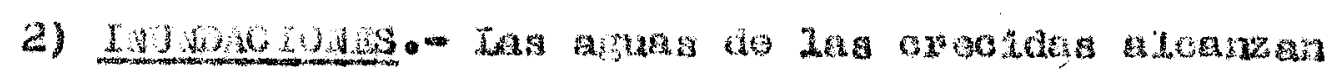

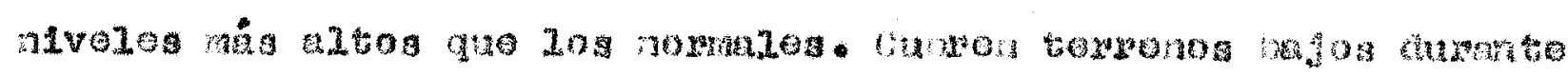

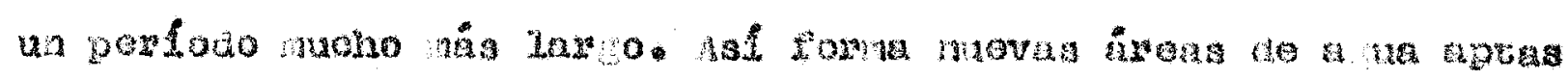
para 12000 ats.

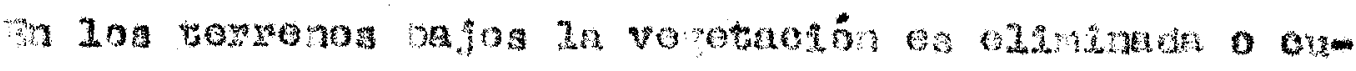




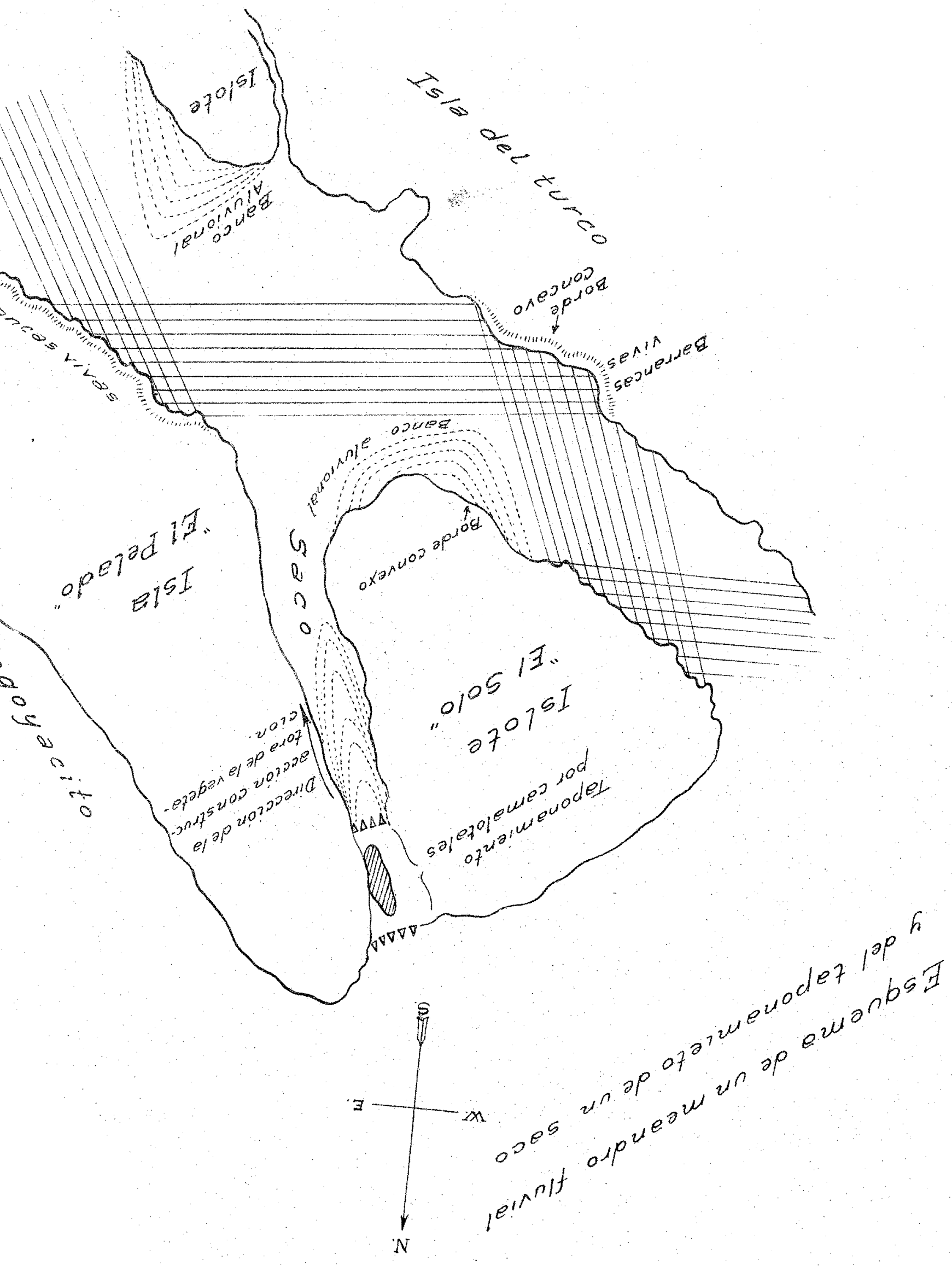




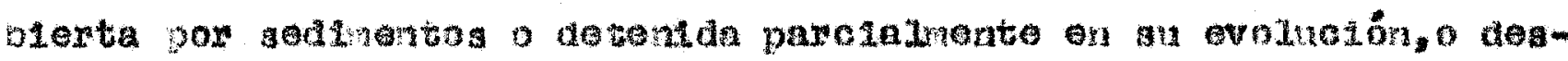

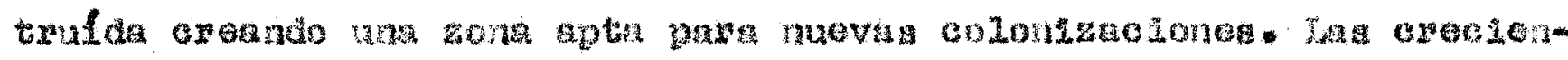

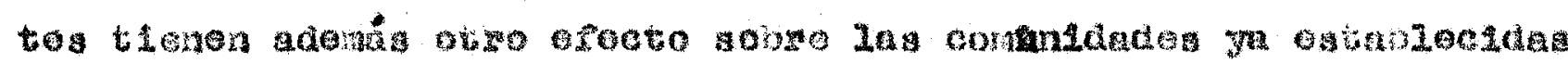

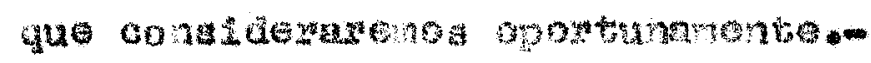

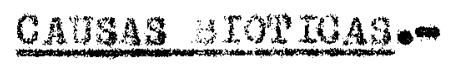

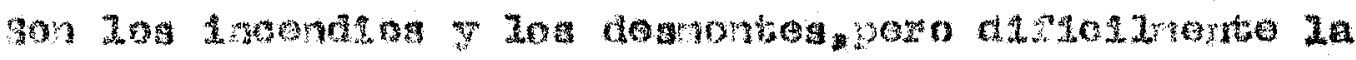

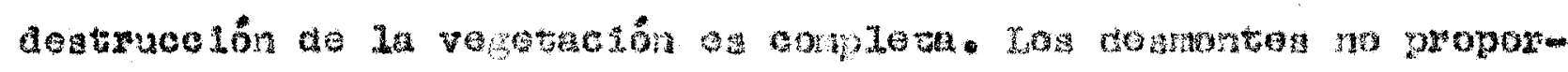

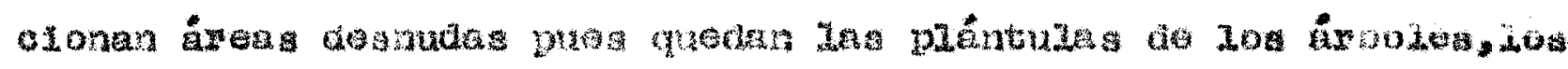

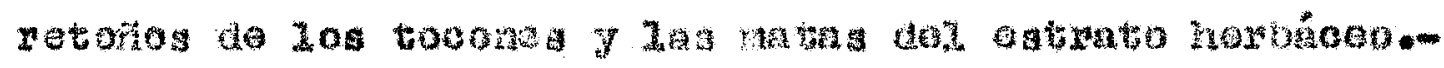

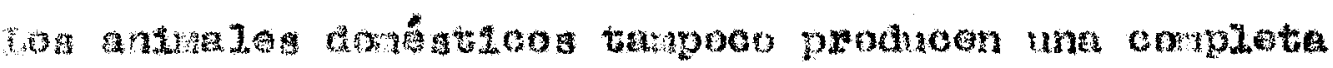

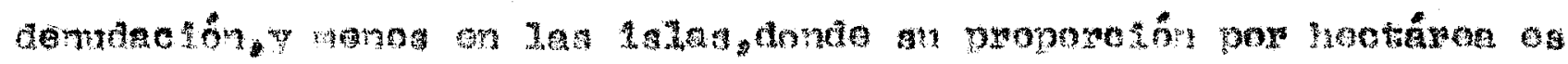
de 1 a anated

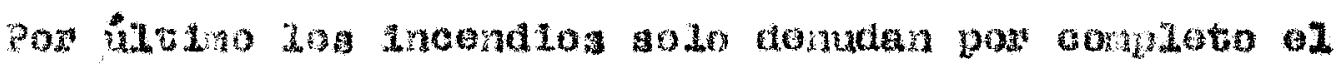

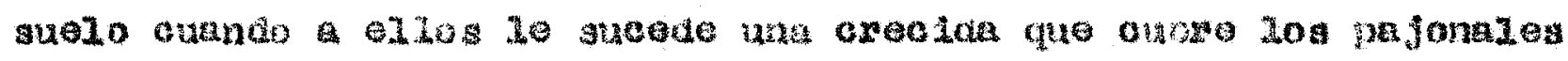

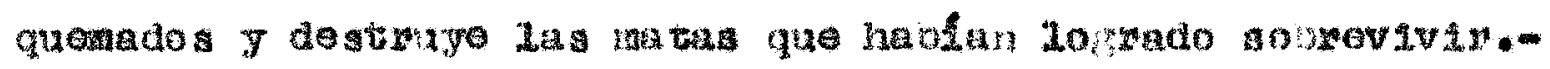

b) $10 x+3040$

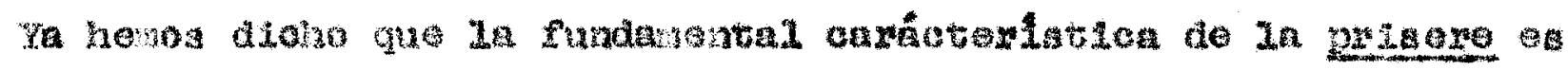

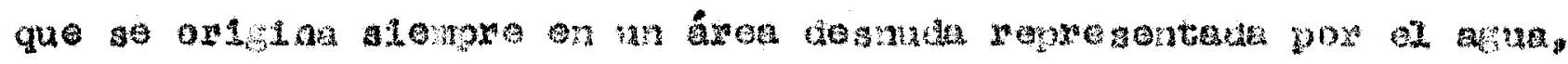

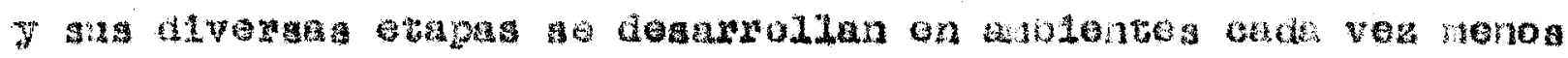

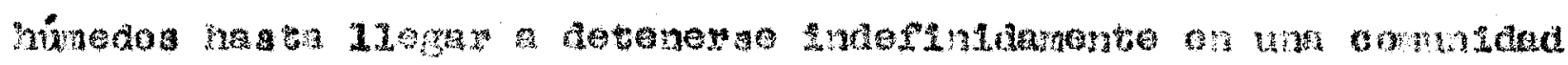

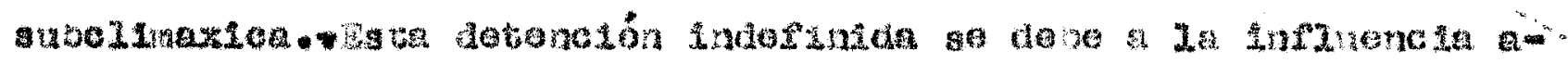

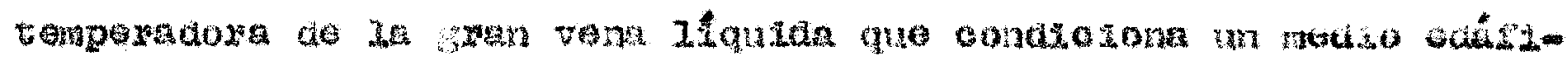

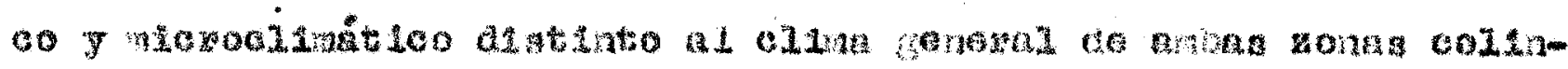

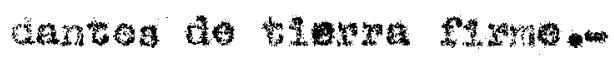

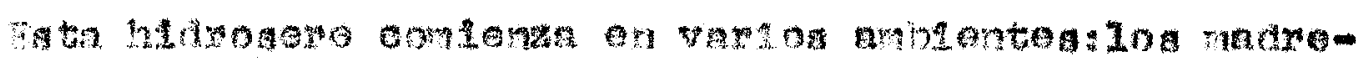

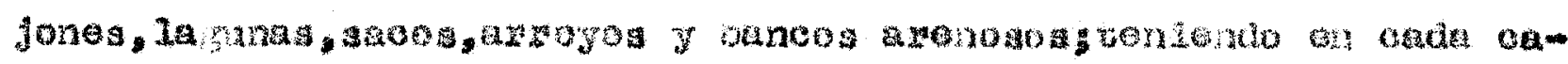

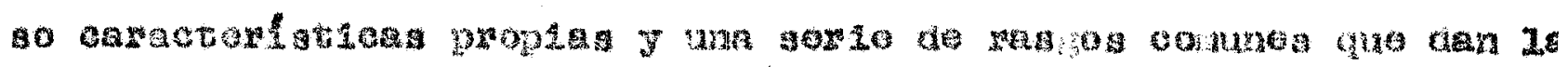

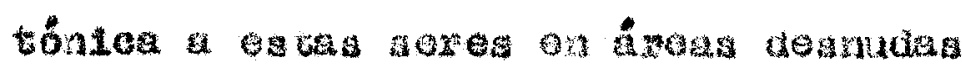

0.

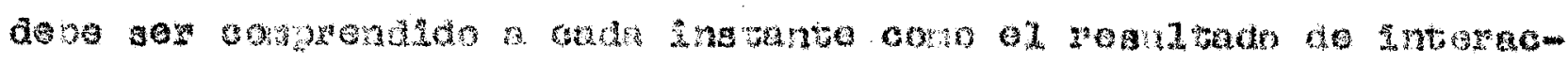

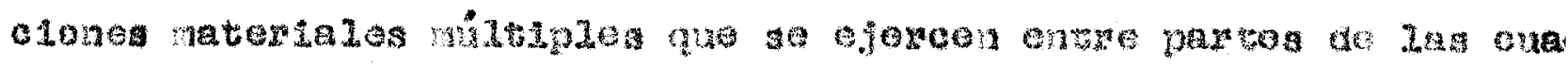

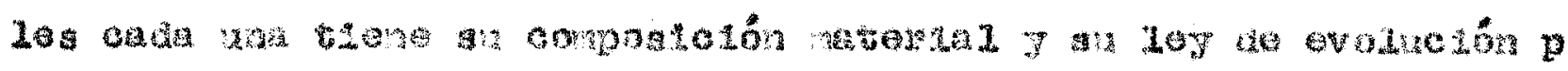




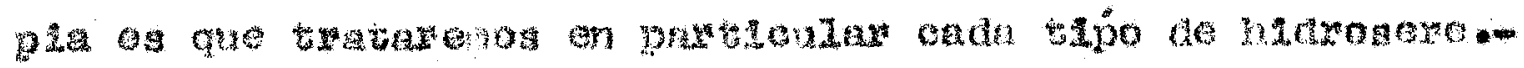

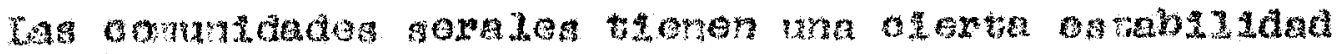

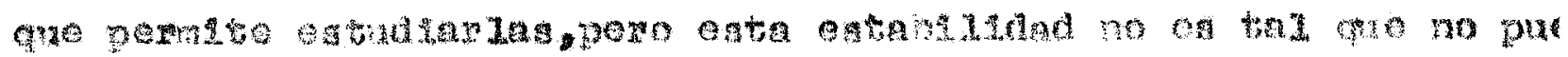

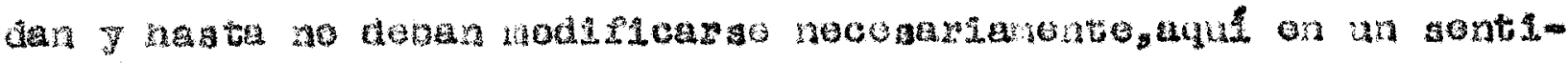
no alá on otwo-

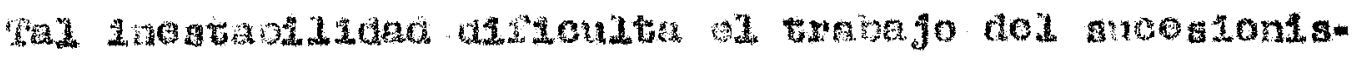

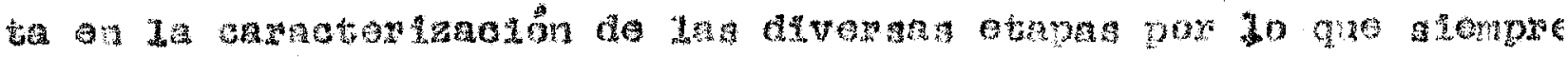

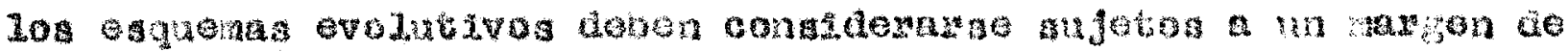
$\operatorname{crcos}$

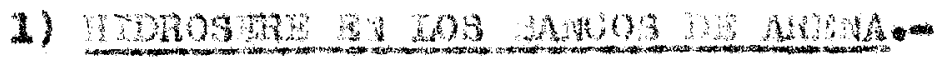

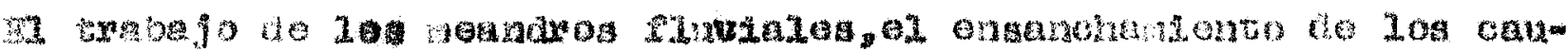

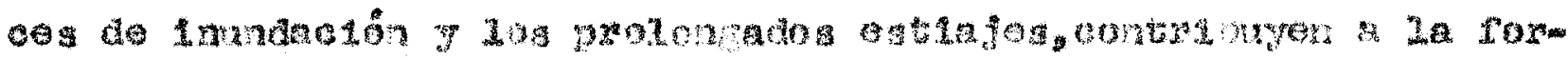

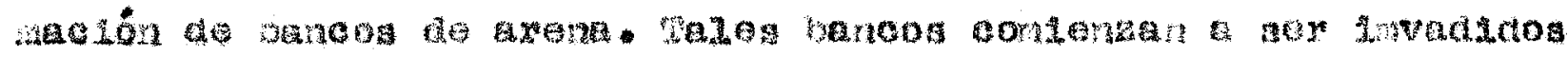

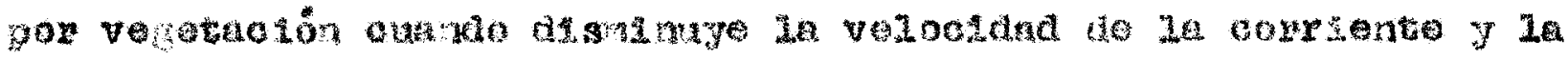

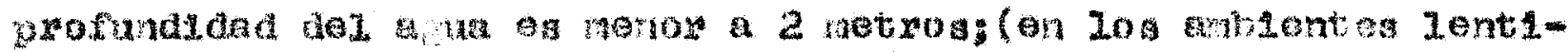

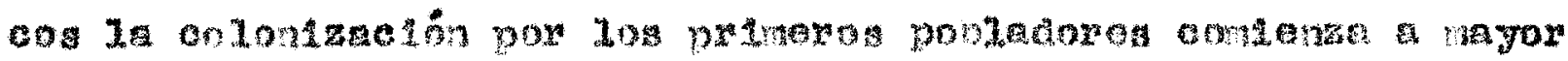

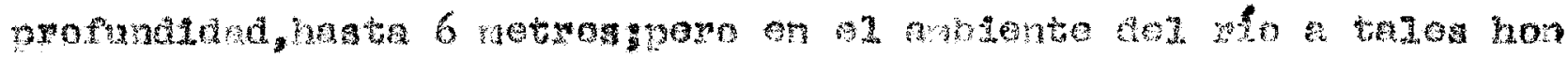

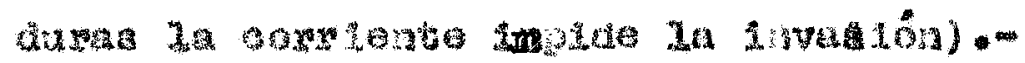

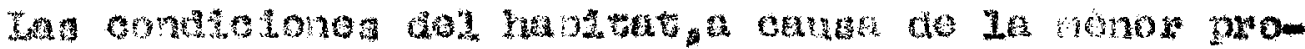

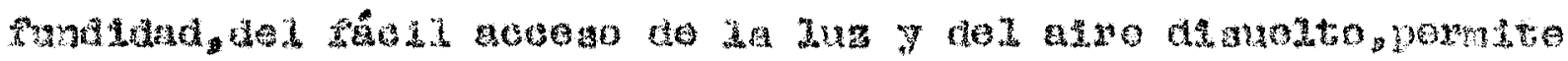

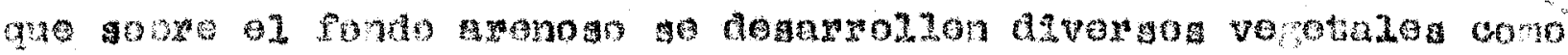

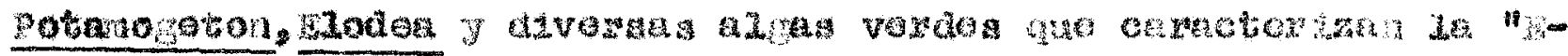

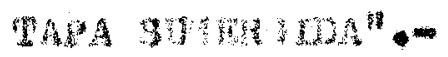

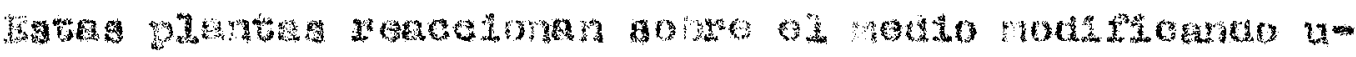

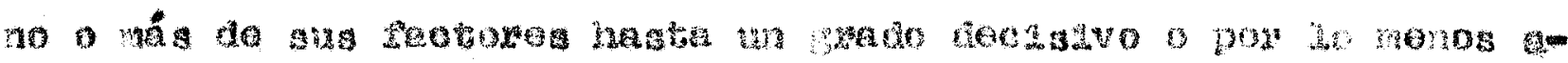

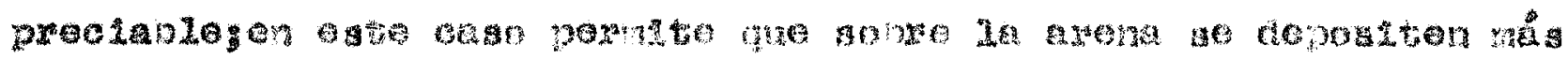

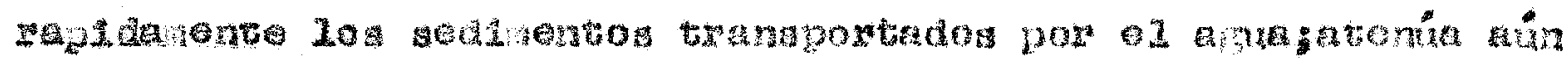

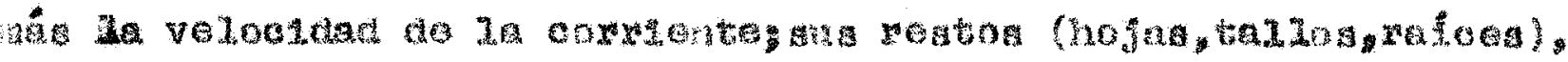

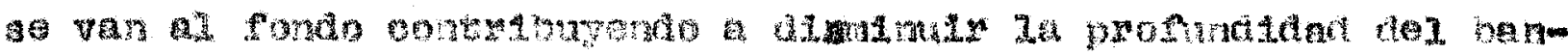

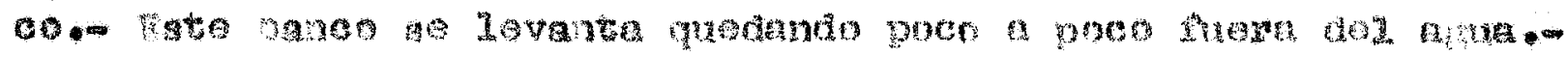

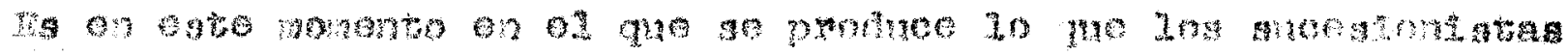

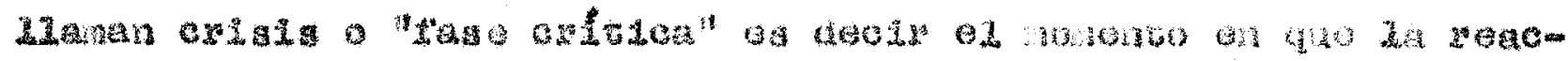




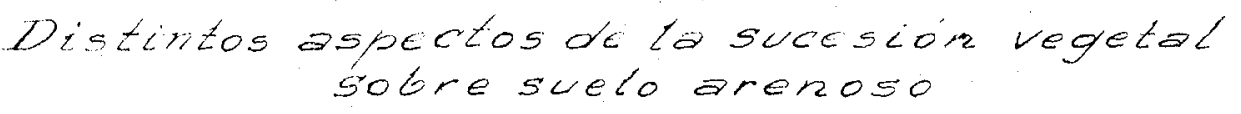

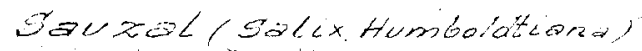
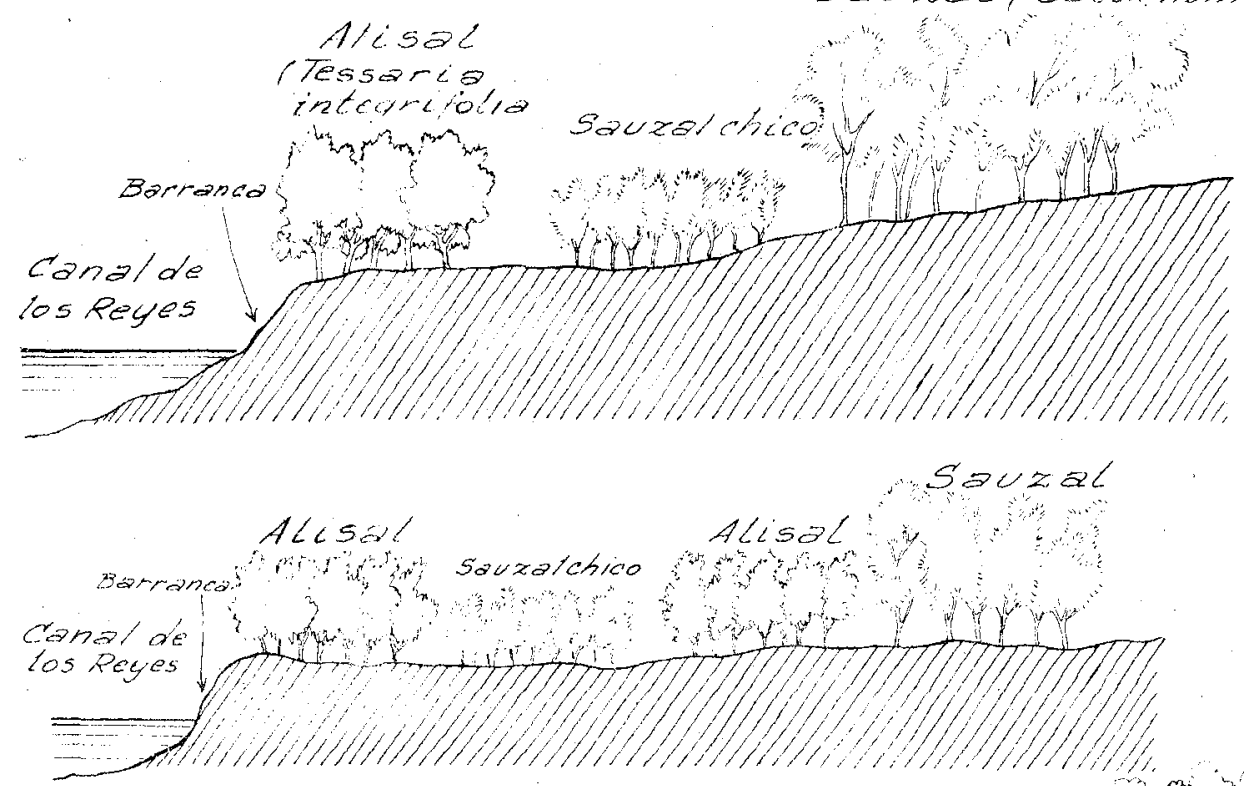

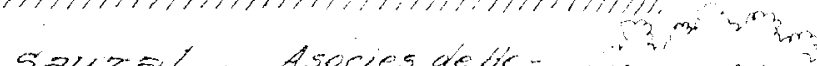

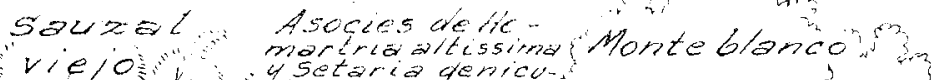

chilcalcon terio. Spuzal

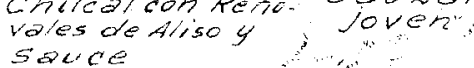

viejo "i Moto
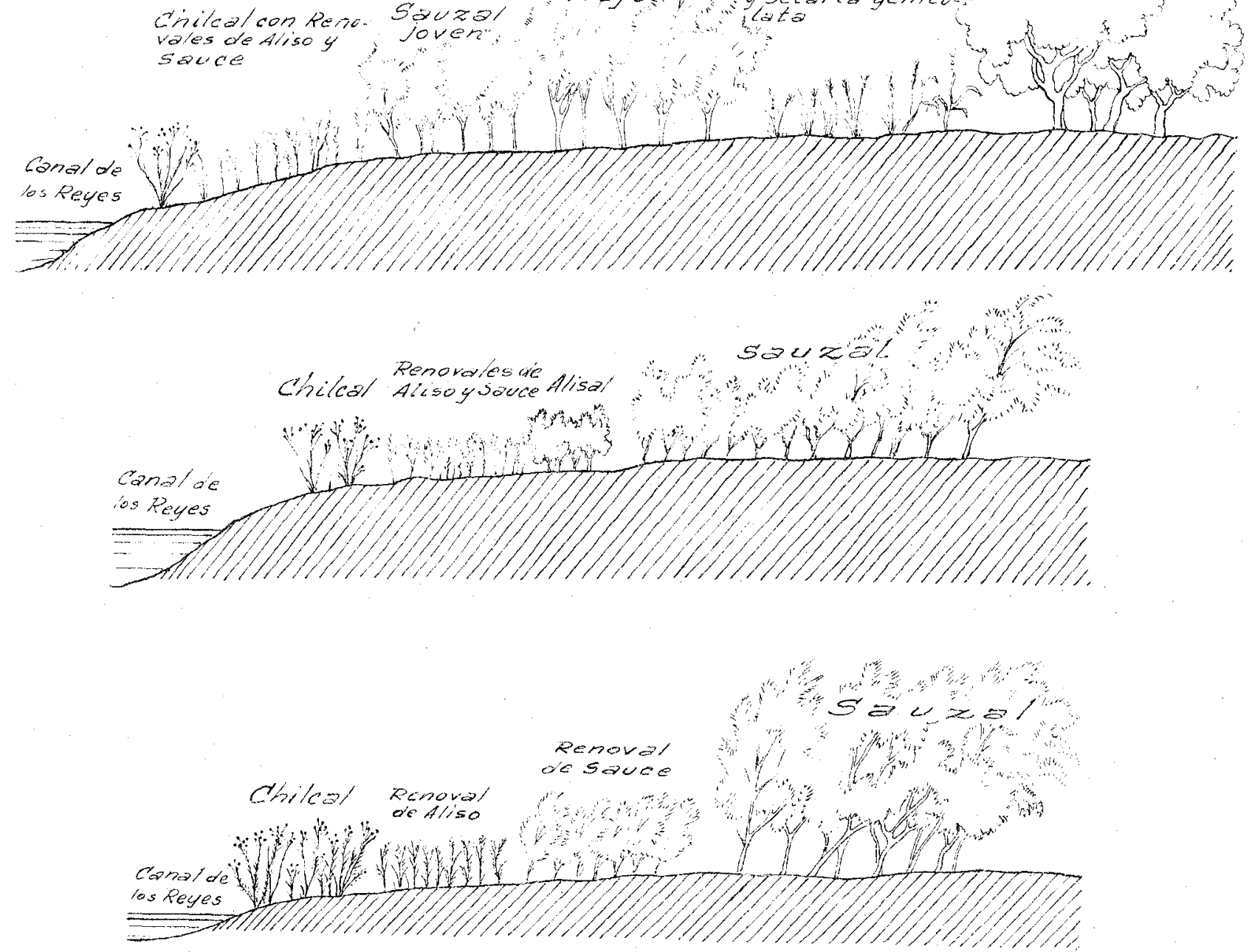


\section{El Islote}

Distintos ospectos de la sucesion vegetal sobre suelo arenoso
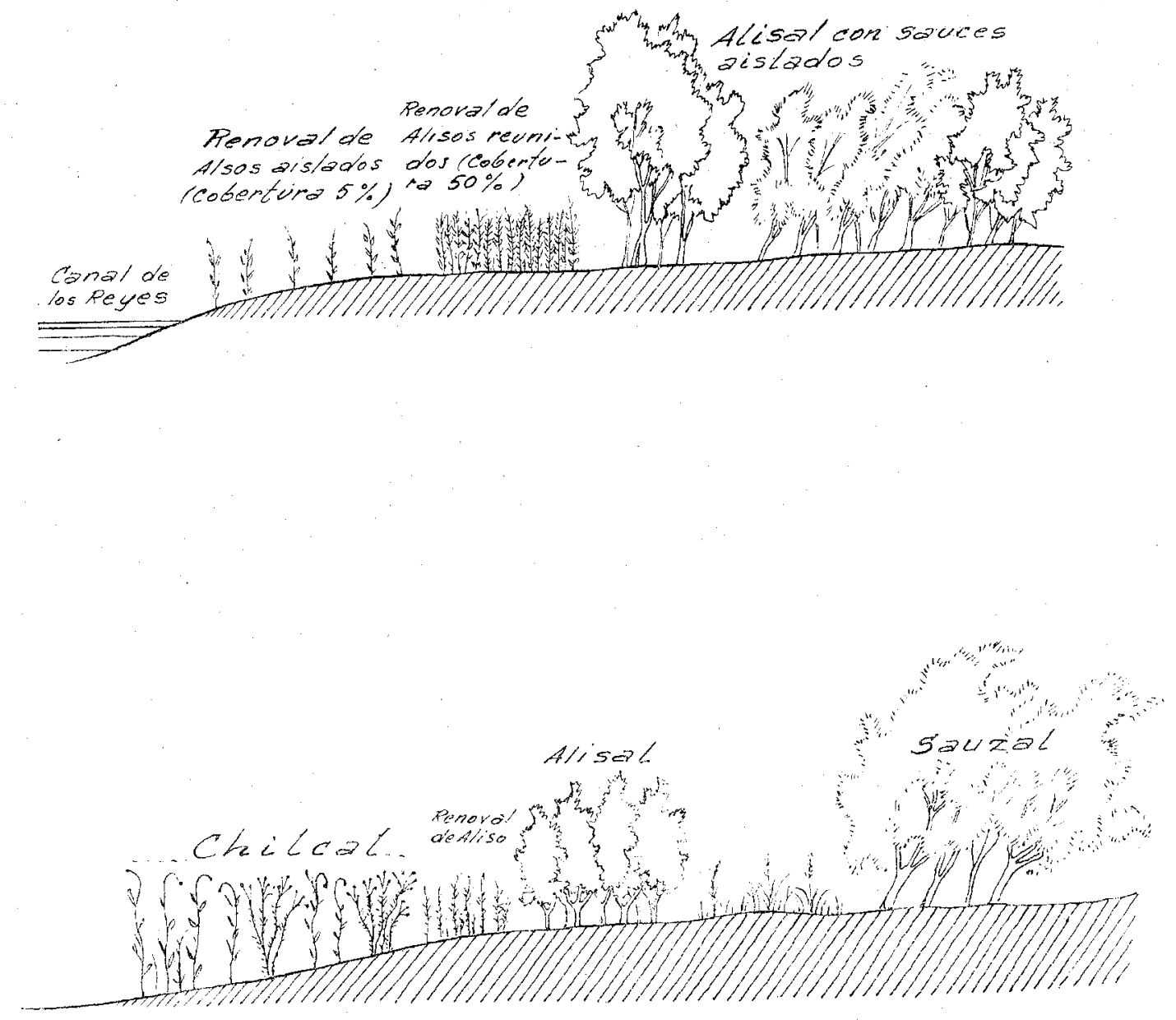


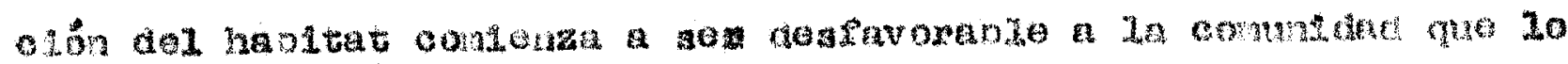

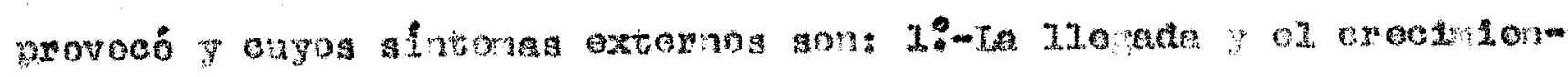

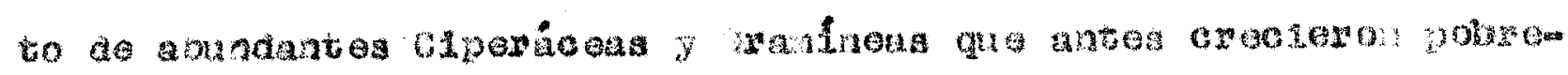
monte o no croctoron.-

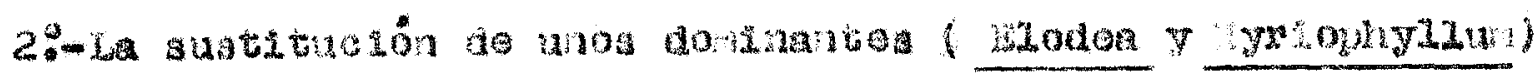

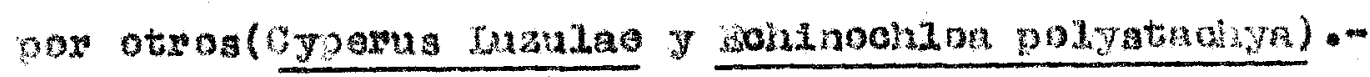

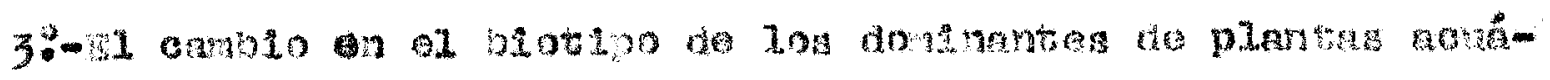

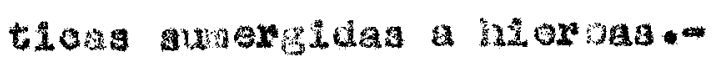

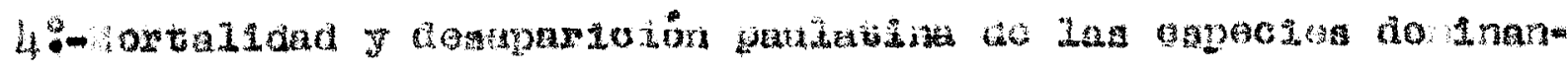
누읭-

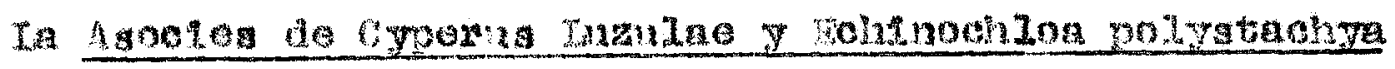

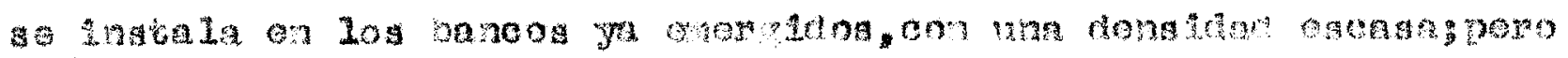

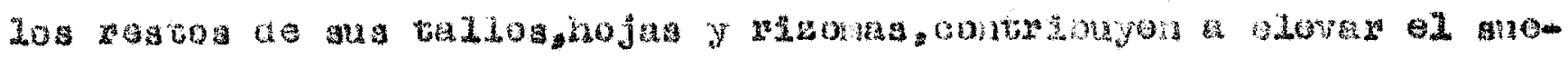

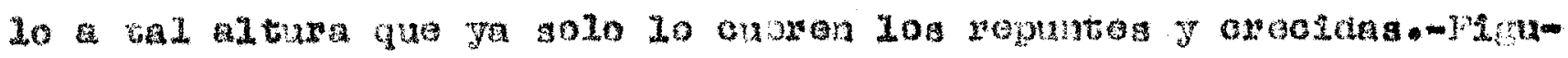

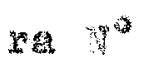

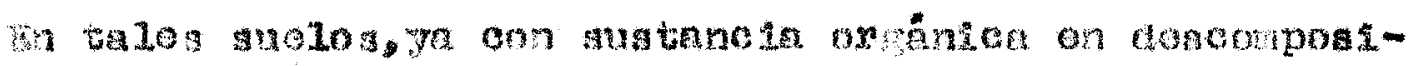

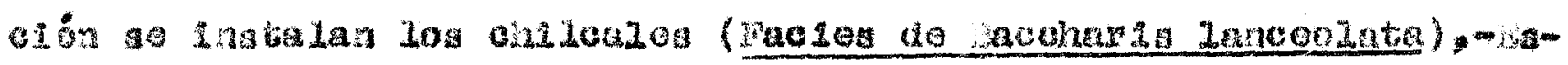

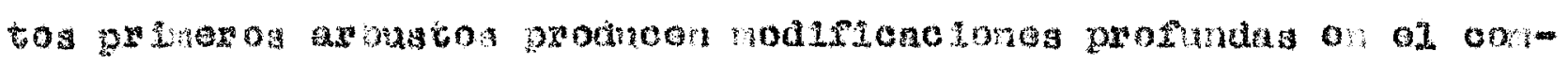

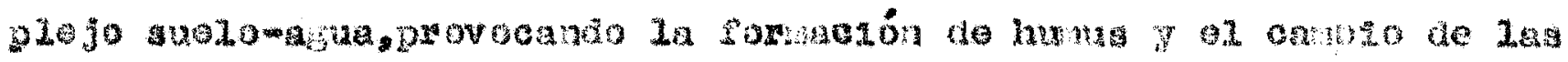

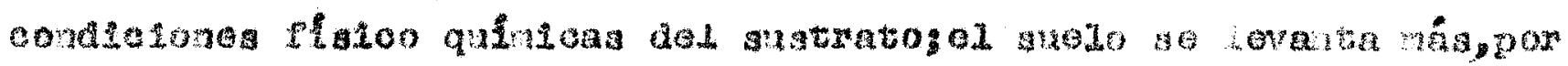

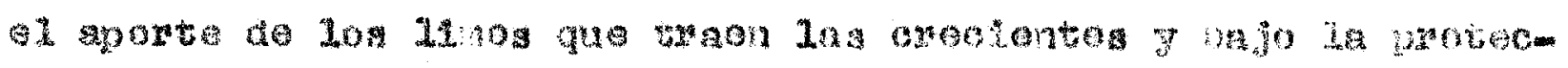

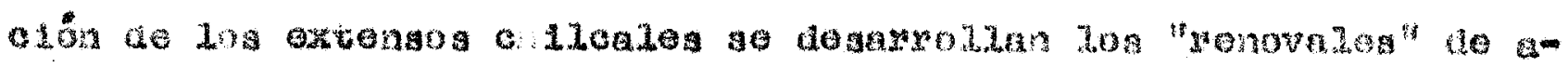
Hao y auce.

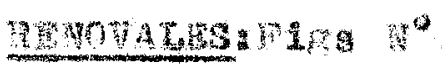

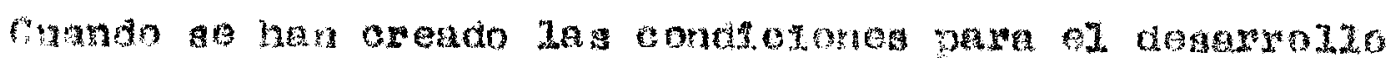

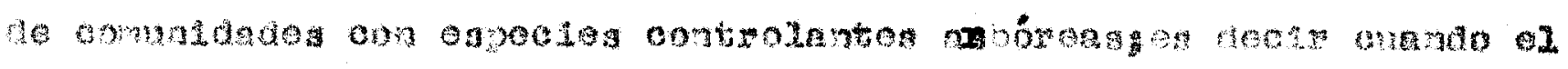

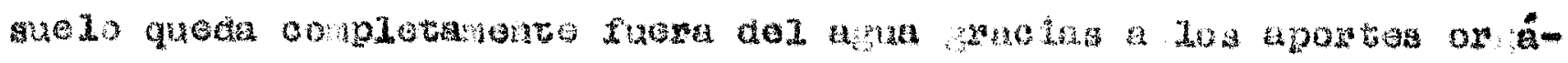

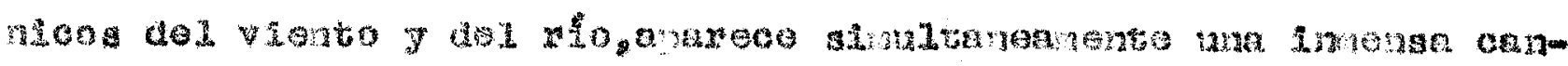

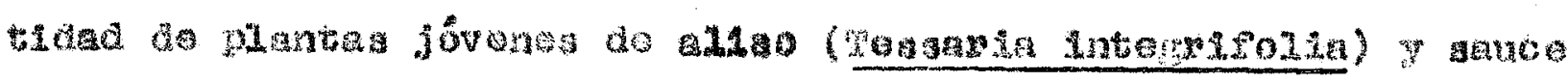

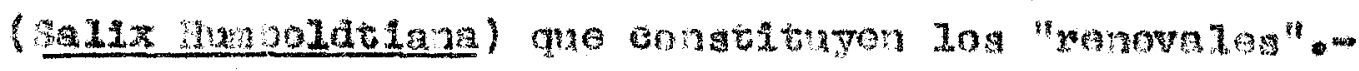

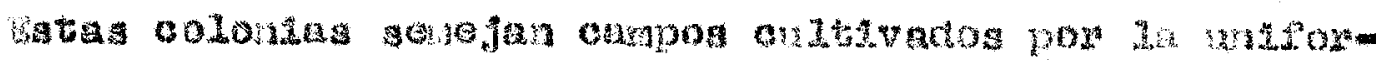

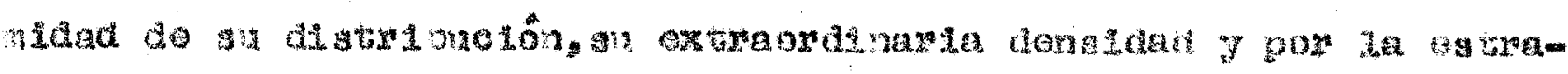

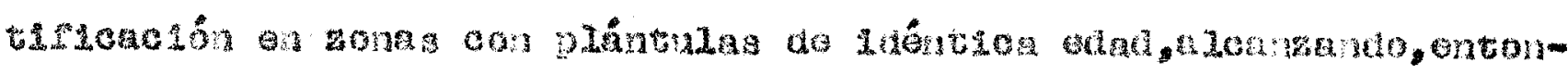


Censo grafico correspondiente al renoval de Aliso

Tressaria integrifolia) y Sauce (Salix Humbalatiana)

Superficie estudiada en $m^{2}=25$

flecha 2-2-49

Cobentura: $100 \%$

Altura de la vegetacion. 1,50m

Suelo arenoso mug trumedo

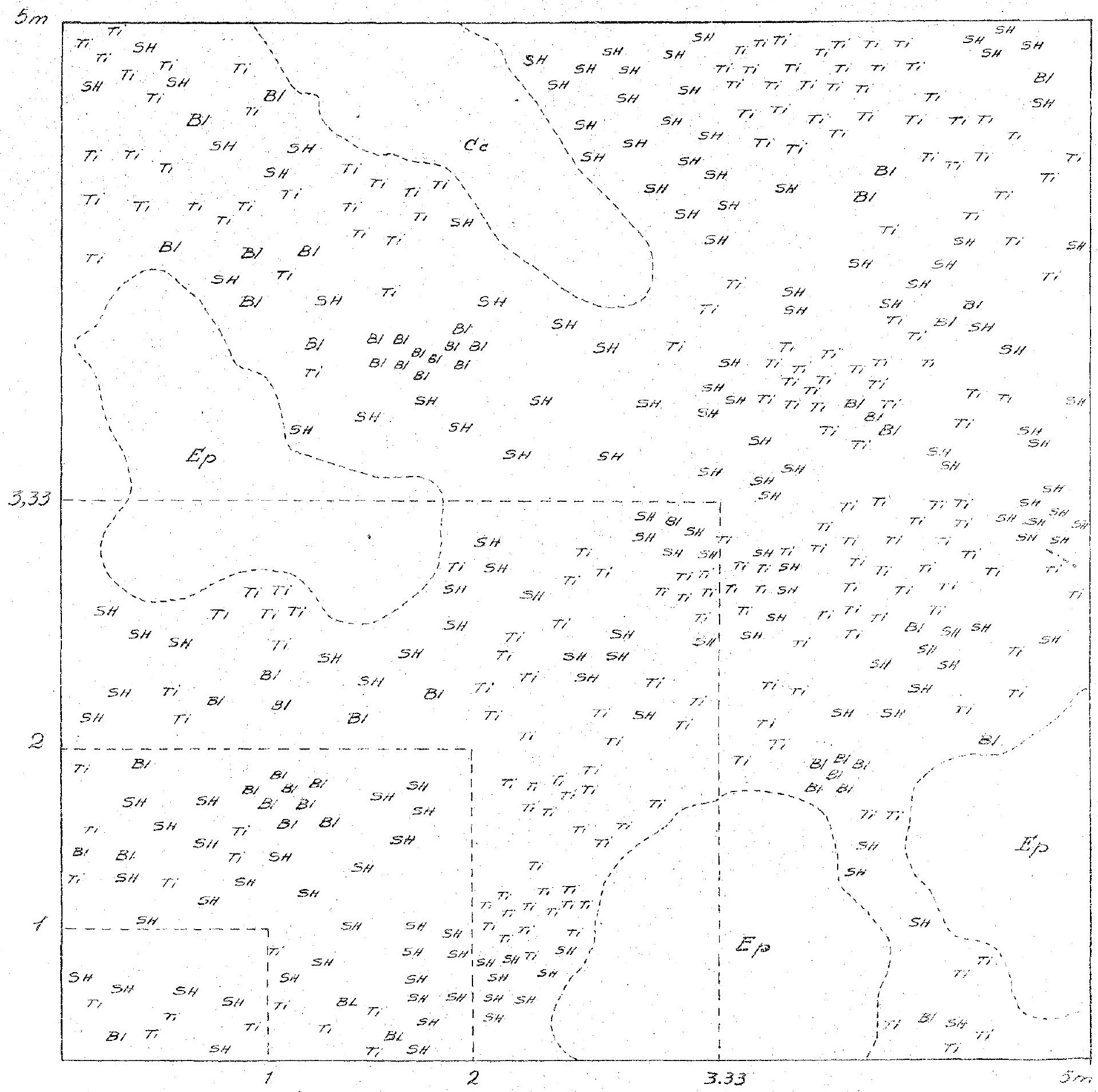

B/ = Baccharis lanceolata

Ce: Cuperus Luzulae.

Ep Eichinochloa polystachya

SH: Salix tumboldtiana 
coa 1a n19ua altuda -

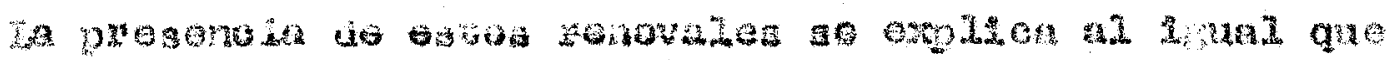

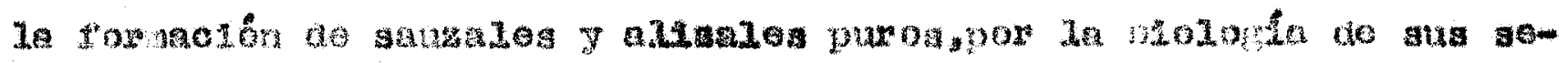

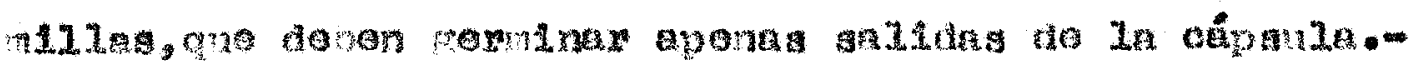

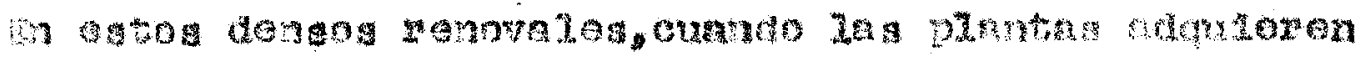

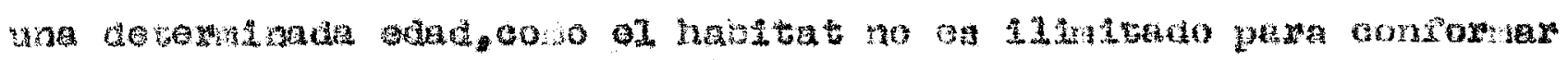

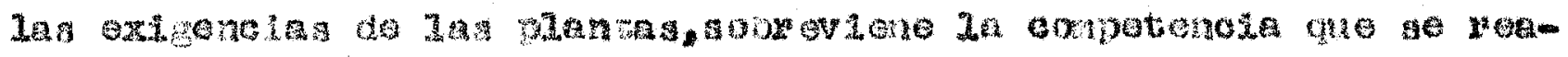

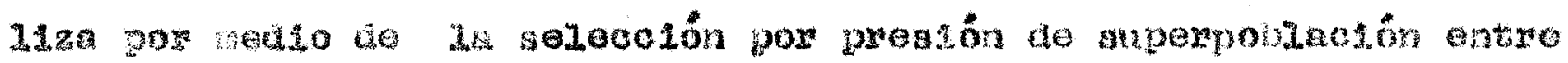

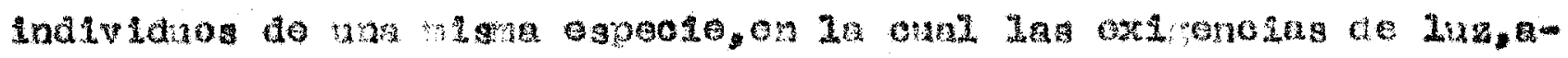

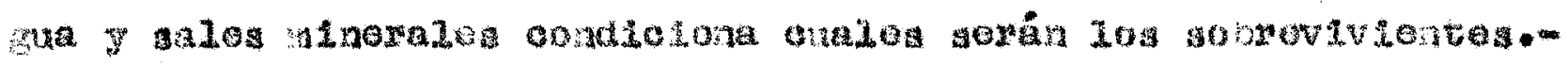

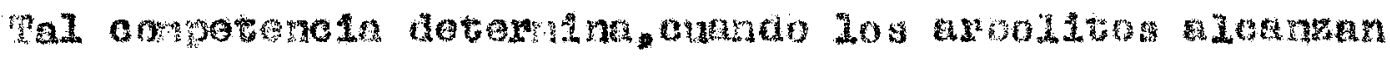

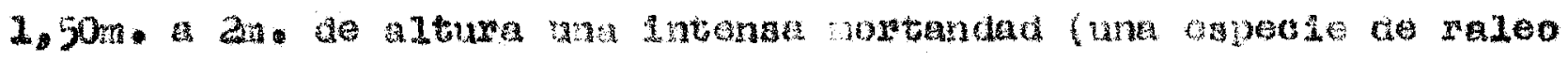

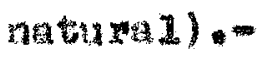

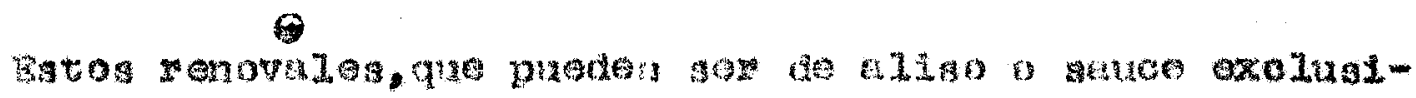

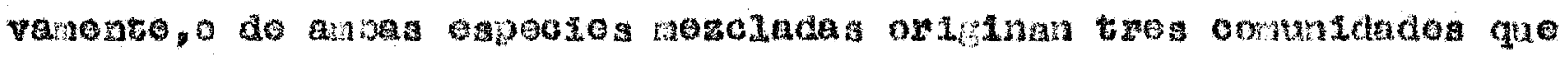

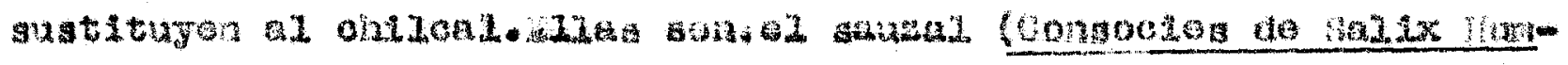

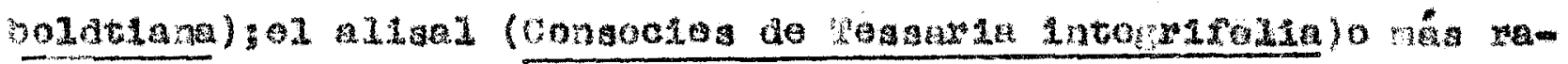

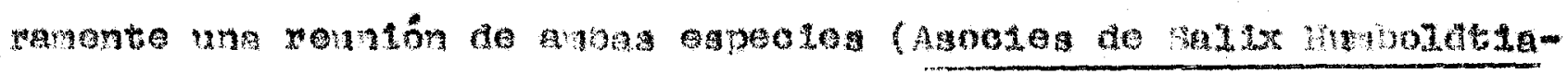
Ia

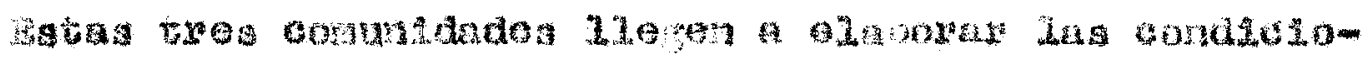

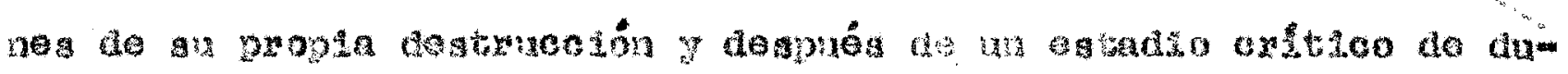

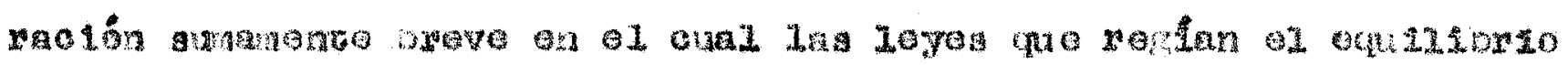

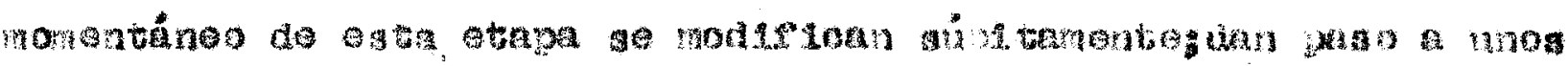

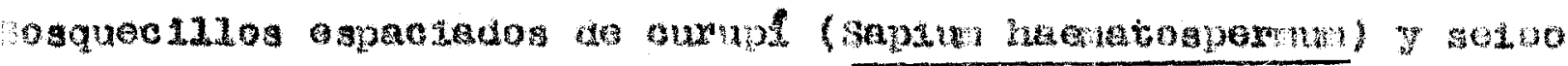

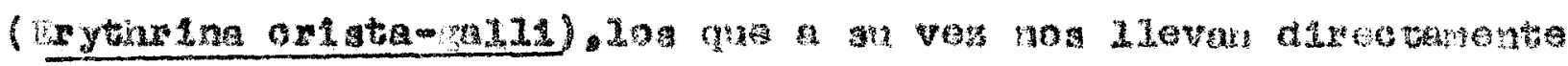

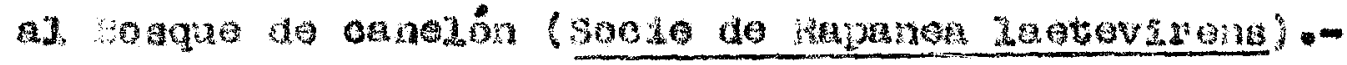

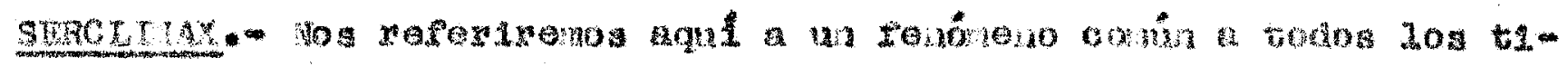

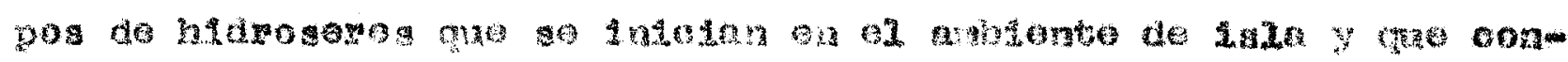

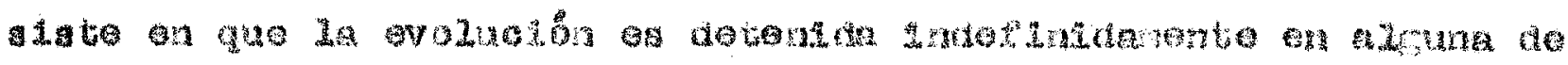

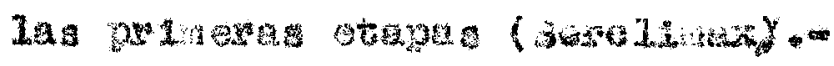

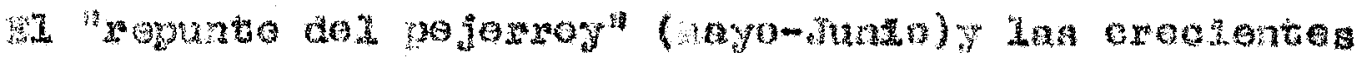

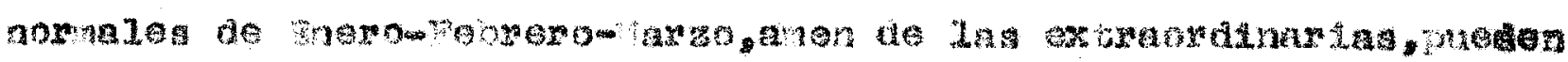

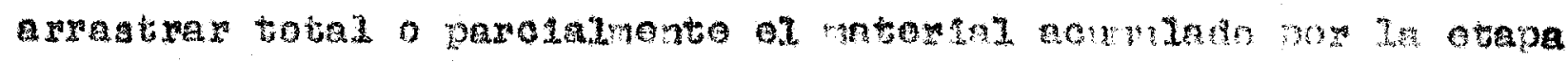




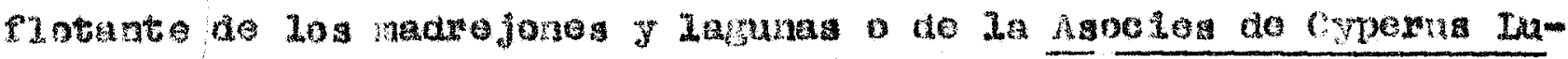

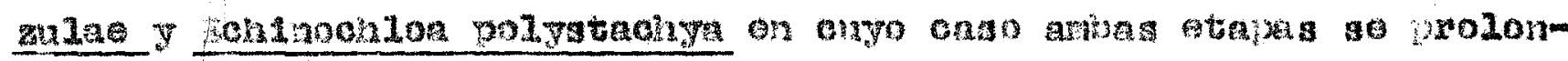

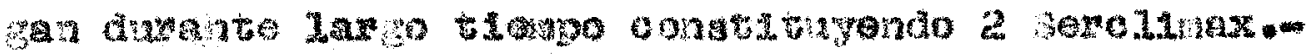

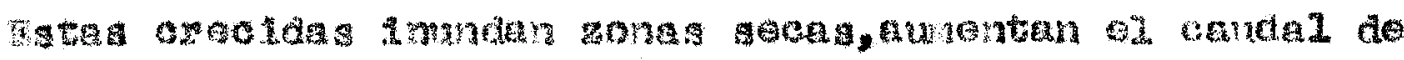

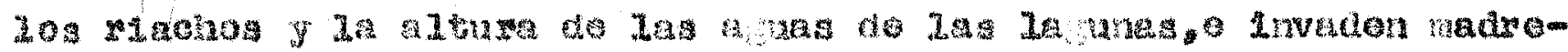

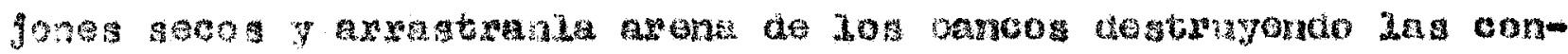

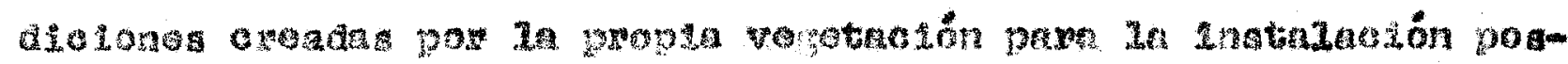

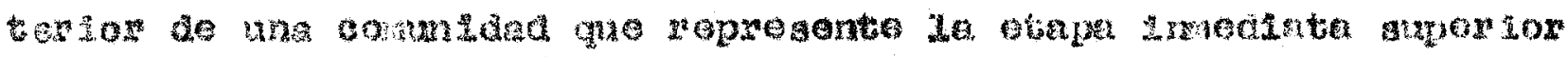

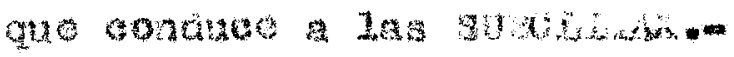

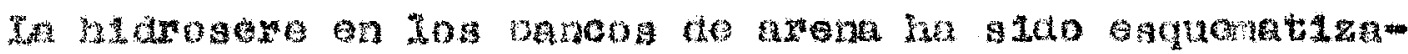
da on ol ovadro

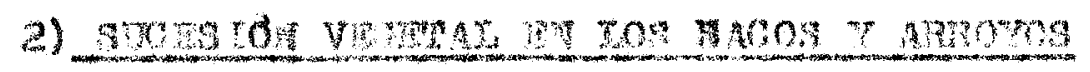

Las a

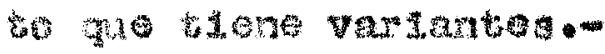

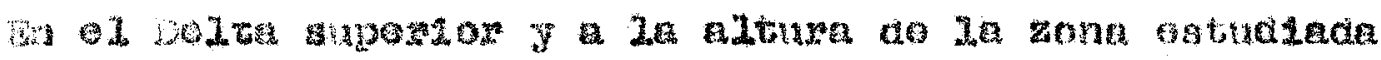

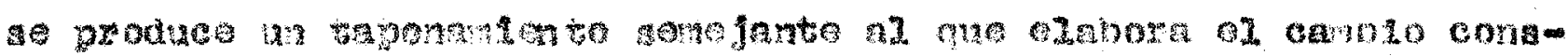

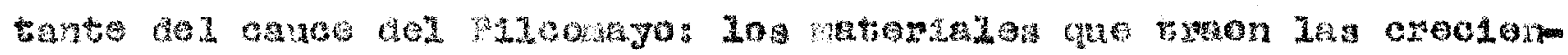

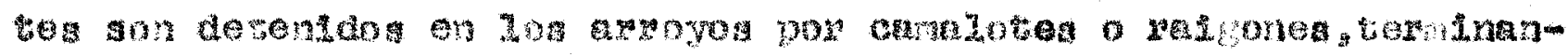

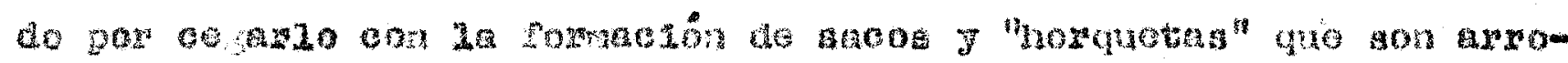

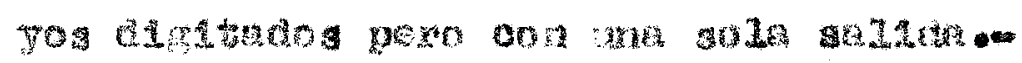

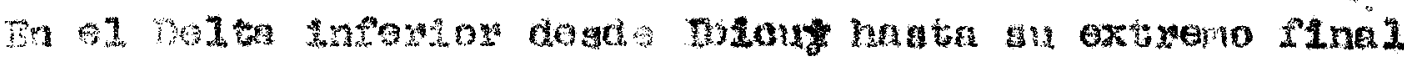

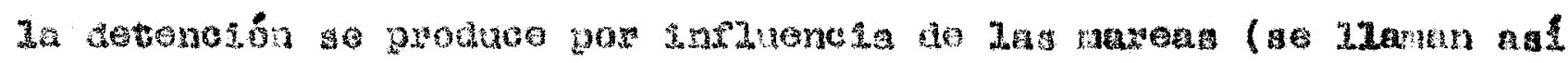

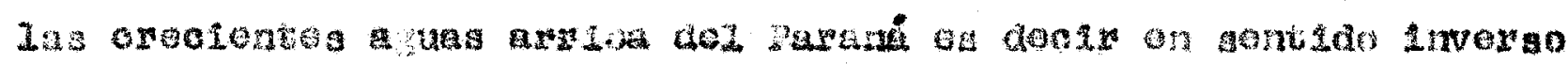

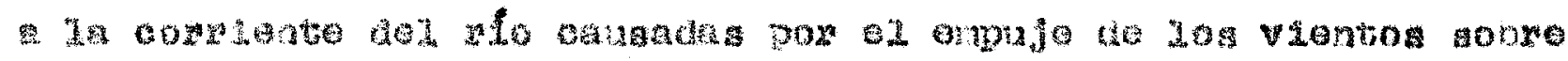

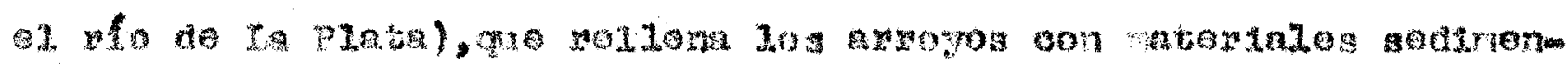

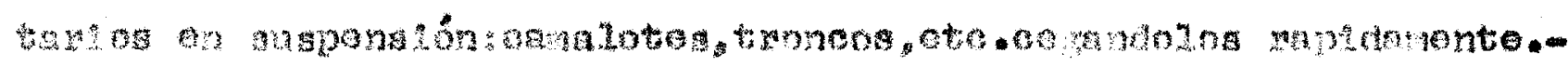

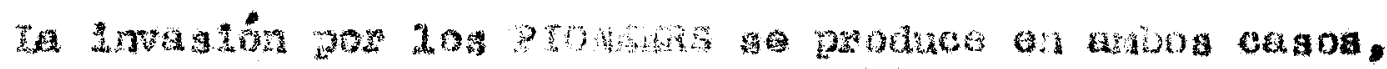

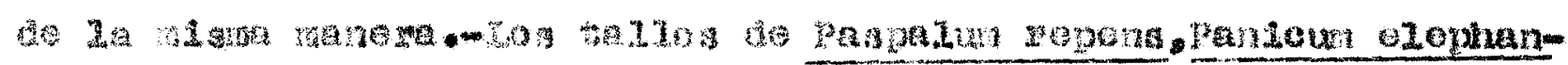

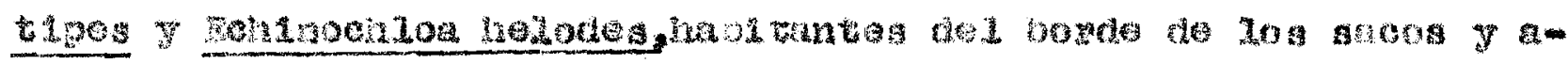

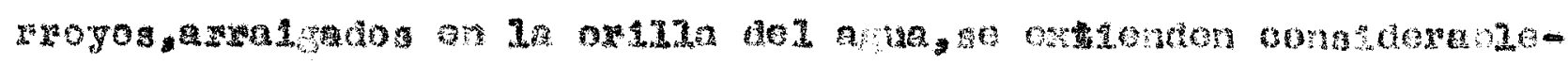

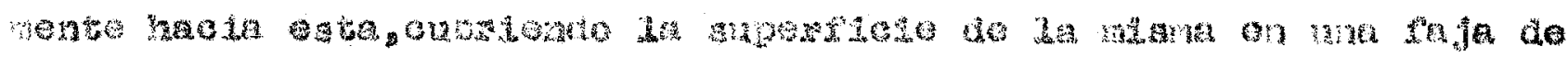

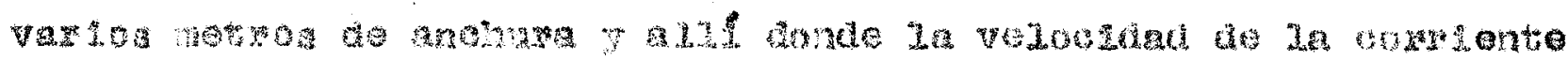




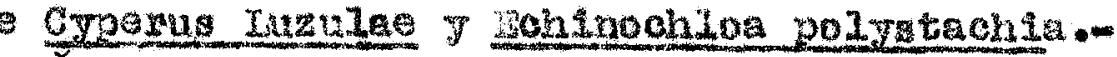

$\gamma$

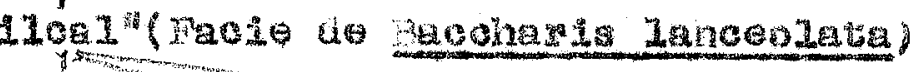

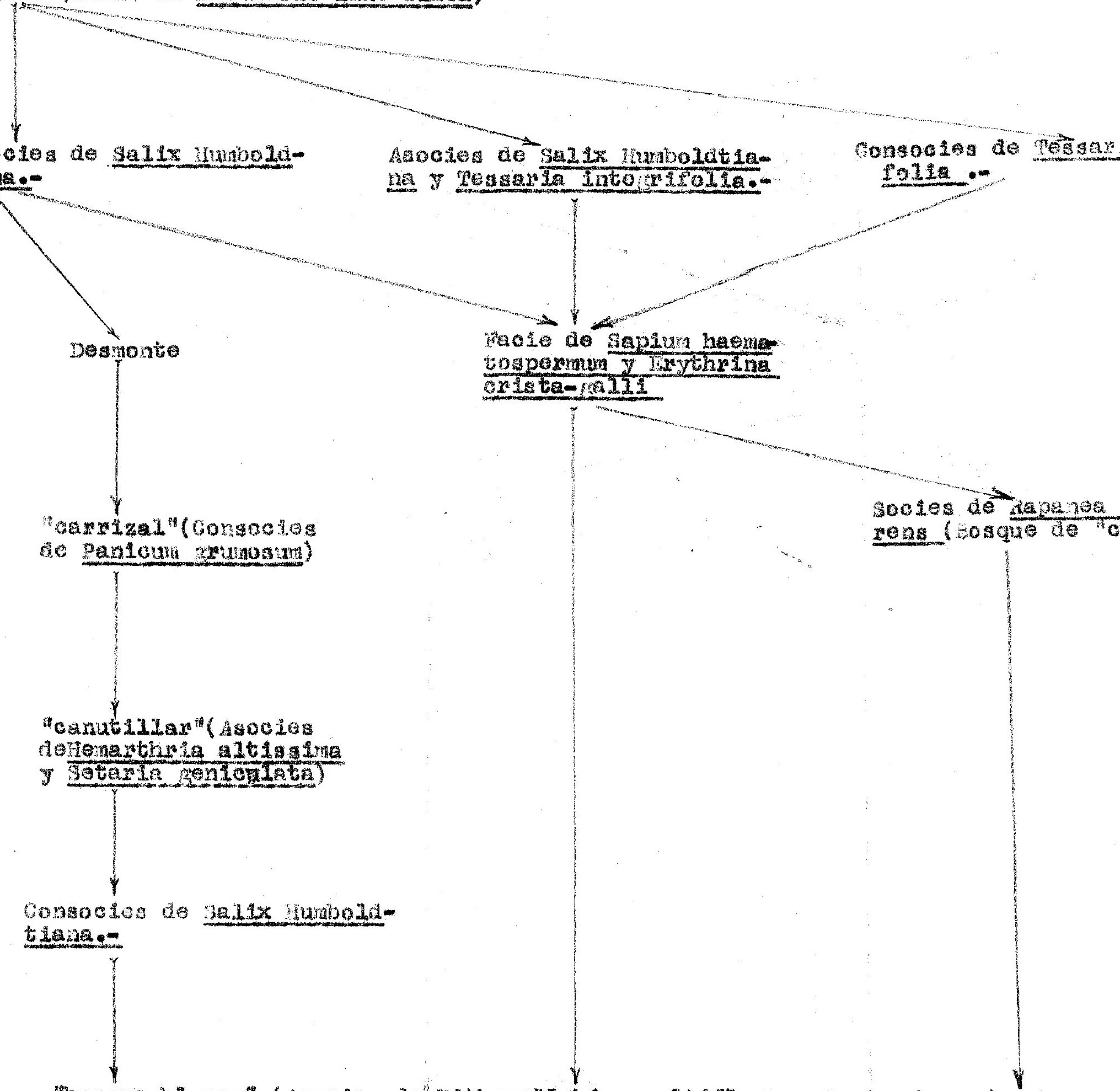

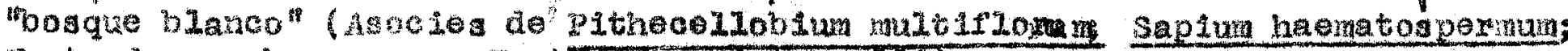
Jectandra menbranacea y Eythrina Criata-EanII 
Hed 10s astogo:-
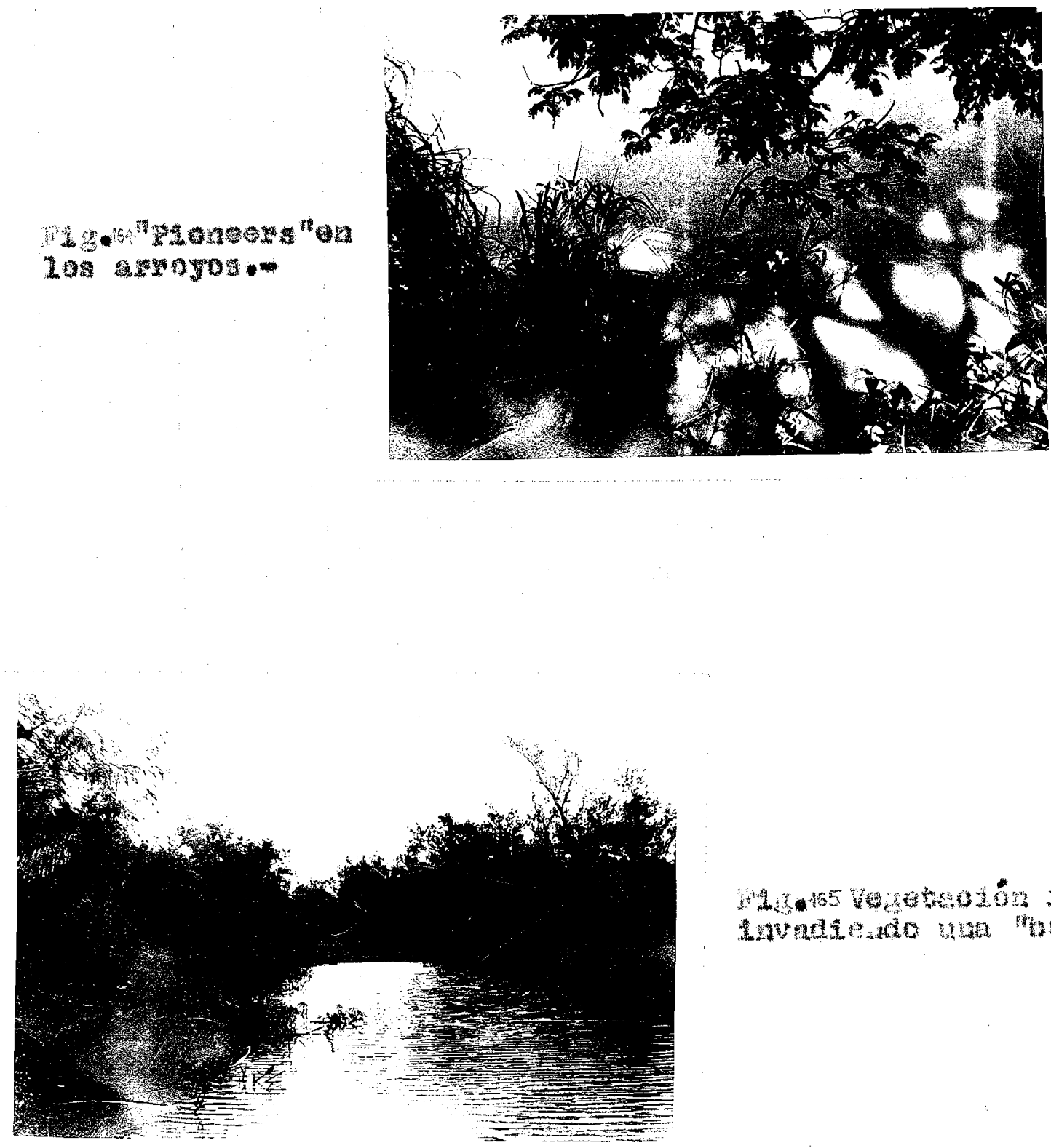

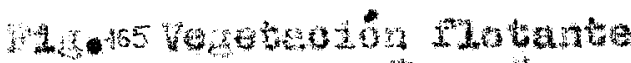

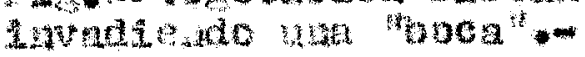

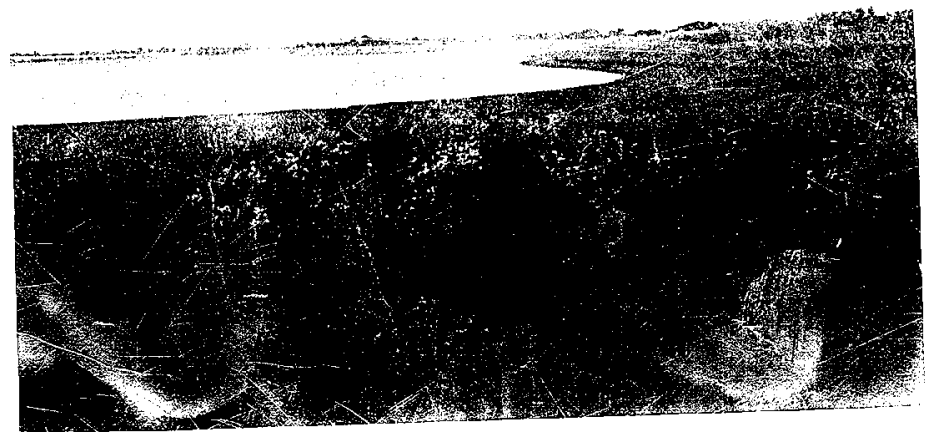

F1g *166 Lagune de nátrgenes axenosas des proviata de vegetaolón eluture.- 


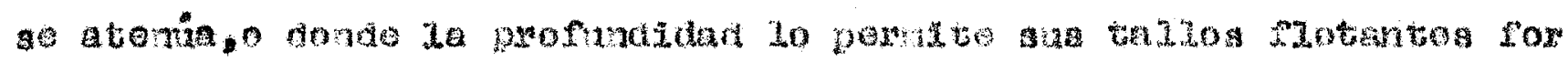

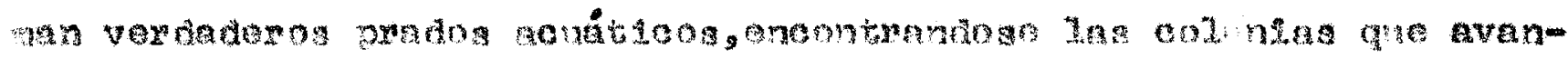
zan desco andea tán

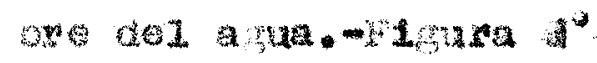

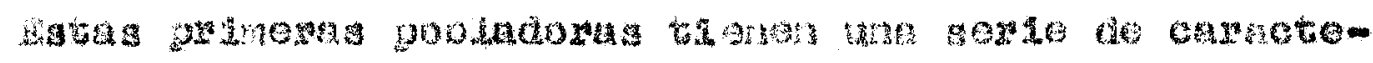
2.

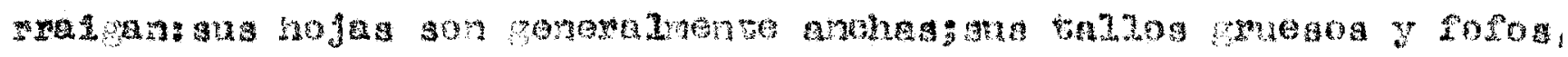

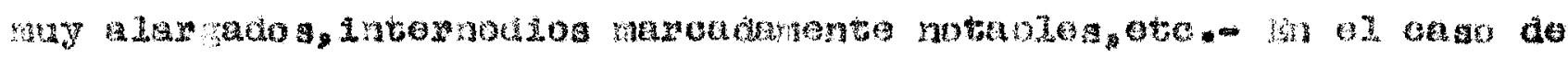

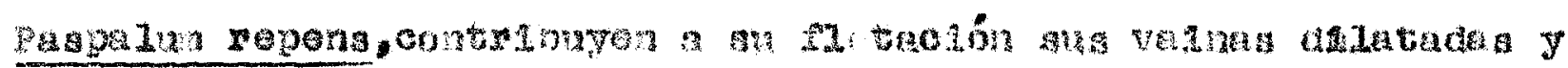
eaconogato

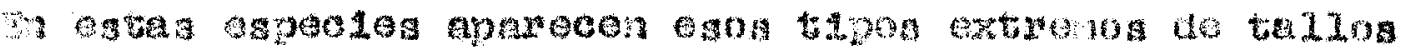

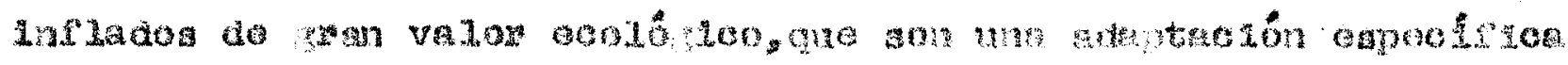

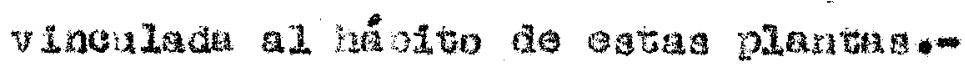

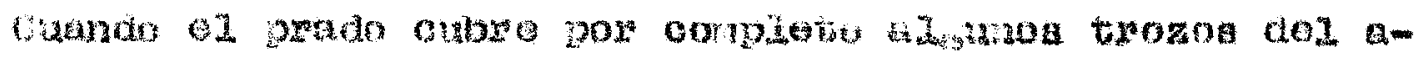

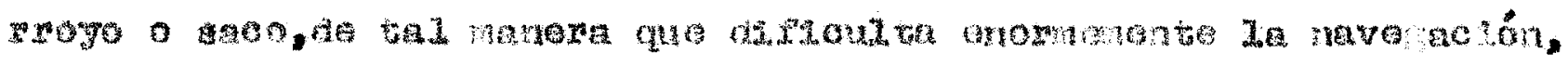

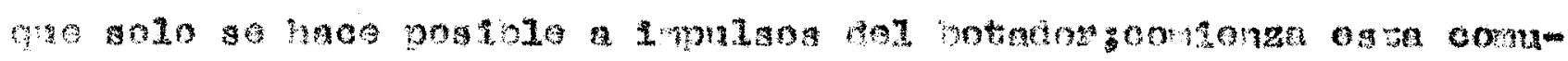

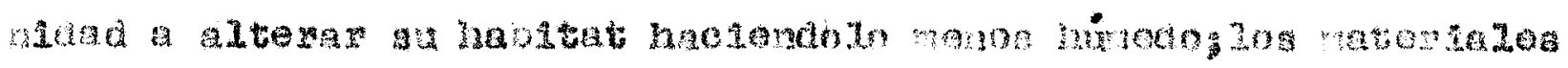

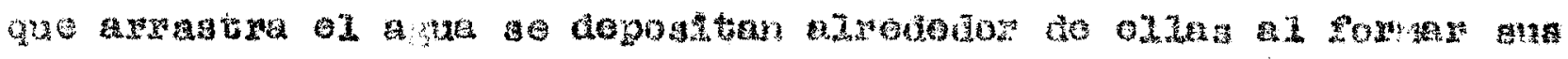

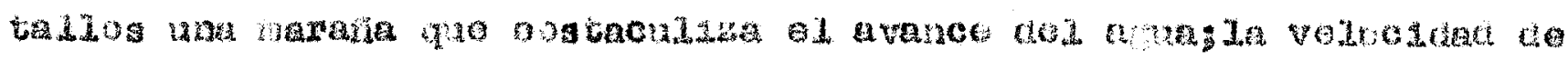

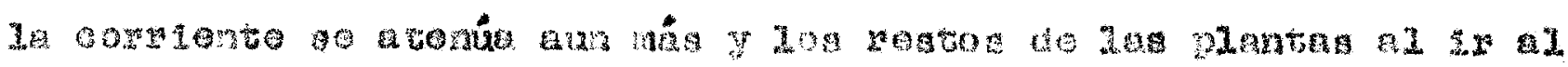

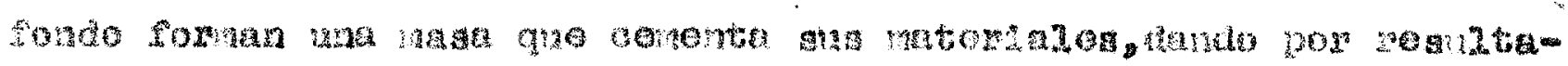

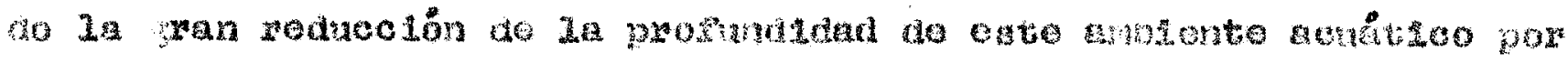

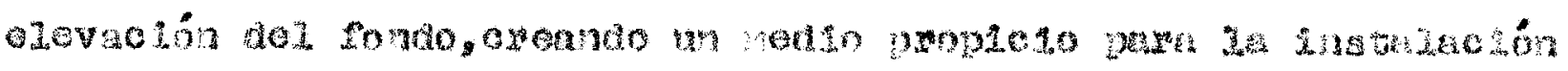

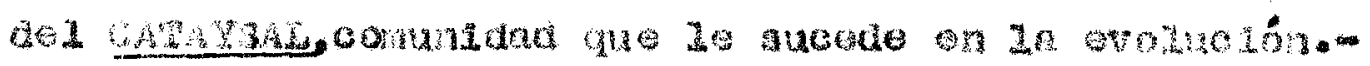

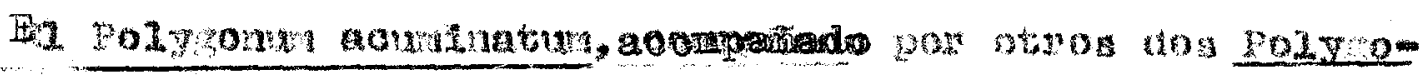

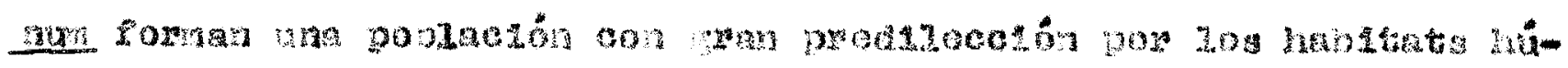

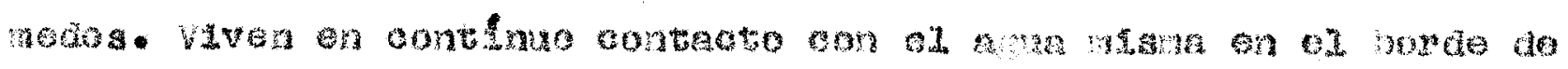

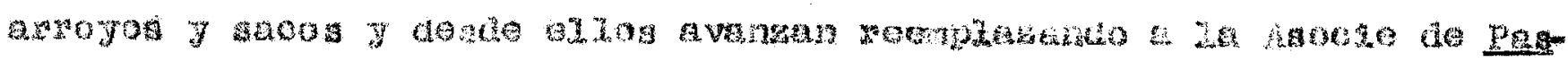

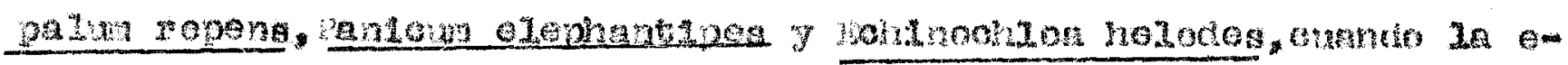

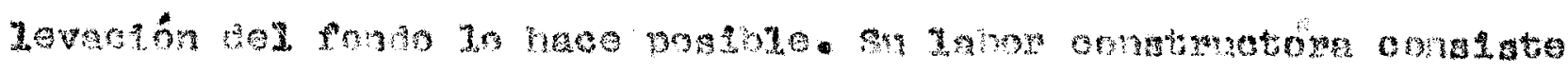

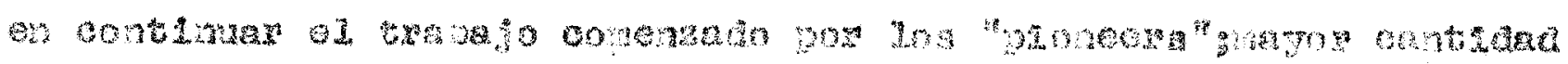

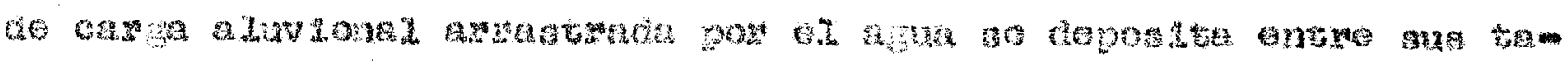




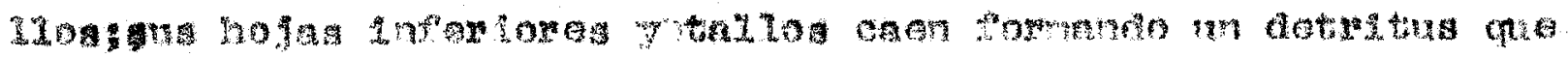

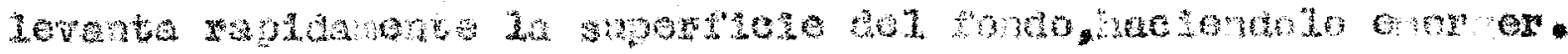

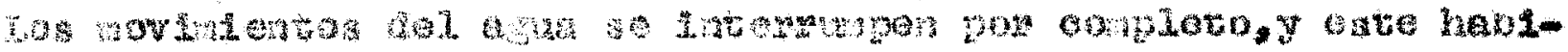

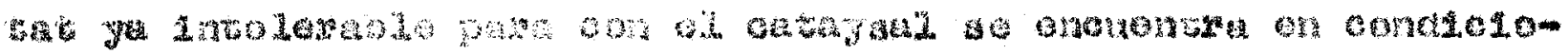

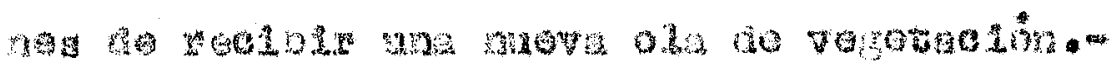

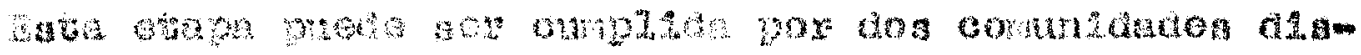
thatras a

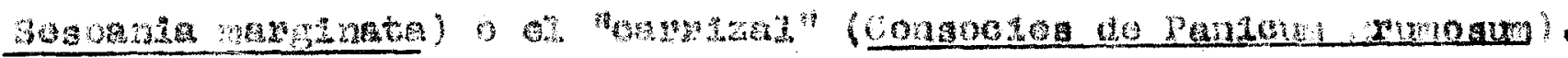

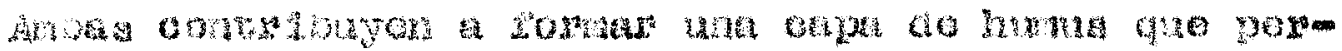
7.

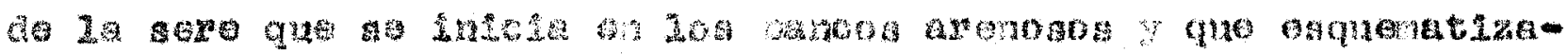

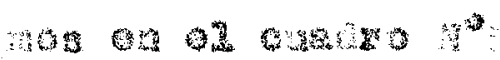

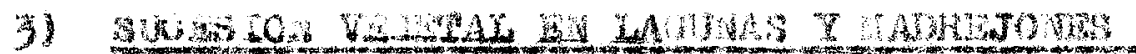

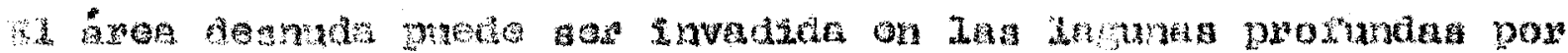

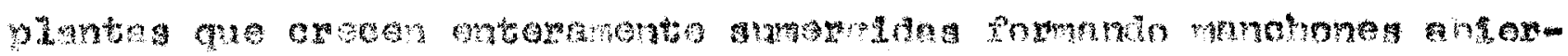

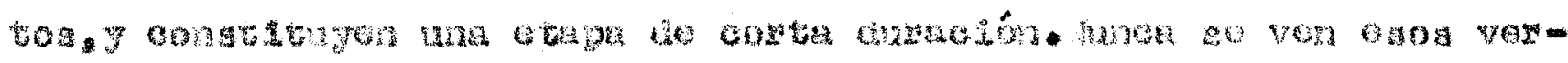

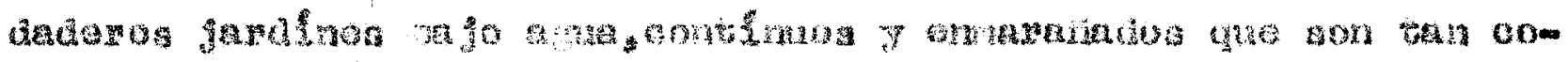

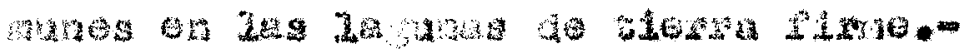

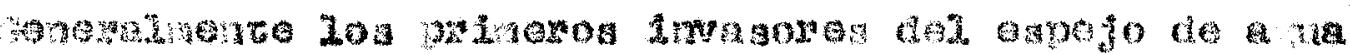

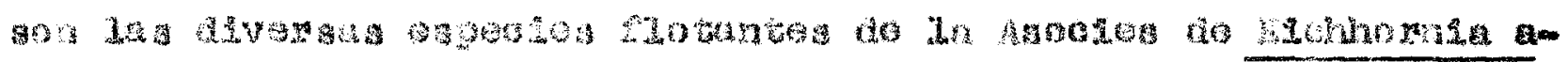
21

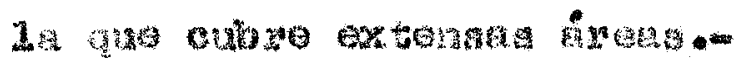

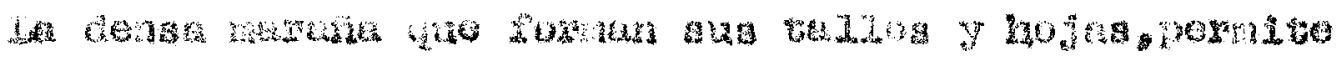

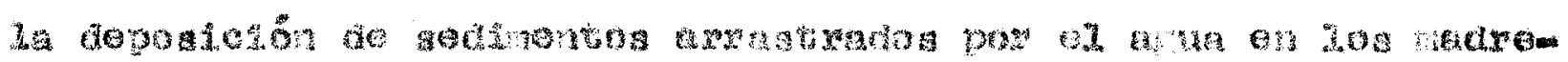

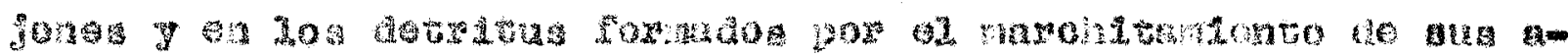

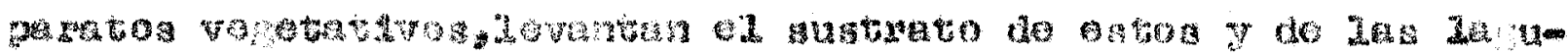
and

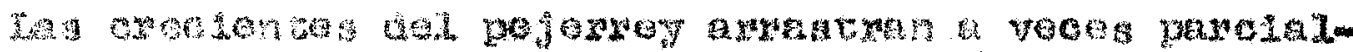
120

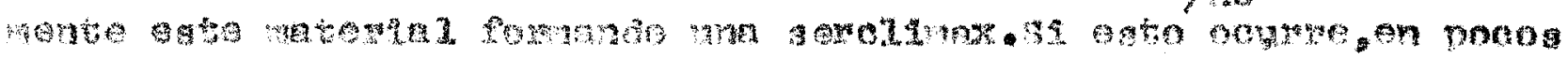

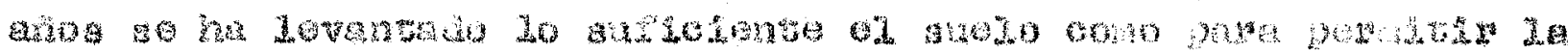

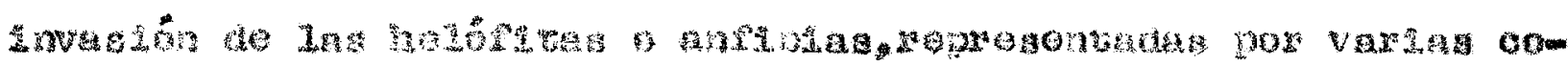

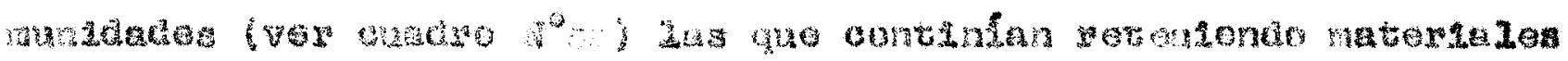




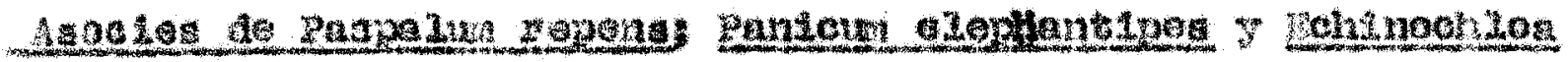
nezoder

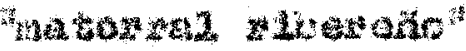

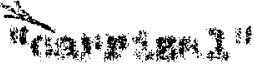

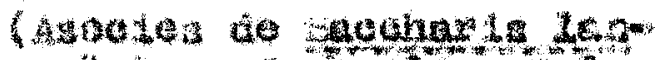

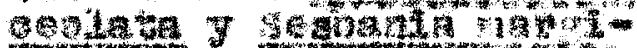

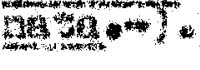

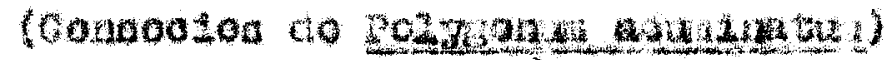
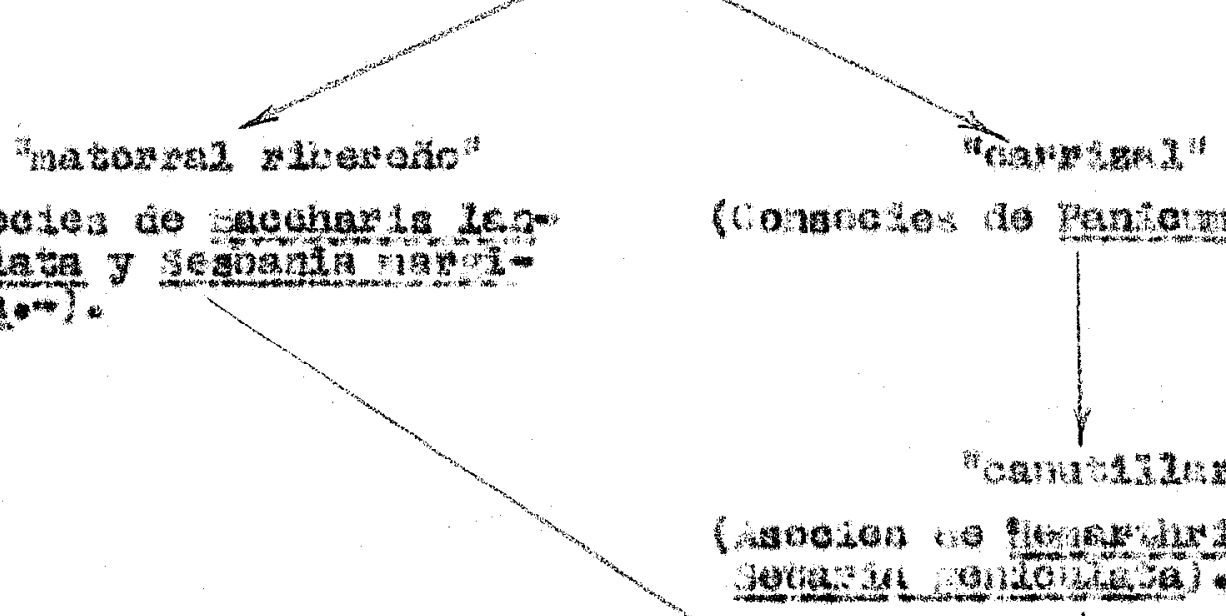

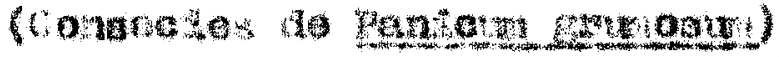

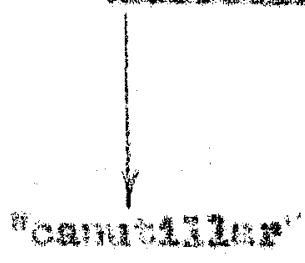

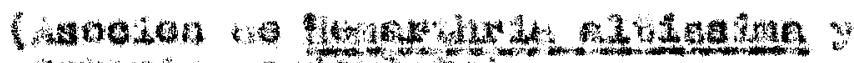

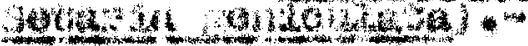

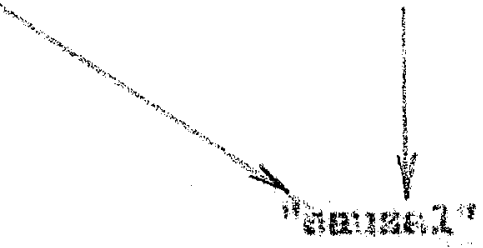

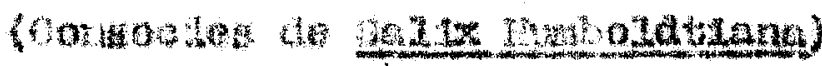

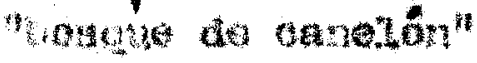

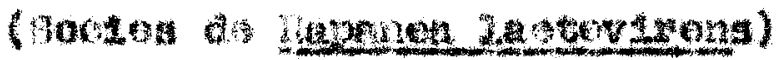

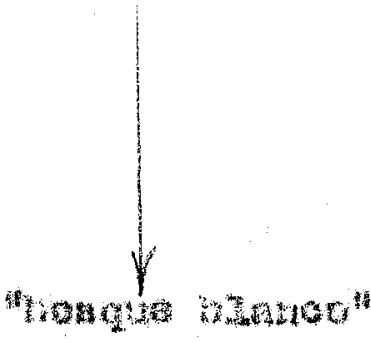

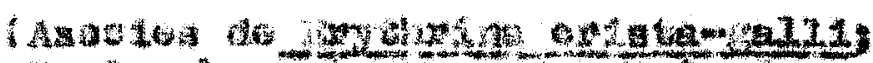

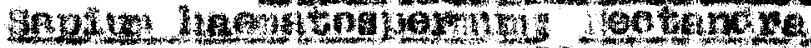

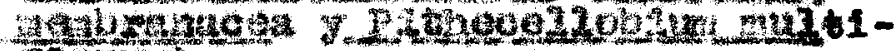


Wepresentación esquematica de la distribución de la vegetacion en $l a$ Lagura "El sauce"

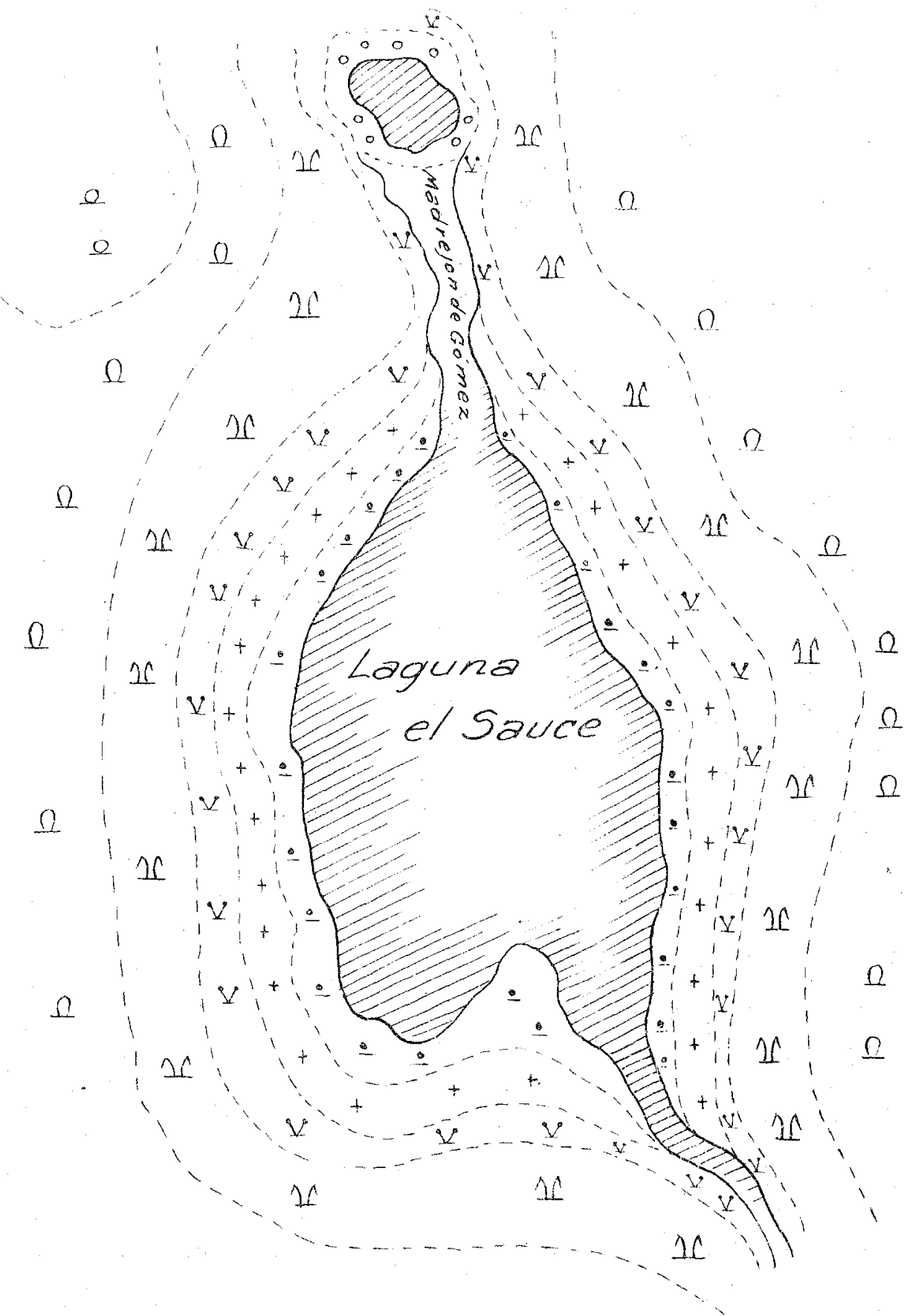

on Espincllar r consocies de Acacio carenca) o Facies de paricum elephantipes Y larillal (Consocies de salanwm glaucum) If Pojonal de Panicumprionitis g toratay + + Vega degramireasy wiperaceas N Monte blancio o Alisal

- Verdalagal f facie de Yussieudrepers) 


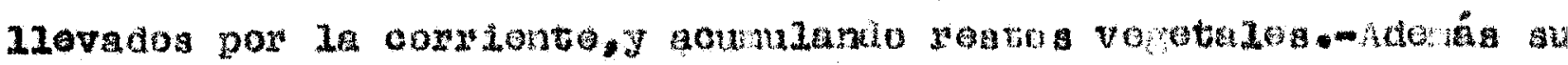

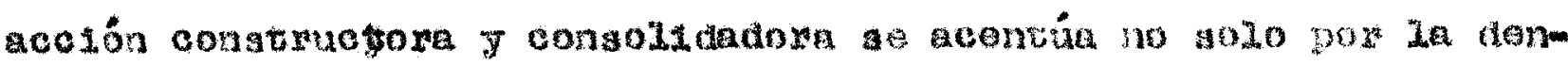

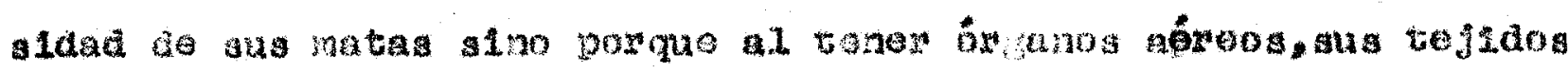

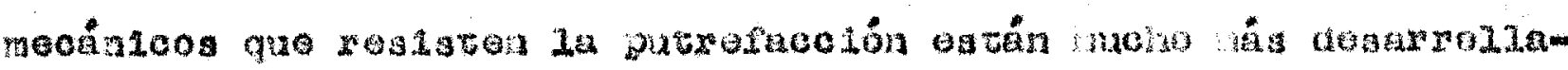
dos .-

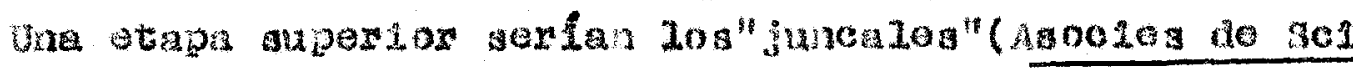

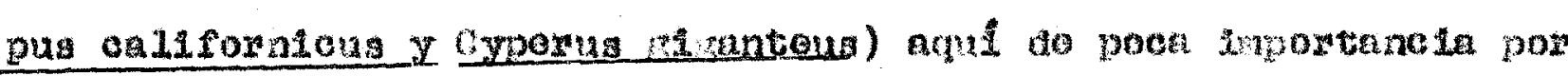

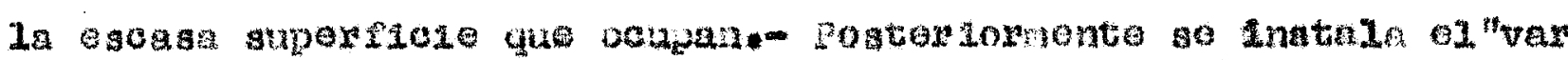

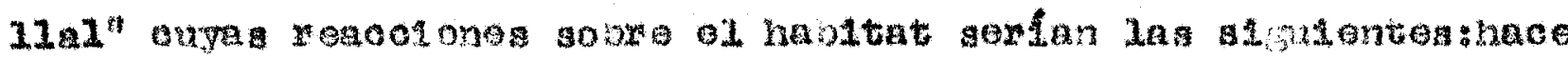

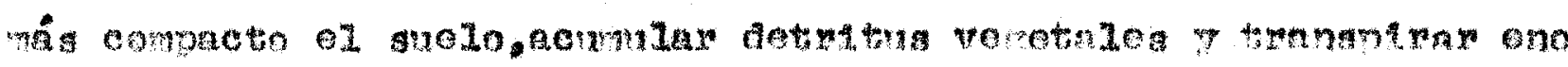
mes cantrdados de asua.-

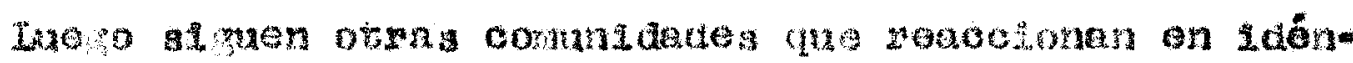

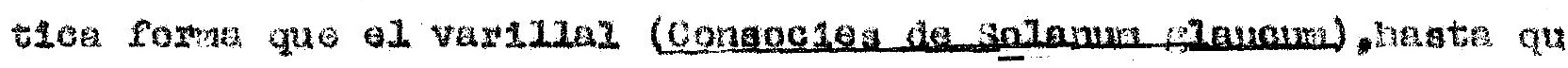

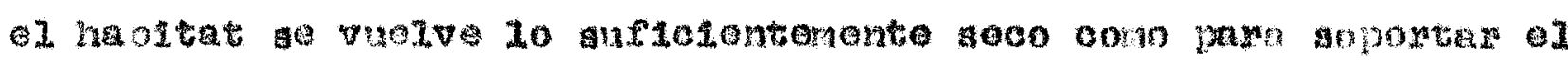

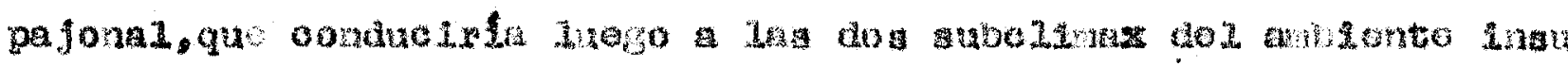

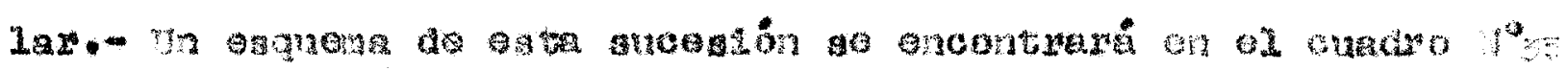

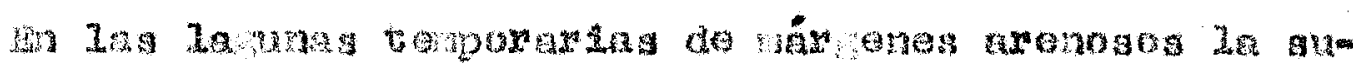

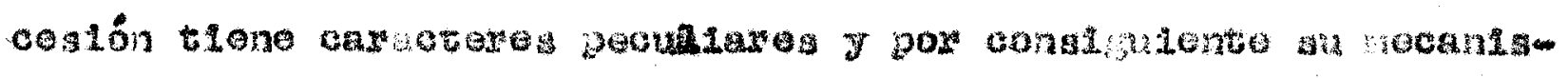

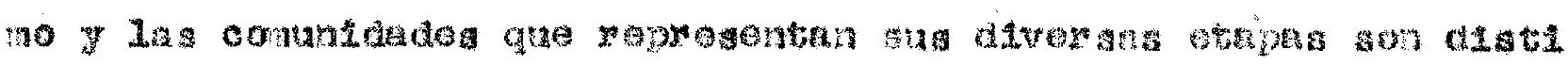
tas do las gue hamos viato.m

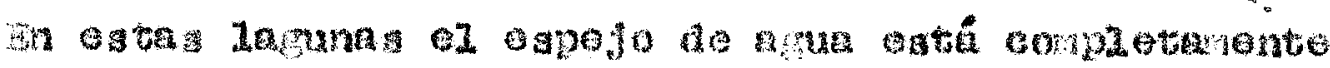

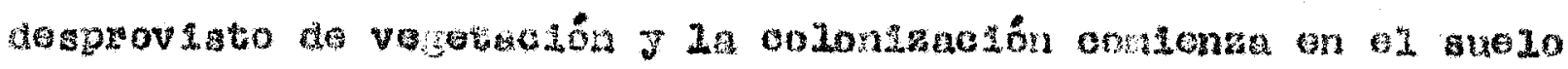

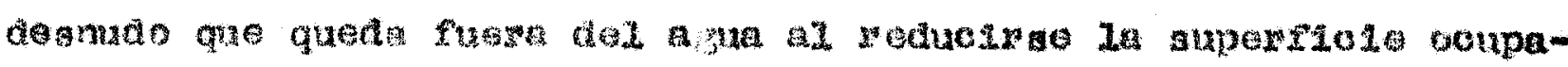
ca potenta

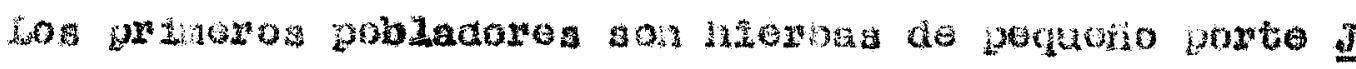

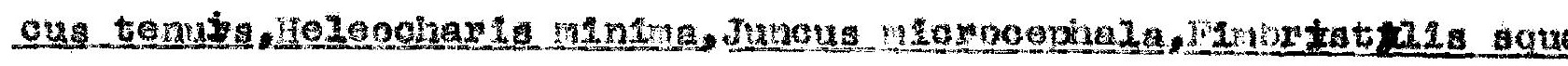

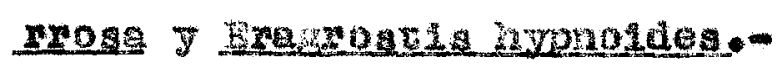

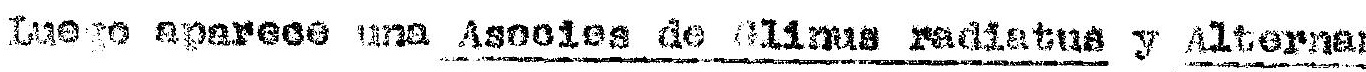

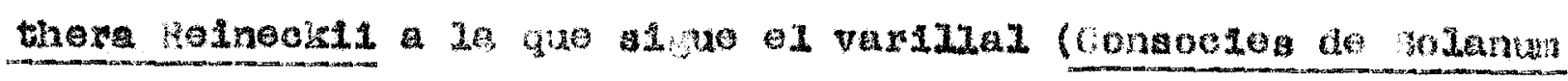

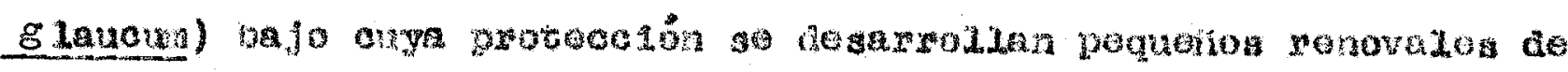

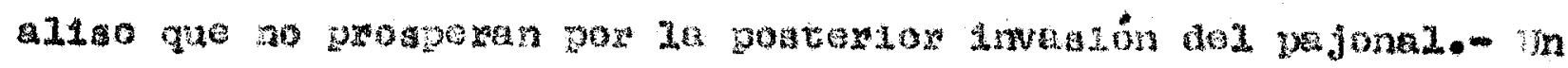

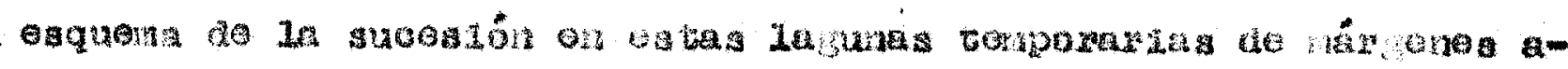




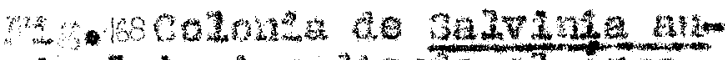

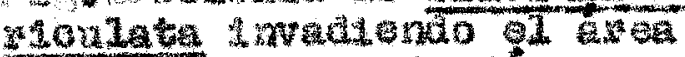

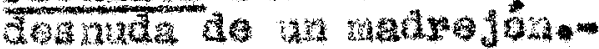
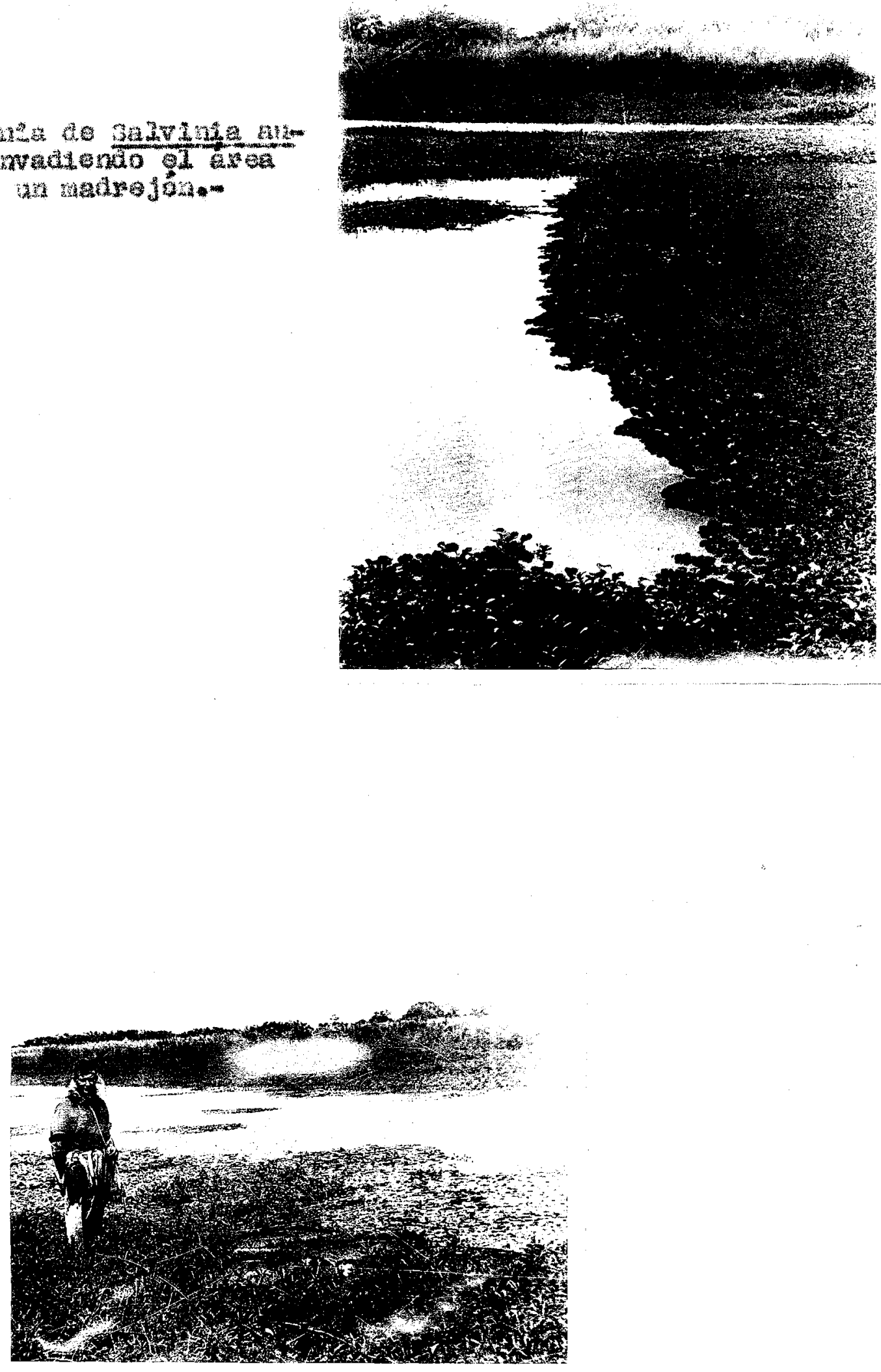

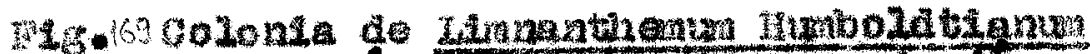

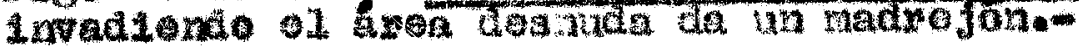




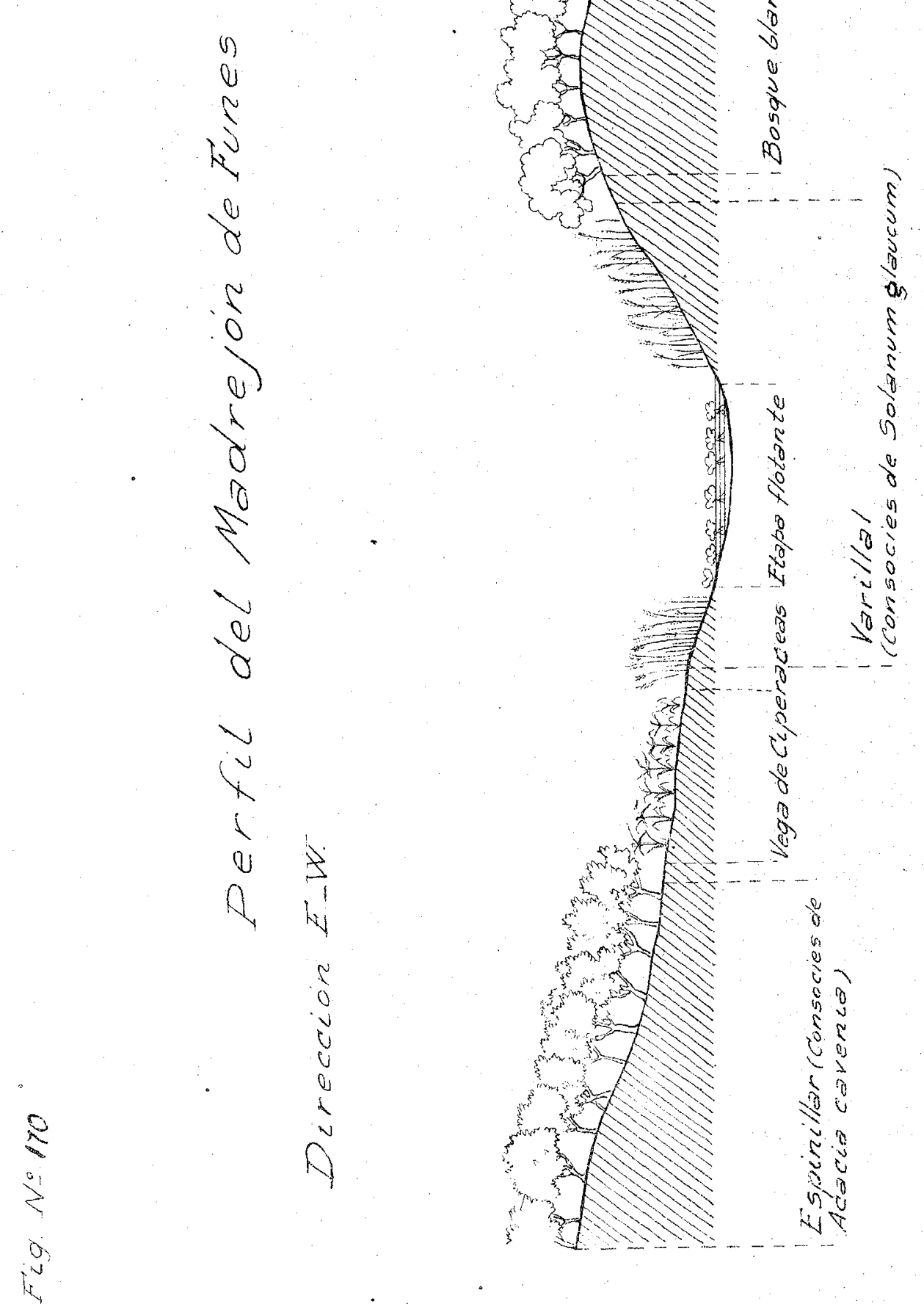




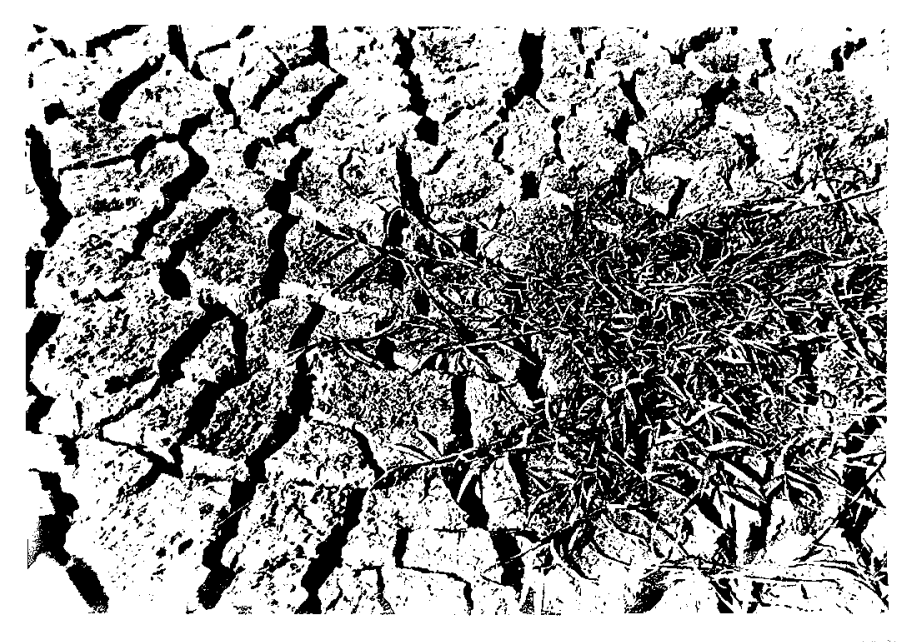

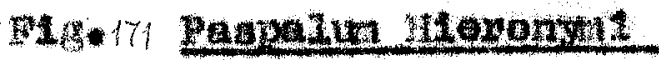

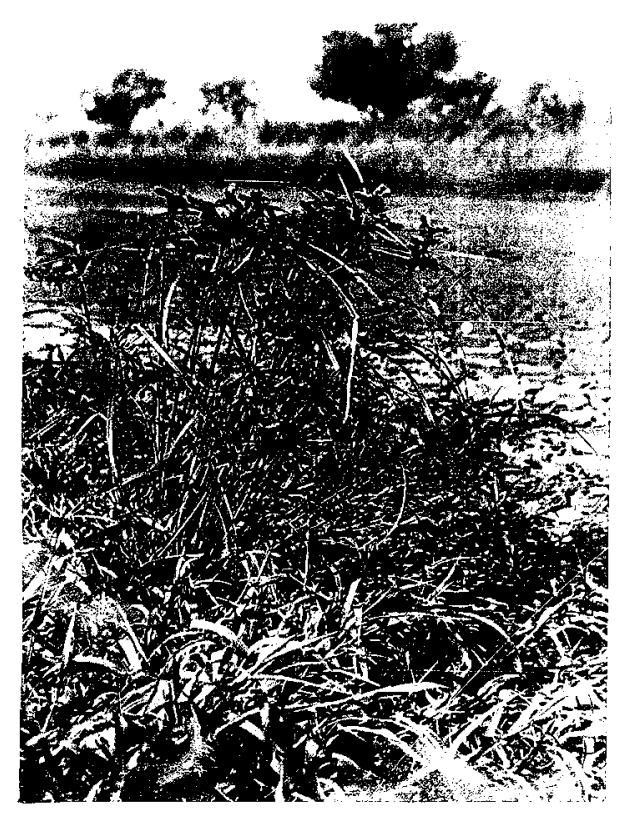

N4 172 Cxpenue Lusulas

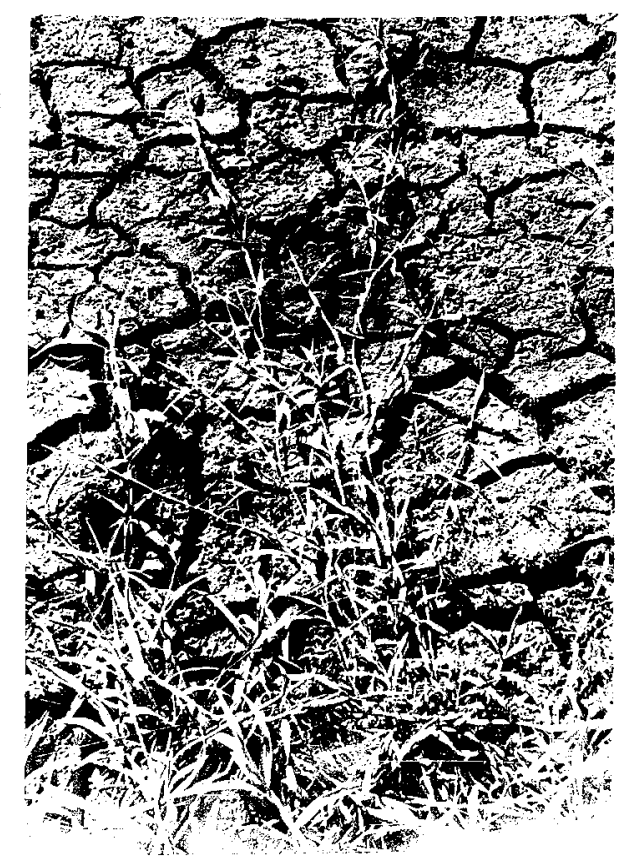

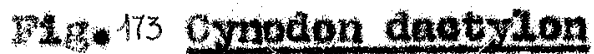

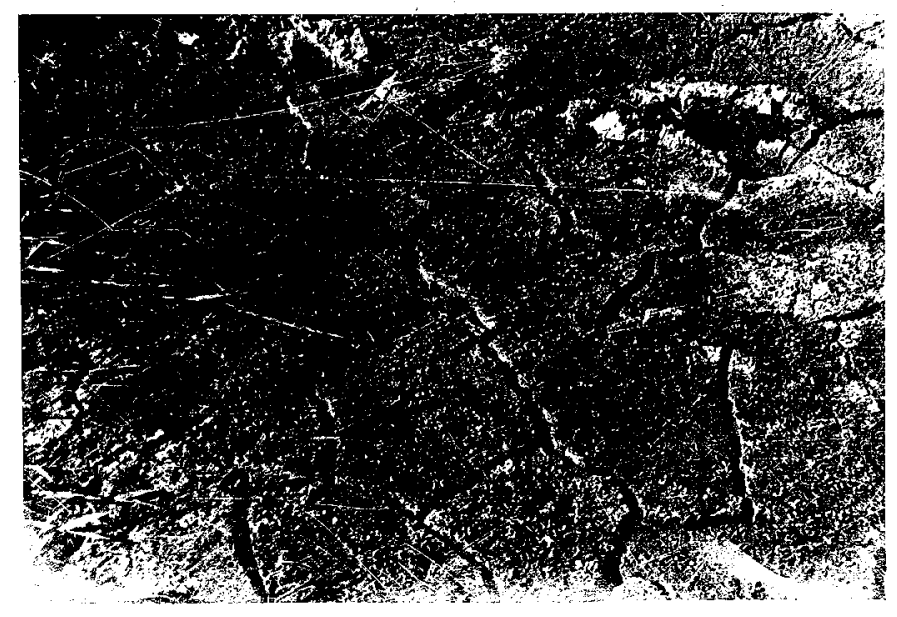

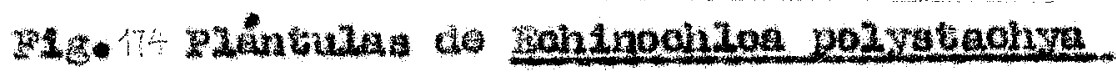




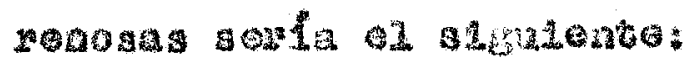

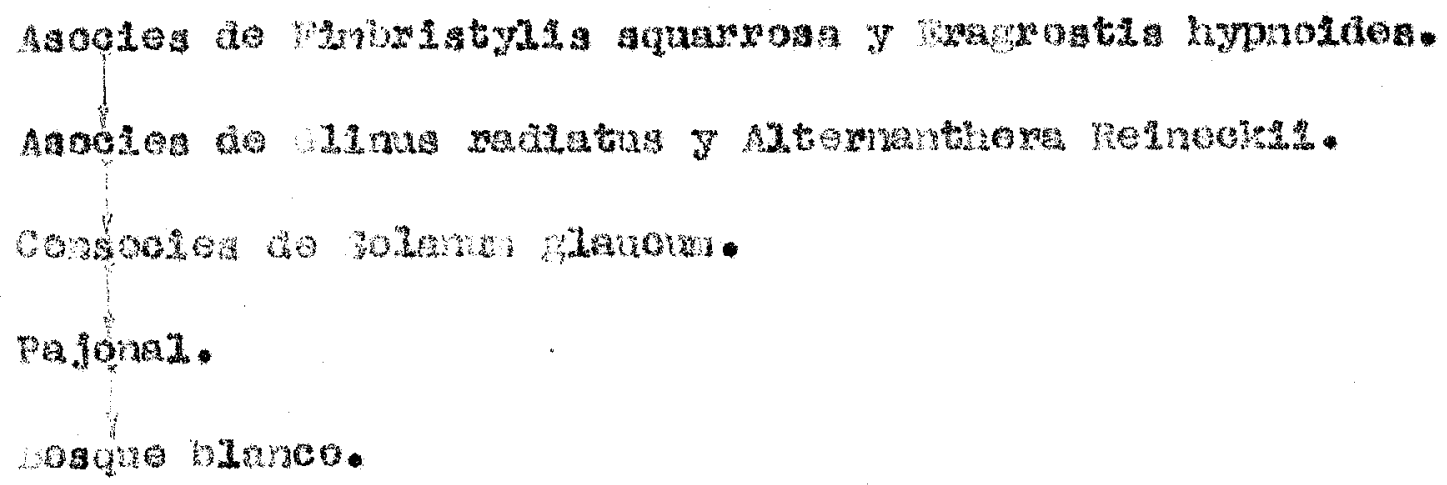

\section{c) 3045469}

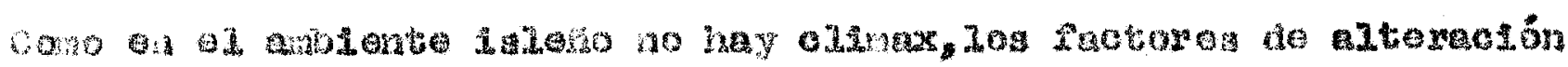

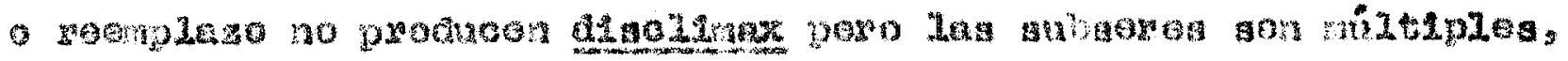

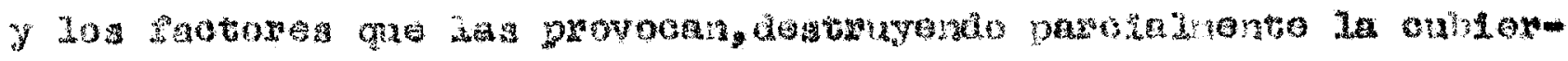

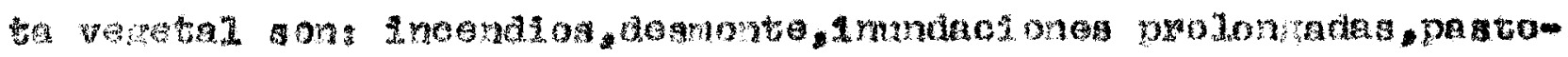

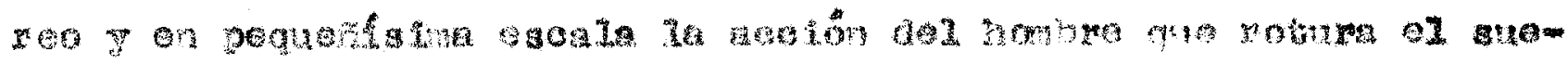
20

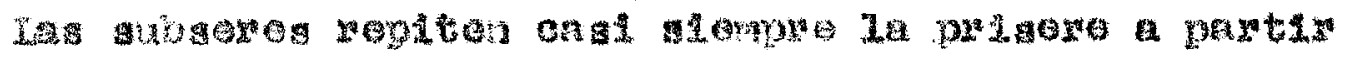

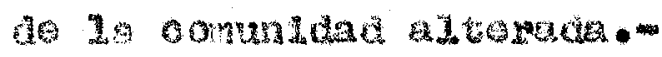

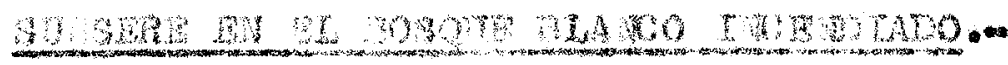

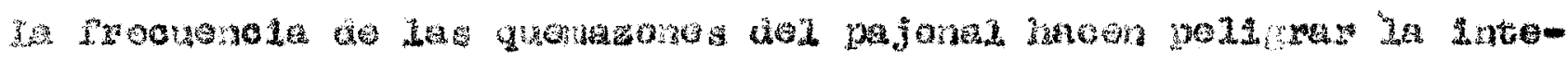

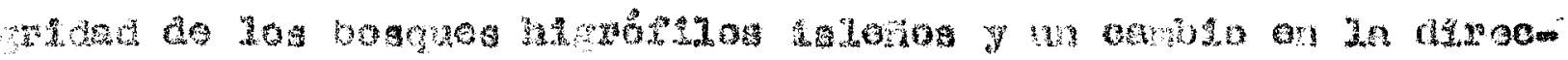

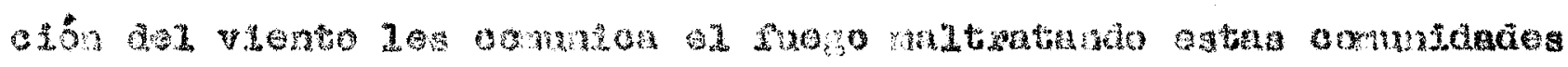

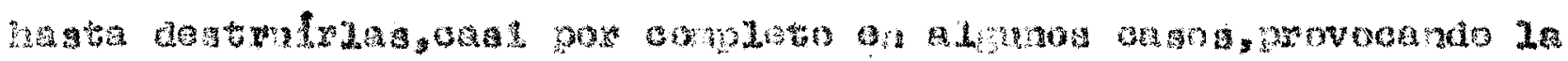

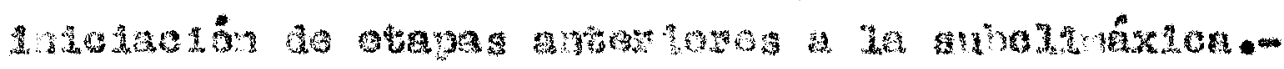

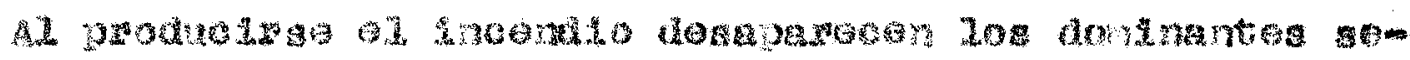

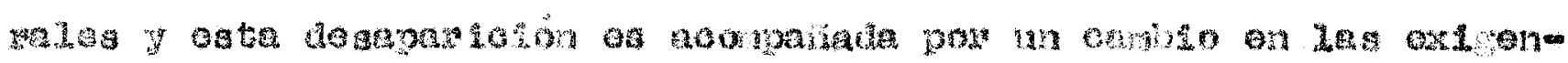

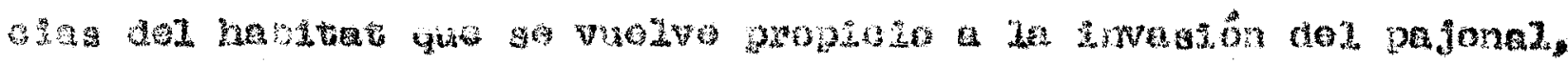

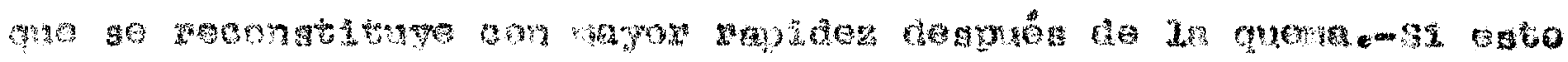

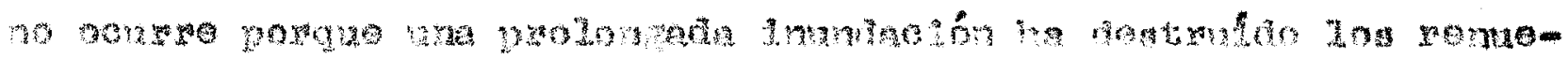

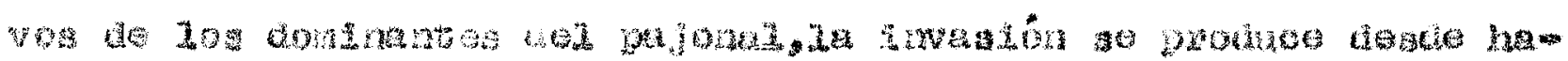

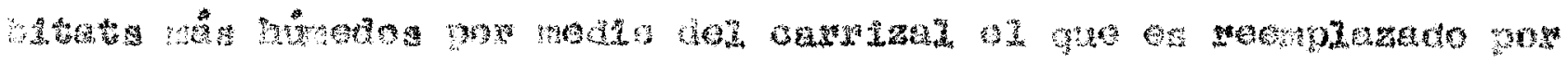

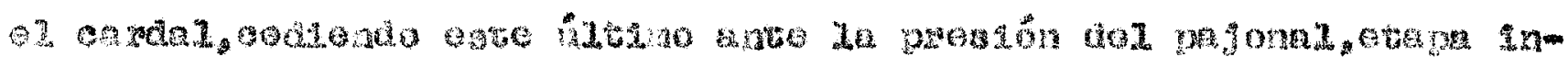

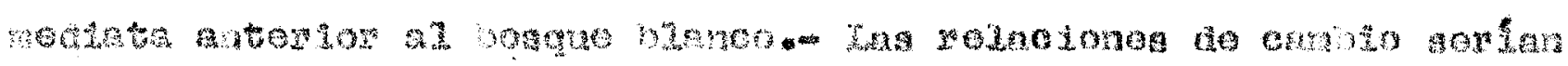
$2 a$ a 


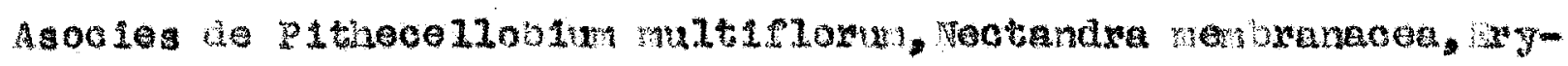

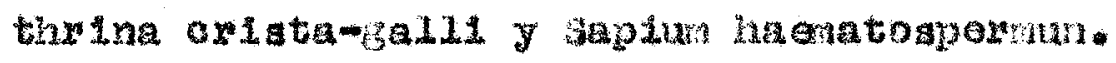

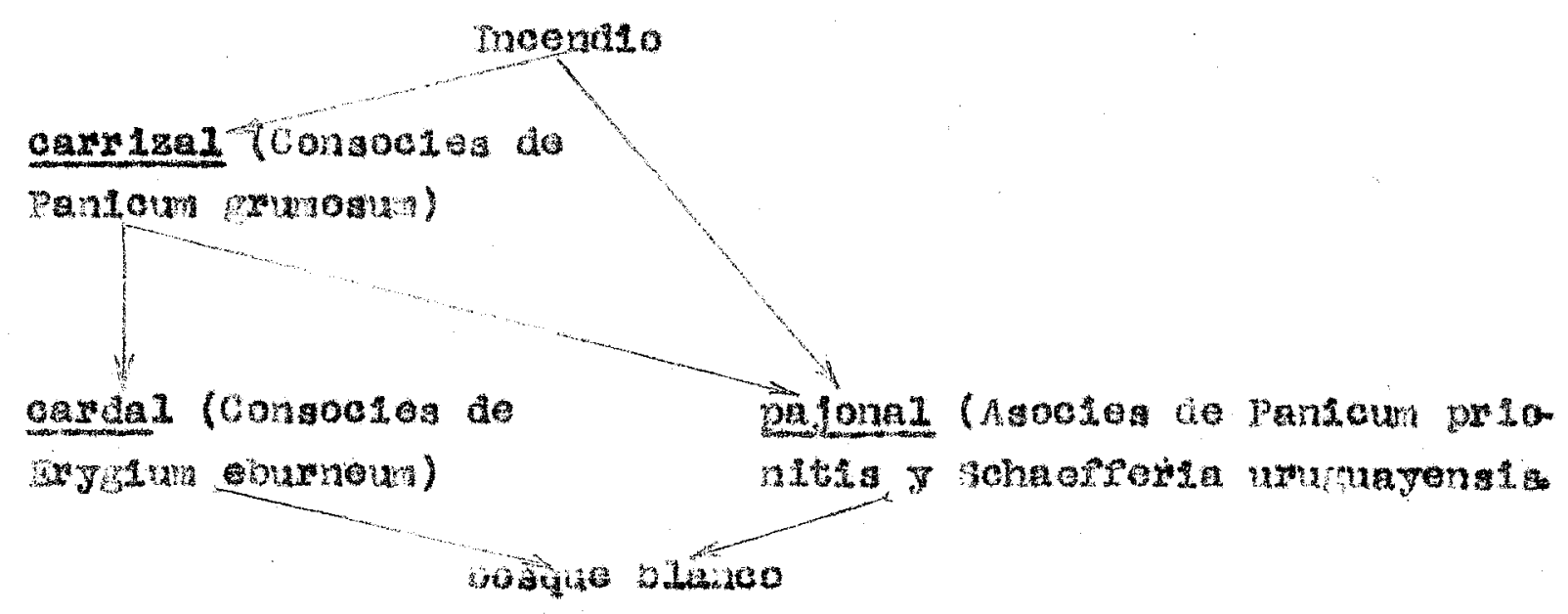

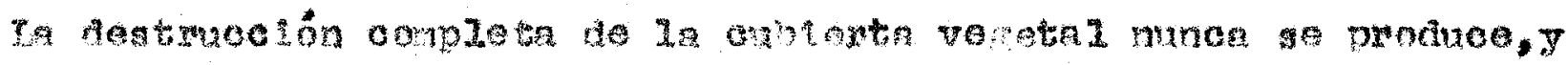

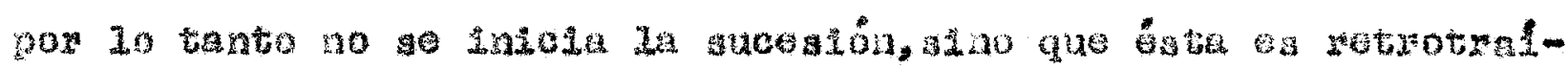

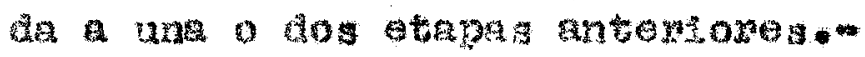

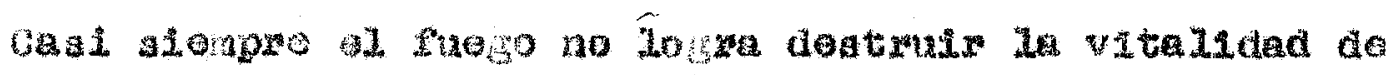

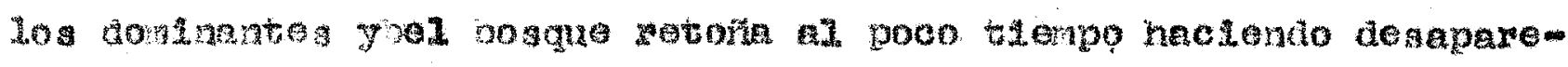

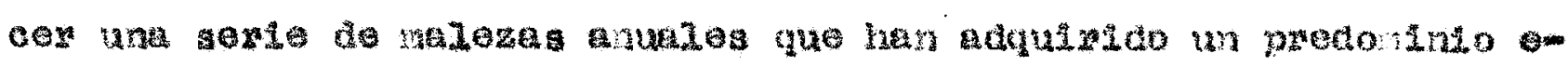
flnexo al qrenaxal das oopar.

\section{SUSBME}

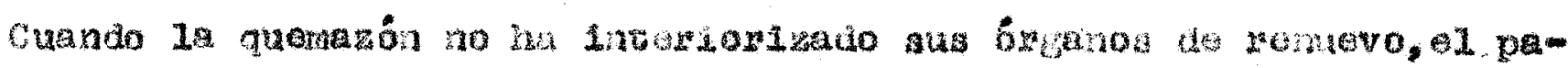

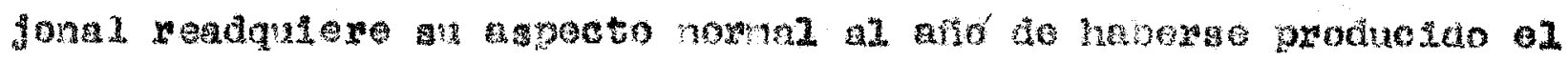

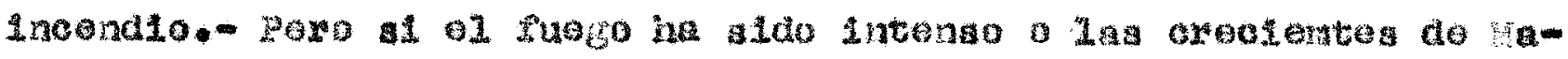

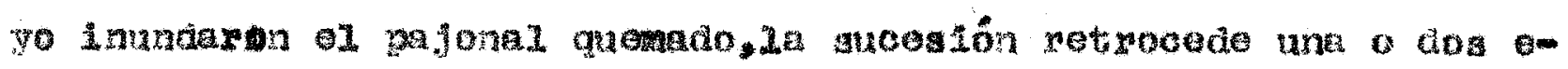

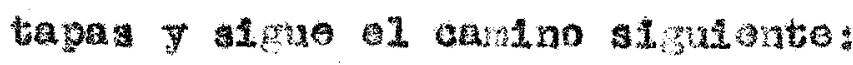

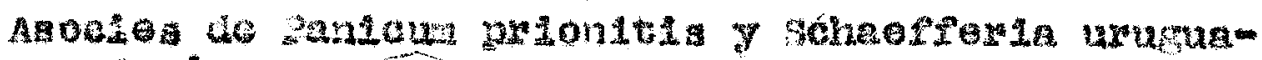
gensis.

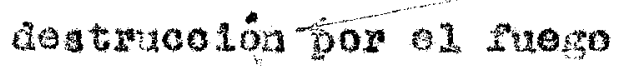

canut121ax (Asoclos de setaria

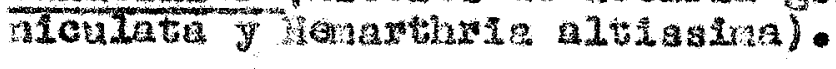

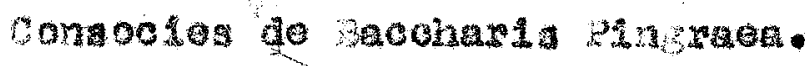

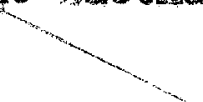

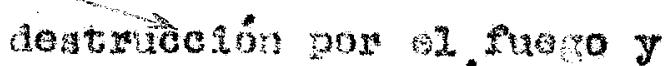

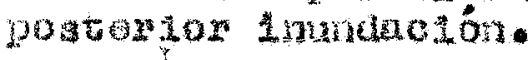
vard12h (comboson de sola-

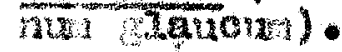

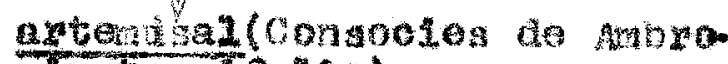
sin totrateda).

Conaodes de 3acoharas pum inada

\section{pa. ponat}

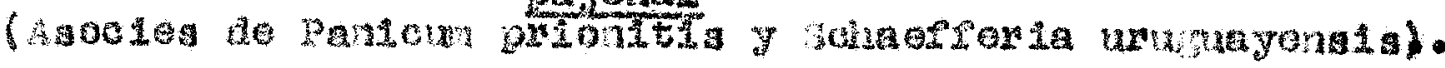


Grando ol pajonal os dostrulas por lat poturacion 7 a

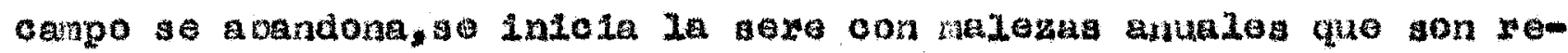
omplazadas po: el camplilay y a ato aucode la consocioa de BucchaIs Pingraea que conduce al pa jonal.

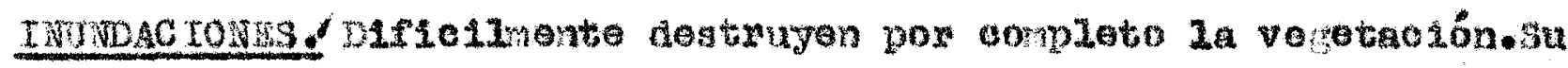

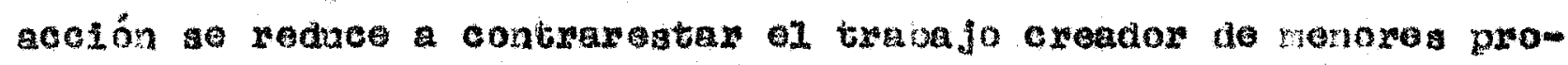

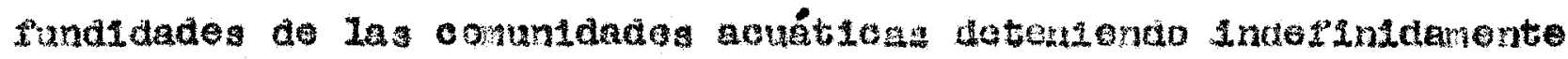

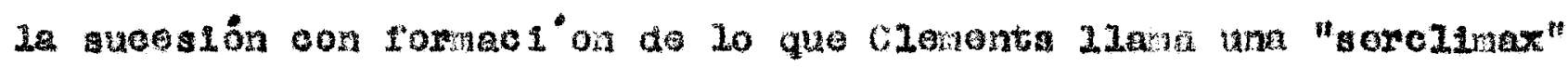

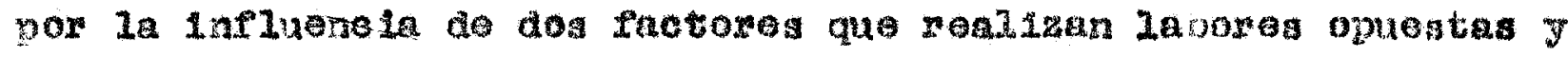

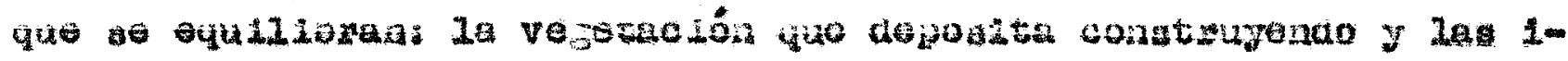
muadac lones que arastran destruyondo...

Sncla a esta acclón recipoce, la vegetación fiatanto

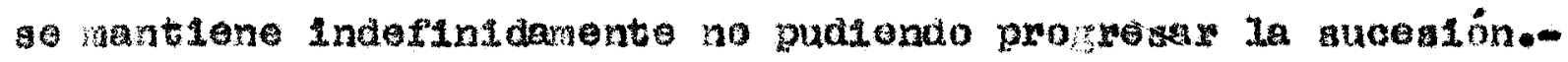

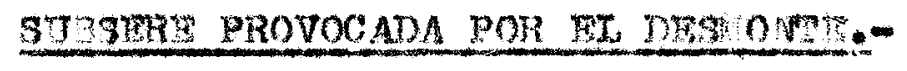

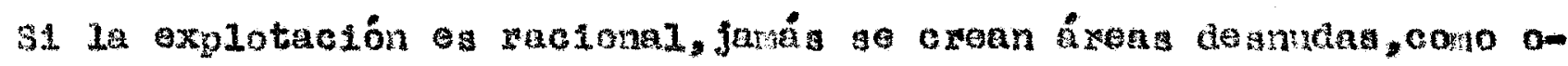
cuxre en el delta entroxirano donde lo bosques vienen alendo explotados deado hace 300 años sin que la aporflele ocupada por ellos naye distauldo.-

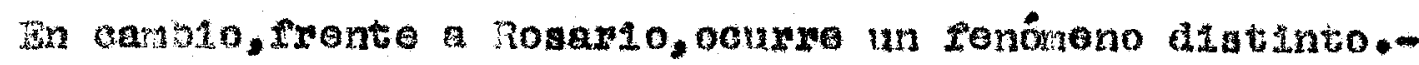

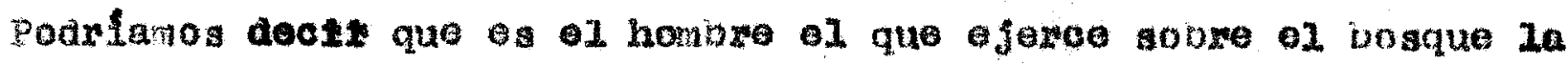

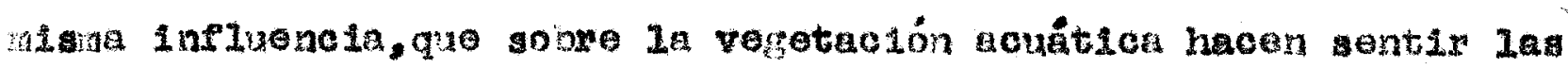
coc lentea.-

thanto tallo adquiero un frosos que 10 hace ntilsablo.

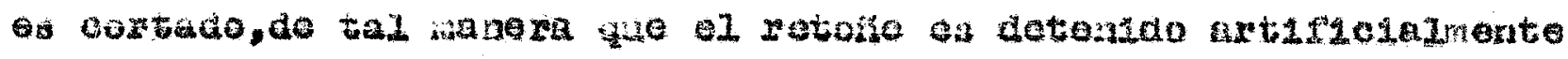

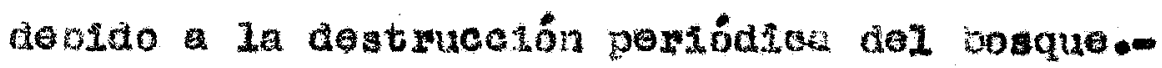

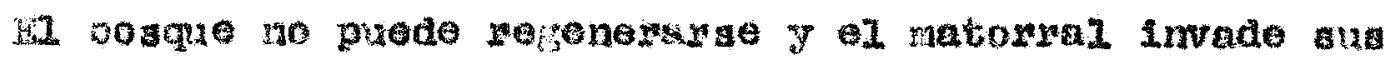
doninios recias a la ta peranonte do los dominantes.- 


\section{RECUENO DE SNTLLOS DE CEACIMTHWTO}

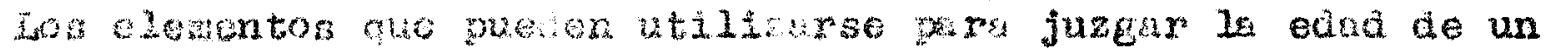

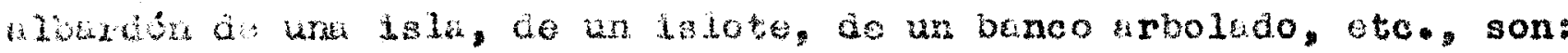

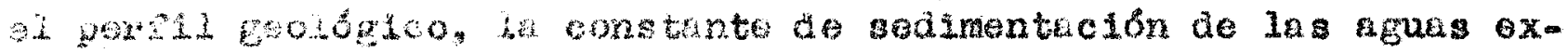

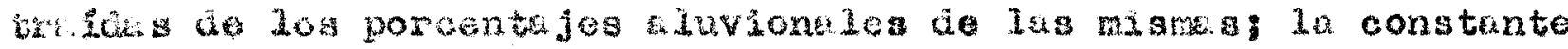

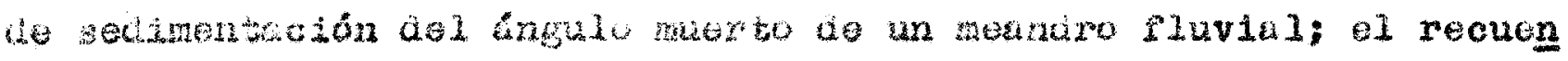

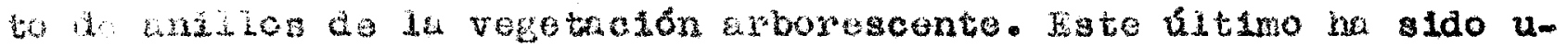

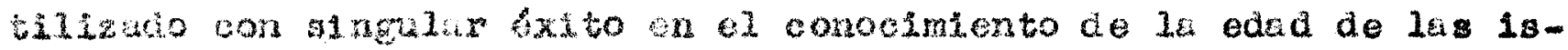

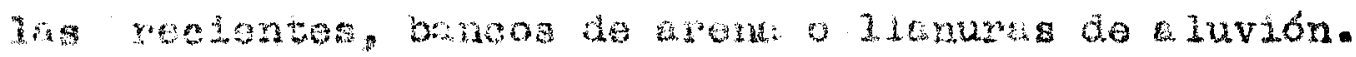

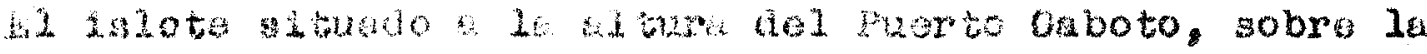

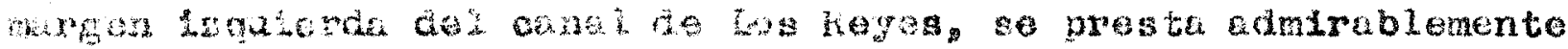

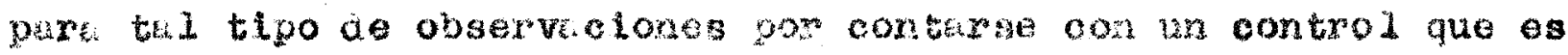

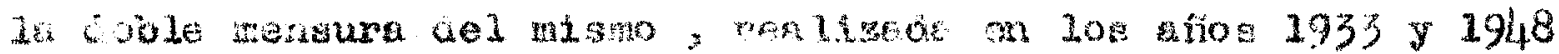

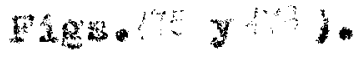

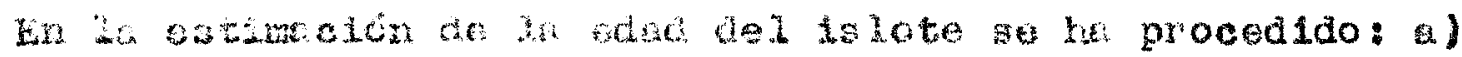

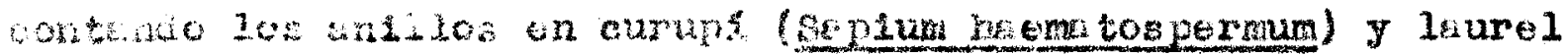

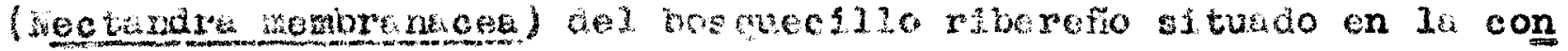

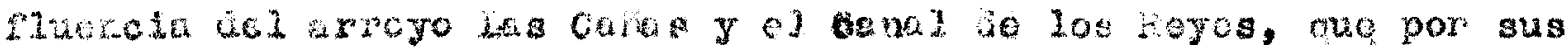

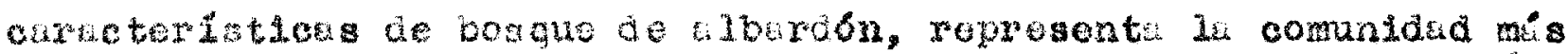

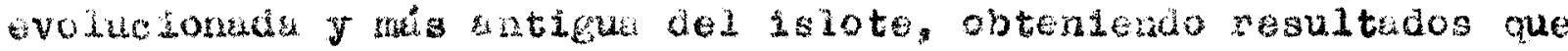

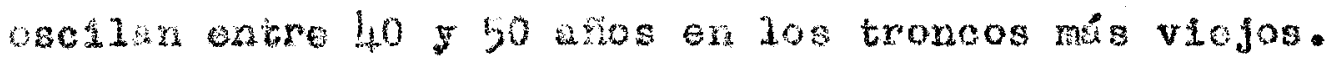

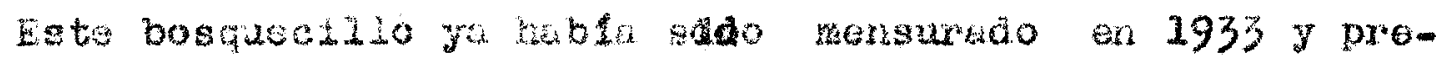

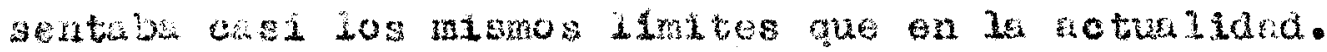

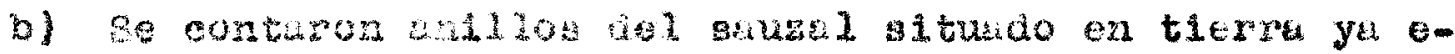

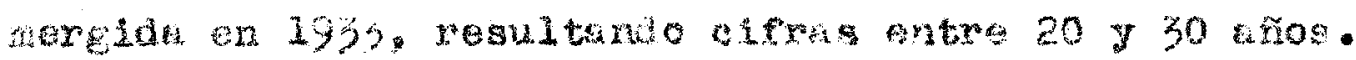

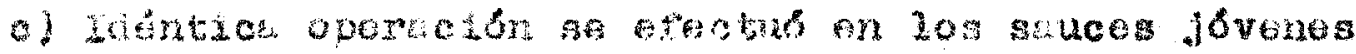

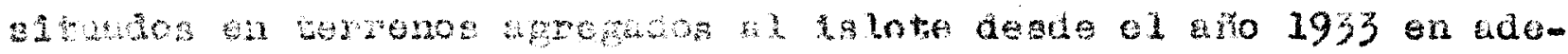

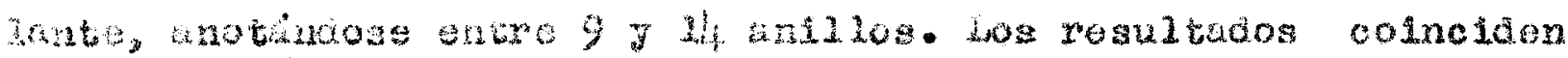

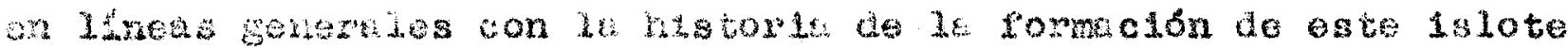

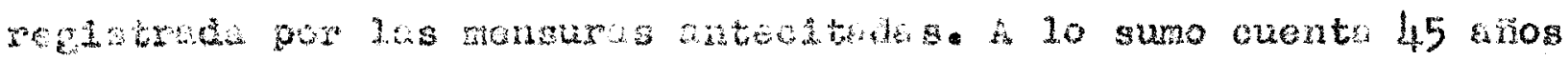

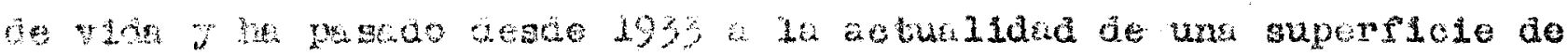
33 hectirek a 250. 
Representación equematica del islote segün mensurio del año 1933

Superficie 53 hectoreas

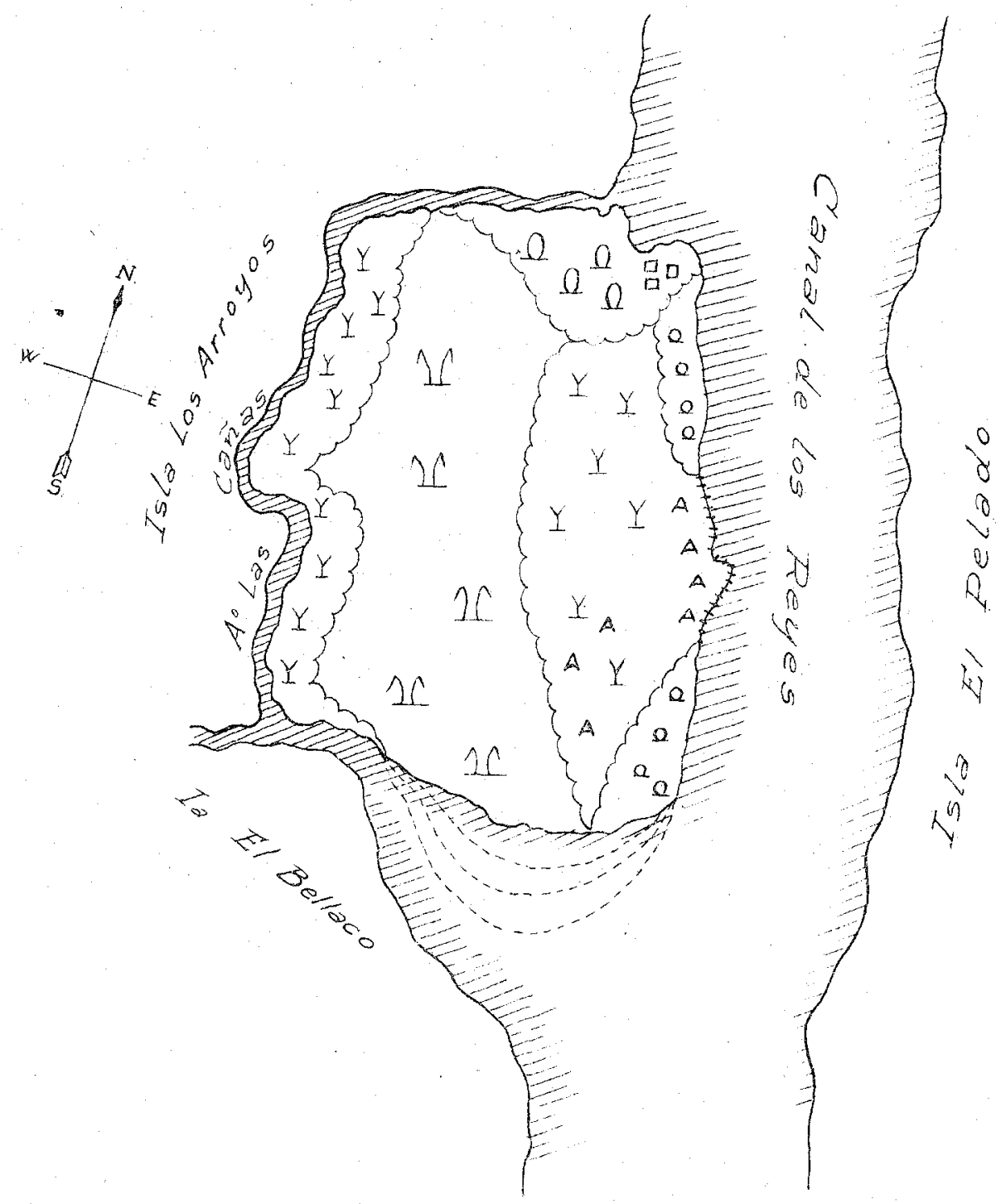

Y Saveal (Consocies de Solix Hwmboldtiona)

If Pajonal de Carrizo o complzal consocies de panilum grumosumil

A Alisal (Consouies de Tessamia integmifolia rampoliamdra)

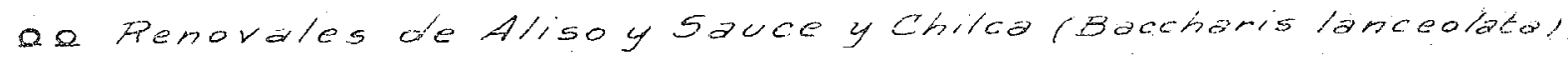

mexperaraco

…. Banco de arera

Q $\Omega$ Monte blanco

DO TORChO.S 
Representación esquematica del Islote en 1949

sup ap. 250 Ha.

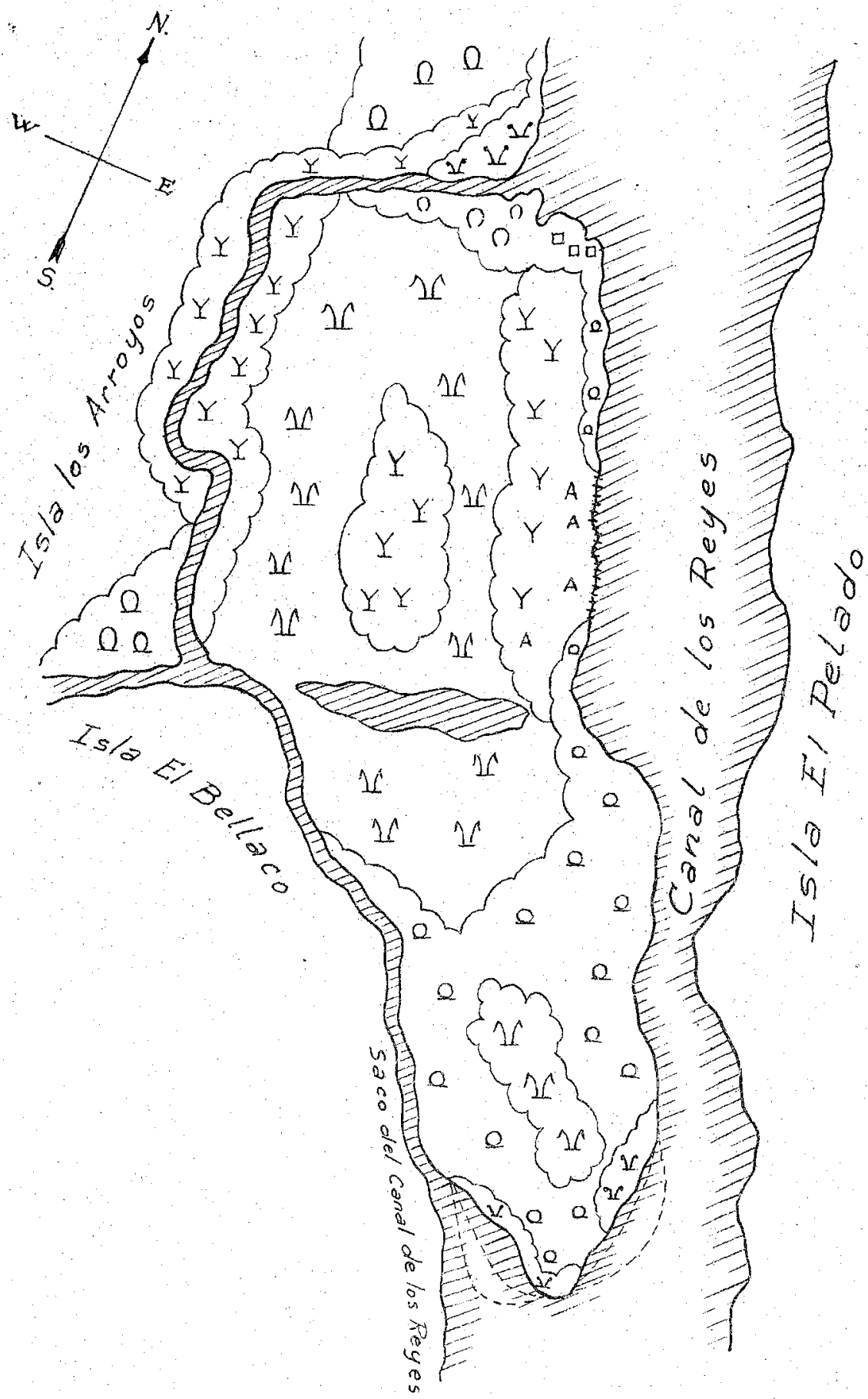

A Bosque blanco

X Sauzal (comsocies de Salix turntolutiana)

If Chilcat rconsocies de Bachtames Hanceolata

ar Penovales de Alisol Sauce

If Pojonal de carrizo (consocies de Panicim grumosum)

A Alisal (Consocies de Tessamia incegrifolia vam poiramára)

- Cosas

warterest Baranca 
En el lalote 1lankdo "El soid" abus do unos 7 k116metros *guss arribe del anterlor y sobre la mergen dercha jel cenel de 1 Los zeyes, ce contron and

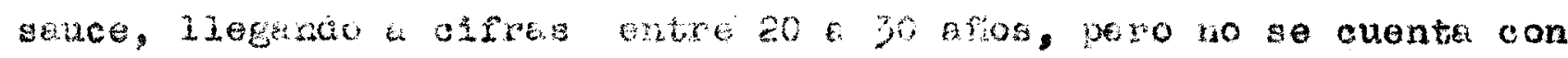

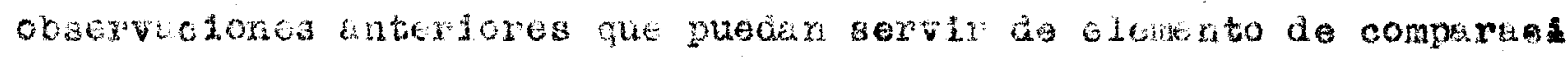
ton.

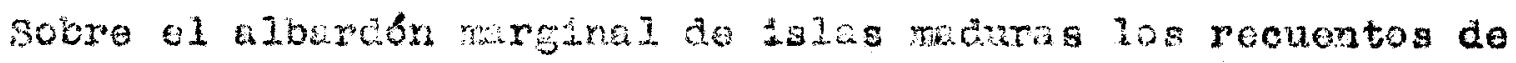

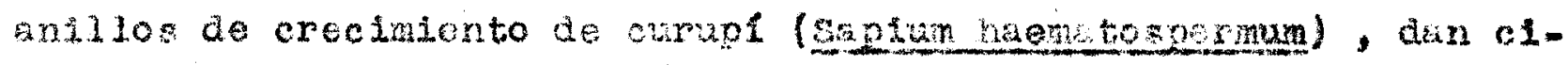

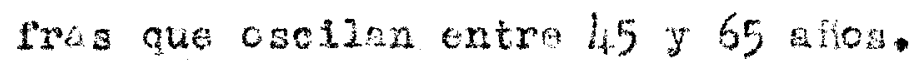

El esvesor de los ensilos (que depende de la velocided de crecimiento) proporclona muchos di to raliogos neferentes a cl1-

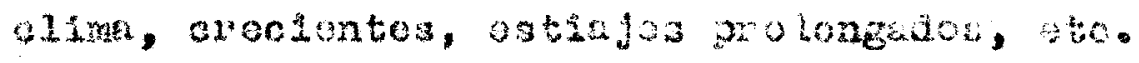

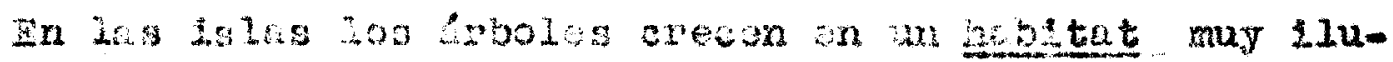

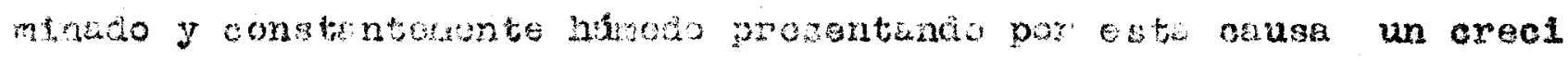

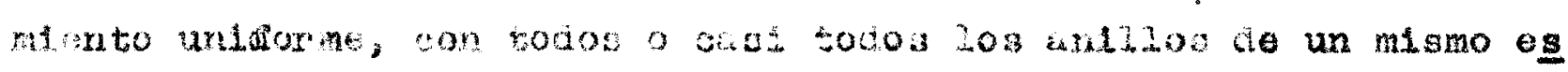
pesor.

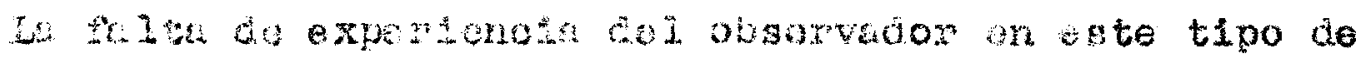

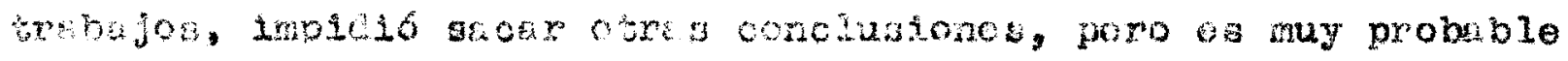

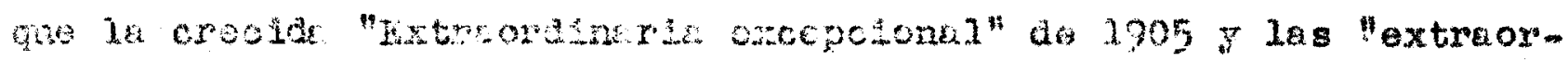

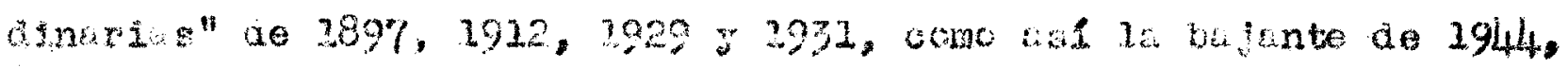

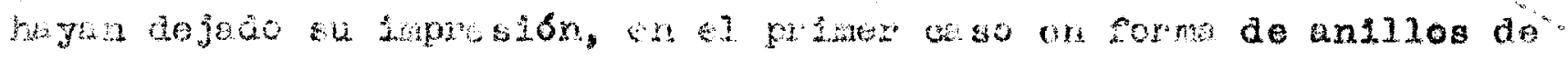
poco espesor por $2 \mathrm{e}$ areacion pobre $y$ an al do watijes prolonga

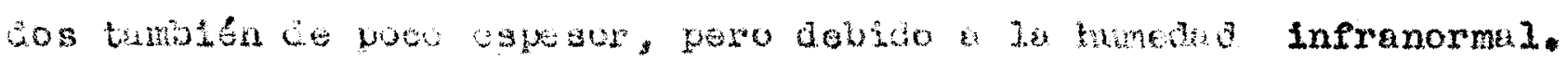


El comportamiento alnkmico se refiere la influencia de $1 a$ especies sobre la génests de las comunidades de su sero. Es 1. calificación y cuantificeción, en cuanto ello es posible, de un fenomeno sut11 $¥$ complojo, como es el de la crención de conalciones que hacen posible la instalacion de nuevas olas de vegetación, en un habitat modificado por influencia multiples, entre 6stas la de las plantas $y$ un Intento para designar las clases de comportamiento dinámico de ellas es la siguiente escala (cain, 1947):

clase 1 - Aquellas especies que son constructlvas para la comunidat

\begin{tabular}{|c|c|c|c|c|c|c|c|}
\hline$c 1 a b e 2-$ & n & " & " & $n$ & conservadoras & $n$ & n \\
\hline $\operatorname{clase} 3=$ & " & n & 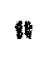 & $n$ & consolidadoras & $n$ & $n$ \\
\hline clase $4=$ & $n$ & " & $n$ & w & neutrgas & $"$ & $n$ \\
\hline$C 12=5-$ & $n$ & $n$ & $n$ & $n$ & destructivas & $"$ & $"$ \\
\hline
\end{tabular}

Una tentative para demostrar el papel de alguna especies en la seres, que ge intcian en los bancos de rena, es el diagrame sigulente:

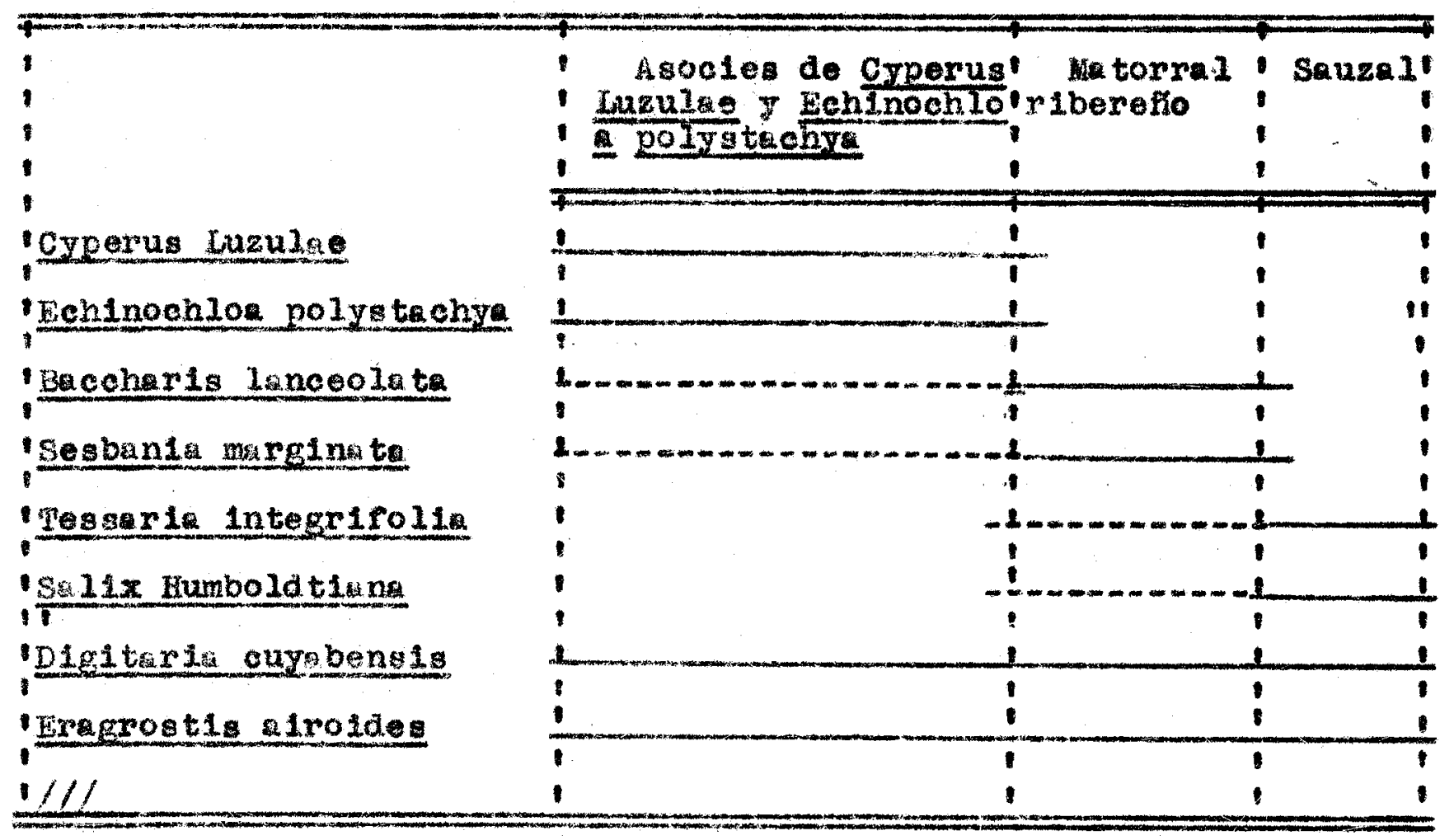

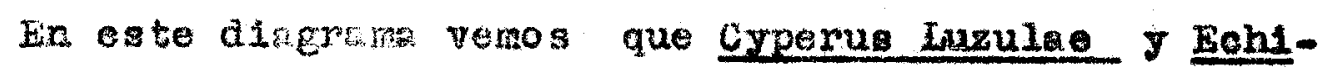
nochloa polystachrat son "conservadoras" puesto que no forman parte do 1a asocies subsiguiente; Bfecharis lanceolata y Sesbania margina- 
nate son "destructivas" park la asocies de Gyoerus Luzulie J Echinochlog polvgtechia poraue su apricion conduce al "roktorril ribe-

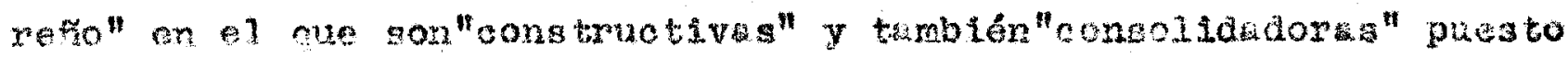

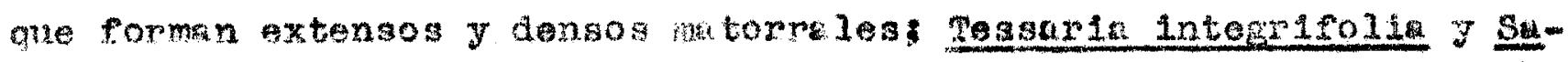
12x Humboldtians aon "destruetiva" con reapocto al "matoxral 1 -

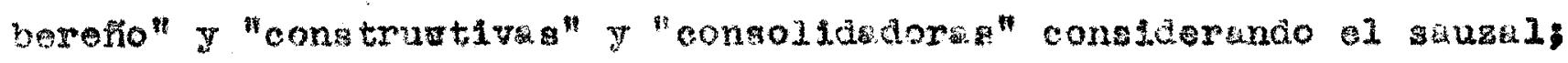

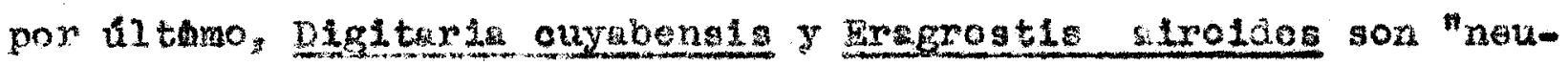
trites" puesto gue se extienden lgukmonte por las tres topa de 1s sere. 
Cada planta es un medio b1ologico que nos permite calif1car, quista con major exactitud ane los nfilis del suelo, termowetros, eta. planta os lgual que la comunidad el resultado de la interacion de numerosisimos factores y uno nedida del habltat bajo el cual vegetas.

De toda lis especies componentes de una comunidad, las más importantes on las domingntas, como indioadora, porque reciben la influenola total dol habltat. In $\theta 1$ mblente estudiado exis. ten olezta comuniades que indican condiciones edafleas, climbicas y olotica espociales.

1) Yas comunidades hidróflias seña lan una provisión excesiva de guf y en conzecuencia una aereación insuficiente.

a) El bosque de canelón (Sogles de Repunea laetevirens) Indies un habitst on intonsidades Iuminosas bajks.

3) El bosque blineo domuestra un lbarab́n cuyo suelo tie. ne uni projuctiviand potenelal enome park la agricultura.

4) E1 1.sal (Consocies de Tesara integrifolia) senia 1a suelos greno-limosos o arenosos soltmente.

5) da dominancia temporaria o superabundanela de gramiñén

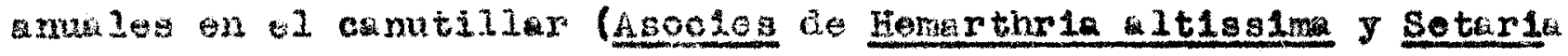
genievlatel represente exceso de pustoreo puesto que une de las domantes, el canut1130, os al amento preferido del ganado, unque con ello nunca se 11 ega a un ancudo stado de empobrecimiento ni a dzemer el ritmo de la sucesión pués, en la majoría de los casos,

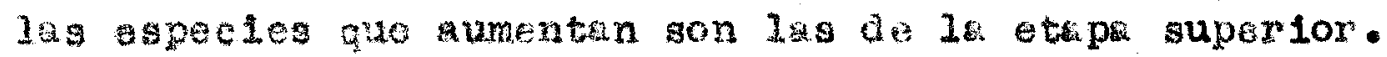

6) 21 pumento de melez enulas on el pajonki inalca

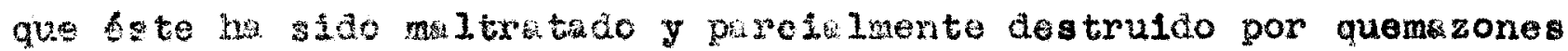
- por corte.

7) Log renovies an suelos ltos o alosranes son relictos Indicadores de bosques prexistontes destruidos por 1m tala.

8) Frente Foasio, el miterid ribereño (Asocles de Beociaris laneoolata $\$$ Sesbania maginatal reflejan bosques ante- 
rores, pues el frea libre de la competencla de la dominantes subclimixlcas, gue han sido ajestruidas por la tala, es Invada por os tos arbustos que representan etaps més primtiva en el desarrollo suceslonal gue el bosque higrofilo 1510 fio.

9) La presencle del pajonal sobre los lbardones indtex indios destruceión del bosque por tala o incendio. 
Los tipos de vegetación que encontramos en las $2 \mathrm{ala}$, según la sis-

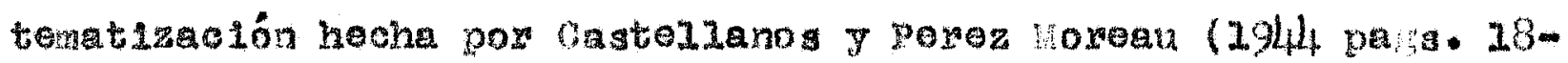

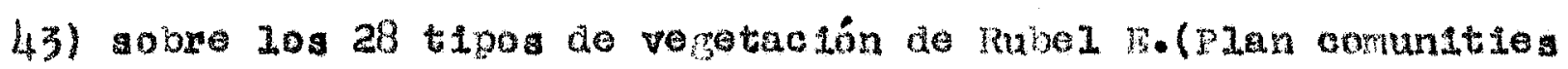
of the worda 1936 ), son:

LIGNOSA (CIIma aróneo)

1) Pluv11a11vae, árboles altoa (nogafanopófitoa), poco o nada samirlcados, porennitolios 7 con eplriton.-

Selva en galerla, commidades de bosques ens 1 vecidos quo v1ven a la vera de los cursos do agua perianentes y gozan de condiclones odáflca y clinát Lea particularea.-

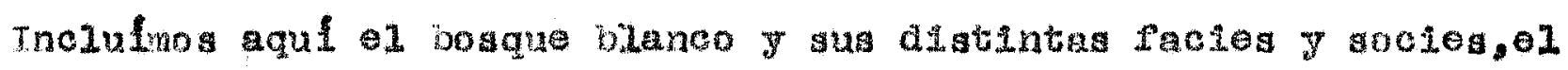
sauzal $y$ el allat, anngue ostor b́ltirnos gozan de caracteristicas do bosque \$ no do selya.

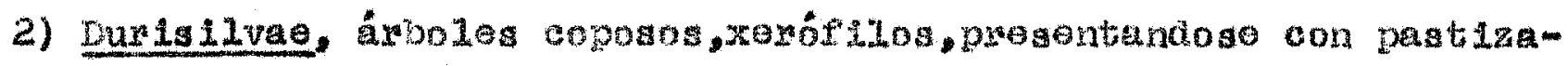

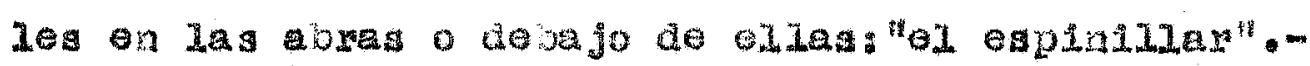

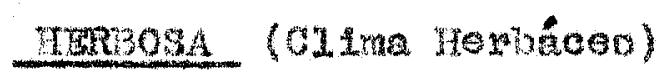

Sabana: Denara comundadeg herbáceas on las que dominan tratineas altas pesennes - Tnclulnos aqui ol pajonal de Panicum prionttia

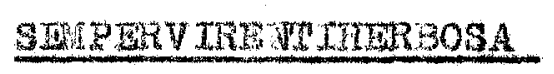

Densas comunidades herbácea oon dominancla de rrantheas.- Todas ias Asocles que tepar los olaros de los lalntes poupados pox el sauzal.EITRS ITERSOSA

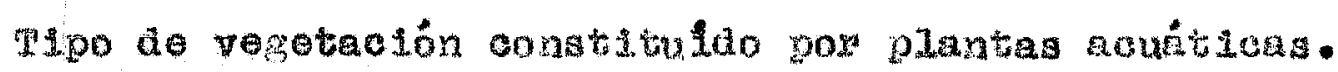

1) Canavera leg, comundades acuhticar con dontnanela de altas Graralneas J Gporáceaz - In el arblente InaLar os el tipo más fre-

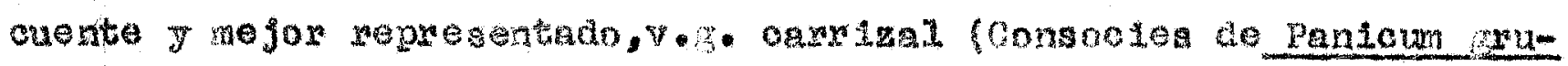

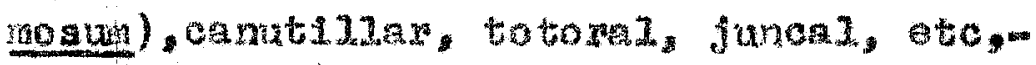

Pleuston, comunlades de puntas acuétioas nadantes que choren Ia supenflole de aga dulioe en las lagnnas, onenoos o cursos de agua

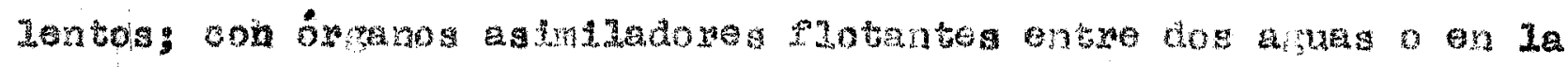

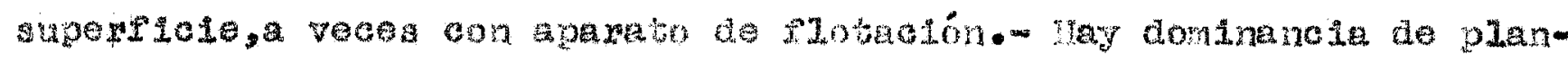


ta vasculares.- Rate tipo de vegetación se conoce tamblén con los

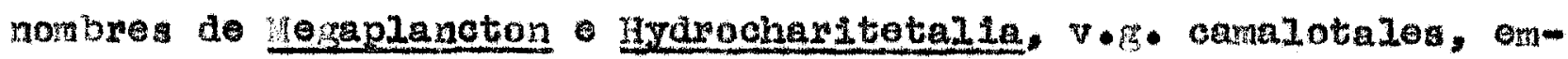
balsados, $60 .-$

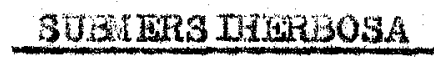

Planta totalmente amergiaa, o en partes flotantea, fijas on los 11mos.-

Ilmabenthos, corunidades de plantas on au mayo La vascularea,

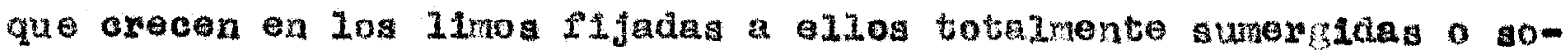

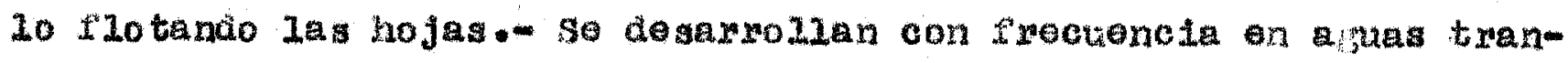
qullas y son menos abundante on 10 s clina tamplados que en 10 tropicales, V.g. colonias de Vlotonia cruzlana. Socles de Limnanthemum Euraboldt 1anum, etc.- 


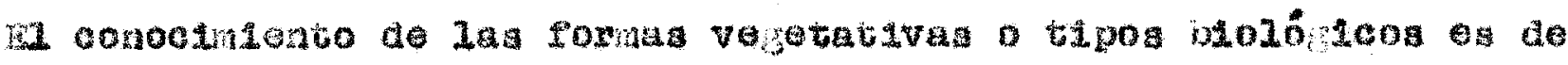

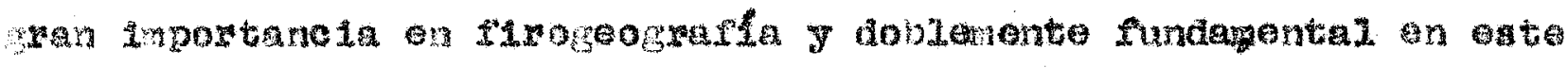

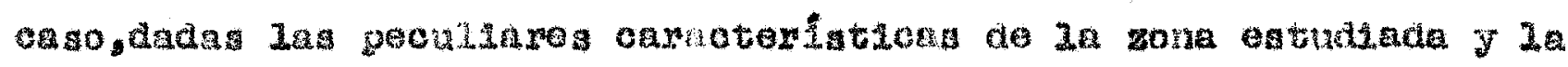

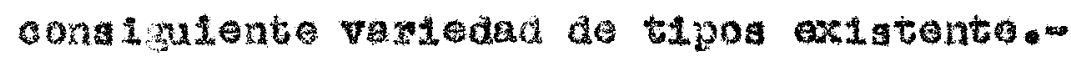

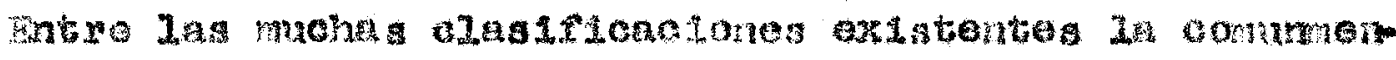

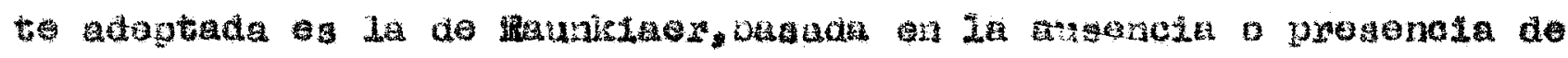

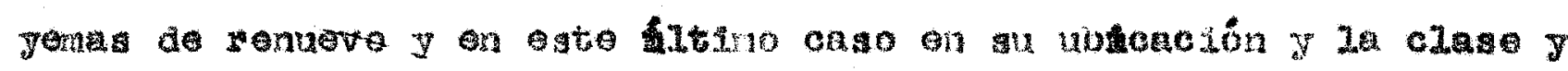

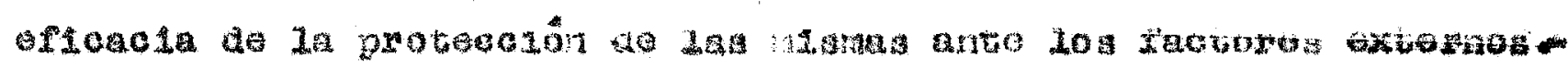

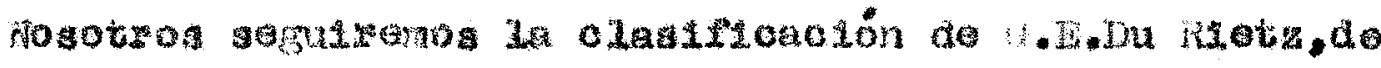

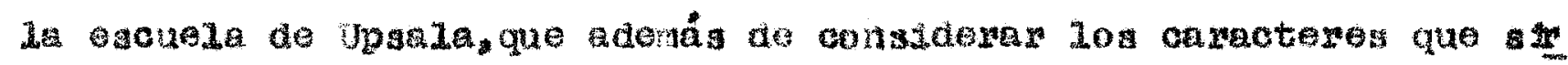

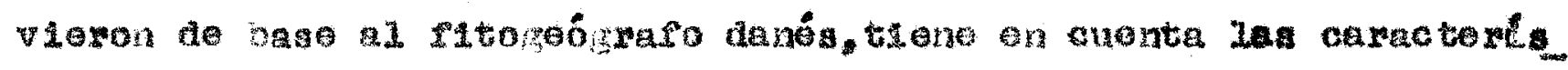

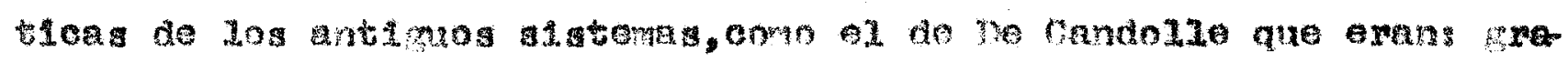
do de 11 gnowidad, itonoo, otc.-

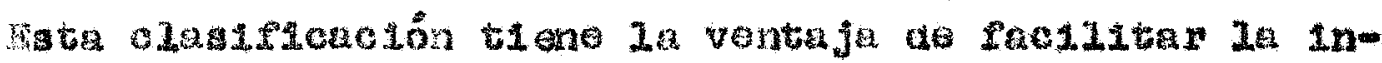

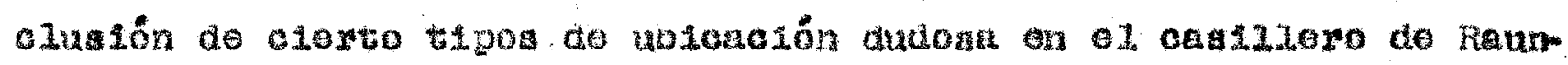

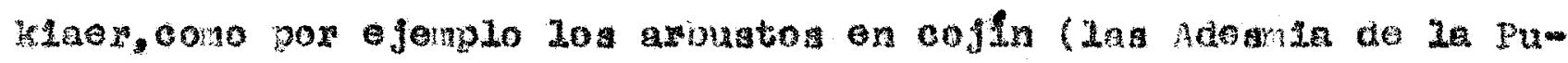

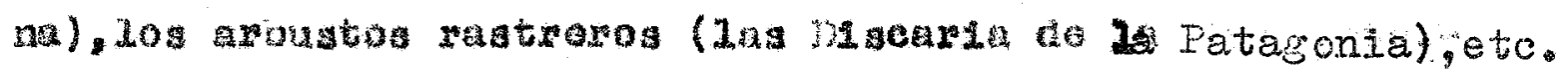

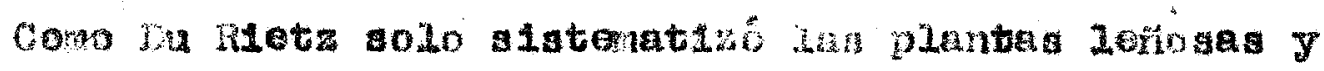

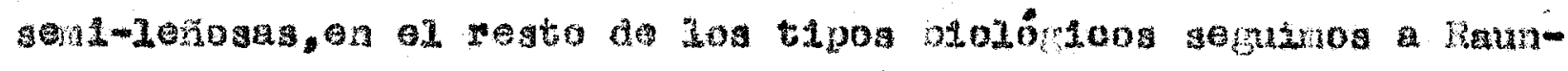

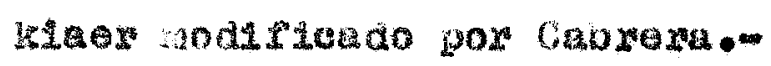

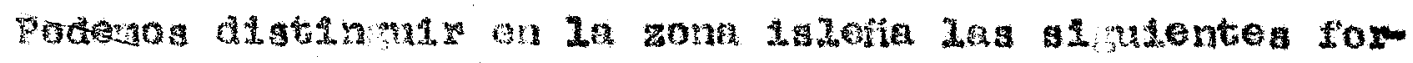
sat vo vetativas:

1.- BOLOH LAS.

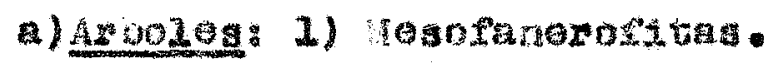

2) Ironotanerofitata

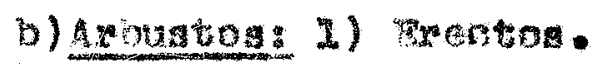

2) Volutas.

I. HEIXILAS.

TLI. LIXHSAS.

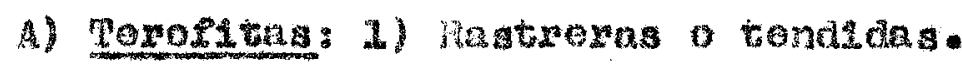

2) ralingas.

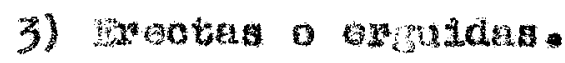




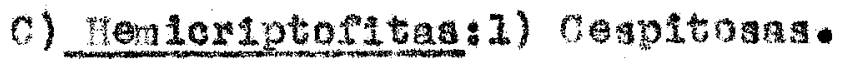

2) Axrosovadas.

3) Suzarogotadas.

4) Caulogoenten

5) Rastiveng.

b) Vozudies.

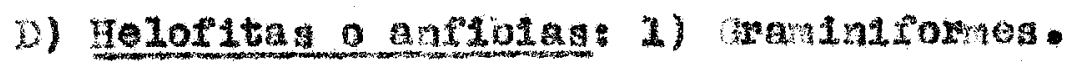

2) Junc Lfontos.

3) Tatedoudatas.

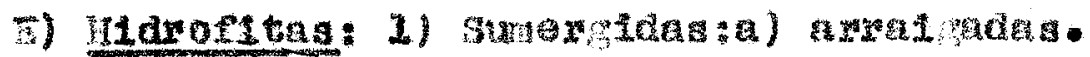

b) 2thro:

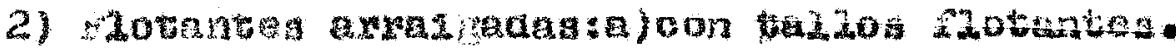

b) con hojer futantes.

3) Motantas 11 oreas

c) Con tallos slotantos.

a) oon peololos putantea.

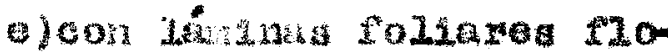
tontes.

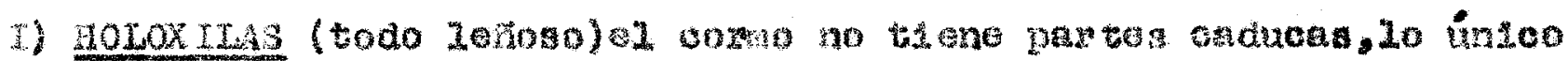

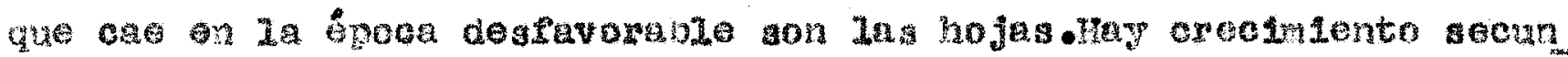

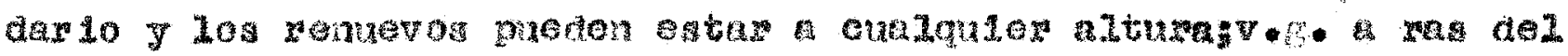

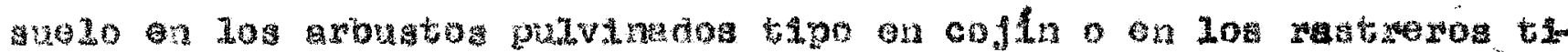

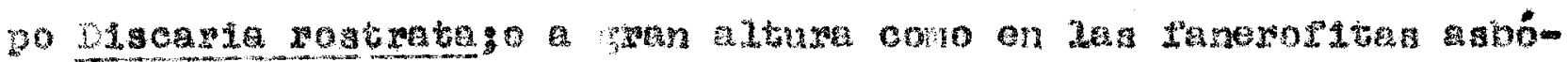
mota

\section{a) Arboles: on urtuonco peincipal w}

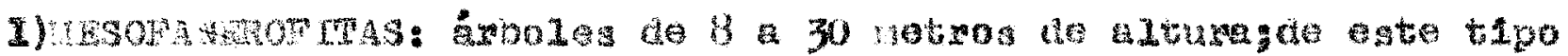

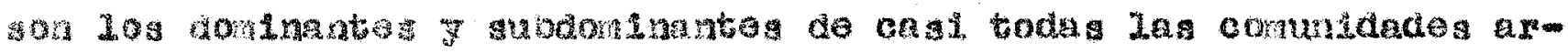

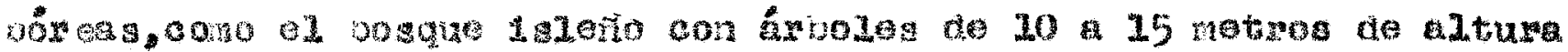

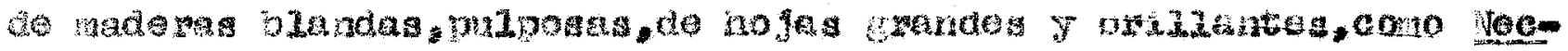

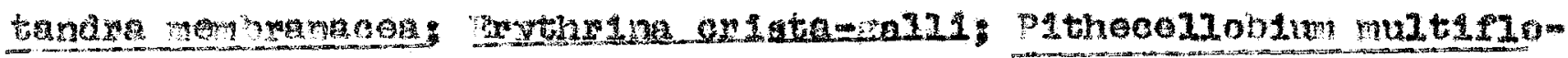

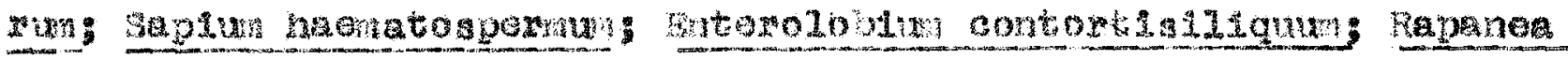

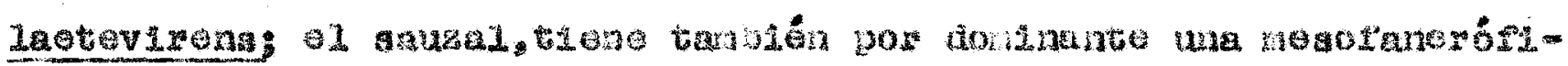
ta: Sazz Humboldtianan-

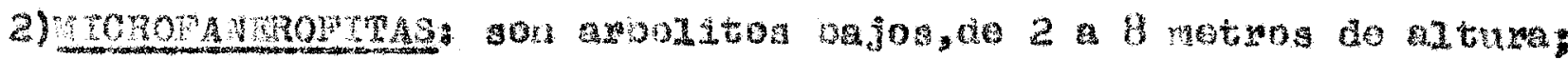


V.S. Acacla caventa, árol quo foma osques clasos, de medera dura,

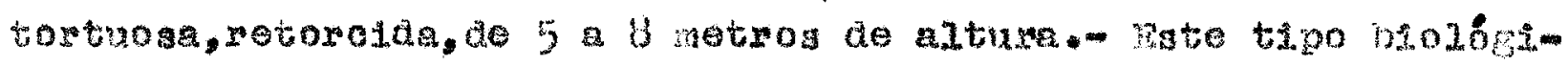

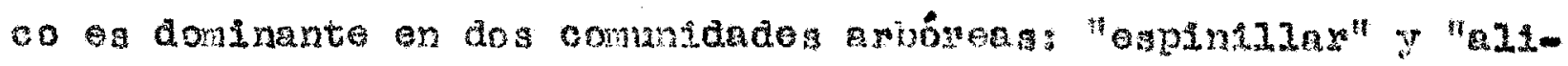

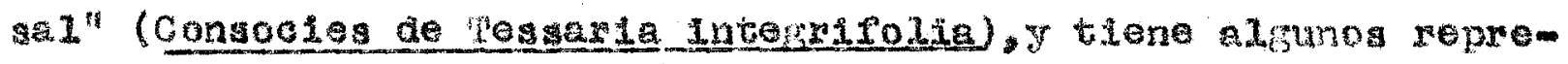
sontantes on otras cono cassta corymoosas cophalanthus glabratua, ete..

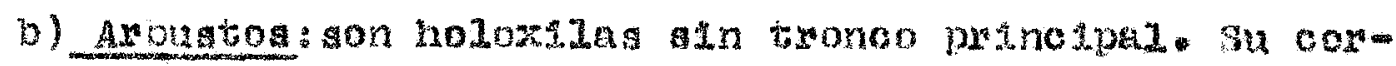

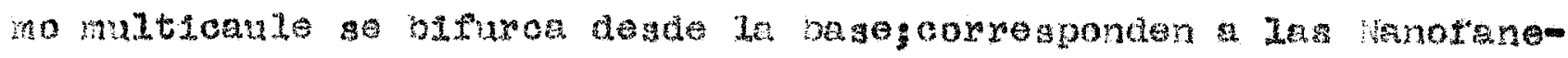
rofitag de Randraen.-

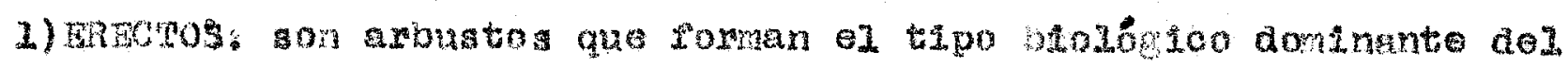

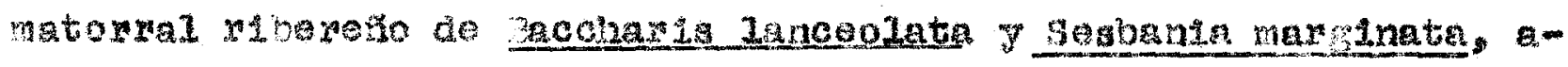
demás foman el extrato ambutivo del boaque isleno on Acallpha

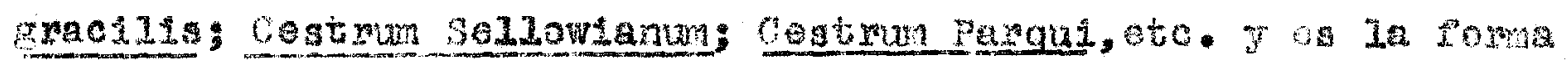

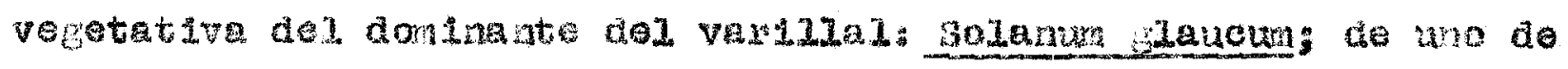

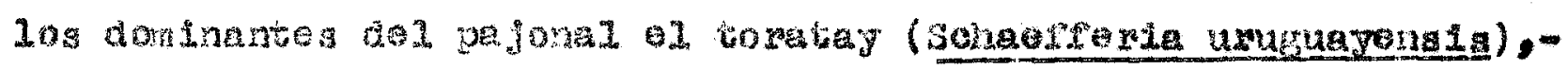

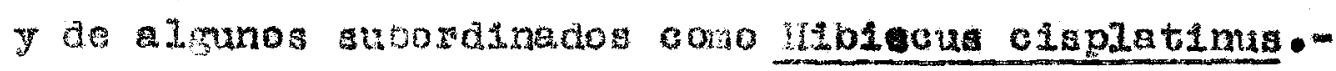

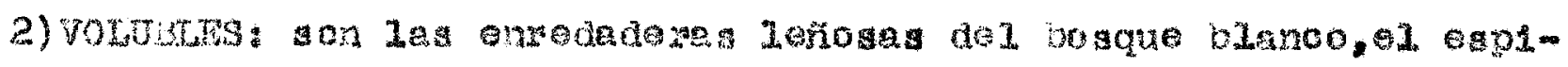

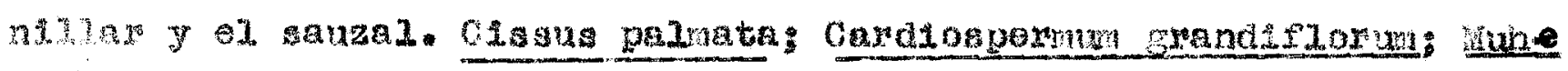

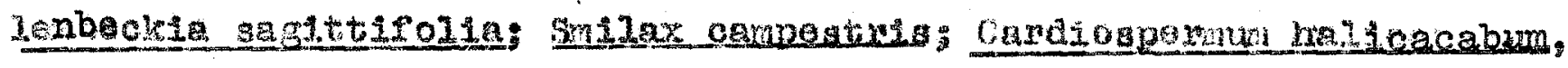
etc.

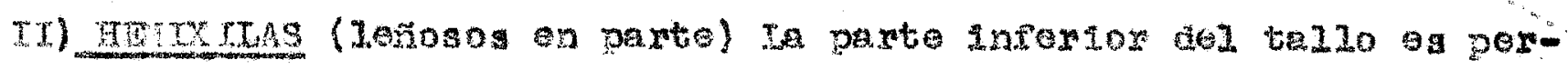

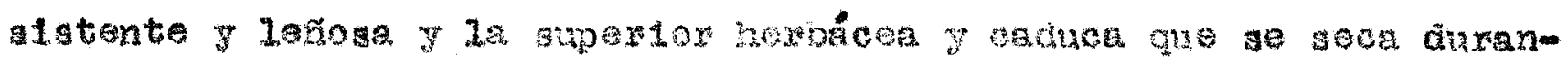
te La ogtación Invernal. -

S* Malan Lncluida en esta caterorla entre otra las

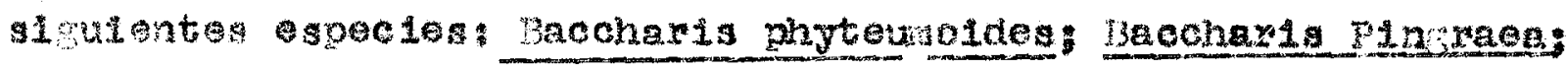
S1da hatate; 1 da montopolia.-

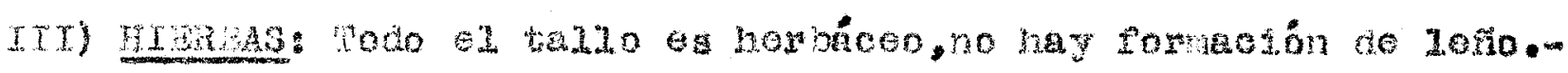

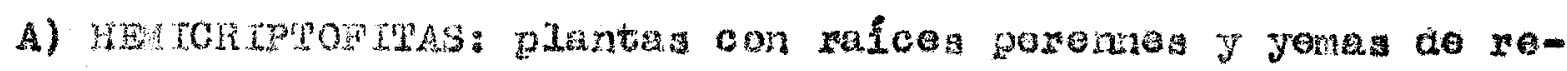

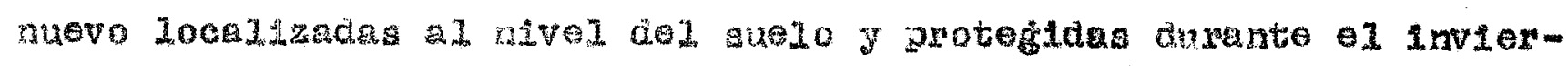

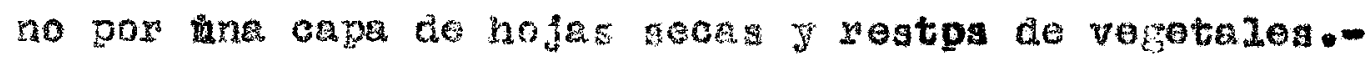

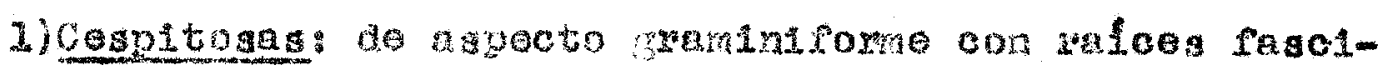

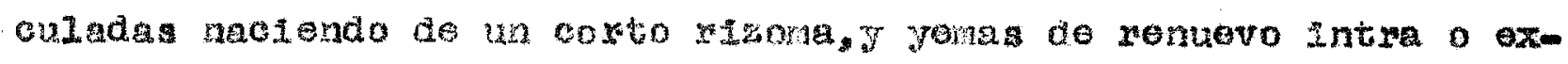




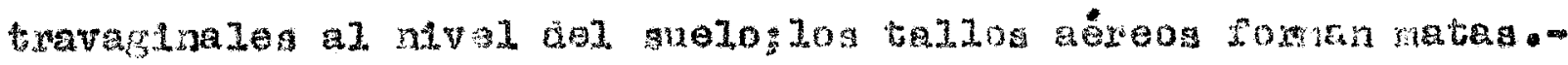

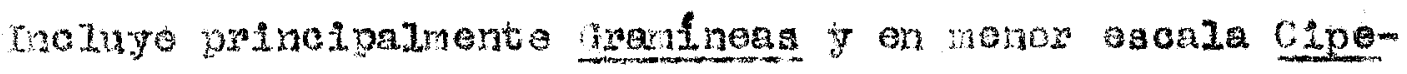

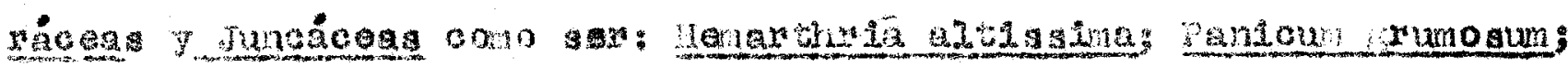

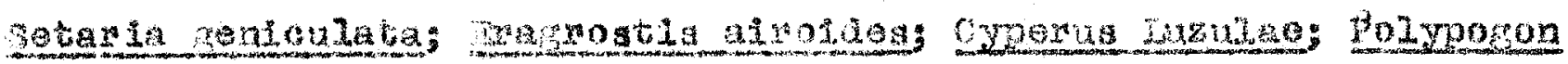

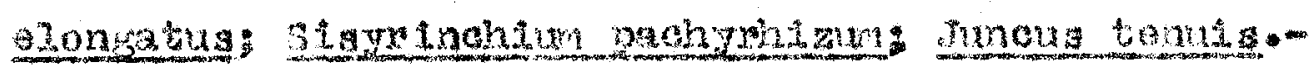

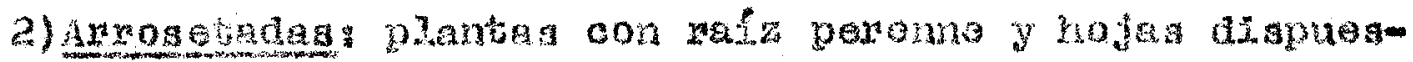

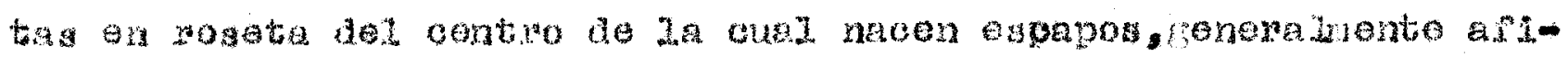

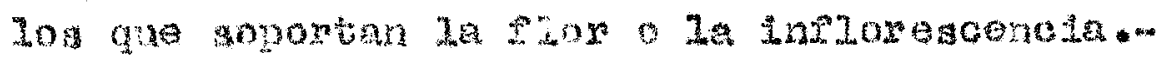

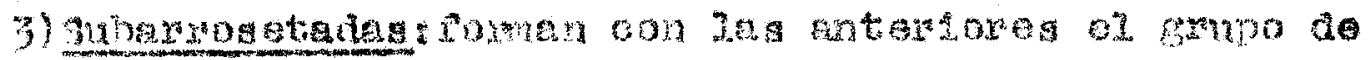

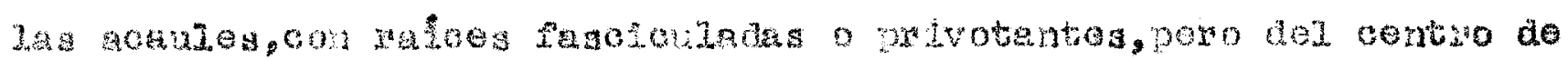

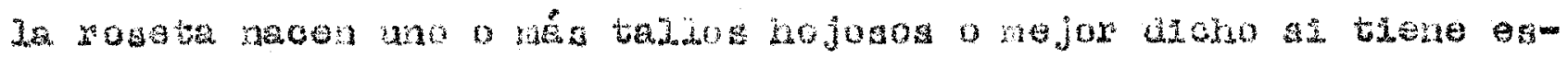

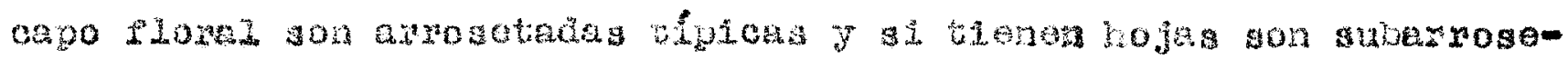

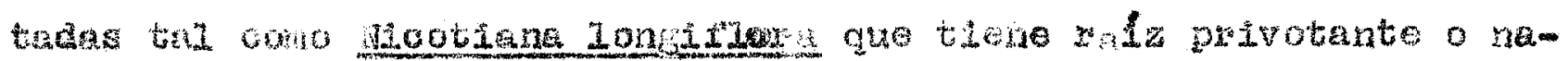

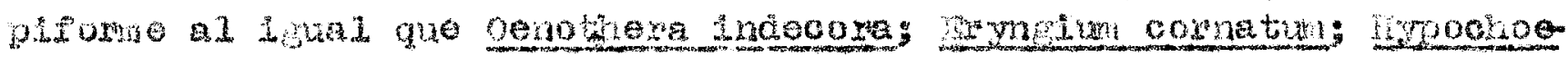

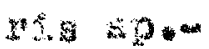

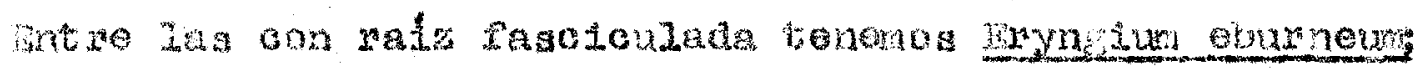
atso.

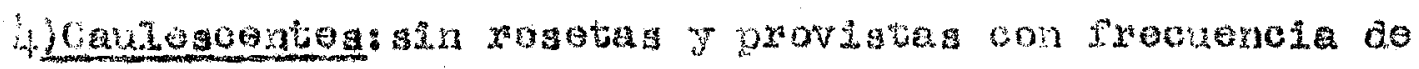

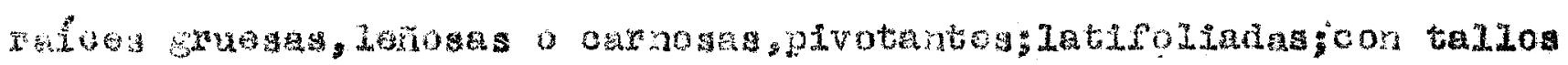

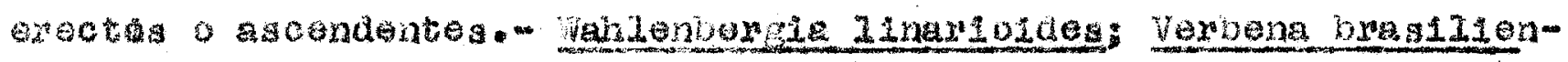

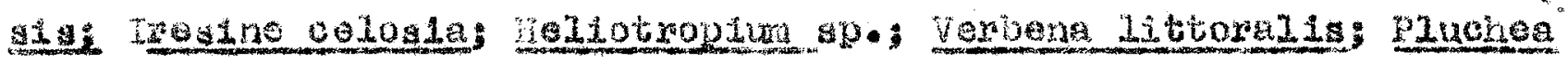

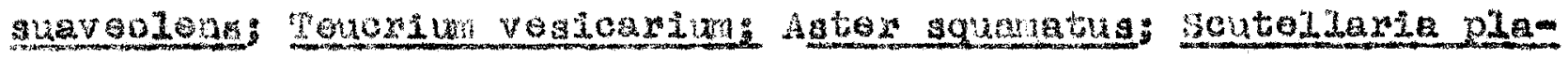

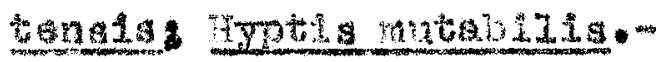

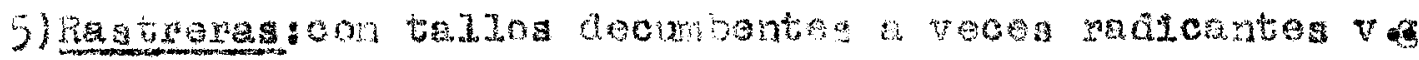
Splanthes stolonicoma. -

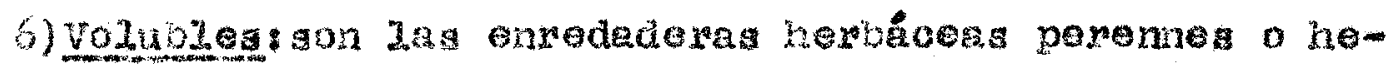

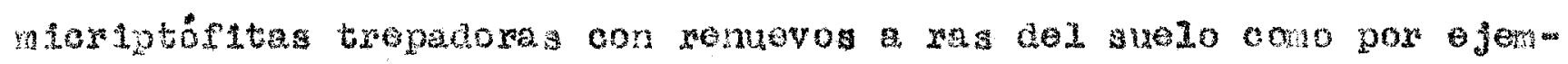

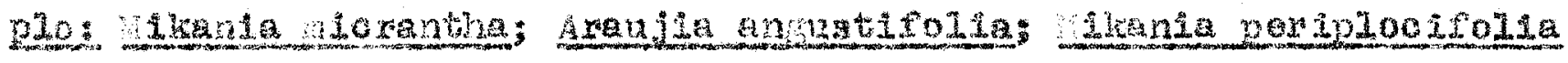

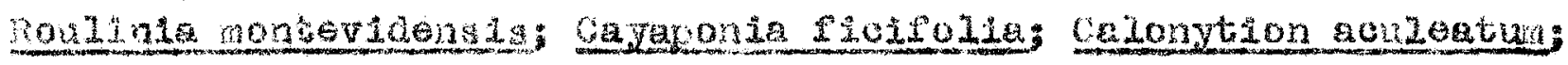

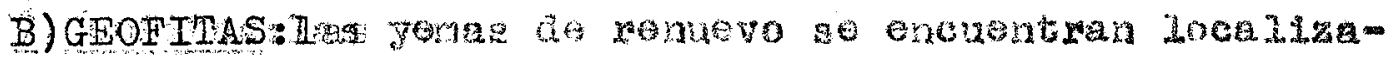

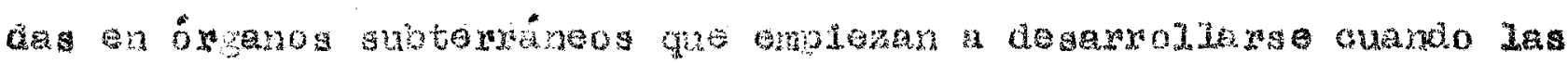

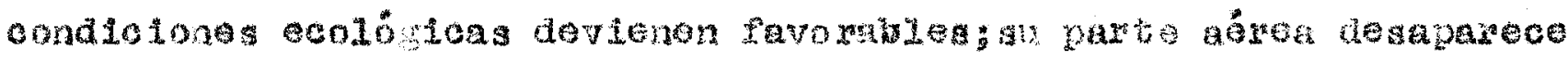




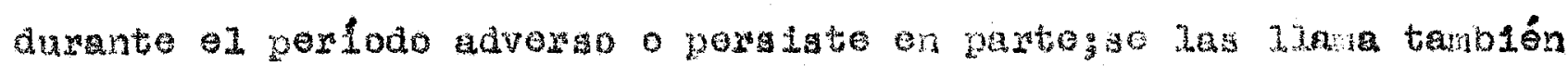
criptositas.-

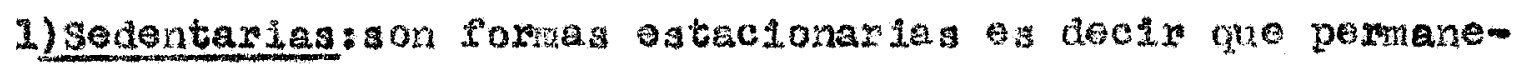
con tode su vada an un mlano pubto:

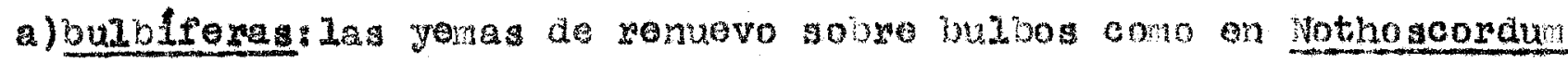
sagana:-

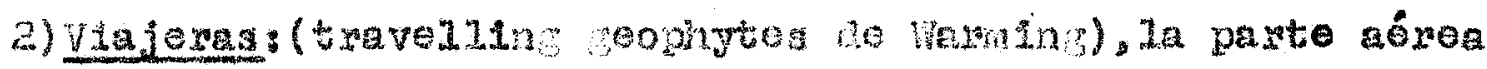

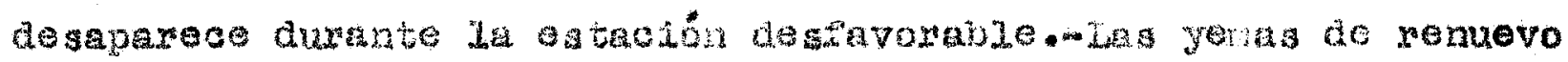

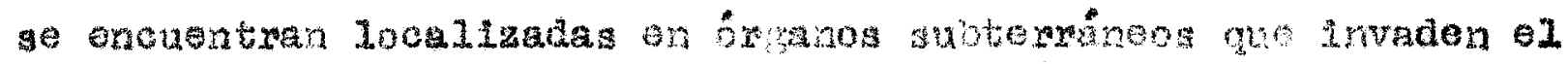

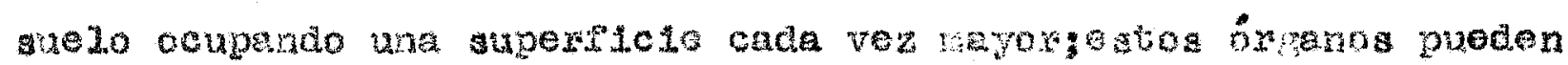

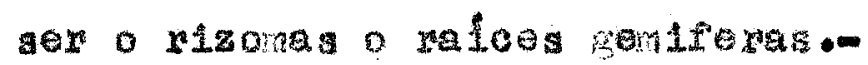

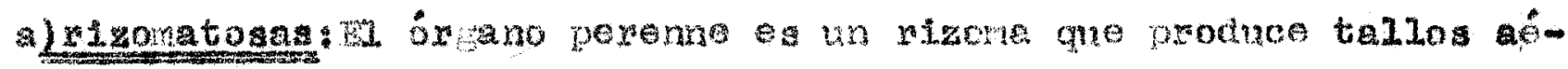

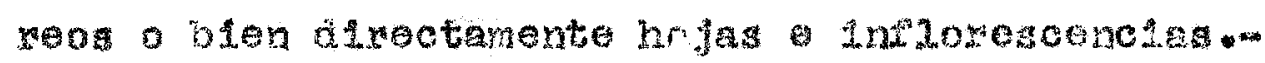

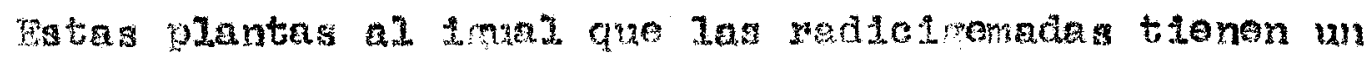

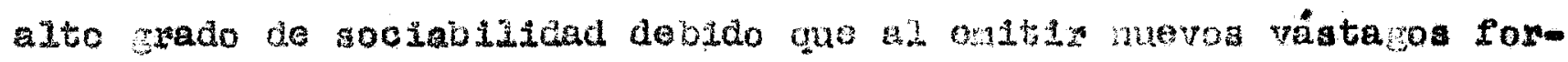
man grupos compactos a

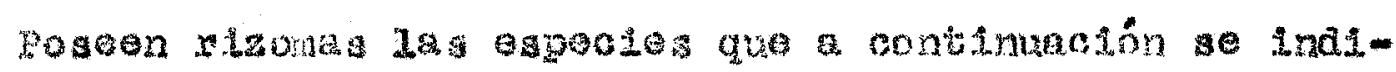

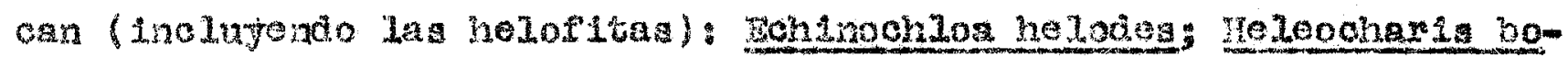

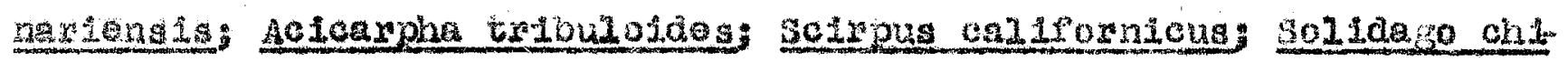

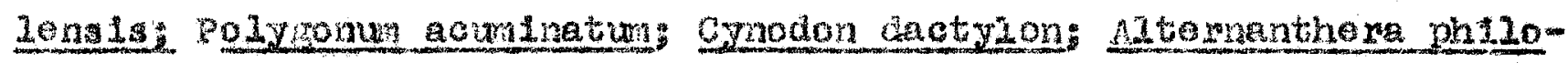

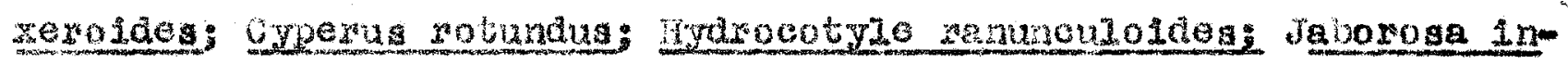
Cegrifo.11a.-

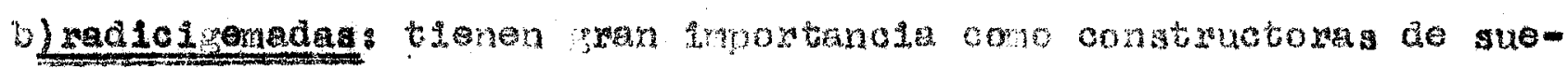
Ios y conolidadoras do lo bancos aronssos an oate ambionte do sue-

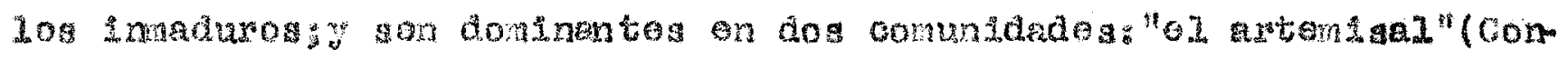

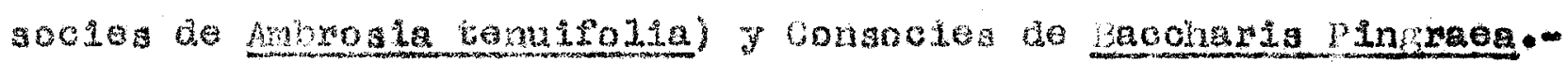

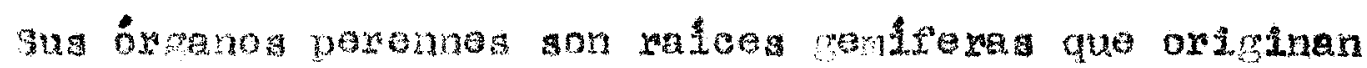

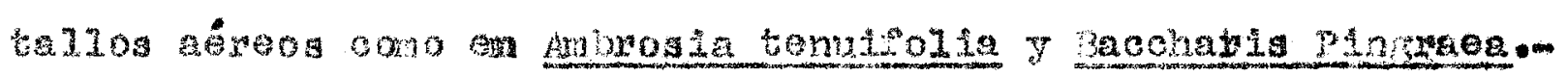
C)ILROEITAS:pLantas gue amples an c1010 ovolutivo on un ario; 1a b-

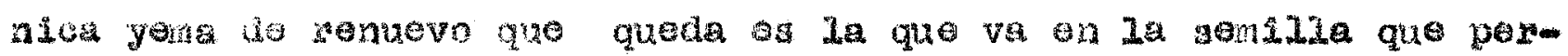

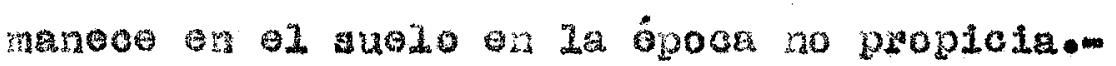

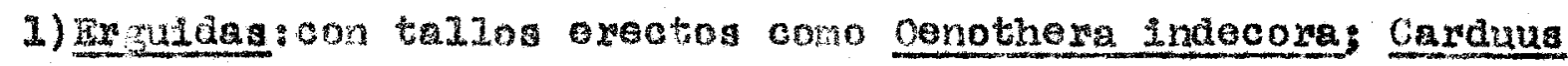

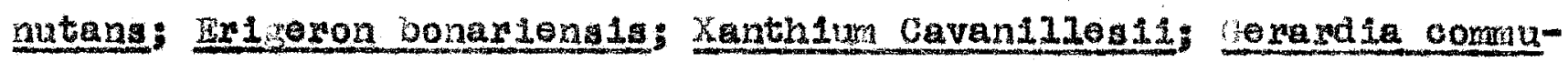


2) Volubles: con talios onposcantos, hojas proviatas do zarol-

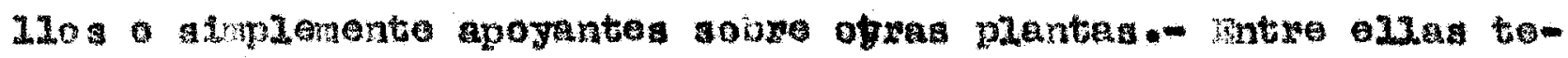
zeros: Ylola zrargines: Iathyzug sp.,-

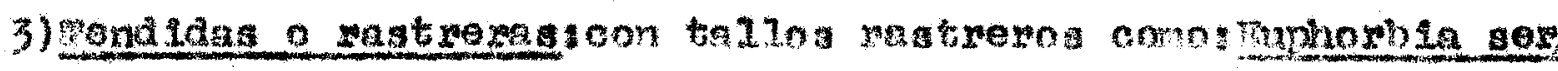
pong: Portulaca ols racera

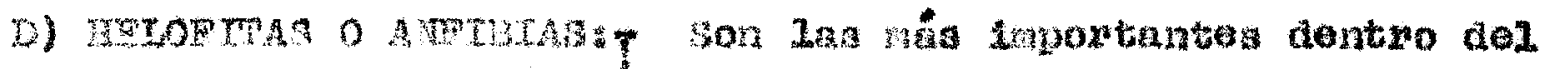

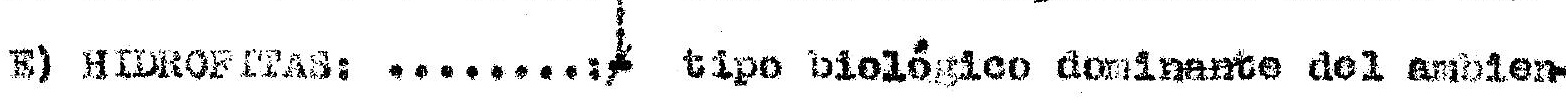

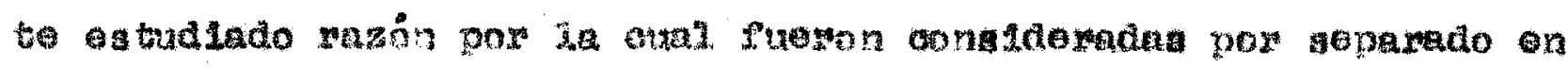

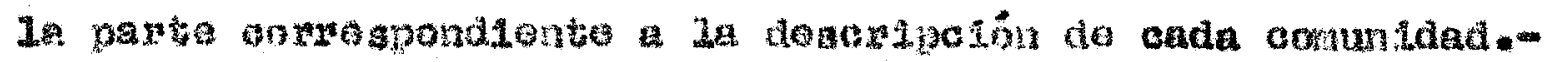

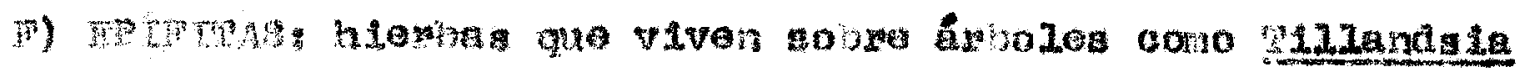

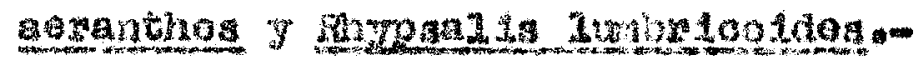




\section{I - SALUNLACLEE}

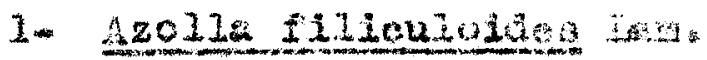

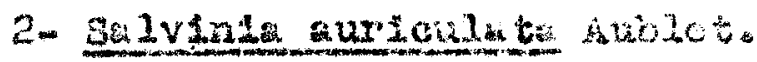

3.* 3s2y

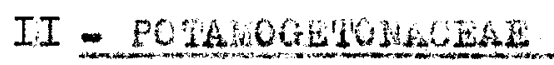

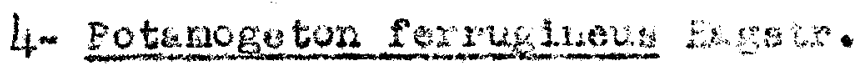

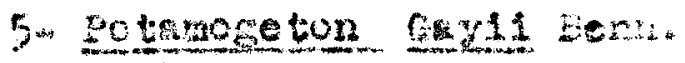

III

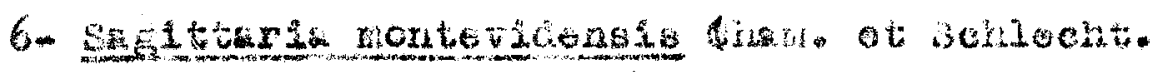
$I V-$ QASHNAS

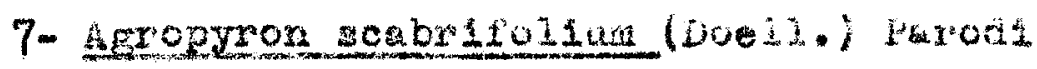

8. Axonopua comprossua bouv.

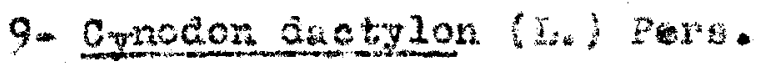

10. DIgltarla suyubersts (

11- D12

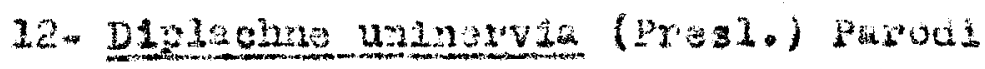

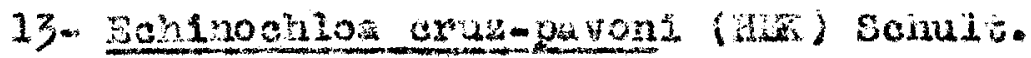

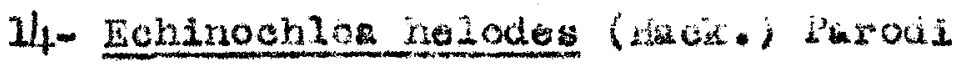

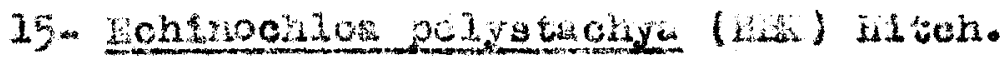

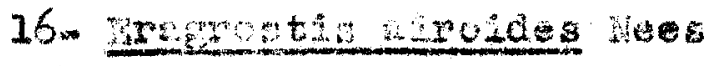

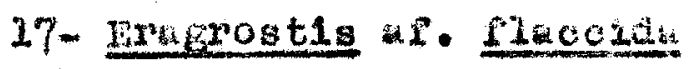

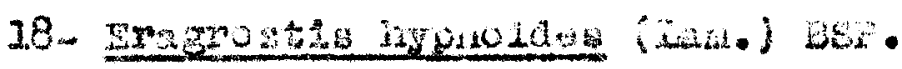

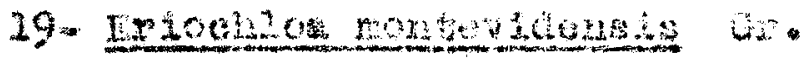

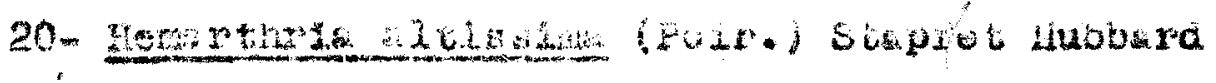

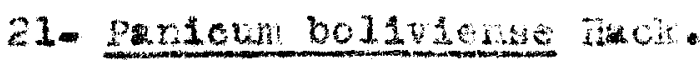

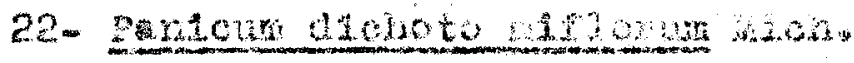

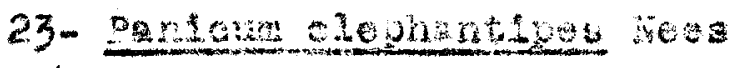

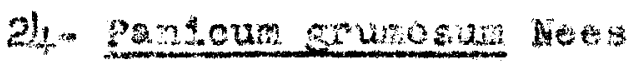

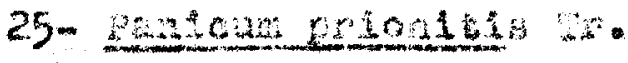

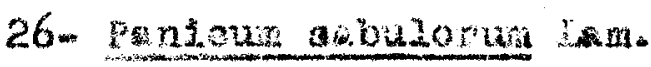

27- Paspin dum distichum I. 
32.

28- Paspazun HLeronym is is:

29- Pagpolum notatum F1. Vur. Saurue Purodi

30- pagpalum repeng serg.

31- Bolypogon chilengis (Funth) pilg.

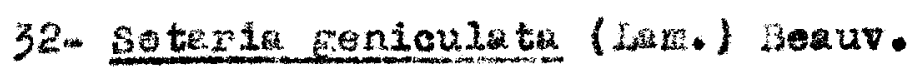

33- Setaribi globulifera (stoud.) $\mathrm{gr}^{2}$

$$
\mathrm{V}-\mathrm{orpmaces}
$$

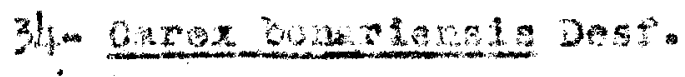

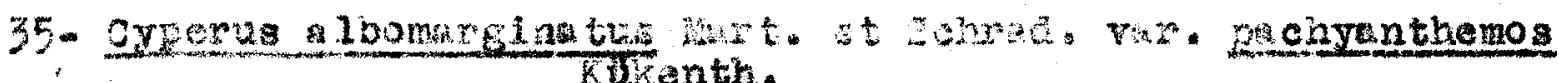

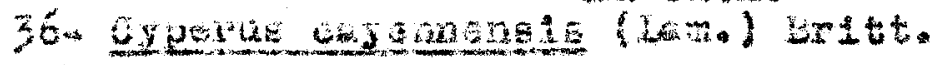

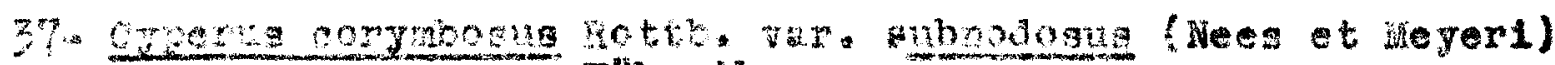
Klkenth.

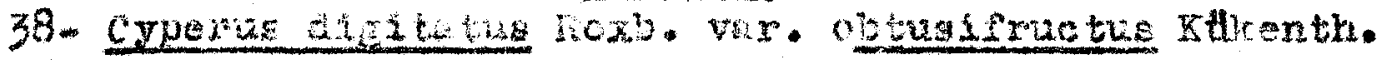

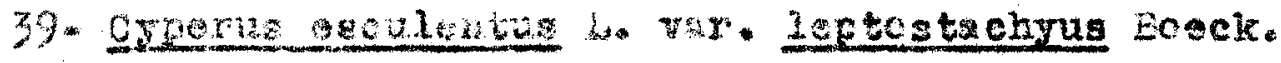

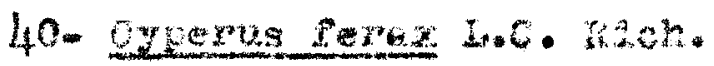

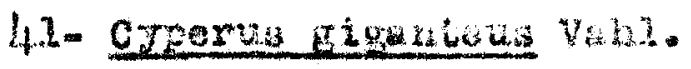

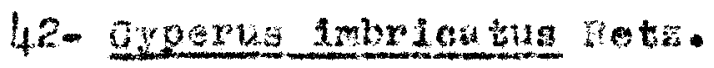

43- Grperus jastug runth. subrp. costachyug (noss) kikenth.

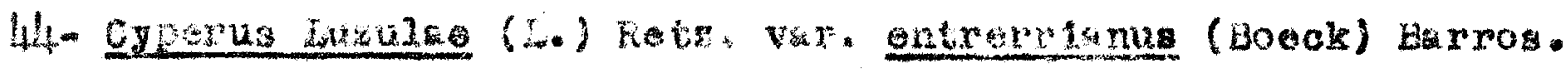

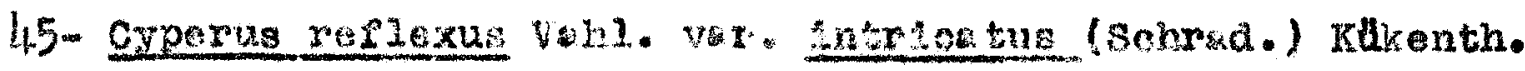

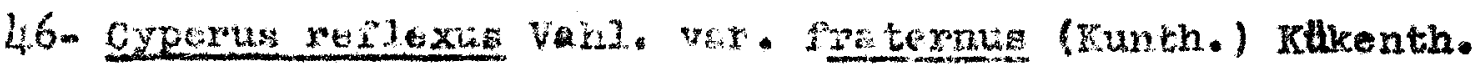

47- Gygerus gurimacias notb.

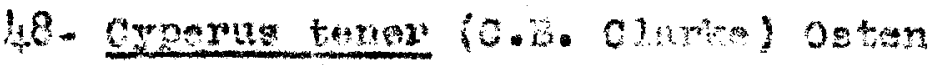

49- geperus vixens inson

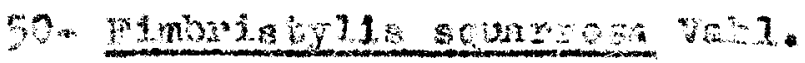

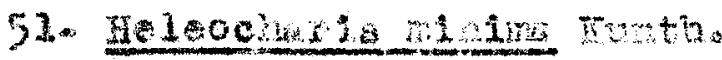

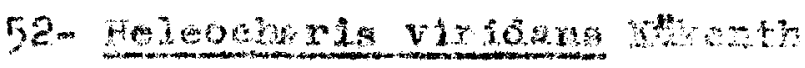

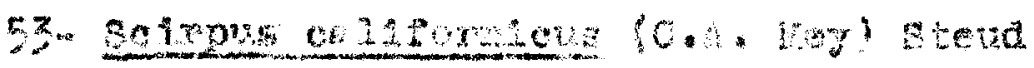

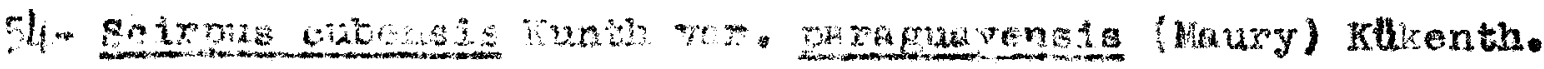

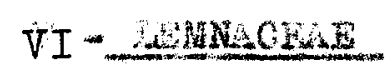

55- Lomne valdiviara Fhil.

$$
\text { VII- ARACLAE }
$$




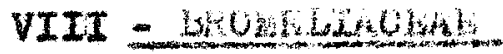

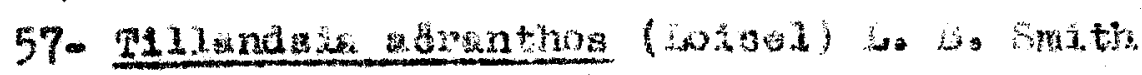

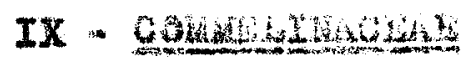

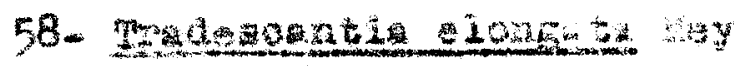

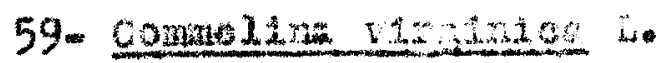

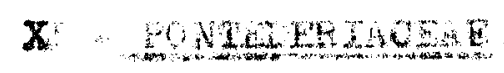

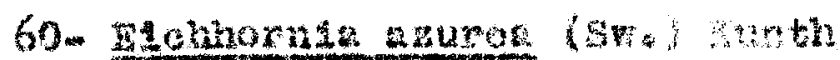

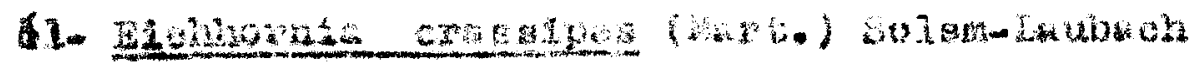

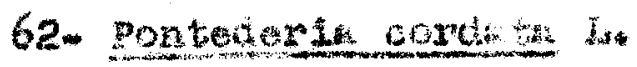

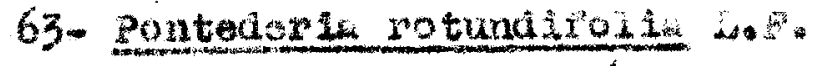

$$
\text { XI - yUMOES }
$$

64- Jingze cutus in.

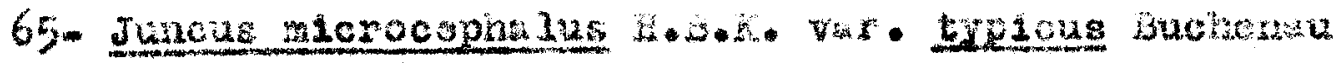

66- Tuneug tonus milas

XIJ $2 I S A C H E$

67- Notroscoreman

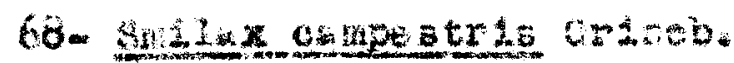

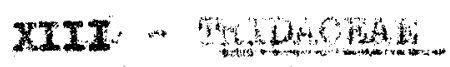

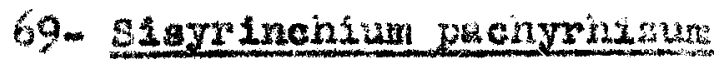

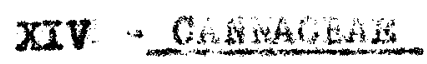

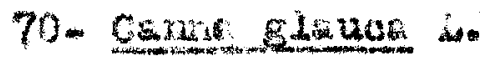

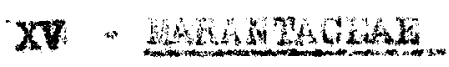

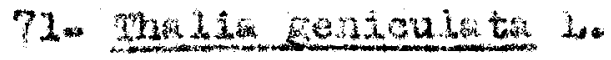

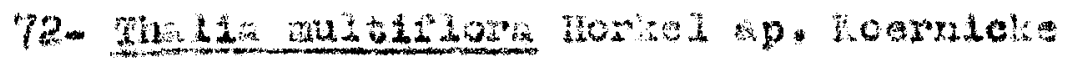

$$
\mathrm{XVI}=\sin 2 \mathrm{Lgcts}
$$

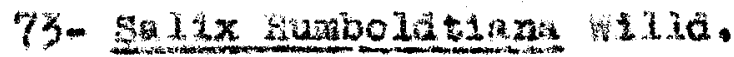

$$
\text { XVIT USTCHGESE }
$$

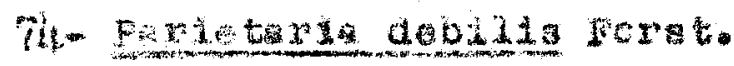

$$
\text { XVIII - OLYOOHAOHA }
$$

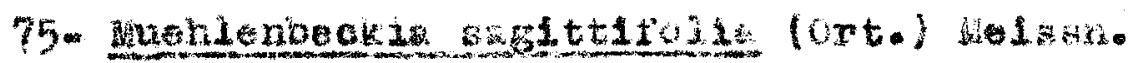

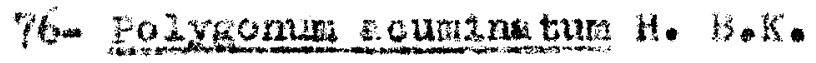

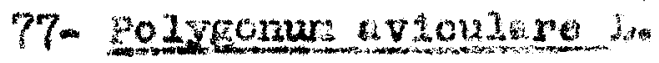

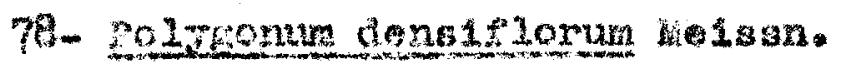


79- Polygonum puncta tum E1110t

80- Rumex argentinus Rechinger

81- Rumex crlspus L.

82- Rumex paraguayensis D. Parodi.

XIXX - CHENOPODIACEEE

83- Chenopodium album L.

84- Chenopodium hircinum schrad.

85- Chenopodium multifidum L. X DMALANTHACEE

86- Alternanthera ph1loxeroldes (Mkrt.) Griseb., var. obtusifolia (1roq.) Hick.

87- A. ternanthera pungens B.B.K.

88- Alternenthere paronychloldes St. H11.

89- Alterninthere Reineckil Briq.

90- Amaranthus aff. hybridus L.

91- Iresine celosia L.

92- Pfaffir stenophylla (Spreng.) Stuchl.

$$
X O A=-A I Z O A C E A E
$$

93- Glinus radiatus $R$. ot $P$.

94- Mollugo verticillate

XXIT- PORTULECACEAE

95- Portulace sp.

96- Portulach oleracea L.

$$
\text { XXIIT - CARYOPHYLLACLAE }
$$

97- Corastium humifusum Camb.

98- Cardionema ramosissimum (Tinein.) Nols et hiobr.

99- Sagina apeta $1 \mathrm{~s}$ L.

100- Spergularia platensis (Cambss,) Fenzl.

101-

$$
\text { XXIV = NTMPHAEACEAE }
$$

101- Victoria cruziana $D^{\prime}$ orb.

$$
X X V=\text { LURACEAE }
$$

1024 Nectandra membranacea (Spr.) Hasslex var. fulcifolia (Nees.) XXVI- CAPPARTDLCEAE

103- Cleome spinose L. 
104- Lapidium spica tum Desv.

105- Nasturtium pkinstre

106- Nesturtium pumparum speg. XXVIII - LEGUHANOSAE

107- Acacis ch venta (Hol.) H. et A.

108- Aeschynomene montevidensis Vog.

109- Aeschynomene virgin10s (L.)B.S.F.

110- $\mathrm{cass12} \mathrm{sp}$

211- Cass1a b1capsularis I.

112- C1ssepelos pareire t.

113- Crotalaria anugyroldes H.B.K.

114- Enterolob1um contort1s111 gurm (Ve11.) Horkng

115- Erythrina crista-gal11 L.

116- Inga uruguens 1s Hot. Arn.

117- Lathyrus nigrivalvis Eurist

118- Lathyrus pubescens Hook et Arn.

119- Luplnus Inca nus Grahn

120. Luplnus mult1florus Desv:

121. Limosa p1gxa L.

122- H1moss Vollosiella Herter

123- Phaseolus adenminths Mey.

124- P1thecelloblum multiflorum (Kth.) Benth.

125- Serbonla marginati Benth.

126- Vic1a Eraminea Smith

127- V1gne 1uteola (Jacq.) Benth.

$$
\text { XXIX - OXALIDACEAE }
$$

128. Oxalis cordobensis Knuth.

$$
X X X-\text { GERANIACSAE }
$$

129- Gergnium sp.

$$
\text { XXXI - WALPTCHIACLAE }
$$

130- StIgma tophyl Ium Hass lorianum Nied. 
132 - Caperonia palustris L. St. Hil.

133- Croton sp.

134- Euphorbia sp.

135- Euphorb1e brasilensis La.

136- Euphorbla serpens H.B.K.

137- Julocroton argenteus (L.) Didx.

138- Phyllanthus 1a thyroideg J. Hueller Arg.

139- Saplum ha oma to spermum Mtl1. ArE.

XXXIII - CELASTRACEAE

140. Schaef er 1a uruguayengis

XXXIX - SAPINDACEAE

141- cardiospermum grandiflorum Sw.

142- Caralospermum ha lica cabum L.

$$
\text { XXXV - VITACEAE }
$$

143- C1ssus palmata Poir.

$$
\text { XXXVI - MALVLCEAE }
$$

144- Abut1Ion pauciflorum St. H11.

145- Hiblscus ciaplatinus st. H11.

146- Modiola caroliniana (L. A. Don.

477- Hod1olastrum geranio1des (G111) Baker.

148- pavonia hastata Cav.

149- Pavonia sepium st. H11.

150. Sida sp.

151- S1aa hastata st. H11.

152- S1da rhombifolia L.

153- S10a spinose L.

154- Sphaercicea miniata (Cav.) Spach.

$$
\text { XXXVII - PASSIFLORACEAE }
$$

155- Passiflora coerulea

XXXVIII - CACTACGE

156- Rhypsa 11s lumbricoldes (Lom.) Lem.

XXXIXX - MYRTACEAE

157- Eugenie myrcionthes Vidzu. 
$\mathrm{XI}-$ OENOTHERACEAE

158- Jussiese repens L.

159- Denothere Indecora Camb.

XLT - BALORREAGACEAE

160- MyrLophylium bras1liense Camb.

XLII - UMBELIFLEAL

161- Apium leptophy Llum

162- Eryngium corona tum Hook. et Arn.

163- Enrnglum Kurtz1

164- Exynglum pandanifolium Cham. et Sohlecht

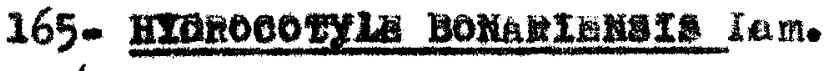

266- Hydrocotyle ranunculozdes Lo f.

XLIII - WYRSINACEAE

167- Rapanea laetevirens Mez.

XLIV - GENTLANACEAE

168- IImnanthemum Humbold t1amum Griseb.

XLV - ASCLEPIADACEAE

169- Araujia angustifol1a Docel is

170- Roulinia montevidens is (Spreng.) Mtime.

XLVI - CONVOLVULACEAE

171- Aniso1a argent1na (N.E. Brown) O'Don

172- Galonyction aculeatum (L) R. Br.

173- Convolvulus bonariensis

174- Convolvulus Hermanniae

175- Cuscuta sp.

176- Dlohonera repens Forst.

177- Ipomea sp.

178- Ipomea cairica (L.) Sweet

XLVII - HXOROPHYLLACEAE

179- Phacelia artemisioldes artsob.

XIVIII - BOFHAGINACEAE

180- Hellotropium $\mathrm{sp}$.

181- Hellotropium nlcotiana e follum polr. 
182- Lippia alba

183- Zerbene brasiliensis

184- Verbena brasiliensig Vell.

185- Verbeng grac1lescens (Cham.) Hert.

186- Verbena 11ttoralis H.B.X.

187- Verbena megapotamies

$$
\text { L- } \triangle A B I A T A E
$$

188- Hyptis mutabilis (Ricn.) Briq.

189- Marrubium vulgare L.

190- Salvia guaranities st. Hi. ox Benth.

191- Seutellarie platenslas speg.

192. Scuteliaria ma comoge pexs.

193- Stachys Michellane Eriquet

194- Teucr Lure vesicarium Hi11.

$$
\text { LI - SOLARACEAE }
$$

195- Cestrum Parqui L'Herit.

196- Cestrum Sellon1anum Sendt.

197- Jeborosa Integrifol1s Lam.

198. MLotlana Ionglflora Cavan.

199- Mierembergla striota Miers.

200- Petunia Iinearis (Hooker) Paxt.(Johnston).

202- Petunia vlolecee Lind.

202- Physalis Viscona Lo

203: Solanum sp.

204.- Sola num amygdalifolium

205. Solanum boerhavifollum Send th.

206- Solanum glaucum Dus.

207- Solanum grac12e otto

208- Solanum slsymbrilfollum Lam.

LIT - SCROPTIULARIACEAE

209- Cerardia communis cham. et Sehiecht

210- Scoparta sp. 
212- Dicl1ptera Tweodiana Nees.

213- Justicla obtusifolia (Hees) Lindau LIV - PLANTGGINACEAE

214- Plantego myosurus Lam.

LV - RUBIACEAE

215- Borrerla vertlaillata (L.) Hoy.

216- Cepha lanthus flabracus (Spreng) Schum.

217- D10d1a bras111ensig Spreng.

218- D1od1e polmorpha Ch. et Schlecht

219- Relbunium $\mathrm{sp}$

220- Spermecoce glabra Hehx.

LVI - VALIBIIANACEAE

221- Valeriana bonaerensis speg.

LVII - CUCURBITACEAE

222- Caraponia flc1folia (Lam.) Cogn.

223 IVIII $=$ CAMPANUIACEAE

223- Pratia hederacea cham.

224- Wahlenbergia 11nario1deg (Lam.) D.C.

LIX - CALYCERACEAE

225- Aolcarpha tribuloides Juss.

IX - COMPOSITAE

226- Ambrosia tenuifolia sprens. det. Cabrara

227- Asp1lla silphloldog (Hook. et Arn.) Benth. et Hook det. Cabrer

228. Aster squamatus (Spreng.) Hieron. det. Cabrora

229- Aster aquaratus (Spreng.) Hieron. vas. Braminifollum Bak.

230- Aster af. squamatus det. Cabrera.

231- Baccheris laneenlata H. B.K. det. Cabrera

232- Bacoharls Perningtonil Heer det. Cabrera

233- Bacchar19 phyteumo1aes D.C. det. Cabrera

234- Bacohar18 Pingraea D.C. det. Cabrera

235- Carcuud nutang L. var. macrocephalus (Besf.)det. Cabrera

2360 Centaurea Pweediel Hook et An. det. Cabrera 
239- cleanthes hierac101des Don. det. Cabrera

240- Aclipta alba (L.) Hask. det. Cabrera

2l+1- Enindara anagalis Garan. det. Cabrera

242- Exiseron Blakel Cabr. det. Cabrerg

243- Erlgeron bonarelenets L. det. cabrera

244- Er Lgexon bonatlensia L. var. angustifolius Cabr. det. Cabrera 245- Erigeron Garaner11 Cabr. det. vabrera

246- Er1geron sordidus 0111. det. Cabreta

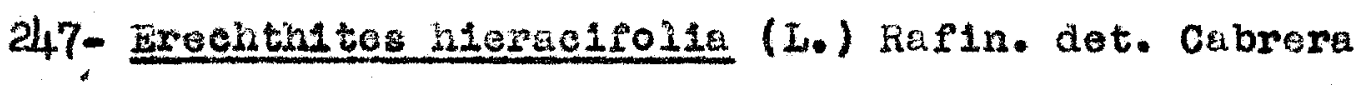

248: Eupatorlum Cando 11 leanum Look et Arn. det. Cabrera

249- Iupatorium hecetanthiar $(0.0$.$) Bak. det. Cabrera$

250- Grapha 1lua Gaud Lohauatanum D.C.

251- Inepha 11um puppureum L.

252- Gymococoronis spllantholdes (Don.) D.C.

253- Hypochoeris microcopha1a (Sch. Bip.) Cabrera

254- Eypochoexis kicrooaphala (Sch. B1p.) Cabrera var. albiflora 255- 造10ropsid dosycarge (Griseb.) Beauverd

256- Manania merantina H.B.X.

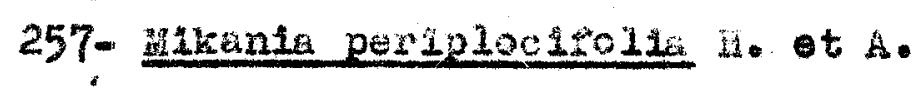

258. Flagloche11us tinacotoldes Haenk.

259- Eluchea suaveoleng (VeI1.) 0.K.

260-501tdacochtlensis Miejon.

262- Sol1va anthemidifolia (Juss.) R. Br.

262- Spllanthes stolonifera D.C.

263- Vernonia incuna Less.

264- Messaria integritolia fulz ot pavon

265- Xanthlum Cavali11eg1i Schow

266- xanthiun spinosum L. 
Anónime, 1943, "E1 régimen pluviométrico de la República Argenm tinc. Normales de Iluvira de 25 most Ministerio de Agrioulturs. Direccion de Meteorologia, Geoflsiog a Harologia", Serie F. Pubi. ne 2.

1944, "Egtadisticas climatológlcas, Valores promedios noolutos registrados en el periodo 1928" - 1937Minist. de Agr., Direc. de Heteor., Geof. Hiar. Serie B, Publ. ne 1.

-...-. "Los suelos de la provinoia de Santa Fe desde el punto de vista vial" Dep. de Quimica Agricola y Edafologia del Instituto Experimental de Santa Fó.

1937, "Instituto Experimental de Investigacion y Fomento Agricola-Ganadero. Su organización y Labor! Santa Fe,

Beez J. R., 1923, "Breve noticia sobre la vegetación do los departamentos Parand y Diamante (E. Rlos)", en Circular 35, Sec. Prop. Inf. Hinist. Agric. Nac. Buenos Alres. ....... 1937. "Area de dispersión actula do la Palmácens en

1a flora de Entre kiost en Geen, 5: 63-78

1942, "Regiones forestales de Entre Rfog". Edic. Miñ. Agr. Nac. Parane.

1944, "Reseñ sobre las pasturas de Entre Fios", en Rev. Arg. Agr. II (2): 129-14.2. Bs. As.

Begie-Horeno, No 1943, "Rosario de santa Fé. Cartografia y pobla c1on, $1744-1942^{\prime \prime}$ en Kevista del Huseo de La Blata

(Nueve Serie) I Sección Geologia, 259-298. Braun Blenguet J., 1932, "Plant soclology", New York and London. Qurkart A., 29/42. "Las Leguminoses Argentinas silvestros $\mathrm{g}$ cultivadas". Buenos Aires.

Cabrera A. L.e 1939, "Restos de bosques indigenas on los alredodores de La Plata", en Boletín de Agr1cultura, 7 Ganaderia e Industrias, $19(7-9) 12-16$.

1943. "Suelo y Vegetacion", en Boletin de Agricul- 
ra on 2 hibera Argentine del rlo de la Plata", en Nevista del huseo de La Plate (Nueve Serie)-Secciba Botanica, t. $\mathbf{x}$, press. 267-38z.

Qabrerg A. Ie. 1945, "Aguntes sobre la vegetoción del partido de Pellegrin1" en DAGI, Publichciones Ténica, t. III, ne 1 .

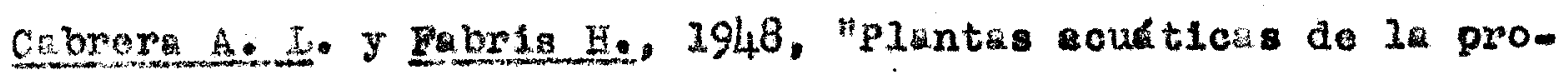
Vinola de Buenos Alres", en Publickiciones Ténicas, continuajón de $1 a$ serie D.A.G.I., t. v, $n$. 2. Cabrera A. If 1948, "Las comunidades vagetales de $10 \mathrm{~s}$ irodedores de In Plata (Inélto)" Trabajo presentado al congreso sudamericado de Botánica de Tucumán. Coln, S. A. 2932, "Considerclones sobne dgunos conceptos fitosoclologleos", en Boletin de 1a sociedud Argent1na de Botánica", t. II, ne 1, p6ga. 1-38.

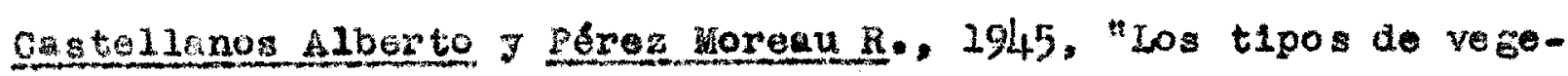
trcion de la hepúbica Argentina", Tucumín. Gagtellanos Alfredo, "II subsuelo de hosar10", an Anales de la Sooledad cientiflck Argentins, t. oxxVI, I págs. 313.

Gastelianos A., 1943, "Fl Preensenadense es un horizonte geológlco o uns focts", en Publictolones del Instituto de Flalografla y Geologis de 20 Fucultad do Ciencias Me temuticas, etc. de ia Valversided del Litoral. Cagt1110 B.S., 1945, "al Delta Entrarrano", an Boletin del Departumento de estudios etrografleos y coloniales". I (1): 119-122. Sant Fé.

Glements E. Es, 1928, "Plant succession and indicators", N. York. 1936, "Na ture and struoture of the climex", an The Journal of Ecolog., 24 (1): $252-284$. -........., 1938, climetic cycles and human populations in the Great PIfing", en The sclentific Monthly (3):293210. 
gropecuerio NacionaI, t. III.

V111ar Fuguet del, 1999, "Geobotzinica", Barcelona.

Du Fletz Q. I. 1930, "Clsisiffertion a nomonclature of vegetition ", on svensk. Botan. Tiaskr., 24: 489-503.

............ 1935, "Classiftestion and nomenclature of vegeta. tion units", en Zesde Intertational Botanisch Congre 2. $104=105$.

F1ebris C.. 1933, "Ensayo fitogeográfloo sobre el ahaco Ecron $1^{*}$, on la hovisto del Jardín Botúnico y Riseo de Hsotoric Hatural del Paraguay, t. III.

Frenguell1 J., 1922, "Algunos dros sobre 12 falla del rio paxana y 1s estructura de sus labtos", en Revista de 1 in Inersidad de suenos Ares, t. XLIX, 1890 278. B8. 48 .

............ 1941, "Rasgos principelea de Fitogeografla Argentina", en Fevista del Museo de Le Platu, t. III. Bot. ne 13, Nueve Serie.

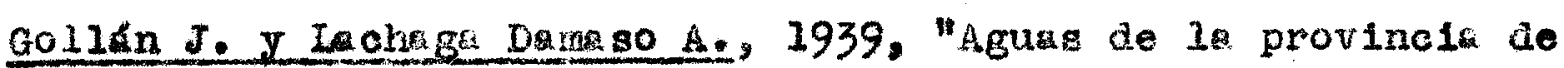
Sante Fe. Primern contribucion su conociniento". Sante. Fé.

Houman I., 1918, "La vegetación primtiten de 1, ribera argentina del rlo de la PIata" on Rov1sta del Centro Eatudiantes de Agronomia $y$ Veterinaria, no $96: 345-$ 355.

........... 1925, "La vegetation de 1'1le de Martin Garcia dans le rio de la Plata", en Publicaciones der Inatituto de Investgetones Geogrifica, 10: 1$390^{\circ}$

- "Les modifications de la flore argentine sous I"action de la ofvitiation", Mern. Acad. Roy. Belgique, t. $\mathrm{Ix}$.

* Taqu1seo phytogbogr phtare de I"Argentine subtroptculo et das as reitions vec la Geobotani- 
foyrie de Botarique de Beleique, 64 (1) $20-64$. Hauman Lo. Burkart A. Parod LoR. Y Gebrera A.Lee 1947, La vagetacion de la kepública treentira" en Geograta ae la lepubl1cr Axgentink, t. VIII, Gaea, Buenos Ares.

Lombardo Ati110, 1943, "Noticin de la vegetación de la costa orlenti 1 del rio Uruguay, on 10 departamentos Paysandú, Sirito y Axtigus" en Comunicáciones botónicas del huseo de Historia waral do Hontevideo, vol. $1, n^{2} 4$.

Lorentz P. G.e. 1876, "Cuadro de 1a vegetacion de la kepubllea Argentin", en R. Napp, Leptbliza Argentina, Buenos Airee.

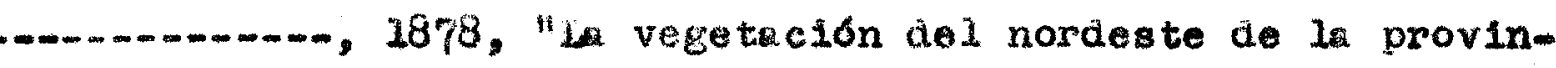
clik de Entre Klos", Feediclón del Goblerno de la probineia de Entre His, 1947.

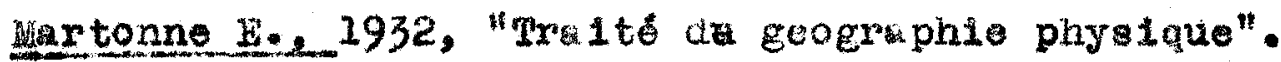
Mel10 Lelteo C. de, 1940, "Alguns comentarios de Ecologla Geral ena "Cienc1" I (4) 145-152. Mexico H.F.

Parod1 I.H._, 1929, "Observiciones sobre la vegetución de 1s

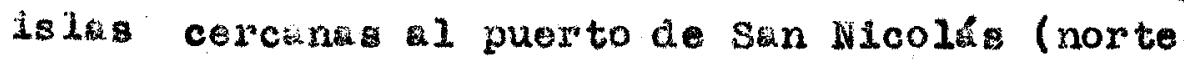
de la provincla de duenos Alree)", on Tomo commenorstivo del XXV aniversarto de la facultad de Bgronomia y Veterineria, 73-94.

- 1930, "Enasyo fitogeogrúflco sobre el partido

ce Pergamino. Lstudio de la pradera pampean en - I norte de Ia provinola de Buenos hires" on Revistik de la fac. de Agron. y Veter. Buenos Al= $r \cdot 7.65-271$.

- 1934, "La vegetación de Reconquista", Rebista Geograficu americina, I, no 6, págs. 389-407. -............... "la vegetición del departamento San Martin en Cowrientes (Argenting $)^{n}$, en Darwiniank, 6 (2) 


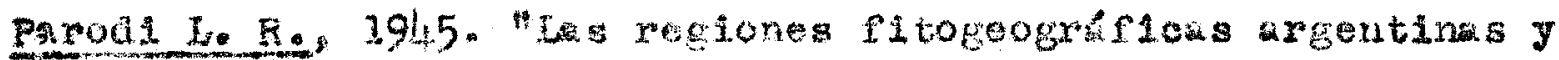
sus relciones on la jnowstria forestal" en plants and Plat-science in latin America, Wa 1

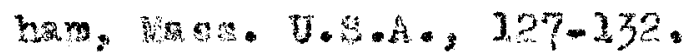

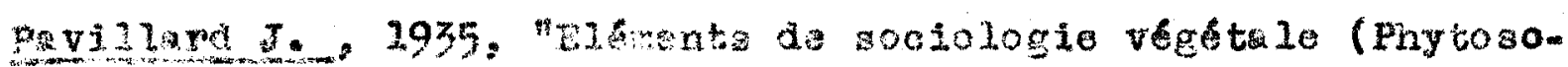

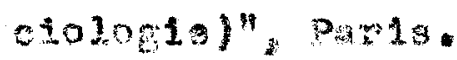

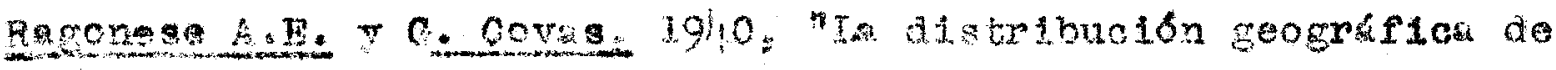

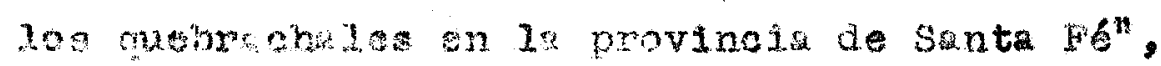
en Rev. Arg* de Agron., t. VIT, n2 3, págs. $176-184$

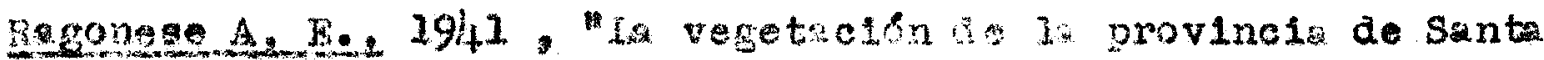
Fe (R.A.), Darwinjara knenos Ares, t. V, 369416.

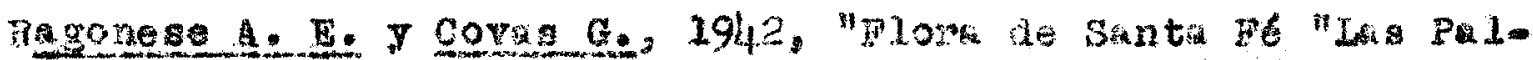

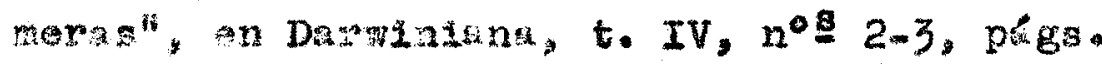
$285-302$

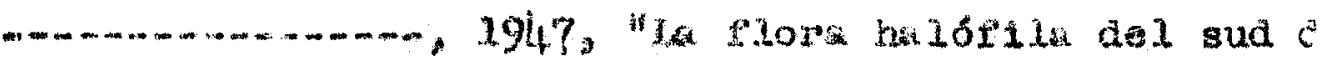

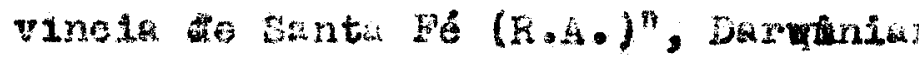
Ares, to yIJ, ne 3, pkgs. 401-495.

Eaunkiger.0. 193/, "The 1sfo forms olknts and stati plant geogranhy oyfora university !

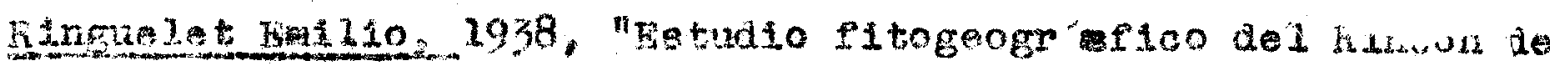
viedm (Bahla se Bamborombon)" Fev. Fac. A

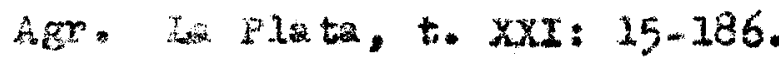

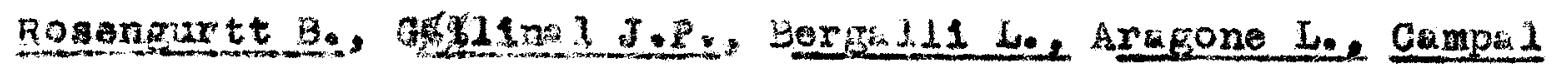
F. F, 1939, "Etudes sobre proderas nuturaleg da Iruguag. La variabijidad de la composloion te lus pradores", on Revista de la

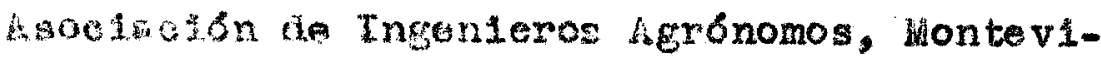
deat tomo vI (6).

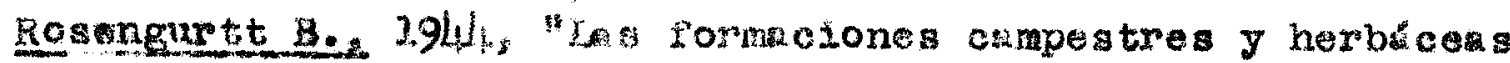
de. Eruguay". Montevideo. 


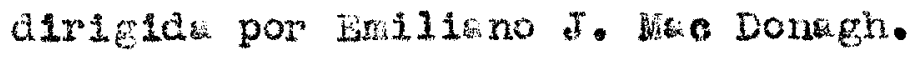

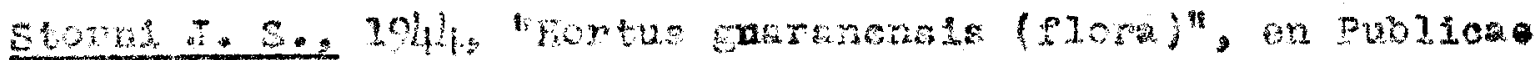

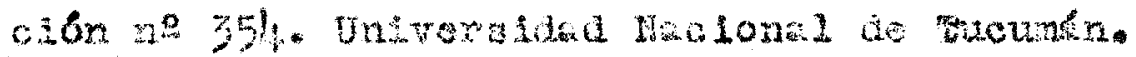

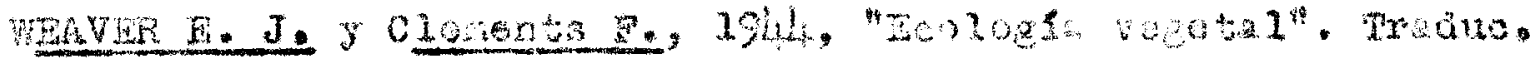

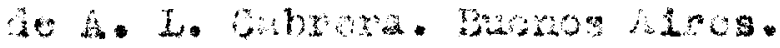

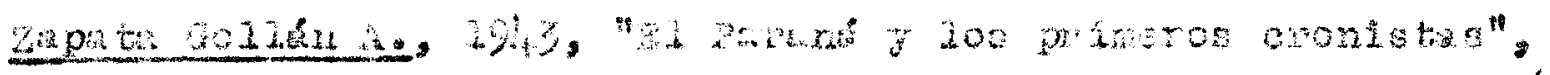

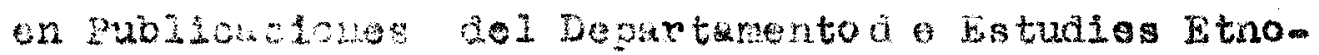

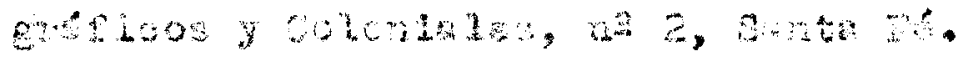

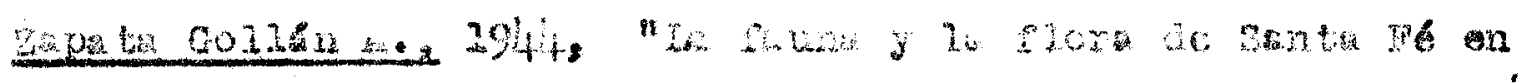

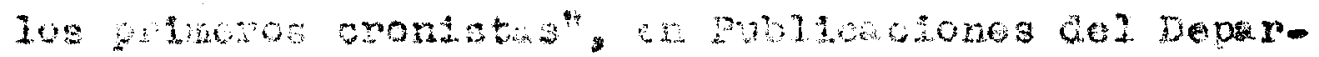

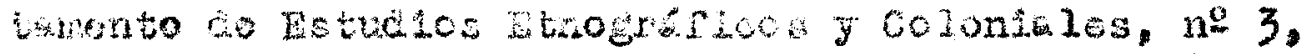
Santis. Pe.
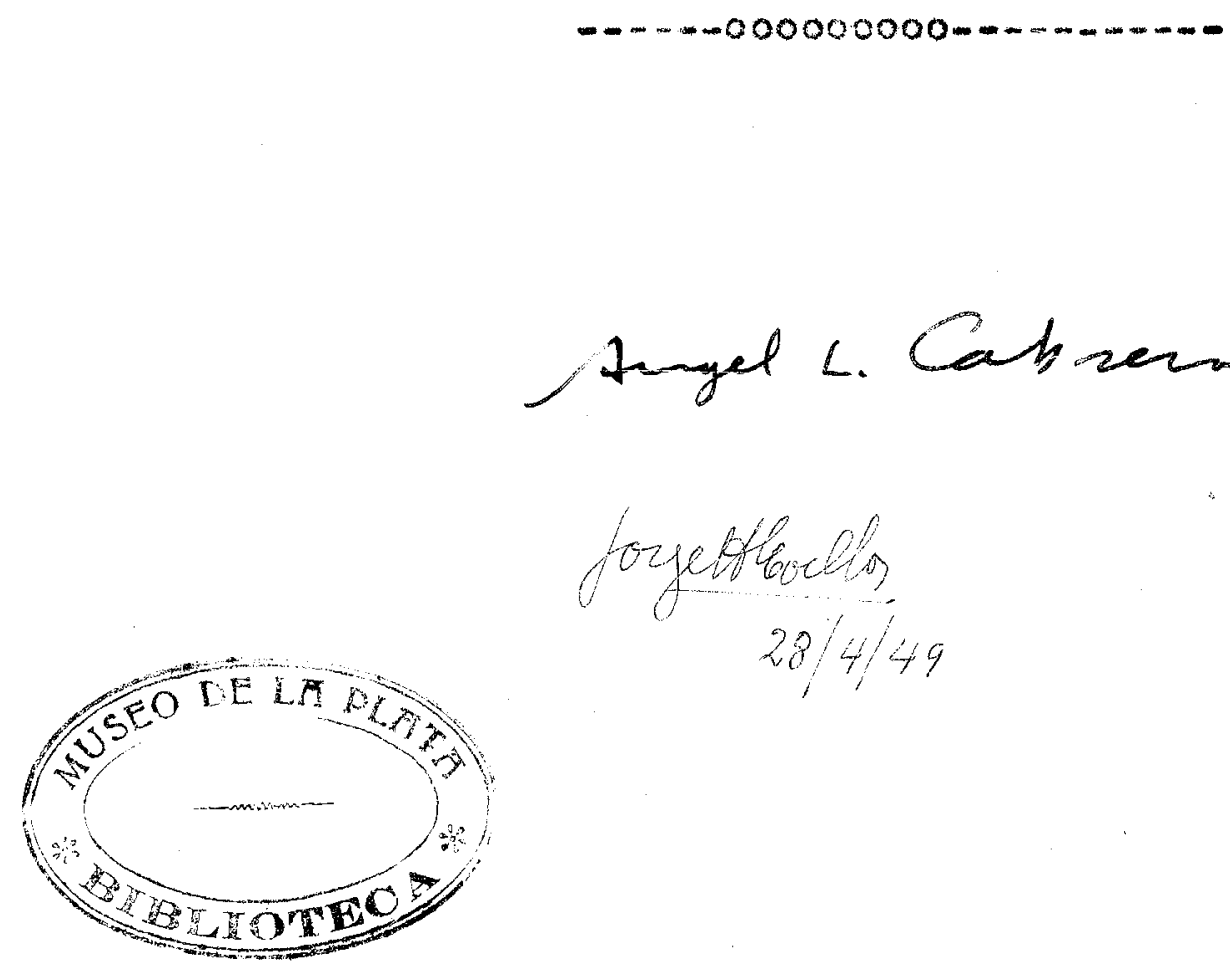

sungel L. Cabsern.

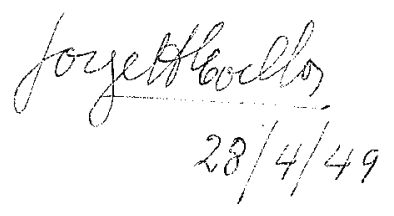

